Federal Building and Fire Safety Investigation of the World Trade Center Disaster

\title{
Analysis of Aircraft Impacts into the World Trade Center Towers \\ Chapters 9, 10, 11 \& Appendix A
}

Steven W. Kirkpatrick

Robert T. Bocchieri

Fahim Sadek

Robert A. MacNeill

Samuel Holmes

Brian D. Peterson

Robert W. Cilke

Claudia Navarro 



\section{TABLE OF CONTENTS}

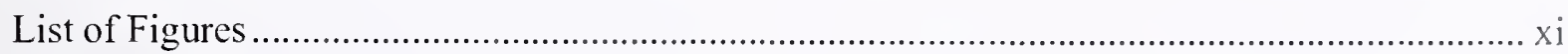

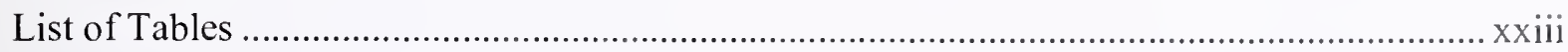

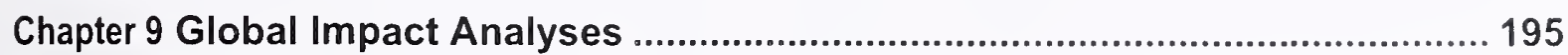

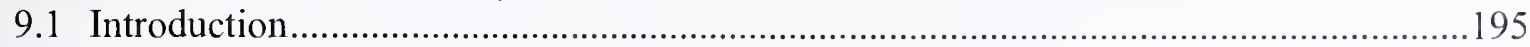

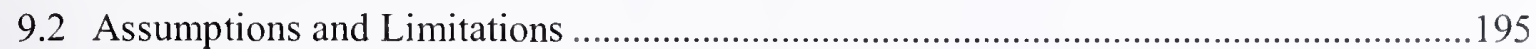

9.3 Models for the base case Impact Analyses ........................................................ 197

9.4 WTC 1 Base case Impact Analysis .....................................................................201

9.4.1 WTC 1 Base Case Impact Analysis - Structural Damage ..................................208

9.4.2 WTC 1 Base Case Impact Analysis - Fuel and Debris Distributions ..................218

9.5 WTC 2 Base case Impact Analysis .......................................................................228

9.5.1 WTC 2 Base Case Impact Analysis - Structural Damage .................................235

9.5.2 WTC 2 Base Case Impact Analysis - Fuel and Debris Distributions ..................246

9.6 Additional WTC 1 Global Impact Analyses ........................................................256

9.6.1 More Severe WTC 1 Global Impact Analysis..............................................257

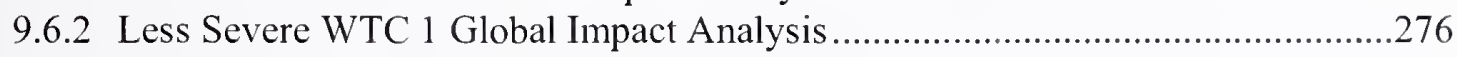

9.7 Additional WTC 2 Global Impact Analyses ............................................................290

9.7.1 More Severe WTC 2 Global Impact Analyses ...........................................292

9.7.2 Less Severe WTC 2 Global Impact Analyses ................................................ 312

9.8 Comparison of Different Severity WTC 1 Impact Analyses ........................................327

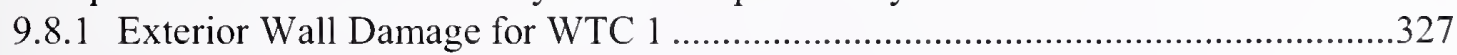

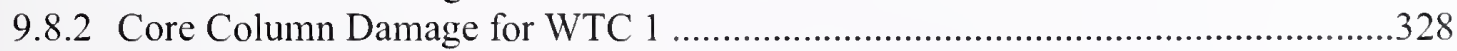

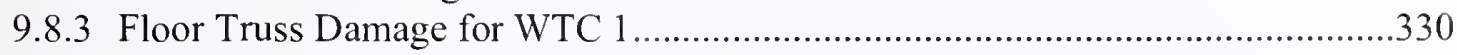

9.9 Comparison of Different Severity WTC 2 Impact Analyses .....................................331

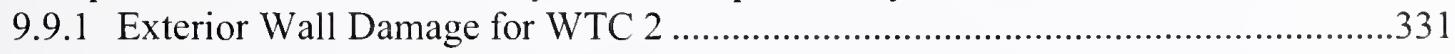

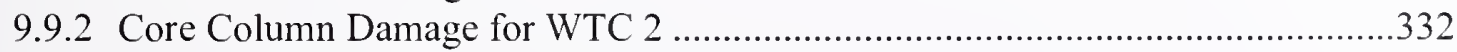

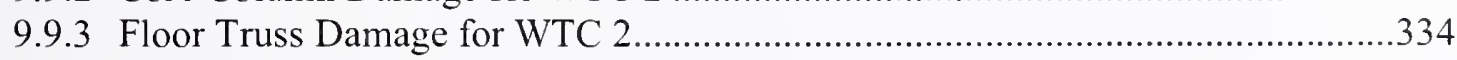

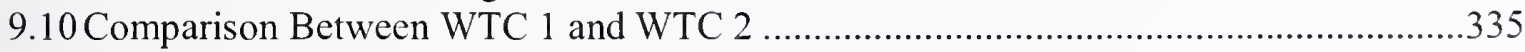

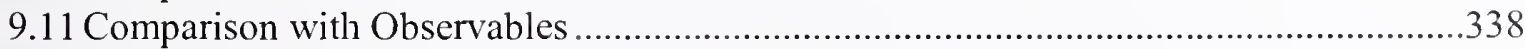

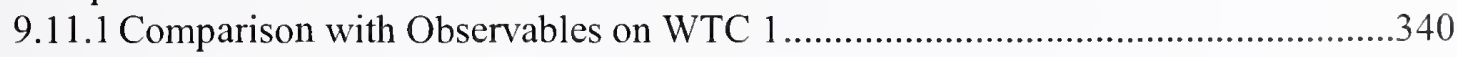

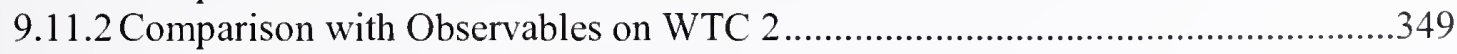

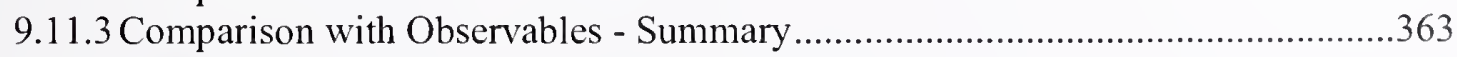

9.12 Comparison with Previous Studies ....................................................................... 363

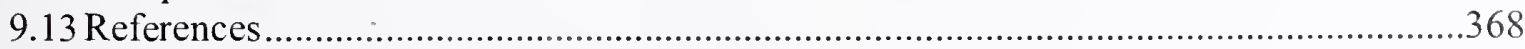

Chapter 10 Supporting Simplified Analyses .................................................... 369

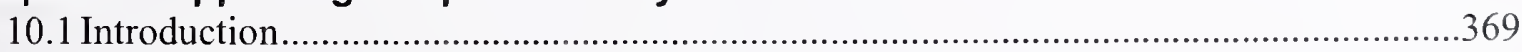

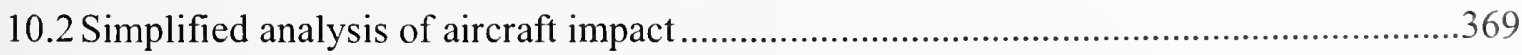

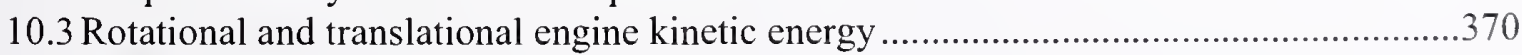

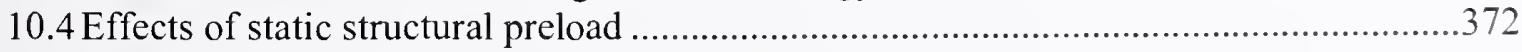

10.5 Simplified analysis of Core Column Damage .......................................................3 374

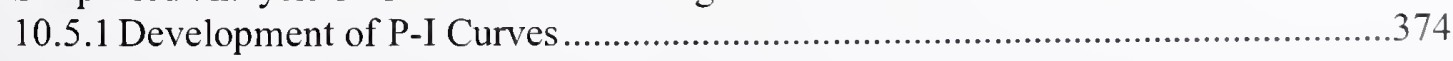


10.5.2 Core Column Damage Analyses ................................................................ 375

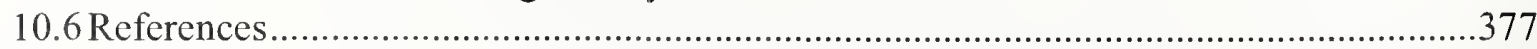

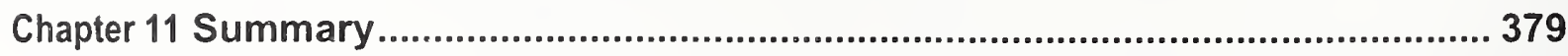

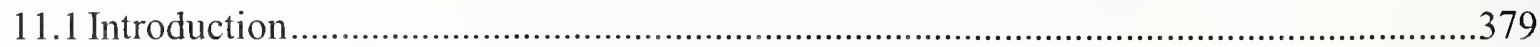

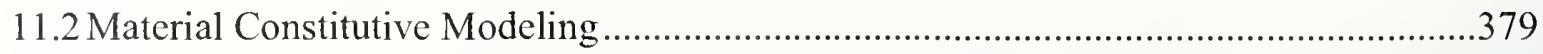

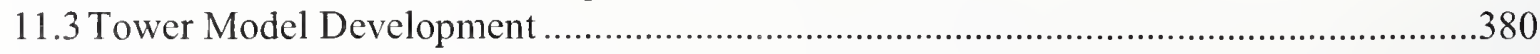

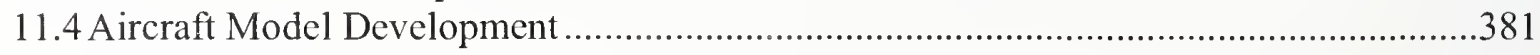

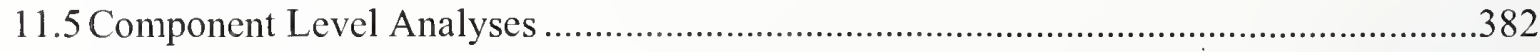

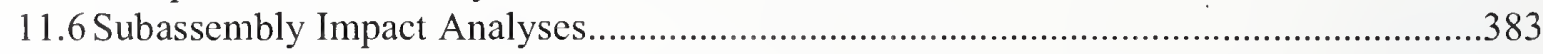

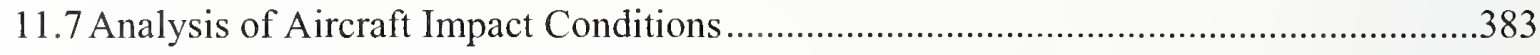

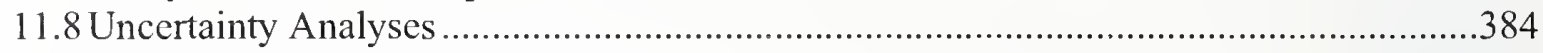

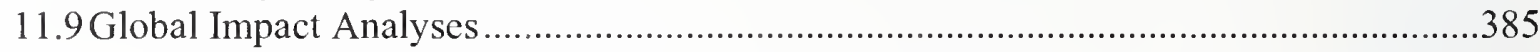

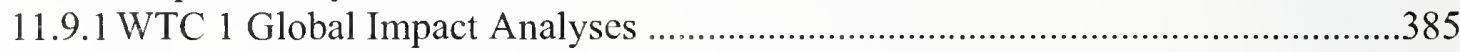

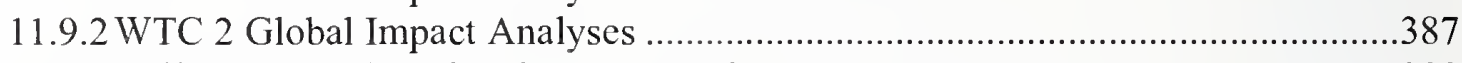

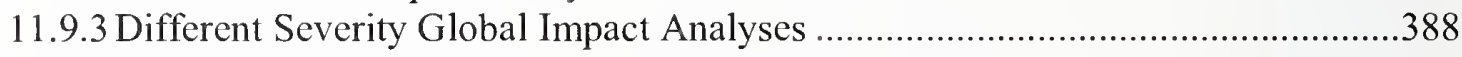

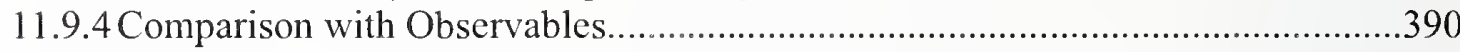

11.9.5 Comparison with Previous Studies............................................................... 390

$11.10 \quad$ Supporting Simplified Analyses............................................................. 


\section{LIST OF FIGURES}

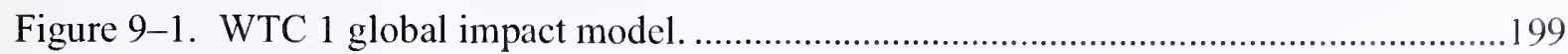

Figure 9-2. WTC 2 global impact modcl. ..................................................................200

Figure 9-3. WTC 1 base case global impact model. .......................................................201

Figure 9-4. WTC 1 base case global impact analysis (side view)....................................202

Figure 9-5. WTC 1 base case global impact analysis (plan view).....................................204

Figure 9-6. Normalized aircraft momentum for the WTC 1 base case impact. .....................206

Figure 9-7. Aircraft breakup and debris in the base case WTC 1 impact. ...........................207

Figure 9-8. Base case impact damage to the WTC 1 exterior wall......................................209

Figure 9-9. Base case impact damage to the WTC 1 core frame structures. ..........................210

Figure 9-10. Base case impact damage to the WTC 1 core columns.....................................212

Figure 9-11. Summary of core column damage for the base case WTC 1 impact..................213

Figure 9-12. Classification of damage levels in core columns. ..........................................214

Figurc 9-13. Base case impact damage to the WTC 1 core floor framing (plan view).............215

Figure 9-14. Base case impact damage to the WTC 1 floor trusses (front vicw)..................216

Figure 9-15. Base case impact damage to the WTC 1 floor trusses (plan view)....................217

Figure 9-16. Base case impact damage to the WTC 1 floor slab (plan view).........................218

Figure 9-17. Calculated fuel distribution in the base case WTC 1 analysis (plan view)..........220

Figure 9-18. Calculated fuel distribution in the base case WTC 1 analysis (side view)..........221

Figure 9-19. Calculated WTC 1 building contents, fuel, and aircraft debris distribution..........222

Figure 9-20. Calculated floor 94 contents, fuel, and aircraft debris distribution....................223

Figure 9-21. Calculated floor 95 contents, fuel, and aircraft debris distribution.....................224

Figure 9-22. Calculated floor 96 contents, fuel, and aircraft debris distribution.....................225

Figure 9-23. Calculated floor 97 contents, fuel, and aircraft debris distribution....................226

Figure 9-24. Calculated floor 98 contents, fuel, and aircraft debris distribution.....................227

Figure 9-25. WTC 2 base case global impact model. .....................................................229

Figure 9-26. WTC 2 base case global impact analysis (side view)....................................230

Figure 9-27. WTC 2 base case global impact analysis (plan view) ....................................232

Figure 9-28. Normalized aircraft momentum for the WTC 2 base case impact. ....................235

Figure 9-29. Aircraft breakup and debris in the base case WTC 2 impact. ...........................236 
Figure 9-30. Base case impact damage to the WTC 2 exterior wall...................................238

Figure 9-31. Base case impact damage to the WTC 2 core. .................................................239

Figure 9-32. Base case impact damage to the WTC 2 core columns....................................240

Figure 9-33. Summary of core column damage for the base case WTC 2 impact..................241

Figure 9-34. Base case impact damage to the WTC 2 core floor framing (plan view).............242

Figure 9-35. Base case impact damage to the WTC 2 floor truss (front view).......................243

Figure 9-36. Base case impact damage to the WTC 2 floor trusses (plan view)....................244

Figure 9-37. Base case impact damage to the WTC 2 floor slab (plan view).........................245

Figure 9-38. Calculated fuel distribution in the base case WTC 2 analysis (plan view).........247

Figure 9-39. Calculated fuel distribution in the base case WTC 2 analysis (side view)..........248

Figure 9-40. Calculated WTC 2 building contents, fuel, and aircraft debris distribution.........249

Figure 9-41. Calculated floor 78 contents, fuel, and aircraft debris distribution.....................250

Figure 9-42. Calculated floor 79 contents, fuel, and aircraft debris distribution....................251

Figure 9-43. Calculated floor 80 contents, fuel, and aircraft debris distribution....................252

Figure 9-44. Calculated floor 81 contents, fuel, and aircraft debris distribution.....................253

Figure 9-45. Calculated floor 82 contents, fuel, and aircraft debris distribution....................254

Figure 9-46. Calculated floor 83 contents, fuel, and aircraft debris distribution.....................255

Figure 9-47. More severe WTC 1 global impact analysis (side view) .................................259

Figure 9-48. More severe WTC 1 global impact analysis (plan view)..................................261

Figure 9-49. More severe impact damage to the WTC 1 exterior wall..................................263

Figure 9-50. More severe impact response of the WTC 1 core. ..........................................264

Figure 9-51. More severc impact response of the WTC 1 core columns..............................265

Figure 9-52. More severe impact damage to the WTC 1 core floor framing (plan view)........266

Figure 9-53. Summary of core column damage for the more severe WTC 1 impact...............268

Figure 9-54. More severe impact damage to the WTC 1 floor truss (front view)..................269

Figure 9-55. More severe impact damage to the WTC 1 floor truss (plan view)...................270

Figure 9-56. More severe impact damage to the WTC 1 floor slabs (plan view).....................271

Figure 9-57. Calculated more severe WTC 1 impact response of floor 94 contents. ...............272

Figure 9-58. Calculated more severe WTC 1 impact response of floor 95 contents. ..............273

Figure 9-59. Calculated more severe WTC 1 impact response of floor 96 contents. ...............274

Figure 9-60. Calculated more severe WTC 1 impact response of floor 97 contents. ..............275

Figure 9-61. Calculated more severe WTC 1 impact response of floor 98 contents. ..............276

Figure 9-62. Less severe impact damage to the WTC 1 exterior wall...............................277 
Figure 9-63. Less severe impact response of the WTC 1 corc ...........................................279

Figure 9-64. Less scvcre impact response of the WTC 1 core columns..............................2280

Figurc 9-65. Less severe impact damage to the WTC 1 corc floor framing (plan vicw).........28 1

Figure 9-66. Summary of core column damage for the Iess severe WTC 1 impact................282

Figurc 9-67. Less severe impact damage to the WTC 1 floor truss (front view)...................283

Figure 9-68. Less sevcre impact damage to the WTC 1 floor truss (plan view).....................284

Figure 9-69. Less sevcre impact damage to the WTC 1 floor slab (plan vicw)....................285

Figure 9-70. Calculated less scvere WTC 1 impact response of floor 94 contents..................286

Figure 9-71. Calculatcd less scvere WTC 1 impact responsc of floor 95 contents.................287

Figure 9-72. Calculated less severe WTC 1 impact response of floor 96 contents.................288

Figure 9-73. Calculated less severe WTC 1 impact response of floor 97 contents..................289

Figure 9-74. Calculated less severe WTC 1 impact rcsponse of floor 98 contents..................290

Figure 9-75. More severe WTC 2 global impact analysis (side view).................................293

Figure 9-76. More severe WTC 2 global impact analysis (plan view) ...............................2295

Figure 9-77. More severe impact damage to the WTC 2 exterior wall..............................297

Figure 9-78. More severe impact response of the WTC 2 core. ............................................298

Figure 9-79. More severe impact response of the WTC 2 core columns.............................299

Figure 9-80. More severe impact damage to the WTC 2 core floor framing (plan view)........300

Figure 9-81. Summary of core column damage for the more severe WTC 2 impact...............302

Figure 9-82. Representative exterior wall strain rates for the more severe WTC 2 impact (view

from tower exterior).

Figure 9-83. Representative core frame strain rates for the more severe WTC 2 impact (impact

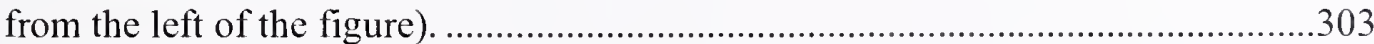

Figure 9-84. More severe impact damage to the WTC 2 floor truss (front view). ...................304

Figure 9-85. More severe impact damage to the WTC 2 floor truss (plan view)....................305

Figure 9-86. More severe impact damage to the WTC 2 floor slab (plan view). ....................306

Figure 9-87. Calculated more severe WTC 2 impact response of floor 78 contents................307

Figure 9-88. Calculated more severe WTC 2 impact response of floor 79 contents. ...............308

Figure 9-89. Calculated more severe WTC 2 impact response of floor 80 contents. ...............309

Figure 9-90. Calculated more severe WTC 2 impact response of floor 81 contents. ...............310

Figure 9-91. Calculated more severe WTC 2 impact response of floor 82 contents. ...............311

Figure 9-92. Calculated more severe WTC 2 impact response of floor 83 contents................312

Figure 9-93. Less severe impact damage to the WTC 2 exterior wall.................................313 
Figure 9-94. Less severe impact response of the WTC 2 core .315

Figure 9-95. Less severe impact response of the WTC 2 core columns. ...............................316

Figure 9-96. Less severe impact damage to the WTC 2 core floor framing (plan view)..........317

Figure 9-97. Summary of core column damage for the less severe WTC 2 impact. .................318

Figure 9-98. Less severe impact damage to the WTC 2 floor truss (front view)....................319

Figure 9-99. Less severe impact damage to the WTC 2 floor truss (plan view).....................320

Figure 9-100. Less severe impact damage to the WTC 2 floor slab (plan view)....................321

Figure 9-101. Calculated less severe WTC 2 impact response of floor 78 contents.................322

Figure 9-102. Calculated less severe WTC 2 impact response of floor 79 contents..................323

Figure 9-103. Calculated less severe WTC 2 impact response of floor 80 contents................324

Figure 9-104. Calculated less severe WTC 2 impact response of floor 81 contents.................325

Figure 9-105. Calculated less severe WTC 2 impact response of floor 82 contents.................326

Figure 9-106. Calculated less severe WTC 2 impact response of floor 83 contents..................327

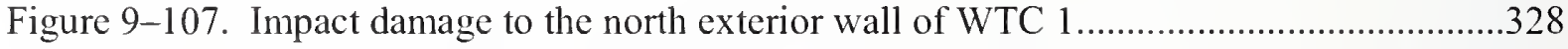

Figure 9-108. Comparison of core column damage for the WTC 1 impact analyses..............329

Figure 9-109. Comparison of floor truss damage for the WTC 1 impact analyses...................331

Figure 9-110. Impact damage to the south exterior wall of WTC 2 ....................................332

Figure 9-111. Comparison of core column damage for the WTC 2 impact analyses...............333

Figure 9-112. Comparison of floor truss damage for the WTC 2 impact analyses...................334

Figure 9-113. Comparison of base case impact damage to the exterior wall..........................336

Figure 9-114. Comparison of base case impact damage to the core columns. ........................337

Figure 9-115. Comparison of base case impact damage to floor truss (front view)................338

Figure 9-116. Impact damage to the exterior walls of the WTC towers...............................339

Figure 9-117. Representative floor plan (based on floors 94 to 95 of WTC 1)......................340

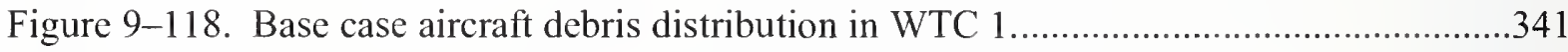

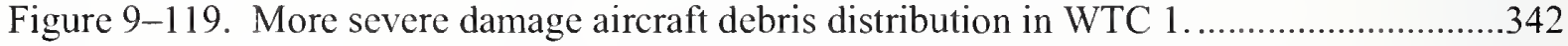

Figure 9-120. Less severe damage aircraft debris distribution in WTC 1 ...........................343

Figure 9-121. Damage to the south face of WTC 1 from the more severe damage global analysis.

Figure 9-122. Landing gear found at the corner of West and Rector streets. [wtc05-orig-2001-

09-1 1-09-13-05-Charles-Marsh.jpg - need approval to use and source].... 345

Figure 9-123. Landing gear found embedded in exterior panel knocked free from WTC 1.

[Roll_3 13.jpg - need approval to use and source] .346 
Figure 9-124. Base casc stairwell disruption in WTC 1.

Figure 9-125. Calculated and observed WTC 1 damage (front view).

Figure 9-126. Impact Damage to the Northeast Corner of the Exterior Wall of WTC 2.

[AP_Drew_68655891_5.jpg - need final permission to use].

Figure 9-127. Documented damage to the 81st floor of the northeast corncr of WTC 2........350

Figure 9-128. Base case analysis on the 81st floor of the northcast corncr of WTC 2 ............351

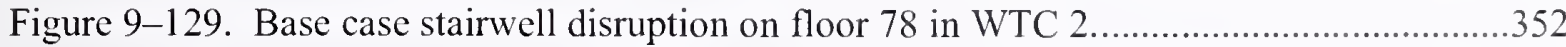

Figure 9-130. Base case damage aircraft debris distribution in WTC 2. ..............................354

Figure 9-131. Aircraft debris distribution in the more severe WTC 2 impact........................355

Figure 9-132. Aircraft debris distribution in the less severe WTC 2 impact. ........................356

Figure 9-133. Starboard engine fragment trajectory in the base case global analysis of WTC 2.357

Figure 9-134. Speed of the aft portion of the starboard engine ............................................358

Figure 9-135. Calculated and observed engine damage...................................................359

Figure 9-136. Starboard engine impact with the south face of WTC 2 in the base case global analysis.

Figure 9-137. Projected debris path for the WTC 2 north face cold spot. .............................362

Figure 9-138. Base case WTC 2 impact orientation and trajectory (vertical approach angle $=6^{\circ}$,

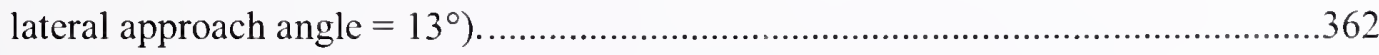

Figure 9-139. Comparison of impact damage to the WTC 1 exterior wall..............................365

Figure 9-140. Comparison of impact damage to the WTC 2 exterior wall..............................366

Figure 10-1. Internal components of the aircraft engine model.....................................371

Figure 10-2. Problem geometry for analysis of axial preload effects. ..................................372

Figure 10-3. Dynamic column response with and without axial preload.............................3 373

Figure 10-4. Development of damage and failure P-I curves for a structure...........................375

Figure 10-5. Core column P-I failure curves and concentrated fuel impact loading................376

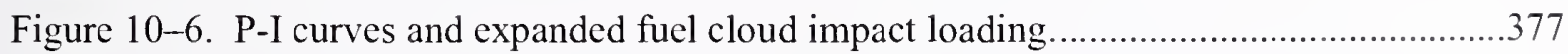

Add a paragraph return between each major section after updating the list. 
This page intentionally left blank. 


\section{LIST OF TABLES}

Table 9-1. Summary of the WTC global impact models. ...................................................198

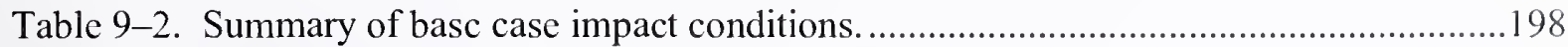

Table 9-3. Summary of core column damage for the base case WTC 1 impact....................213

Table 9-4. Fuel and aircraft debris distribution for the base case WTC 1 impact. ..................228

Table 9-5. Summary of core column damage for the base case WTC 2 impact.....................241

Table 9-6. Fuel and aircraft debris distribution for the base case WTC 2 impact. ..................256

Table 9-7. Input parameters for additional WTC 1 global impact analyses. ...........................257

Table 9-8. Core column response for the more severe WTC 1 impact..................................267

Table 9-9. Core column response for the less severe WTC 1 impact. ..................................278

Table 9-10. Input parameters for additional WTC 2 global impact analyses. .......................291

Table 9-11. Core column responsc for the more severe WTC 2 impact.................................301

Table 9-12. Core column response for the less severe WTC 2 impact. ...................................318

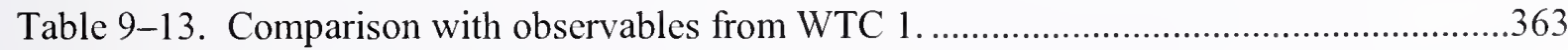

Table 9-14. Comparison with observables from WTC 2 ..............................................363

Table 9-15. Comparison of damage to core columns from various studies...........................367

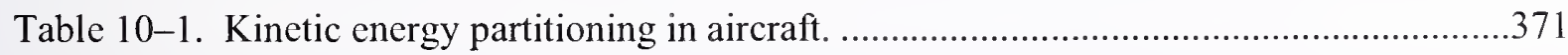

Add a paragraph return between each major section after updating the list. 
This page intentionally left blank. 


\section{Chapter 9 \\ GLOBAL IMPACT ANALYSES}

\section{$9.1 \quad$ INTRODUCTION}

The primary objective of this project was to dctermine the condition of the two World Trade Center (WTC) towers immediately following the aircraft impacts. This assessment includes both the determination of the structural damage that degraded their strength and the condition and position of nonstructural contents such as partitions, workstations, aircraft fuel, and other debris that influcnccd the behavior of the subsequent fires in the towers. The global impact analyses were the primary method by which most of the information on the tower damage was obtained. The analyses described in the other chapters of this report, such as the component and subassembly impact analyses, were performed to support the development and validation of these global impact models.

\section{$9.2 \quad$ ASSUMPTIONS AND LIMITATIONS}

A fundamental limitation of the global impact simulations was the maximum finite element model size that can be executed on the available 32-bit computer clusters. Since LS-DYNA uses addressable memory for domain decomposition, the combined aircraft and tower model could not exceed approximately 2.3 million nodes. The primary assumptions and limitations of the global impact analyses were the result of reducing the model size to meet these decomposition limitations as well as to achieve a run time that allowed the necessary global impact analyses to be completed within the duration of the investigation.

Although the analyses were performed on a 32 bit computer cluster, the precision used in the analyses can be controlled by the analysis software. Both single precision and double precision versions of LS-DYNA were available for the impact analyses. In general, single precision analyses are more efficient and the precision is sufficient for the type of impact simulation being performed. However, when the dimensions of the structure being analyzed are sufficiently large, the single precision analyses can introduce rounding errors in the analyses. The rounding errors occur since the analysis is resolving deformations or analyzing element penetrations on a local scale that is several orders of magnitude smaller than the controlling dimension.

In preliminary simulations, the coordinate system for the models of the tower structures was located near the base of the tower. As a result, the largest dimensions were the vertical position of the structures in the impact zone. This large vertical dimension controlled the size scale in the impact analyses and introduced rounding errors that were manifested as unstable element behaviors. To eliminate this precision problem, the tower model coordinate system was moved to be centered on the impact zone of the tower. The largest controlling dimension was therefore the distance across tower (significantly smaller than the height of the tower). After adjusting the coordinate location, the unstable element behaviors were no longer observed. 
To confirm the adequacy of the single precision analysis, subassembly impact analyses (Chapter 6) were performed on the same model in both single and double precision. The comparison of the two analyses showed no substantial difference in the impact response and damage.

Specific assumptions and limitations introduced in the analyses to meet the computational constraint included:

- Tower structures away from the impact zone had a coarse mesh resolution. Therefore, damage in those regions may not be as accurately captured as that in the impact zone. An example is the potential damage to the exterior panels on the far side of the tower (opposite to impact). As debris passed through the building and struck a panel on the far side of the building, the coarse mesh refinement and merged boundary conditions at column, ends (as opposed to bolted connections in the impact zone) underestimated the secondary impact damage.

- Tower contents (workstations and nonstructural walls) were only included in the expected path of the aircraft impact and subsequent debris cloud. Therefore, debris and fuel that passed beyond this region could move more freely through the structure, only interacting with primary structural components.

- The analysis of the impact response of the aircraft fuel cloud had several limitations. Smooth Particle Hydrodynamics (SPH) was used to model the fuel in the impacting aircraft, and approximately $60,000 \mathrm{SPH}$ particles were used for the approximately $60,000 \mathrm{lb}$ of fuel in each aircraft. Therefore, the particle size in the fuel cloud was approximately one pound. The air in and around the towers was not modeled, so the deceleration of the fuel particles in the cloud by aerodynamic resistance was not included. The contact algorithm for the fuel particles and tower did not include a sticking or "wetting" behavior so the fuel particles bounce off of components in the tower. The results of these limitations would spread the fuel cloud over a larger region in the simulation. Finally, the deflagration of the fuel was not modeled, and the resulting dynamic over-pressures in the tower from the combustion process were not included in the analysis.

- Windows were not modeled on the exterior of the tower. The open space between the exterior columns allowed fuel particles and small debris fragments from the aircraft and tower to escape that may have been contained if the windows were included. Note that the weight of the windows was added to the columns as part of the superimposed dead loads (see Section 3.2.4).

- The rotational velocity of the spinning aircraft engine components was not modeled. The effects of the rotational kinetic energy, spin stabilization of the engine trajectory, and potential for engine thrust during impact were, therefore, not included in the analysis. An analysis was performed to estimate the magnitude of this assumption, as described in Section 10.3. The analyses indicated that the rotational kinetic energy of each engine was approximately one percent of the aircraft initial kinetic energy. In addition, much of this rotational energy was probably dissipated by internal deformations of the engine components following impact with the tower exterior. Therefore, this approximation should have a small influence on the global impact damage. 
- Aeroelastie forces were not applied to the aireraft wings sinee the generated stresses were not expected to affect the impact response. The energy associated with the acroclastic stresses are much less than the energy absorbed during impact. Note that a wing tip deflcction was applied as explained in Section 4.3.

- Initial service loads (stresses) in the tower and aireraft were not ineluded. The material internal energy associated with the clastic service loads were small compared to the material internal energy eapacity. Therefore, it was not expectcd to have a significant influence on the dynamic impact response and deformation. Simplified analyses were performcd to evaluate the magnitude of this assumption for the impact response of a core column, as deseribed in Section 10.4. These analyses indicated that ignoring the static preload in the column had little influence on either the dynamic column deformations or the resulting collapse strength of the column. Gravitational aceeleration was modeled during the impact analyses to include the gravitational acceleration on debris movement and potential contributions to the collapse of the damaged truss floor regions.

- The impact analyses are subject to uneertainties in the input parameters, such as initial impact conditions, material properties and failure eriteria, aireraft mass and stiffness properties, mass distribution inside the towers, the jet fuel distribution and dispersion, connections behavior, the presence of nonstruetural building contents, ete. (see Chapter 8 for further details). The global analyses presented in this chapter not only provide a "base case" based on a best estimate of all input parameters (based on photographic and video evidence, material testing, and data in the open literature), but also provide more and less severe damage estimates based on variations of the most influential parameters, identified in the scnsitivity analyses (Chapter 8 ). These more and less severe damage seenarios provide a range of damage estimates of the towers due to aircraft impact.

\subsection{MODELS FOR THE BASE CASE IMPACT ANALYSES}

The development of the tower models and the development of the Boeing 767 aircraft model were described in detail in Chapters 2 and 3, respectively. Similarly, the analysis of the aireraft impact conditions was deseribed in Chapter 7. In this seetion, a brief deseription of the combined global model of the tower and aireraft used for the impaet simulations is provided. Similar to the component and subassembly analyses, the global impact analyses were performed using the LS-DYNA general purpose finite element software package.

The combined aircraft and tower models developed for the base ease global impact conditions of WTC 1 and WTC 2 are shown in Figure 9-1 and Figure 9-2, respectively. The global impact models were each in excess of two million nodes. A detailed summary of the number and types of elements in each model is provided in Table 9-1. The bulk of the aireraft and tower structures were modeled using shell elements. Solid elements were used for specific components, such as the exterior wall butt plates and for some of the thick hubs and flywheels in the aireraft engines. Beam elements were used primarily in the WTC tower floor truss structures and for the bolted connections in the impact zone of the exterior wall. 
Table 9-1. Summary of the WTC global impact models.

\begin{tabular}{|l|c|c|}
\hline & WTC 1 Tower Model & WTC 2 Tower Model \\
\hline Number of Nodes & $2,068,736$ & $2,110,970$ \\
\hline Belytschko-Tsay Shell Elements & $1,682,615$ & $1,716,249$ \\
\hline Constant Stress Solid Elements & 73,189 & 72,906 \\
\hline Hughes-Liu Beam Elements & 47,952 & 53,488 \\
\hline SPH Fuel Particles & 60,672 & 60,672 \\
\hline
\end{tabular}

The objective of the base case impact analyses was to provide an estimate of the impact scenario based on an analysis with a best estimate of all the variables obtained from photographic and video evidence, material testing, and data in the open literature. A summary of the aircraft impact conditions used for the base case global impacts of the towers is provided in Table 9-2.

Table 9-2. Summary of base case impact conditions.

\begin{tabular}{|c|c|c|}
\hline & WTC 1 & WTC 2 \\
\hline Impact Speed (mph) & 443 & 546 \\
\hline $\begin{array}{l}\text { Vertical Approach Angle } \\
\text { (Velocity vector) }\end{array}$ & $\begin{array}{l}10.6^{\circ} \text { below horizontal } \\
\text { (heading downward) }\end{array}$ & $\begin{array}{c}6^{\circ} \text { below horizontal (heading } \\
\text { downward) }\end{array}$ \\
\hline $\begin{array}{l}\text { Lateral Approach Angle } \\
\text { (Velocity vector) }\end{array}$ & $\begin{array}{l}180.3^{\circ} \text { clockwise from } \\
\text { Structure North }\end{array}$ & $\begin{array}{c}13^{\circ} \text { clockwise from Structure } \\
\text { North }\end{array}$ \\
\hline $\begin{array}{l}\text { Vertical Fuselage Orientation } \\
\text { Relative to Trajectory }\end{array}$ & $\begin{array}{c}2^{\circ} \text { nose-up from vertical } \\
\text { approach angle }\end{array}$ & $\begin{array}{c}1^{\circ} \text { nose-up from vertical } \\
\text { approach angle }\end{array}$ \\
\hline $\begin{array}{l}\text { Lateral Fuselage Orientation } \\
\text { Relative to Trajectory }\end{array}$ & $\begin{array}{c}0^{\circ} \text { clockwise from lateral } \\
\text { approach angle }\end{array}$ & $\begin{array}{l}-3^{\circ} \text { clockwise from lateral } \\
\text { approach angle }\end{array}$ \\
\hline Roll Angle (left wing downward) & $25^{\circ}$ & $38^{\circ}$ \\
\hline Total Aircraft Weight & $283,600 \mathrm{lb}$ & $277,600 \mathrm{lb}$ \\
\hline Aircraft Fuel Weight & $66,100 \mathrm{lb}$ & $62,000 \mathrm{lb}$ \\
\hline Aircraft Cargo Weight & $40,600 \mathrm{lb}$ & $38,700 \mathrm{lb}$ \\
\hline
\end{tabular}




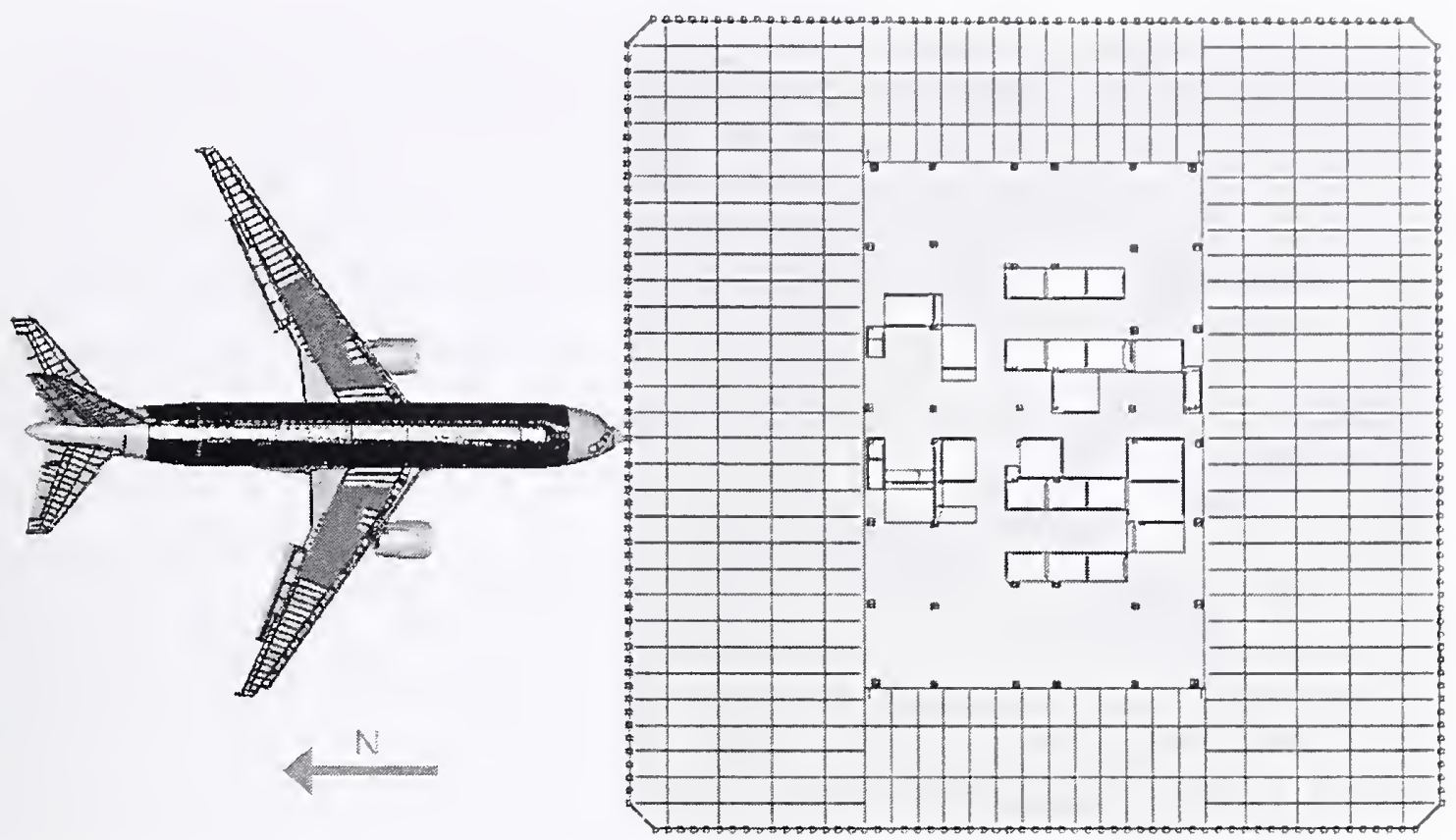

(a) Plan view

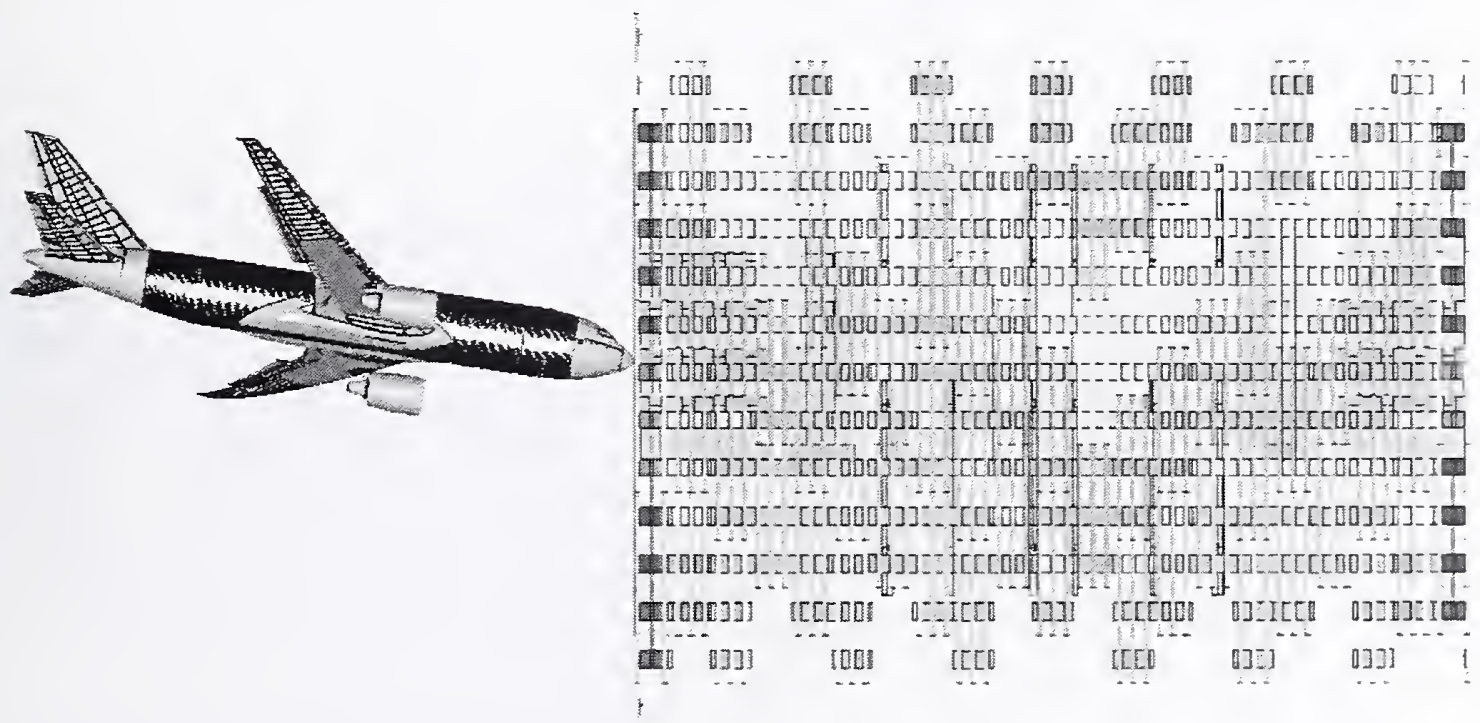

(b) Side view

Figure 9-1. WTC 1 global impact model. 


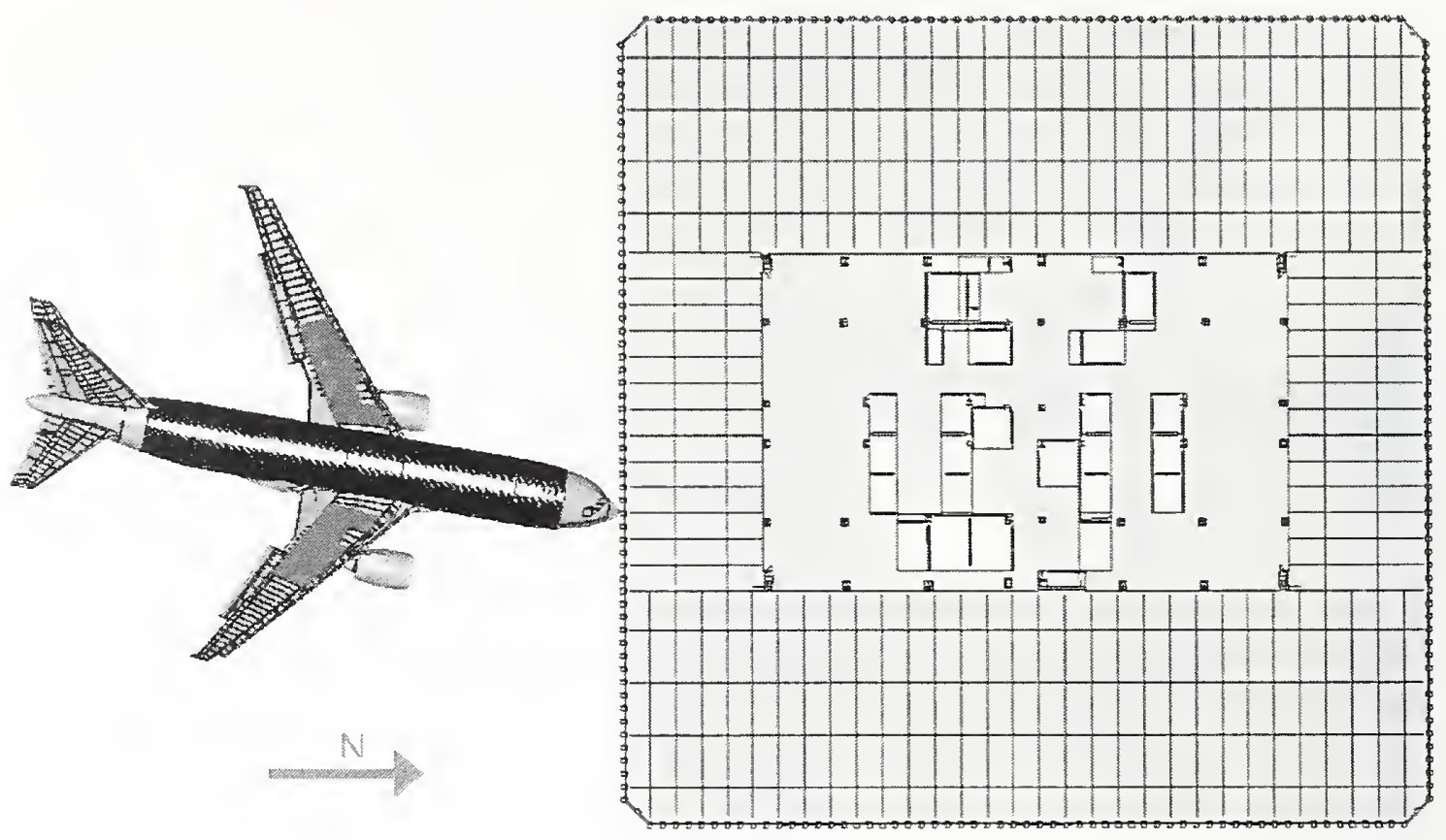

(a) Plan view

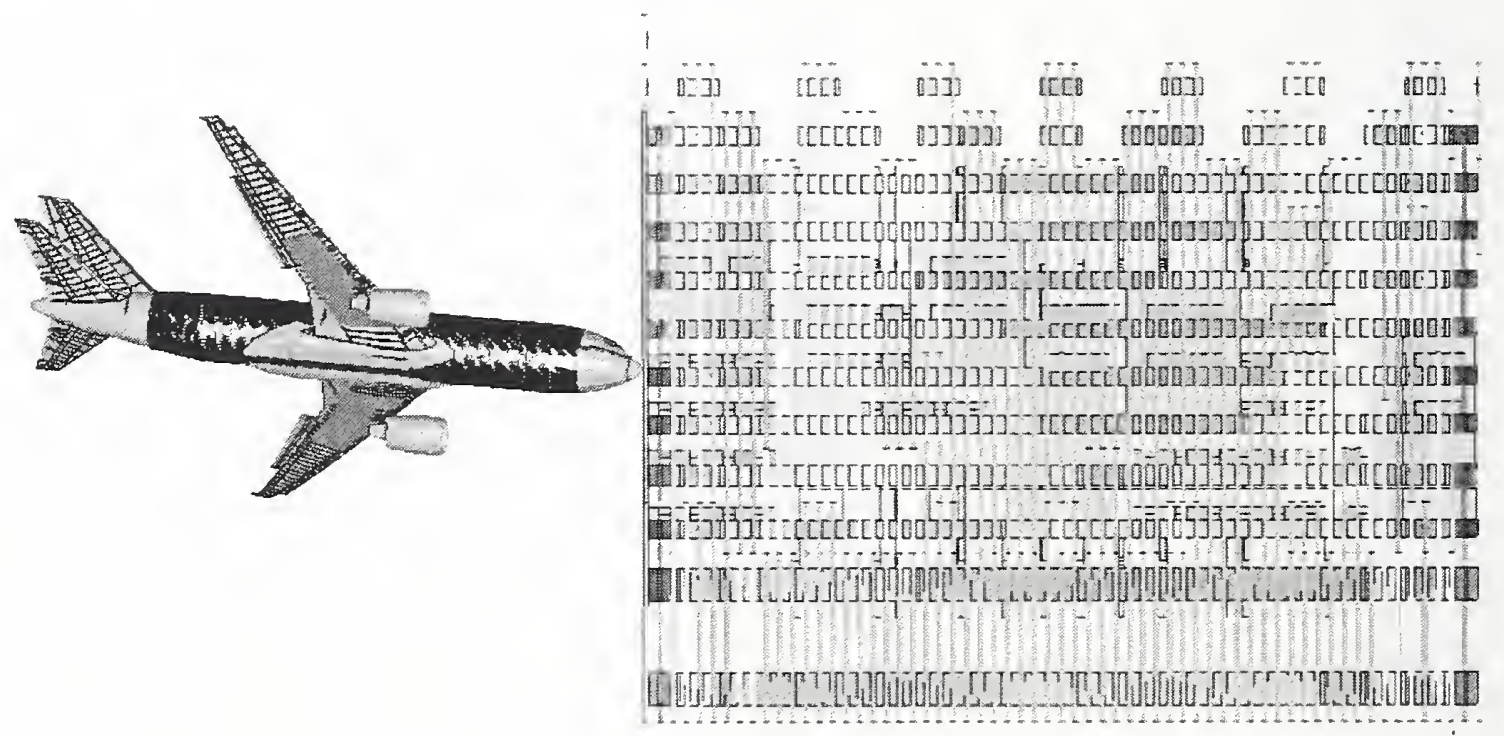

(b) Side view

Figure 9-2. WTC 2 global impact model. 


\subsection{WTC 1 BASE CASE IMPACT ANALYSIS}

This case is referred to as Case A for the remainder of the WTC Investigation reports. The WTC 1 base case analysis was performed for a $0.715 \mathrm{~s}$ duration following initial impact of the aircraft nosc with the north exterior wall. The analysis was performed on a computer cluster using twelve $2.8 \mathrm{GHz}$ Intel Xcon processors, each on a separate node of the cluster. The run time for this analysis was approximatcly two weeks. The progress of the global impact simulations was monitored on average every two days. The calculations were terminated when the damage to the towers reached a steady statc and the motion of the debris was reduced to a level that was not expected to produce significant impact damage. A typical value for the residual kinetic energy in the airframe components at the termination of a global impact simulation was less than one percent of the initial kinetic energy at impact.

A side view of the base case WTC 1 global impact model is shown in Figure 9-3. The tower interior contents were removed, and the tower structures were shown as transparent, so that the impact response in the tower interior could be seen. The floor numbers and core columns for the tower model are labeled in the figure. The corresponding side view was used to illustrate the base case global aircraft impact response in Figure 9-4. The response is shown at intervals of $0.1 \mathrm{~s}$ from impact through the initial $0.5 \mathrm{~s}$ of the response. Corresponding plan view images of the progression of aircraft impact response are shown in Figure 9-5.

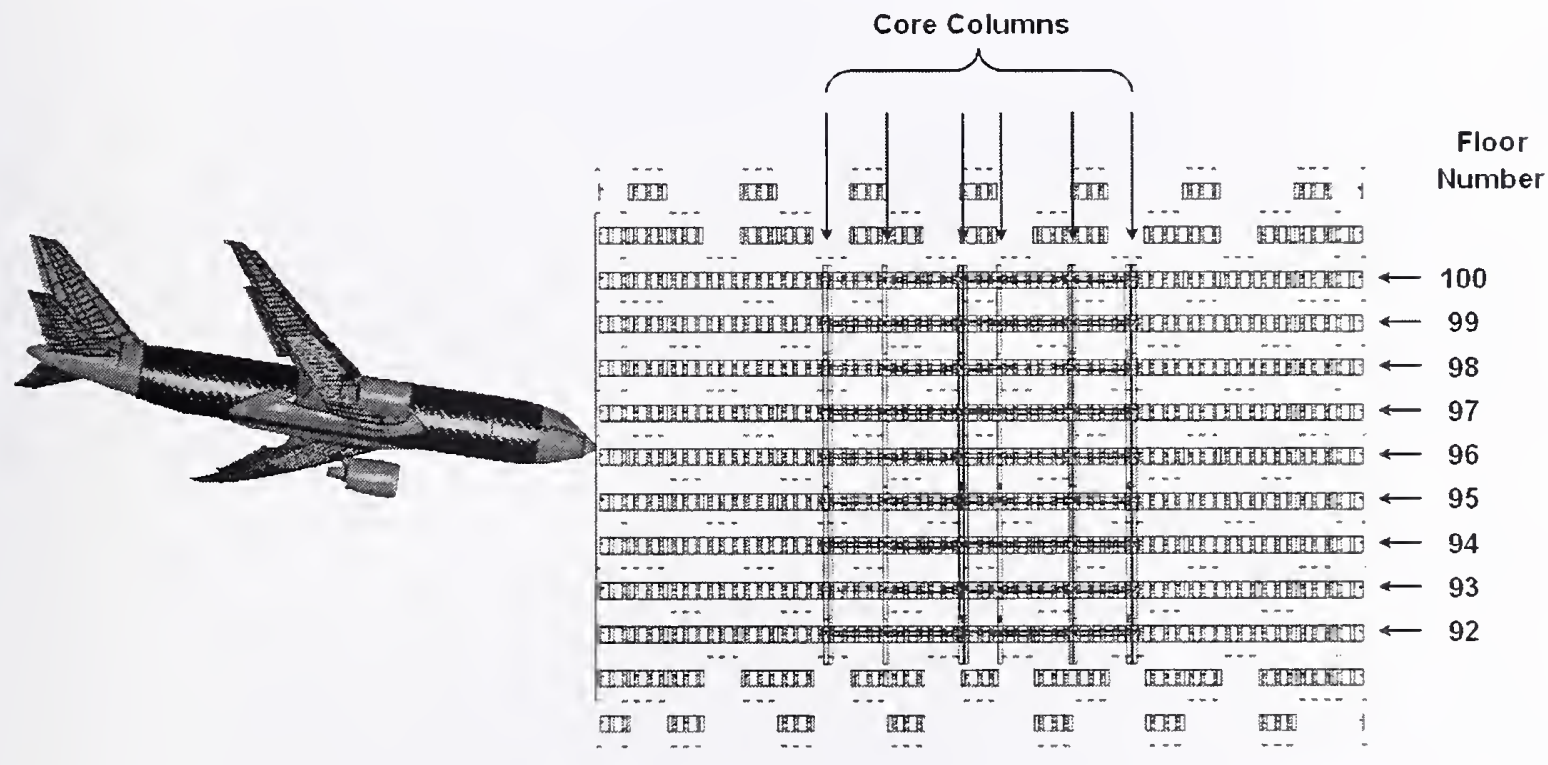

Figure 9-3. WTC 1 base case global impact model.

The initial $0.1 \mathrm{~s}$ of the base case global aircraft impact response, shown in Figure 9-4(b) and Figure 9-5(b), was dominated by the impact, penetration, and fragmentation of the forward fuselage structures. The engines and wing sections were just starting to impact the exterior wall. The forward fuselage structures were severely damaged both from the penetration through the exterior columns and the penetration of the 96 th floor slab that sliced the fuselage structures in half. The downward trajectory of 
the aircraft structures caused the airframe to collapse against the floor, and the subsequent debris motion was redirected inward along a more horizontal trajectory parallel to the floor.

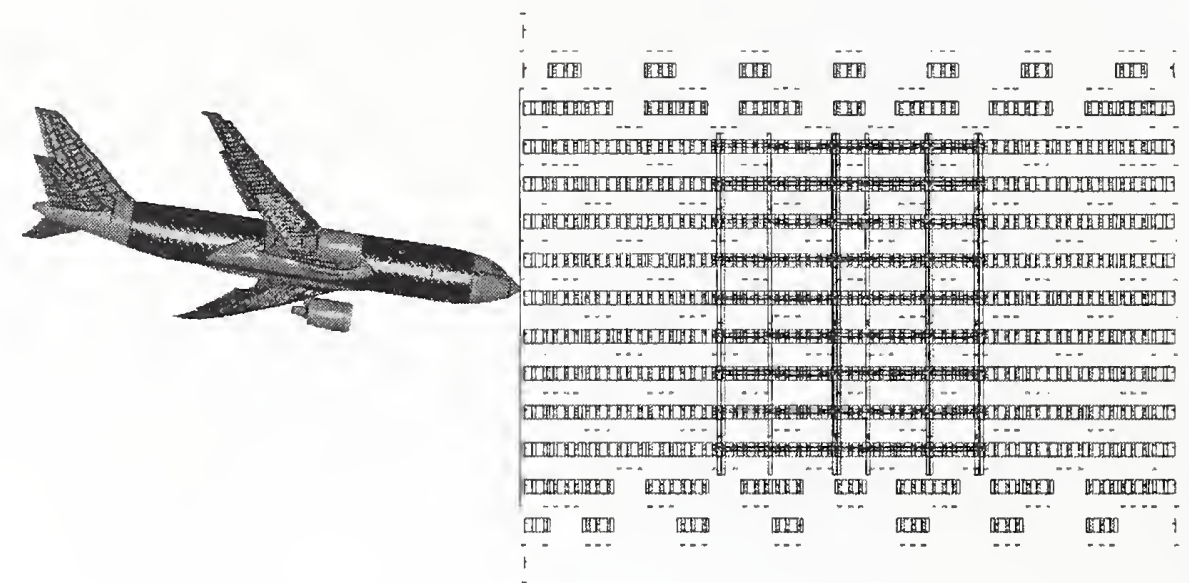

\section{(a) Time $=0.00 \mathrm{~s}$}

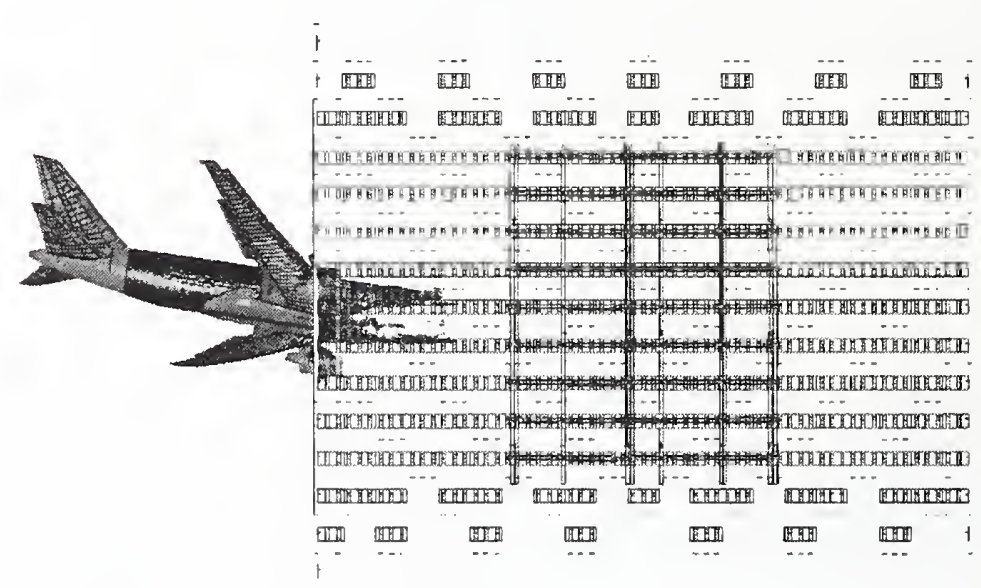

(b) Time $=0.10 \mathrm{~s}$

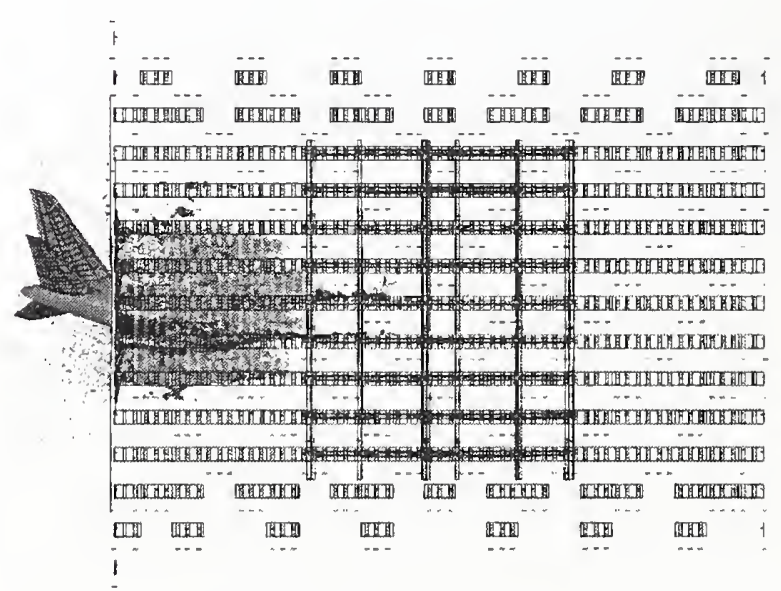

(c) Time $=0.20 \mathrm{~s}$

Figure 9-4. WTC 1 base case global impact analysis (side view). 


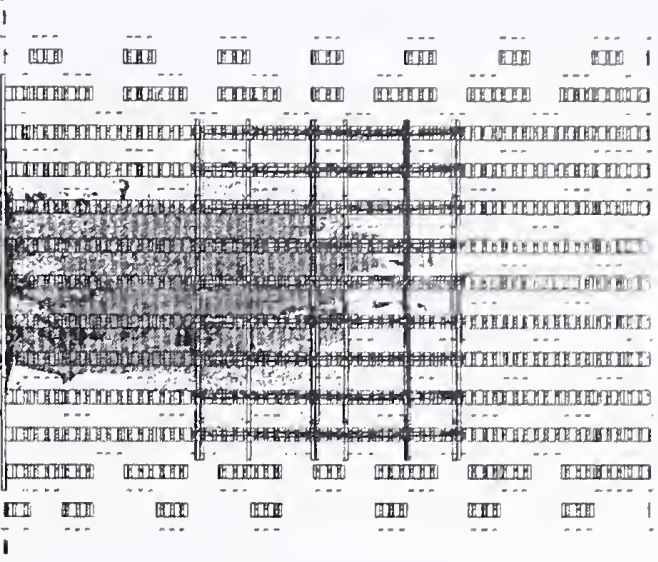

(d) Time $=0.30 \mathrm{~s}$

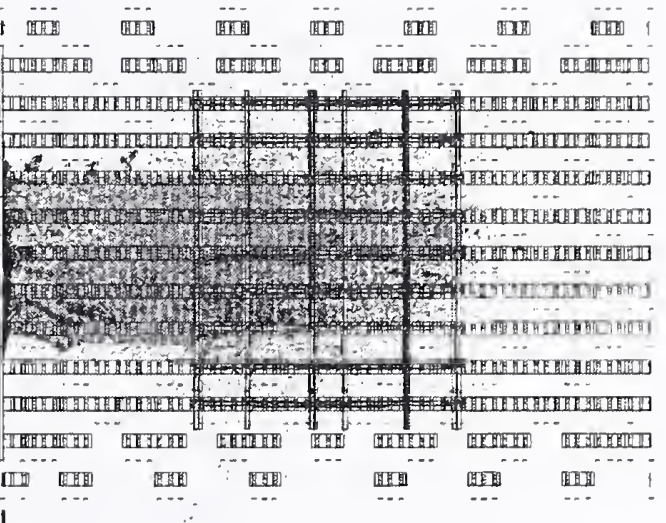

(e) Time $=0.40 \mathrm{~s}$

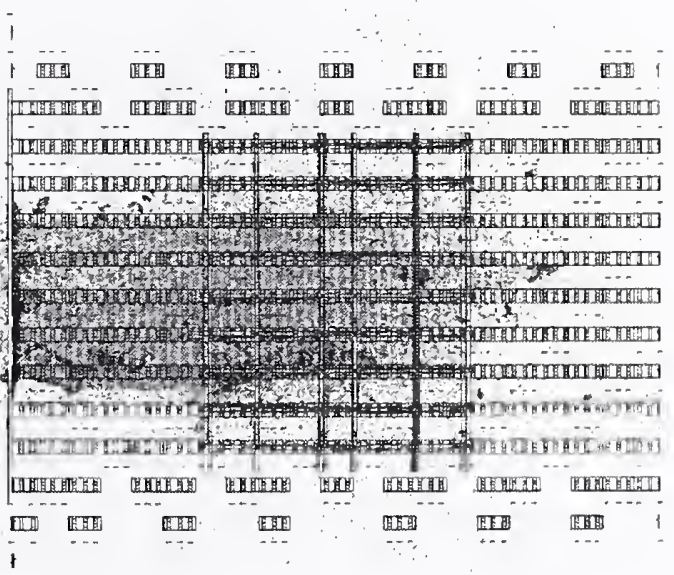

(f) Time $=0.50 \mathrm{~s}$

Figure 9-4. WTC 1 base case global impact analysis (side view) (continued). 


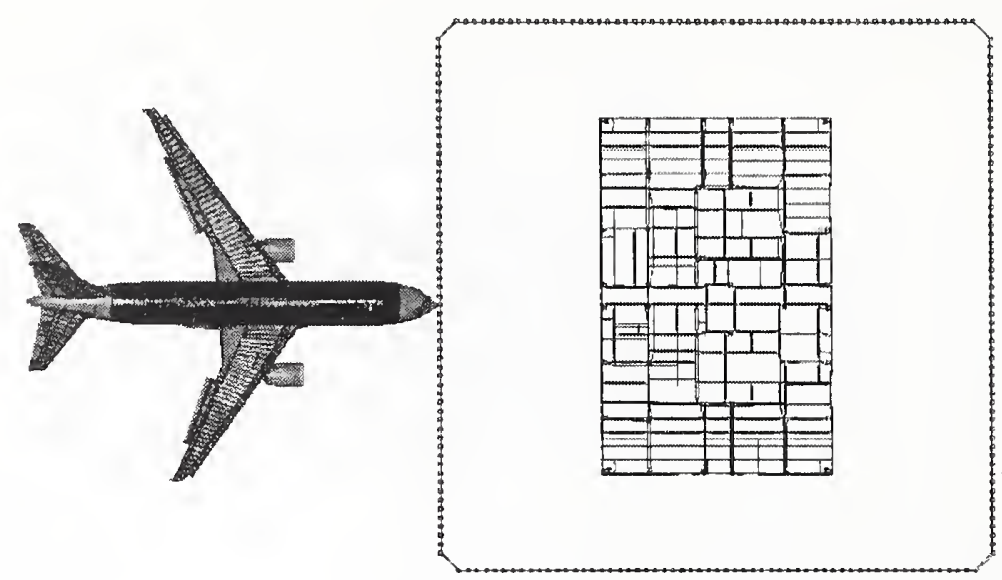

(a) Time $=0.00 \mathrm{~s}$

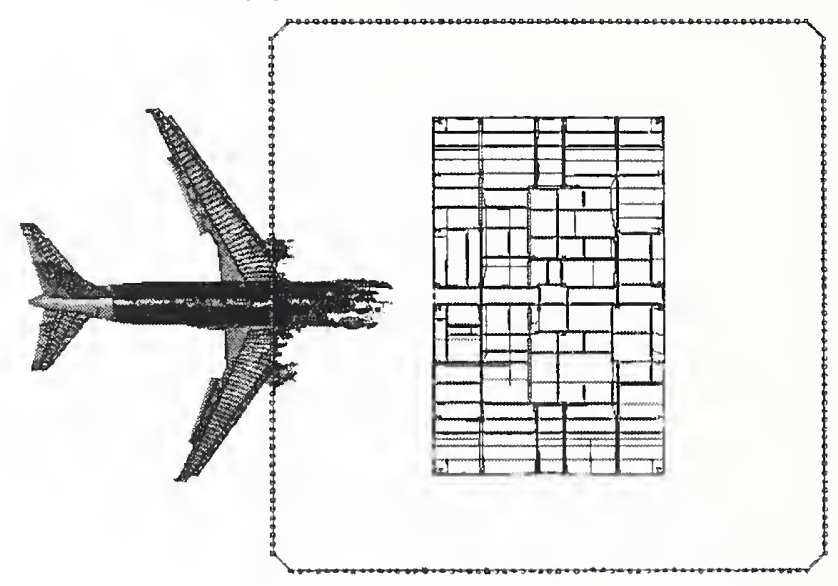

(b) Time $=0.10 \mathrm{~s}$

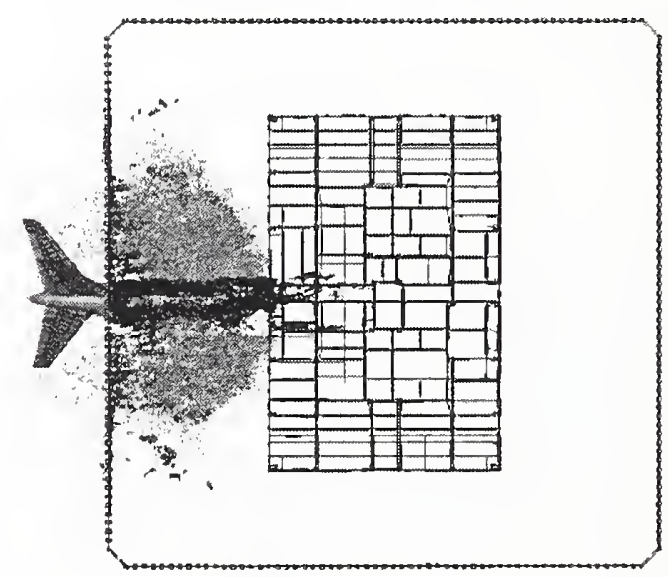

(c) Time $=0.20 \mathrm{~s}$

Figure 9-5. WTC 1 base case global impact analysis (plan view). 


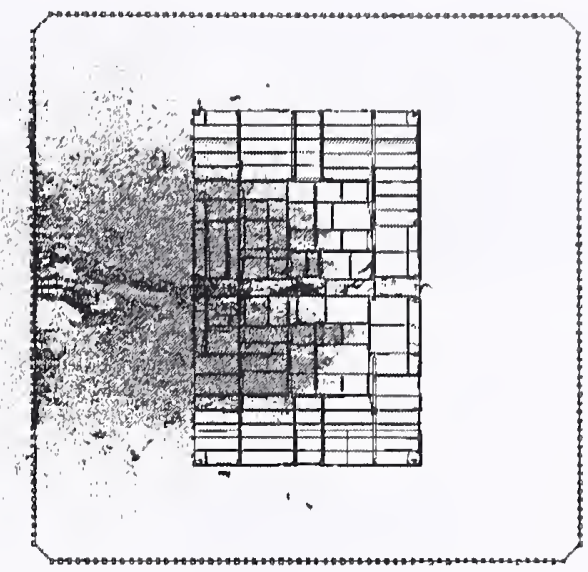

(d) Time $=0.30 \mathrm{~s}$

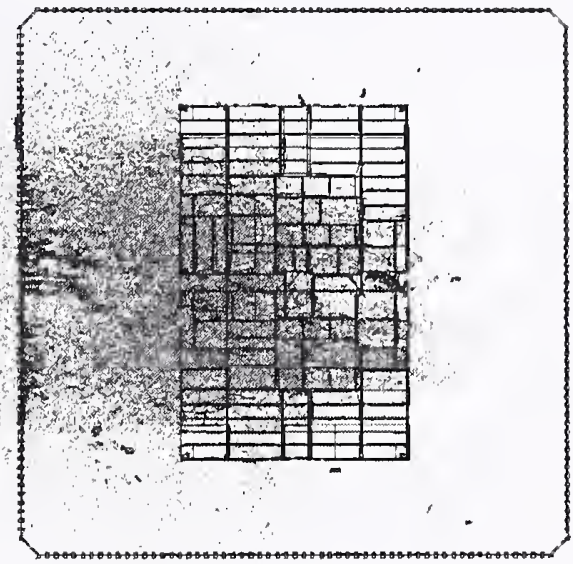

(e) Time $=0.40 \mathrm{~s}$

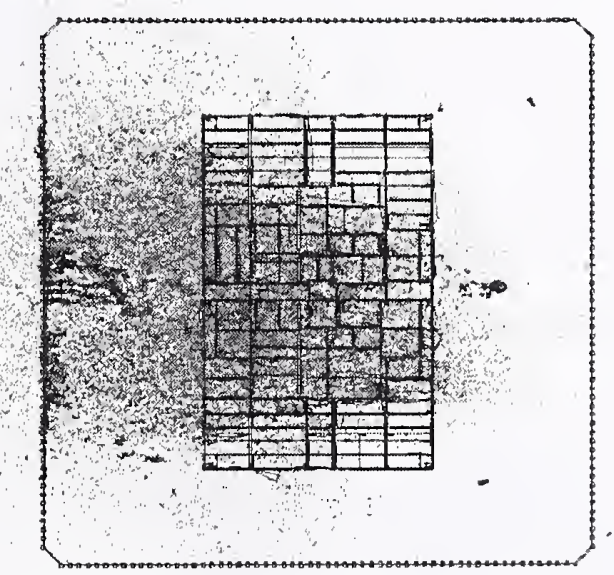

(f) Time $=0.50 \mathrm{~s}$

Figure 9-5. WTC 1 base case global impact analysis (plan view) (continued). 
At $0.2 \mathrm{~s}$ after impact, the wings had completely penetrated the exterior wall, and only the tail structures were still outside of the tower, as shown in Figure 9-4(c) and Figure 9-5(c). The wing structures were completely fragmented by the penetration through the exterior wall. The aircraft fuel cloud was starting to spread out, but was still relatively dense, and the leading edge of the fuel was just reaching the tower core. By $0.2 \mathrm{~s}$, the downward trajectory of the aircraft structures had transferred sufficient vertical load that the truss floor structures on the 95th and 96th floors were starting to collapse in the impact zone.

At $0.3 \mathrm{~s}$ after impact, the aircraft was completely inside of the tower (full penetration completed at approximately $0.25 \mathrm{~s}$ ), as shown in Figure 9-4(d) and Figure 9-5(d). The airframe was mostly broken up, but some large sections of the aft fuselage and tail were still intact, having penetrated through the opening in the tower wall produced by the forward fuselage structures. The aircraft fuel cloud penetrated approximately half the distance through the core and was spreading out. However, the subsequent motion of the aircraft fragments and fuel debris cloud began to be noticeably slowed beyond this time. The fuel and debris did continue to spread through the tower, but at a much slower rate, as seen in the remaining images in Figure 9-4 and Figure 9-5.

The load transfer of the aircraft impact can be shown by the history of the resultant momentum of the aircraft as shown in Figure 9-6. The momentum plotted is for all of the aircraft structures and contents (including fuel) and is normalized by the initial momentum magnitude. The curve illustrates an initial rate of load transfer during the first $0.1 \mathrm{~s}$ of impact as the forward fuselage penetrated the exterior wall and impacted the interior structures. Between $0.1 \mathrm{~s}$ and $0.25 \mathrm{~s}$, a more rapid load transfer rate was observed, as the area of the impact was greater (extending outward in the wing impact regions), and a higher percentage of the aircraft mass was impacting the interior structures. At $0.25 \mathrm{~s}$, as indicated in Figure $9-6$, the aircraft completely penetrated the building and retained approximately 30 percent of its initial momentum. Beyond this time, the rate of load transfer was steadily decreasing, with very little load transfer after approximately $0.5 \mathrm{~s}$.

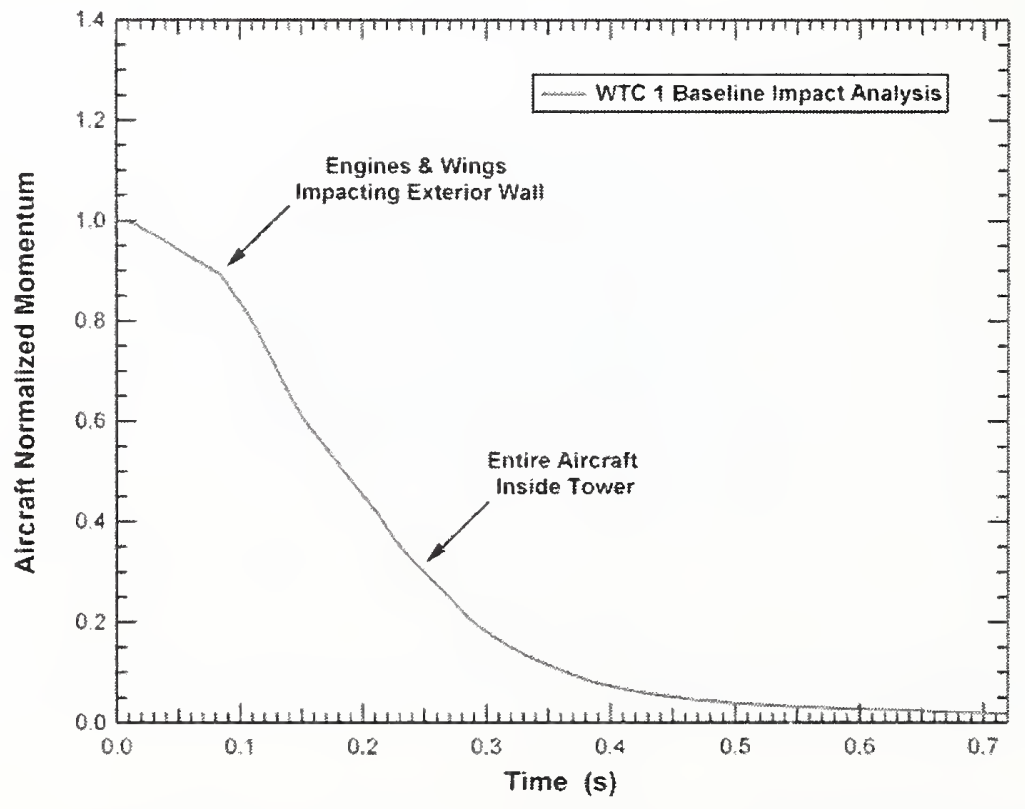

Figure 9-6. Normalized aircraft momentum for the WTC 1 base case impact. 
The aircraft was severely broken into debris as a result of the impaet with the tower, as shown in Figure 9-7. At the end of the impaet analysis, the aireraft was broken into thousands of debris fragments of various size and mass, as shown in Figure 9-7(b). A eloser inspeetion of the debris field shows that larger fragments still oeeurred for specific components sueh as the engines, shown in Figure 9-7(e). At the end of the simulation, the port engine was still inside the eore, and the starboard engine was roughly one third of the distanee from the core to the south extcrior wall. Both had a speed of less than $50 \mathrm{mph}$.

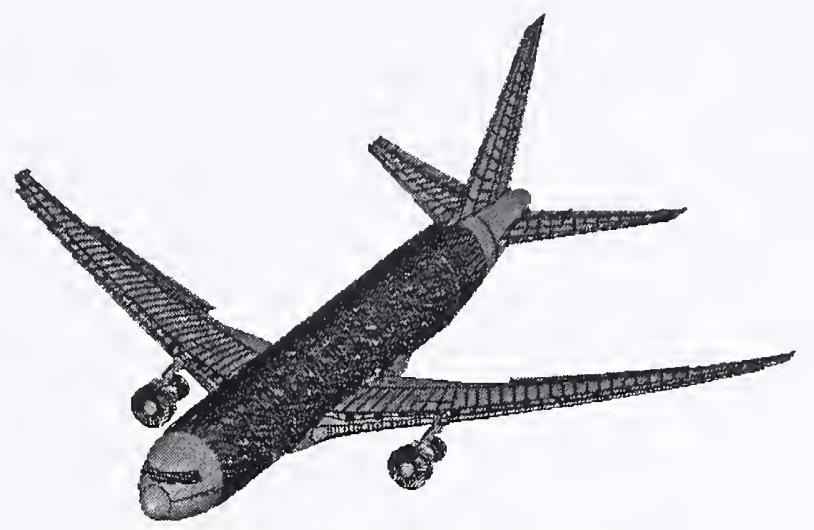

(a) Aircraft structure (time $=0.00 \mathrm{~s}$ )

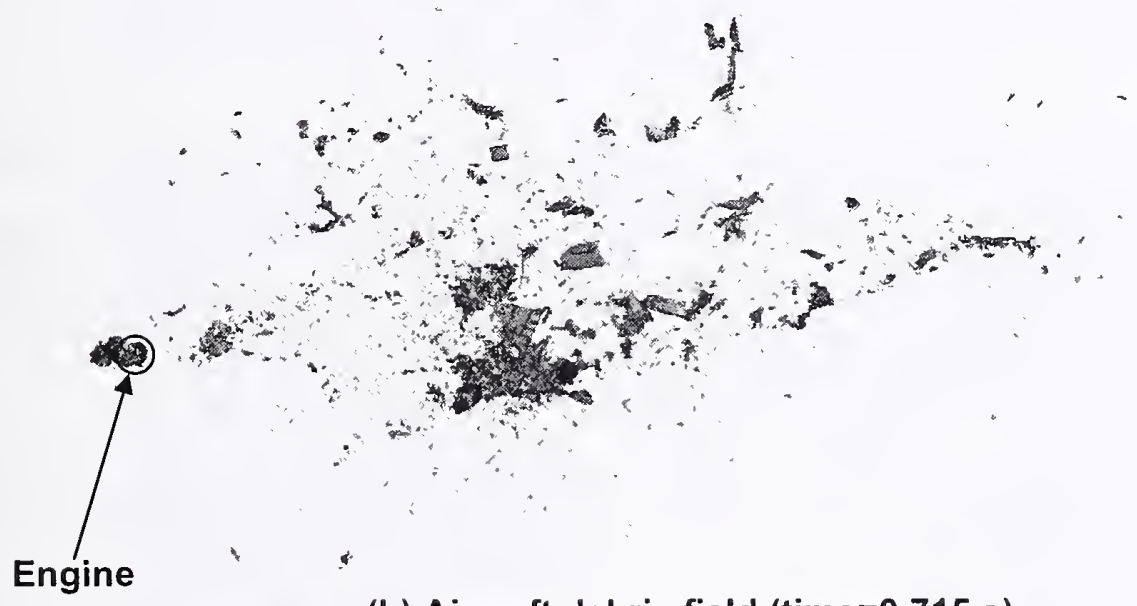

(b) Aircraft debris field (time $=0.715 \mathrm{~s}$ )
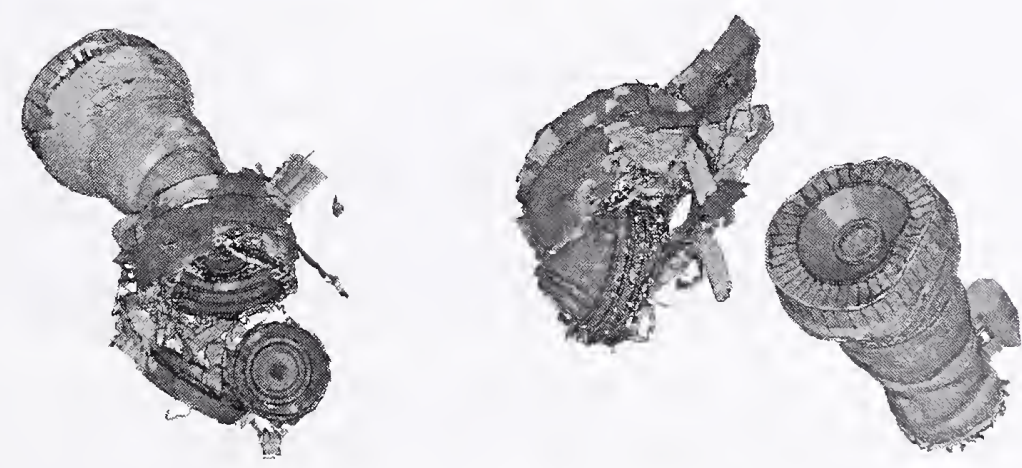

(c) Major engine debris (time $=0.715 \mathrm{~s}$ )

Figure 9-7. Aircraft breakup and debris in the base case WTC 1 impact. 


\subsubsection{WTC 1 Base Case Impact Analysis - Structural Damage}

The structural damage to the WTC 1 tower by the base case impact conditions is described in this section. The primary structural components of interest were the exterior wall, core columns and core framing components, and the floor structures and concrete floor slab. The response of the internal contents, walls, and partitions were also of interest to provide the initial conditions for the fire dynamics simulations.

\section{Exterior Wall Damage}

The calculated damage to the exterior wall is significant for two reasons: (1) the exterior wall contributed significantly to the strength of the tower, and the degradation in exterior wall strength was important for the collapse analyses, and (2) the exterior wall was the one structural system for which direct visual evidence of the impact damage was available. Therefore, the comparison of the calculated and observed exterior wall damage can provide a partial validation of the analysis methodologies used in the global impact analyses.

A comparison of the north exterior wall observed and calculated damage from the base case WTC 1 global impact analysis is shown in Figure 9-8. The calculated impact damage to the exterior wall is shown with color fringes representing plastic strain magnitude, with undamaged sections in blue and strains at or above 5 percent shown in red. The schematic of observed damage was developed from inspections of the video and photographic data collected on the tower after impact. Both the observed and calculated damage wall regions shown in Figure 9-8 illustrate a region of the exterior wall from column 108 to column 152, extending from floor 91 to floor 100 (spandrels at floors 92 through 100).

The first observation from the comparison of the calculated and observed damage was that the geometry and location of the impact damage zone were in good agreement. This agreement in the position and shape of the impact damage served to validate the geometry of the aircraft model, including the aircraft orientation, trajectory, and flight distortions of the wings.

The second observation was the agreement in the magnitude and mode of impact damage on the exterior wall. The exterior wall completely failed in the regions of the fuselage, engine, and fuel-filled wing section impacts. Damage to the exterior wall was observed all the way out to the wing tips, but the exterior columns were not completely failed in the outer wing and vertical stabilizer impact regions. Failure of the exterior columns occurred both at the bolted connections between column ends and at various locations in the column, depending on the local severity of the impact load and the proximity of the bolted connection to the impact. The agreement of both the mode and magnitude of the impact damage served to partially validate the constitutive and damage modeling of the aircraft and exterior wall of the tower.

\section{Core Structural Damage}

The determination of the damage to the core columns and core beams was important in determining the residual strength for the subsequent analyses of structural stability and collapse. The overall model for the core structure and calculated impact damage to the core is shown in Figure 9-9. The figure shows that the core had significant damage in the region close to the impact point. The columns in line with the 
aircraft fuselage failed on the impact side, and several of the core beams were also severely damaged or failed in the impact zone.

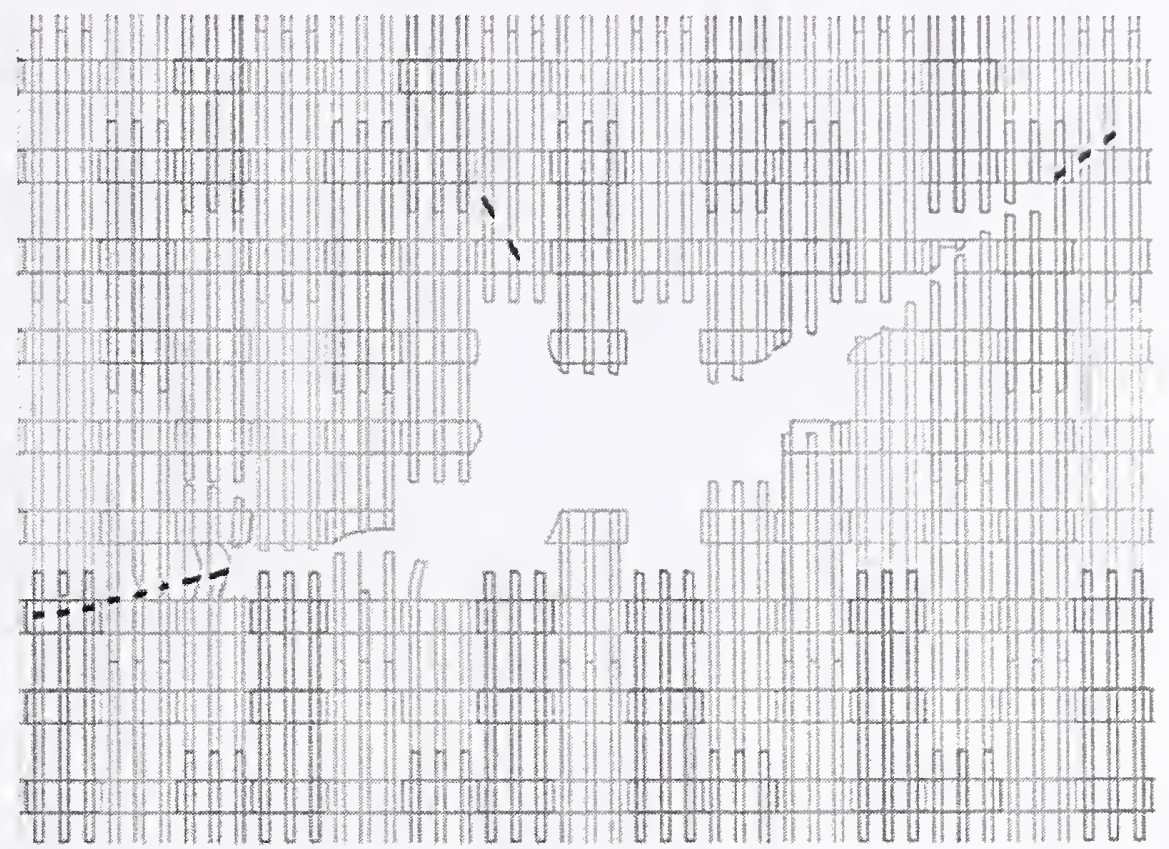

(a) Schematic of observed damage

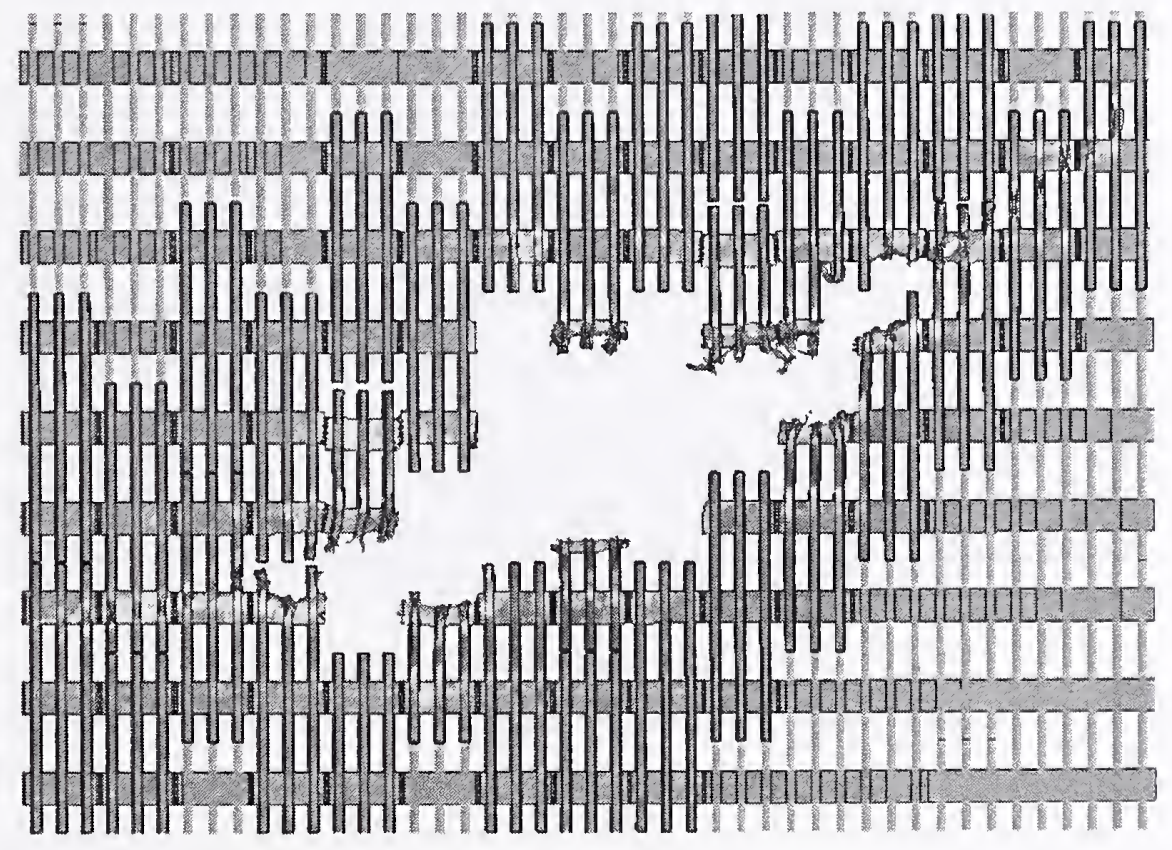

(b) Calculated damage ( $\mathrm{t}=0.715 \mathrm{~s}$ )

Figure 9-8. Base case impact damage to the WTC 1 exterior wall. 


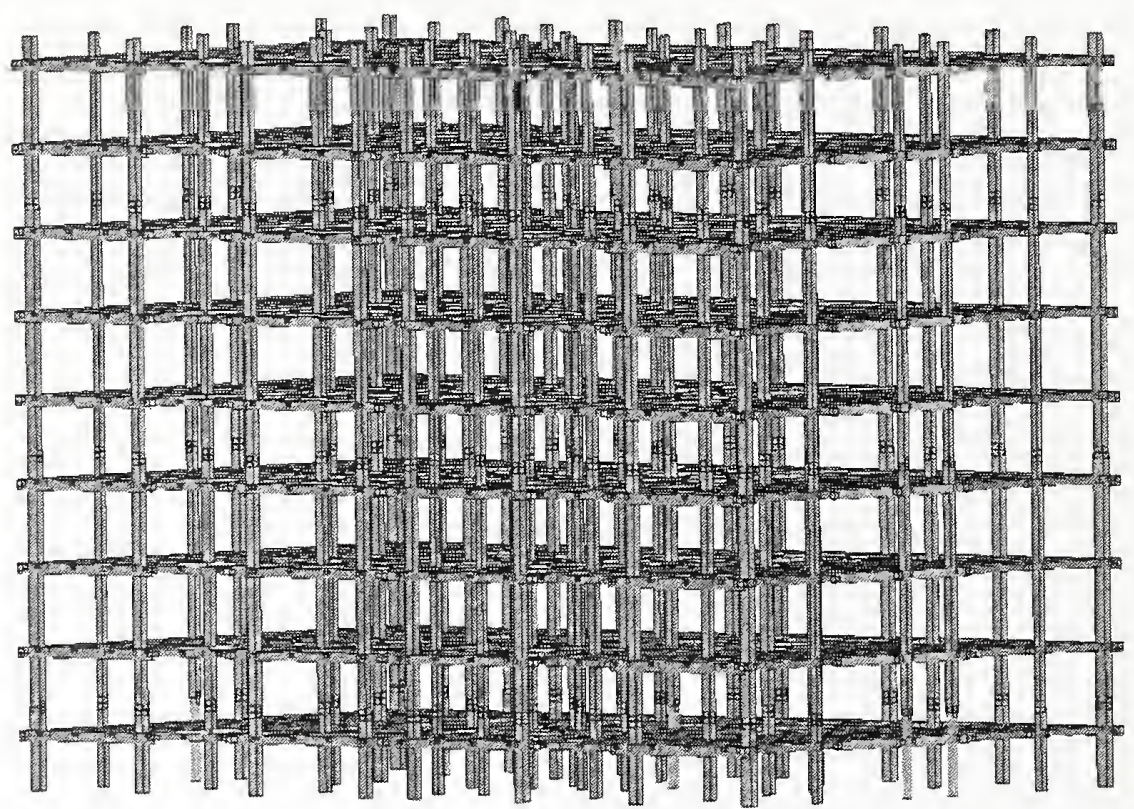

(a) Initial geometry

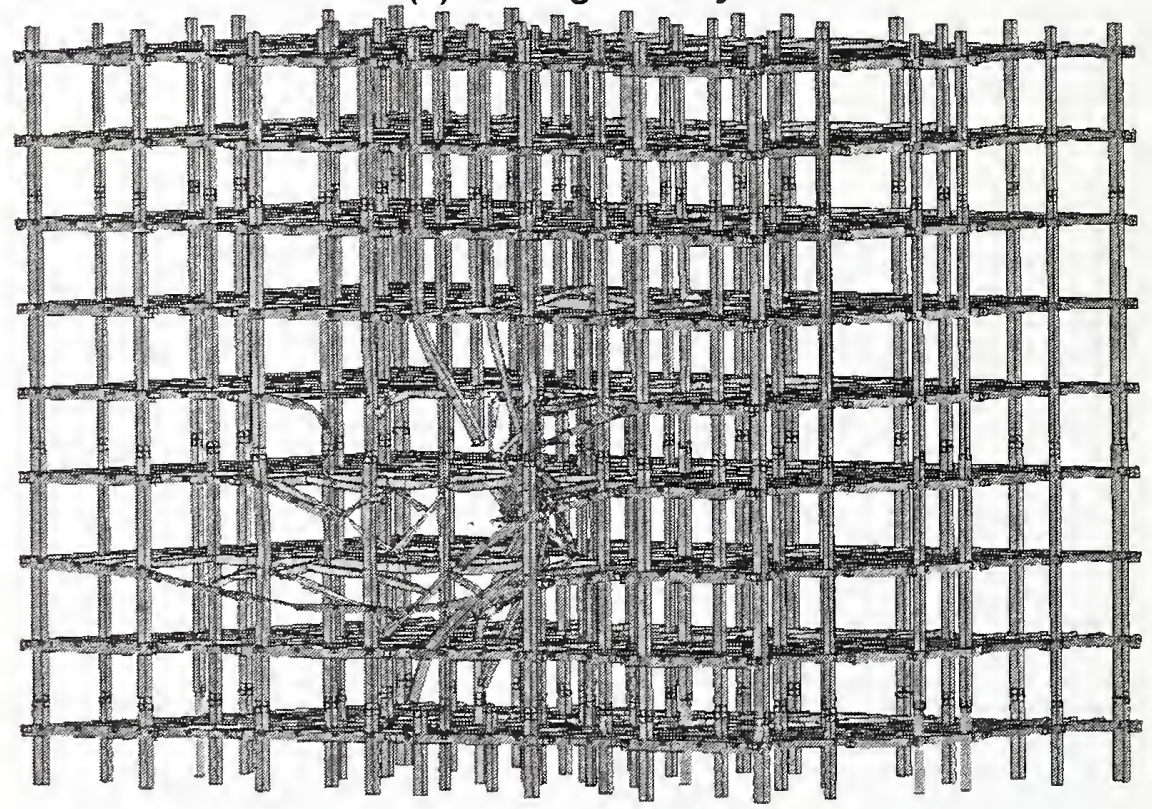

(a) Calculated impact damage

Figure 9-9. Base case impact damage to the WTC 1 core frame structures. 
The calculated damage to the corc columns by row is shown in Figurc 9-10. The columns are shown with color fringes representing plastic strain magnitude with undamaged sections in bluc and strains at or above 5 percent shown in red. A summary of the column damagc is listcd in Tablc 9-3 and shown graphically in Figure 9-11. The qualitative classification of the column damage lcvels is shown in Figure 9-12. The classification levels were light damage, moderatc damagc, hcavy damagc, and failcd (severed). The light damage level was defined as having evidence of impact (low levcl plastic strains), but without significant structural deformations. The moderate damagc lcvel had visible local distortions of the column cross section (e.g. bending in a flangc) but no latcral displacements of the column centerline. The heavy damage classification was for impacts that produced global deformation of the column, resulting in a permanent deflection of the column centerlinc. The scvercd columns were completely failed and could carry no residual load. A summary of the floor-by-floor damagc to the core framing is shown in Figure 9-13.

$\mathrm{P}-\Delta$ effects generated due to the sway of the towers aftcr impact, as observed in video evidence (see NIST NCSTAR 1-5A), were not expected to affect or impose additional damage to the core columns. The core columns were designed as axially loaded members without continuity of framing, and thus would not develop significant P- $\Delta$ moments (see Chapter 5 of NIST NCSTAR 1-2A).

\section{Floor Truss and Slab Damage}

The impact damage to the floor trusses and floor slabs could contribute significantly to the loss of structural strength and subsequent collapse. The truss floor sections provided lateral support to the exterior wall at each floor level. Any damage or holes in the concrete floor slab could provide a path for the fires to spread from floor-to-floor. Therefore, the calculation of the floor system damage was an important component of the global impact analyses.

An overall front view of the floor truss structure in the impact zone, along with the calculated impact damage to the floor trusses, is shown in Figure 9-14. The truss structures shown are for the detailed truss floor section models described in Section 3.2.3 and Section 3.2.5. The figure is from a view point exterior to the tower, looking toward the impact point, and shows that the trusses experienced significant damage in the impact zone. A plan view of the calculated damage to the truss on each floor is shown in Figure 9-15. The calculated impact response produced severe damage to the truss structures in the primary impact path of the fuselage. The truss structures were severely damaged from the exterior wall to the core. The truss floor system on floors 94 through 96 were damaged and sagging downward as a result of the impact loading. 


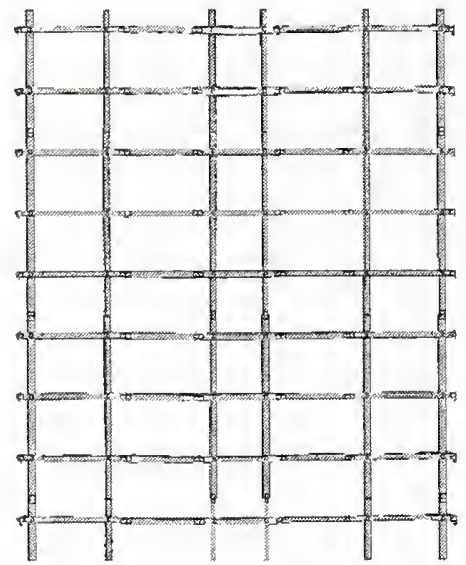

(a) Columns 501-1001

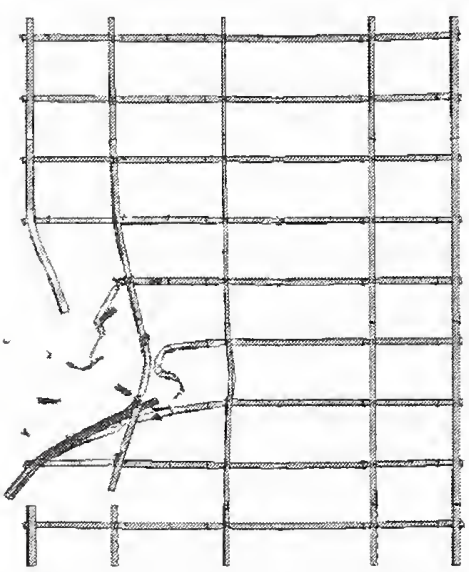

(d) Columns 504-1004

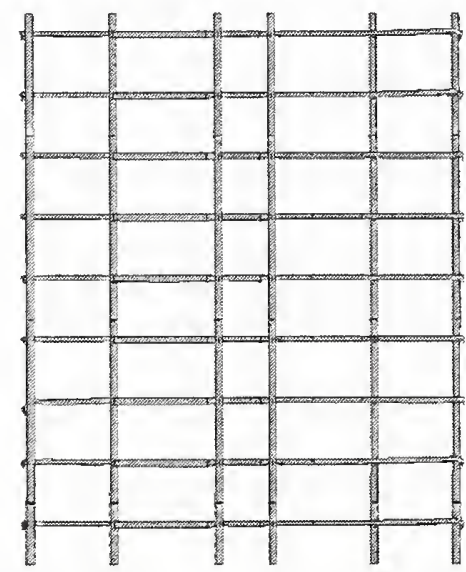

(g) Columns 507-1007

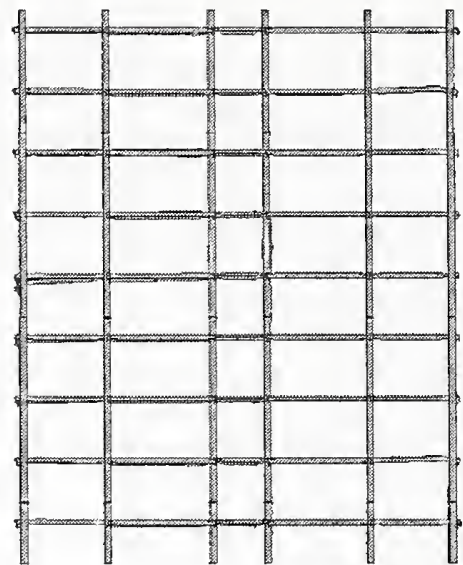

(b) Columns 502-1002

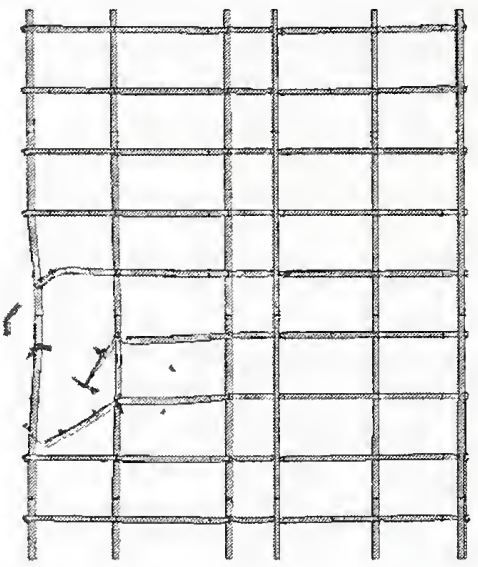

(e) Columns 505-1005

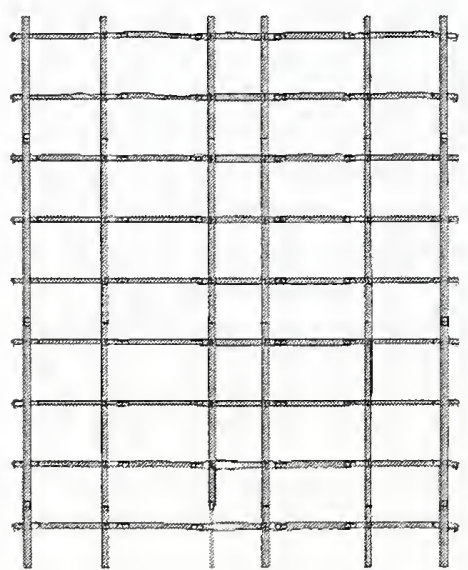

(h) Columns 508-1008

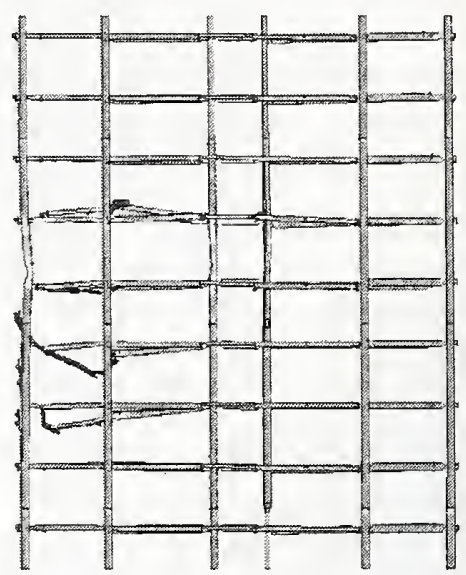

(c) Columns 503-1003

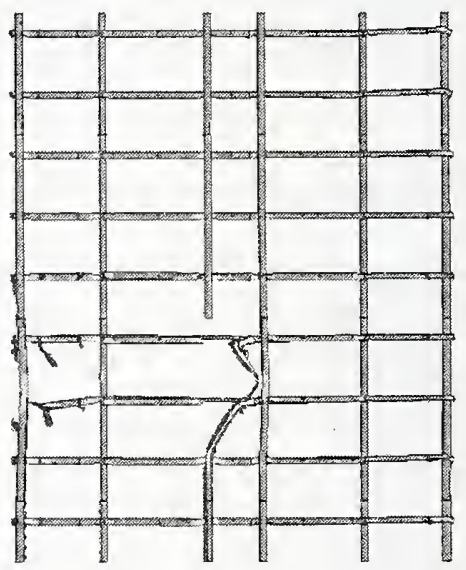

(f) Columns 506-1006

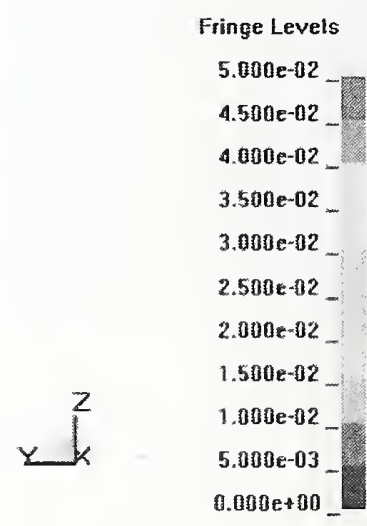

(i) Reference scale

Figure 9-10. Base case impact damage to the WTC 1 core columns. 
Table 9-3. Summary of core column damage for the base case WTC 1 impact.

\begin{tabular}{|c|c|c|c|}
\hline Column & Location & Damage Level & $\begin{array}{c}\text { Lateral Deflection of } \\
\text { Column Centerline (in.) }\end{array}$ \\
\hline Column 503 & Floor 96 & Heavy & 18 \\
\hline Column 504 & Floors 92-96 & Severed & \\
\hline Column 505 & Floors 93-96 & Heavy & 20 \\
\hline Column 506 & Floors 93-94 & Heavy & 10 \\
\hline Column 604 & Floors 92-96 & Severed & \\
\hline Column 605 & Floors 94-95 & Moderate & \\
\hline Column 702 & Floor 96 & Moderate & \\
\hline Column 703 & Floor 96 & Moderate & \\
\hline Column 704 & Floor 94 & Heavy & \\
\hline Column 705 & Floor 95 & Moderate & \\
\hline Column 706 & Floors 93-95 & Severed & \\
\hline Column 802 & Floor 96 & Moderate & \\
\hline Column 805 & Floor 94 & Moderate & \\
\hline
\end{tabular}

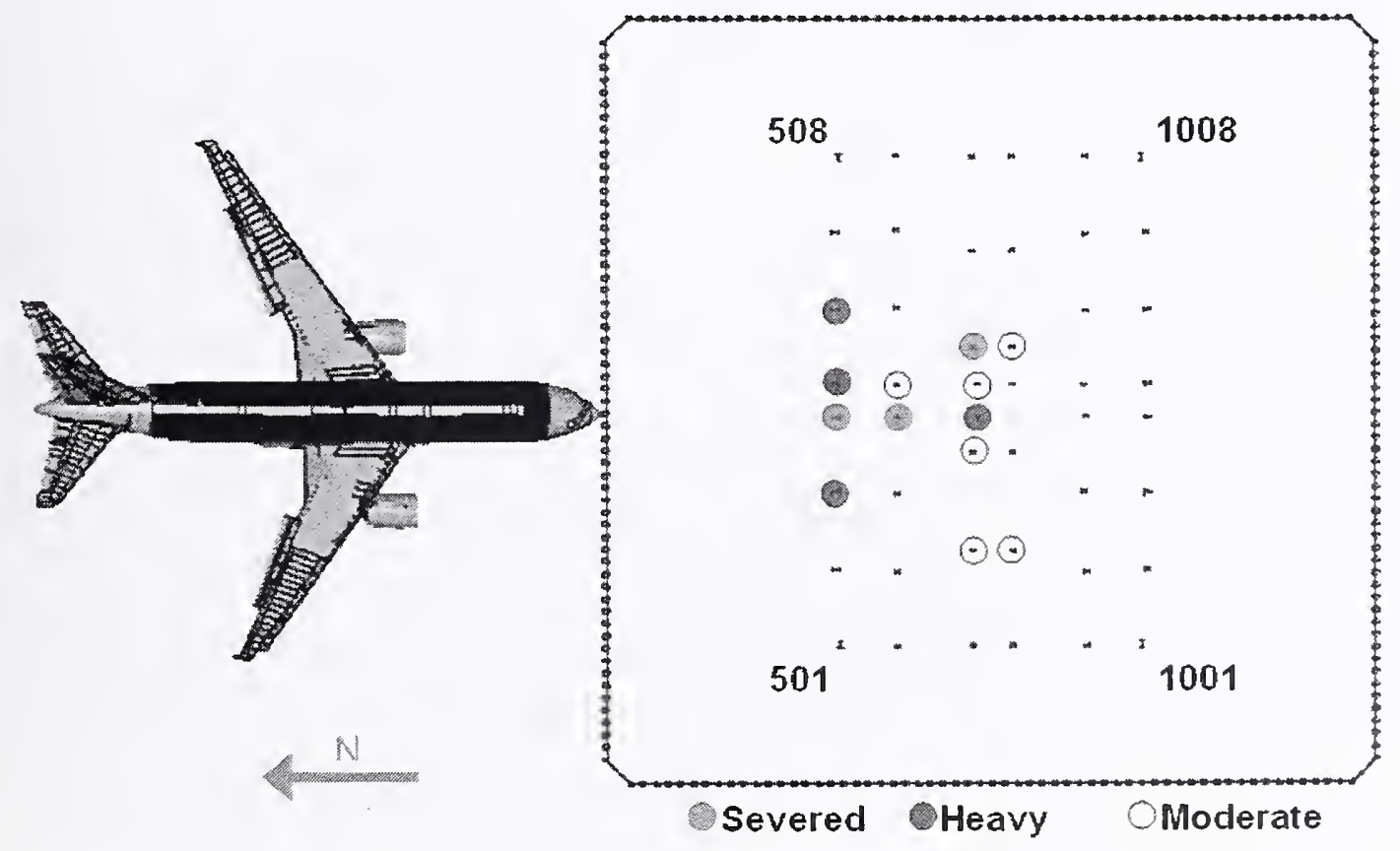

Figure 9-11. Summary of core column damage for the base case WTC 1 impact. 

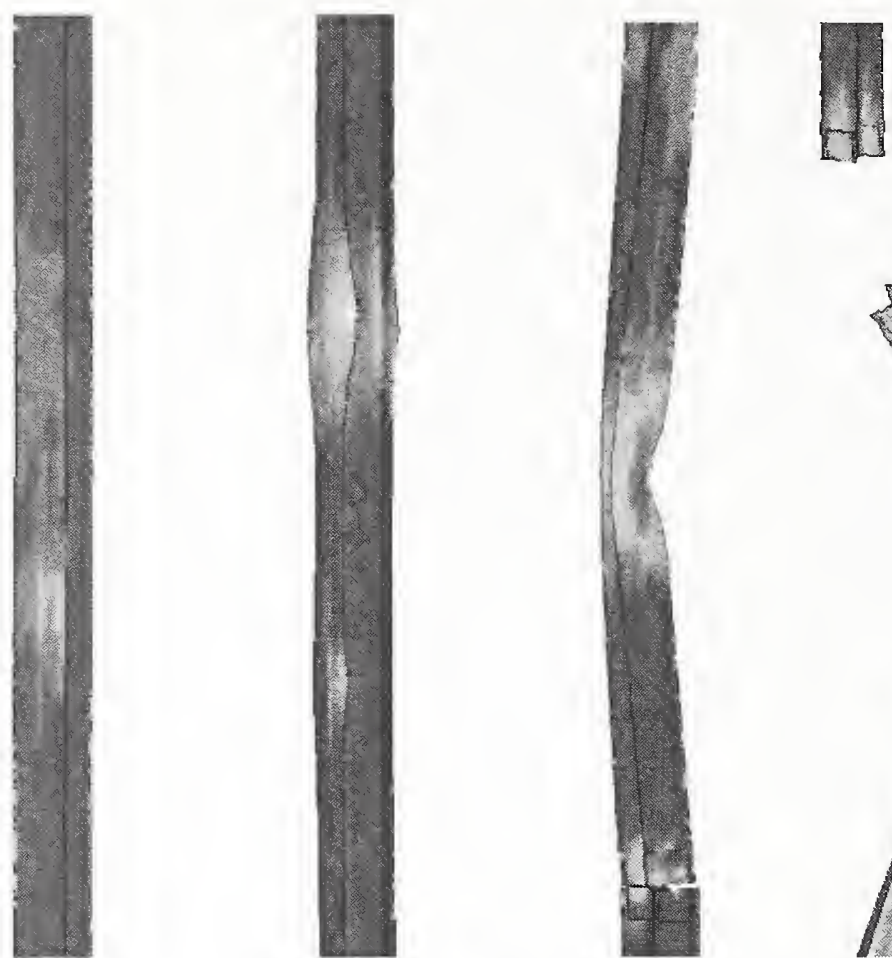

Fringe Levels

$1.000 \mathrm{e}-01$

$9.000 e-02$

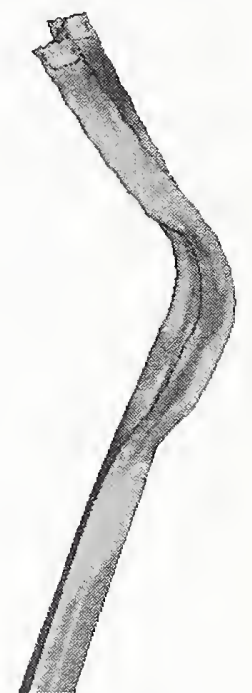

$8.000 \mathrm{e}-02$

$7.000 \mathrm{e}-12$

$6.000 \mathrm{e}-02$

$5.000 \mathrm{e}-02$

$4.000 \mathrm{e}-02$

$3.000 \mathrm{e}-02$

$2.000 \mathrm{e}-12$

$1.000 \mathrm{e}-02$

$0.000 \mathrm{e}+00$
(a) Light
(b) Moderate
(c) Heavy
(d) Severed

Figure 9-12. Classification of damage levels in core columns. 


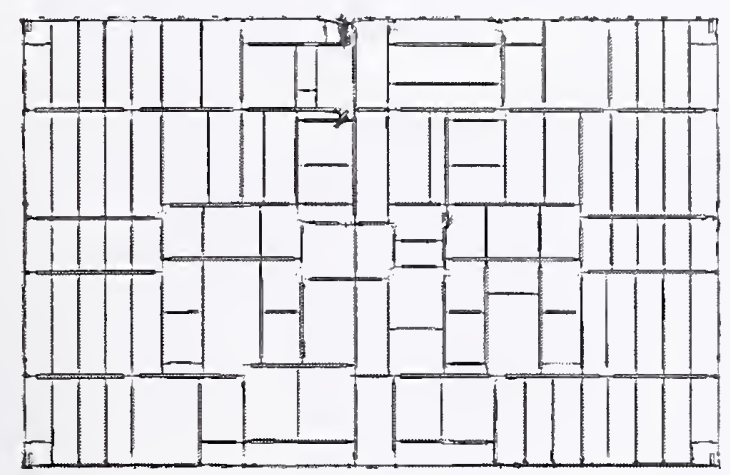

(a) Floor 93 core framing damage

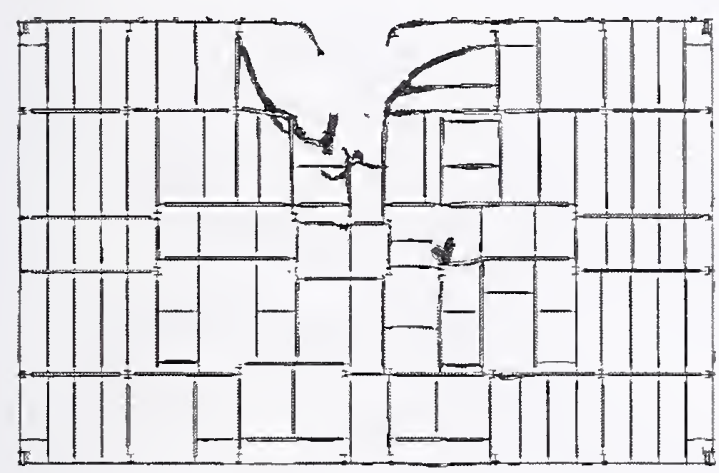

(c) Floor 95 core framing damage

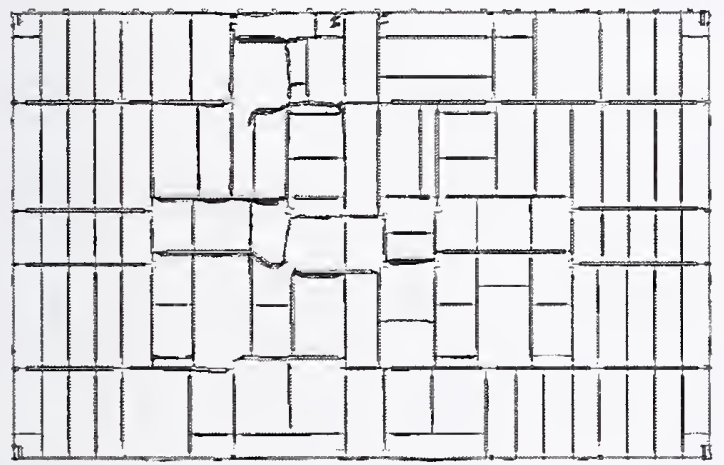

(e) Floor 97 core framing damage

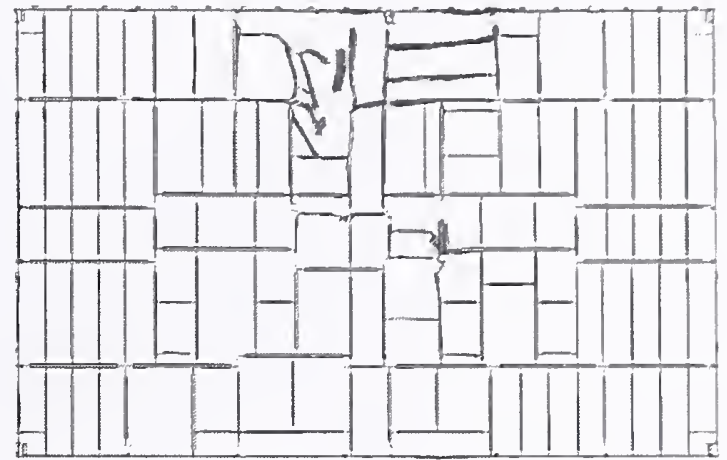

(b) Floor 94 core framing damage

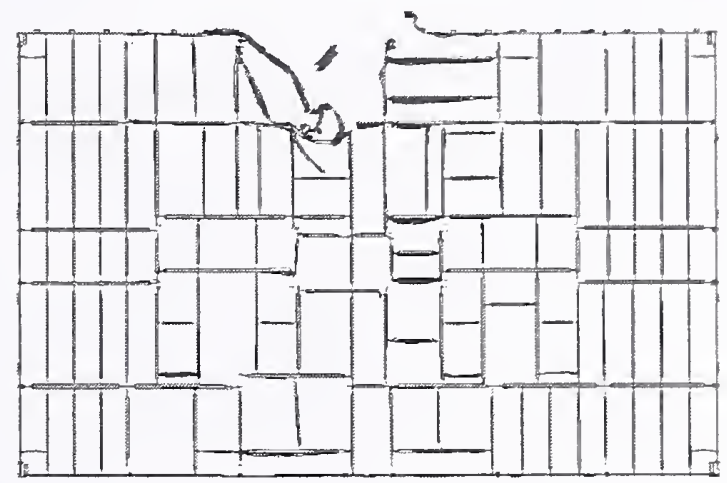

(d) Floor 96 core framing damage

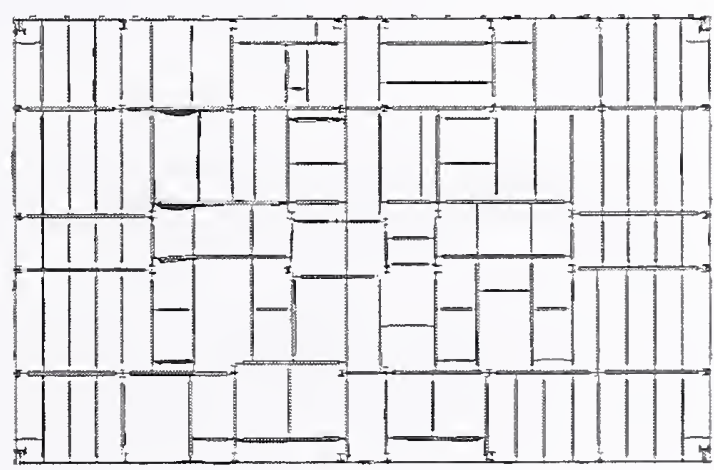

(f) Floor 98 core framing damage

Figure 9-13. Base case impact damage to the WTC 1 core floor framing (plan view). 

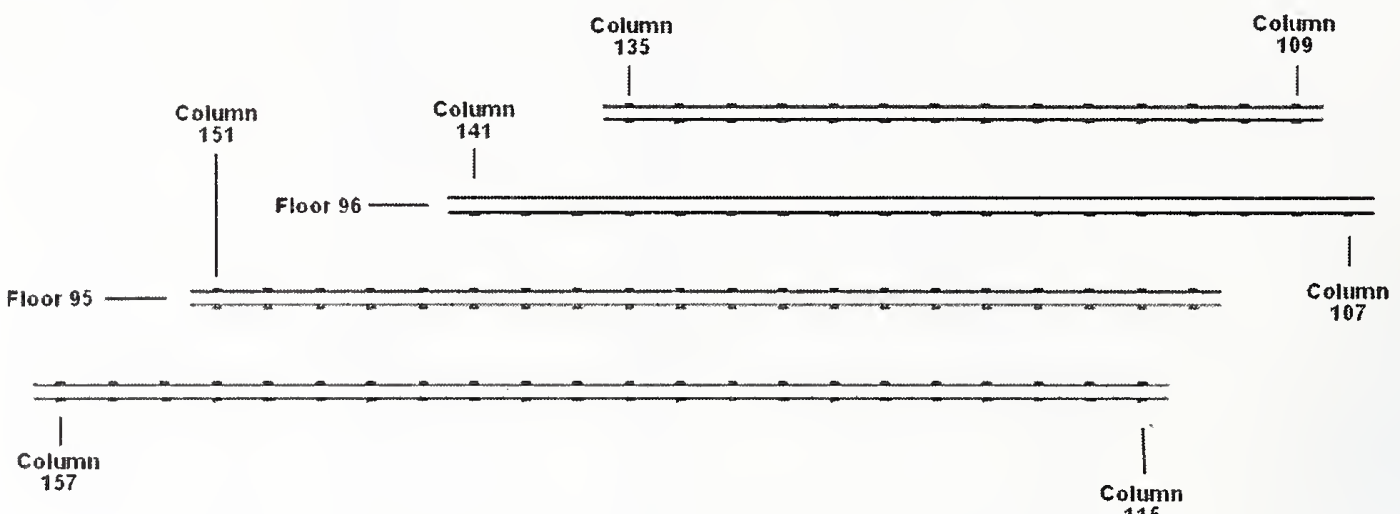

(a) Initial detailed truss structures

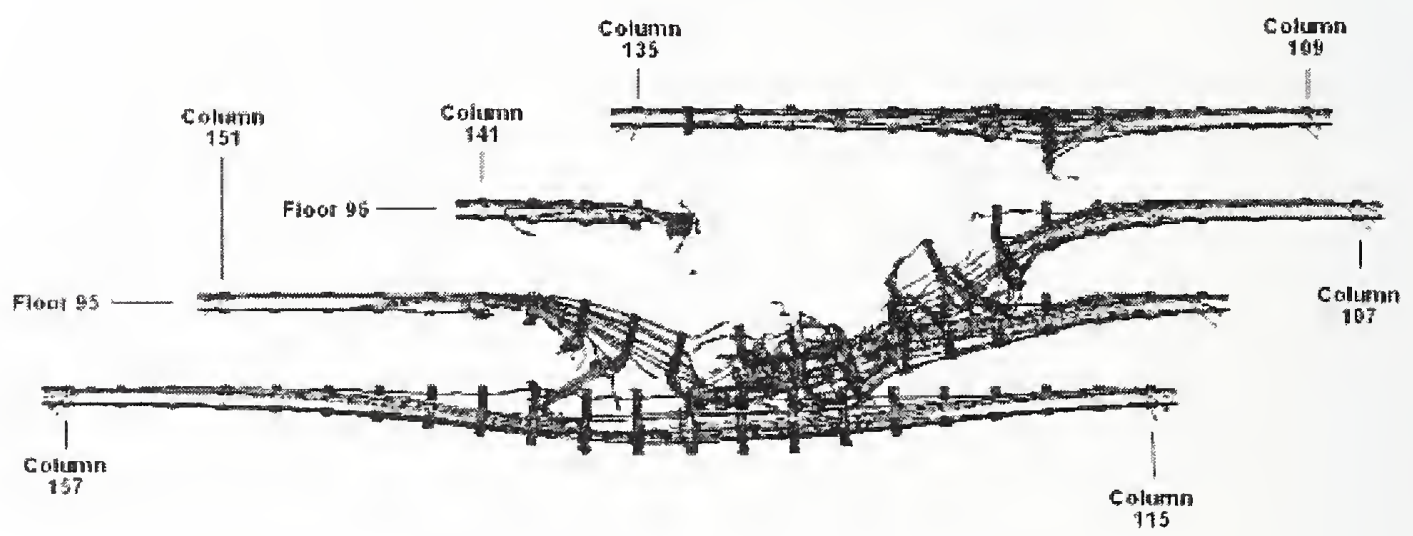

(b) Calculated damage $(\mathrm{t}=\mathbf{0 . 7 1 5} \mathrm{s})$

Figure 9-14. Base case impact damage to the WTC 1 floor trusses (front view).

The calculated damage to the WTC 1 floor slab for floors 94 through 97 is shown in Figure 9-16. The fringes of damage were set such that the concrete slab failed in the regions colored red ( 2 percent plastic strain was used corresponding to the zero strength strain limit for the concrete in unconfined compression). At these strain levels, the concrete was severely damaged and probably removed, exposing the supporting metal decking. Beyond 2 percent plastic strain, the strength of the floor slab was severely reduced in the analyses to model the residual strength of the metal deck after the concrete failure, breakup, and removal. At a plastic strain of 30 percent, corresponding to failure levels for the metal decking material, the elements were eroded (seen as holes ruptured in the floor slabs shown). The line of damage, visible around the edge of the core in Figure 9-16, is believed to be the result of numerical precision errors and interference in the modeling methodology at the connection of the floor slab rather than impact damage. 


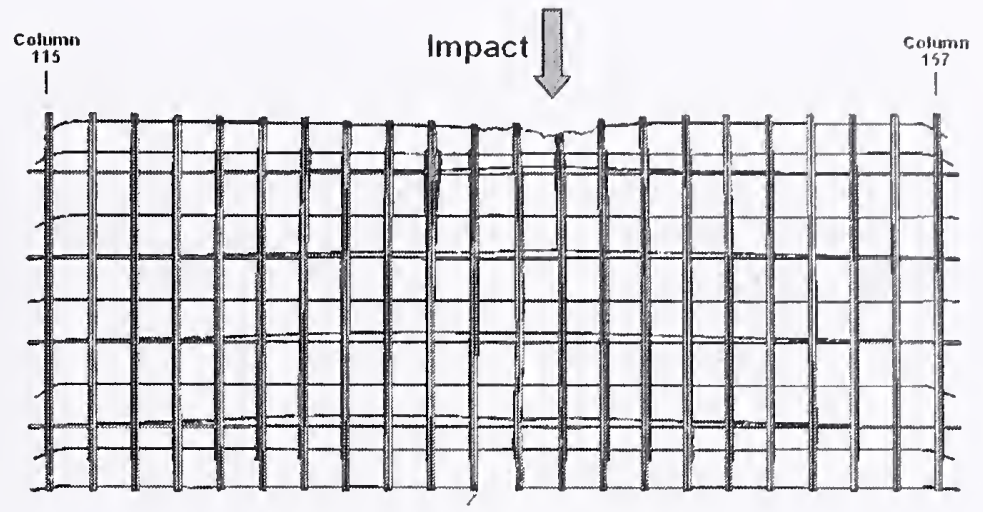

(a) Floor 94 truss damage

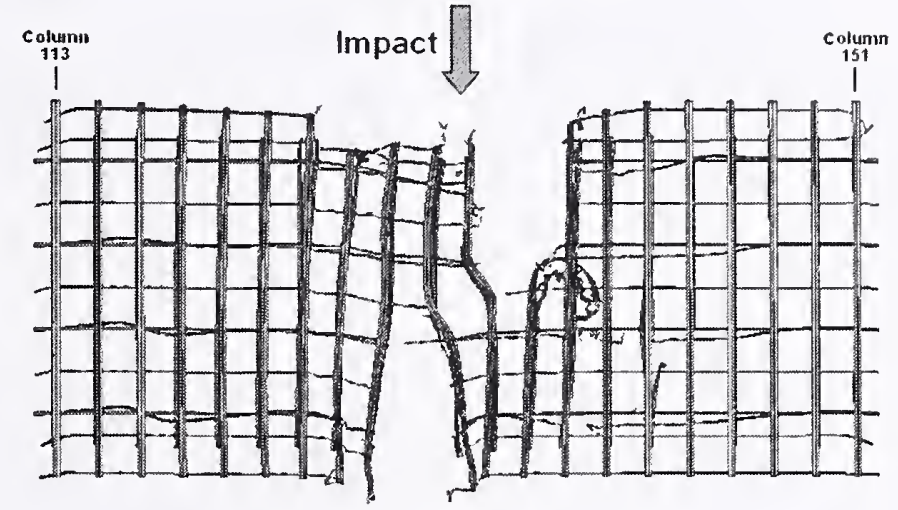

(b) Floor 95 truss damage

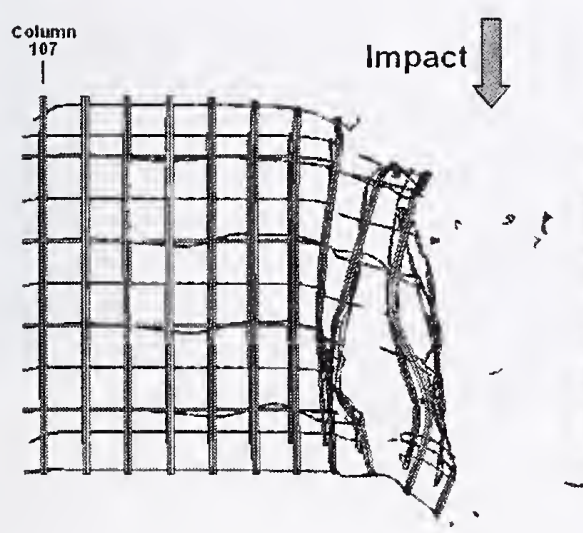

(c) Floor 96 truss damage

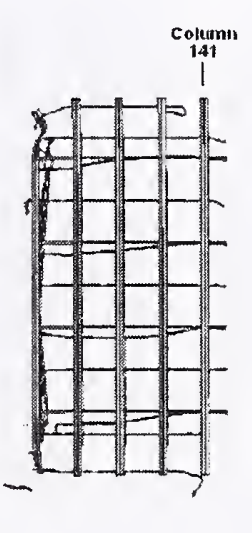

Figure 9-15. Base case impact damage to the WTC 1 floor trusses (plan view). 


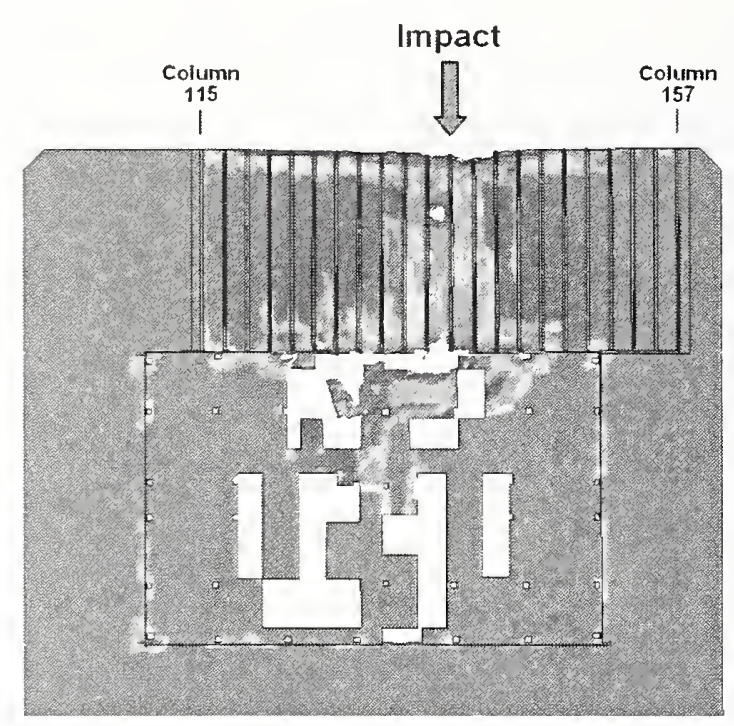

(a) Floor 94 slab damage Impact

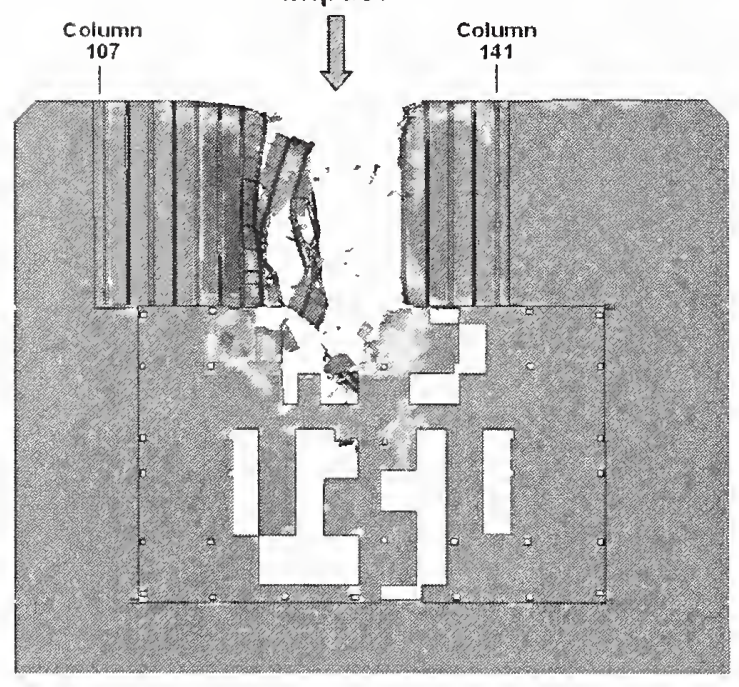

(c) Floor 96 slab damage

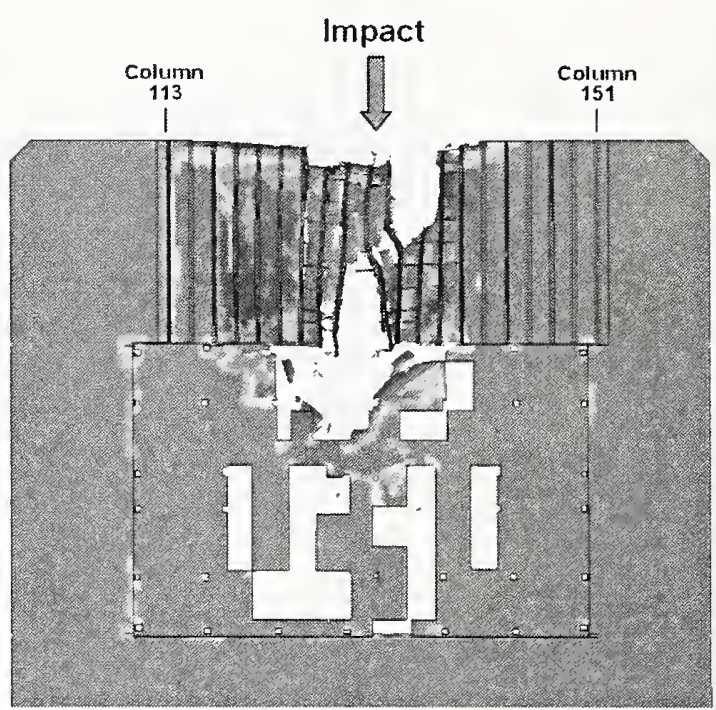

(b) Floor 95 slab damage

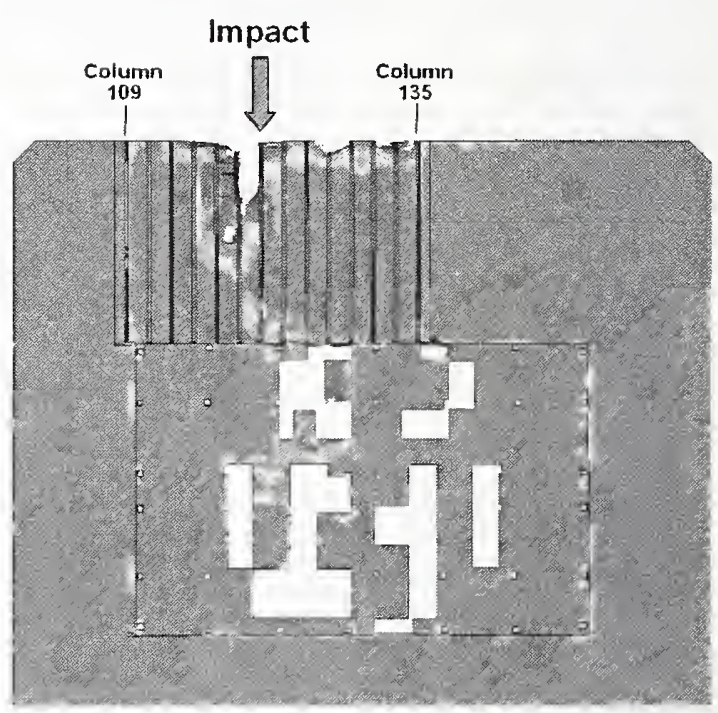

(d) Floor 97 slab damage

Figure 9-16. Base case impact damage to the WTC 1 floor slab (plan view).

\subsubsection{WTC 1 Base Case Impact Analysis - Fuel and Debris Distributions}

The objectives of the global impact analyses included the determination of both the structural damage and the initial conditions that influenced the initiation and propagation of the fires in the towers, including the distribution of the jet fuel in the towers, the distribution of tower contents and aircraft debris that provided flammable materials for the fires, and the condition of the partitions and walls that provided barriers to air flow and spreading of the fires.

The global impact results presented in this section included the distribution of the jet fuel inside the tower, the damage to the building contents (partition walls and workstations), and the aircraft debris distribution in the towers. The jet fuel was modeled using the smoothed particle hydrodynamics (SPH) algorithm in 
LS-DYNA, as described in Section 5.5.3. For the base case WTC 1 global impaet analysis, the ealeulated distribution of the fuel in the tower and shape of the fuel cloud in a plan view and side vicw arc shown in Figure 9-17 and Figure 9-18, respectively. At the termination of the global impact analysis, the residual momentum of the jet fuel in the impact direetion was less than one percent of the initial momentum, indieating that the fuel eloud was nearly at rcst at about $0.715 \mathrm{~s}$.

To more clearly present the ealeulated response of the structures that influenced the firc propagation, thc structural components were rcmoved from the visualization, with the exeeption that the core columns were maintained in the visualizations for reference positions. A plan view of the response of the remaining building contents and aireraft debris is shown in Figure 9-19. Similar plan views of floor-byfloor slices through the building eontents and debris field are provided in Figure 9-20 through

Figure 9-24 for floors 94 through 98, respectively. The bulk of the aircraft debris and fuel were arrested prior to exiting the far side of the tower core. A small amount of aircraft debris was calculated to exit the far side of the tower (south wall of WTC 1).

A quantitative characterization of the fuel and aircraft debris distribution was obtained by slicing the model at vertical floor locations and calculating the mass at each floor level. A summary of the floor-byfloor fuel and debris distributions is given in Table 9-4. The bulk of the fuel and aircraft debris was dcposited in floors 93 through 97, with the greatest concentration on floor 94 . Approximately 18,000 lb, or 7 percent, of aircraft mass was eliminated from the debris cloud at the final state as a result of the erosion in the aireraft struetures due to impact and breakup. This mass was not accounted for in the fuel and debris distributions provided in Table 9-4. A first approximation would be to increase the airframe debris distribution proportionately to account for the eroded mass. This eroded mass was maintained in the calculation but was no longer included in the contact algorithm. As a result, any residual momentum at the time of erosion could not be subsequently transferred to the tower.

The calculated debris distribution included $17,400 \mathrm{lb}$ of debris and $6,700 \mathrm{lb}$ of aircraft fuel outside of the tower at the end of the impact analysis, either rebounding from the impact face (north wall) or passing through the tower (south wall). These estimates of mass outside the tower were expected to be overestimated in the calculation since the exterior walls were not modeled with windows that eould contain the fuel cloud and small debris inside the towers. In addition, the impact behavior of the aireraft fuel cloud did not include the ability to stick to, or wet, interior components. Rather, the aircraft fuel SPH particles tended to bounce off of internal structures.

The physies of fuel impaet and dispersion in this type of impact event is complex and no appropriate validation data could be found. The fuel starts as a continuous fluid within the tanks and ends up distributed both on the tower structures and as small droplets that interaet with the atmosphere surrounding the impact zone. No single analysis technique is eurrently available that can analyze this full range of fuel dispersion without significant uncertainties.

Both the SPH and ALE analysis techniques (see Section 5.5.3) available for the analysis of the fuel impact and dispersion had limitations. Details of the fuel behavior such as the wetting of the fuel against tower structures and interior contents or the physies of the fuel breakup into droplets are not accurately reproduced in either analysis technique. However, the momentum transfer from the fuel to the tower structures and subsequent impaet damage produced by the fuel ean be modeled by both analysis techniques. 
Time $=0.715$

$+\stackrel{1}{1}^{x}$

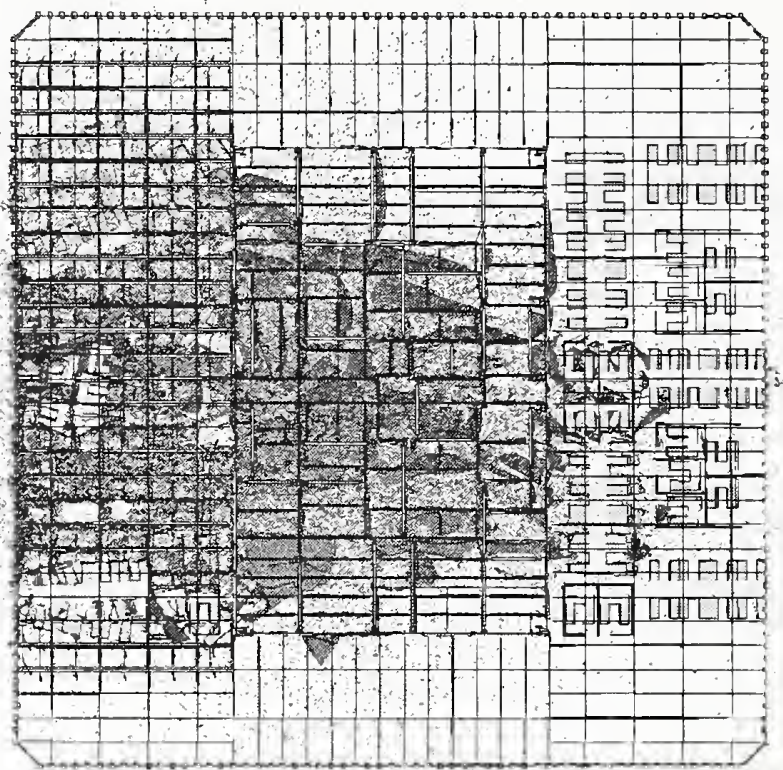

(a) Calculated impact response (floor slab removed)

Time $=\mathbf{0 . 7 1 5}$

(b) SPH fuel distribution

Figure 9-17. Calculated fuel distribution in the base case WTC 1 analysis (plan view). 
Time $=0.715$

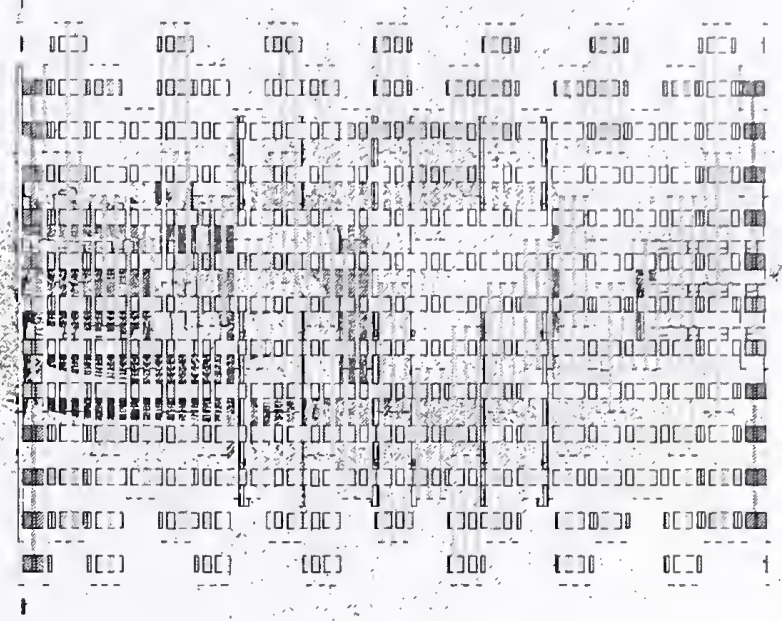

$\frac{2}{2}$

(a) Calculated impact response

Time $=0.715$

(b) SPH fuel distribution

Figure 9-18. Calculated fuel distribution in the base case WTC 1 analysis (side view). 


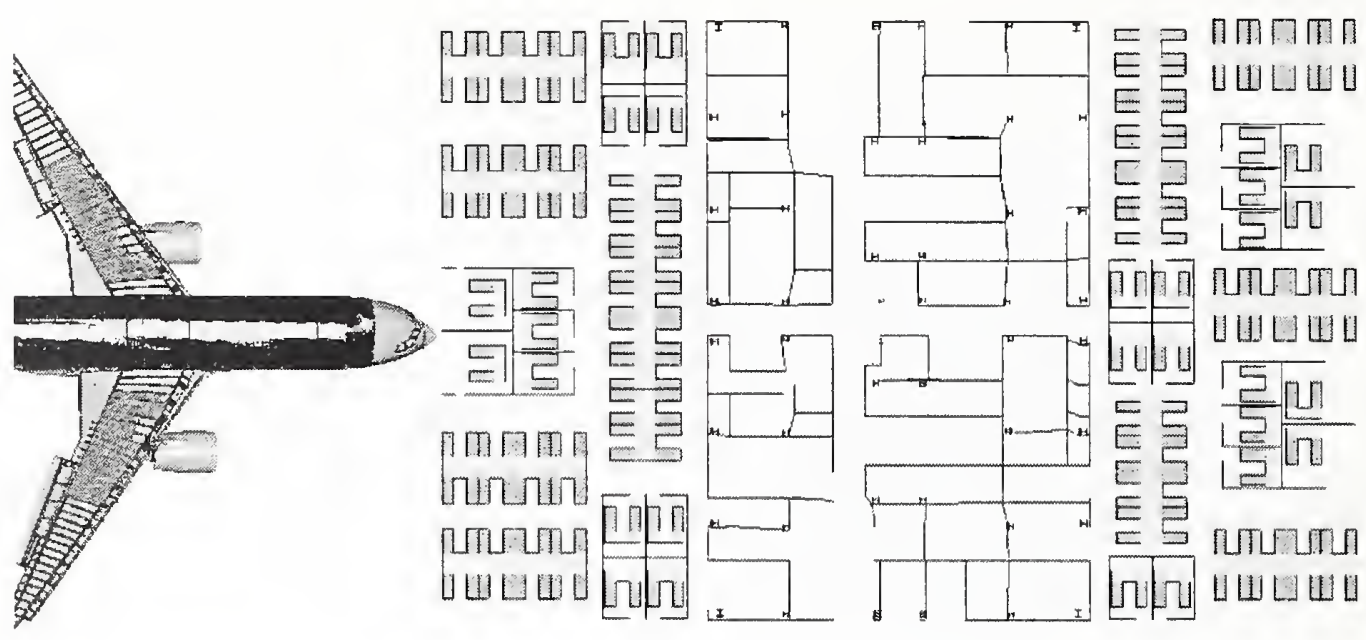

(a) Impact configuration (plan view)

Time $=-0.715$

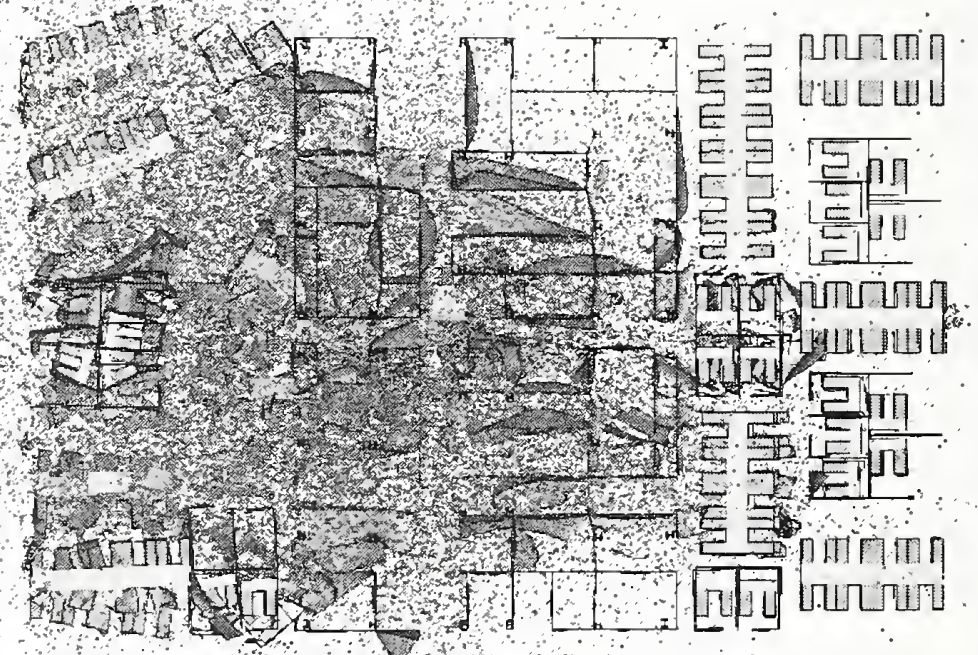

(b) Calculated impact response $(\mathrm{t}=\mathbf{0 . 7 1 5 )}$

Figure 9-19. Calculated WTC 1 building contents, fuel, and aircraft debris distribution. 


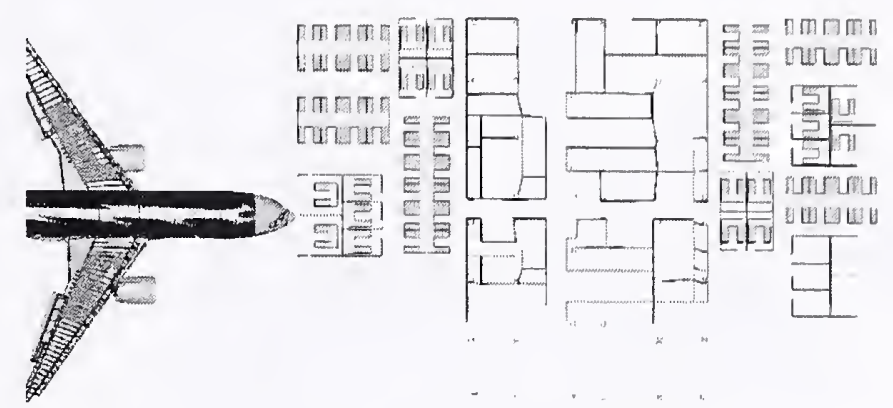

(a) Initial impact configuration

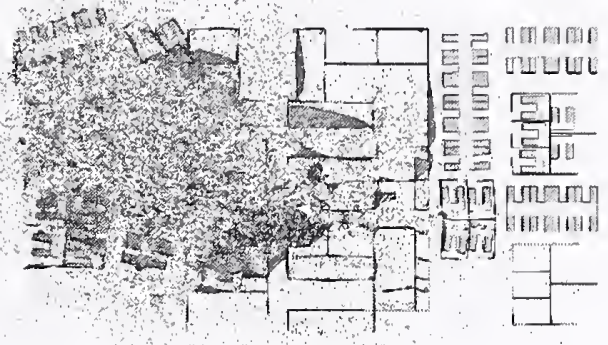

(b) Calculated impact response

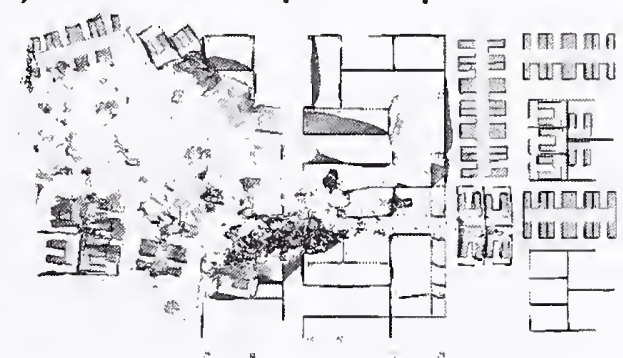

(c) Calculated impact response (fuel removed)

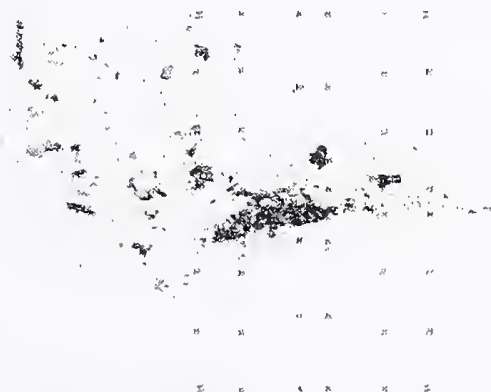

(d) Calculated aircraft debris

Figure 9-20. Calculated floor 94 contents, fuel, and aircraft debris distribution. 


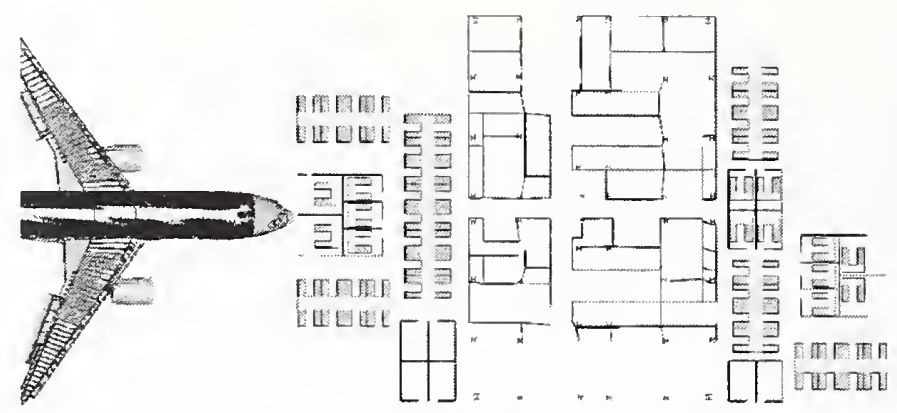

(a) Initial impact configuration

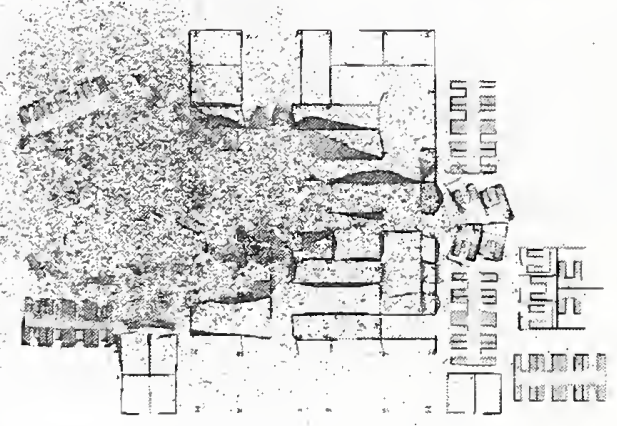

(b) Calculated impact response

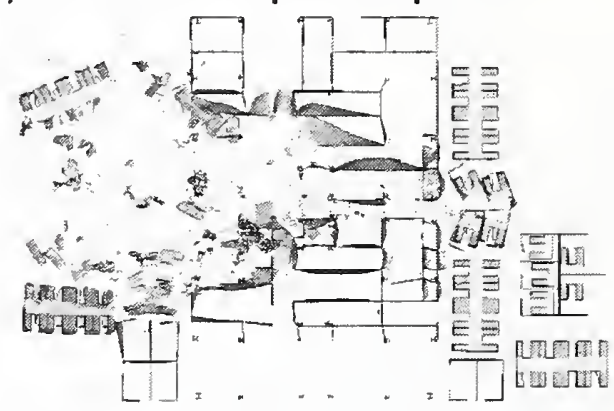

(c) Calculated impact response (fuel removed)

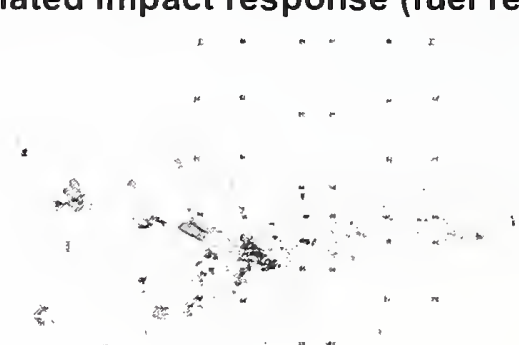

(d) Calculated aircraft debris

Figure 9-21. Calculated floor 95 contents, fuel, and aircraft debris distribution. 


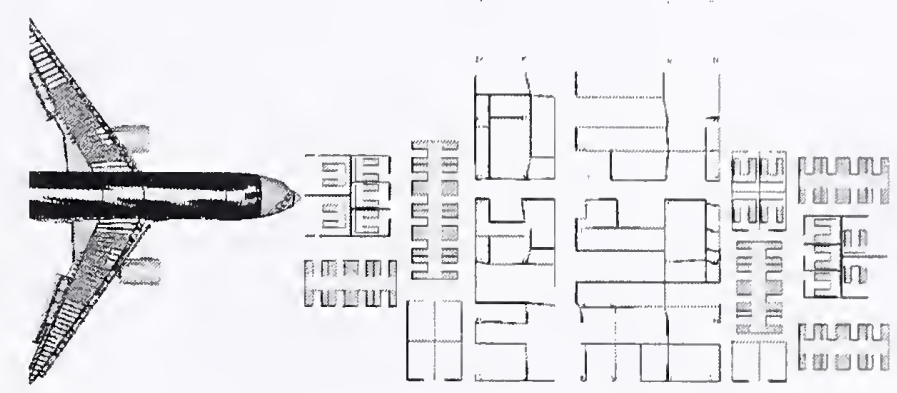

(a) Initial impact configuration

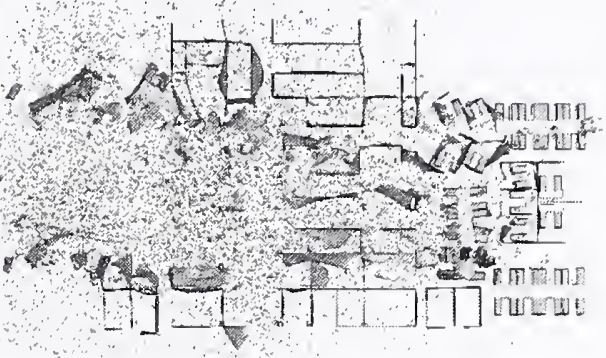

(b) Calculated impact response

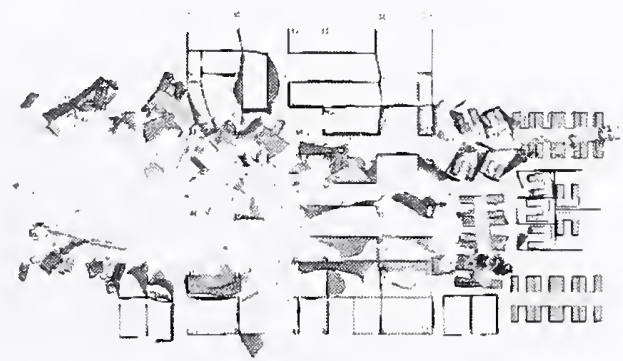

(c) Calculated impact response (fuel removed)

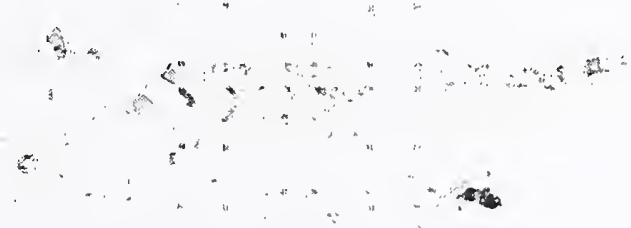

(d) Calculated aircraft debris

Figure 9-22. Calculated floor 96 contents, fuel, and aircraft debris distribution. 


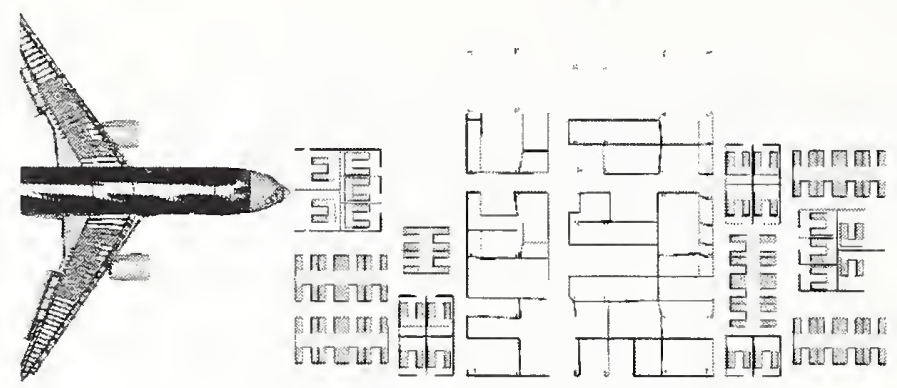

(a) Initial impact configuration

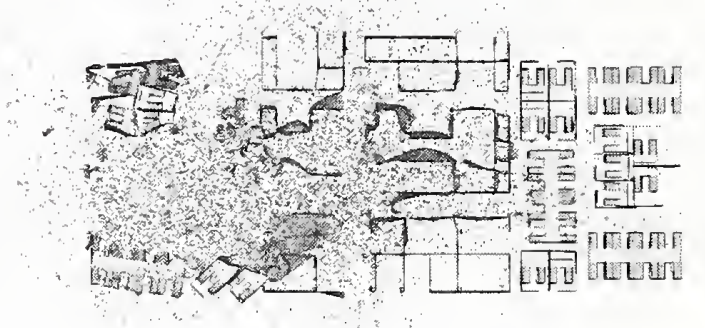

(b) Calculated impact response

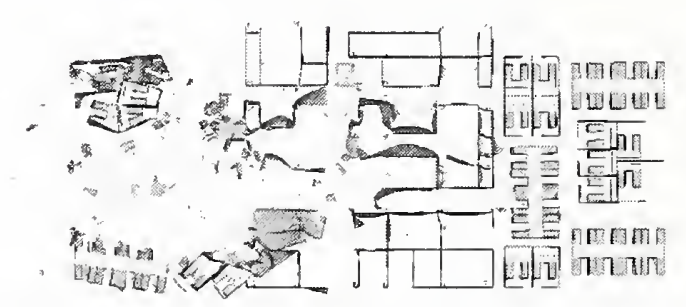

(c) Calculated impact response (fuel removed)

(d) Calculated aircraft debris

Figure 9-23. Calculated floor 97 contents, fuel, and aircraft debris distribution. 


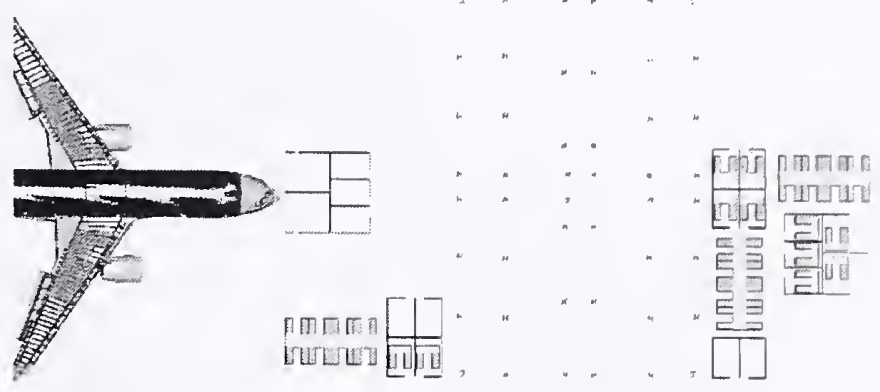

(a) Initial impact configuration

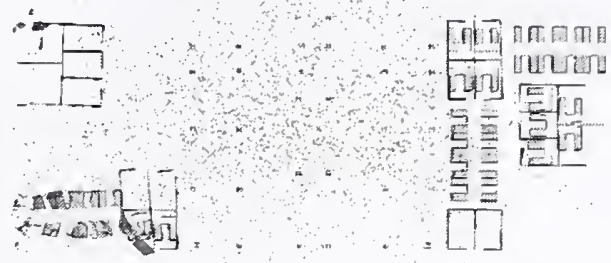

(b) Calculated impact response

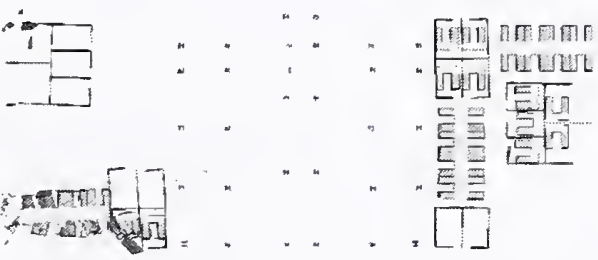

(c) Calculated impact response (fuel removed)

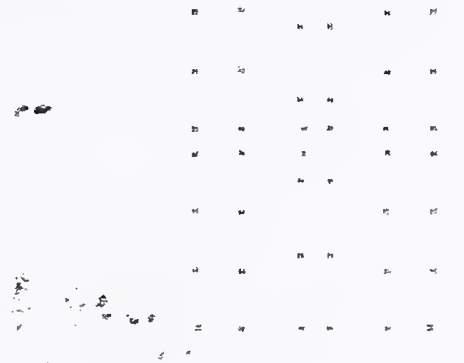

(d) Calculated aircraft debris

Figure 9-24. Calculated floor 98 contents, fuel, and aircraft debris distribution. 
The detailed predictions of the fuel dispersion and distribution using SPH in the global impact analyses had significant uncertainties in the absence of improved validation testing. However, some aspects of the distribution had a higher confidence. The floors confined the vertical motion of the fuel, and the floor-byfloor distribution of fuel was controlled more by the geometry of the tower and impact conditions. As a result, this distribution by fioor has a higher level of confidence. Similarly, the interior contents and partition walls, and the damage to these structures, controlled the spread of fuel.

Table 9-4. Fuel and aircraft debris distribution for the base case WTC 1 impact.

\begin{tabular}{|l|c|c|}
\hline \multicolumn{1}{|c|}{ Tower Location } & Aircraft Fuel & Aircraft Debris \\
\hline Total Outside Tower & $6,700 \mathrm{lb}$ & $17,400 \mathrm{lb}$ \\
\hline WTC 1 Floor 92 & $810 \mathrm{lb}$ & $260 \mathrm{lb}$ \\
\hline WTC 1 Floor 93 & $6,100 \mathrm{lb}$ & $22,600 \mathrm{lb}$ \\
\hline WTC 1 Floor 94 & $16,100 \mathrm{lb}$ & $96,000 \mathrm{lb}$ \\
\hline WTC 1 Floor 95 & $12,200 \mathrm{lb}$ & $28,000 \mathrm{lb}$ \\
\hline WTC 1 Floor 96 & $11,700 \mathrm{lb}$ & $19,400 \mathrm{lb}$ \\
\hline WTC 1 Floor 97 & $9,500 \mathrm{lb}$ & $6,000 \mathrm{lb}$ \\
\hline WTC 1 Floor 98 & $2,200 \mathrm{lb}$ & $6,000 \mathrm{lb}$ \\
\hline WTC 1 Floor 99 & $770 \mathrm{lb}$ & $90 \mathrm{lb}$ \\
\hline Total Weight & $66,100 \mathrm{lb}$ & $196,000 \mathrm{lb}$ \\
\hline
\end{tabular}

\subsection{WTC 2 BASE CASE IMPACT ANALYSIS}

This case is referred to as Case B for the remainder of the WTC Investigation reports. The WTC 2 base case impact analysis was performed for a $0.62 \mathrm{~s}$ duration following initial impact of the aircraft nose with the south exterior wall. A side view of the base case WTC 2 global impact model is shown in Figure 9-25. The tower interior contents were removed, and the tower structures were shown as transparent in the figure so that the impact response in the tower interior was visible. The floor numbers and core columns for the tower model are labeled in the figure. The corresponding side view is used to illustrate the base case global aircraft impact response in Figure 9-26. The response is shown at intervals of $0.1 \mathrm{~s}$ from impact through the initial $0.5 \mathrm{~s}$ of the response. Corresponding plan view images of the progression of aircraft impact response are shown in Figure 9-27. 


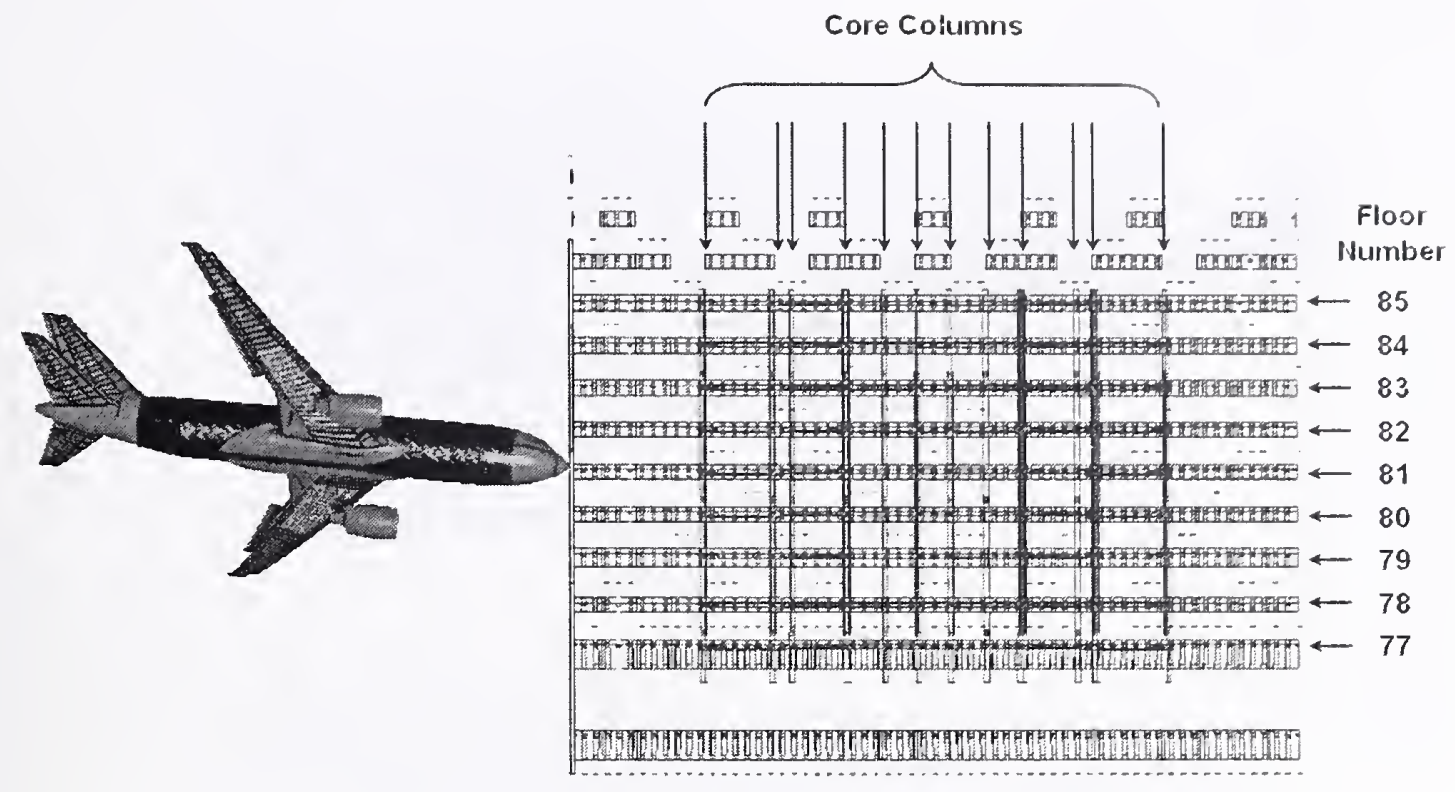

Figure 9-25. WTC 2 base case global impact model. 


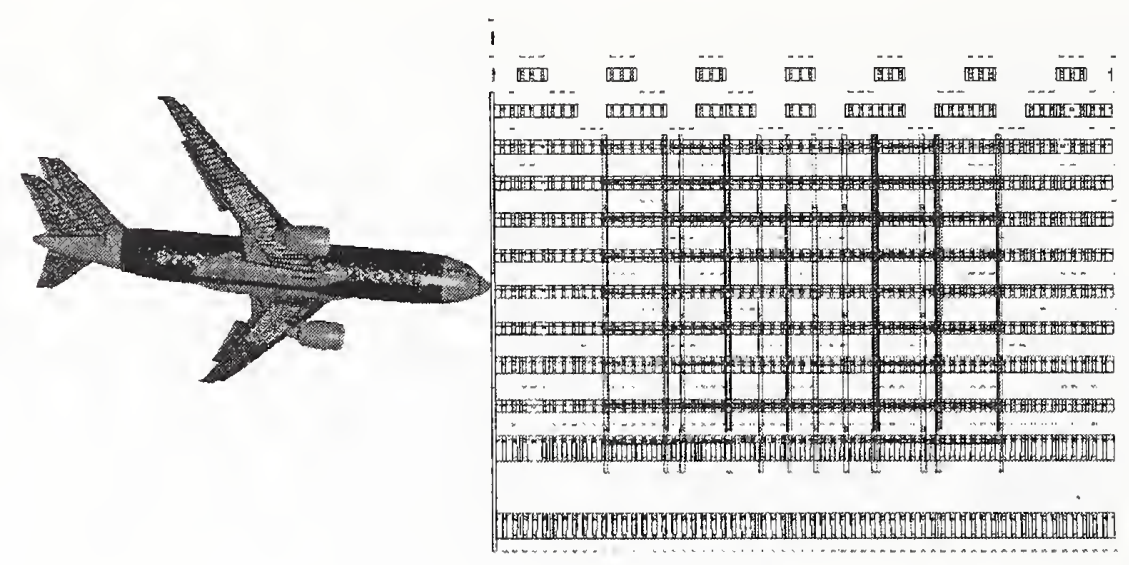

(a) Time $=0.00 \mathrm{~s}$

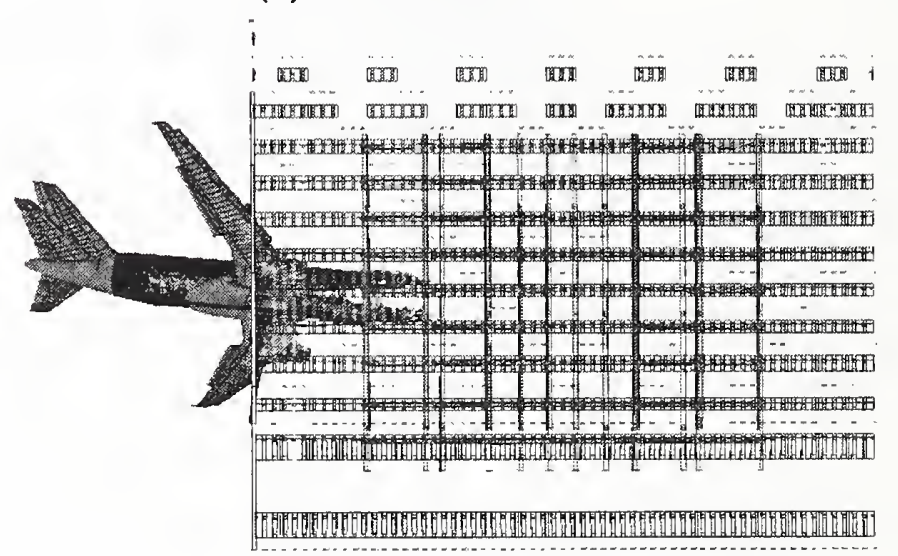

(b) Time $=0.10 \mathrm{~s}$

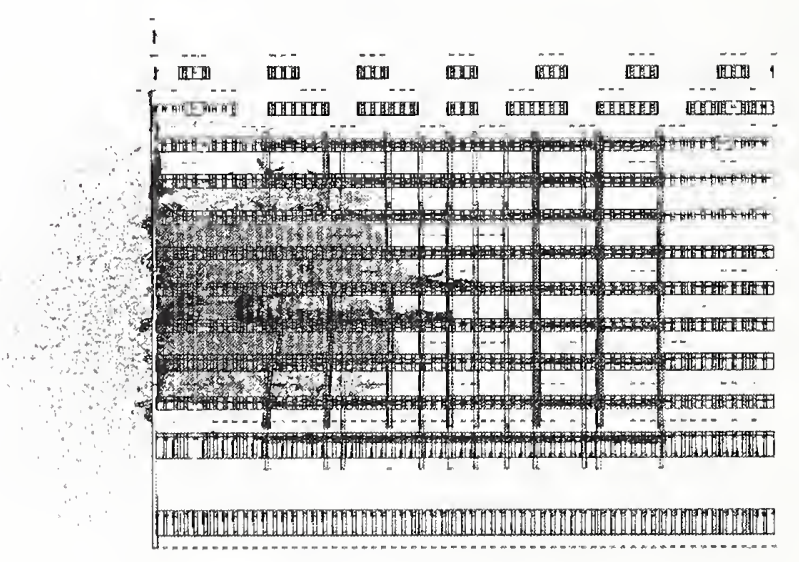

(c) Time $=0.20 \mathrm{~s}$

Figure 9-26. WTC 2 base case global impact analysis (side view). 


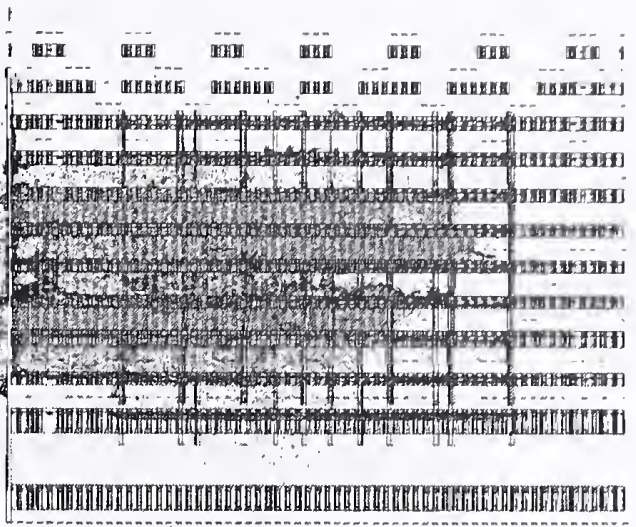

(d) Time $=0.30 \mathrm{~s}$

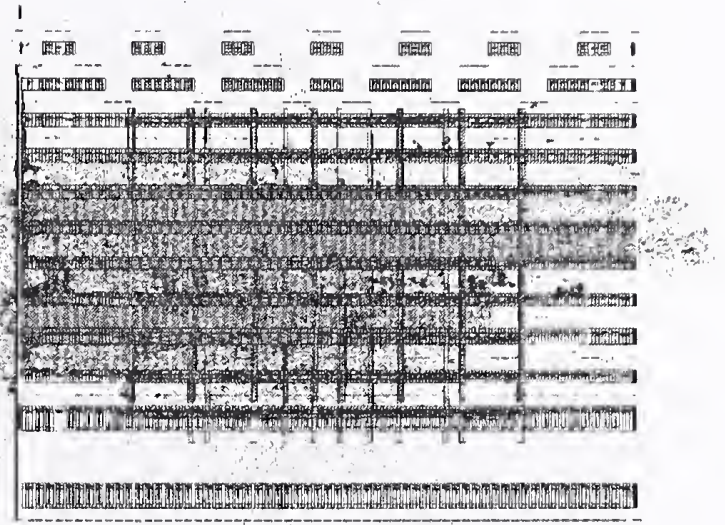

(e) Time $=0.40 \mathrm{~s}$

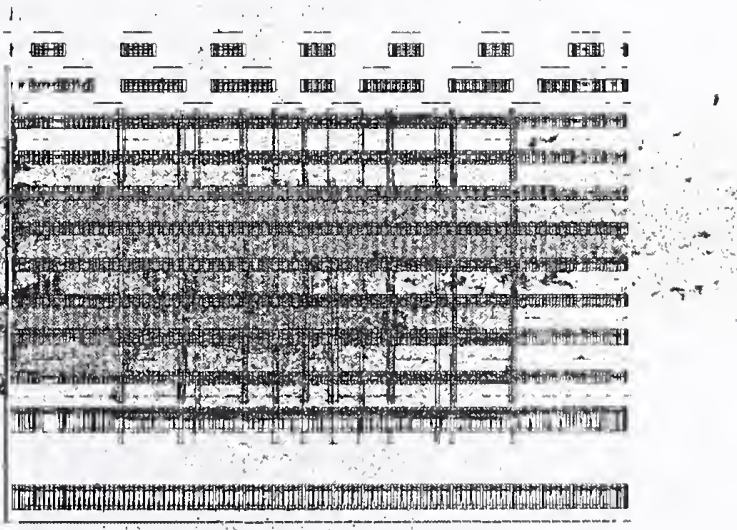

(f) Time $=0.50 \mathrm{~s}$

Figure 9-26. WTC 2 base case global impact analysis (side view) (continued). 


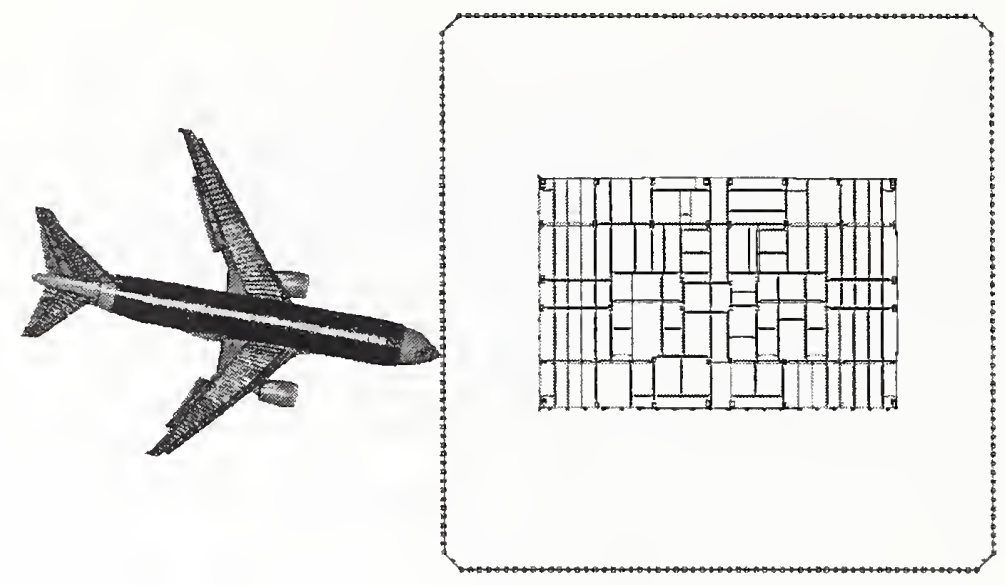

(a) Time $=0.00 \mathrm{~s}$

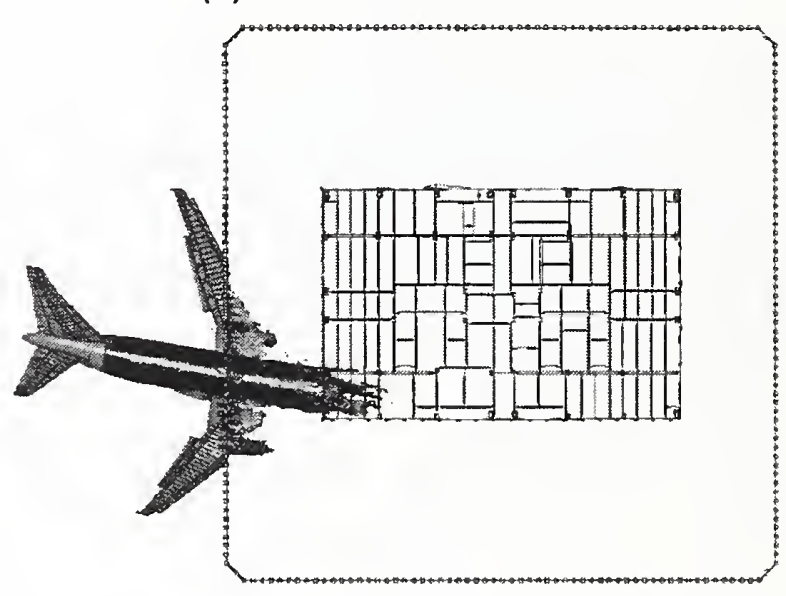

(b) Time $=0.10 \mathrm{~s}$

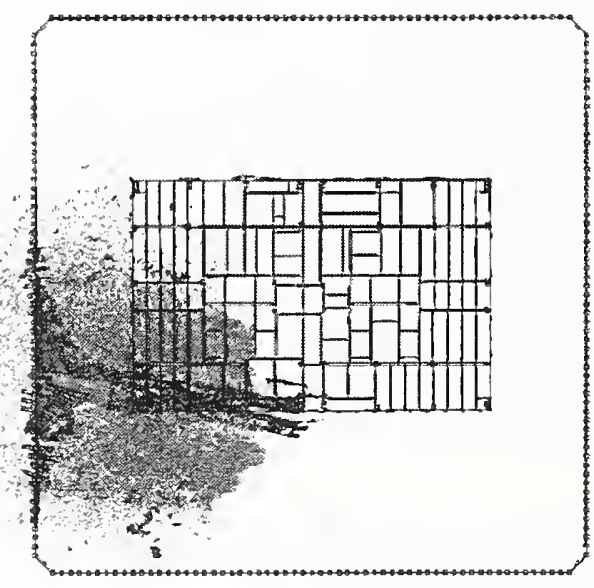

(c) Time $=0.20 \mathrm{~s}$

Figure 9-27. WTC 2 base case global impact analysis (plan view). 


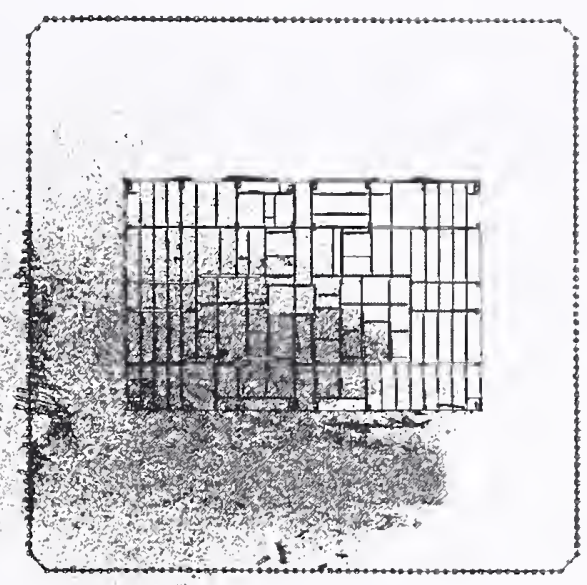

(d) Time $=0.30 \mathrm{~s}$

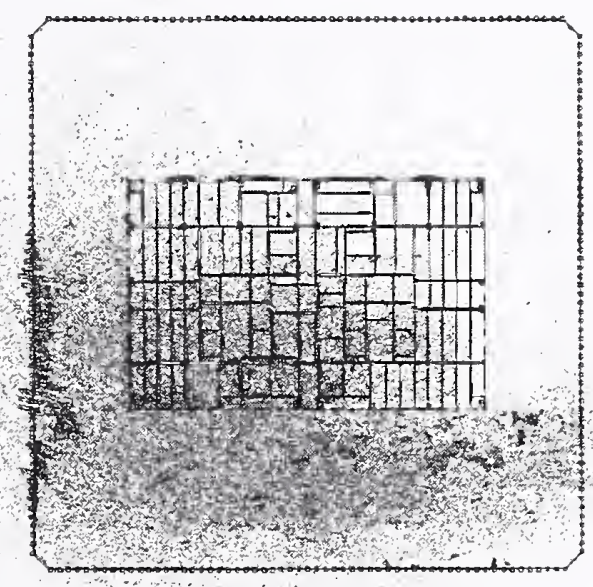

(e) Time $=0.40 \mathrm{~s}$

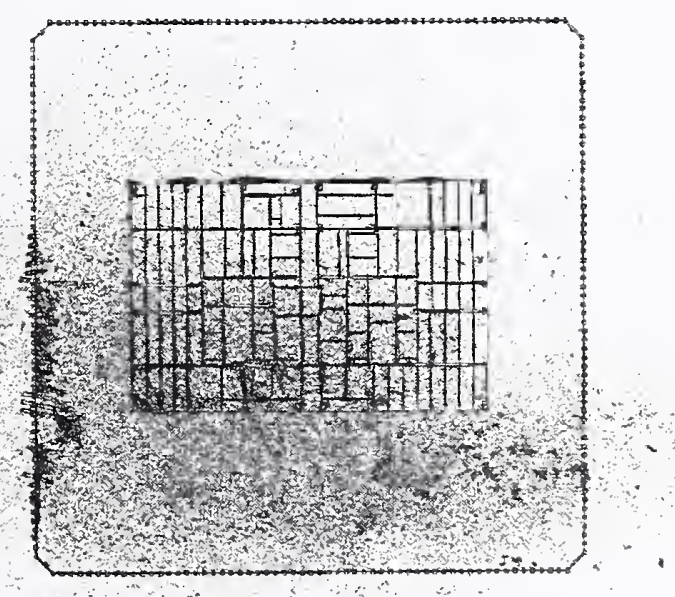

(f) Time $=0.50 \mathrm{~s}$

Figure 9-27. WTC 2 base case global impact analysis (plan view) (continued). 
The initial $0.1 \mathrm{~s}$ of the base case global aircraft impact response, shown in Figure 9-26(b) and Figure 9-27(b), was dominated by the impact, penetration, and fragmentation of the forward fuselage structures. The engines and leading portions of the wings penetrated the exterior wall. The forward fuselage structures were severely damaged both from the penetration through the exterior columns and the penetration of the 81 st floor slab that sliced the fuselage structures in half. The downward trajectory of the aircraft structures caused the airframe to collapse against the floor, and the subsequent debris motion was redirected inward along a more horizontal trajectory parallel to the floor. The higher impact speed and short truss floor span in this impact orientation had the forward fuselage structures well into the tower core by this time.

At $0.2 \mathrm{~s}$ after impact, the full penetration of the aircraft into the tower was just completed, as shown in Figure 9-26(c) and Figure 9-27(c). The airframe was mostly broken up, but some large sections of the aft fuselage and tail were still intact, having penetrated through the opening in the tower wall produced by the forward fuselage structures. The aircraft fuel cloud was starting to spread out but was still relatively dense, and the leading edge of the fuel was approximately one-third through the tower core. By $0.2 \mathrm{~s}$, the downward trajectory of the aircraft structures had transferred sufficient vertical load that the truss floor structures on the 80 th and 81 st floors were starting to collapse in the impact zone.

At $0.3 \mathrm{~s}$ after impact, the aircraft fuel cloud had penetrated approximately two-thirds the distance through the core and was spreading out, as shown in Figure 9-26(d) and Figure 9-27(d). However, the subsequent motion of the aircraft fragments and fuel debris cloud began to be noticeably slowed beyond this time. The fuel and debris did continue to spread through the tower, but at a much slower rate, as seen in the remaining images in Figure 9-26 and Figure 9-27. The spread of the fuel and debris cloud was more rapid and extensive in the open truss floor regions than through the core as a result of the open volume above the workstations in the truss floor zone.

The load transfer of the base case WTC 2 aircraft impact can be shown by the history of the resultant momentum as shown in Figure 9-28. The curve illustrates an initial rate of load transfer during the first $0.1 \mathrm{~s}$ of impact as the forward fuselage penetrated the exterior wall and impacted the interior structures. Between $0.1 \mathrm{~s}$ and $0.2 \mathrm{~s}$, a more rapid load transfer rate was observed, as the area of the impact was larger (extending outward in the wing impact regions), and a higher percentage of the aircraft mass was impacting the interior structures. At $0.2 \mathrm{~s}$, as indicated in Figure 9-28, the aircraft completely penetrated the building and retained approximately 30 percent of its initial momentum. Beyond this time, the rate of load transfer was steadily decreasing with very little load transfer after approximately $0.4 \mathrm{~s}$. The behavior was very similar to that of the base case WTC 1 impact, shown in Figure 9-6, but with a slightly compressed time scale resulting from the higher impact speed on WTC 2. 


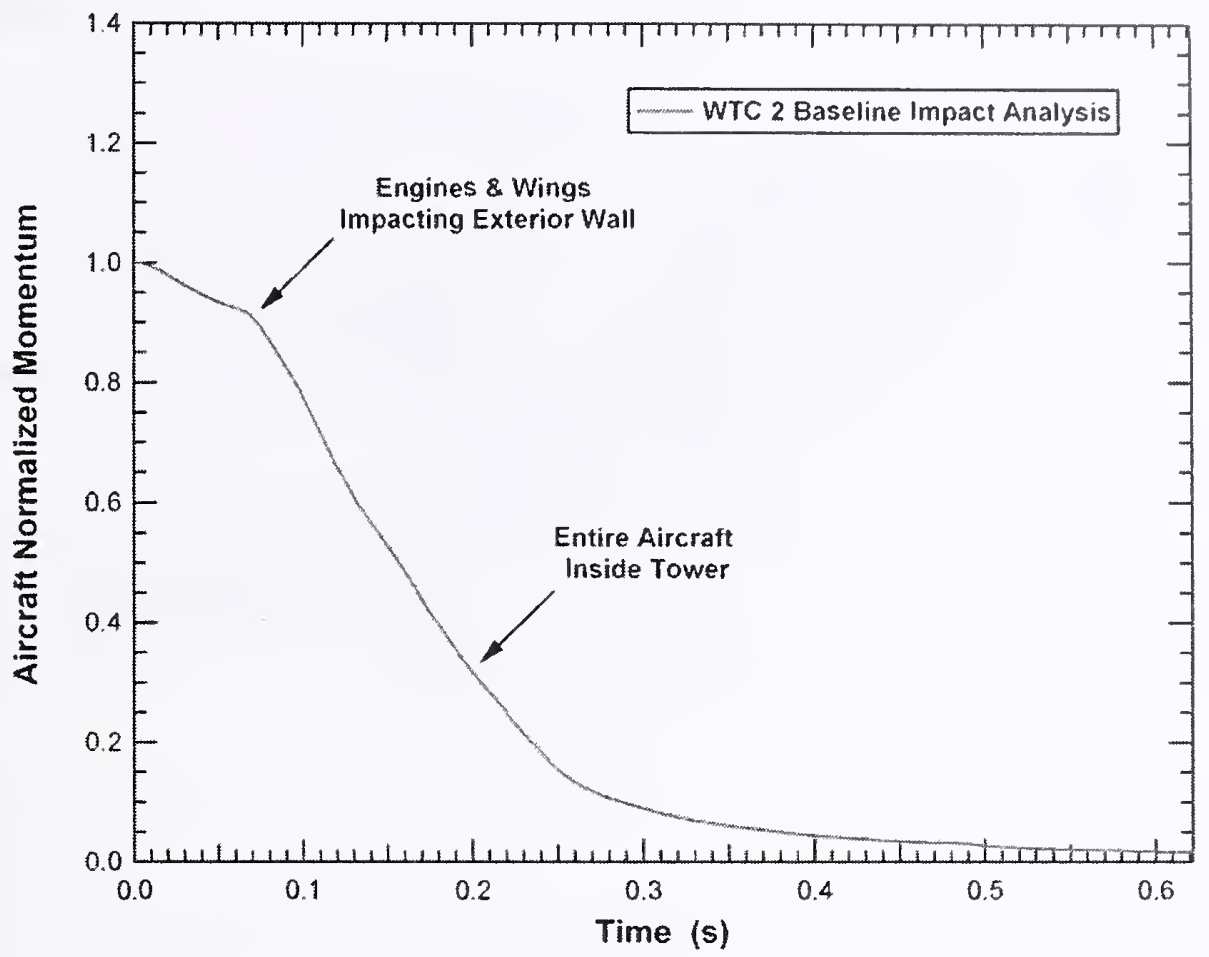

Figure 9-28. Normalized aircraft momentum for the WTC 2 base case impact.

The aircraft was severely broken into debris as a result of the impact with WTC 2 as shown in Figure 9-29. At the end of the impact analysis, the aircraft was broken into thousands of debris fragments of various size and mass, as shown in Figure 9-29(b). A closer inspection of the debris field showed that larger fragments still occurred for specific components such as the engines and landing gear components. This behavior was very similar to the WTC 1 aircraft brcakup shown in Figure 9-7.

\subsubsection{WTC 2 Base Case Impact Analysis - Structural Damage}

The structural damage to the WTC 2 tower by the base case impact conditions is described in this section. The details of the base case WTC 2 aircraft impact conditions were summarized previously in Section 9.3 (shown in Figure 9-2 and summarized in Table 9-2). The primary structural components of interest were the exterior wall, core columns and core framing components, and the floor structures and concrete floor slab. The response of the internal contents, walls, and partitions as well as fuel dispersion was also of interest as initial conditions for the fire analysis. 


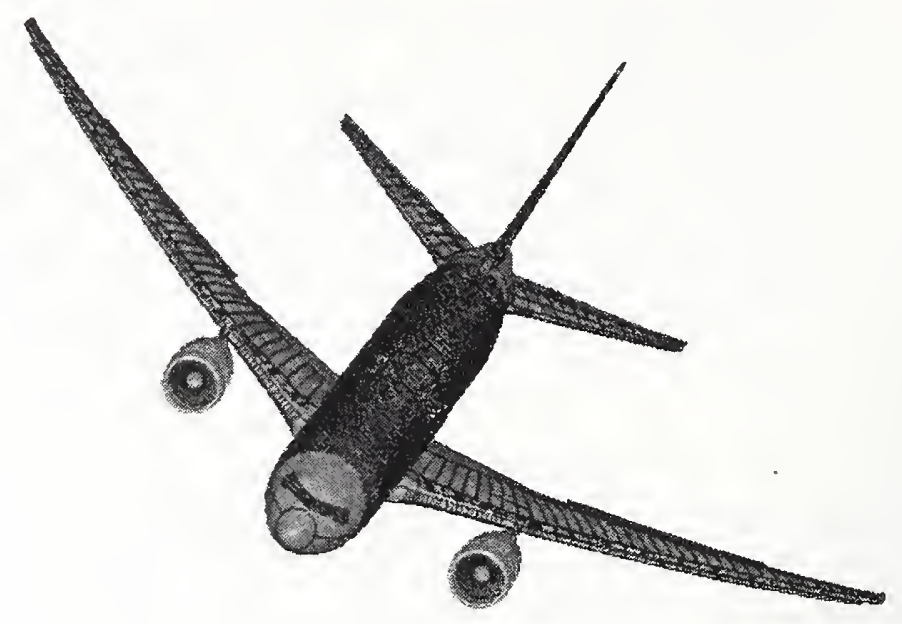

(a) Aircraft structure (time $=0.00 \mathrm{~s}$ )

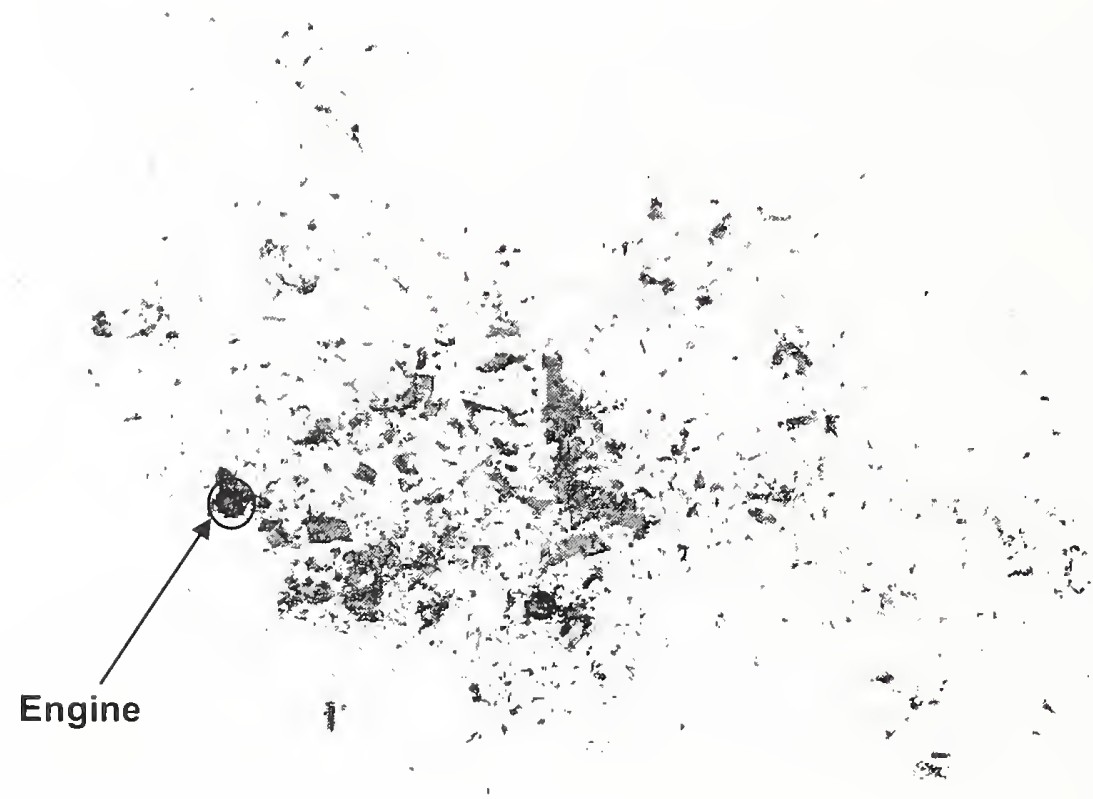

(b) Aircraft debris field (time $=0.62 \mathrm{~s}$ )

Figure 9-29. Aircraft breakup and debris in the base case WTC 2 impact. 


\section{Exterior Wall Damage}

A comparison of the south exterior wall obscrved and calculated damage from the base case WTC 2 global impact analysis is shown in Figure 9-30. The calculated impact damage to the exterior wall is shown with color fringes representing plastic strain magnitude with undamaged sections in blue and strains at or above 5 percent shown in red. The schematic of observed damage was developed from inspections of the video and photographic data collected on the tower after impact. Both the observed and calculated damage regions shown in Figure 9-30 illustrate a region of the extcrior wall from column 402 to column 446, extending from floor 76 to floor 86 (spandrels at floors 77 through 86).

The exterior wall completely failed in the regions of the fuselage, engine, and fuel-filled wing section impacts. Damage to the exterior wall cxtended to the wing tips, but the exterior columns were not completely failed in the outer wing and vertical stabilizer impact regions. Failure of the exterior columns oceurred both at the bolted connections between column ends and at various locations in the column, depending on the local severity of the impact load and the proximity of the bolted connection to the impact.

The initial observation from the comparison of the calculated and observed damage was that the geometry and location of the impact damage zone were in good agreement. This agrecment in the position and shape of the impact damage served to validate the geometry of the aircraft model, including the aircraft orientation, trajectory, and flight distortions of the wings. The agreement of both the mode and magnitude of the impact damage served to partially validate the constitutive and damage modeling of the aircraft and exterior wall of the tower.

\section{Core Structural Damage}

The estimation of the damage to the core columns and core beams was important for the subsequent analysis of structural stability and collapse. The overall model for the WTC 2 core structure and calculated impact damage to the core is shown in Figure 9-31. The figure shows that the core had significant damage in the region close to the impact point, in particular the southeast comer of the core. The columns in line with the aircraft fuselage failed on the impact side, and several of the core beams were also severely damaged or failed in the impact zone. In some cases, failure of the column splices located on floors 77,80 , and 83 contributed significantly to the failure of the core columns. This was particularly true for the heavy column number 1001 at the corner of the core that failed at the three splice locations.

The calculated damage to the core columns by row is shown in Figure 9-32. The columns are shown with color fringes representing plastic strain magnitude with undamaged sections in blue and strains at or above 5 percent shown in red. A summary of the column damage is listed in Table 9-5 and shown graphically in Figure 9-33. The qualitative classification of the column damage levels were provided previously in Figure 9-12. A summary of the floor-by-floor damage to the core framing is shown in Figure 9-34. 


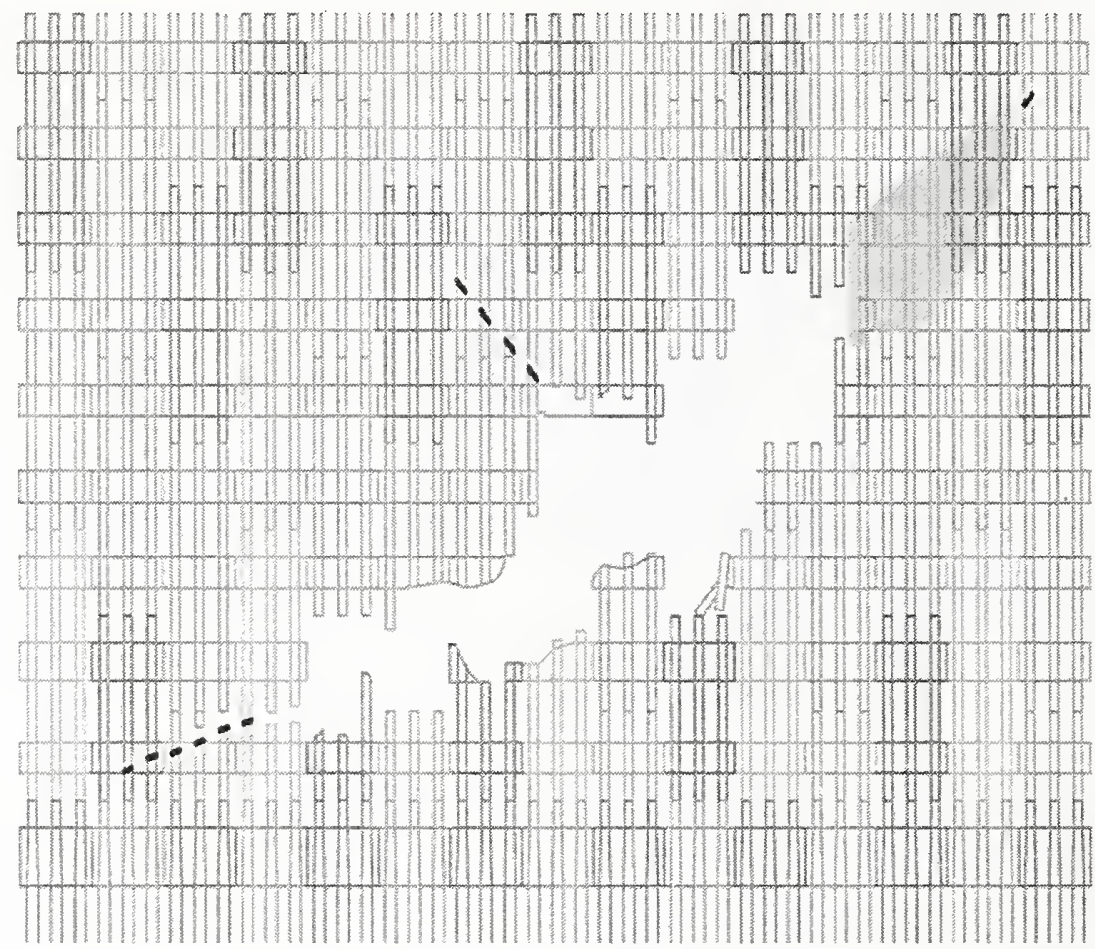

(a) Schematic of observed damage

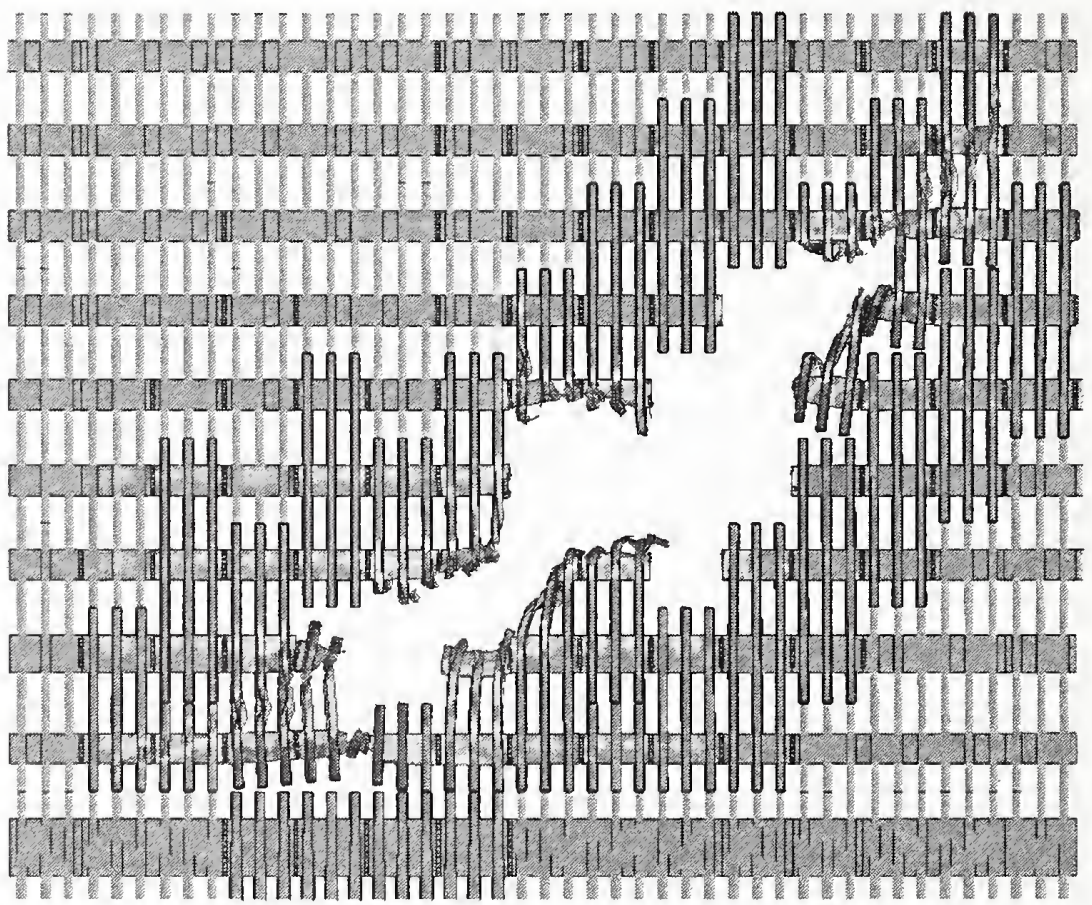

(b) Calculated damage ( $\mathrm{t}=0.62 \mathrm{~s}$ )

Figure 9-30. Base case impact damage to the WTC 2 exterior wall. 


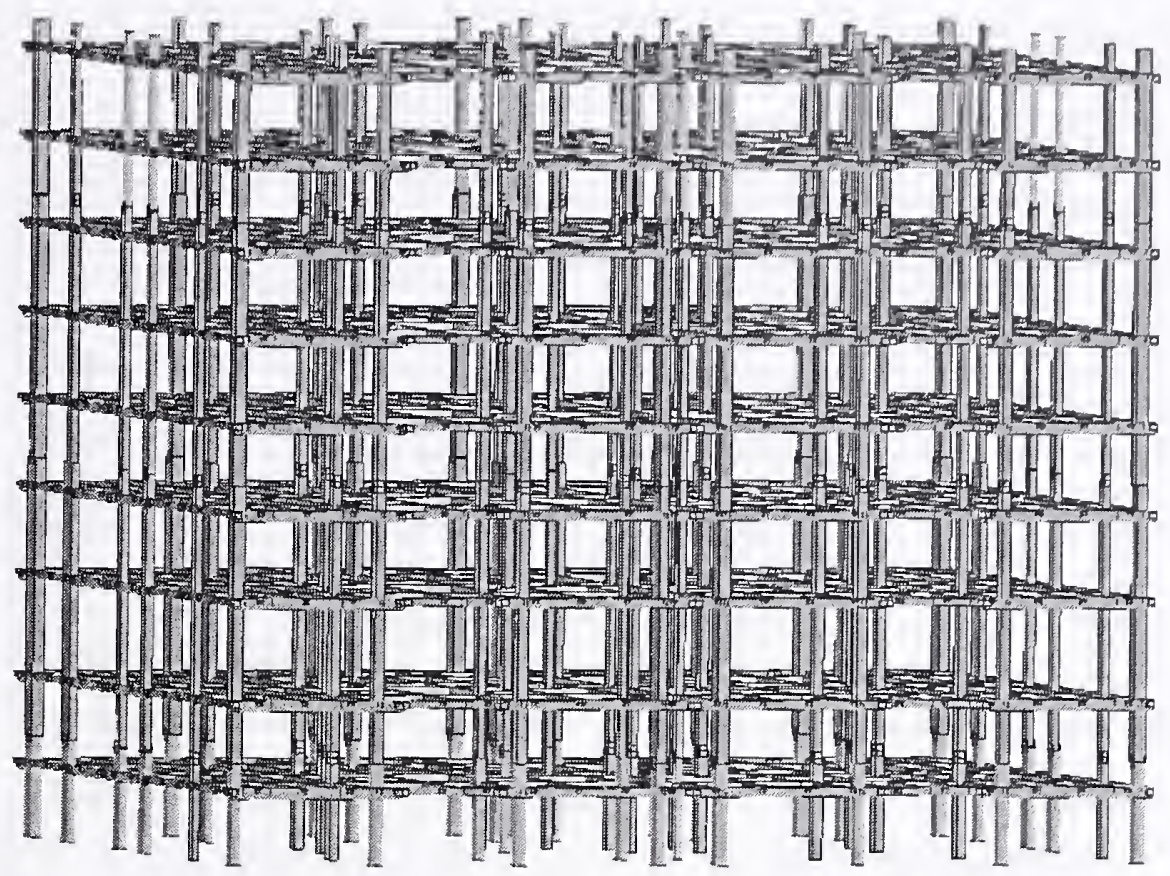

(a) Initial geometry

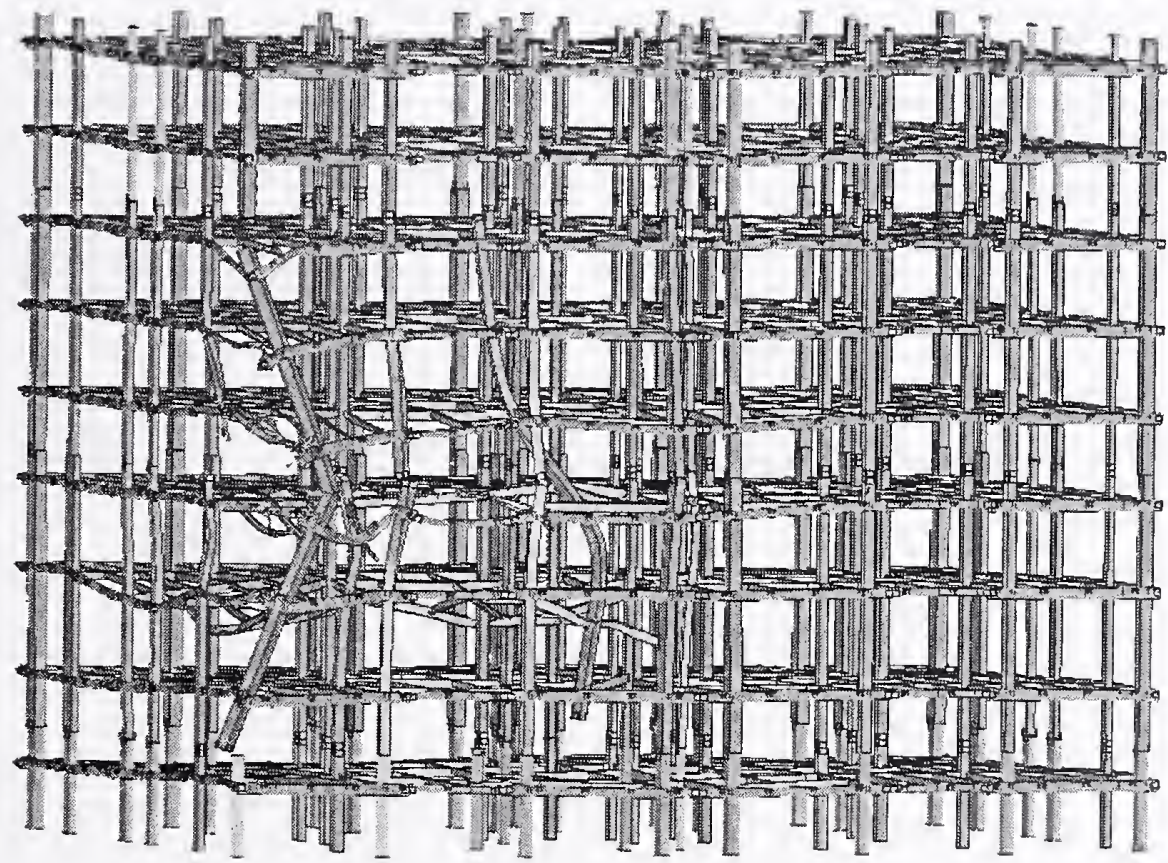

(a) Calculated impact damage

Figure 9-31. Base case impact damage to the WTC 2 core. 


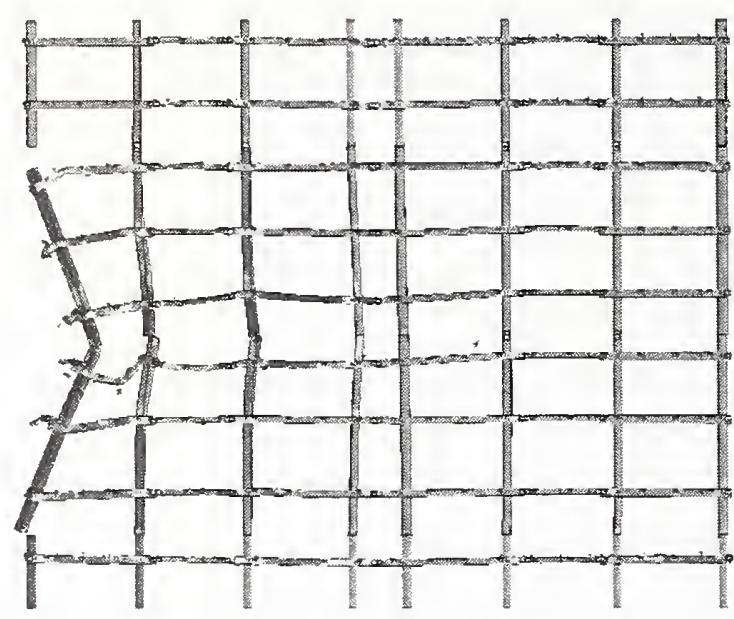

(a) Columns 1001-1008

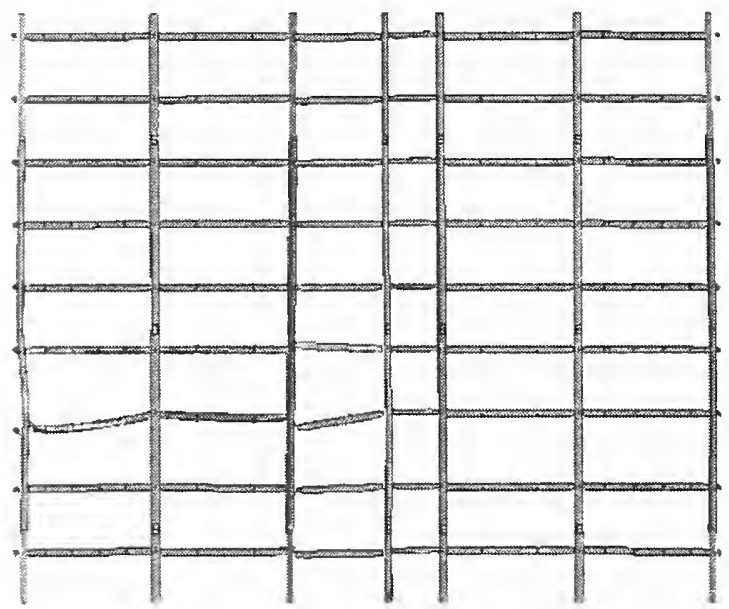

(c) Columns 801-807

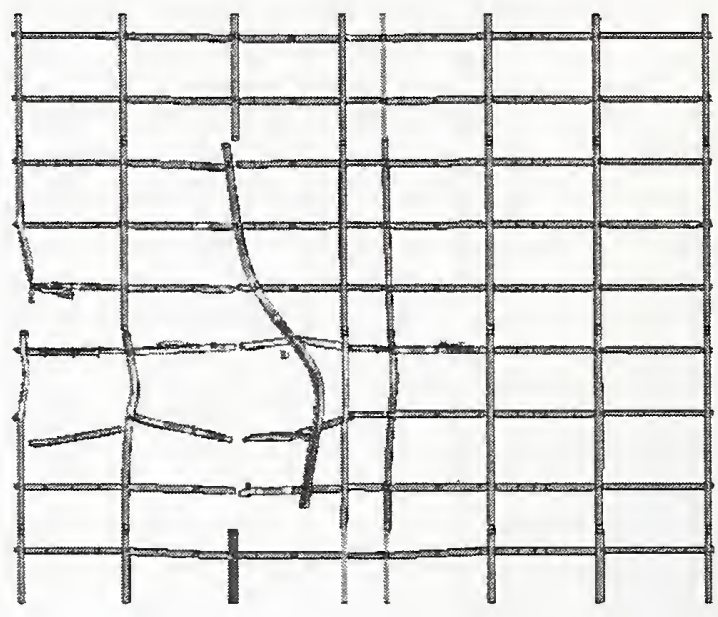

(b) Columns 901-908

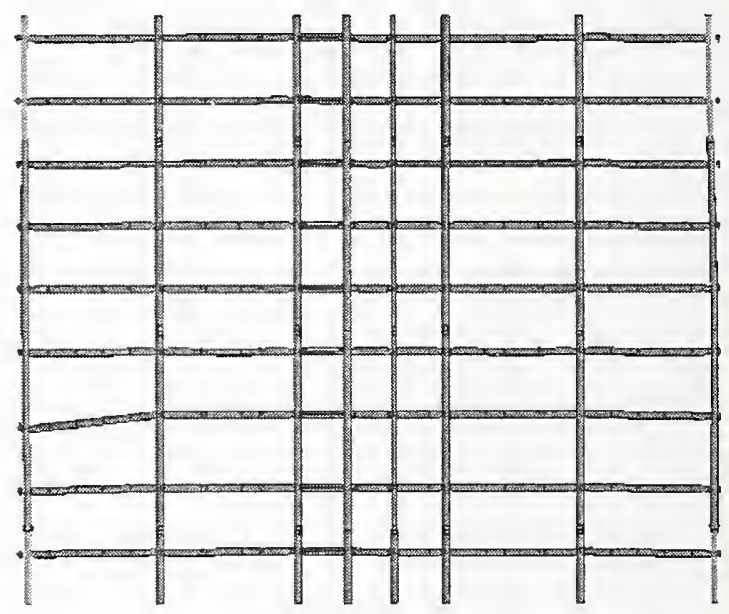

(d) Columns 701-708

Figure 9-32. Base case impact damage to the WTC 2 core columns. 
Table 9-5. Summary of core column damage for the base case WTC 2 impact.

\begin{tabular}{|c|c|c|c|}
\hline Column & Location & Damage Level & $\begin{array}{c}\text { Lateral Deflection of } \\
\text { Column Centerline (in.) }\end{array}$ \\
\hline Column 801 & Floor 79 & Heavy & 10 \\
\hline Column 901 & Floors $79-82$ & Severed & 32 \\
\hline Column 902 & Floor 79 & Heavy & \\
\hline Column 903 & Floors $77-83$ & Severed & 18 \\
\hline Column 904 & Floor 79 & Moderate & \\
\hline Column 905 & Floor 79 & Heavy & \\
\hline Column 1001 & Floors $77-83$ & Severed & \\
\hline Column 1002 & Floors $79-81$ & Severed & 18 \\
\hline Column 1003 & Floor 80 & Severed & \\
\hline Column 1004 & Floor 80 & Heavy & \\
\hline
\end{tabular}

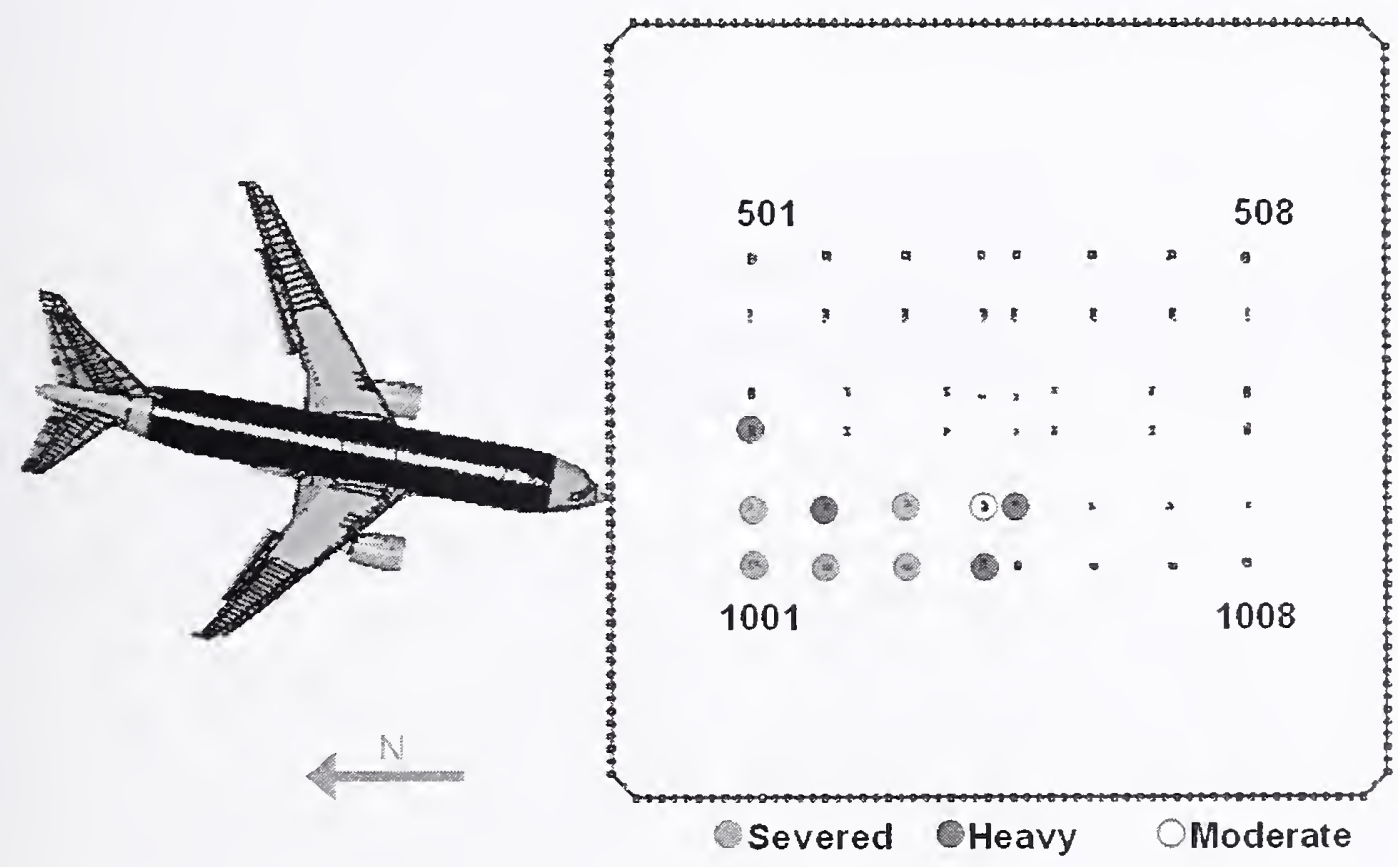

Figure 9-33. Summary of core column damage for the base case WTC 2 impact. 


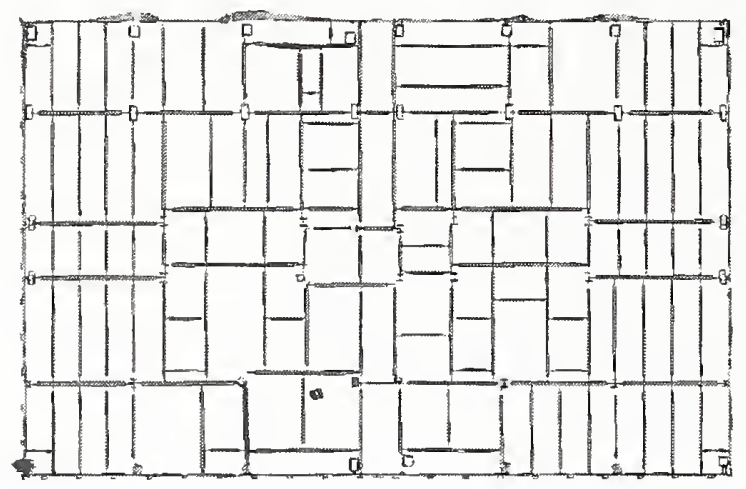

(a) Floor 77 core framing damage

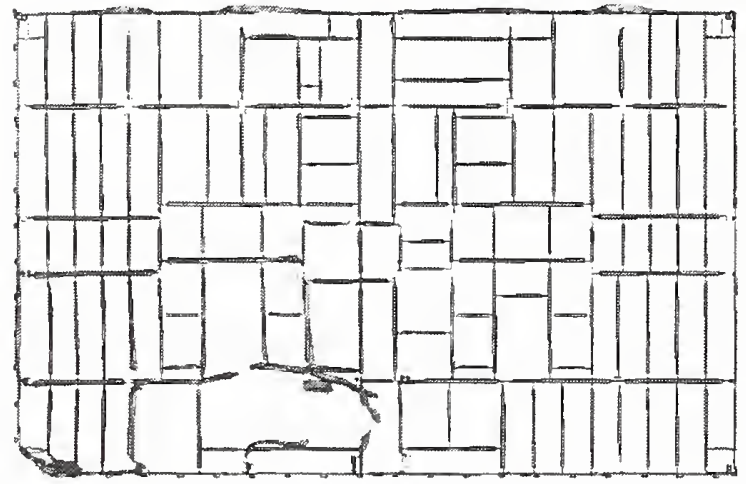

(c) Floor 79 core framing damage

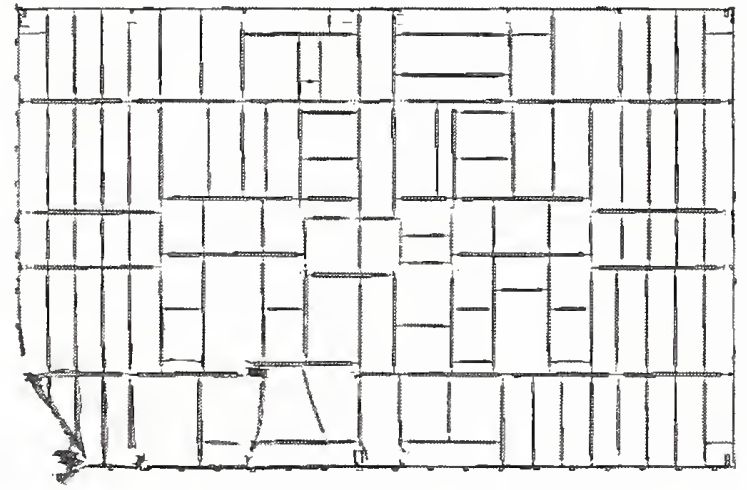

(e) Floor 81 core framing damage

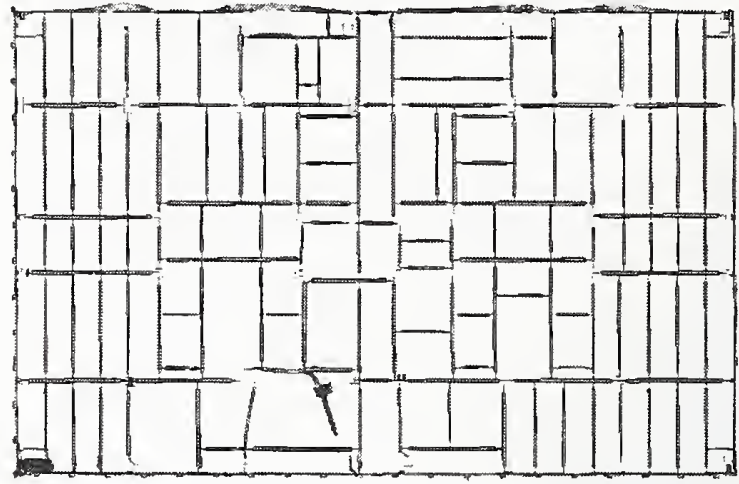

(b) Floor 78 core framing damage

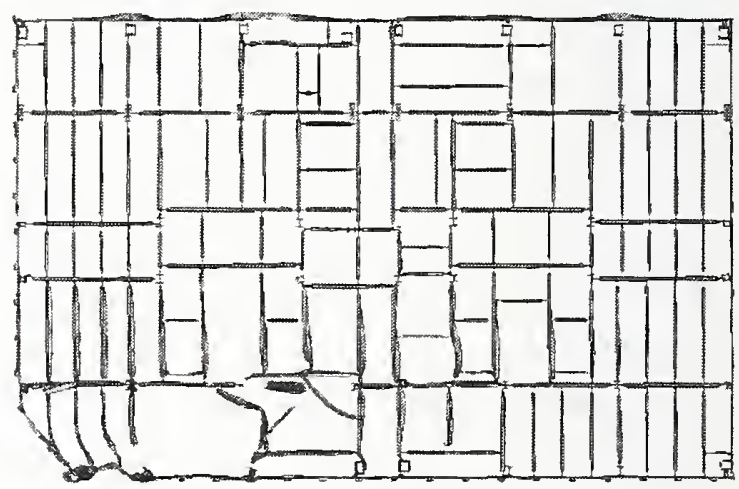

(d) Floor 80 core framing damage

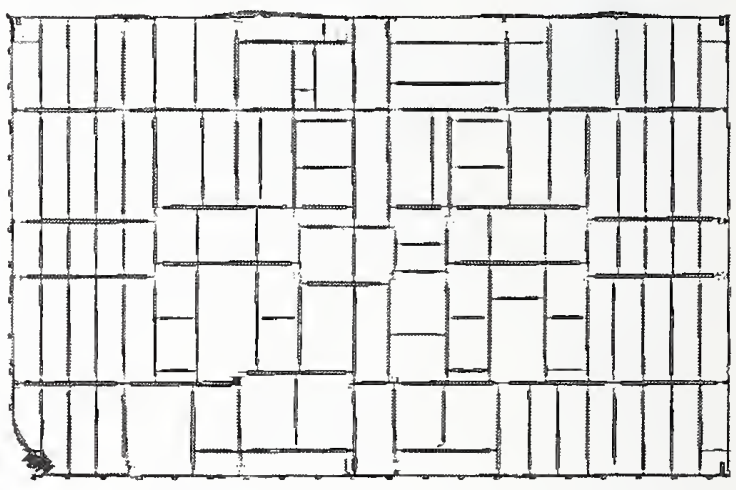

(f) Floor 82 core framing damage

Figure 9-34. Base case impact damage to the WTC 2 core floor framing (plan view). 


\section{Floor Truss and Slab Damage}

An overall view for the floor truss structurc in the WTC 2 impact zonc, along with the caleulated base case impact damage to the trusses, is shown in Figurc 9-35. The figurc shows a front view of the trusses that were modeled in detail before and aftcr impact by the aircraft. Note that the coarsely meshed trusses on these floors are not shown in the figure. The trusses cxperienced significant damagc in the impact zone, with the largest damage on floor 81. A plan view of the calculatcd damage to the trusses on cach floor is shown in Figure 9-36. The calculated impact response produeed severe damage to the truss structures in the primary impact path of the fuselage. The truss structures were severely damaged from the exterior wall to the core. The truss floor system on floors 79 and 81 had sufficient damage from the impact that truss floor scctions were sagging downward as a result of the impact.

Floor 82

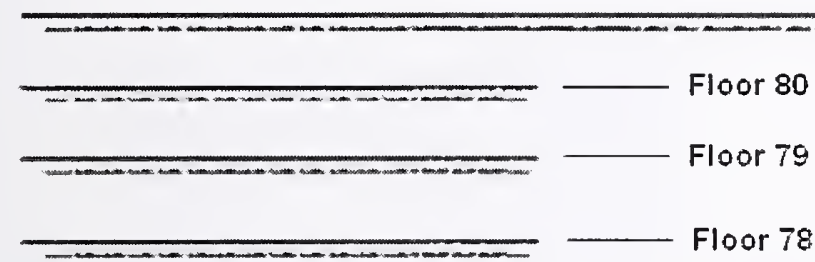

(a) Initial detailed truss structures

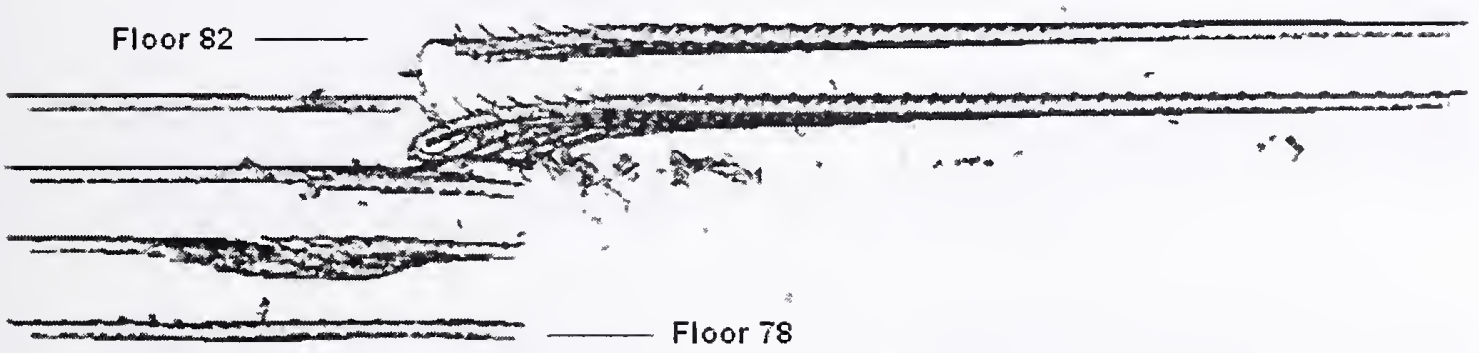

(b) Calculated damage

Figure 9-35. Base case impact damage to the WTC 2 floor truss (front view).

The calculated damage to the WTC 2 floor slab for floors 78 through 83 are shown in Figure 9-37. The fringes of damage were set such that the concrete failed in the regions eolored red ( 2 percent plastic strain). In these regions, it is expeeted that the concrete had been severely damaged and potentially removed, exposing the supporting metal decking. The strength of the floor slab was severely reduced in the analysis beyond this strain to model the residual strength of the metal deck after the concrete failure, breakup, and removal. At a plastic strain of 30 percent, corresponding to failure levels for the metal decking material, the elements were eroded (seen as holes ruptured in the floor slab shown). The line of damage, visible around the edge of the core in Figure 9-37, was believed to be the result of numerical precision errors and interference in the modeling methodology at the connection of the floor slab rather than impaet damage. 


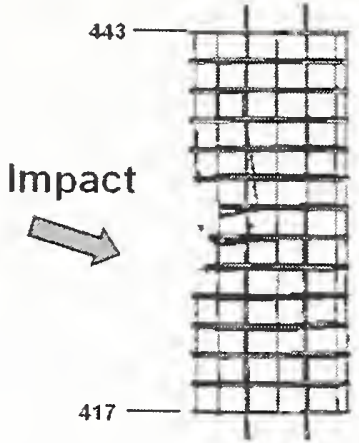

(a) Floor 79 truss damage
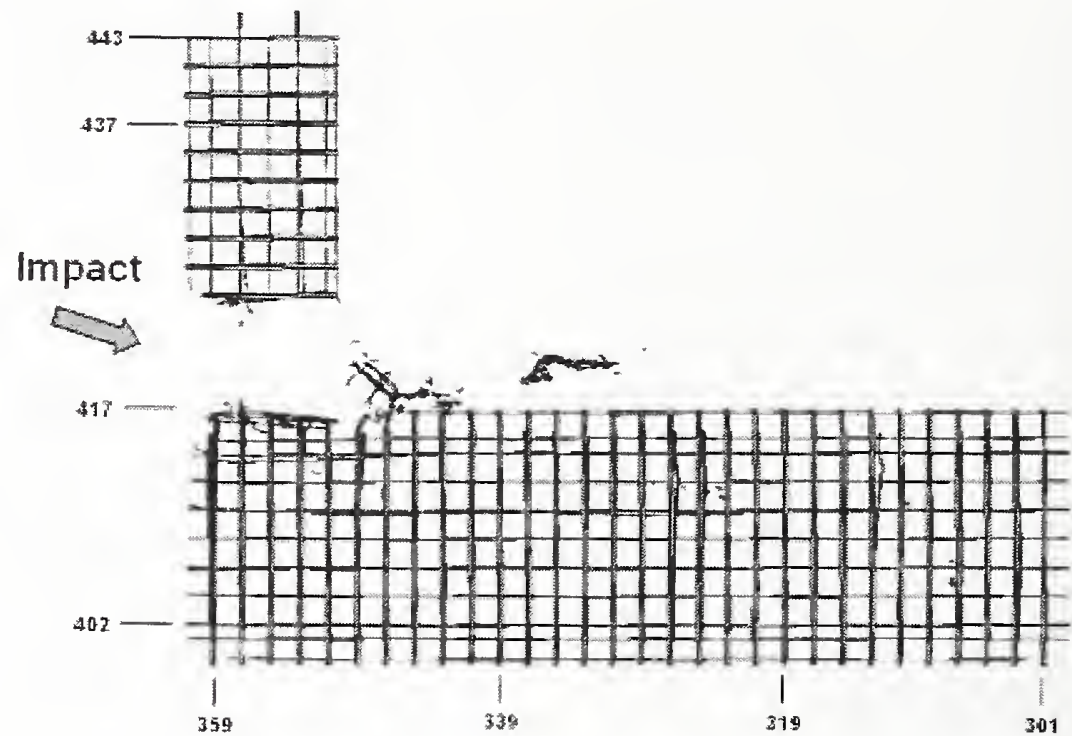

(c) Floor 81 truss damage

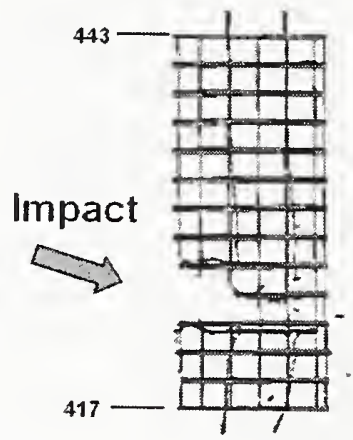

(b) Floor $\mathbf{8 0}$ truss damage

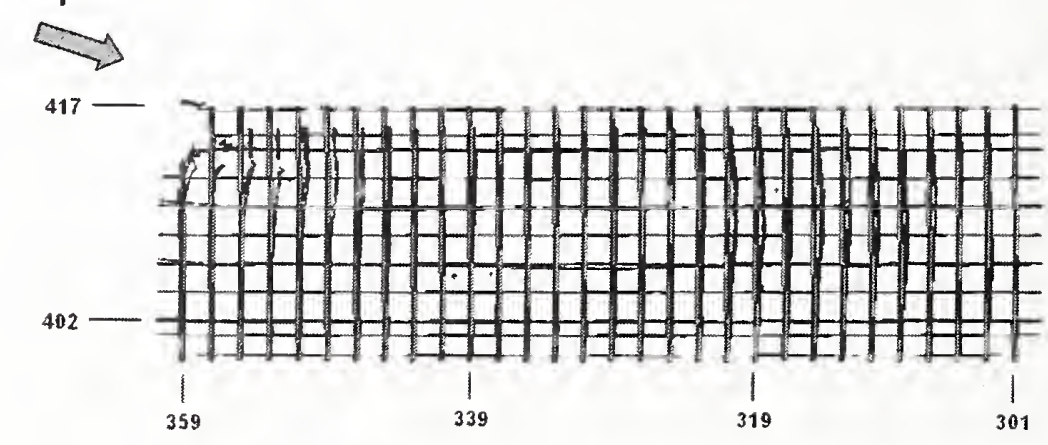

(d) Floor 82 truss damage

Figure 9-36. Base case impact damage to the WTC 2 floor trusses (plan view). 


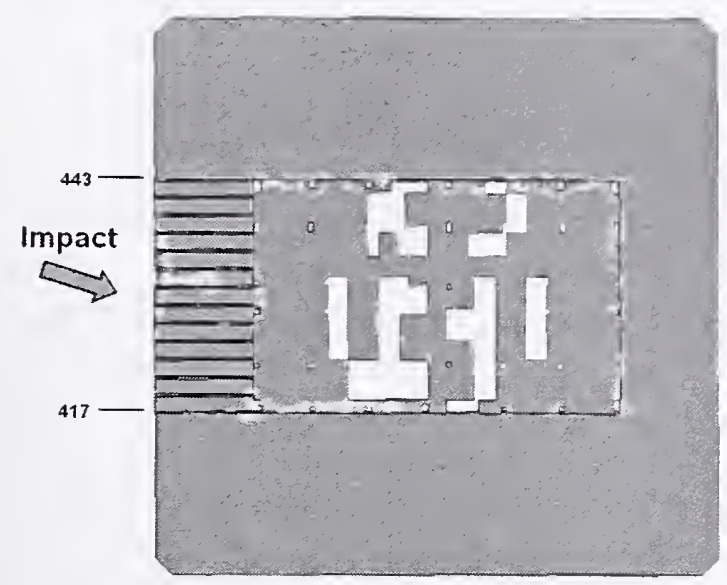

(a) Floor 78 slab damage

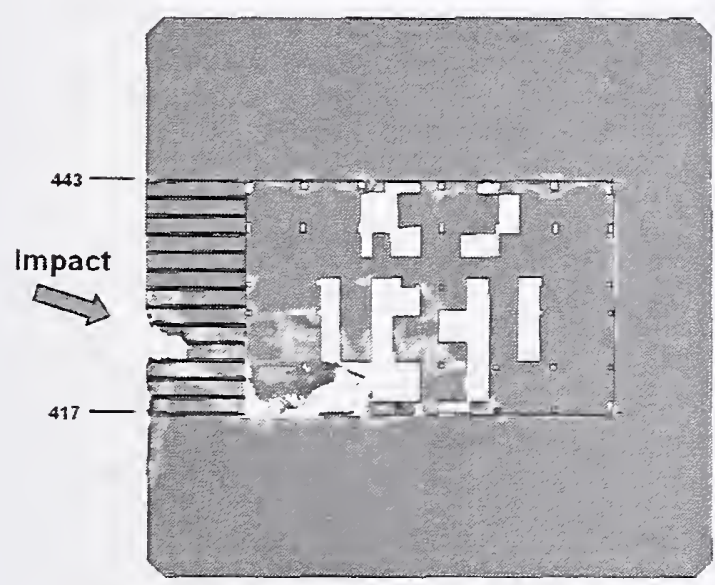

(c) Floor $\mathbf{8 0}$ slab damage

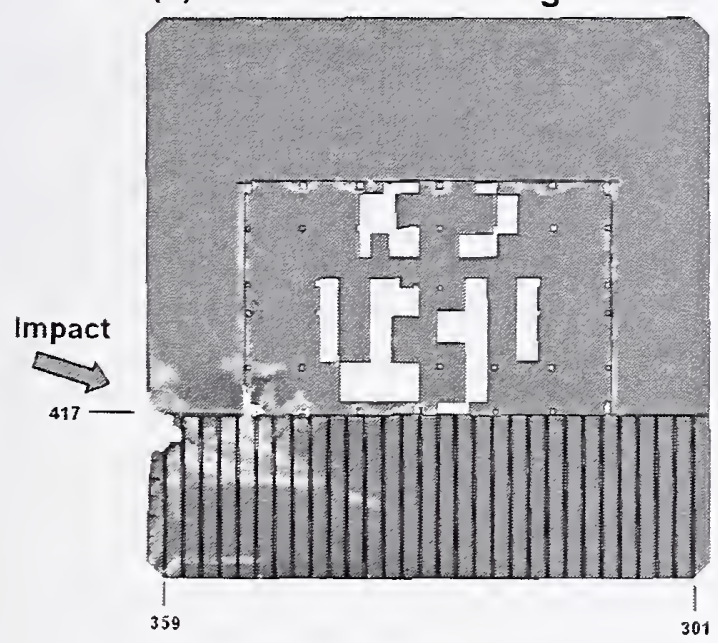

(e) Floor 82 slab damage

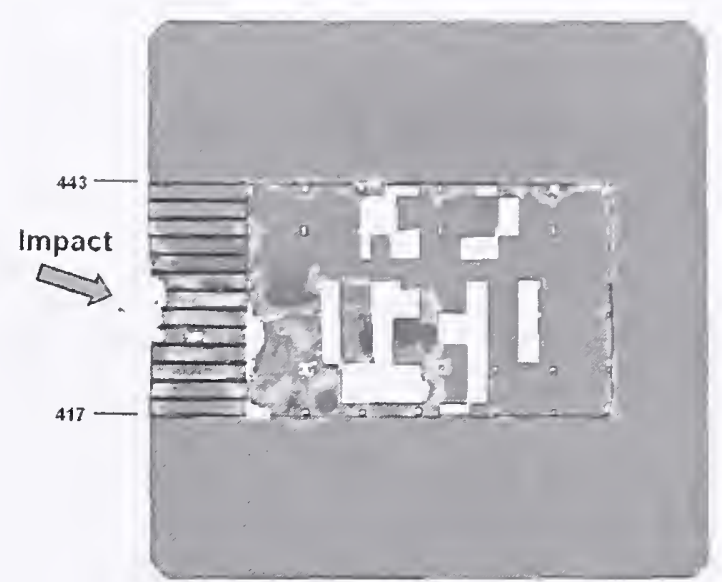

(b) Floor 79 slab damage

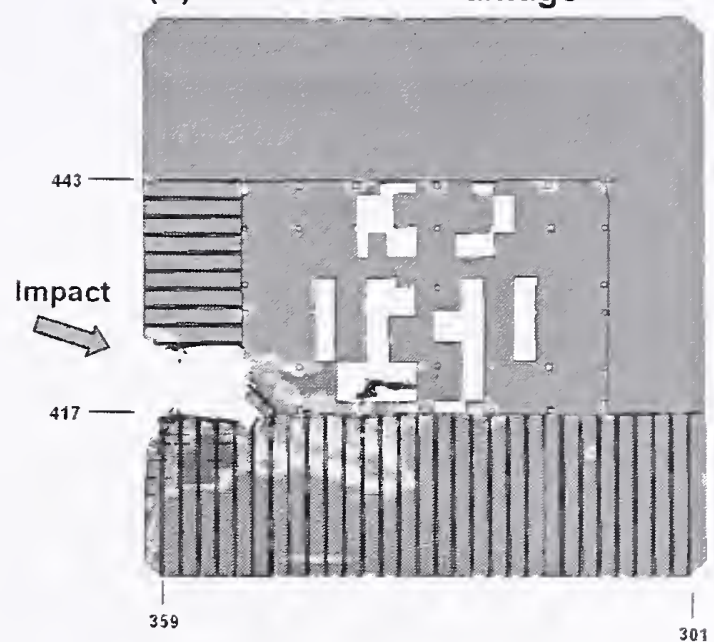

(d) Floor 81 slab damage

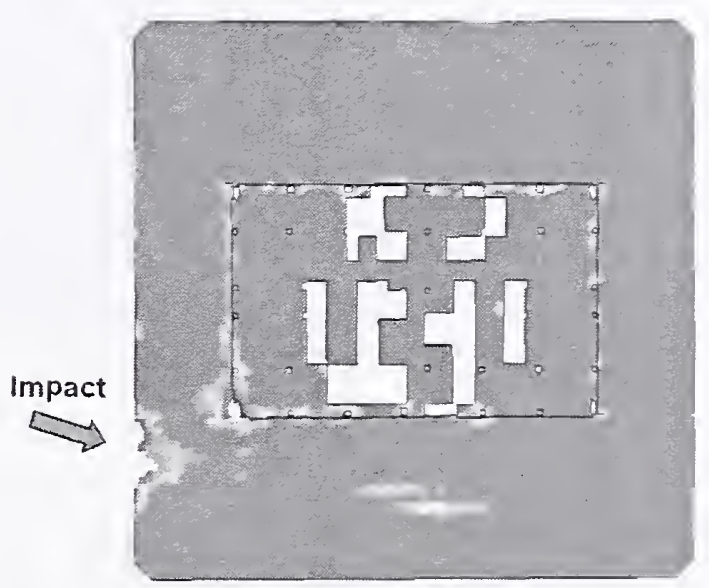

(f) Floor 83 slab damage

Figure 9-37. Base case impact damage to the WTC 2 floor slab (plan view). 


\subsubsection{WTC 2 Base Case Impact Analysis - Fuel and Debris Distributions}

The global impact results presented in this section include the distribution of the jet fuel and aircraft debris in the WTC 2 tower, and the damage to the building contents (partition walls and workstations). For the base case WTC 2 global impact analysis, the calculated distribution of the fuel in the tower and shape of the fuel cloud in a plan view and side view are shown in Figure 9-38 and Figure 9-39, respectively. At the end of the analysis, the residual momentum of the jet fuel in the impact direction was less than one percent of the initial momentum, indicating that the fuel cloud was nearly at rest at about $0.62 \mathrm{~s}$.

To more clearly present the calculated response of the structures that influenced the fire propagation, the structural components were removed from the visualization, with the exception that the core columns were maintained in the visualizations for reference positions. A plan view of the response of the remaining building contents and aircraft debris are shown in a plan view in Figure 9-40. Similar plan views of floor-by-floor slices through the building contents and debris field are provided in Figure 9-41 through Figure 9-46 for floors 78 through 83 , respectively. The bulk of the aircraft debris and fuel was arrested prior to exiting the tower structures. However, a significant amount of aircraft debris was calculated to exit the north and east sides of the tower (Sides 300 and 200 of WTC 2).

A quantitative characterization of the fuel and aircraft debris distribution was obtained by slicing the model at vertical floor locations and calculating the mass at each floor level. A summary of the floor-byfloor fuel and debris distributions is given in Table 9-6. The bulk of the fuel and aircraft debris was deposited in floors 78 through 80 , with the greatest concentration of aircraft debris on floor 80 , and the largest concentration of aircraft fuel on floors 79,81, and 82. Approximately $14,000 \mathrm{lb}$, or 5 percent, of the total aircraft mass was eliminated from the debris cloud in the final state as a result of the erosion in the aircraft structures due to impact and breakup. This eroded mass was maintained in the calculation but eliminated from consideration in the contact algorithm. As a result, any residual momentum at the time of erosion could not be subsequently transferred to the tower.

The calculated debris distribution included $55,800 \mathrm{lb}$ of debris and $10,600 \mathrm{lb}$ of aircraft fuel outside of the tower at the end of the impact analysis, either rebounding from the impact face or passing through the tower. These estimates of mass outside the tower were expected to be overestimated in the calculation since the exterior walls were not modeled with windows that could contain the fuel cloud and small debris inside the towers. In addition, the impact behavior of the aircraft fuel cloud did not include the ability to stick to, or wet, interior components. Rather, the aircraft fuel SPH particles tended to bounce off of internal structures (see Section 9.4.2). 


\section{Time $=0.6219$}

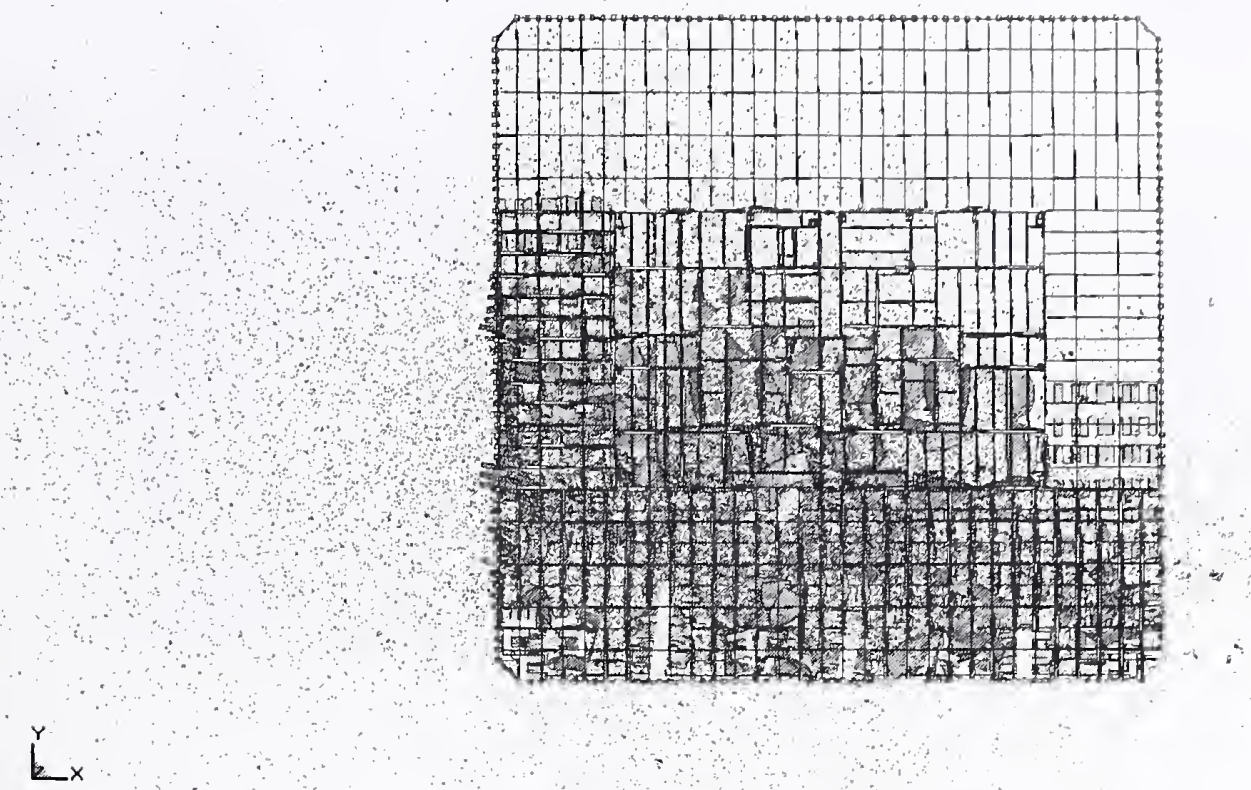

(a) Calculated impact response (floor slab removed)

Time $=0.6219$

(b) SPH fuel distribution

Figure 9-38. Calculated fuel distribution in the base case WTC 2 analysis (plan view). 
Time $=0.6219$
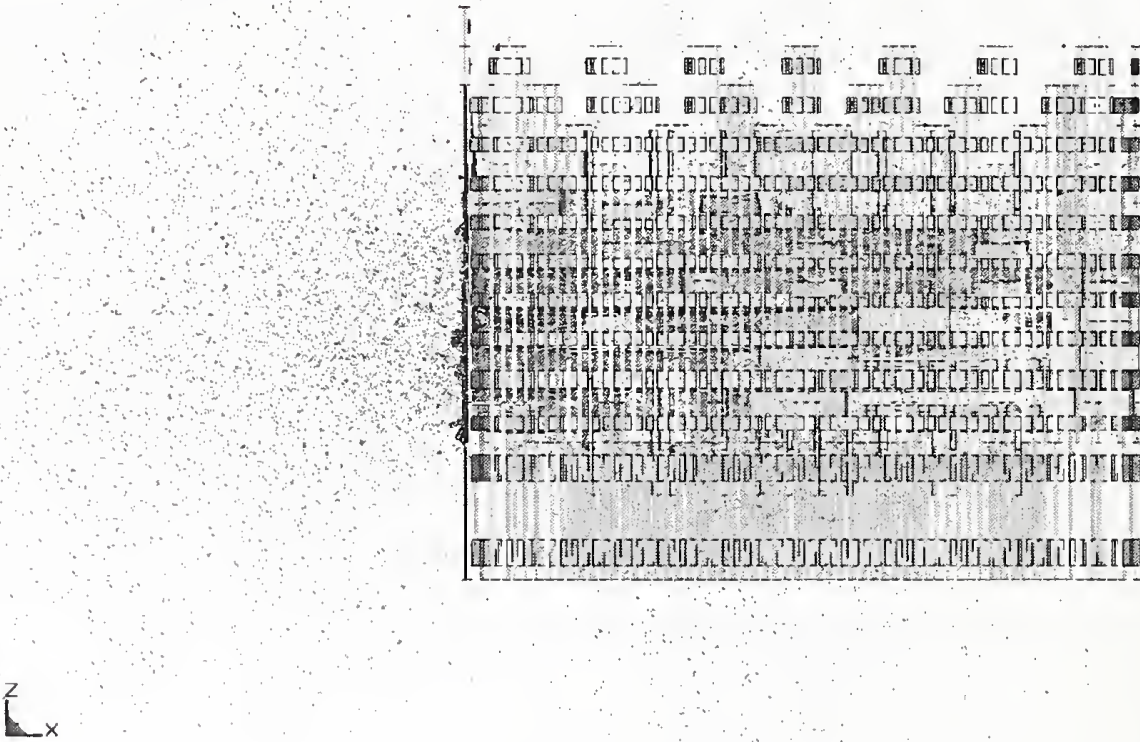

(a) Calculated impact response

Jime $=0.6219$

(b) SPH fuel distribution

Figure 9-39. Calculated fuel distribution in the base case WTC 2 analysis (side view). 


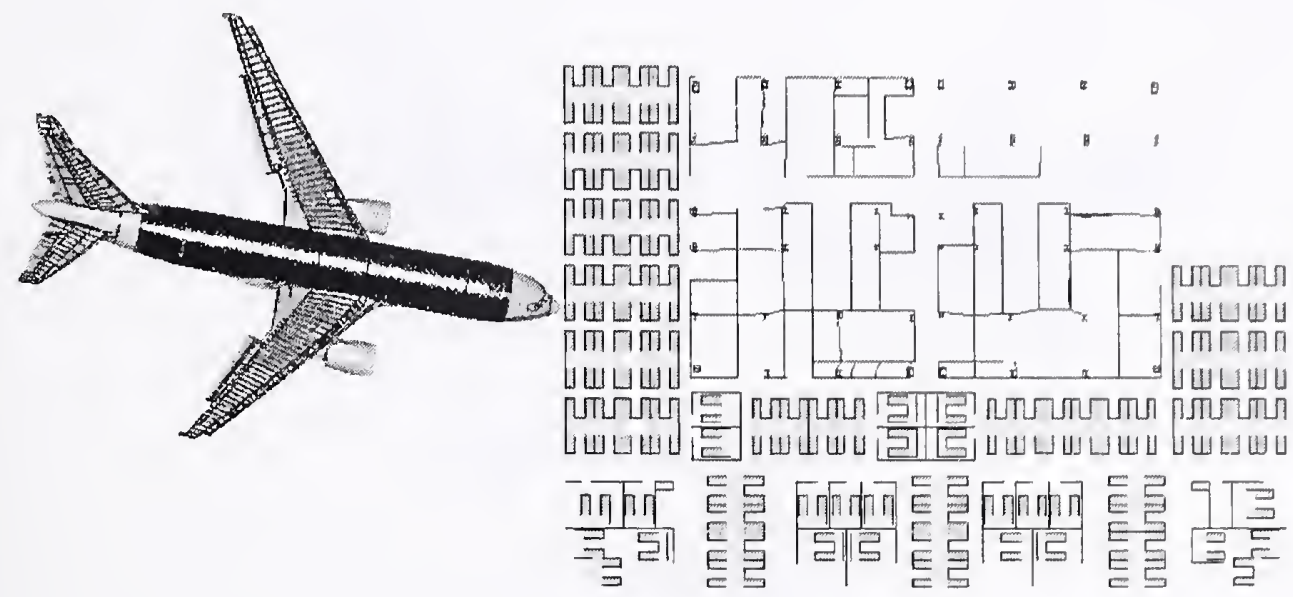

(a) Impact configuration (plan view)

Time $=$ D.6219
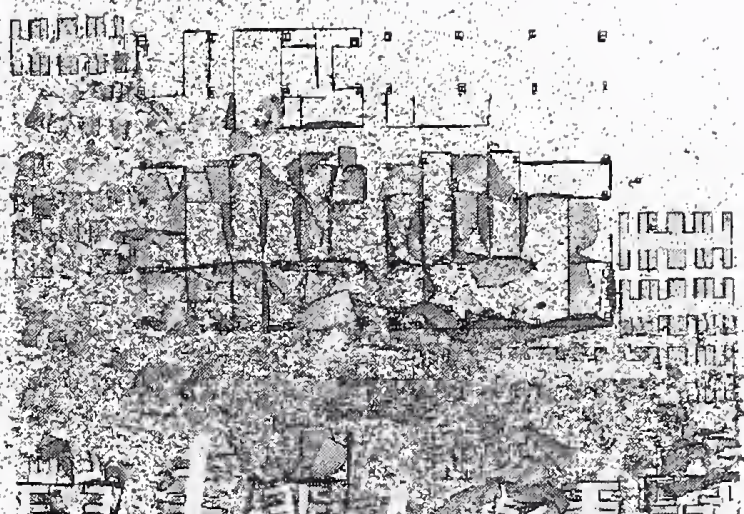

3.

$k_{x}$

(b) Calculated impact response $(t=0.622)$

Figure 9-40. Calculated WTC 2 building contents, fuel, and aircraft debris distribution. 


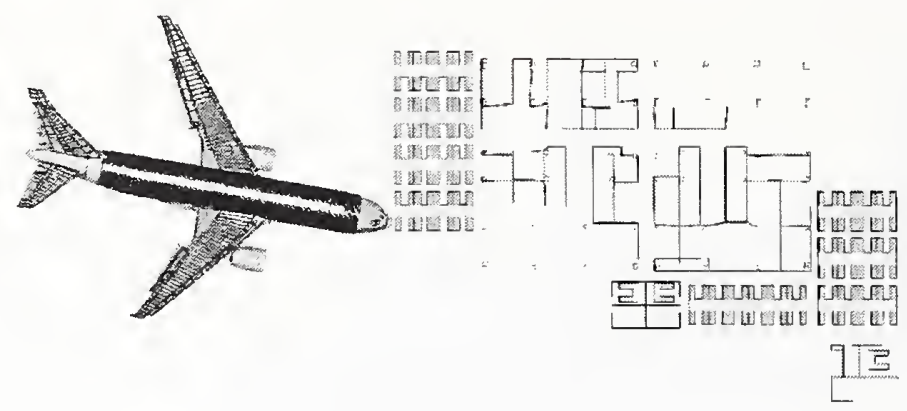

(a) Initial impact configuration

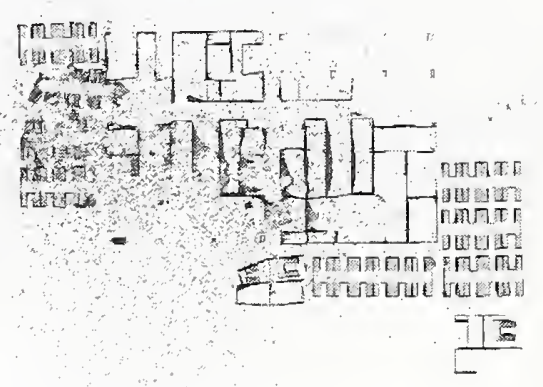

(b) Calculated impact response

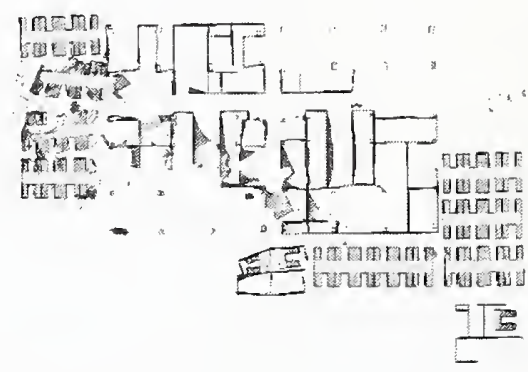

(c) Calculated impact response (fuel removed)

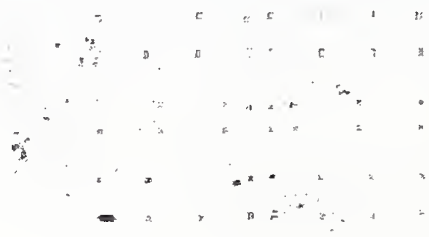

(d) Calculated aircraft debris

Figure 9-41. Calculated floor 78 contents, fuel, and aircraft debris distribution. 


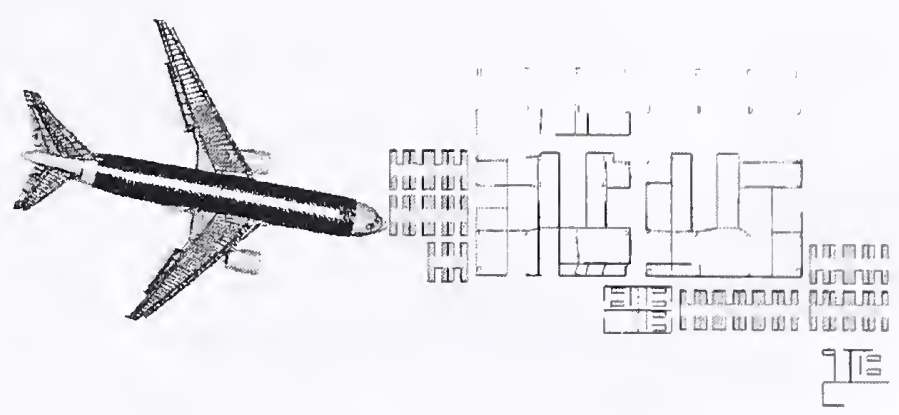

(a) Initial impact configuration

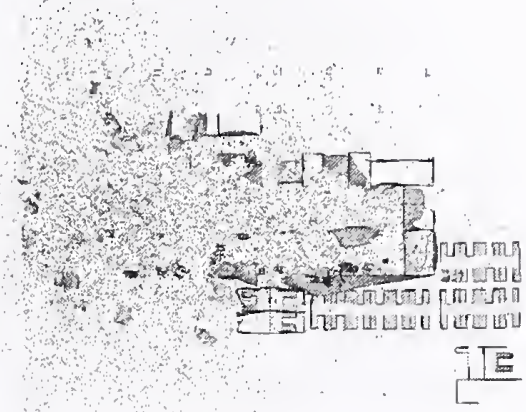

(b) Calculated impact response

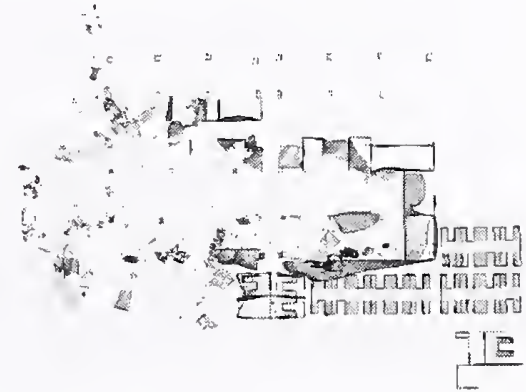

(c) Calculated impact response (fuel removed)

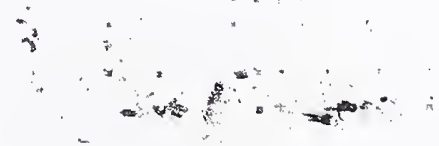

(d) Calculated aircraft debris

Figure 9-42. Calculated floor 79 contents, fuel, and aircraft debris distribution. 


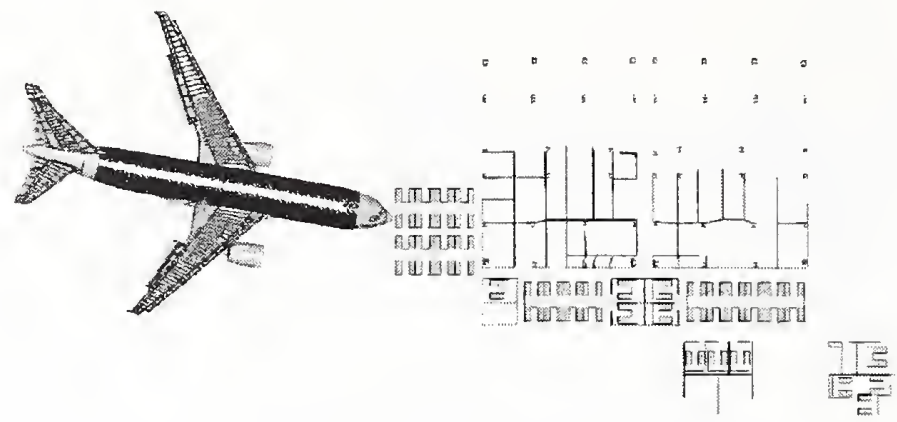

(a) Initial impact configuration

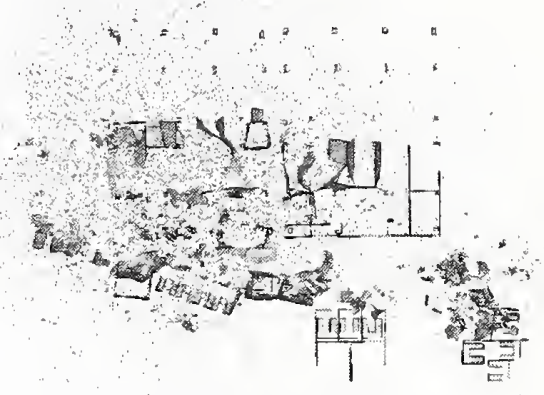

(b) Calculated impact response

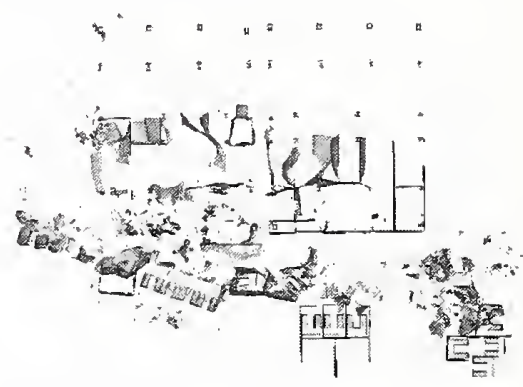

(c) Calculated impact response (fuel removed)

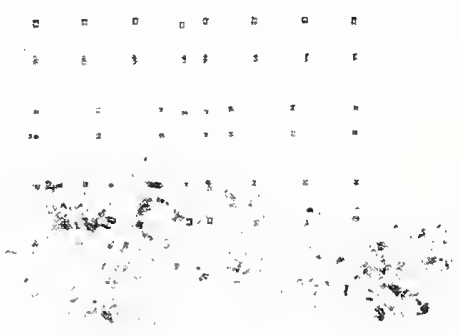

(d) Calculated aircraft debris

Figure 9-43. Calculated floor 80 contents, fuel, and aircraft debris distribution. 


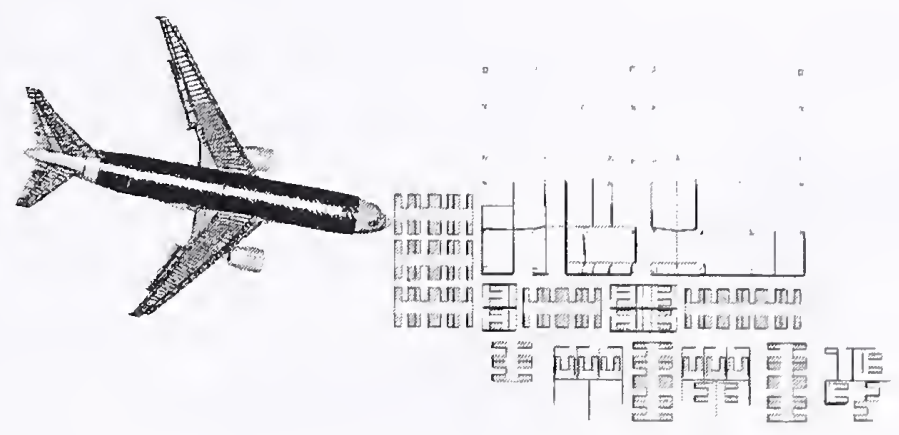

(a) Initial impact configuration

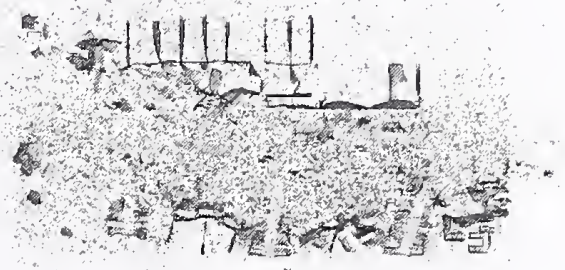

(b) Calculated impact response

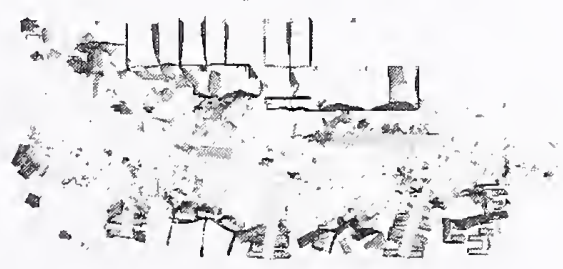

(c) Calculated impact response (fuel removed)

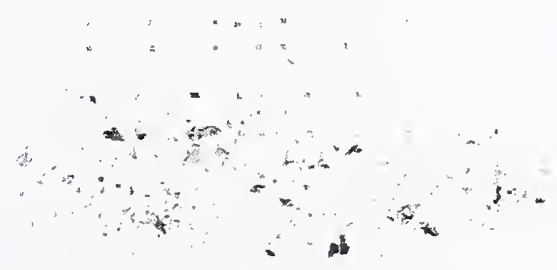

(d) Calculated aircraft debris

Figure 9-44. Calculated floor 81 contents, fuel, and aircraft debris distribution. 


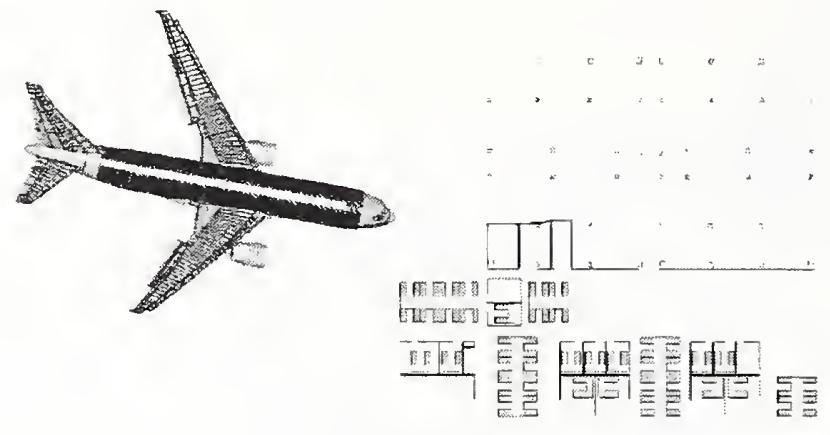

(a) Initial impact configuration

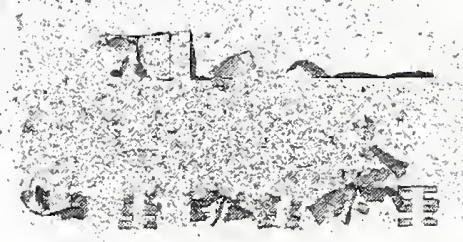

(b) Calculated impact response

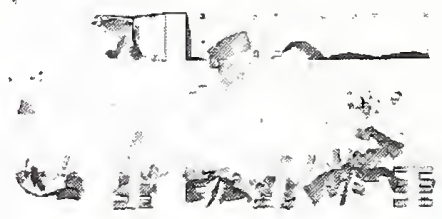

(c) Calculated impact response (fuel removed)

(d) Calculated aircraft debris

Figure 9-45. Calculated floor 82 contents, fuel, and aircraft debris distribution. 


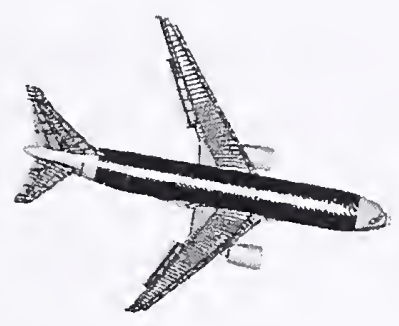

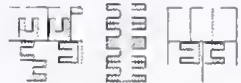

(a) Initial impact configuration

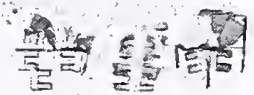

(b) Calculated impact response

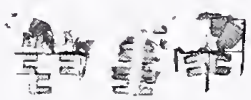

(c) Calculated impact response (fuel removed)

(d) Calculated aircraft debris

Figure 9-46. Calculated floor 83 contents, fuel, and aircraft debris distribution. 
Table 9-6. Fuel and aircraft debris distribution for the base case WTC 2 impact.

\begin{tabular}{|l|c|c|}
\hline \multicolumn{1}{|c|}{ Tower Location } & Aircraft Fuel & Aircraft Debris \\
\hline Total Outside Tower & $10,600 \mathrm{lb}$ & $55,800 \mathrm{lb}$ \\
\hline WTC 2 Floor 77 & $1,300 \mathrm{lb}$ & $400 \mathrm{lb}$ \\
\hline WTC 2 Floor 78 & $6,200 \mathrm{lb}$ & $4,800 \mathrm{lb}$ \\
\hline WTC 2 Floor 79 & $11,400 \mathrm{lb}$ & $16,200 \mathrm{lb}$ \\
\hline WTC 2 Floor 80 & $6,000 \mathrm{lb}$ & $83,800 \mathrm{lb}$ \\
\hline WTC 2 Floor 81 & $14,400 \mathrm{lb}$ & $27,300 \mathrm{lb}$ \\
\hline WTC 2 Floor 82 & $10,600 \mathrm{lb}$ & $3,600 \mathrm{lb}$ \\
\hline WTC 2 Floor 83 & $1,500 \mathrm{lb}$ & $4,300 \mathrm{lb}$ \\
\hline WTC 2 Floor 84 & $200 \mathrm{lb}$ & $500 \mathrm{lb}$ \\
\hline Total Wejght & $62,000 \mathrm{lb}$ & $197,600 \mathrm{lb}$ \\
\hline
\end{tabular}

\subsection{ADDITIONAL WTC 1 GLOBAL IMPACT ANALYSES}

In addition to the base case impact analyses, additional impact analyses were performed for each tower to provide a range of calculated impact-induced damage. The variations in impact analysis parameters were developed based on the result of the uncertainty analyses described in Chapter 8 and additional evaluations of the parameter uncertainties. Additional guidance on the combination of parameters was obtained by engineering analysis of expected responses.

Two additional global impact analyses were performed for each WTC tower impact to evaluate a more severe and less severe impact scenario. The combinations of impact conditions for the more and less severe WTC 1 impact scenarios are compared to the corresponding parameters in the base case analysis in Table 9-7. The impact speeds were $414 \mathrm{mph}$ and $472 \mathrm{mph}$ in the less severe and more severe impact scenarios, respectively. These were the upper and lower bounds obtained from the analysis of aircraft impact conditions described in Chapter 7. The aircraft vertical trajectory angle was also varied from 13.6 degrecs to 7.6 degrees for the less scvere and more severe impact scenarios, respectively. This resulted in more impact energy directed inward toward the core in the more severe impact scenario and less impact energy imparted to the core for the less severe impact. The lateral trajectory was not varied since the impact was close to centered on the tower and normal to the north face of WTC 1. A small variation in the lateral approach angle would have little effect on the energy of the aircraft debris entering the tower and core.

The parameters varied for the aircraft model were the weight of the aircraft and the ductility of the aircraft materials. A 5 percent variation on the total aircraft weight was considered, with the additional weight applied for the more severe impact. The failure strain was varied from 75 to 125 percent of the baseline value for the less severe and more severe impact scenarios, respectively. This relatively large variation in aircraft material ductility was applied for multiple reasons. First, no material characterization testing of specimens cut from a Boeing 767 were performed as a part of this investigation. All of the material properties used for the aircraft were obtained from sources available in the open literature, as described in Section 2.5. Second, the variation in ductility was used as the single parameter in these additional analyses to evaluate the uncertainties in aircraft material energy absorption capacity. An increase in aircraft material strength would have a similar effect to an increase in material ductility for producing 
increased impact damage to the towers. Finally, the matcrial failure parameters were influenced by the resolution of the models in the impact analysis. This effect was described previously in Section 2.3.1, and the material modcls were developed for the resolution in the global impact analysis. However, the mesh refinement effects introduced an incrcased uncertainty on the failure strains in thesc analyses.

Table 9-7. Input parameters for additional WTC 1 global impact analyses.

\begin{tabular}{|l|l|c|c|c|}
\hline \multicolumn{2}{|c|}{ Analysis Parameters } & Base Case & More Severe & Less Severc \\
\hline \multirow{4}{*}{$\begin{array}{l}\text { Flight } \\
\text { Parameters }\end{array}$} & Impact speed & $443 \mathrm{mph}$ & $472 \mathrm{mph}$ & $414 \mathrm{mph}$ \\
\cline { 2 - 5 } & Trajectory - pitch & $10.6^{\circ}$ & $7.6^{\circ}$ & $13.6^{\circ}$ \\
\cline { 2 - 5 } & Trajectory - yaw & $0.0^{\circ}$ & $0.0^{\circ}$ & $0.0^{\circ}$ \\
\cline { 2 - 5 } & Orientation - pitch & $8.6^{\circ}$ & $5.6^{\circ}$ & $11.6^{\circ}$ \\
\cline { 2 - 5 } & Orientation - yaw & $0.0^{\circ}$ & $0.0^{\circ}$ & $0.0^{\circ}$ \\
\hline \multirow{2}{*}{$\begin{array}{l}\text { Aircraft } \\
\text { Parameters }\end{array}$} & Weight & 100 percent & 105 percent & 95 percent \\
\cline { 2 - 5 } $\begin{array}{l}\text { Tower } \\
\text { Parameters }\end{array}$ & Failure Strain & 100 percent & 125 percent & 75 percent \\
\cline { 2 - 5 } & Failure Strain & 100 percent & 80 percent & 120 percent \\
\hline
\end{tabular}

a. Live load weight expressed as a percentage of the design live load.

Finally, the parameters varied for the tower model were the ductility of the steel used in the tower construction and the weight of the contents inside the tower. A variation of 20 perecnt was used to account for the uncertainty in failure strain for the tower materials. However, for the tower the material, failure strain was increased for the less severe impact analysis. The combination of reducing all of the aircraft material ductilities by 25 percent and increasing the tower material ductilites by 20 percent for the less severe impact scenario covered a wide range in relative aircraft and tower strength assumptions.

The variations in internal tower contents (live load weight in Table 9-7) are spccified as a percentage of the design live load as described in Section 3.2.4.

\subsubsection{More Severe WTC 1 Global Impact Analysis}

This case is referred to as Case $\mathrm{C}$ for the remainder of the WTC investigation reports. A side view of the more severe WTC 1 global impact response is shown in Figure 9-47. The tower interior contents were removed and the tower structures were shown as transparent so that the impaet response in the tower interior can be seen. Similar plan view images of the progression of aircraft impaet response are shown in Figure 9-48. The corresponding views were used previously to illustrate the base case global aircraft impact response in Figure 9-4 and Figure 9-5, respectively.

The more severe impact response is qualitatively very similar to that of the base case impact analysis. The initial $0.1 \mathrm{~s}$ of the base ease global aircraft impaet response, shown in Figure 9-47(b) and Figure 9-48(b), was dominated by the impact, penetration, and fragmentation of the forward fusclage structures. The engines and forward wing sections have impacted the exterior wall. At $0.2 \mathrm{~s}$ after impact, the wings had eompletely penetrated the exterior wall and only the tail structures were still outside of the tower, as shown in Figure 9-47(e) and Figure 9-48(c). The wing structures were completely fragmented by the penetration through the exterior wall. The aircraft fuel cloud was starting to spread out, but was still relatively dense and the leading edge of the fuel was entering the tower core. At $0.3 \mathrm{~s}$ after impact, 
the aircraft was completely inside of the tower (full penetration completed at approximately $0.24 \mathrm{~s}$ ), as shown in Figure 9-47(d) and Figure 9-48(d). The aircraft fuel cloud penetrated approximately threequarters of the distance through the core and was spreading out. However, the subsequent motion of the aircraft fragments and fuel debris cloud began to be noticeably slowed beyond this time. The fuel and debris did continue to spread through the tower but at a much slower rate as seen in the remaining images in Figure 9-47 and Figure 9-48.

\section{Exterior Wall Damage for the More Severe WTC 1 Impact}

A comparison of the notth exterior wall observed and calculated damage from the more severe WTC 1 global impact analysis is shown in Figure 9-49. The calculated impact damage to the exterior wall is shown with color fringes representing plastic strain magnitude, with undamaged sections in blue and strains at or above 5 percent shown in red. The wall regions shown in Figure 9-49 illustrate a region of the exterior wall from column 108 to column 152, extending from floor 91 to floor 100 (spandrels at floors 92 through 100). The calculated and observed magnitude and mode of impact damage on the exterior wall was still in good agreement for this more severe impact analysis.

\section{Core Structural Damage for the More Severe WTC 1 Impact}

The overall model for the WTC 1 core structure and calculated response for the more severe global impact analysis is shown in Figure 9-50. The figure shows that the core had extensive damage in the region close to the impact point. The columns in line with the aircraft fuselage failed on the impact side, and several of the core beams were also severely damaged or failed in the impact zone. In some cases, failure of the column splices located on floors 92,95 , and 98 contributed significantly to the failure of the core columns.

The calculated damage to the core columns by row is shown in Figure 9-51, and the floor-by-floor damage to the core framing is shown in Figure 9-52. The core structures are shown with color fringes representing plastic strain magnitude, with undamaged sections in blue and strains at or above 5 percent shown in red. A summary of the core column damage is provided in Table 9-8 and shown graphically in Figure 9-53, with the qualitative classification of the column damage levels provided previously in Figure 9-12. A total of six columns were severed and three columns were heavily damaged, compared to three columns severed and four columns heavily damaged in the base case WTC 1 impact analysis. 


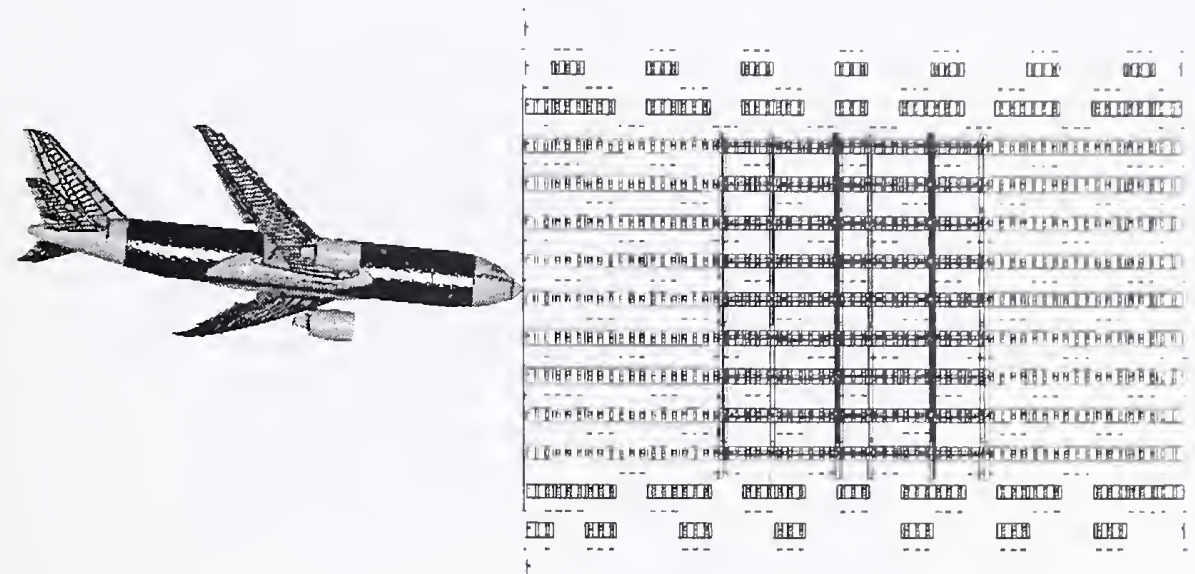

(a) Time $=0.00 \mathrm{~s}$

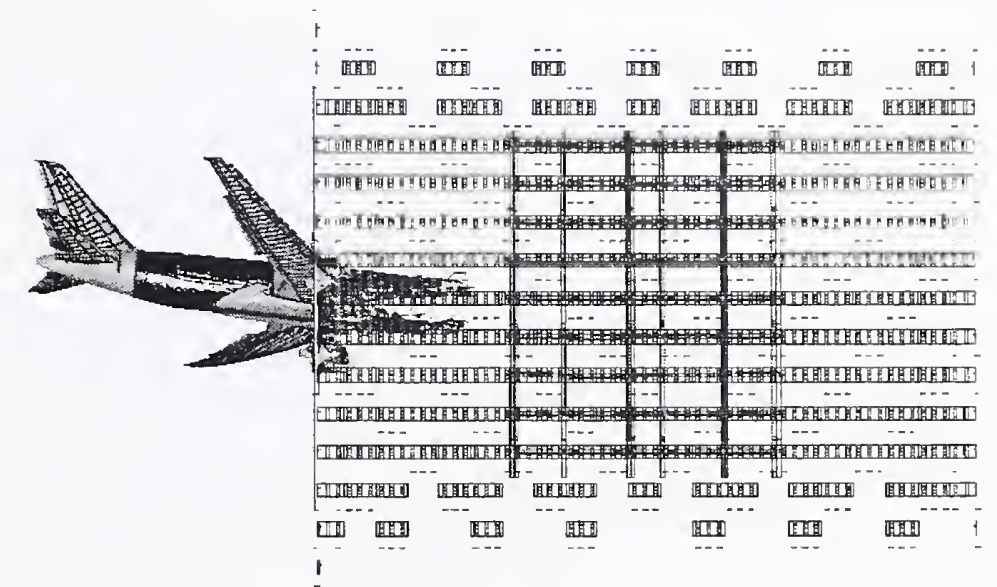

(b) Time $=0.10 \mathrm{~s}$

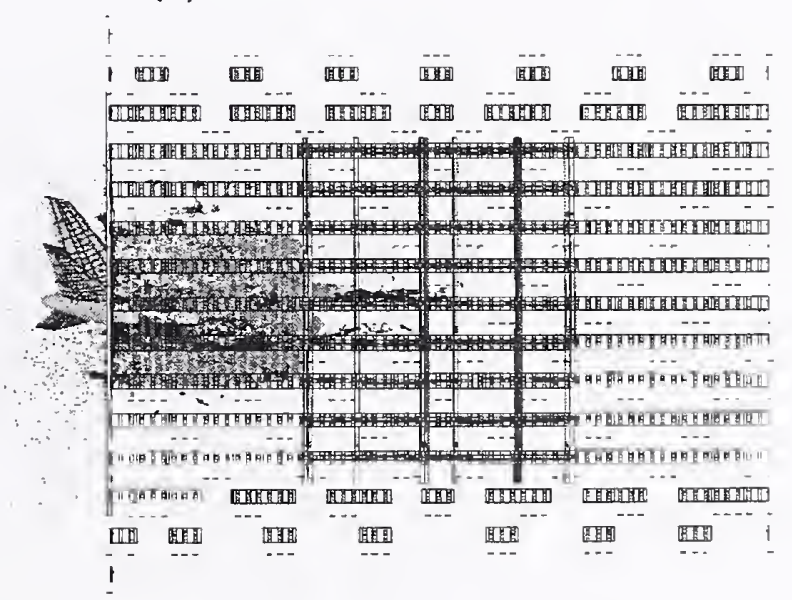

(c) Time $=0.20 \mathrm{~s}$

Figure 9-47. More severe WTC 1 global impact analysis (side view). 


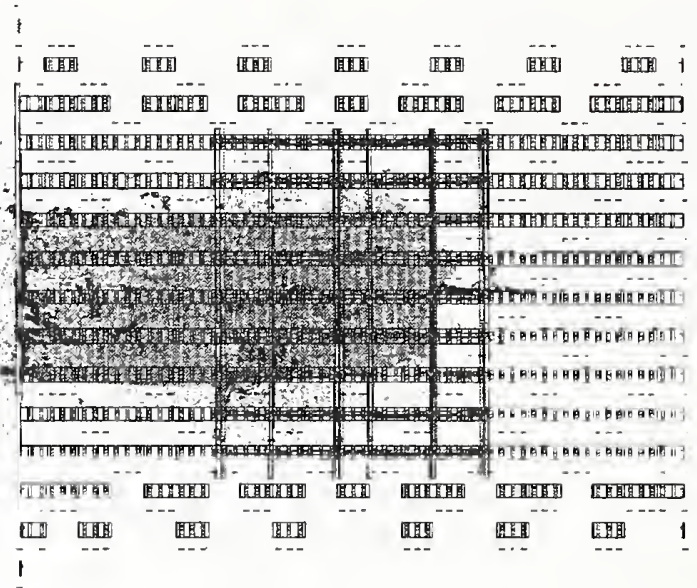

(d) Time $=0.30 \mathrm{~s}$

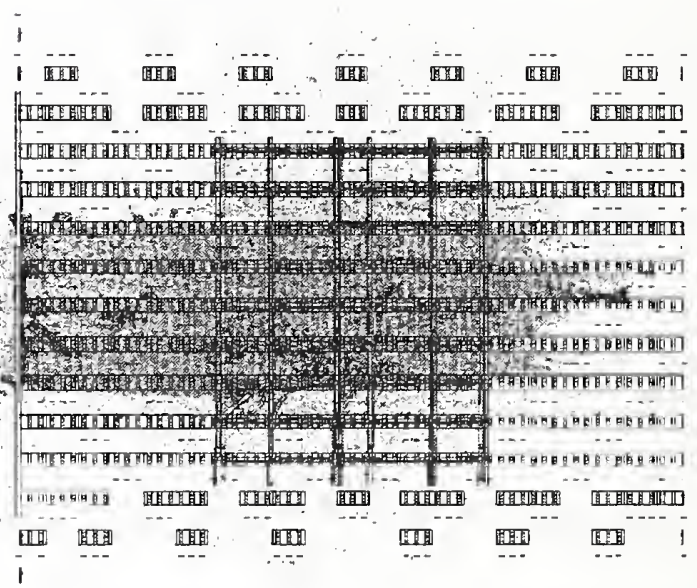

(e) Time $=0.40 \mathrm{~s}$

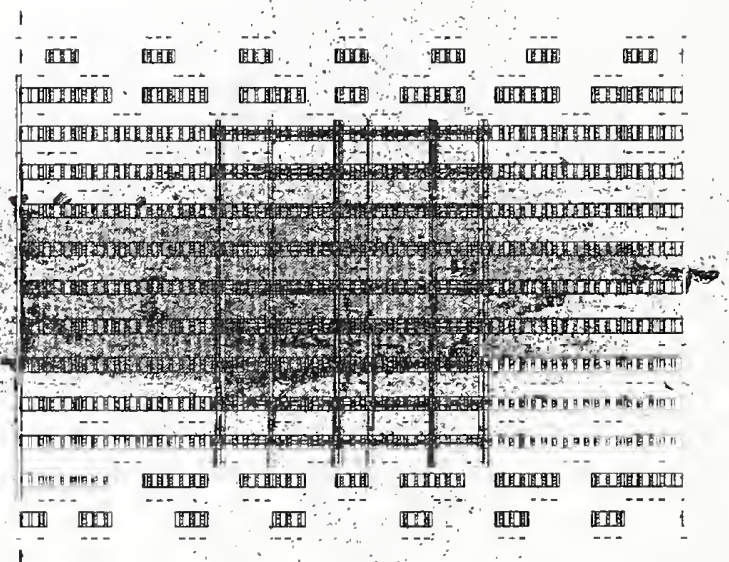

(f) Time $=0.50 \mathrm{~s}$

Figure 9-47. More severe WTC 1 global impact analysis (side view) (continued). 


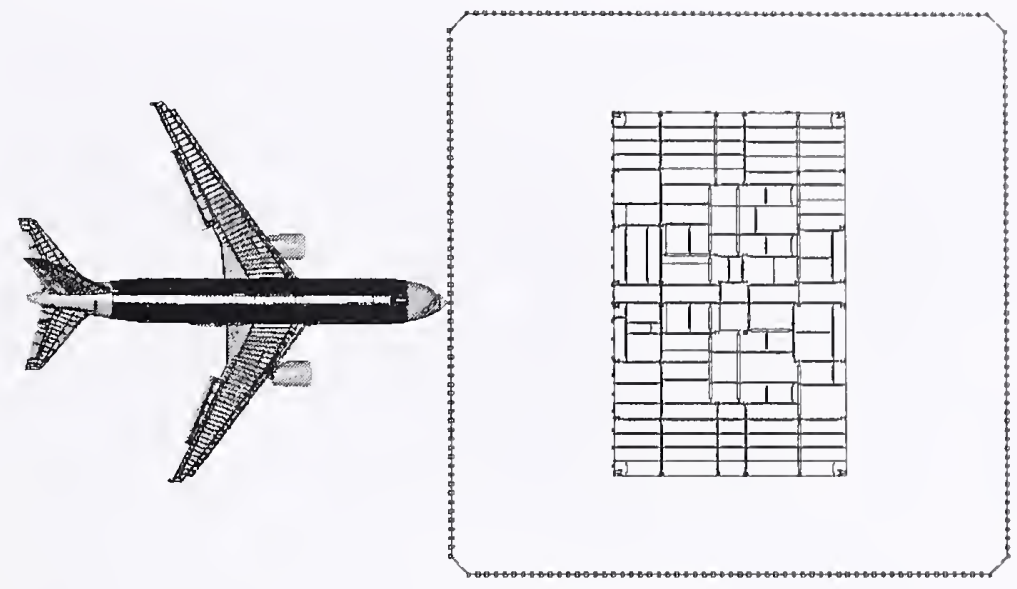

(a) Time $=0.00 \mathrm{~s}$

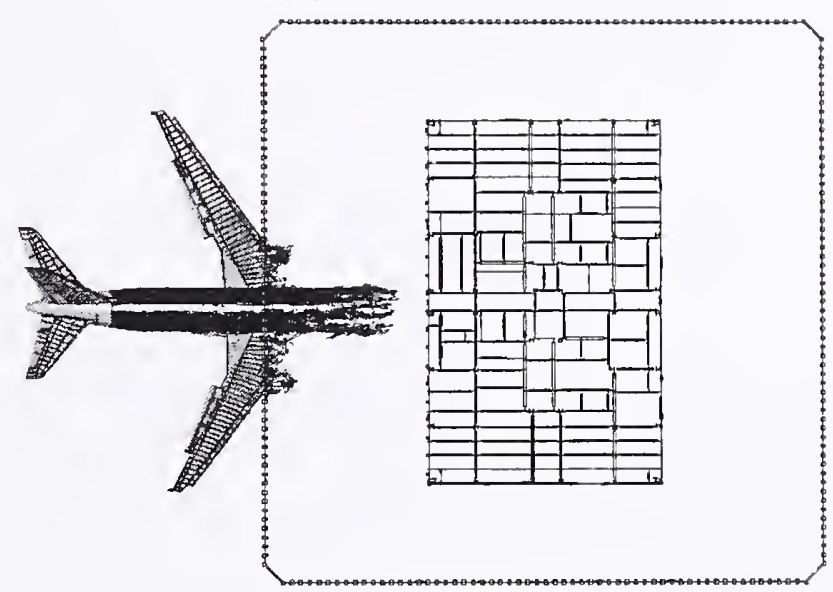

(b) Time $=0.10 \mathrm{~s}$

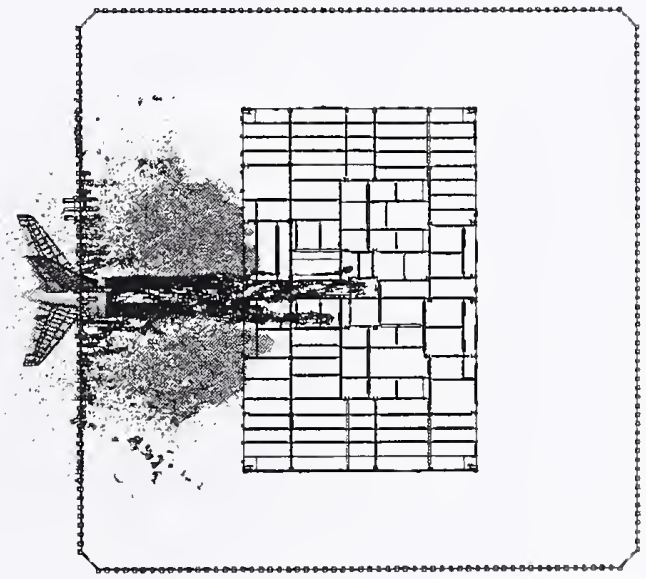

(c) Time $=0.20 \mathrm{~s}$

Figure 9-48. More severe WTC 1 global impact analysis (plan view). 


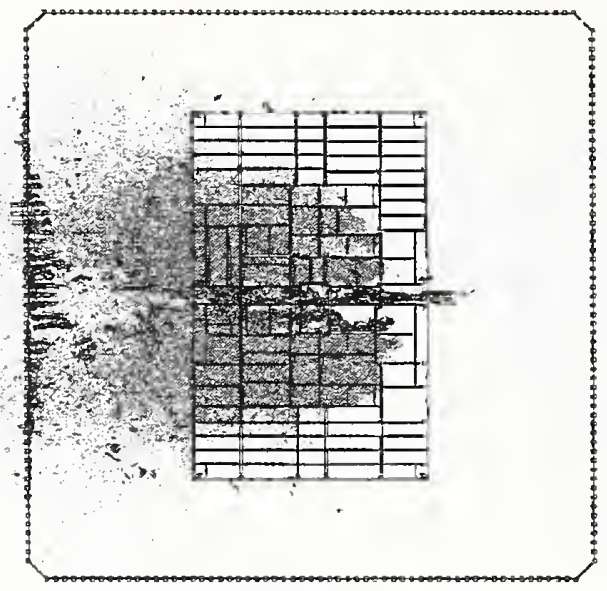

(d) Time $=0.30 \mathrm{~s}$

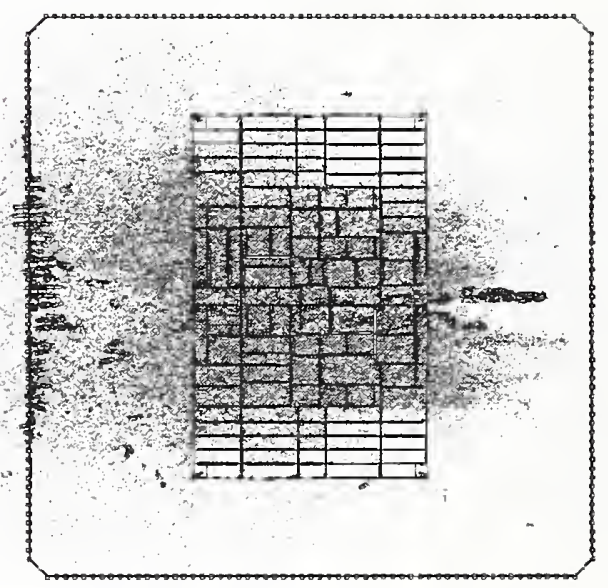

(e) Time $=0.40 \mathrm{~s}$

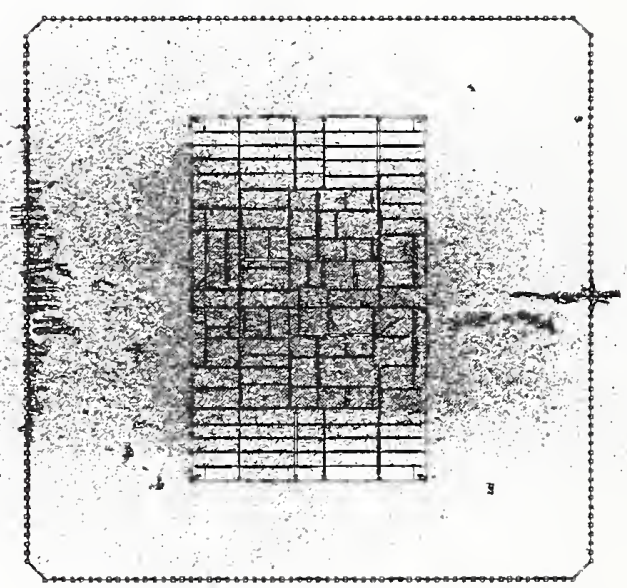

(f) Time $=0.50 \mathrm{~s}$

Figure 9-48. More severe WTC 1 global impact analysis (plan view) (continued). 


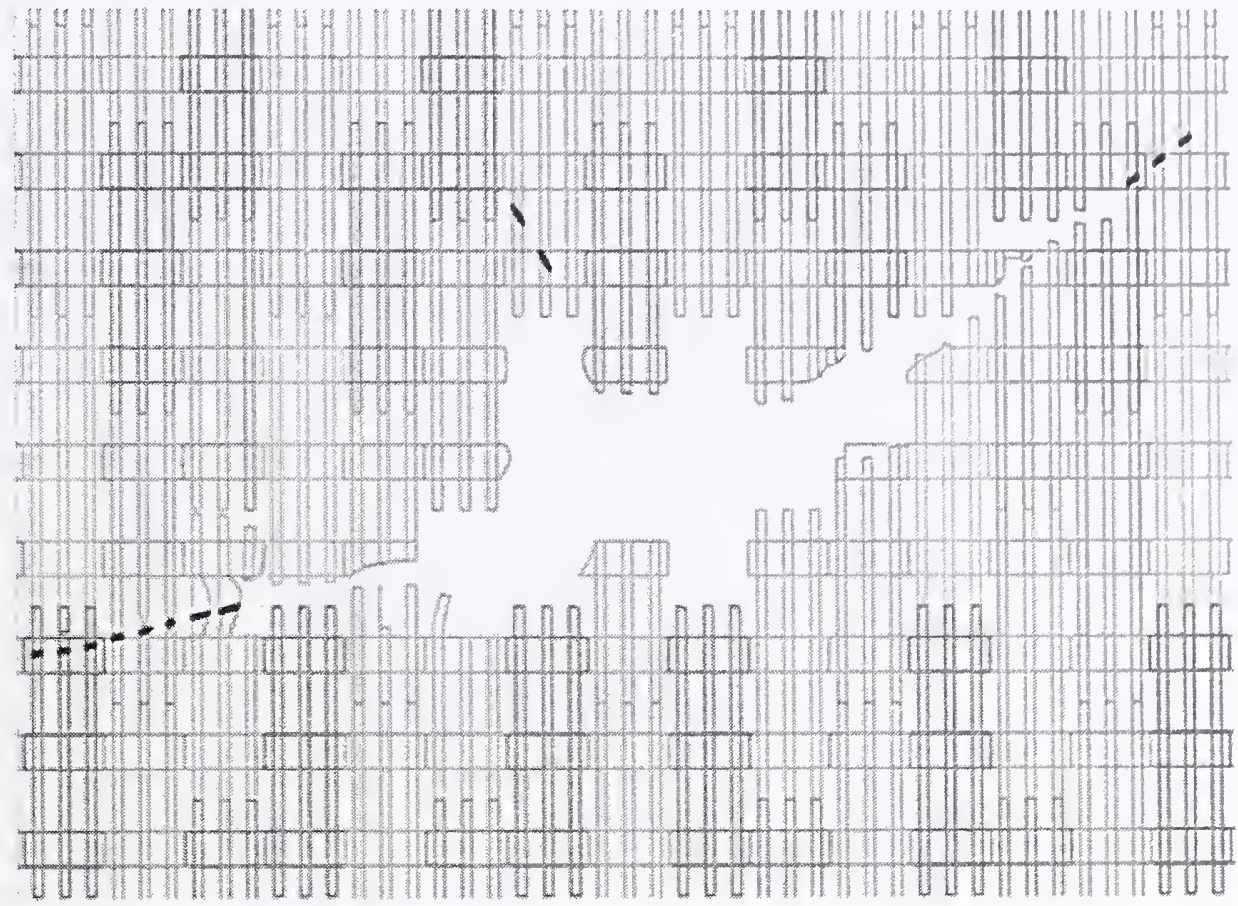

(a) Schematic of observed damage

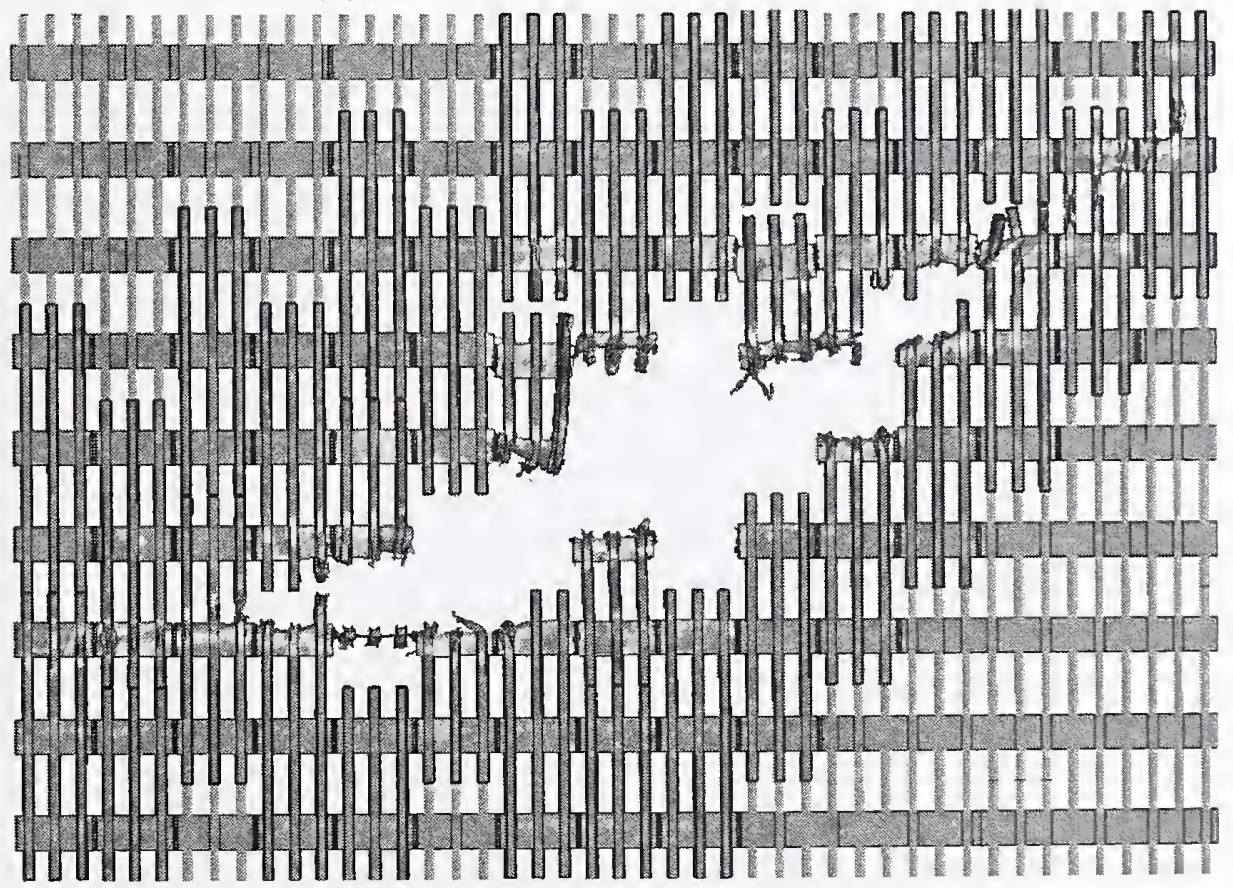

(b) Calculated damage ( $t=0.685 \mathrm{~s})$

Figure 9-49. More severe impact damage to the WTC 1 exterior wall. 


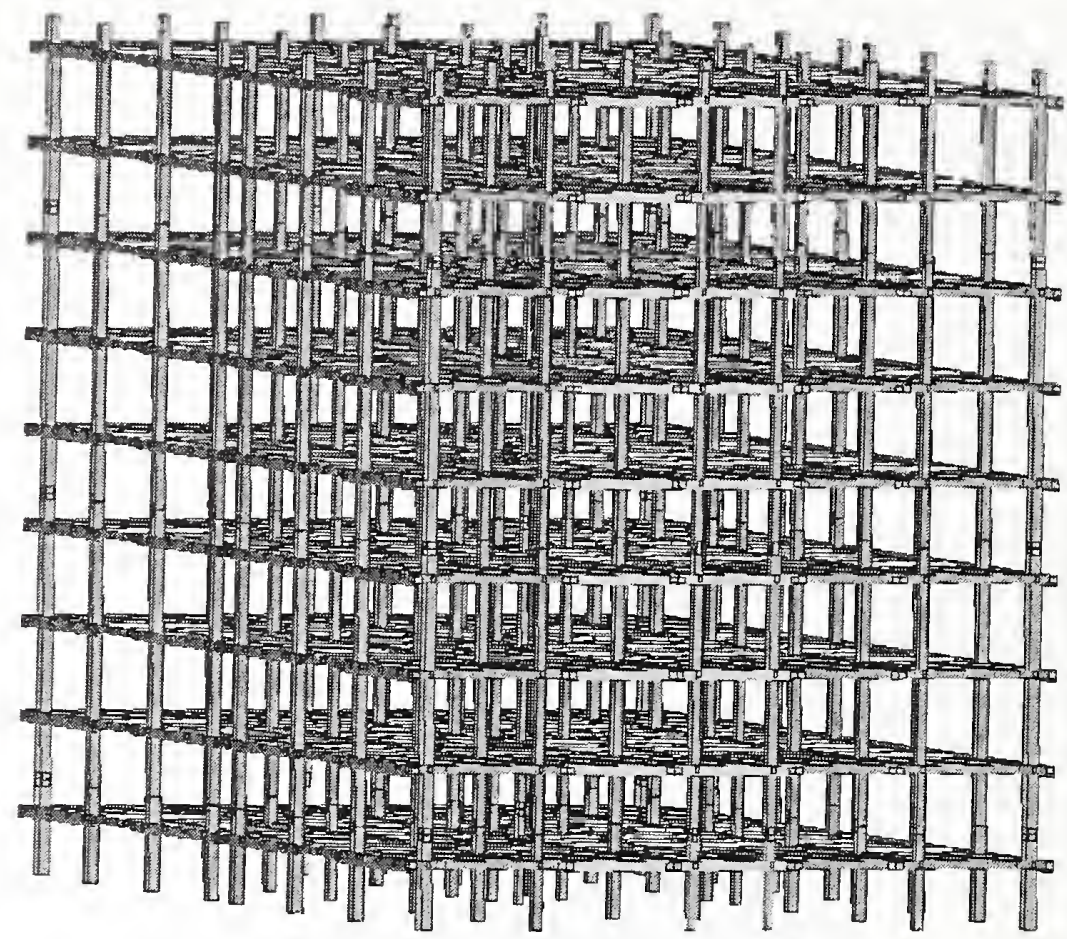

(a) Initial geometry

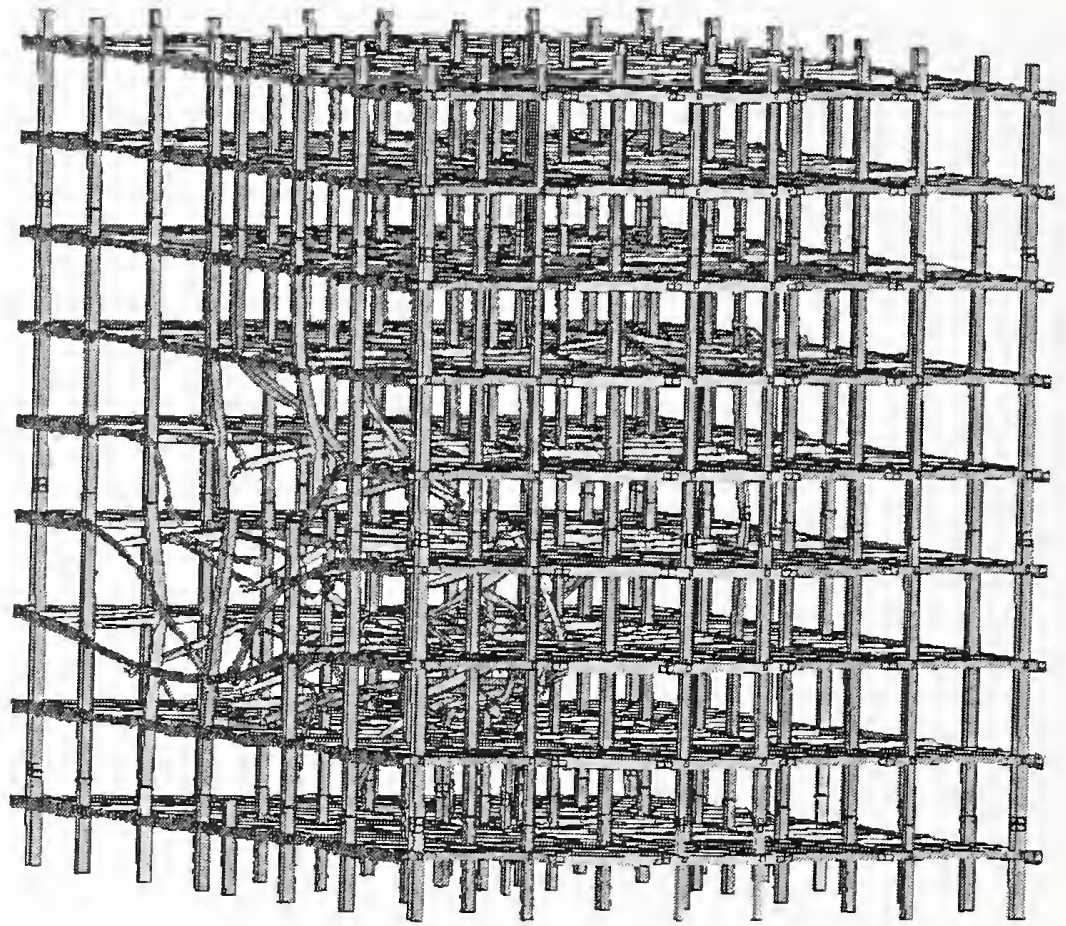

(a) Calculated impact damage

Figure 9-50. More severe impact response of the WTC 1 core. 


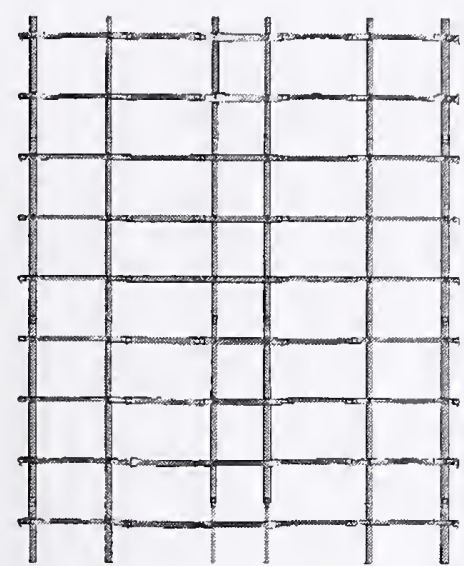

(a) Columns 501-1001

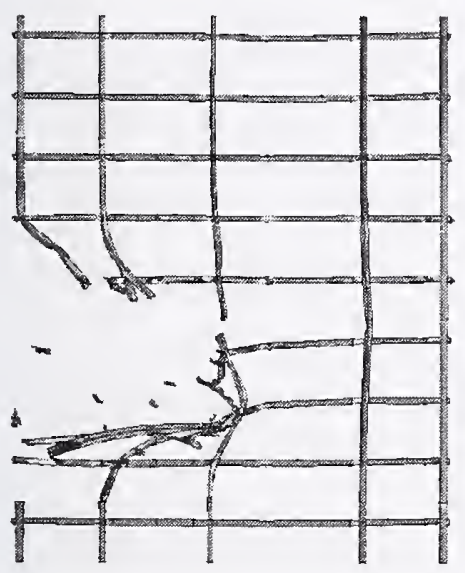

(d) Columns 504-1004

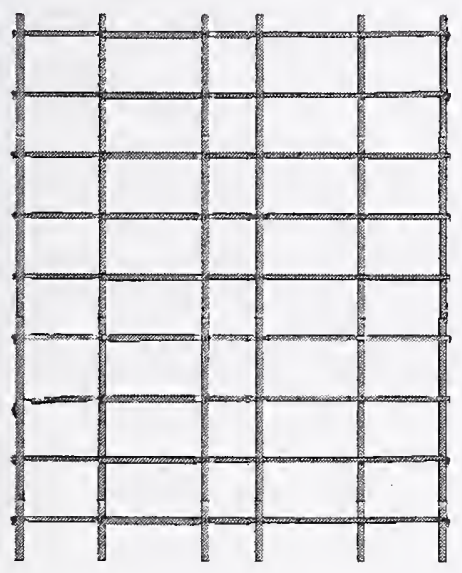

(g) Columns 507-1007

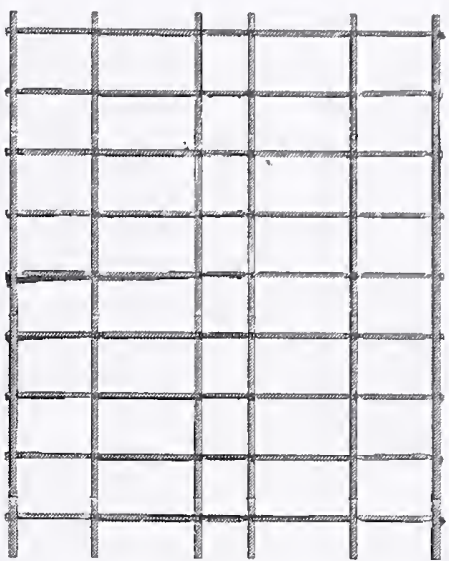

(b) Columns 502-1002

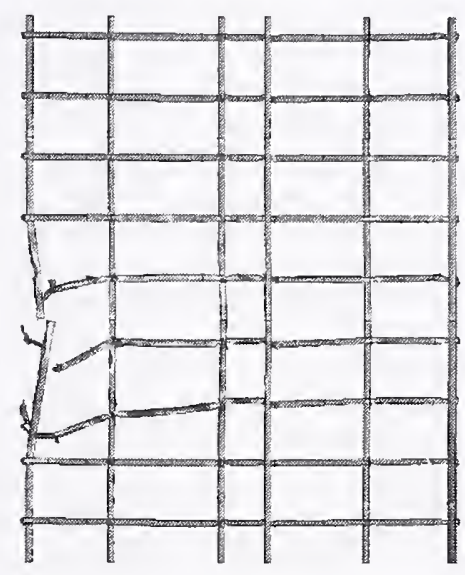

(e) Columns 505-1005

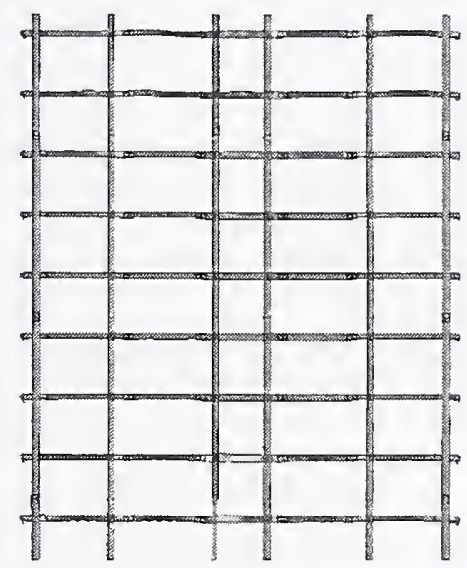

(h) Columns 508-1008

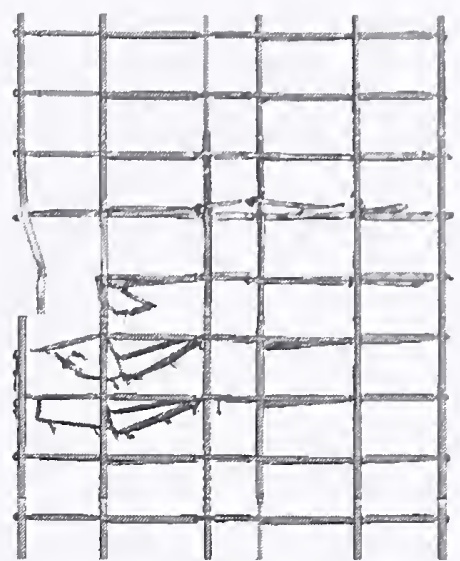

(c) Columns 503-1003

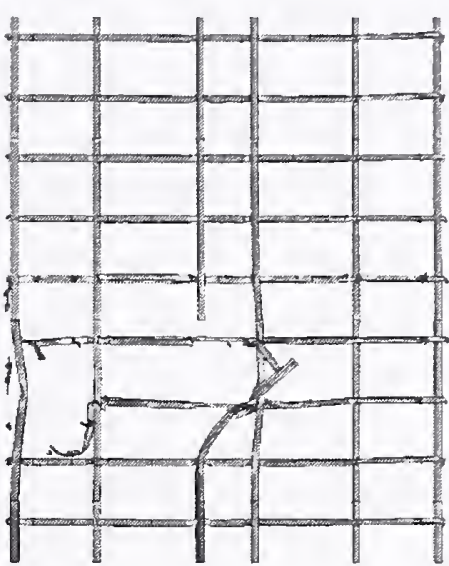

(f) Columns 506-1006

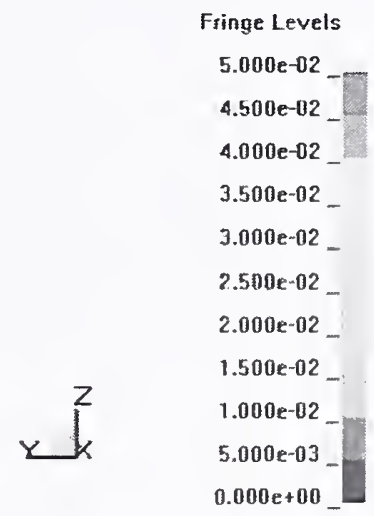

(i) Reference scale

Figure 9-51. More severe impact response of the WTC 1 core columns. 


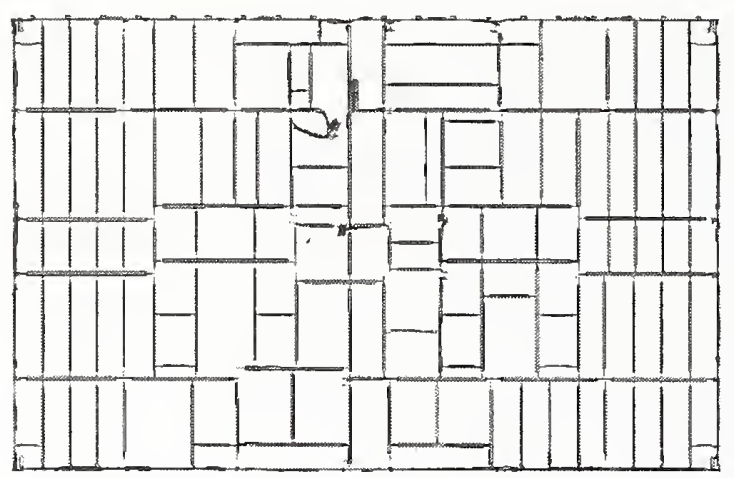

(a) Floor 93 core framing damage

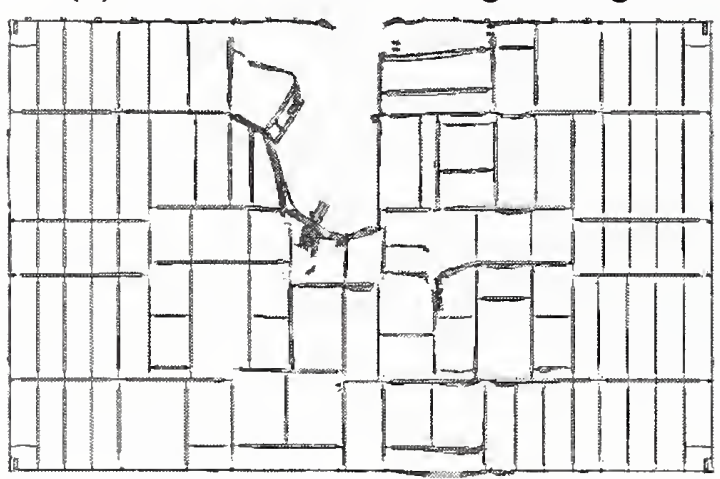

(c) Floor 95 core framing damage

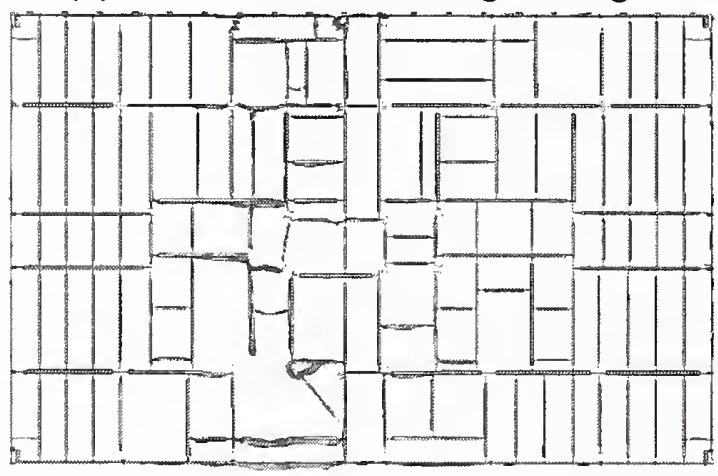

(e) Floor 97 core framing damage

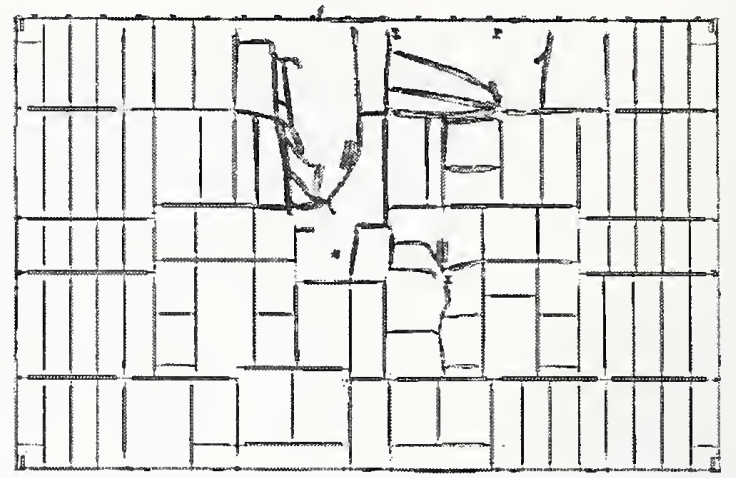

(b) Floor 94 core framing damage

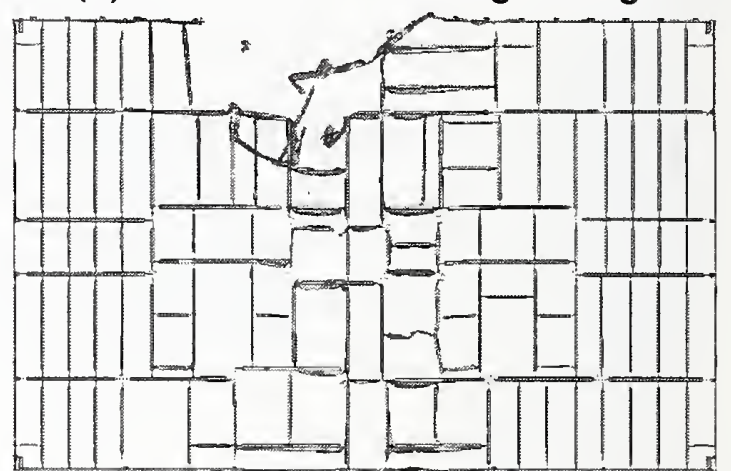

(d) Floor 96 core framing damage

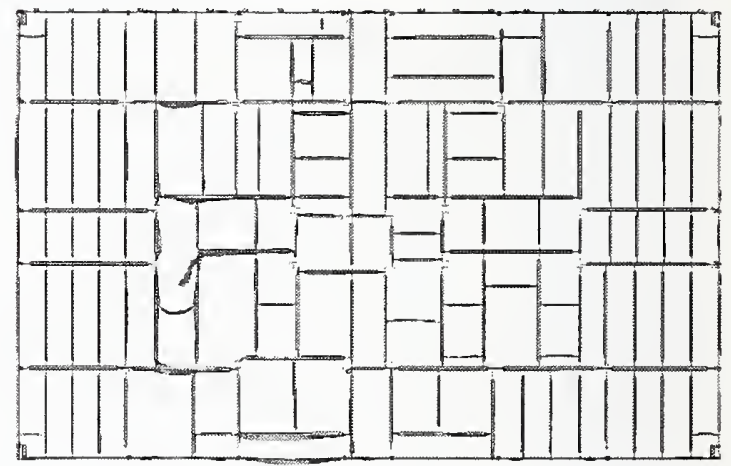

(f) Floor 98 core framing damage

Figure 9-52. More severe impact damage to the WTC 1 core floor framing (plan view). 
Table 9-8. Core column response for the more severe WTC 1 impact.

\begin{tabular}{|l|c|c|c|}
\hline \multicolumn{1}{|c|}{ Column } & Location & Damage Level & $\begin{array}{c}\text { Lateral Deflection of } \\
\text { Column Centerline (in.) }\end{array}$ \\
\hline Column 503 & Floor 95-96 & Severed & \\
\hline Column 504 & Floors 92-96 & Severed & \\
\hline Column 505 & Floors 93-96 & Severed & \\
\hline Column 506 & Floors 93-95 & Heavy & \\
\hline Column 603 & Floors 96-97 & Moderate & \\
\hline Column 604 & Floors 92-96 & Severed & \\
\hline Column 605 & Floors 94-95 & Moderate & \\
\hline Column 606 & Floors 94 & Light & \\
\hline Column 702 & Floor 97 & Light & \\
\hline Column 703 & Floor 96 & Moderate & \\
\hline Column 704 & Floors 92-96 & Severed & \\
\hline Column 705 & Floor 95 & Moderate & \\
\hline Column 706 & Floors 93-95 & Severed & \\
\hline Column 802 & Floor 96 & Light & \\
\hline Column 803 & Floors 96-97 & Moderate & \\
\hline Column 804 & Floor 94-96 & Moderate & \\
\hline Column 805 & Floors 93-95 & Heavy & \\
\hline Column 903 & Floor 96 & Light & \\
\hline Column 904 & Floors 95-96 & Heavy & \\
\hline Column 905 & Floor 95 & Light & \\
\hline
\end{tabular}




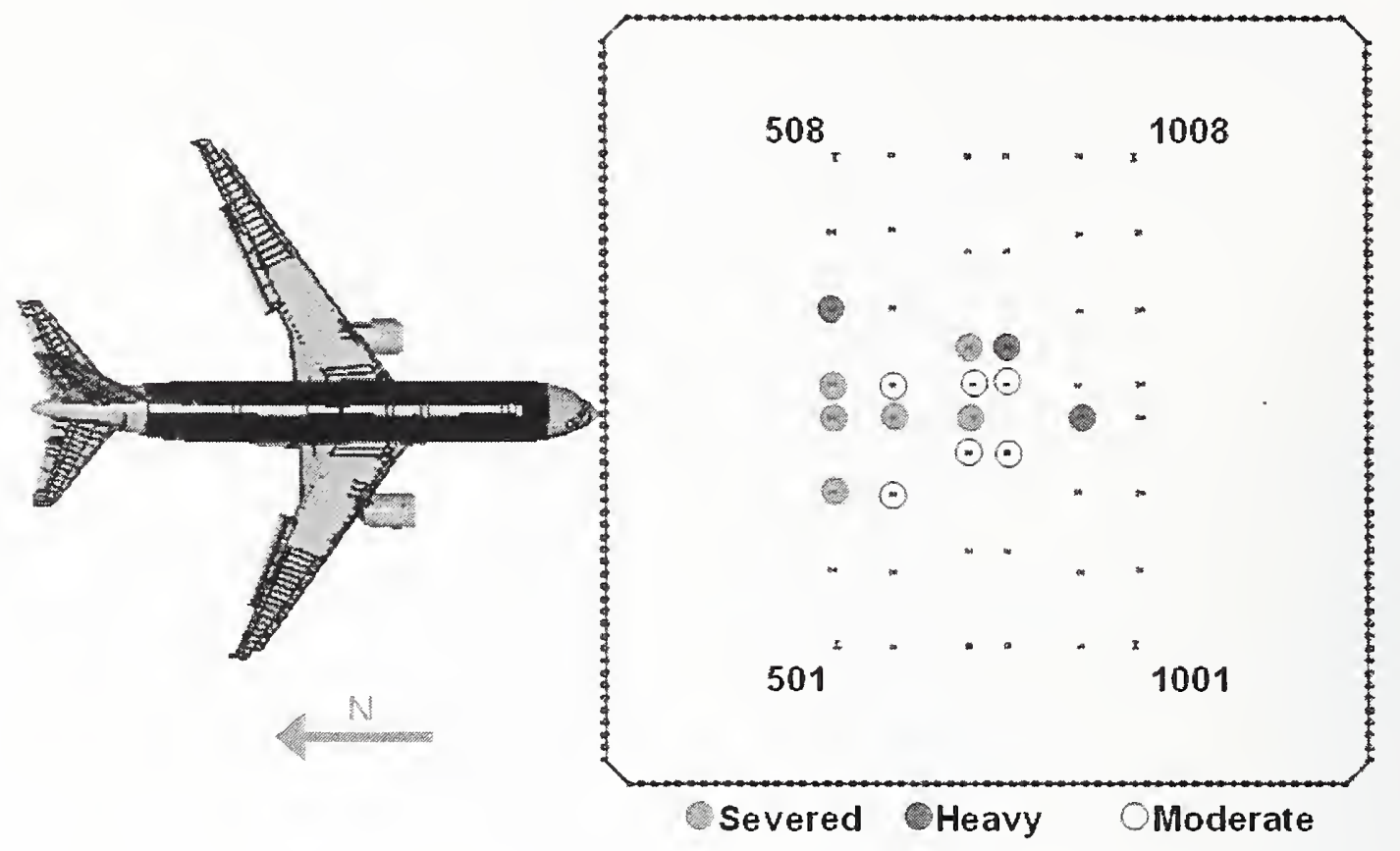

Figure 9-53. Summary of core column damage for the more severe WTC 1 impact.

\section{Floor Truss and Slab Damage for the More Severe WTC 1 Impact}

An overall view of the floor truss structure in the impact zone, along with the calculated more severe impact damage to the floor trusses, is shown in Figure 9-54. The figure shows that the trusses experienced significant damage in the impact zone. A plan view of the calculated damage to the truss on each floor is shown in Figure 9-55. The calculated impact response produced severe damage to the truss structures in the primary impact path of the fuselage. The truss structures were severely damaged from the exterior wall to the core. The truss floor system on floors 94 through 96 were damaged and sagging downward as a result of the impact loading.

The magnitude of truss floor damage was very similar for the base case and more severe global impact analyses. When the floor-by-floor damage was compared for the base case and more severe impact analyses, Figure 9-15 and Figure 9-55 respectively, the damage appears to be slightly less for the more severe impact analysis. The parameters used in the more severe global impact analysis would primarily contribute to an increased damage magnitude for the tower structures. However, the downward impact trajectory angle was reduced from the $\mathbf{1 0 . 6}$ degree angle in the base case analysis to a 7.6 degree angle in the more severe impact analysis. This would have the effect of directing more of the impact energy inward toward the tower core but reducing the normal downward force on the floor structures in the impact zone. As a result, the combined effects of the analysis parameter variations produced slightly less damage to the truss structure in the more severe impact analysis scenario. 

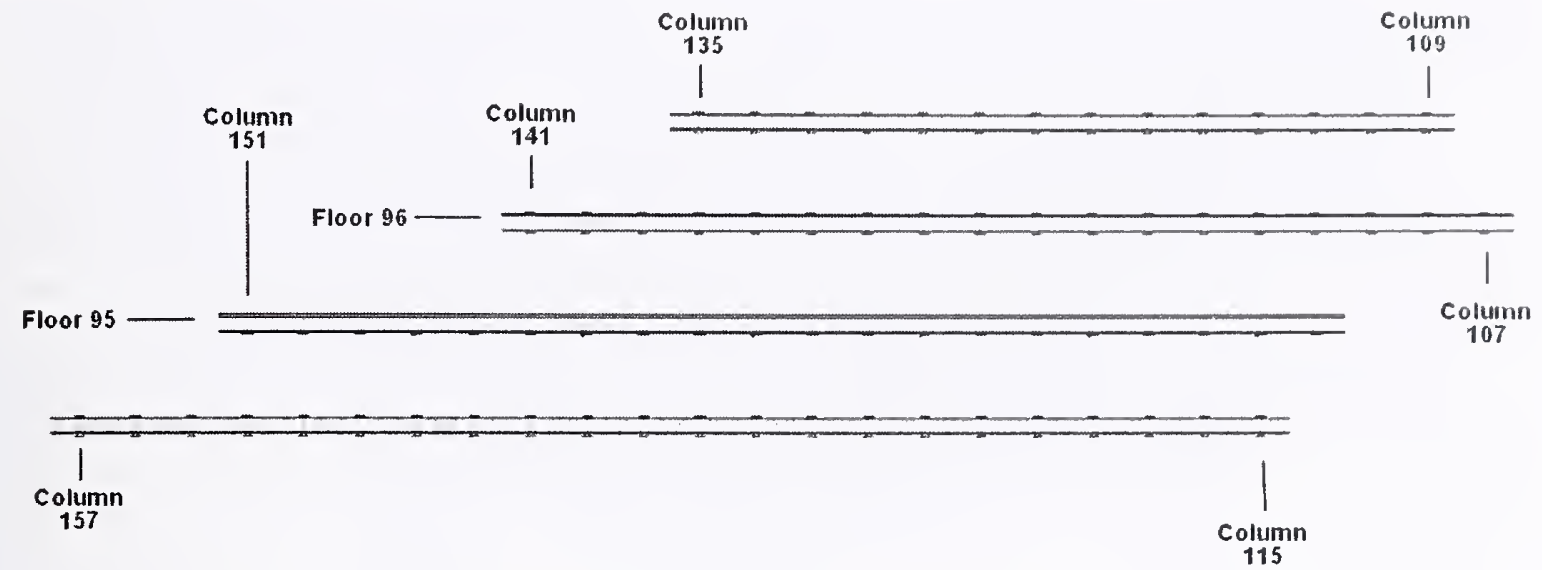

(a) Initial detailed truss structures

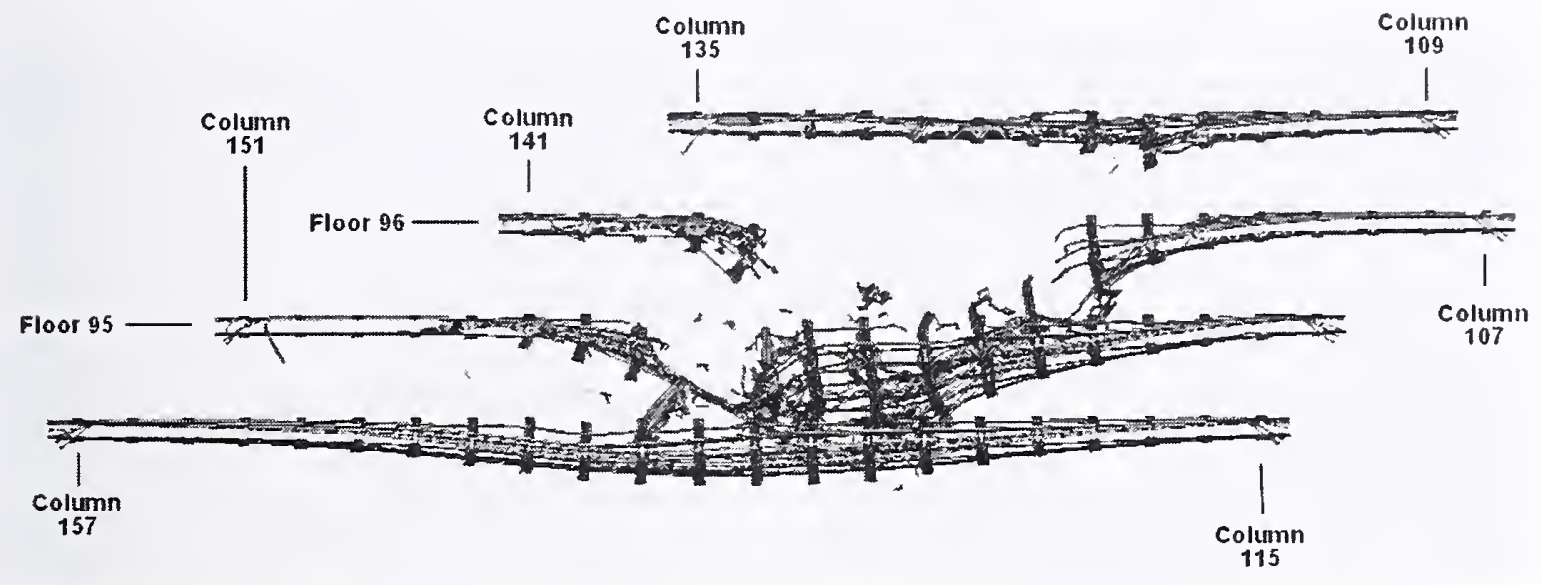

(b) Calculated damage ( $t=0.685 \mathrm{~s})$

Figure 9-54. More severe impact damage to the WTC 1 floor truss (front view). 


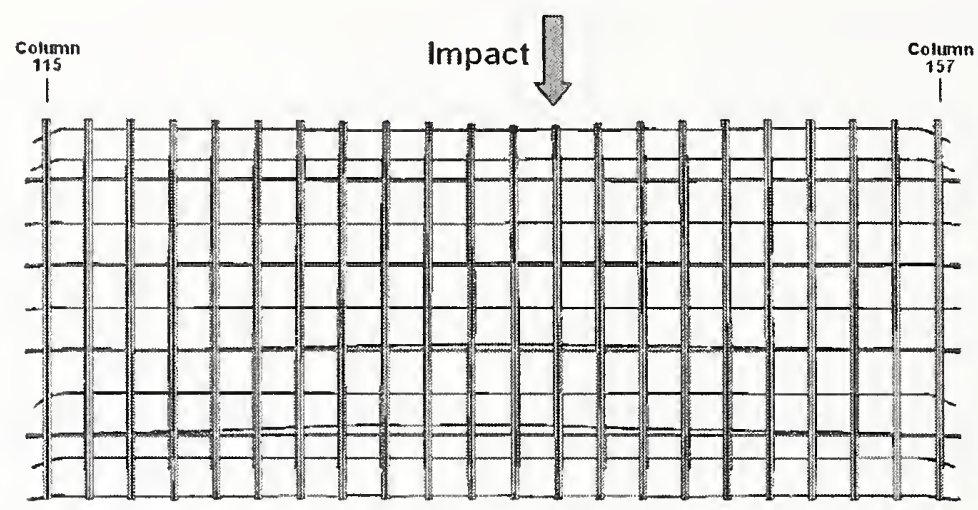

(a) Floor 94 truss damage

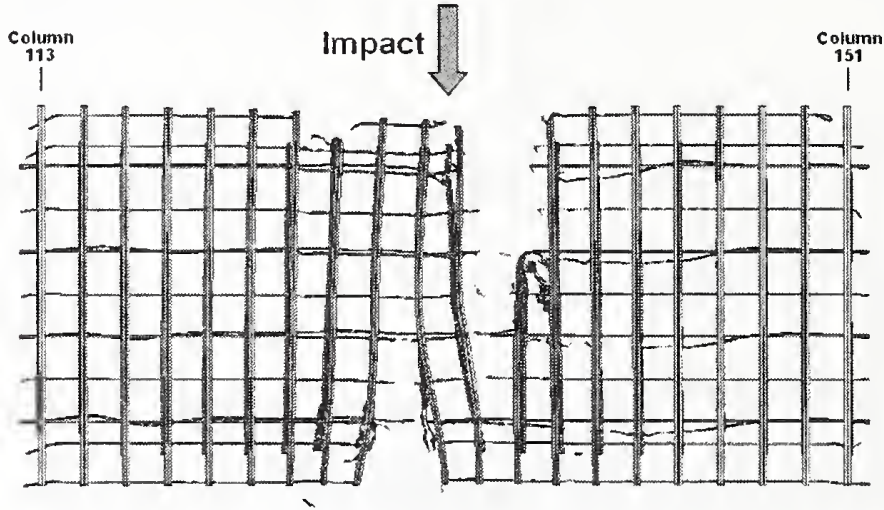

(b) Floor 95 truss damage

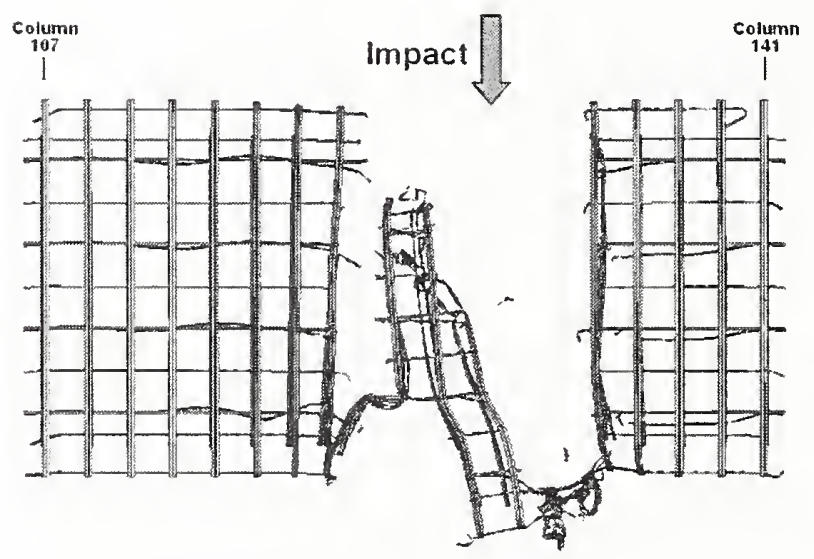

(c) Floor 96 truss damage

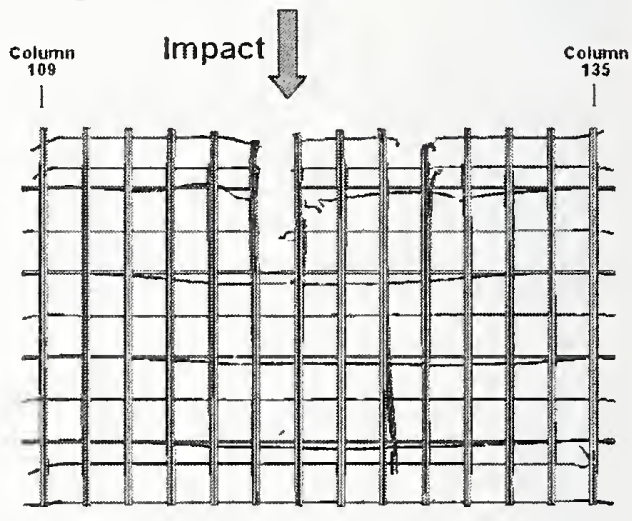

(d) Floor 97 truss damage

Figure 9-55. More severe impact damage to the WTC 1 floor truss (plan view). 
The calculated more severe impact damage to the WTC 1 floor slab for floors 94 through 97 are shown in Figure 9-56. The fringes of damage were set such that the conerete is failed in the regions colored red ( 2 percent plastic strain was used corresponding to the zero strength strain limit for the conerete in unconfined compression). At these strain levels, the concrete was severely damaged and probably removed, exposing the supporting metal decking. Beyond 2 percent plastie strain, the strength of the floor slab was severely reduced in the analyses to model the residual strength of the metal deck after the concrete failure, breakup, and removal. At a plastic strain of 30 pereent, corresponding to failure levels for the metal decking material, the elements were eroded (seen as holes ruptured in the floor slab shown). The line of damage, visible around the edge of the core, was believed to be the result of numerical precision errors and interference in the modeling methodology at the connection of the floor slab rather than impact damage.

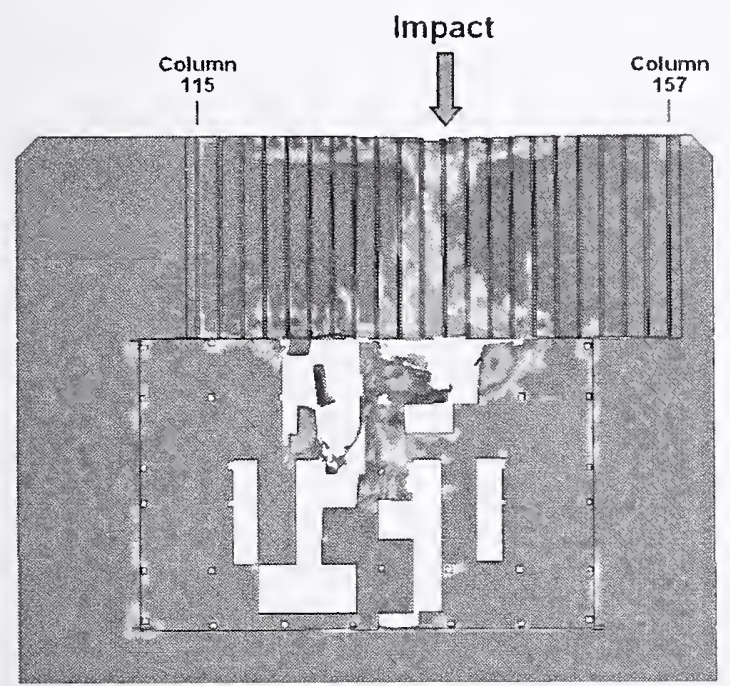

(a) Floor 94 slab damage Impact

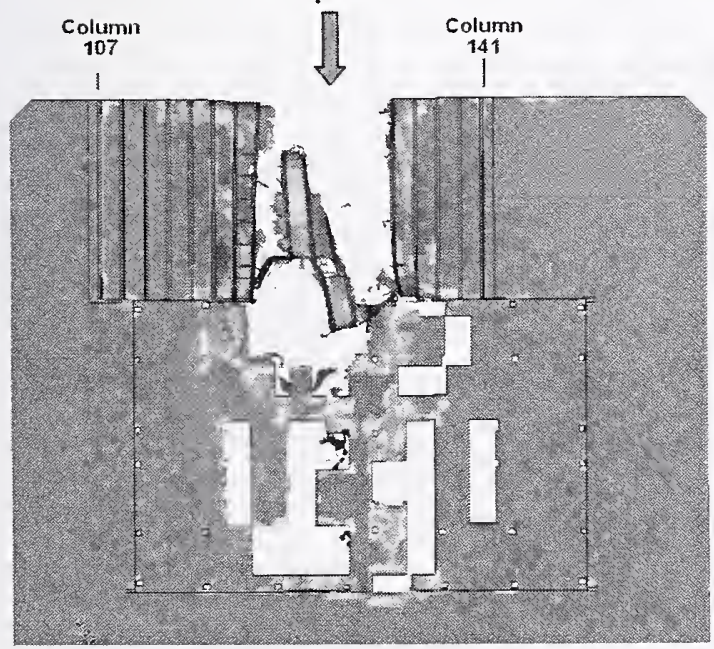

(c) Floor 96 slab damage

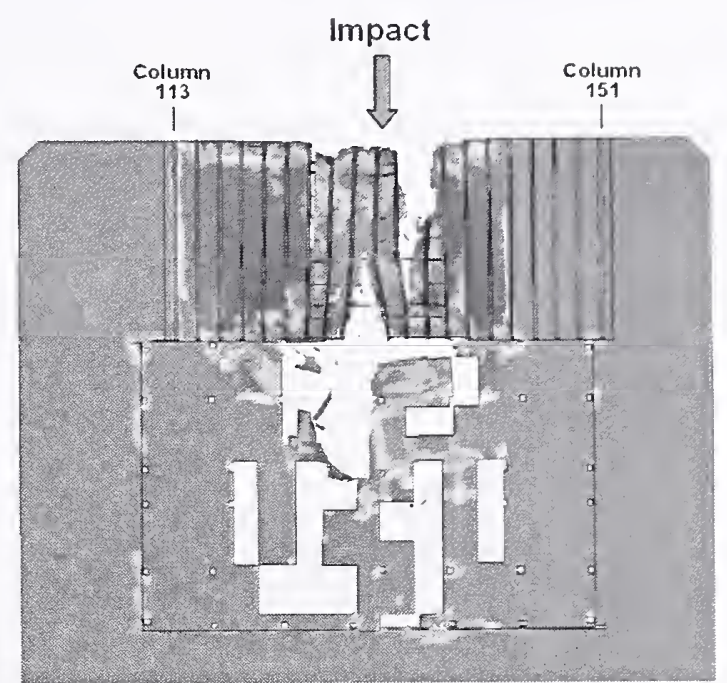

(b) Floor 95 slab damage Impact

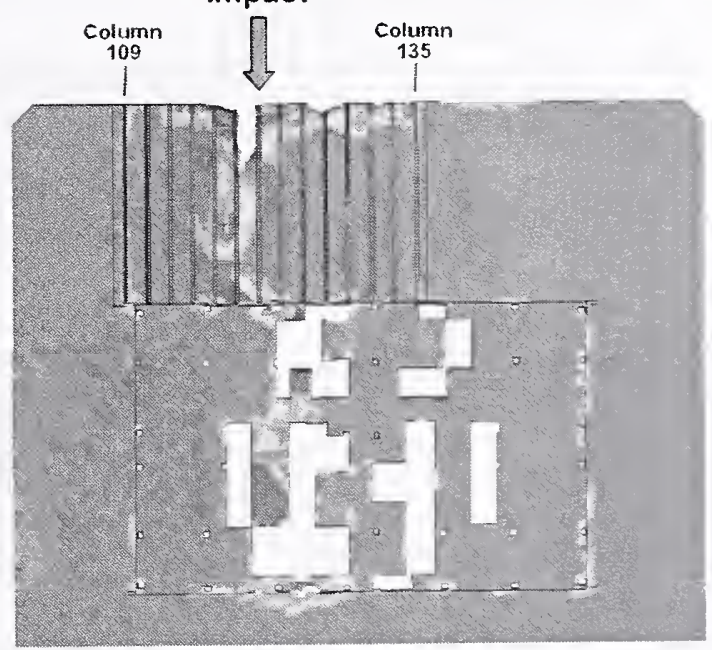

(d) Floor 97 slab damage

Figure 9-56. More severe impact damage to the WTC 1 floor slabs (plan view). 
The magnitude of floor slab damage was, in general, very similar for the base case and more severe global impact analyses. When the floor-by-floor damage was compared for the base case and more severe impact analyses, Figure 9-16 and Figure 9-56 respectively, the damage appears to be slightly less for the more severe impact analysis. Similar to the truss damage, the reduced damage in the floor slab was believed to be the result of the reduction in the downward impact trajectory angle from 10.6 to 7.6 degrees in the more severe impact analysis, reducing the normal downward force on the floor structures.

\section{Damage to WTC 1 Contents for the More Severe Impact}

The calculated damage to the WTC 1 contents for the more severe impact is shown in plan views in Figure 9-57 through Figure 9-61 for floors 94 through 98, respectively. A comparison to the calculated damage for the base case WTC 1 impact analysis, shown previously in Figure 9-20 through Figure 9-24, indicated that the content damage zone is very similar in width but extended further south through the tower in the more severe impact. The more sevcre impact produced significantly greater content damage on the far side of the core and extended more fully through the tower.

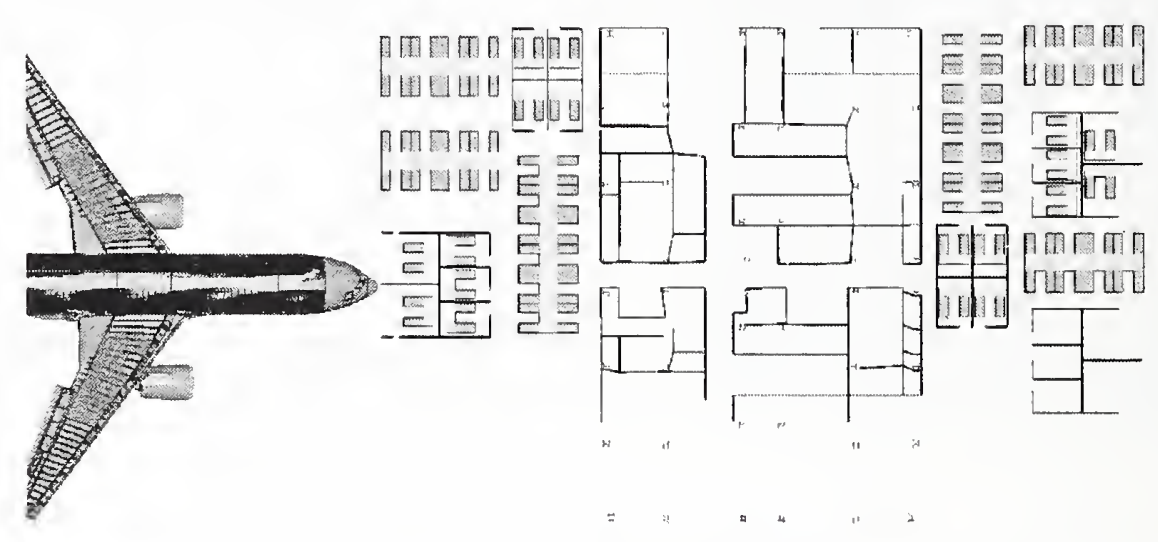

(a) Initial impact configuration

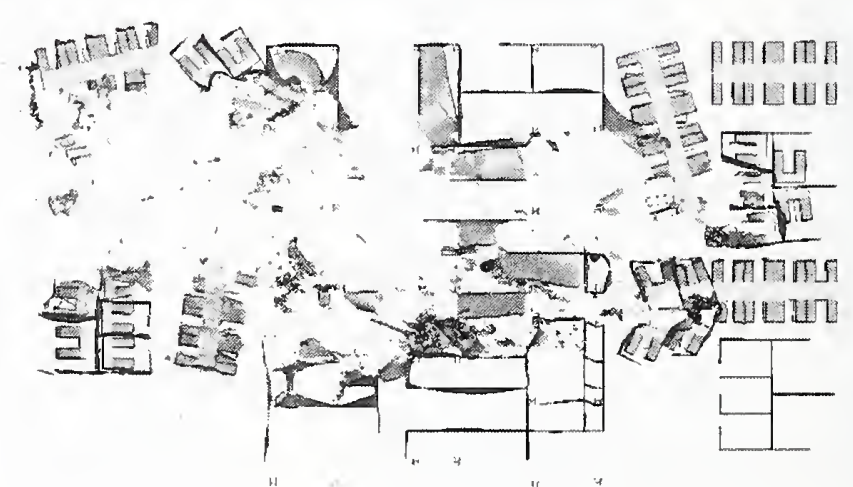

(b) Calculated response of contents

Figure 9-57. Calculated more severe WTC 1 impact response of floor 94 contents. 


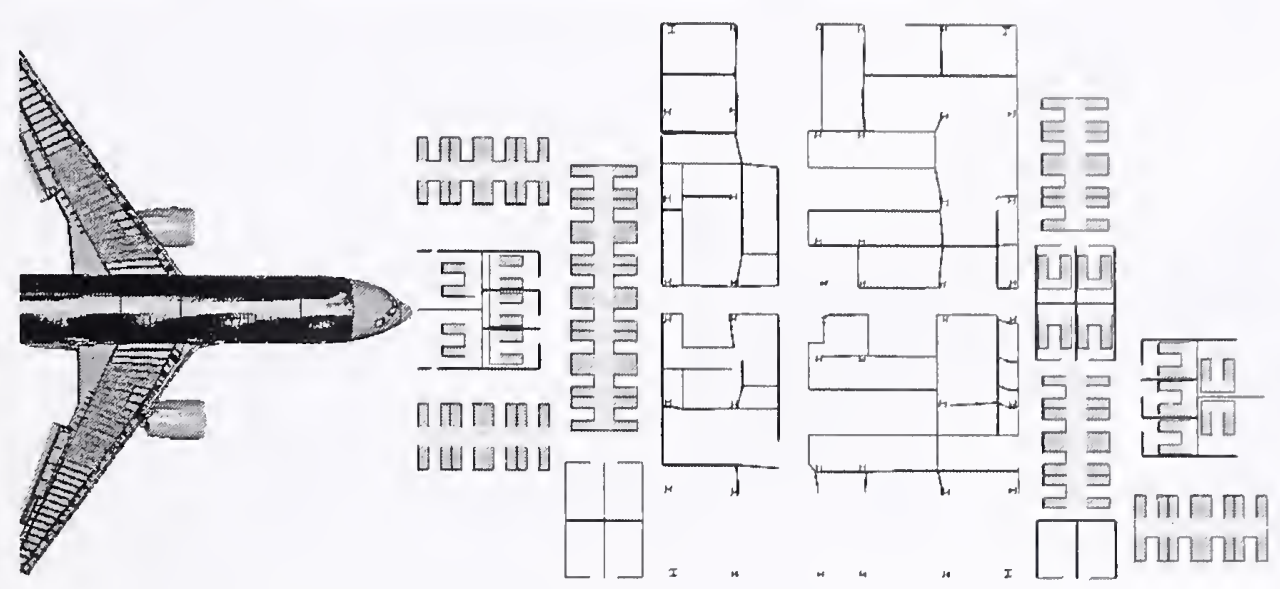

(a) Initial impact configuration

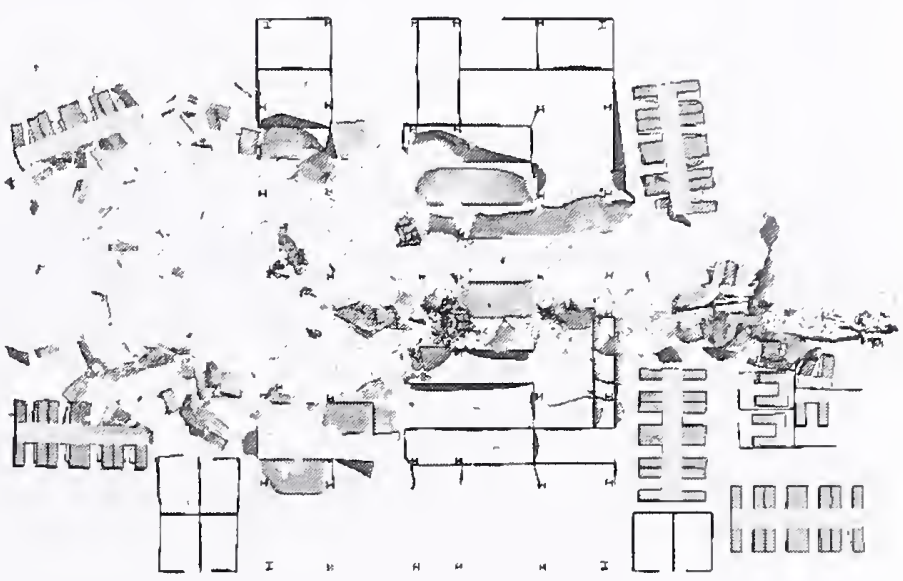

(b) Calculated response of contents

Figure 9-58. Calculated more severe WTC 1 impact response of floor 95 contents. 


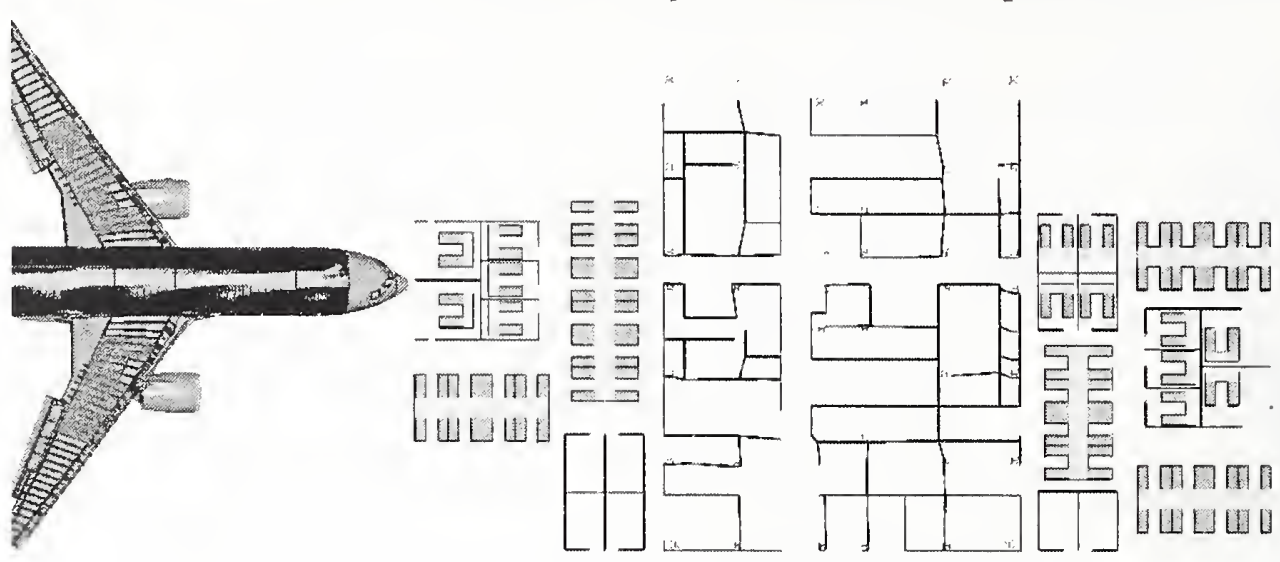

(a) Initial impact configuration

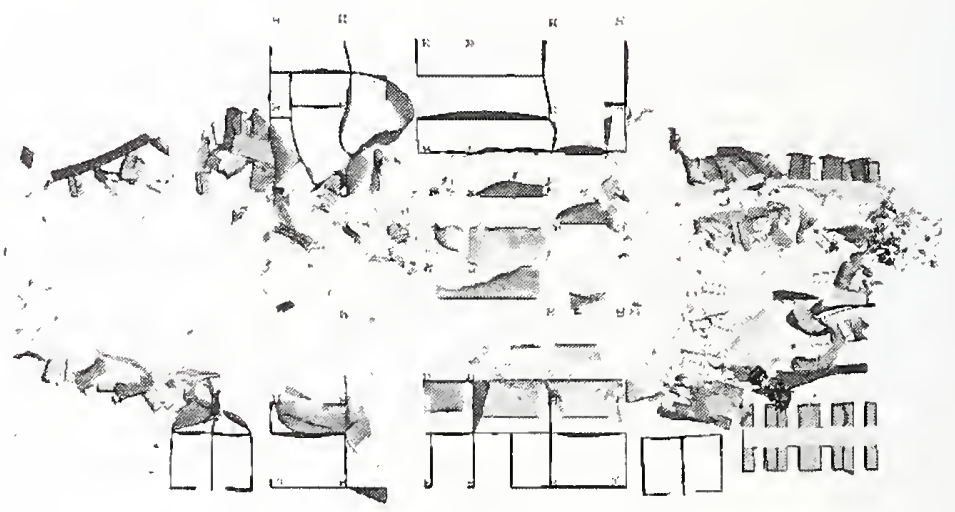

(b) Calculated response of contents

Figure 9-59. Calculated more severe WTC 1 impact response of floor 96 contents. 


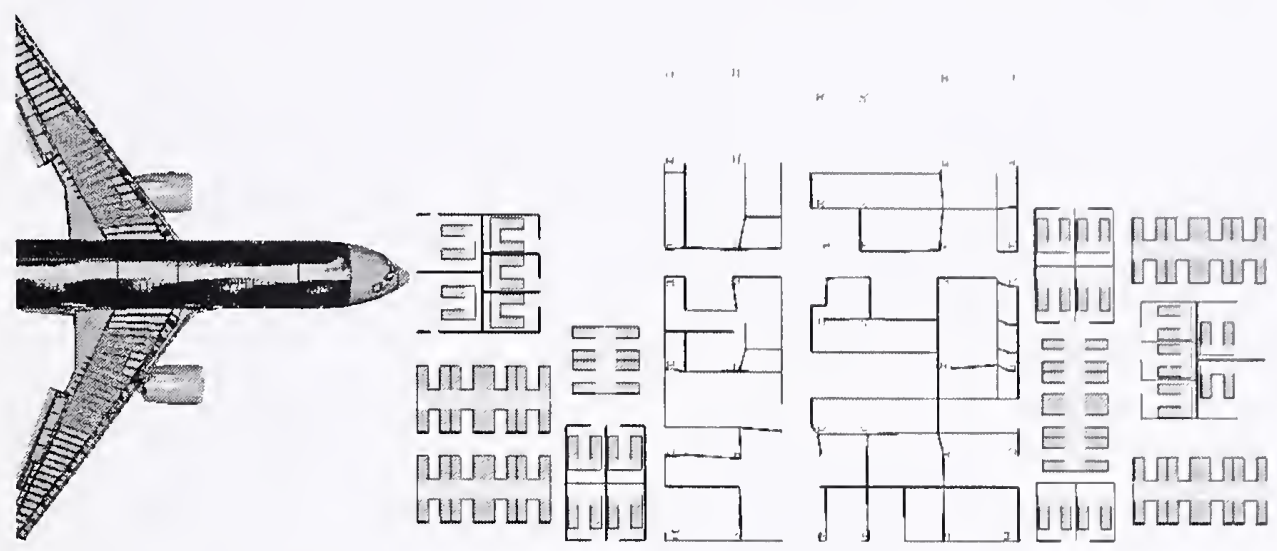

(a) Initial impact configuration

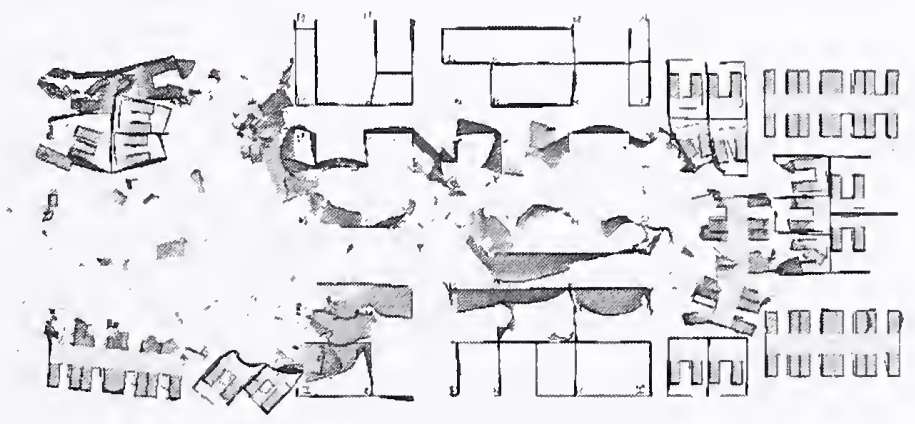

(b) Calculated response of contents

Figure 9-60. Calculated more severe WTC 1 impact response of floor 97 contents. 


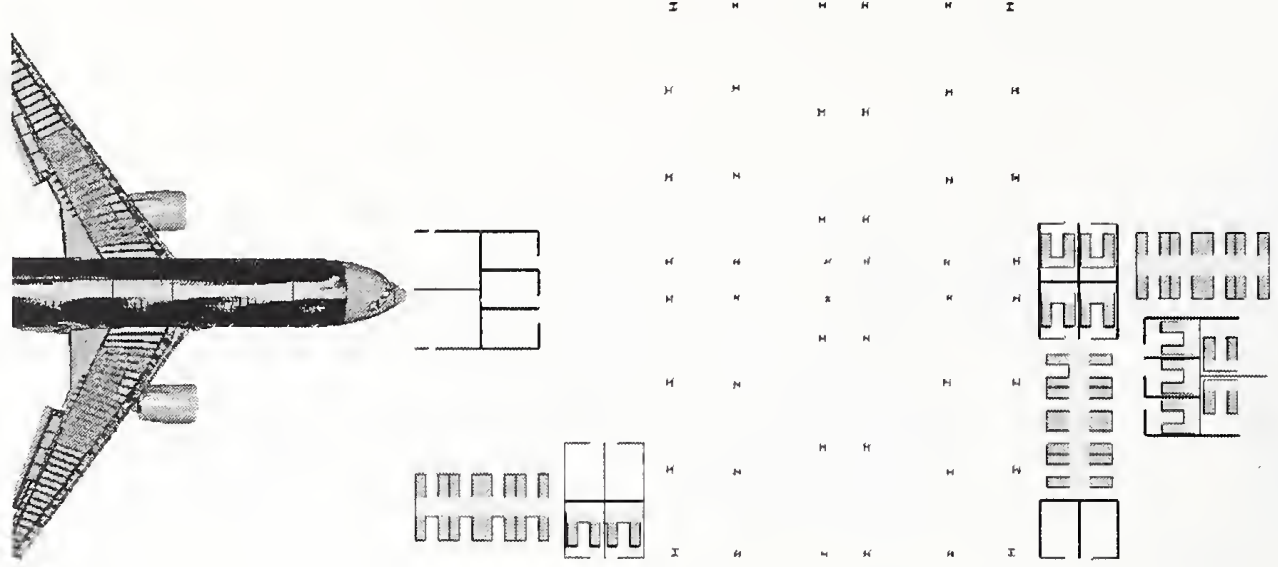

(a) Initial impact configuration

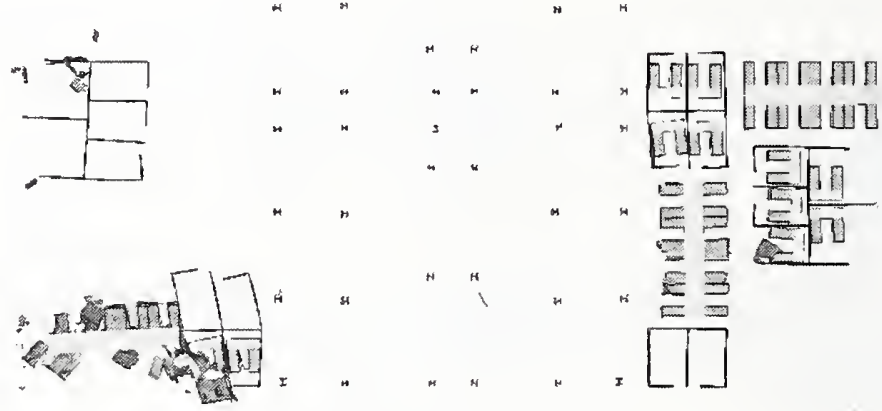

(b) Calculated response of contents

Figure 9-61. Calculated more severe WTC 1 impact response of floor 98 contents.

\subsubsection{Less Severe WTC 1 Global Impact Analysis}

\section{Exterior Wall Damage for the Less Severe WTC 1 Impact}

A comparison of the north exterior wall observed and calculated damage from the less severe WTC 1 global impact analysis is shown in Figure 9-62. The calculated impact damage to the exterior wall is shown with color fringes representing plastic strain magnitude, with undamaged sections in blue and strains at or above 5 percent shown in red. The wall regions shown in Figure 9-62 are from column 108 to column 152, extending from floor 91 to floor 100 (spandrels at floors 92 through 100). The magnitude and mode of impact damage on the exterior wall were still in good agreement with the observed damage for this less severe impact scenario. 


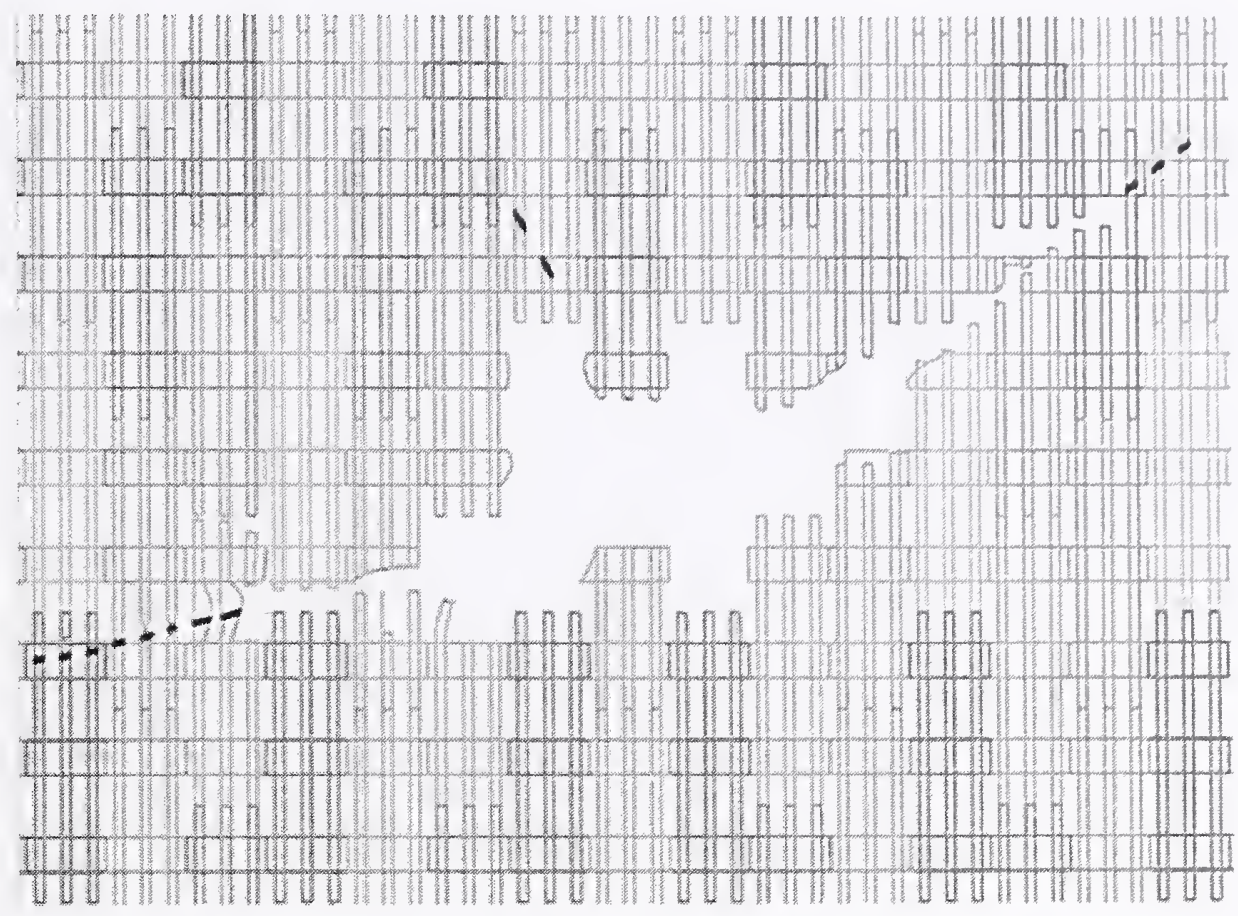

(a) Schematic of observed damage

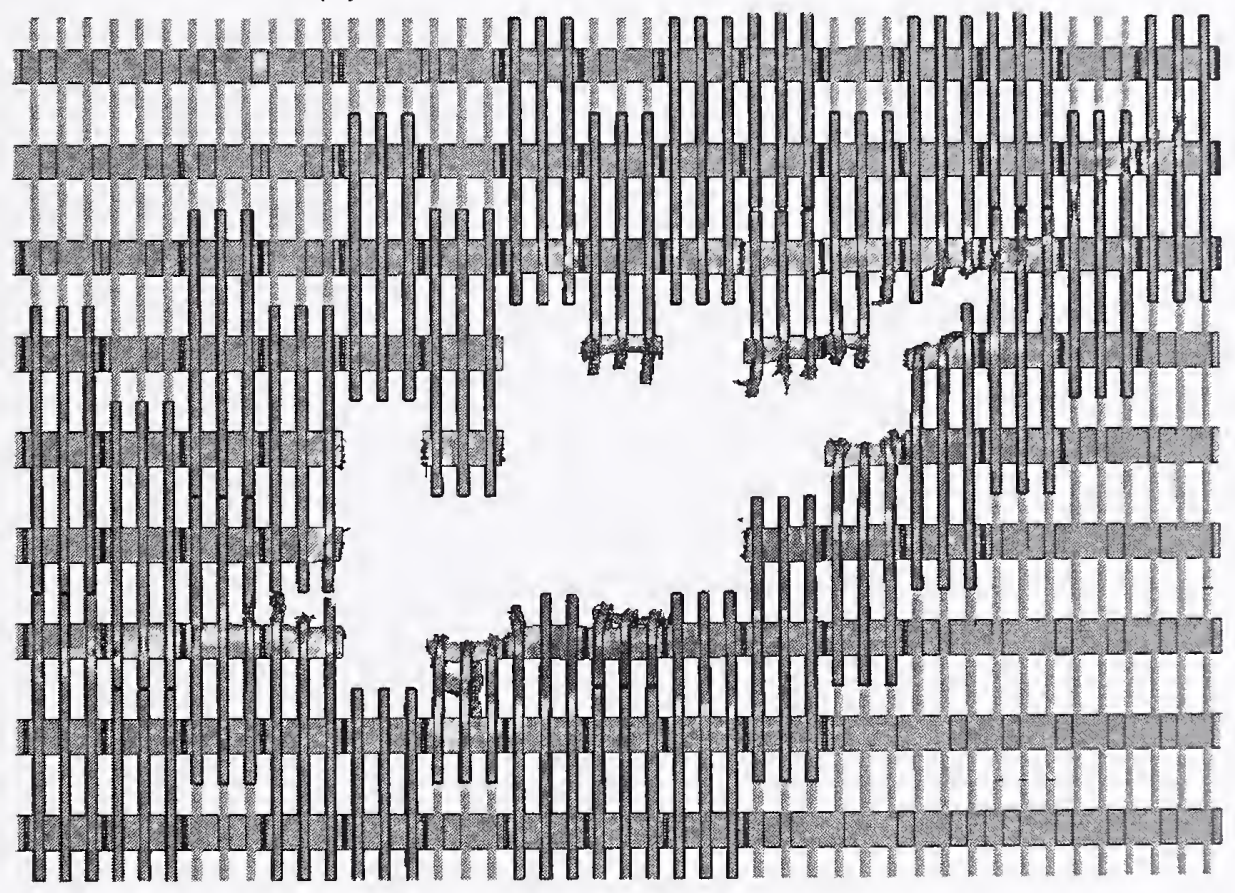

(b) Calculated damage ( $t=0.735 \mathrm{~s}$ )

Figure 9-62. Less severe impact damage to the WTC 1 exterior wall. 


\section{Core Structural Damage for the Less Severe WTC 1 Impact}

The overall model for the WTC 1 core structure and calculated response for the less severe global impact analysis is shown in Figure 9-63. The figure shows that the core had a limited damage confined to the region nearest to the impact point. The calculated damage to the core columns by row is shown in Figure 9-64, and the floor-by-floor damage to the core framing is shown in Figure 9-65. The core structures are shown with color fringes representing plastic strain magnitude, with undamaged sections in blue and strains at or above 5 percent shown in red. A summary of the column damage is provided in Table 9-9 and shown graphically in Figure 9-66, with the qualitative classification of the column damage levels provided previously in Figure 9-12. Only one column was severed, and two columns were heavily damaged, compared to three severed columns and four heavily damaged columns in the base case WTC 1 impact analysis. The failure of the column splices located on floors 92 and 95 contributed to the failure of the core column.

Table 9-9. Core column response for the less severe WTC 1 impact.

\begin{tabular}{|l|c|c|c|}
\hline \multicolumn{1}{|c|}{ Column } & Location & Damage Level & $\begin{array}{c}\text { Lateral Deflection of } \\
\text { Column Centerline (in.) }\end{array}$ \\
\hline Column 504 & Floors 92-96 & Severed & \\
\hline Column 505 & Floors 93-96 & Heavy & 14 \\
\hline Column 506 & Floors 93-94 & Moderate & \\
\hline Column 604 & Floor 96 & Light & \\
\hline Column 606 & Floors 94 & Light & \\
\hline Column 702 & Floor 96 & Moderate & \\
\hline Column 703 & Floor 96 & Light & \\
\hline Column 704 & Floor 96 & Heavy & \\
\hline Column 705 & Floor 96 & Light & \\
\hline Column 802 & Floor 96 & Moderate & \\
\hline Column 805 & Floor 96 & Light & \\
\hline
\end{tabular}




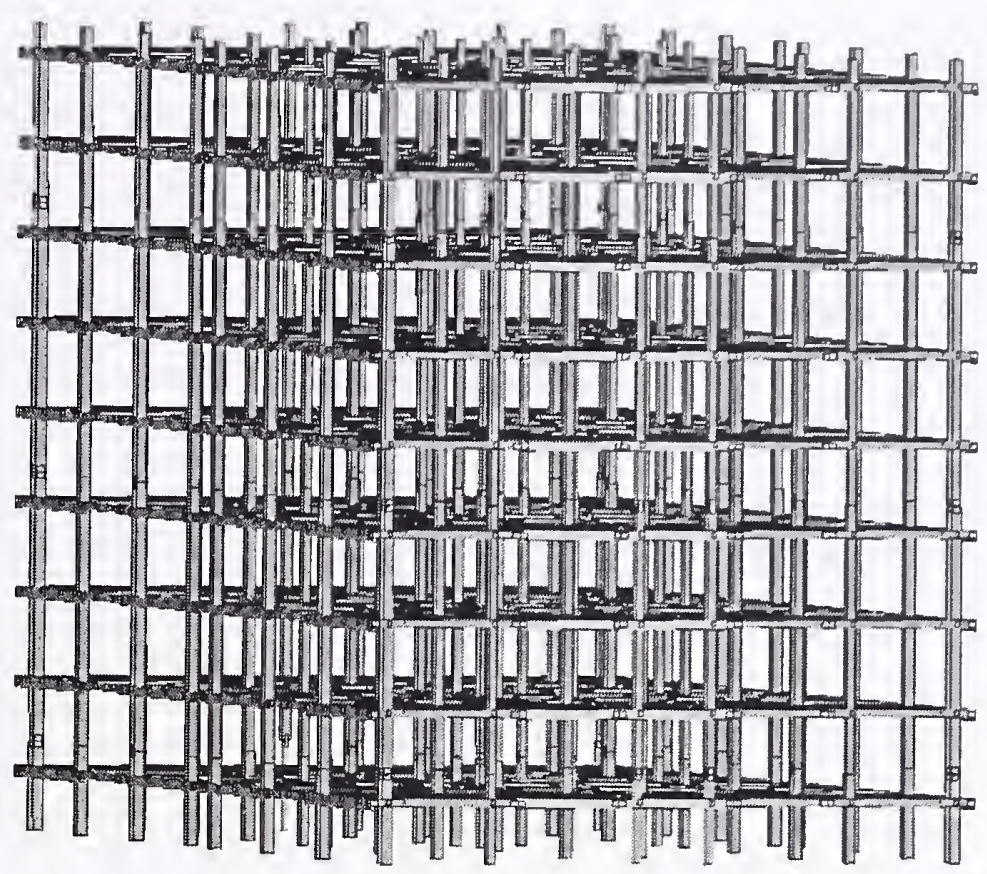

(a) Initial geometry

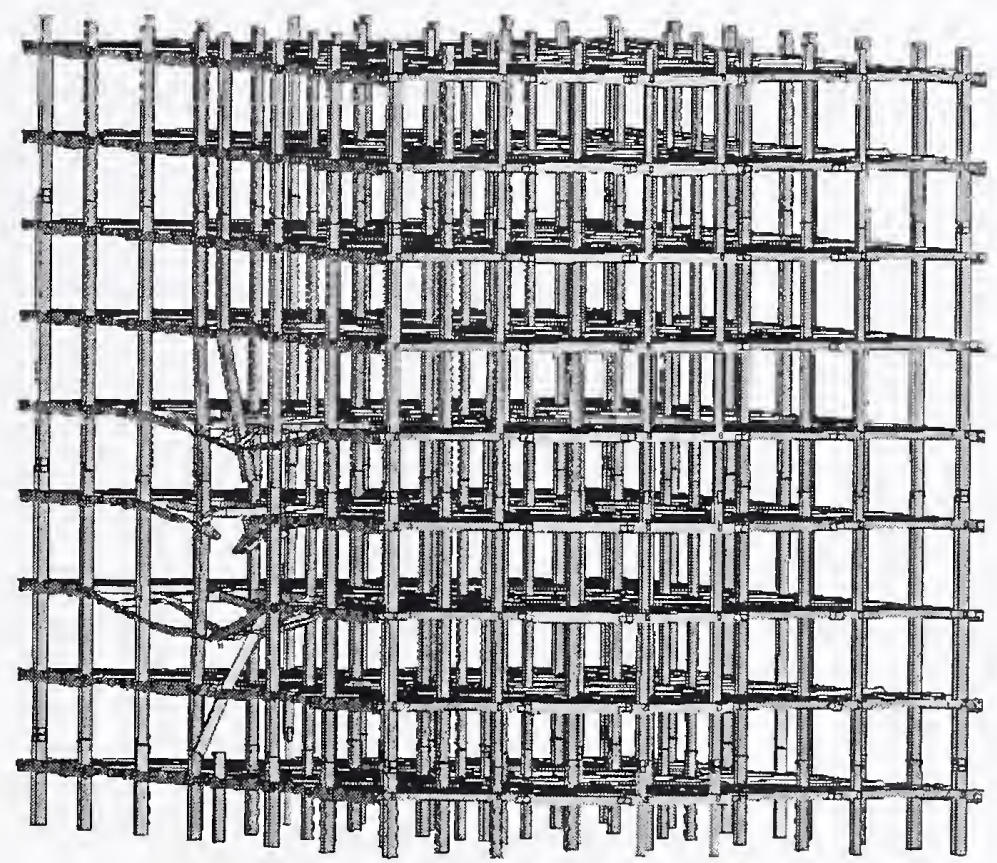

(a) Calculated impact damage

Figure 9-63. Less severe impact response of the WTC 1 core. 


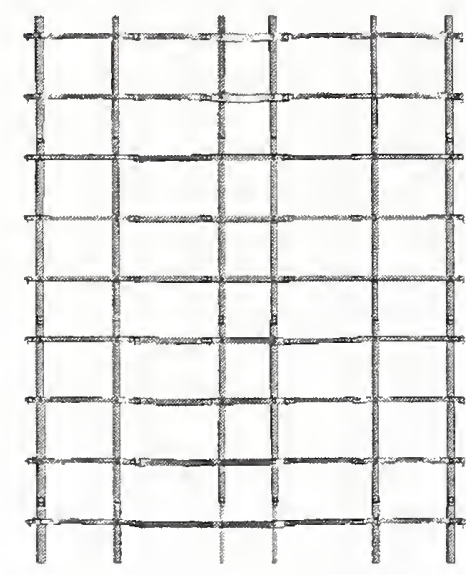

(a) Columns 501-1001

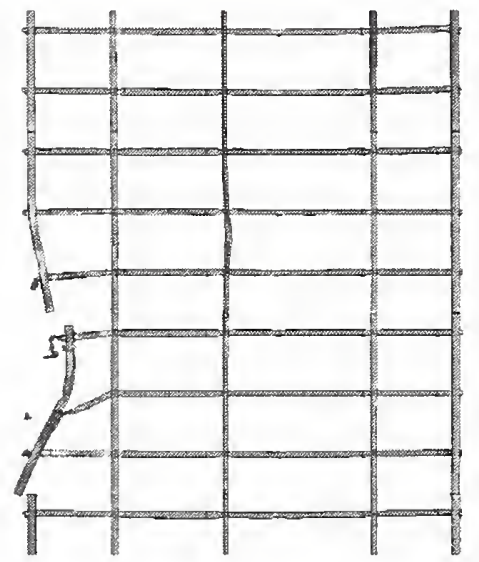

(d) Columns 504-1004

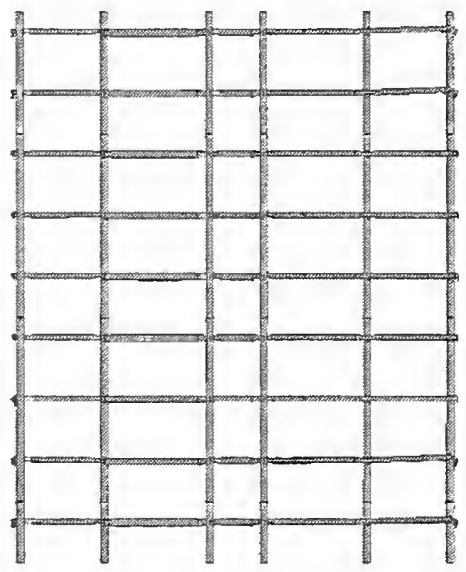

(g) Columns 507-1007

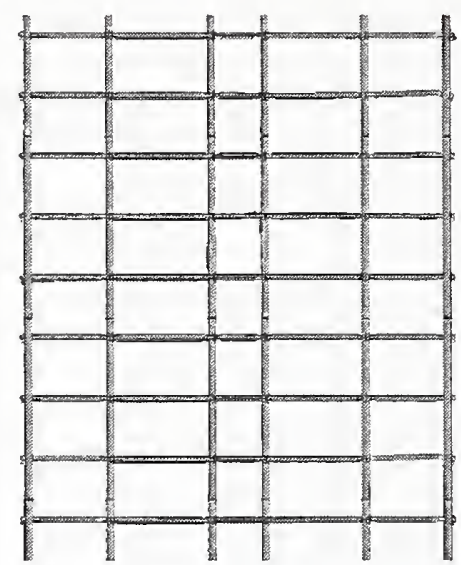

(b) Columns 502-1002

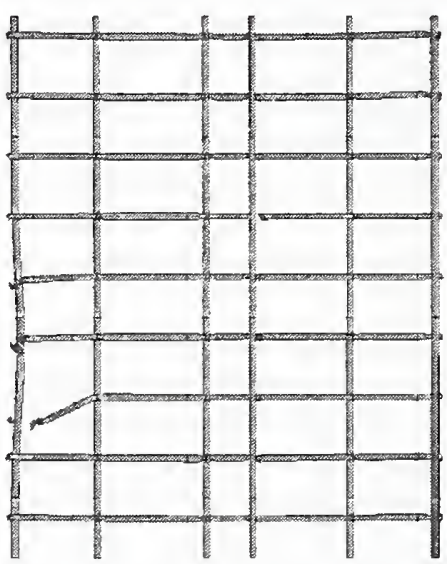

(e) Columns 505-1005

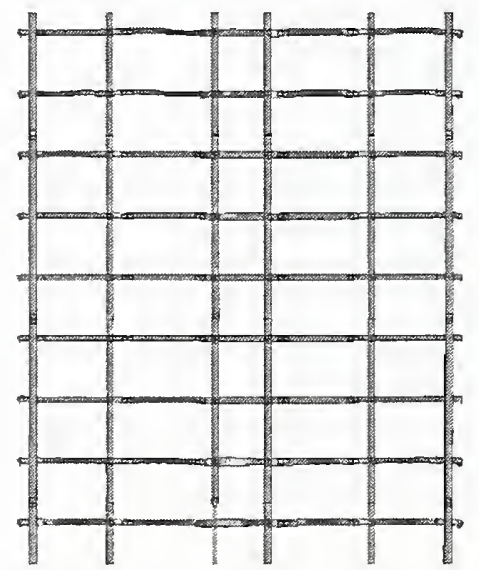

(h) Columns 508-1008

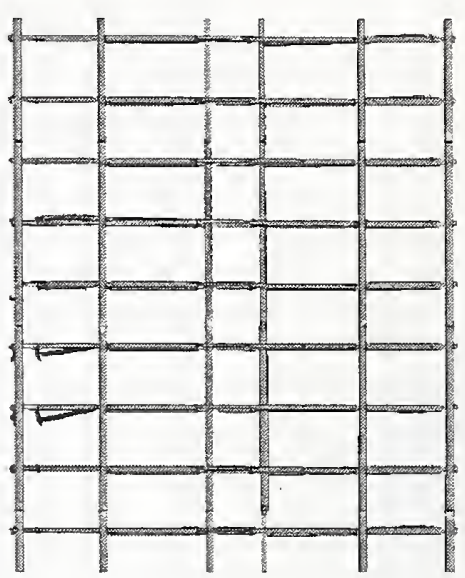

(c) Columns 503-1003

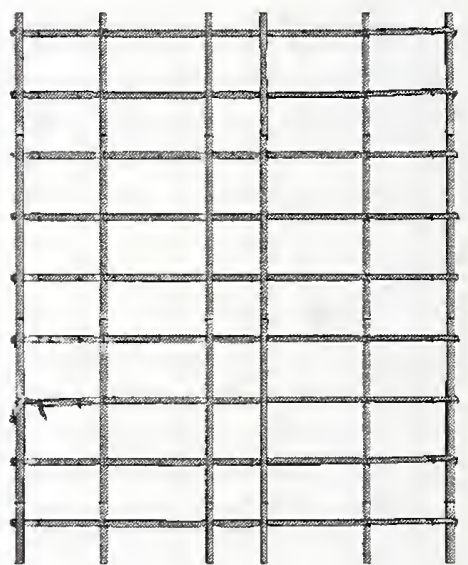

(f) Columns 506-1006

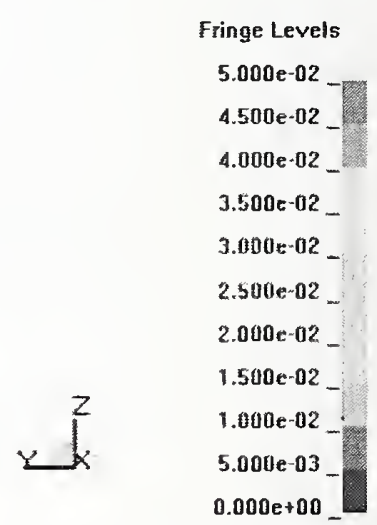

(i) Reference scale

Figure 9-64. Less severe impact response of the WTC 1 core columns. 


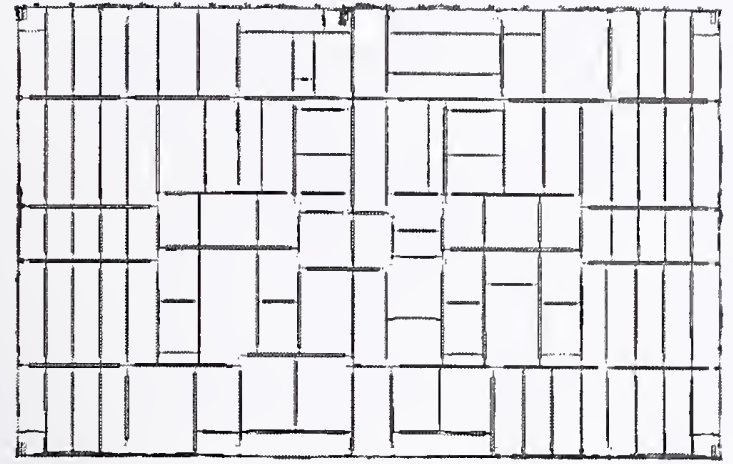

(a) Floor 93 core framing damage

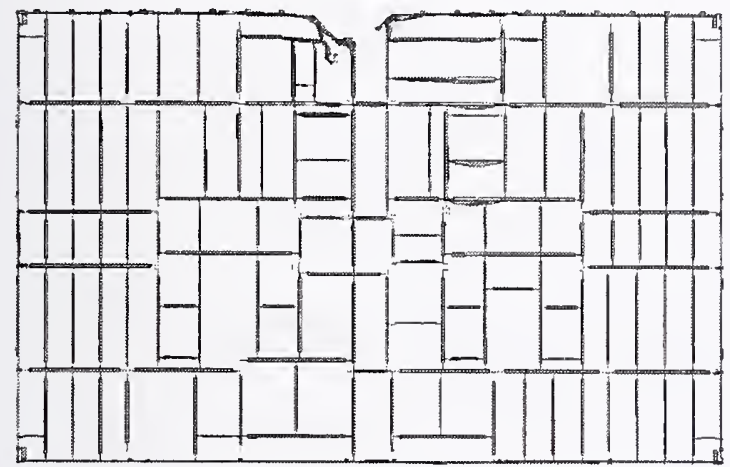

(c) Floor 95 core framing damage

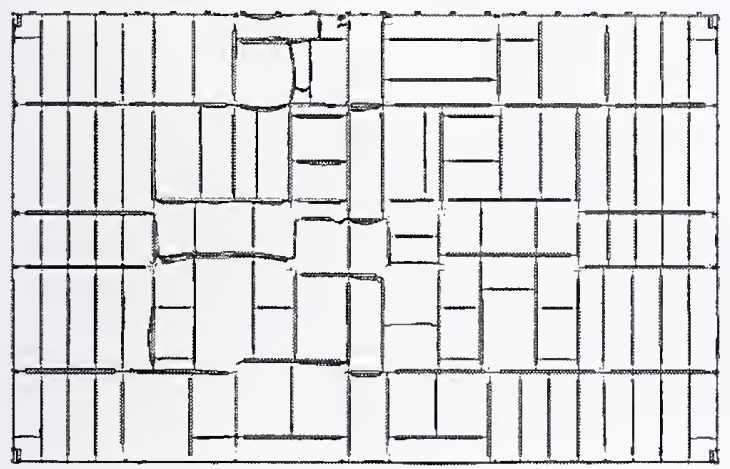

(e) Floor 97 core framing damage

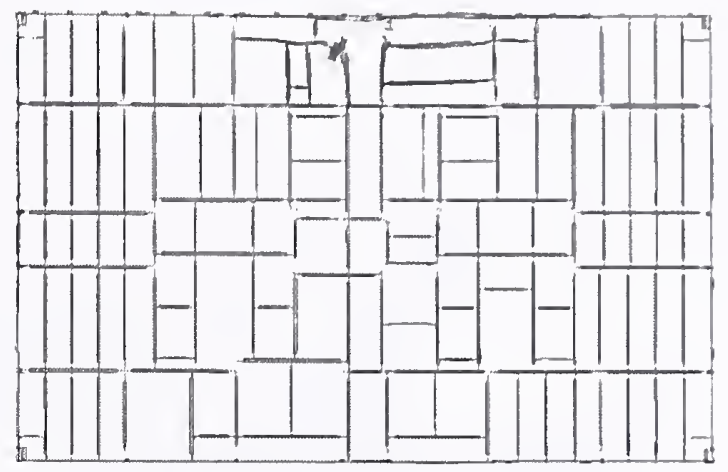

(b) Floor 94 core framing damage

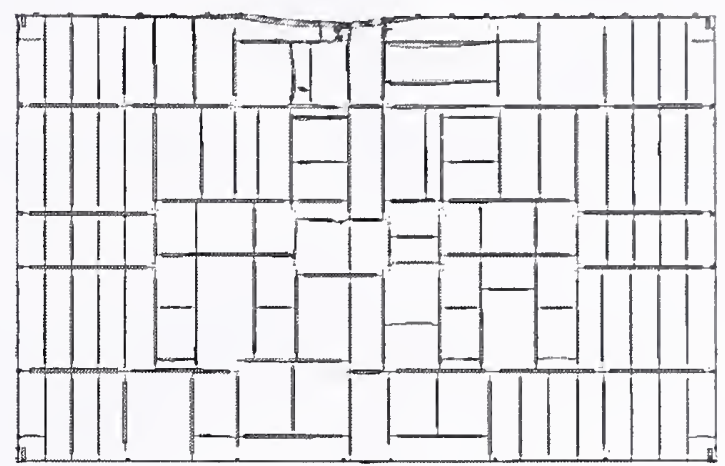

(d) Floor 96 core framing damage

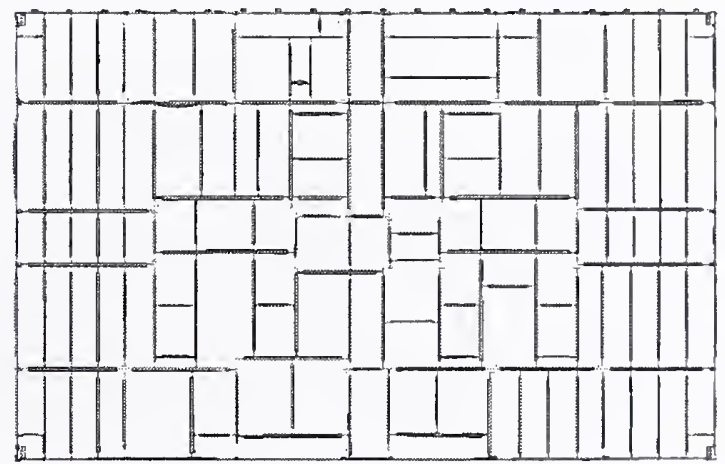

(f) Floor 98 core framing damage

Figure 9-65. Less severe impact damage to the WTC 1 core floor framing (plan view). 

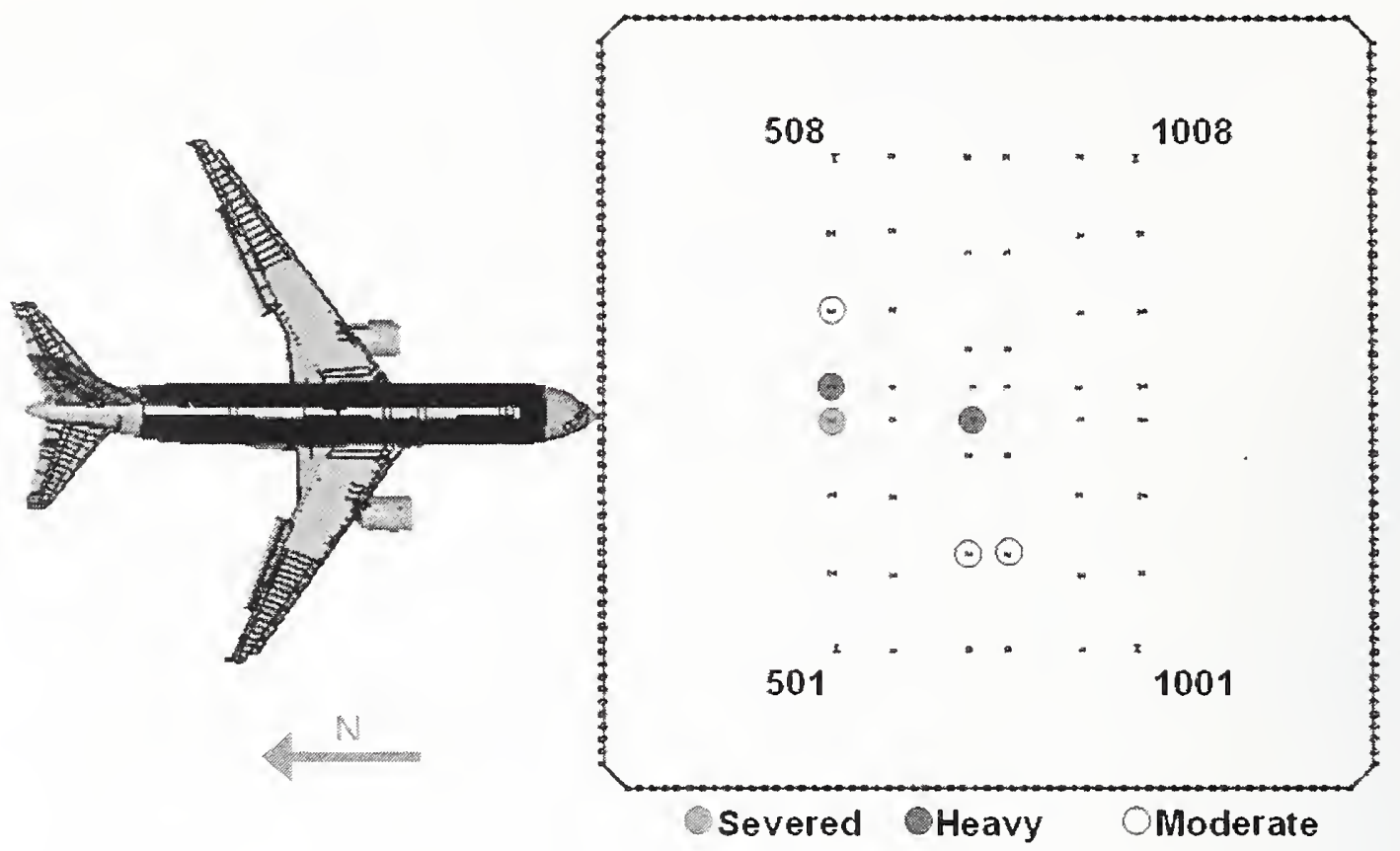

Figure 9-66. Summary of core column damage for the less severe WTC 1 impact.

\section{Floor Truss and Slab Damage for the Less Severe WTC 1 Impact}

An overall view of the floor truss structure in the impact zone, along with the calculated less severe impact damage to the floor trusses, is shown in Figure 9-67. The figure shows that the trusses experienced significant damage in the impact zone. A plan view of the calculated damage to the truss on each floor is shown in Figure 9-68. The calculated impact response produced severe damage to the truss structures in the primary impact path of the fuselage. The truss structures were severely damaged from the exterior wall to the core. The truss floor system on floors 94 through 96 were damaged and sagged downward as a result of the impact loading. 

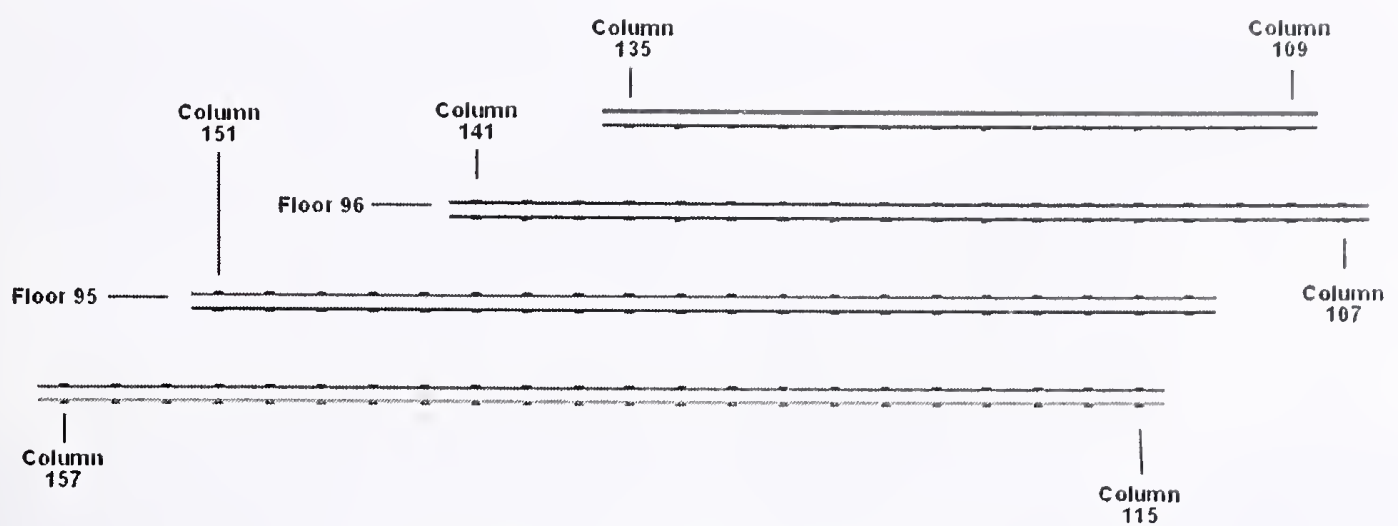

(a) Initial detailed truss structures

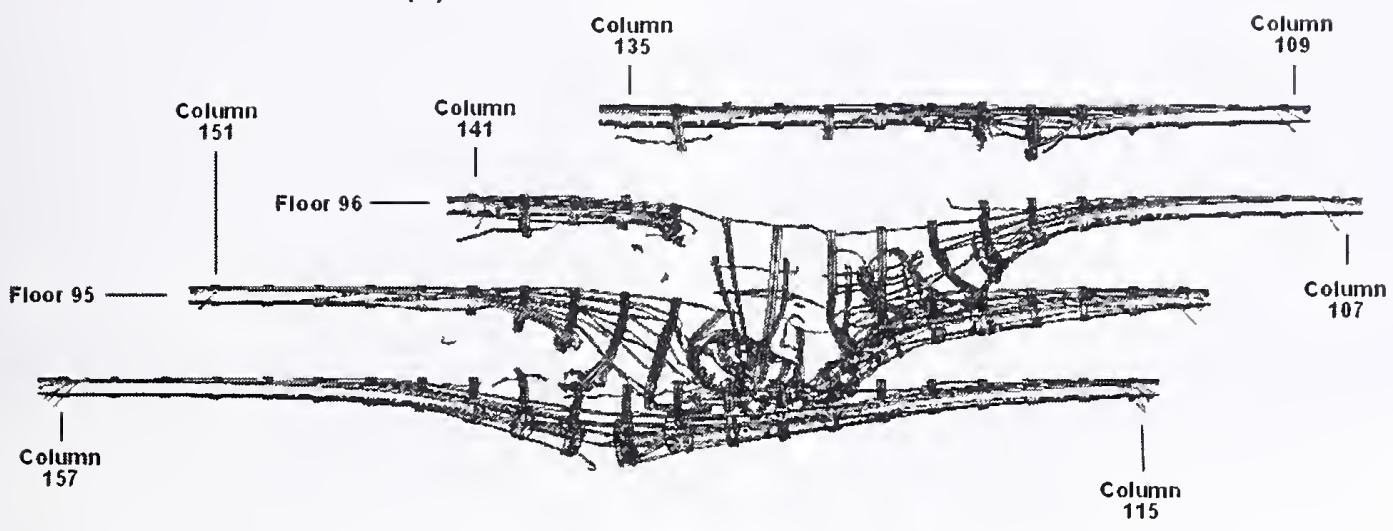

(b) Calculated damage ( $\mathrm{t}=\mathbf{0 . 7 3 5} \mathrm{s})$

Figure 9-67. Less severe impact damage to the WTC 1 floor truss (front view).

The magnitude of truss floor damage was very similar for the base case and more severe global impact analyses. When the floor-by-floor damage was compared for the base case and less severe impact analyses, Figure 9-15 and Figure 9-68, respectively, the damage was slightly increased for the less severe impact analysis. The parameters used in the less severe global impact analysis would primarily contribute to a reduced damage magnitude for the tower structures. However, the downward impact trajectory angle was increased from the 10.6 degree angle in the base case analysis to a 13.6 degree angle in the more severe impact analysis. This would have the effect of directing more of the impact energy downward, increasing the normal force on the floor structures in the impact zone. As a result, the combined effects of the analysis parameter variations produced a small increase in the damage to the truss structure in the less severe impact analysis scenario. 


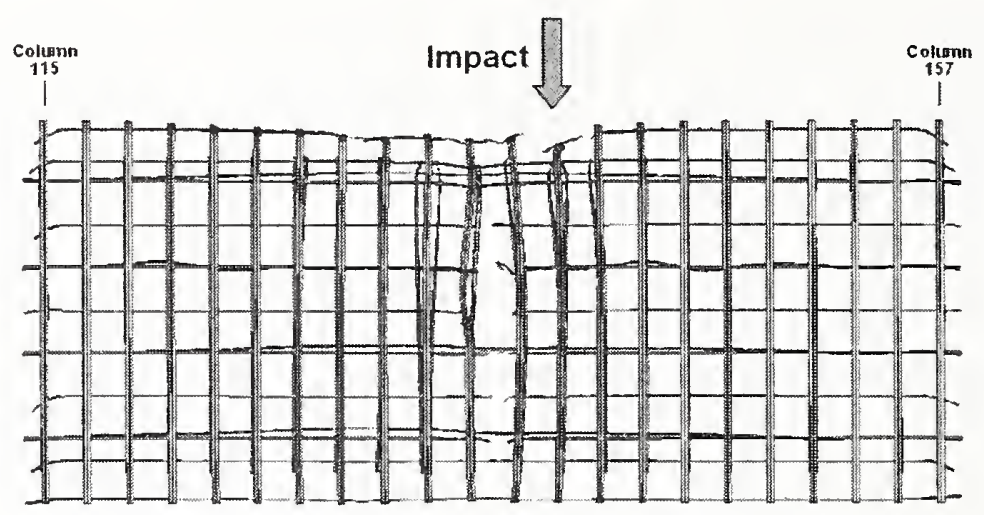

(a) Floor 94 truss damage

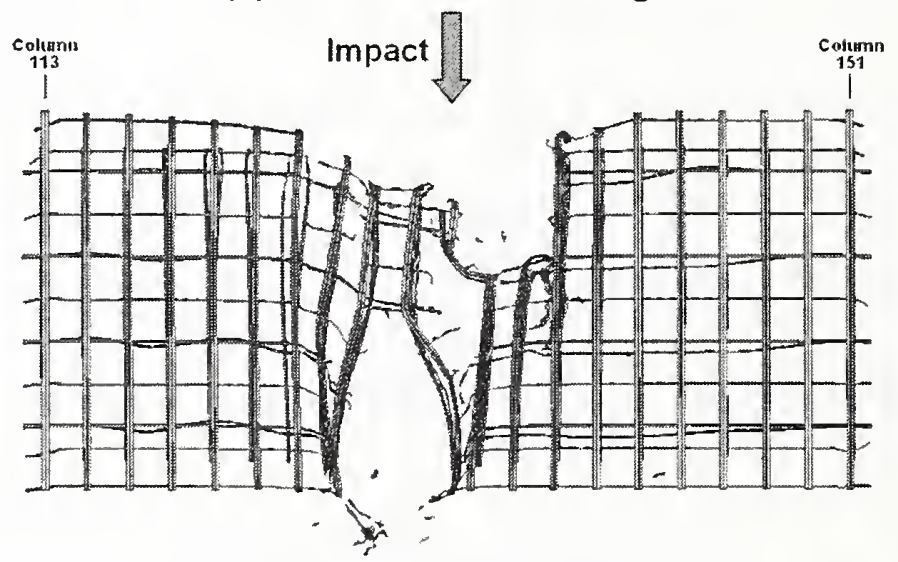

(b) Floor 95 truss damage

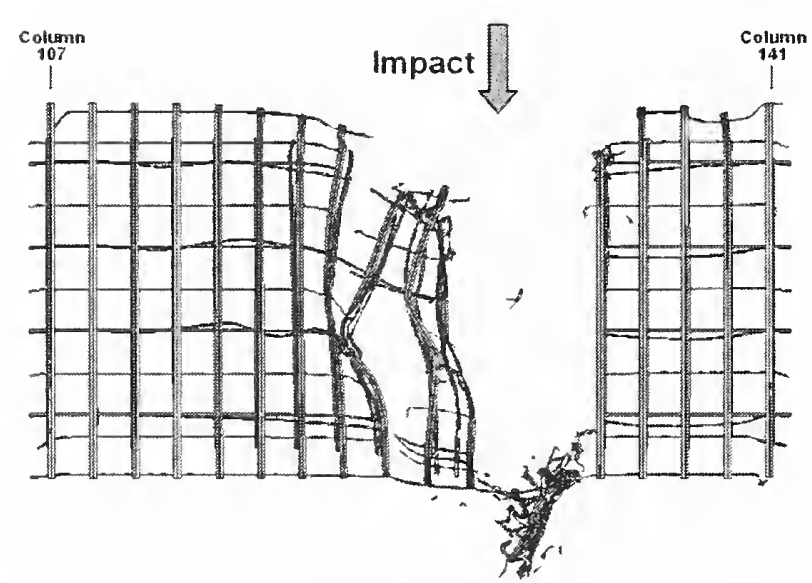

(c) Floor 96 truss damage

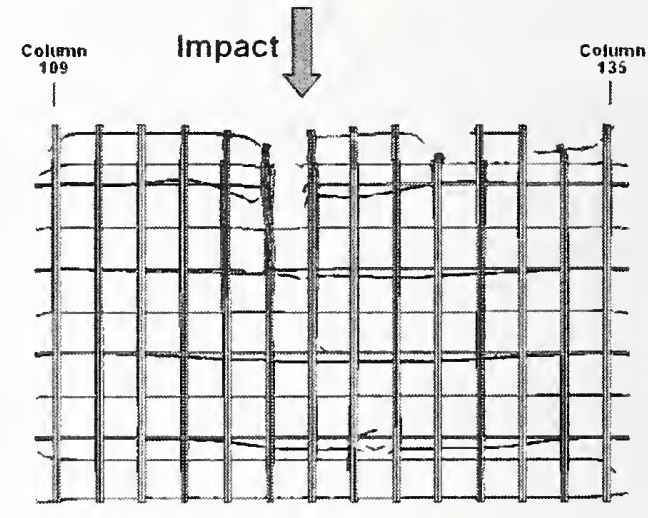

(d) Floor 97 truss damage

Figure 9-68. Less severe impact damage to the WTC 1 floor truss (plan view).

The calculated less severe impact damage to the WTC 1 floor slab for floors 94 through 97 are shown in Figure 9-69. The magnitude of floor slab damage was very similar for the base case and less severe global impact analyses. When the floor-by-floor damage was compared for the base case and less severe impact analyses, Figure 9-16 and Figure 9-69, respectively, the damage appeared to be slightly increased in the truss floor impact zone for the less severe impact. Similar to the truss damage, the increased 
damage in the floor slab was believed to be the result of the inerease in the downward impact trajeetory angle from 10.6 to 13.6 degrees in the more severe impaet analysis, inereasing the normal downward foree on the floor struetures. In eontrast to the truss floor slab, the eore floor slab damage was redueed in the less severe impaet analysis. This was a result of less impaet energy imparted to the core frame. In the base case analysis, the core frame was more severely damaged, resulting in eoupled damage to the core slab.

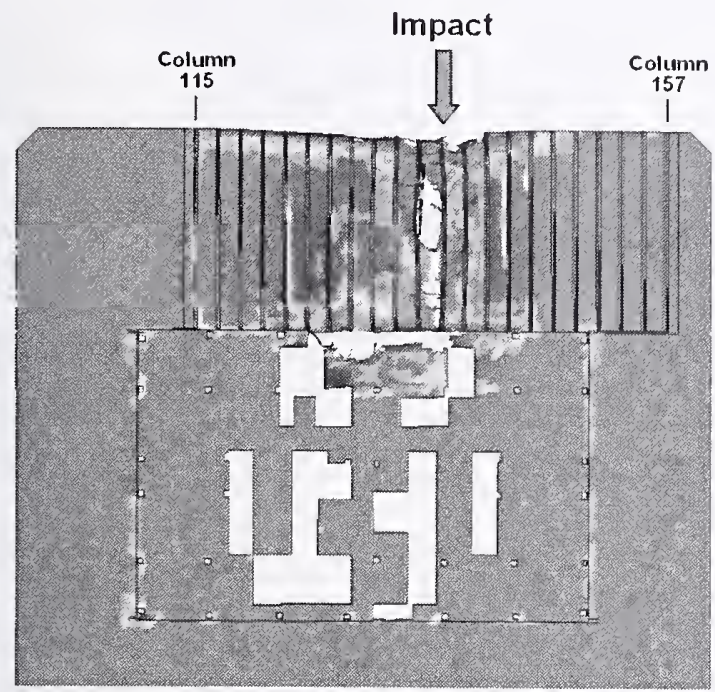

(a) Floor 94 slab damage

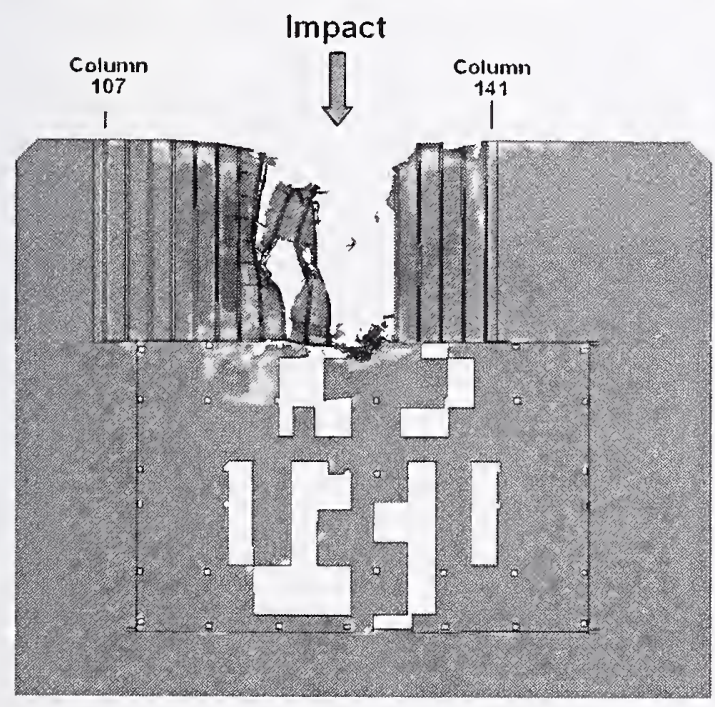

(c) Floor 96 slab damage

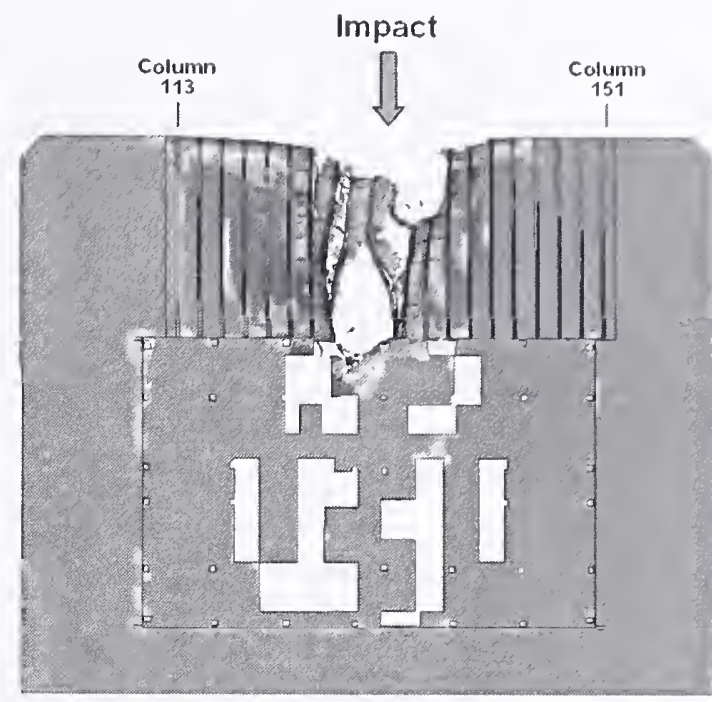

(b) Floor 95 slab damage Impact

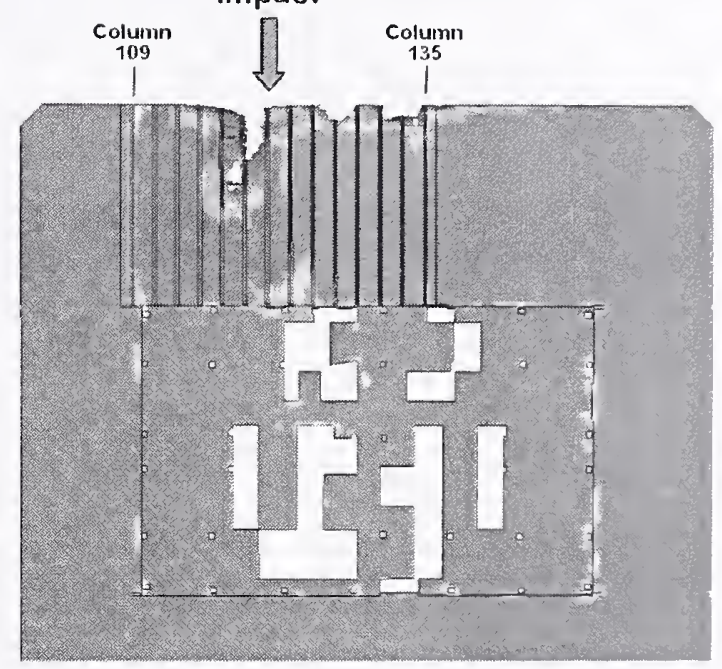

(d) Floor 97 slab damage

Figure 9-69. Less severe impact damage to the WTC 1 floor slab (plan view).

\section{Damage to WTC 1 Contents for the Less Severe Impact}

The ealeulated damage to the WTC 1 contents for the less severe impaet is shown in plan views in Figure 9-70 through Figure 9-74 for floors 94 through 98, respeetively. A eomparison to the ealculated damage for the base case WTC 1 impaet analysis, shown previously in Figure 9-20 through Figure 9-24, 
indicated that the building contents damage zone was very similar in width but did not extend as far through the tower in the less severe impact. The less severe impact produced little content damage on the far side of the core and did not extend fully through the tower. Little or no debris penetration of the south wall of the tower was expected for the less severe impact condition.

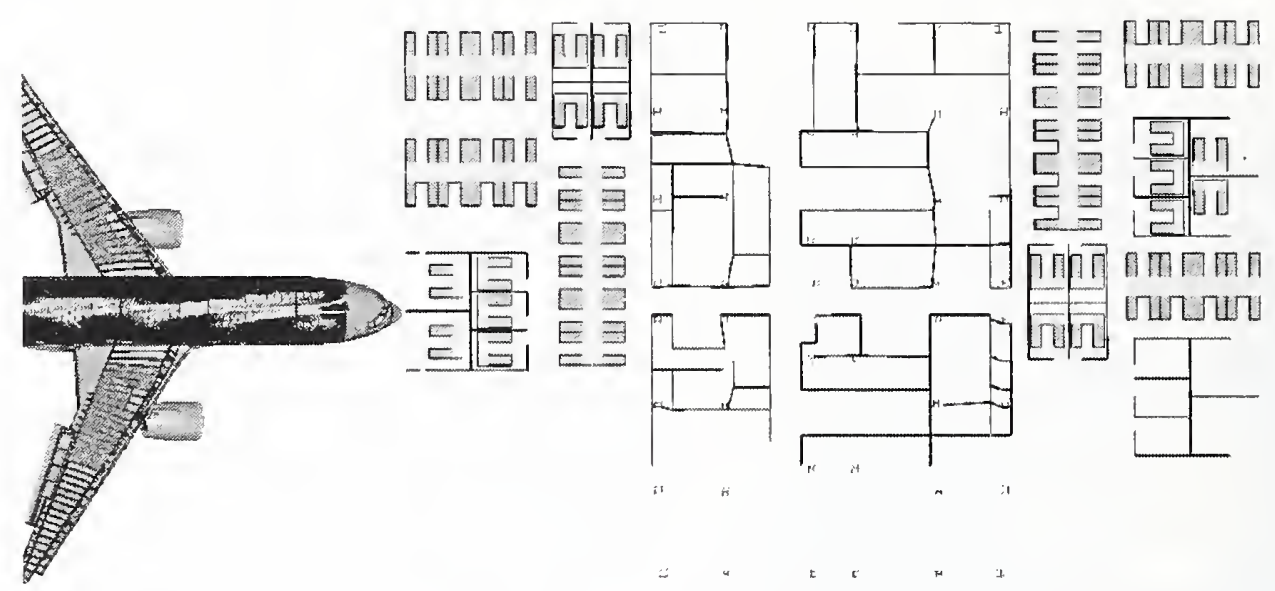

(a) Initial impact configuration

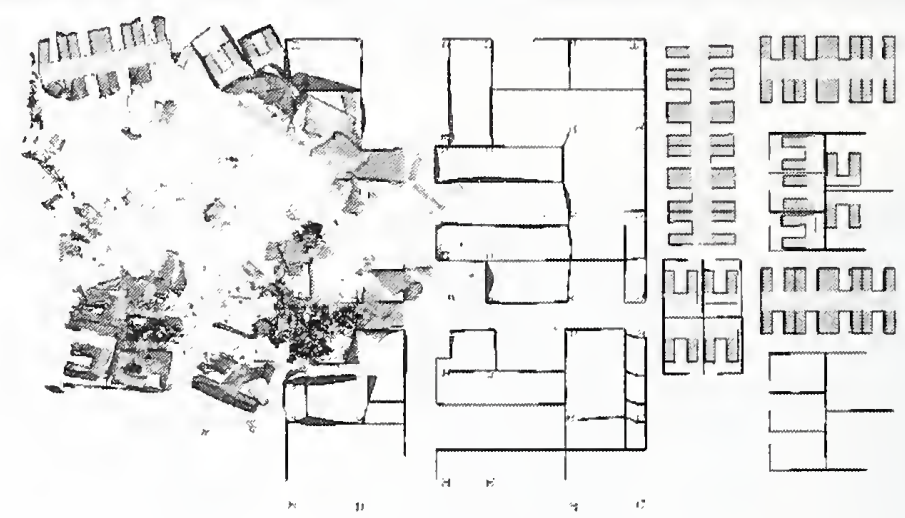

(b) Calculated response of contents

Figure 9-70. Calculated less severe WTC 1 impact response of floor 94 contents. 


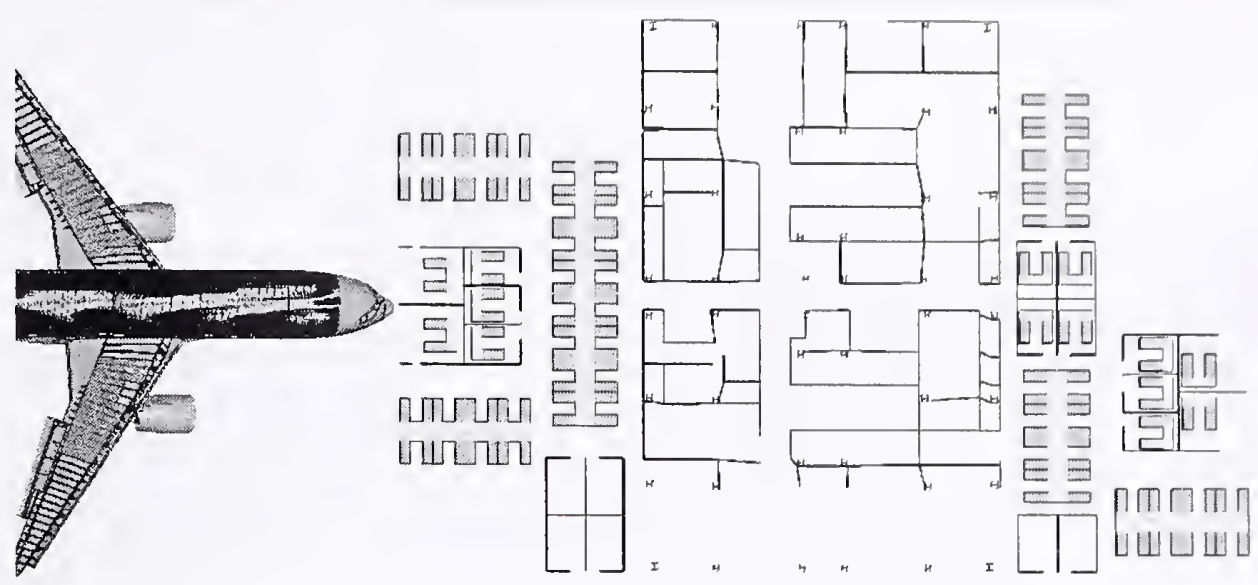

(a) Initial impact configuration

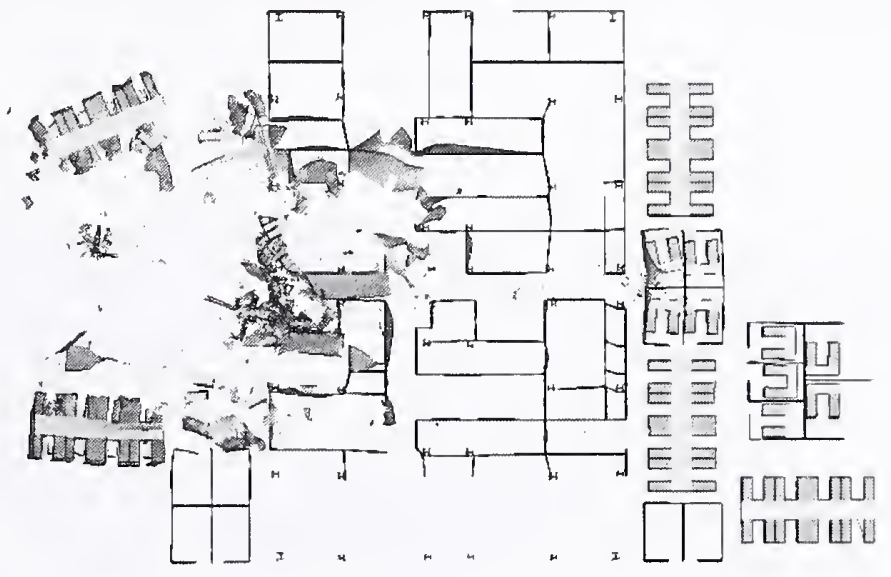

(b) Calculated response of contents

Figure 9-71. Calculated less severe WTC 1 impact response of floor 95 contents. 


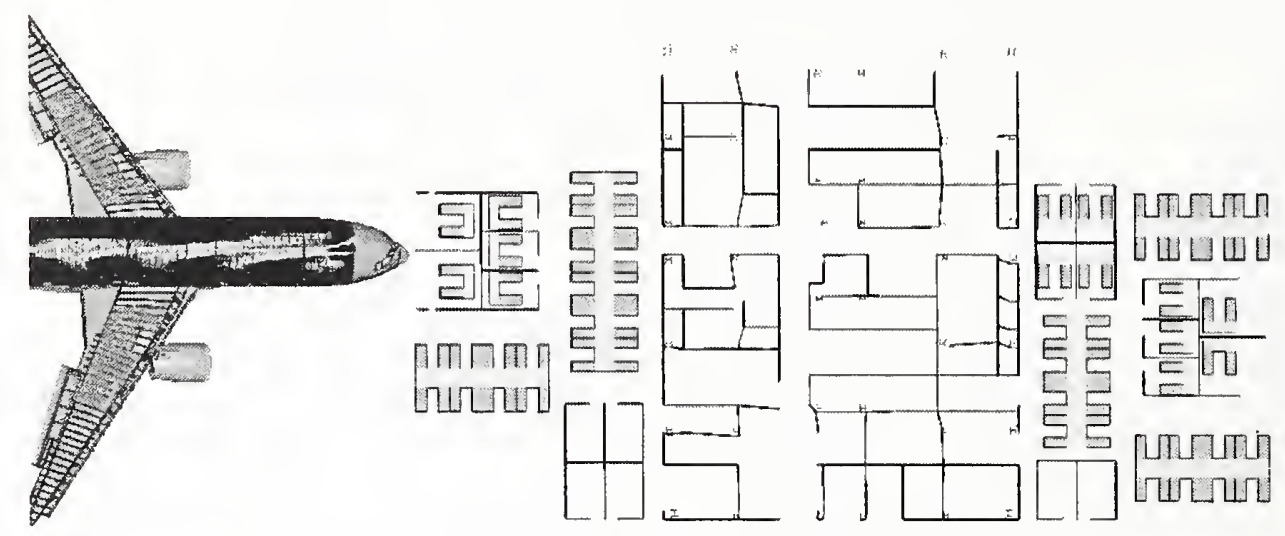

(a) Initial impact configuration

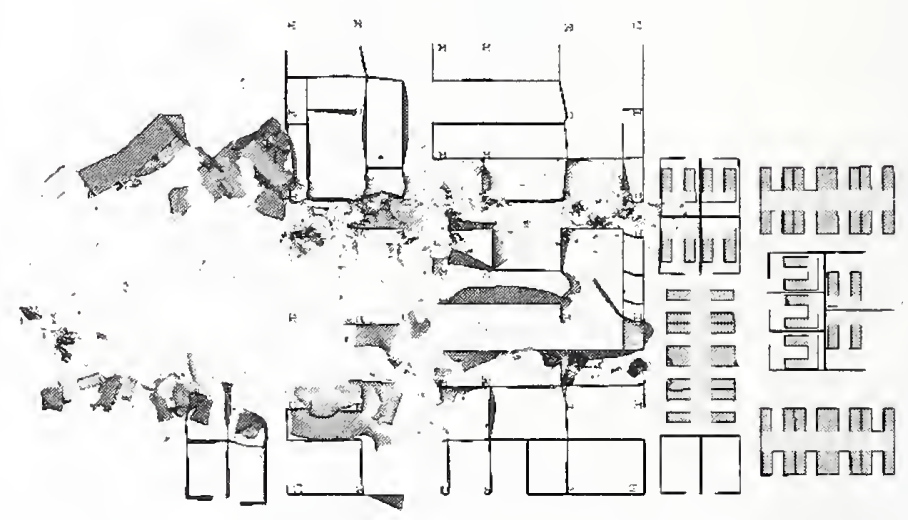

(b) Calculated response of contents

Figure 9-72. Calculated less severe WTC 1 impact response of floor 96 contents. 


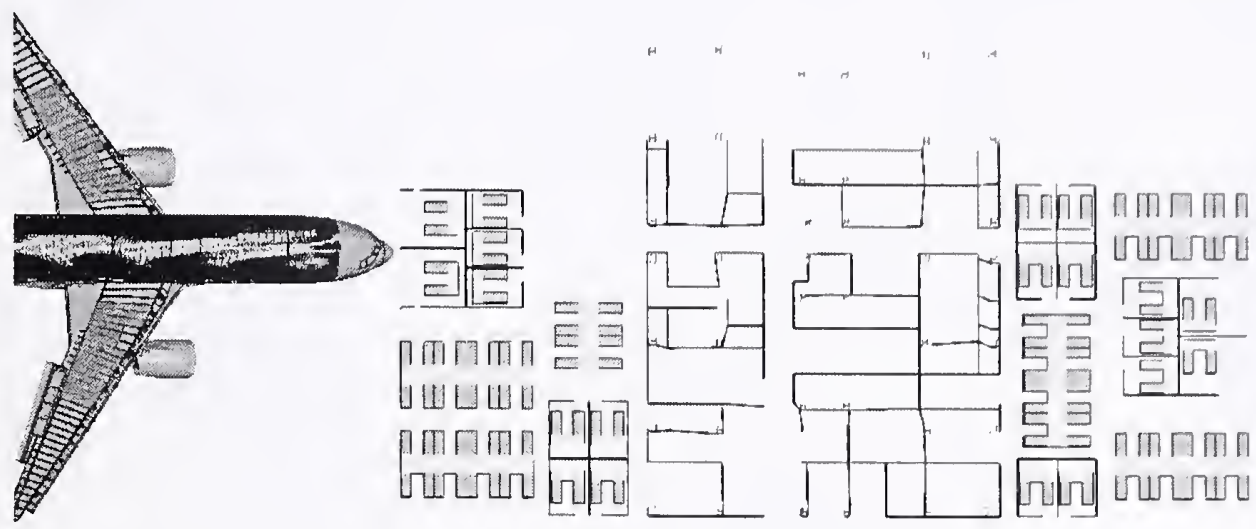

(a) Initial impact configuration

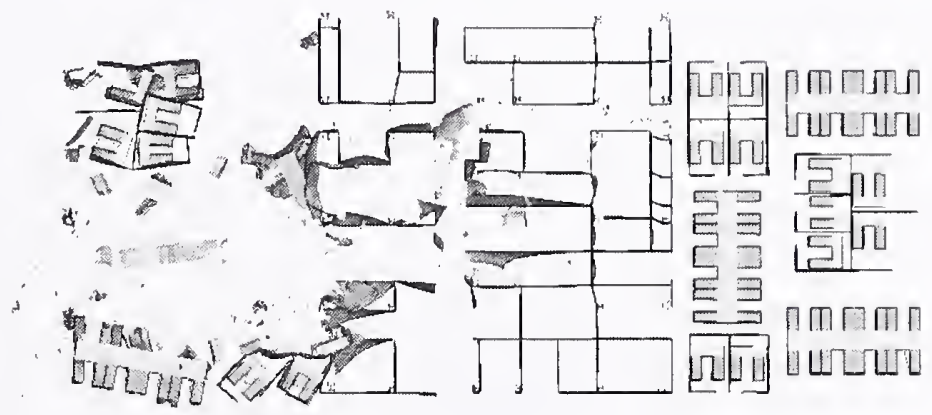

(b) Calculated response of contents

Figure 9-73. Calculated less severe WTC 1 impact response of floor 97 contents. 


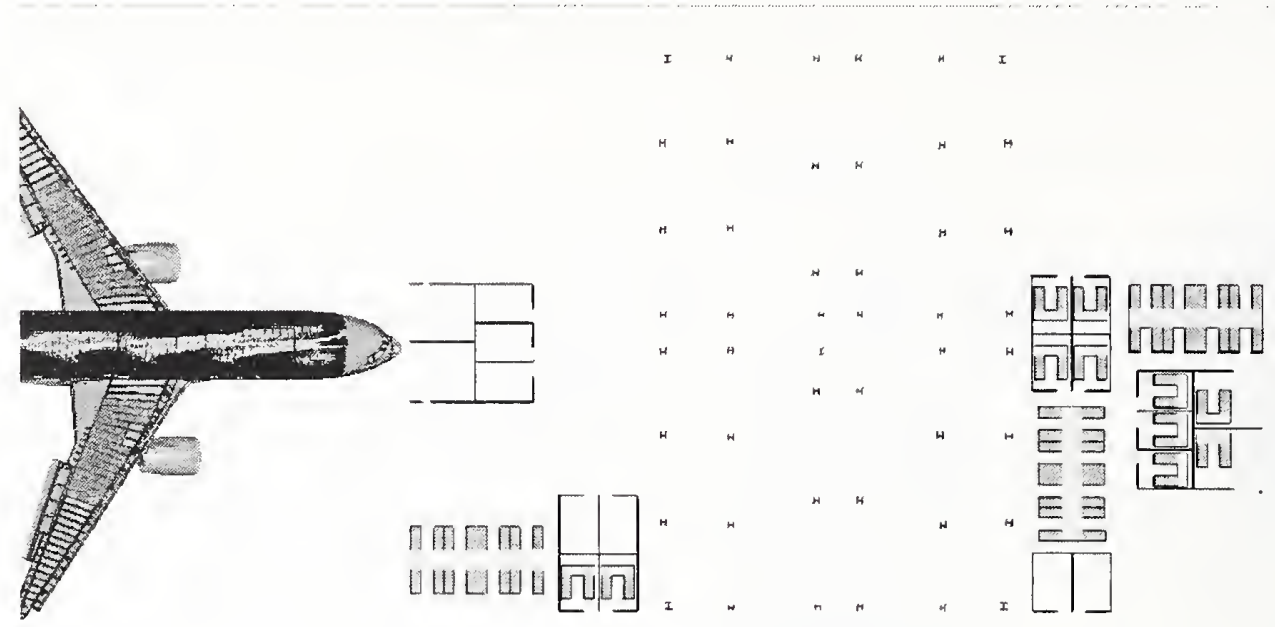

(a) Initial impact configuration

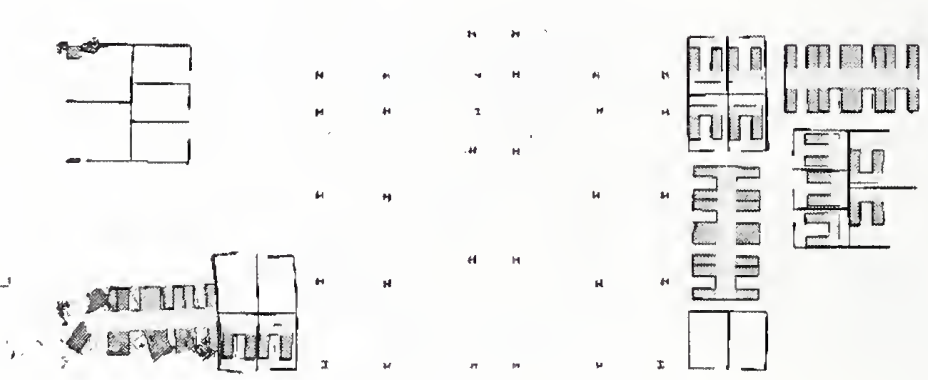

(b) Calculated response of contents

Figure 9-74. Calculated less severe WTC 1 impact response of floor 98 contents.

\subsection{ADDITIONAL WTC 2 GLOBAL IMPACT ANALYSES}

Two additional global impact analyses were performed for the WTC 2 impact to evaluate a more severe and less severe impact scenario. The combinations of impact conditions for the more and less severe impact scenarios are compared to the corresponding parameters in the base case analysis in Table 9-10. The impact speeds were $521 \mathrm{mph}$ and $570 \mathrm{mph}$ in the less severe and more severe impact scenarios, respectively. These were the upper and lower bounds obtained from the analysis of aircraft impact conditions described in Chapter 7. The aircraft vertical trajectory angle was also varied from 8 to 5 degrees for the less severe and more severe impact scenarios, respectively. This resulted in more impact energy directed inward toward the core in the more severe impact scenario and less impact energy in the core for the less severe impact. The lateral trajectory was not varied in these analyses so that the starboard engine trajectory was aligned with exiting the northeast corner of the tower, as was observed from photographic evidence (see Section 9.11). 
Table 9-10. Input parameters for additional WTC 2 global impact analyses.

\begin{tabular}{|c|l|c|c|c|}
\hline \multicolumn{2}{|c|}{ Analysis Parameters } & Base Case & More Severe & Less Scvere \\
\hline \multirow{4}{*}{$\begin{array}{c}\text { Flight } \\
\text { Parameters }\end{array}$} & Impact Velocity & $546 \mathrm{mph}$ & $570 \mathrm{mph}$ & $521 \mathrm{mph}$ \\
\cline { 2 - 5 } & Trajectory - pitch & $6.0^{\circ}$ & $5.0^{\circ}$ & $8.0^{\circ}$ \\
\cline { 2 - 5 } & Trajectory - yaw & $13.0^{\circ}$ & $13.0^{\circ}$ & $13.0^{\circ}$ \\
\cline { 2 - 5 } & Orientation - pitch & $5.0^{\circ}$ & $4.0^{\circ}$ & $7.0^{\circ}$ \\
\cline { 2 - 5 } & Orientation - yaw & $10.0^{\circ}$ & $10.0^{\circ}$ & $10.0^{\circ}$ \\
\hline \multirow{2}{*}{$\begin{array}{c}\text { Aircraft } \\
\text { Parameters }\end{array}$} & Weight & 100 percent & 105 percent & 75 percent \\
\cline { 2 - 5 } Parameters & Failure Strain & 100 percent & 115 percent & 100 percent \\
\cline { 2 - 5 } & Contents Strength & 100 percent & 80 percent & 120 percent \\
\cline { 2 - 5 } & Failure Strain & 100 percent & 90 percent & 25 percent \\
\cline { 2 - 5 } & Live Load Weight & 25 percent & 20 percent & 25 \\
\hline
\end{tabular}

a. Live load weight expressed as a percentage of the design live load.

The parameters varied for the aircraft model were the weight of the aircraft and the ductility of the aircraft materials. A 5 percent variation of the total aircraft wcight was considered, with the additional weight applied for the more severe impact. The failure strain was varied from 75 to 115 percent of the baseline value for the less severe and more severe impact scenarios, respectively. This variation in aircraft material ductility was used as the single parameter in these additional analyses to evaluate the uncertainties in aircraft material energy absorption capacity.

The parameters varied for the tower model were the ductility of the steel used in the tower construction and the weight and strength of the contents inside the tower. The less severe impact analysis used a 20 percent increase in failure strain for the tower materials and the baseline values for the contents weight and strength. The more severe impact analysis used a 10 percent reduction in tower material ductility with a corresponding 20 pcrcent reduction in strength of the internal contents and a reduction of the weight of the content from 25 percent to 20 percent of the design live load capacity for the truss and core floor areas. The design live load is described in Section 3.2.4.

For WTC 2, the variations in the parameters from the base case were similar to those for WTC 1 (see Table 9-7), with two exceptions. The first exception was introduction of the strength of the building contents as a parameter. There was less information available about the layout of building contents in the WTC 2 impact zone and therefore a larger uncertainty associated with the contents was assumed. Recall that the workstation layout from WTC 1 was used for WTC 2. Thus, in the more severe case, the contents strength was reduced to 80 percent of the baseline value.

The second exception was the failure strains for the aircraft and tower materials. For the more severe WTC 1 analysis, 125 percent and 80 percent of the baseline values were used for the aircraft and tower failure strains, respectively. For the more severe WTC 2 analysis, 115 percent and 90 percent of the baseline values were used. The more severe WTC 2 analysis was the final global impact analysis performed. Based on the previous analyses, the variation in damage levels indicated that the WTC 2 more severe impact analysis would produce impact damage state that was not viable (e.g., the amount of debris exiting the north wall). To ensure that a viable damage state was obtained, the aircraft and tower materials were adjusted to the values presented in Table 9-10. 


\subsubsection{More Severe WTC 2 Global Impact Analyses}

This case is referred to as Case D for the remainder of the WTC investigation reports. A side view of the more severe WTC 2 global impact model is shown in Figure 9-75. The tower interior contents were removed and the tower structures were shown as transparent in the figure so that the impact response in the tower interior was visible. Similar plan view images of the progression of aircraft impact response are shown in Figure 9-76. The response is shown at intervals of $0.1 \mathrm{~s}$ from impact through the initial $0.5 \mathrm{~s}$ of the response. Corresponding images of the base case WTC 2 impact response were shown previously in Figure 9-26 and Figure 9-27, respectively.

The initial $0.1 \mathrm{~s}$ of the more severe global aircraft impact response, shown in Figure 9-75(b) and Figure 9-76(b), was dominated by the impact, penetration, and fragmentation of the forward fuselage structures. The engines and forward wing structures also penetrated the exterior wall. At $0.2 \mathrm{~s}$ after impact, the full penetration of the aircraft into the tower was completed, as shown in Figure 9-75(c) and Figure 9-76(c). The airframe was mostly broken up, but some large sections of the aft fuselage and tail were still intact, having penetrated through the opening in the tower wall produced by the forward fuselage structures. The aircraft fuel cloud was starting to spread out, but was still relatively dense and the leading edge of the fuel was approximately one-half through the tower core. At $0.3 \mathrm{~s}$ after impact, the aircraft fuel cloud had penetrated the distance through the core and was spreading out, as shown in Figure 9-75(d) and Figure 9-76(d). The subsequent motion of the aircraft fragments and fuel debris cloud began to be noticeably slowed beyond this time. The slower spread of fuel and debris through the tower is seen in the remaining images in Figure 9-75 and Figure 9-76. The spread of the fuel and debris cloud was more rapid and extensive in the open truss floor regions than through the core as a result of the open volume above the workstations in the truss floor zone.

\section{Exterior Wall Damage for the More Severe WTC 2 Impact}

A comparison of the south exterior wall observed and calculated damage from the more severe WTC 2 global impact analysis is shown in Figure 9-77. The calculated impact damage to the exterior wall is shown with color fringes representing plastic strain magnitude, with undamaged sections in blue and strains at or above 5 percent shown in red. The wall region shown in Figure 9-77 includes column 402 to column 446, extending from floor 76 to floor 86 (spandrels at floors 77 through 86). The mode and magnitude of the calculated and observed impact damage on the exterior wall were still in good agreement in this more severe impact analysis. 


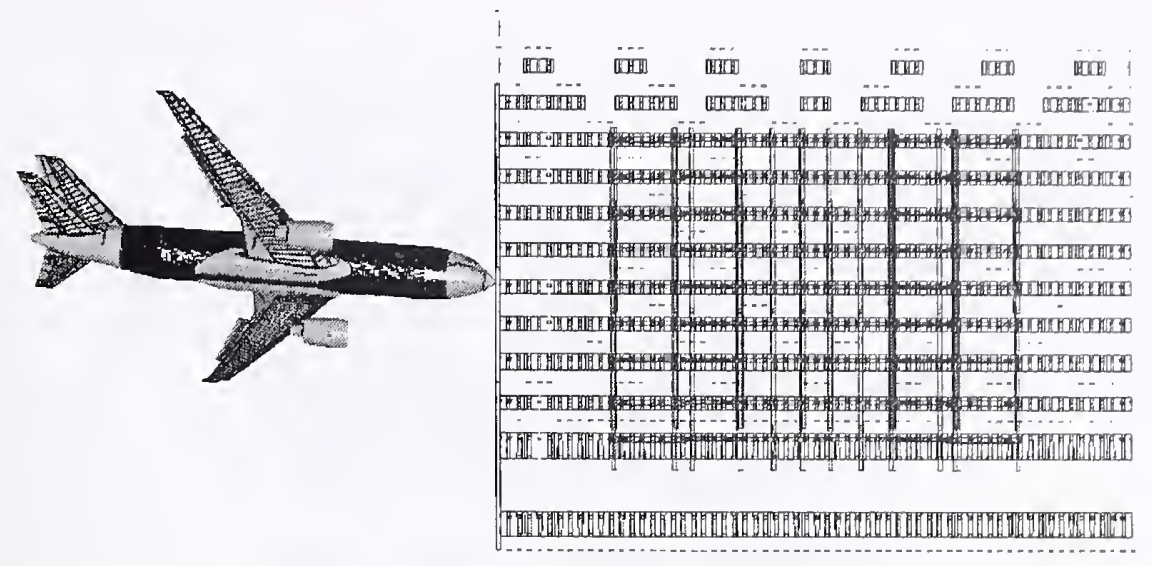

(a) Time $=0.00 \mathrm{~s}$

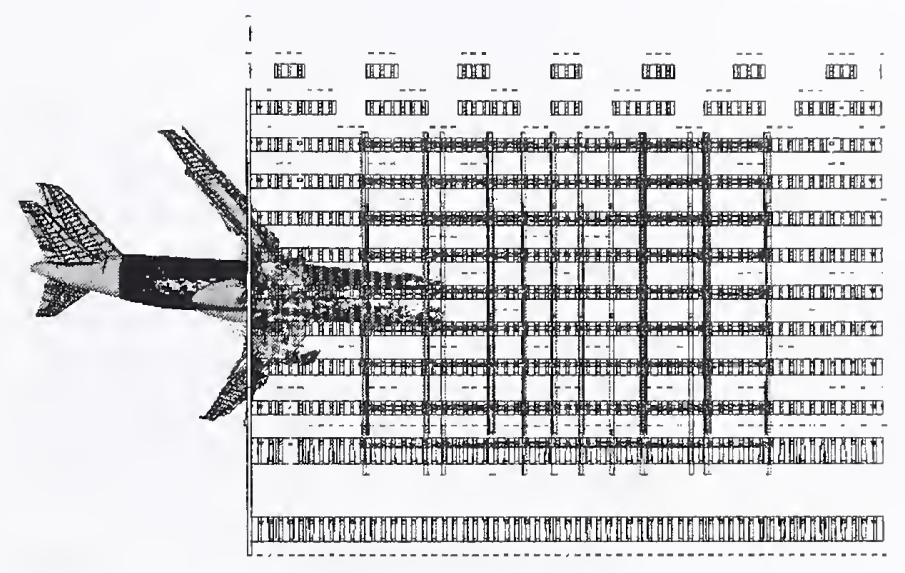

(b) Time $=0.10 \mathrm{~s}$

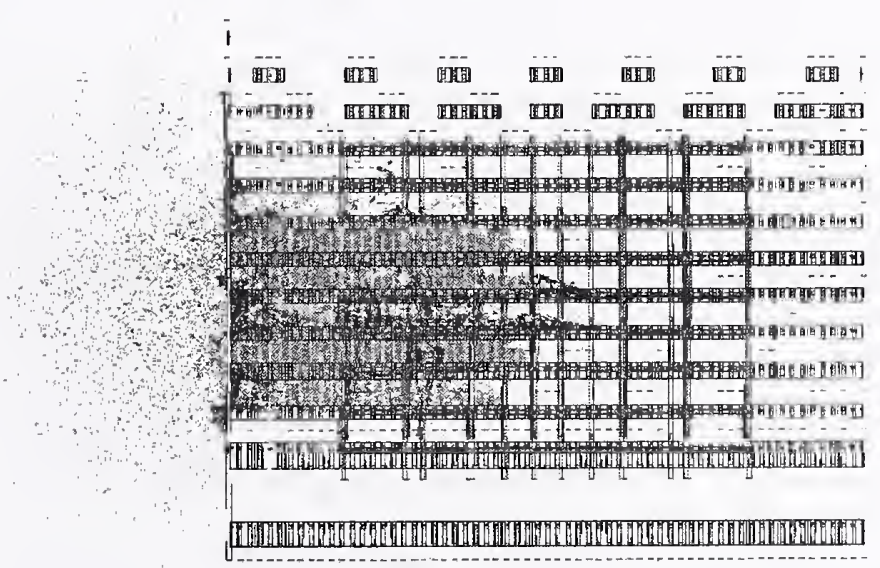

(c) Time $=0.20 \mathrm{~s}$

Figure 9-75. More severe WTC 2 global impact analysis (side view). 


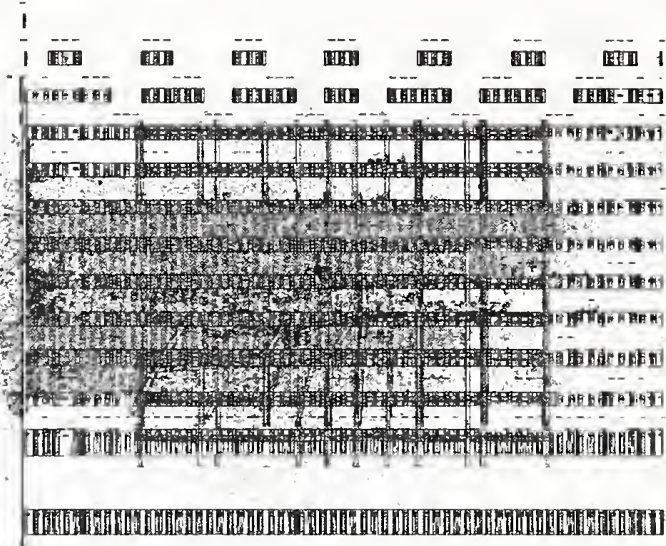

(d) Time $=0.30 \mathrm{~s}$

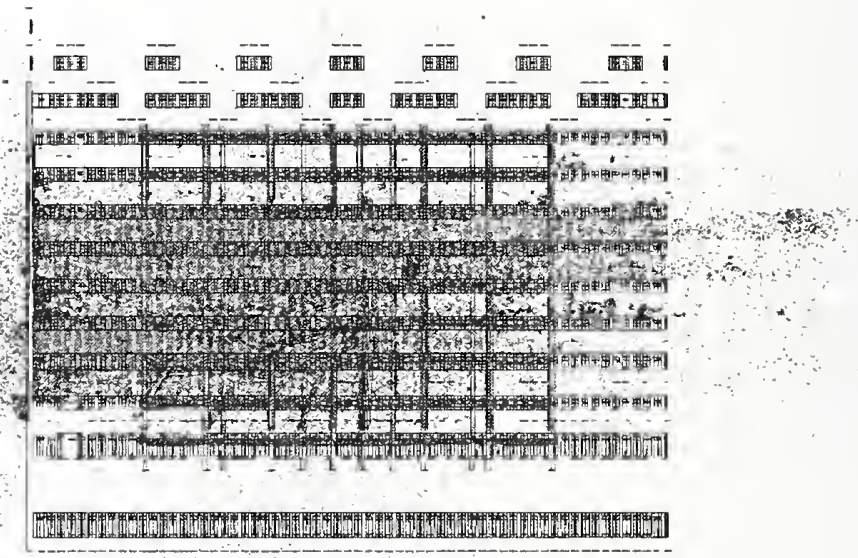

(e) Time $=0.40 \mathrm{~s}$

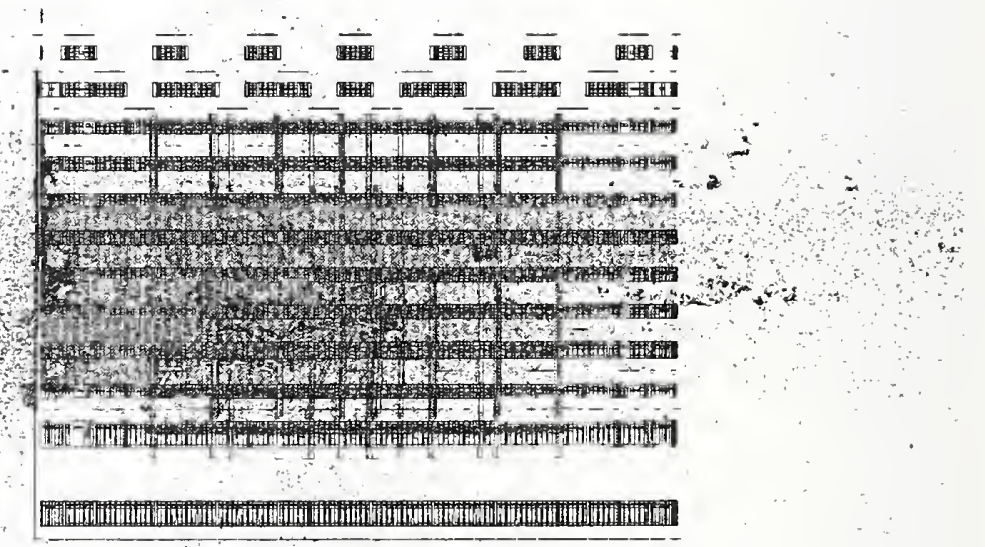

(f) Time $=0.50 \mathrm{~s}$

Figure 9-75. More severe WTC 2 global impact analysis (side view) (continued). 


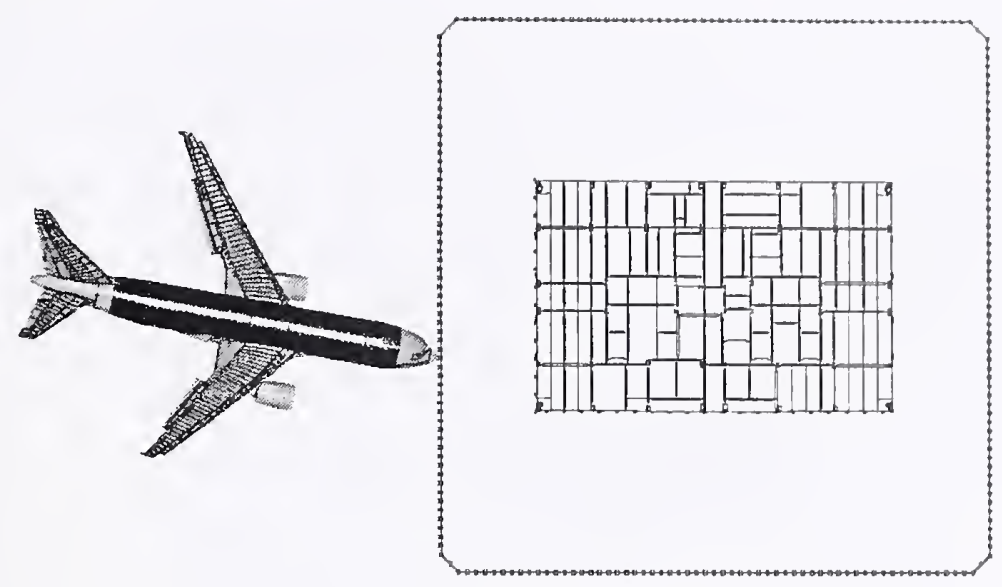

(a) Time $=0.00 \mathrm{~s}$

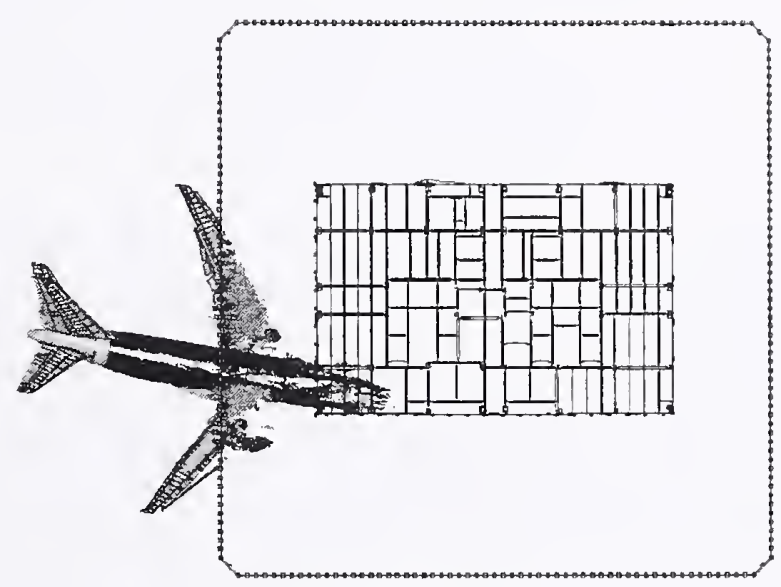

(b) Time $=0.10 \mathrm{~s}$

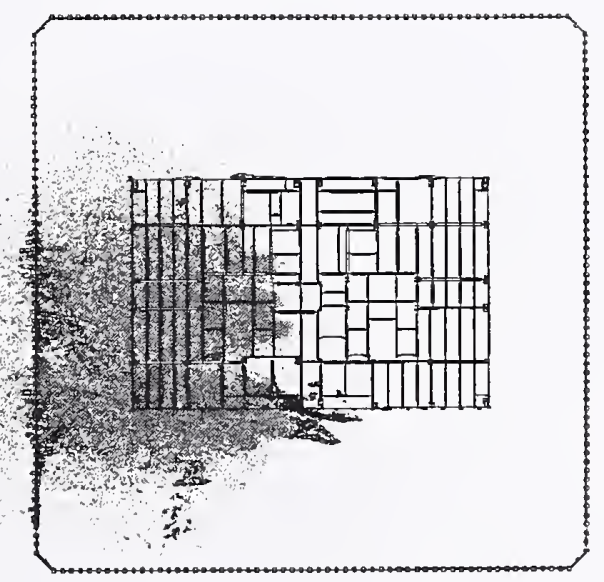

(c) Time $=0.20 \mathrm{~s}$

Figure 9-76. More severe WTC 2 global impact analysis (plan view). 


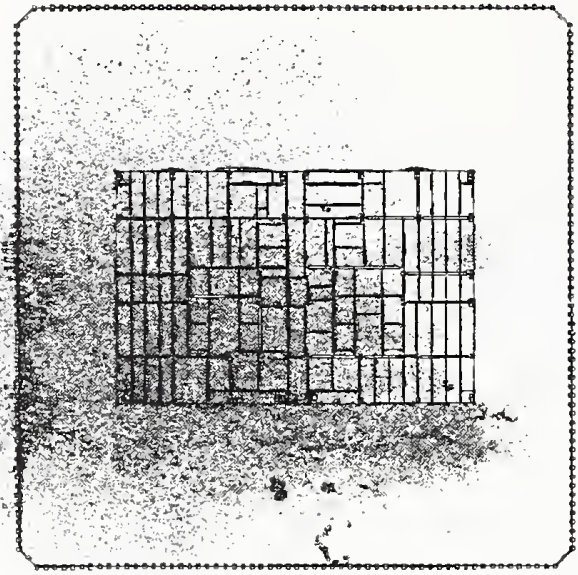

(d) Time $=0.30 \mathrm{~s}$

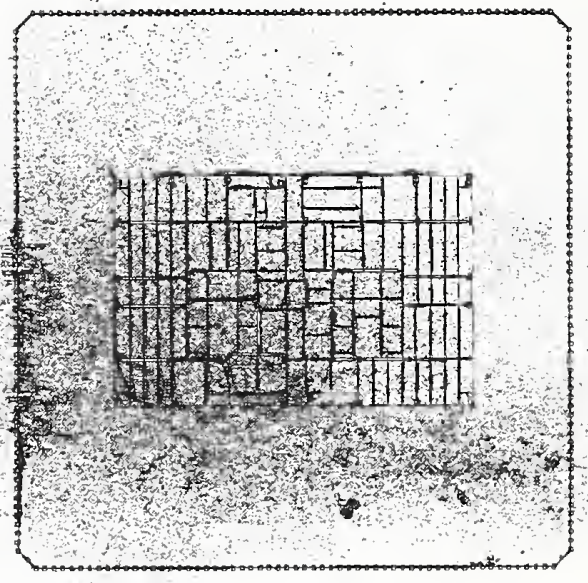

(e) Time $=0.40 \mathrm{~s}$

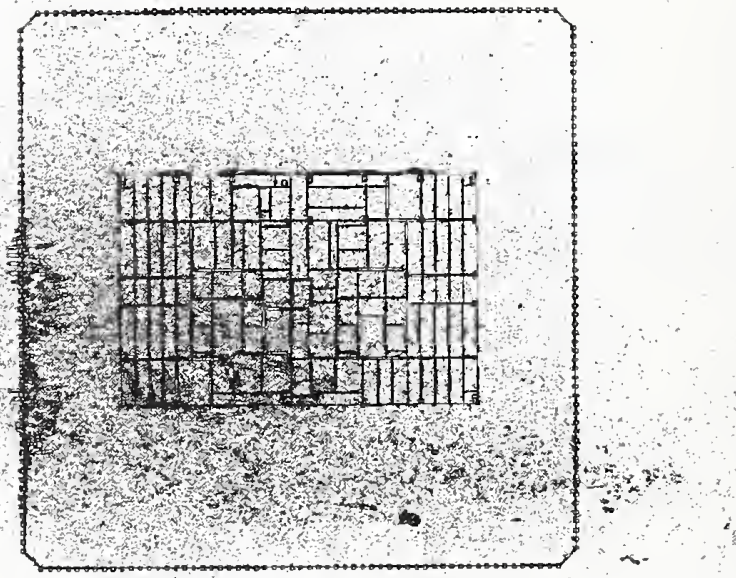

(f) Time $=0.50 \mathrm{~s}$

Figure 9-76. More severe WTC 2 global impact analysis (plan view) (continued). 


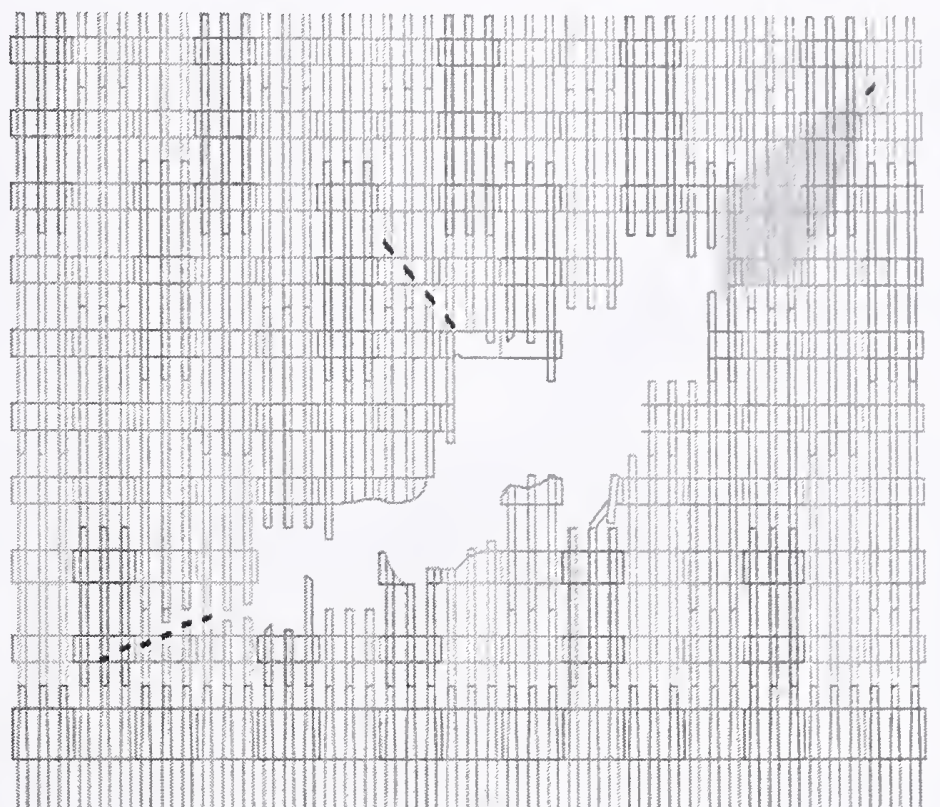

(a) Schematic of observed damage

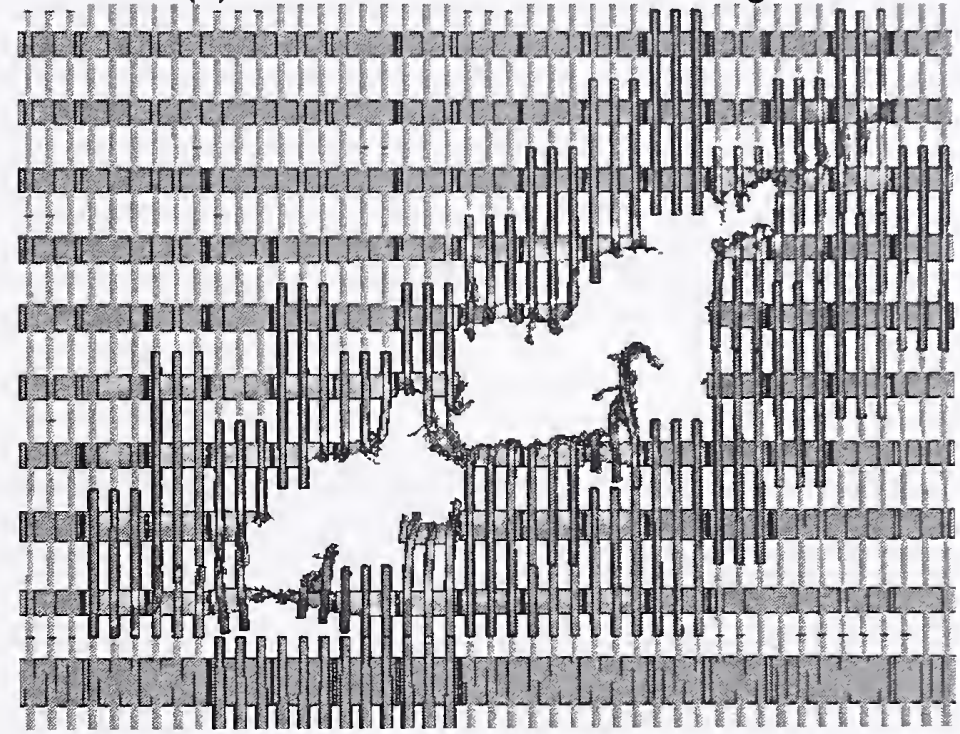

(b) Calculated damage ( $t=0.62 \mathrm{~s})$

Figure 9-77. More severe impact damage to the WTC 2 exterior wall.

\section{Core Structural Damage for the More Severe WTC 2 Impact}

The overall model for the WTC 2 core structure and calculated response for the more severe damage analysis is shown in Figure 9-78. The figure shows that the core had extensive damage in the region close to the impact point. The columns in line with the aircraft fuselage failed on the impact side, and several of the core beams were also severely damaged or failed in the impact zone. In some cases, failure of the column splices located on floors 77,80 , and 83 contributed significantly to the failure of the core columns. 
The calculated damage to the core columns by row is shown in Figure 9-79, and the floor-by-floor damage to the core framing is shown in Figure 9-80. The core structures are shown with color fringes representing plastic strain magnitude, with undamaged sections in blue and strains at or above 5 percent shown in red. A summary of the column damage is provided in Table 9-11 and shown graphically in Figure 9-81, with the qualitative classification of the column damage levels provided previously in Figure 9-12. A total of 10 columns were severed, and one column was heavily damaged, compared to five columns severed and four columns heavily damaged in the base case WTC 2 impact analysis.

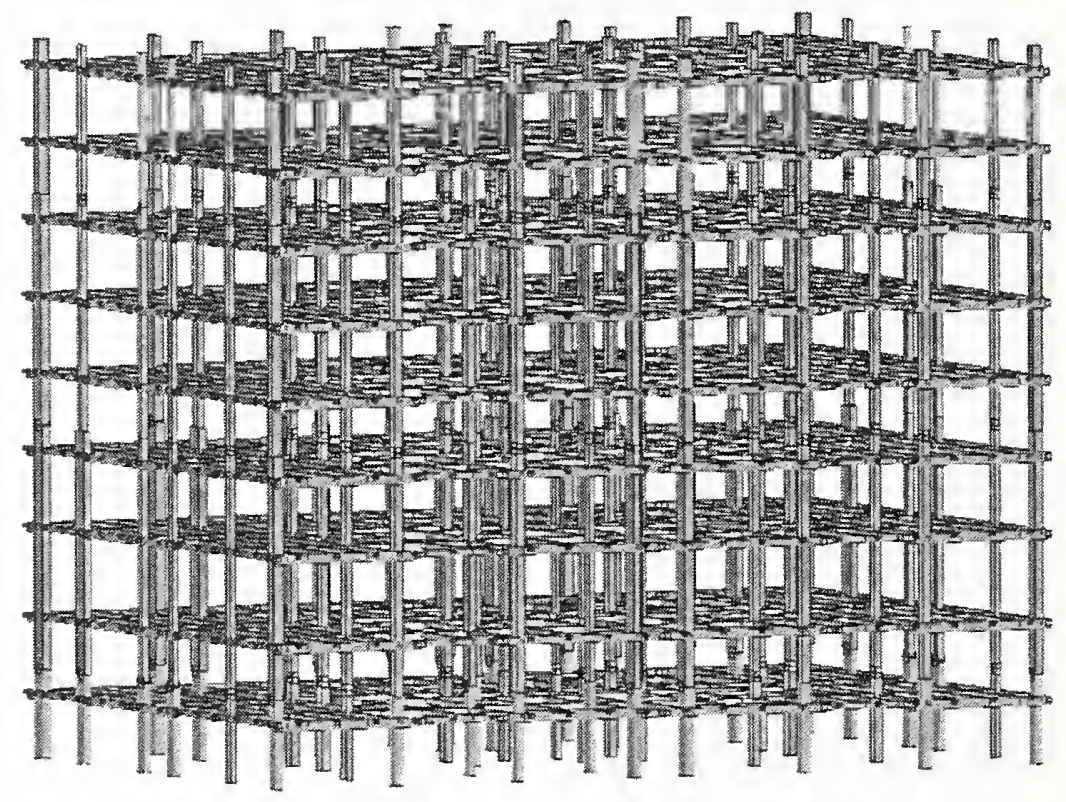

(a) Initial geometry

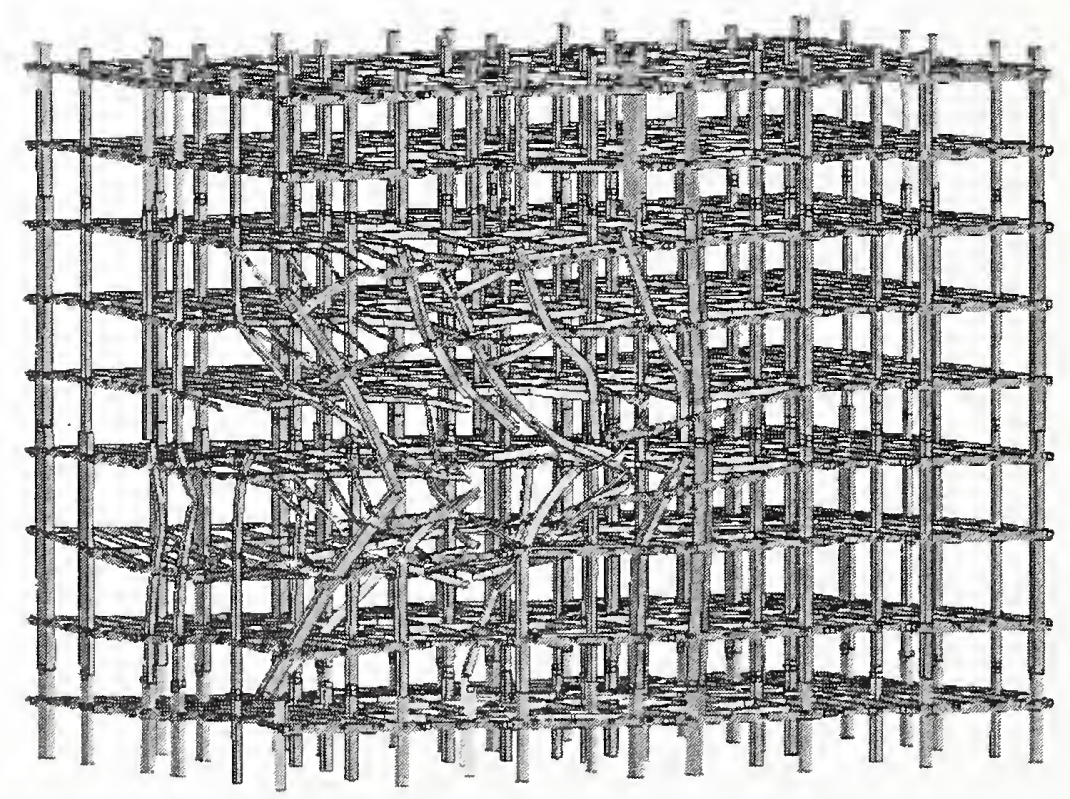

(a) Calculated impact damage

Figure 9-78. More severe impact response of the WTC 2 core. 


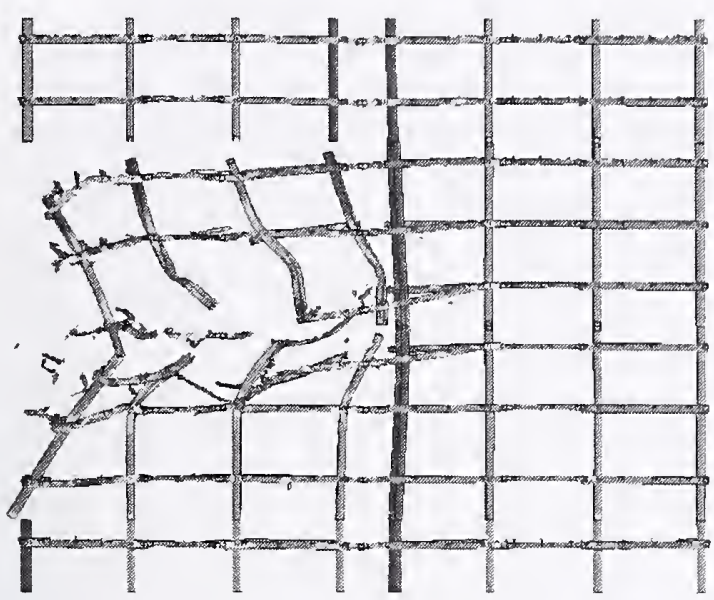

(a) Columns 1001-1008

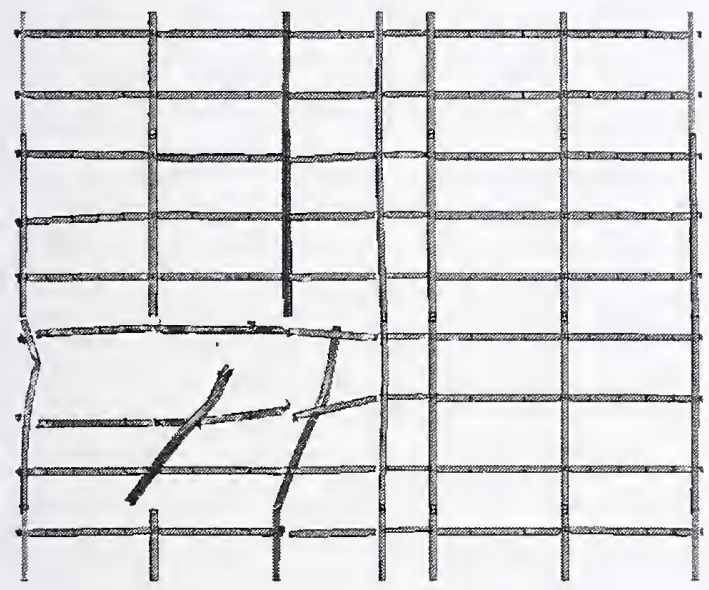

(c) Columns 801-807

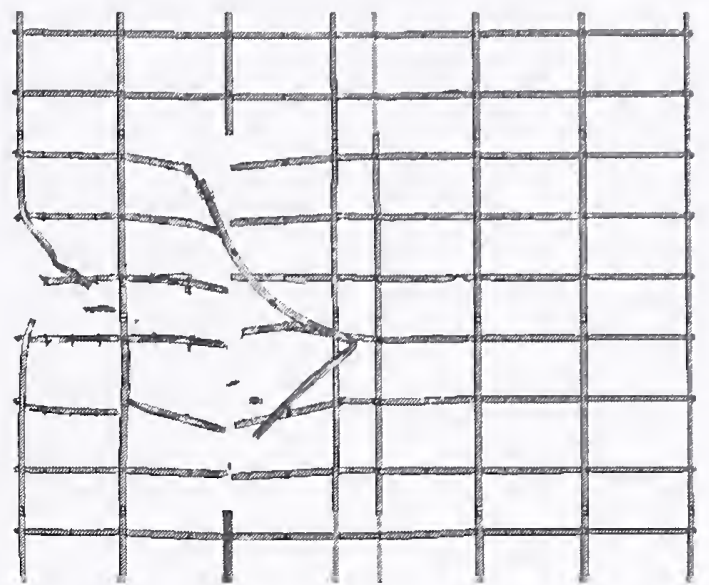

(b) Columns 901-908

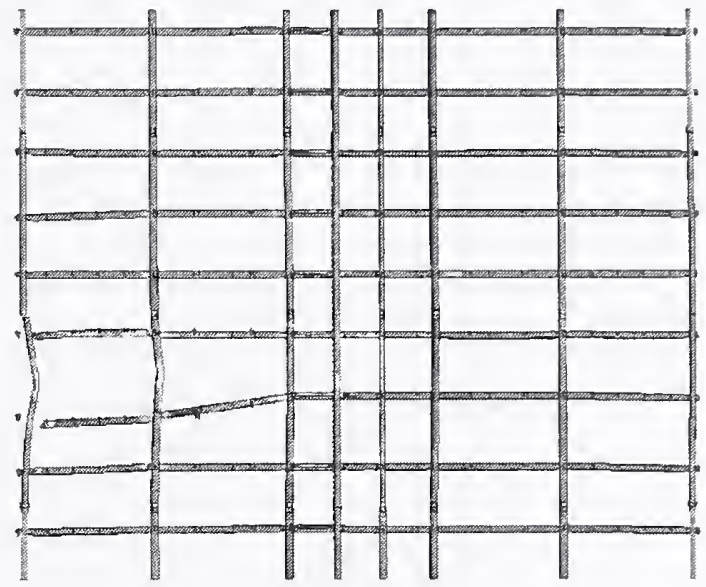

(d) Columns 701-708

Figure 9-79. More severe impact response of the WTC 2 core columns. 


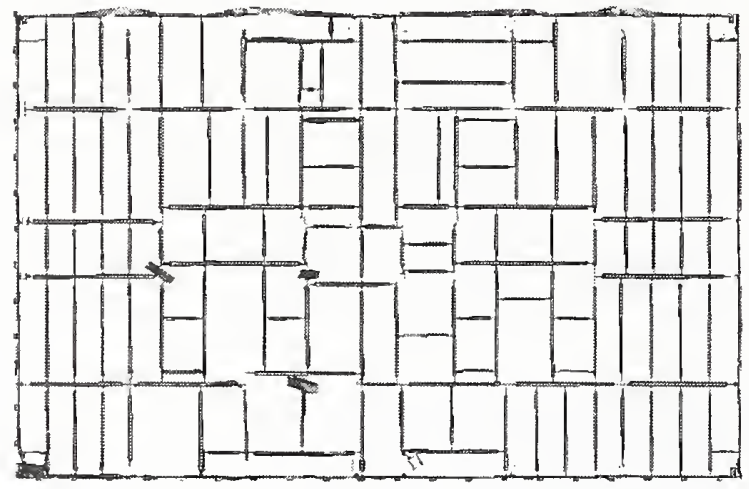

(a) Floor 78 core framing damage

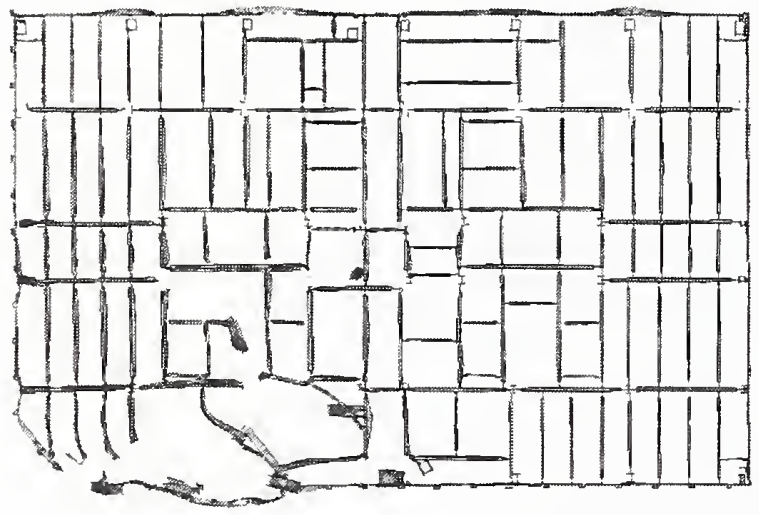

(c) Floor $\mathbf{8 0}$ core framing damage

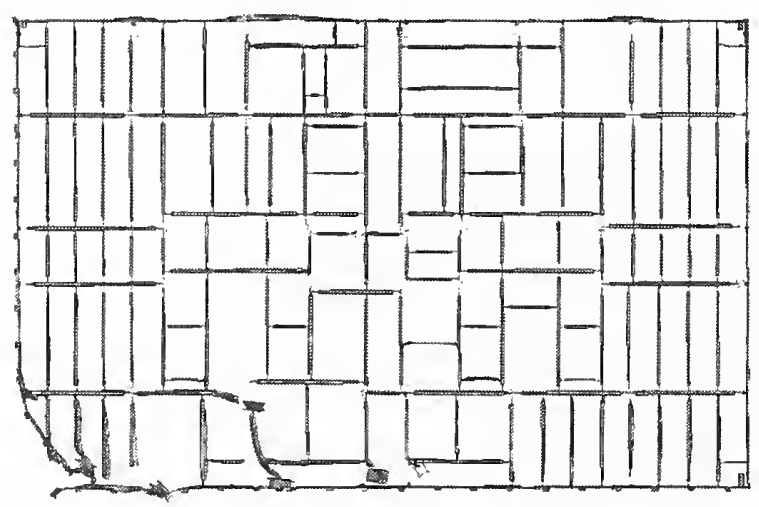

(e) Floor 82 core framing damage

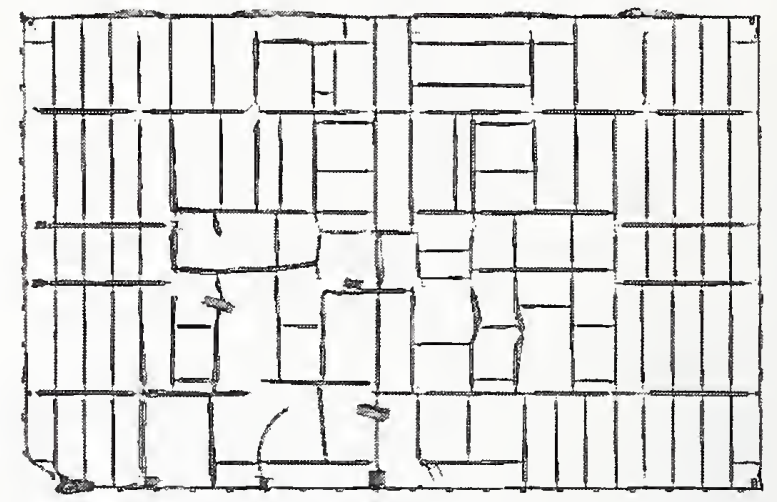

(b) Floor 79 core framing damage

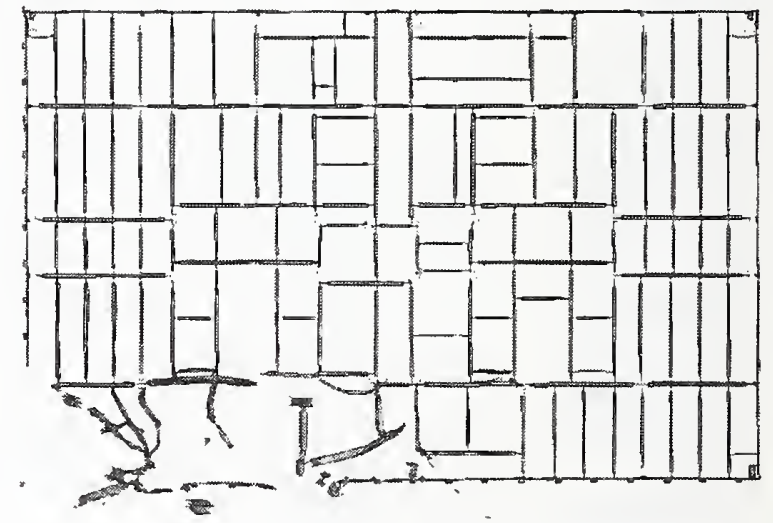

(d) Floor $\mathbf{8 1}$ core framing damage

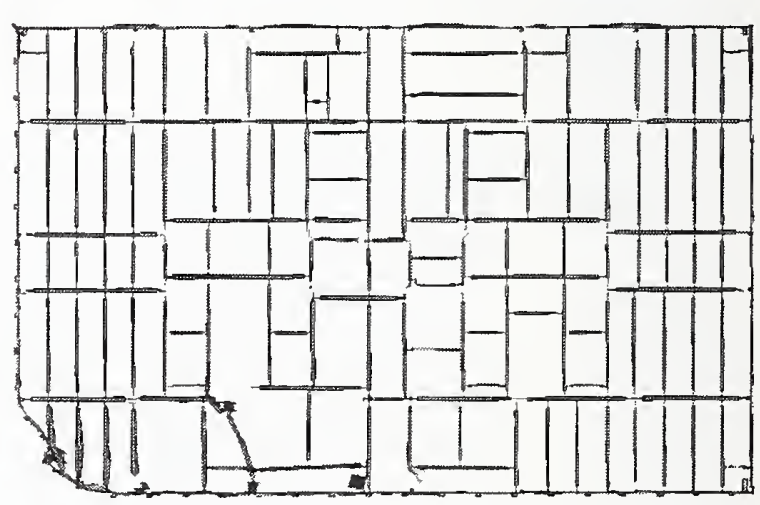

(f) Floor 83 core framing damage

Figure 9-80. More severe impact damage to the WTC 2 core floor framing (plan vièw). 
Table 9-11. Core column response for the more severe WTC 2 impact.

\begin{tabular}{|c|c|c|c|}
\hline Column & Location & Damage Level & $\begin{array}{l}\text { Lateral Deflection of } \\
\text { Column Centerline (in.) }\end{array}$ \\
\hline Column 602 & Floor 79 & Moderate & \\
\hline Column 605 & Floor 79 & Moderate & \\
\hline Column 701 & Floors $79-80$ & Severed & \\
\hline Column 702 & Floor 79 & Heavy & 16 \\
\hline Column 703 & Floor 79 & Moderate & \\
\hline Column 704 & Floor 79 & Light & \\
\hline Column 705 & Floors $78-79$ & Light & \\
\hline Column 705 & Floor 78 & Light & \\
\hline Column 801 & Floors $79-80$ & Severed & \\
\hline Column 802 & Floors $77-80$ & Severed & \\
\hline Column 803 & Floors $77-80$ & Severed & \\
\hline Column 804 & Floor 79 & Light & \\
\hline Column 901 & Floors 80-81 & Severed & \\
\hline Column 902 & Floor 79 & Moderate & \\
\hline Column 903 & Floors 77-83 & Severed & \\
\hline Column 904 & Floors 79-81 & Moderate & \\
\hline Column 905 & Floors $79 \& 81$ & Light & \\
\hline Column 907 & Floor 81 & Light & \\
\hline Column 1001 & Floors $77-83$ & Severed & \\
\hline Column 1002 & Floors 79-83 & Severed & \\
\hline Column 1003 & Floors 79-83 & Severed & \\
\hline Column 1004 & Floors 79-83 & Severed & \\
\hline Column 1005 & Floors 79-81 & Moderate & \\
\hline
\end{tabular}




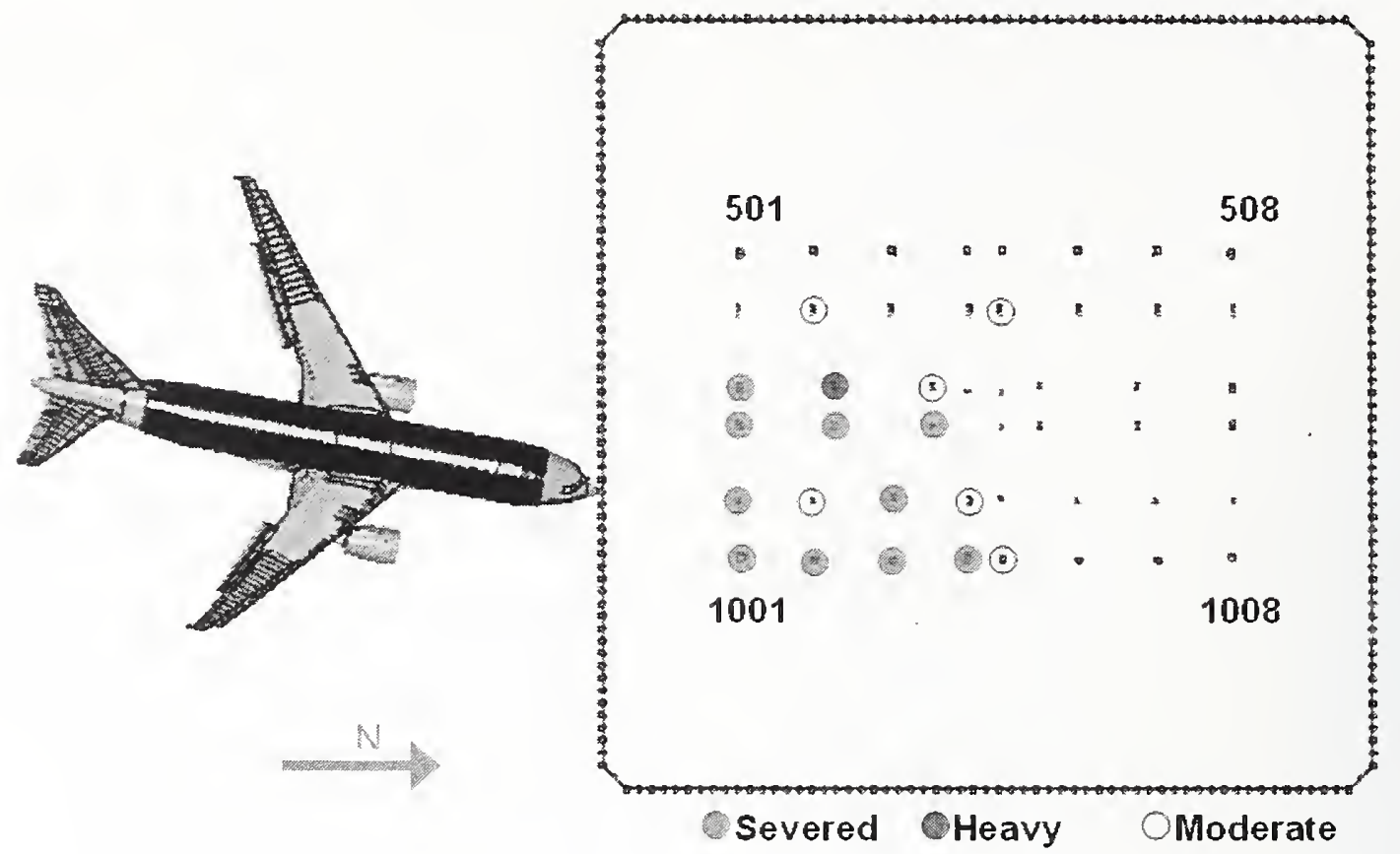

Figure 9-81. Summary of core column damage for the more severe WTC 2 impact.

\section{Strain Rate Observations for the More Severe WTC 2 Impact}

The more severe WTC 2 impact analysis had the highest impact speed of any of the global impact analyses. As a result, the more severe WTC 2 impact is an appropriate case for bounding the expected strain rates for the deformation of the WTC tower structural materials. Fringes of Von Mises effective strain rate for the south exterior wall and core framing are shown in Figure 9-82 and Figure 9-83, respectively. The corresponding times shown are at $90 \mathrm{~ms}$ and $200 \mathrm{~ms}$ for the exterior wall and core framing, respectively. These times were selected as representative of instants when rapid impact deformations over a significant portion of the structure were observed in the calculation.

The strain rates in the exterior wall were significantly higher than those in the core. Peak strain rates were calculated at specific locations for short durations. These strain rates were on the order of a few thousand per second. However, these high strain rates were localized to small regions of the structure and for very short durations. Figure 9-82 shows that the majority of the deformations occurred with strain rates at or below approximately 100 per second. Similarly, the localized peak strain rates in the core were a few hundred per second, and Figure 9-83 shows that the majority of the deformation in the core occurred with strain rates at or below approximately 20 per second.

The expected influence of these elevated strain rates on strength is small. The dominant strain rates seen in the figures are between 1 and 100 per second. The high rate material testing, described previously in Section 2.2.4, shows that the yield stress for the WTC tower materials typically increased by less than 10 percent at these calculated rates. 


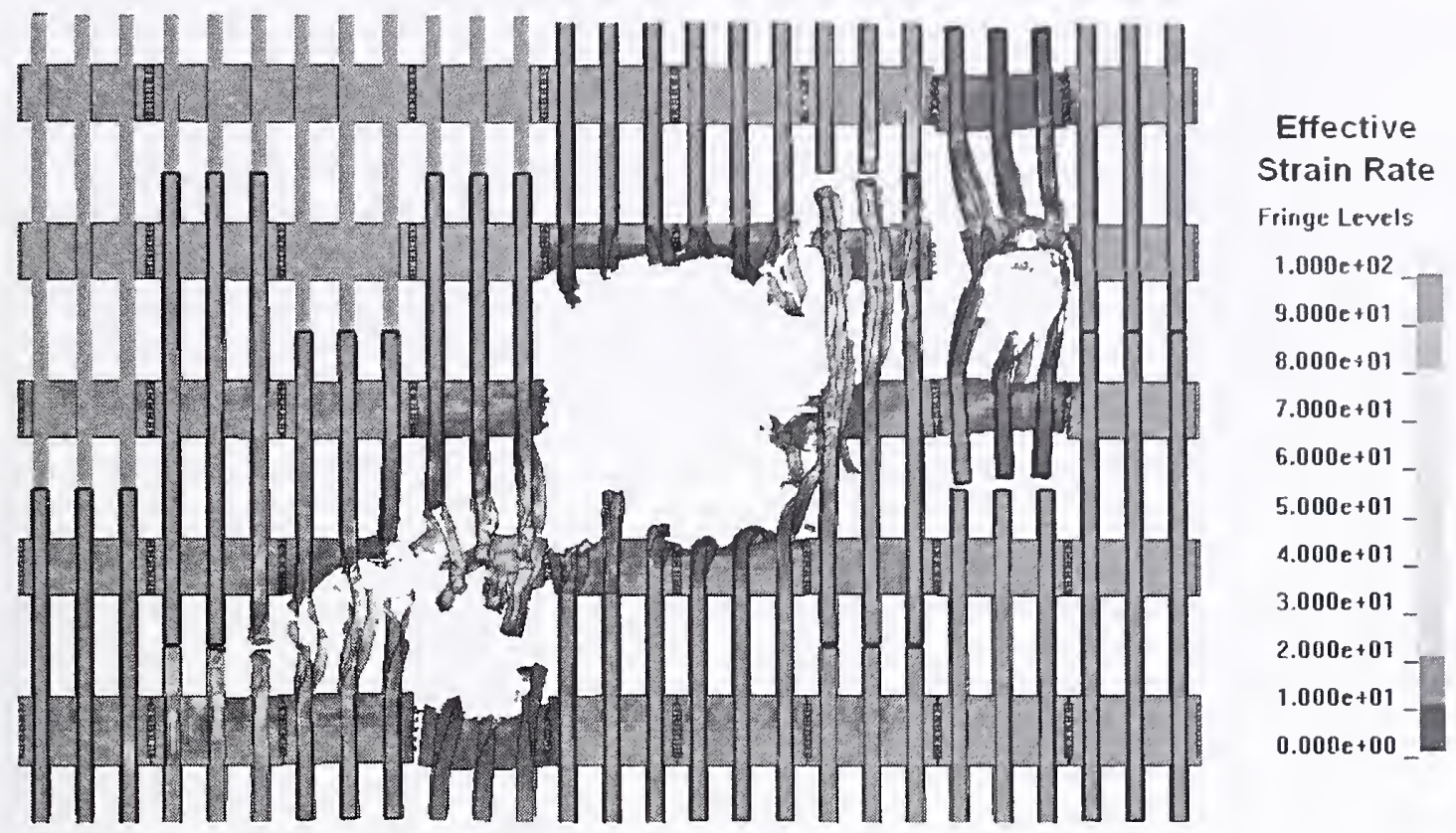

Figure 9-82. Representative exterior wall strain rates for the more severe WTC 2 impact (view from tower exterior).

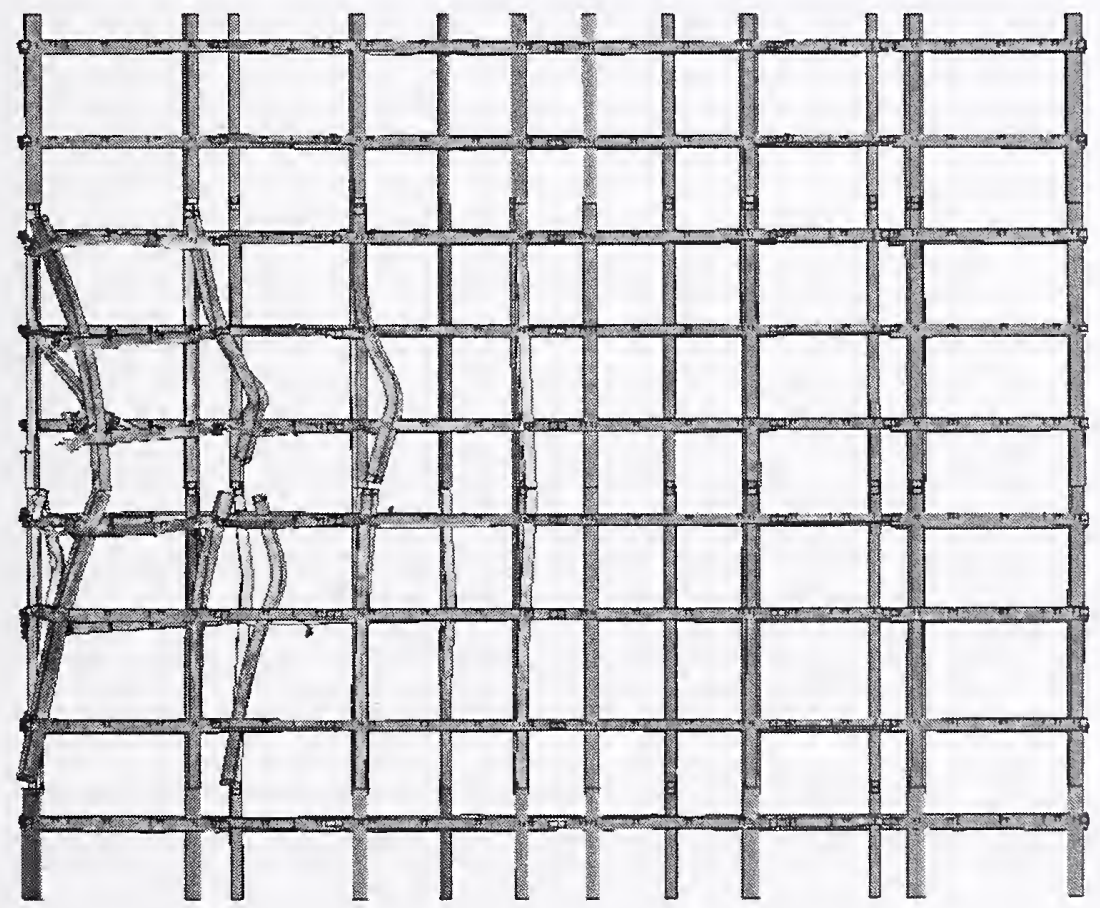

Effective Strain Rate

Fringe Levels

$2.000 \mathrm{e}+01$

$1.800 \mathrm{e}+01$

$1.600 e+01$

$1.400 \mathrm{e}+01$

$1.200 e+01$

$1.009 e+01$

$8.000 e+00$

$6.000 e+00$

$4.000 \mathrm{e}+00$

$2.000 e+00$

$0.000 \mathrm{e}+00$

Figure 9-83. Representative core frame strain rates for the more severe WTC 2 impact (impact from the left of the figure). 


\section{Floor Truss and Slab Damage for the More Severe WTC 2 Impact}

An overall view of the floor truss structure in the WTC 2 impact zone, along with the calculated more severe impact damage to the trusses, is shown in Figure 9-84. The figure shows that the trusses experienced significant damage in the impact zone, with the heaviest damage on floor 81 . A plan view of the calculated damage to the trusses on each floor is shown in Figure 9-85. The calculated impact response produced severe damage to the truss structures in the primary impact path of the fuselage. The truss structures were severely damaged from the exterior wall to the core. The truss floor system on floors 79 through 82 had sufficient damage from the impact that portions of the truss floor sections sagged downward as a result of the impact.

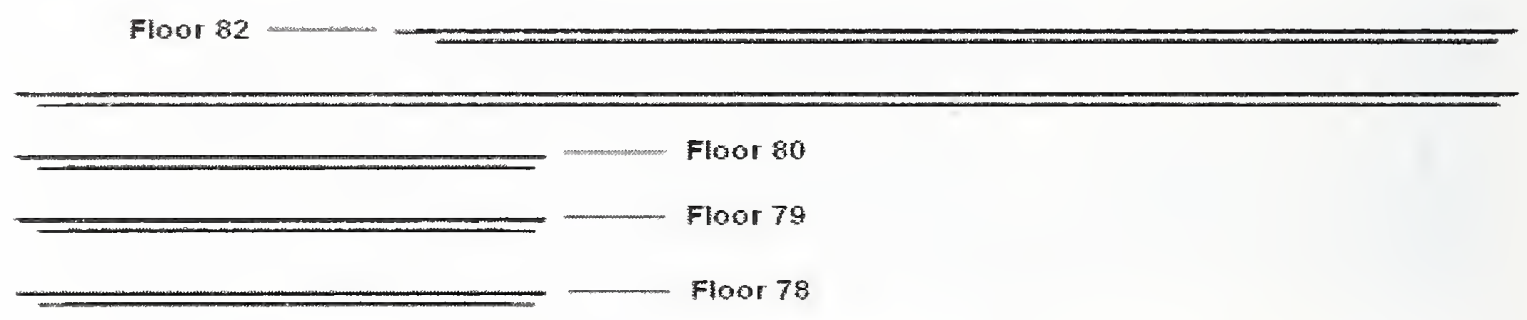

(a) Initial detailed truss structures

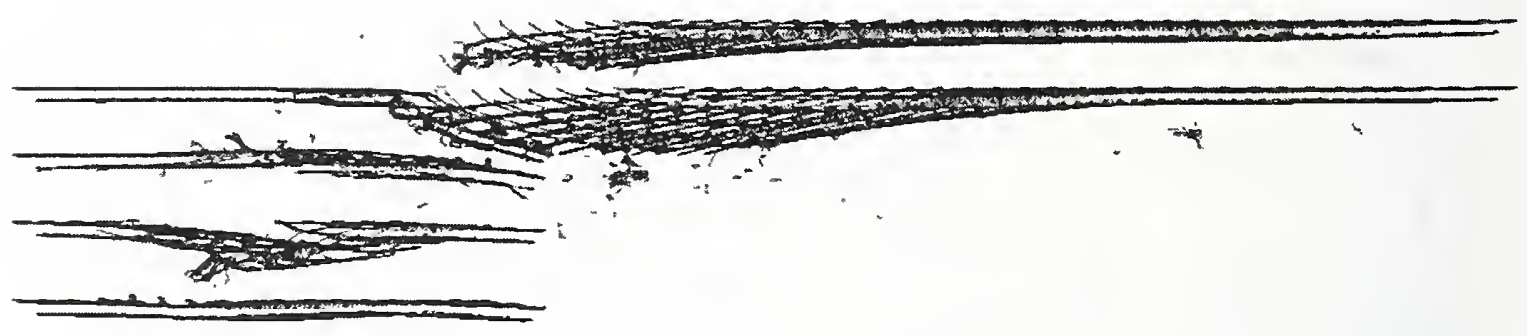

(b) Calculated damage ( $t=0.58 \mathrm{~s})$

Figure 9-84. More severe impact damage to the WTC 2 floor truss (front view).

The magnitude of truss floor damage was very similar for the base case and more severe global impact analyses. The parameters used in the more severe global impact analysis would primarily contribute to increased damage for the tower structures. However, the downward impact trajectory angle was reduced from the 6 degree angle in the base case analysis to a 5 degree angle in the more severe impact analysis. This would have the effect of directing more of the impact energy inward toward the tower core, but reducing the normal downward force on the floor structures in the impact zone. As a result, the combined effects of the analysis parameter variations produced very similar damage to the truss structure.

The calculated damage to the WTC 2 floor slab for floors 78 through 83 for the more severe impact is shown in Figure 9-86. The fringes of damage were set such that the concrete failed in the regions colored red ( 2 percent plastic strain). In these regions, it is expected that the concrete slab was severely damaged and potentially removed, exposing the supporting metal decking. At a plastic strain of 30 percent, corresponding to failure levels for the metal decking material, the elements were eroded (seen as holes ruptured in the floor slab shown). The line of damage, visible around the edge of the core, was believed to be the result of numerical precision errors and interference in the modeling methodology at the connection of the floor slab rather than impact damage. 


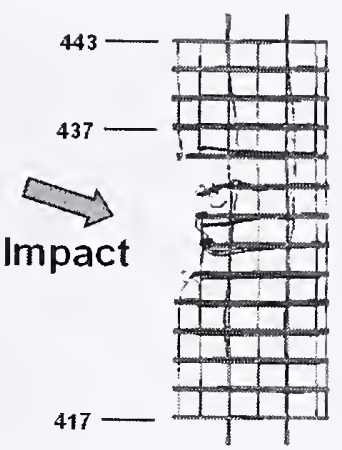

(a) Floor 79 truss damage

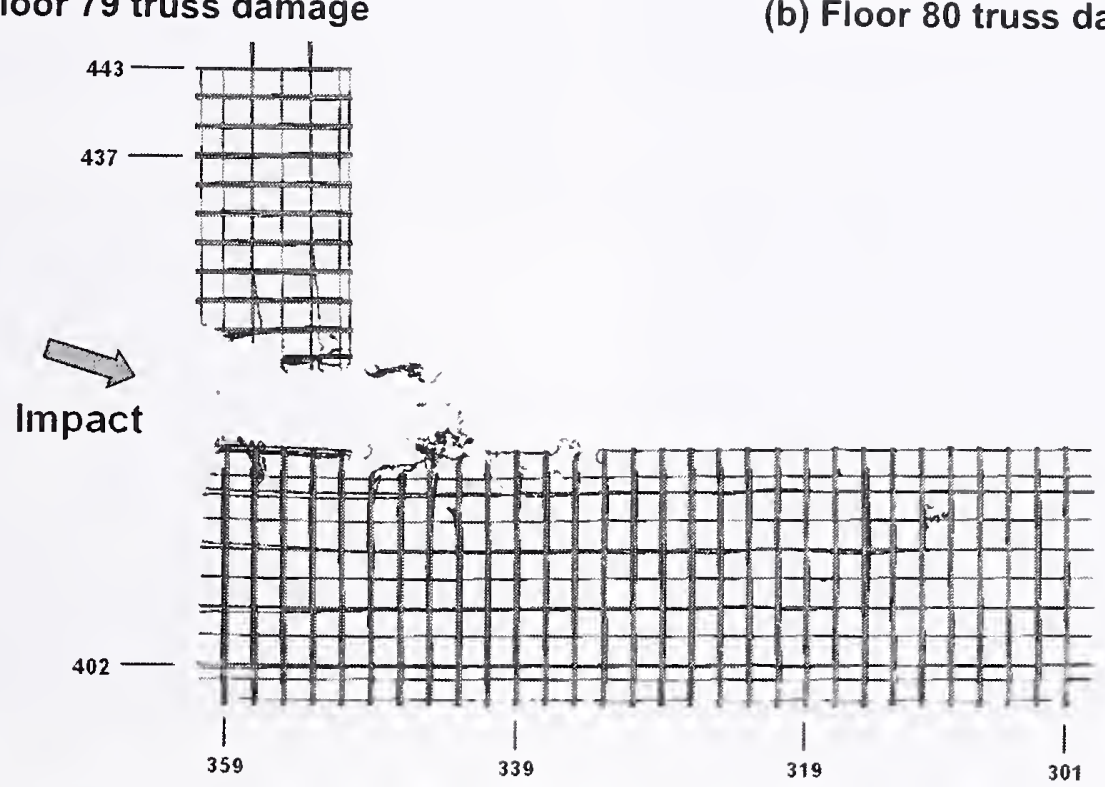

(c) Floor 81 truss damage

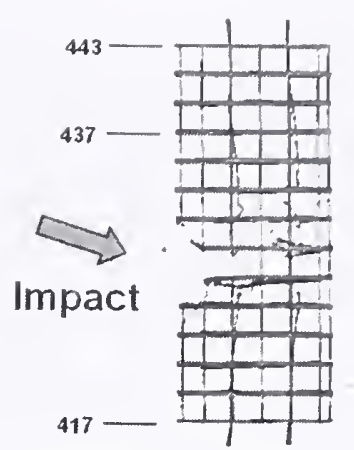

(b) Floor 80 truss damage

Impact

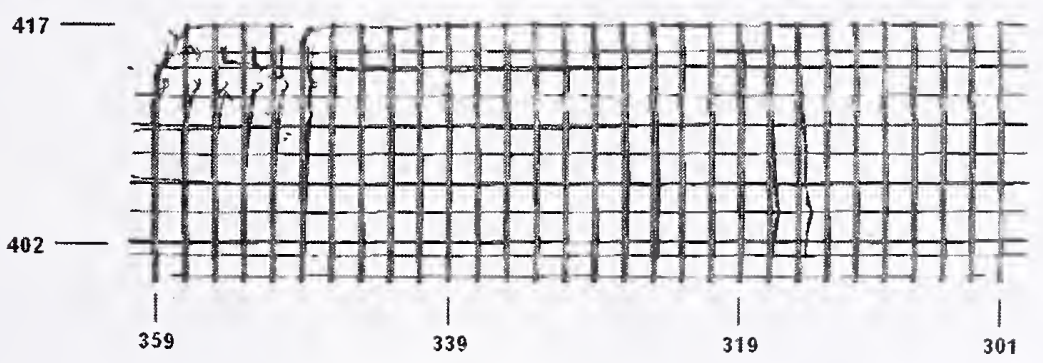

(d) Floor 82 truss damage

Figure 9-85. More severe impact damage to the WTC 2 floor truss (plan view). 


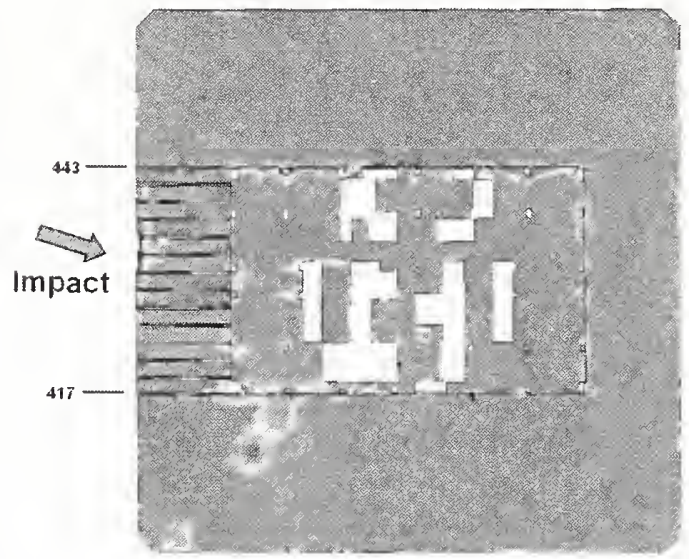

(a) Floor 78 slab damage

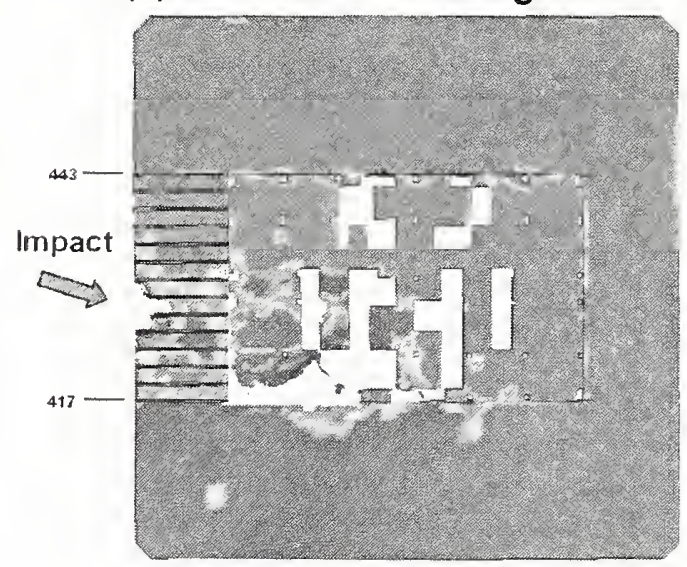

(c) Floor 80 slab damage

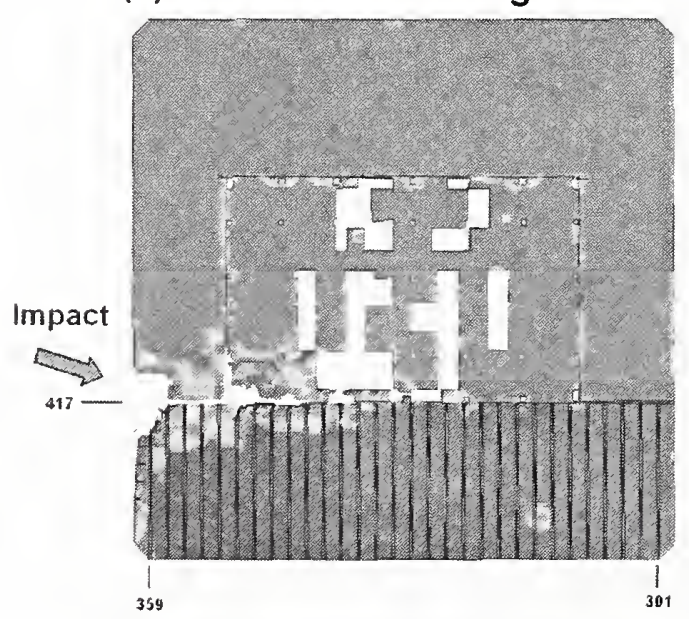

(e) Floor 82 slab damage

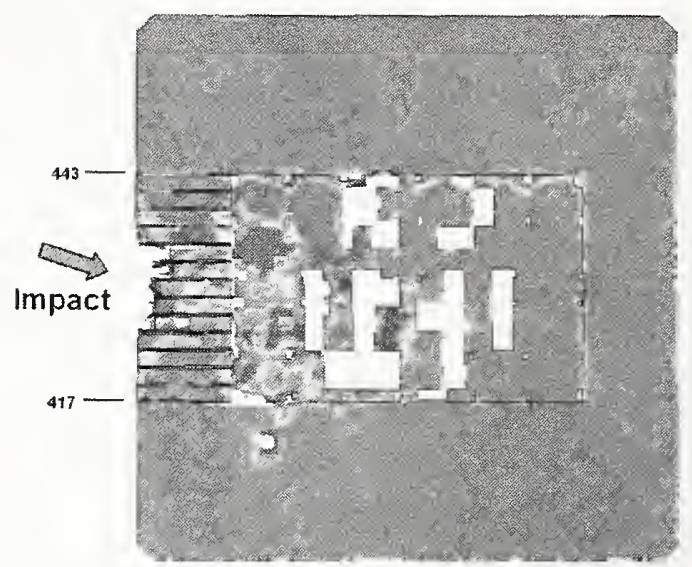

(b) Floor 79 slab damage

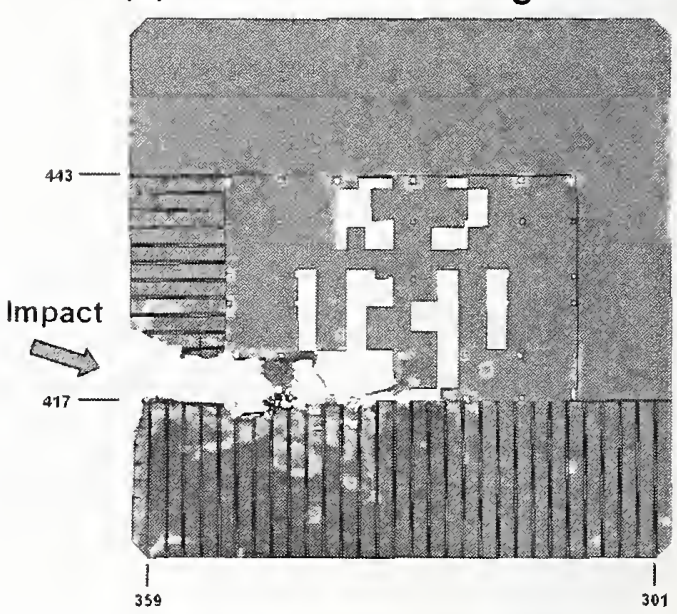

(d) Floor 81 slab damage

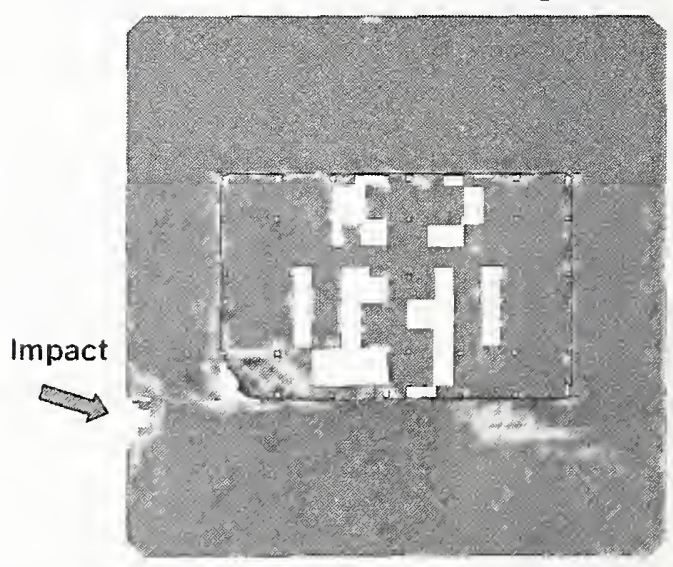

(f) Floor 83 slab damage

Figure 9-86. More severe impact damage to the WTC 2 floor slab (plan view). 
Similar to the damage levels in the floor truss struetures, the magnitude of floor slab damage was very similar for the base ease and more severe global impact analyses. The parameters used in the more severe global impact analysis would primarily contribute to an increased damage magnitude for the tower struetures. However, the downward impact trajectory angle was reduced from the 6 degree angle in the base case analysis to a 5 degree angle in the more severe impact analysis. This would have the effect of directing more impact energy inward toward the tower core, but reducing the normal downward force on the floor structures in the impact zone. As a result, the combined effects of the analysis parameter variations produced very similar damage magnitudes to the floor slab.

\section{Damage to WTC 2 Contents for the More Severe Impact}

The calculated damage to the WTC 2 contents for the more severe impact is shown in plan views in Figure 9-87 through Figure 9-92 for floors 78 through 83, respectively. A comparison to the calculated damage for the base case WTC 2 impact analysis, shown previously in Figure 9-41 through Figure 9-46, indicated that the tower contents damage zone was similar, with a slight increase in damage for the more severe impact.

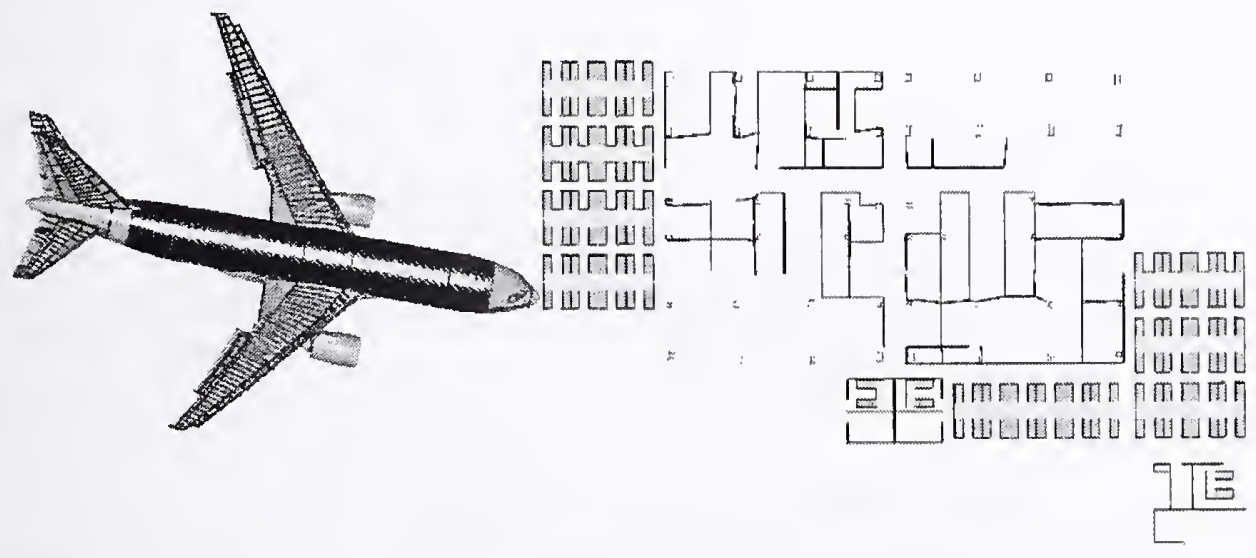

(a) Initial impact configuration

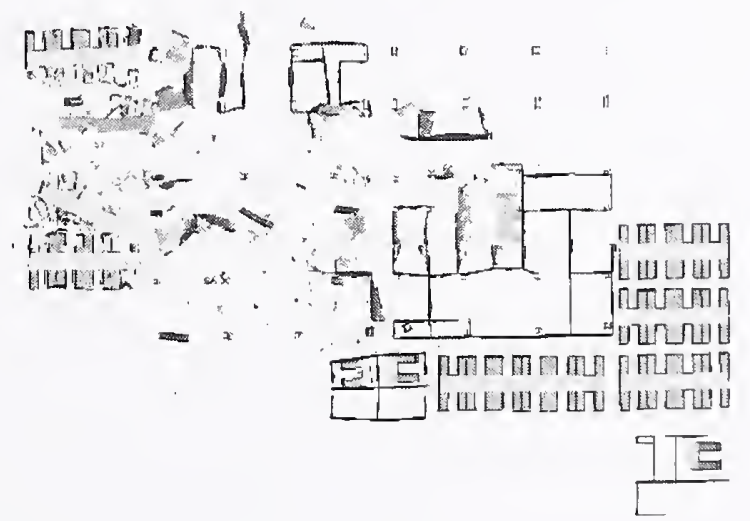

(b) Calculated response of contents

Figure 9-87. Calculated more severe WTC 2 impact response of floor 78 contents. 


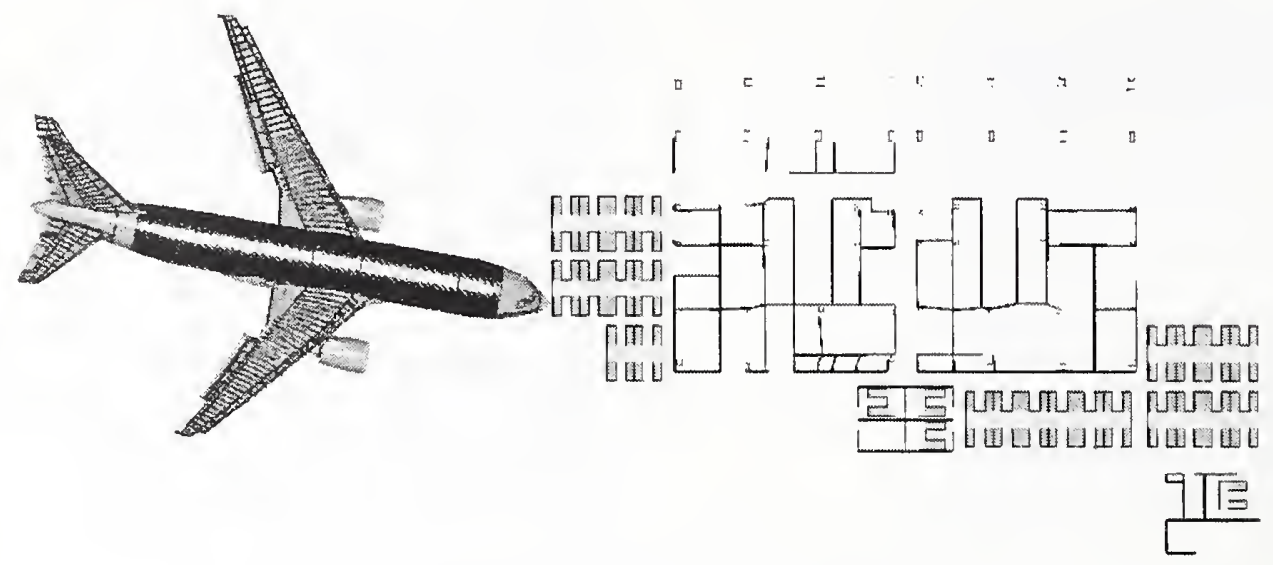

(a) Initial impact configuration

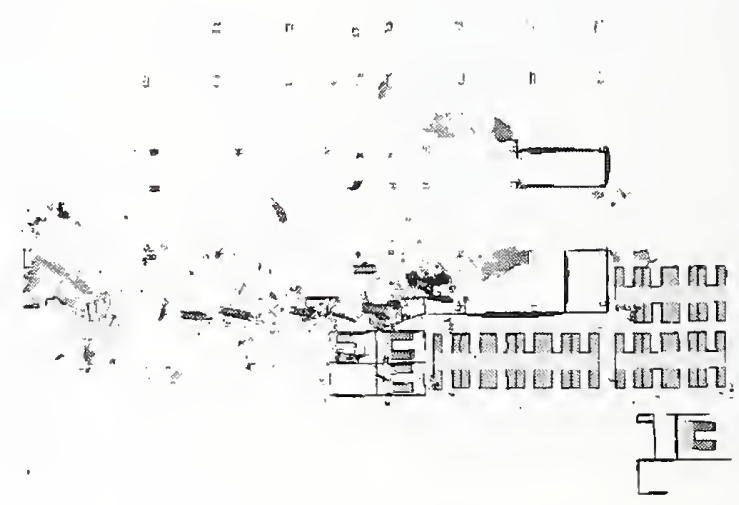

(b) Calculated response of contents

Figure 9-88. Calculated more severe WTC 2 impact response of floor 79 contents. 


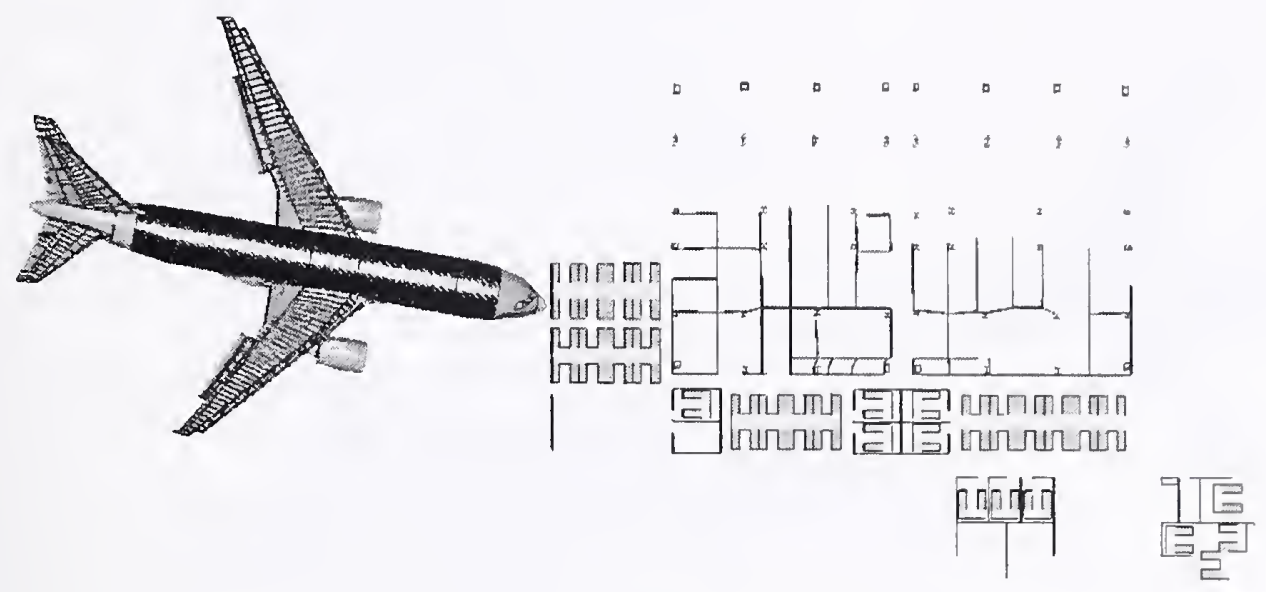

(a) Initial impact configuration

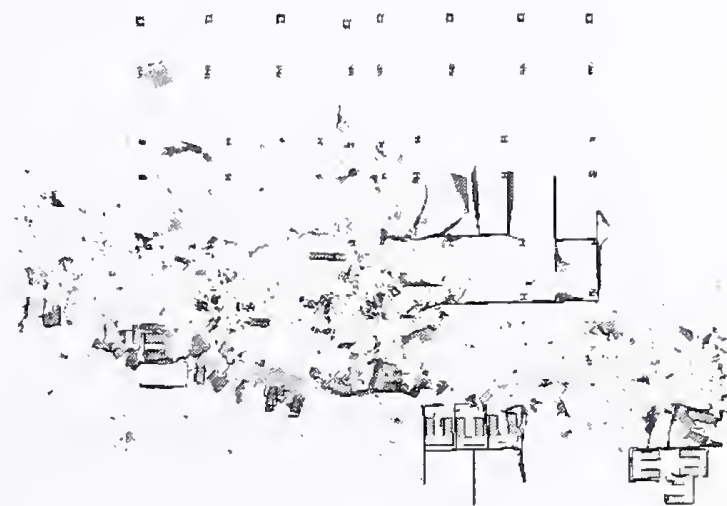

(b) Calculated response of contents

Figure 9-89. Calculated more severe WTC 2 impact response of floor 80 contents. 


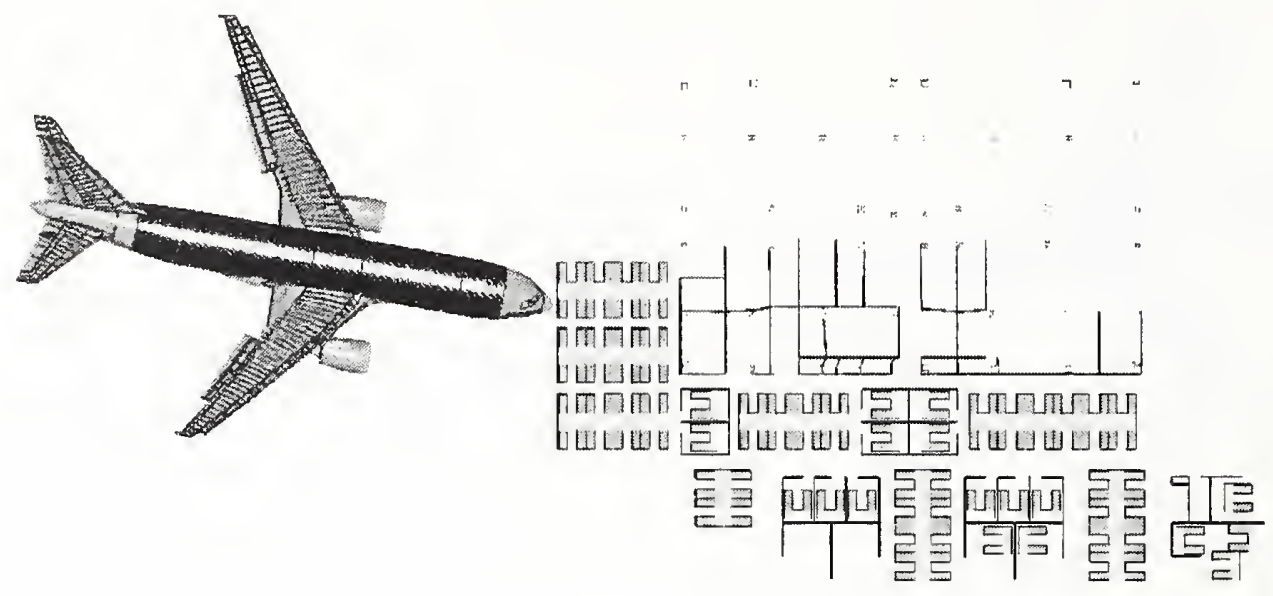

(a) Initial impact configuration

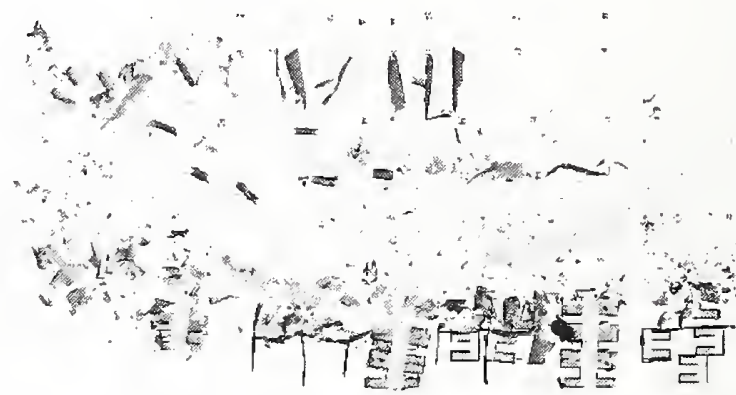

(b) Calculated response of contents

Figure 9-90. Calculated more severe WTC 2 impact response of floor 81 contents. 


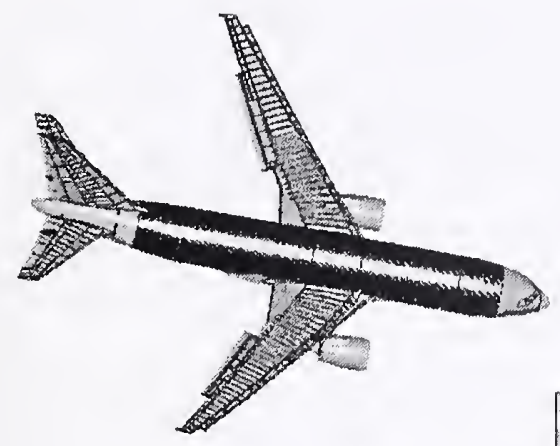

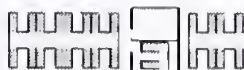

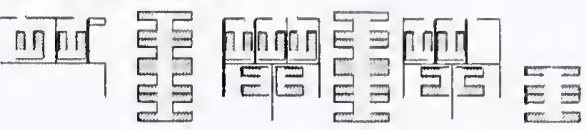

(a) Initial impact configuration

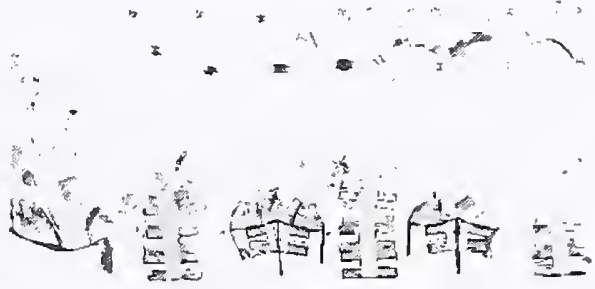

(b) Calculated response of contents

Figure 9-91. Calculated more severe WTC 2 impact response of floor 82 contents. 


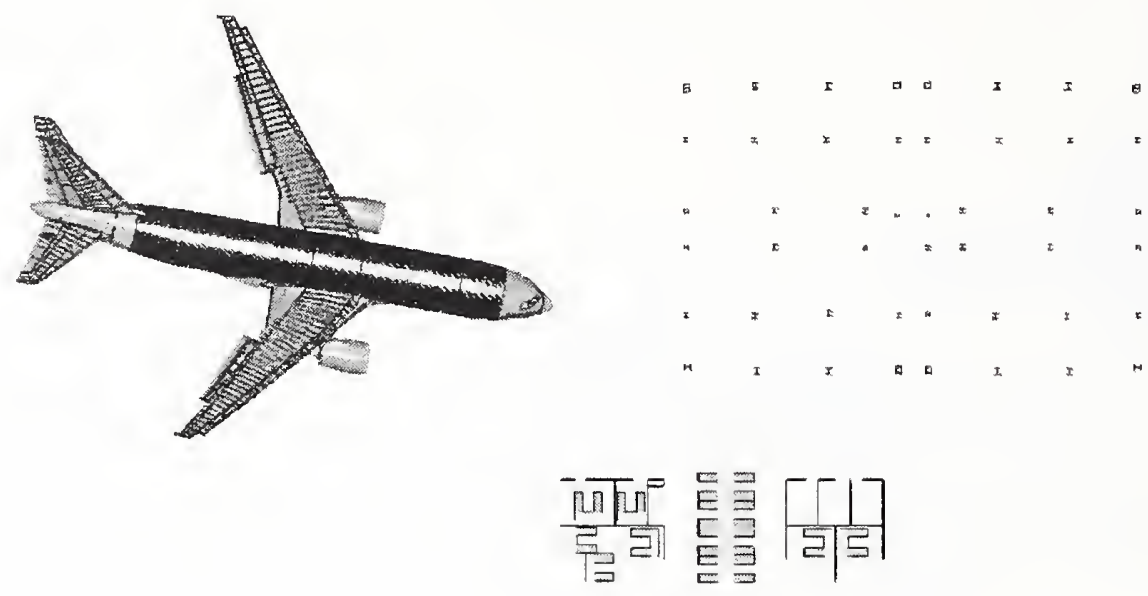

(a) Initial impact configuration

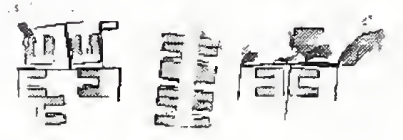

(b) Calculated response of contents

Figure 9-92. Calculated more severe WTC 2 impact response of floor 83 contents.

\subsubsection{Less Severe WTC 2 Global Impact Analyses}

\section{Exterior Wall Damage for the Less Severe WTC 2 Impact}

A comparison of the south exterior wall observed and calculated damage from the less severe WTC 2 global impact analysis is shown in Figure 9-93. The calculated impact damage to the exterior wall is shown with color fringes representing plastic strain magnitude, with undamaged sections in blue and strains at or above 5 percent shown in red. The wall region shown in Figure 9-93 includes column 402 to column 446, extending from floor 76 to floor 86 (spandrels at floors 77 through 86 ). The mode and magnitude of the calculated and observed impact damage on the exterior wall are still in good agreement in this less severe impact analysis. 


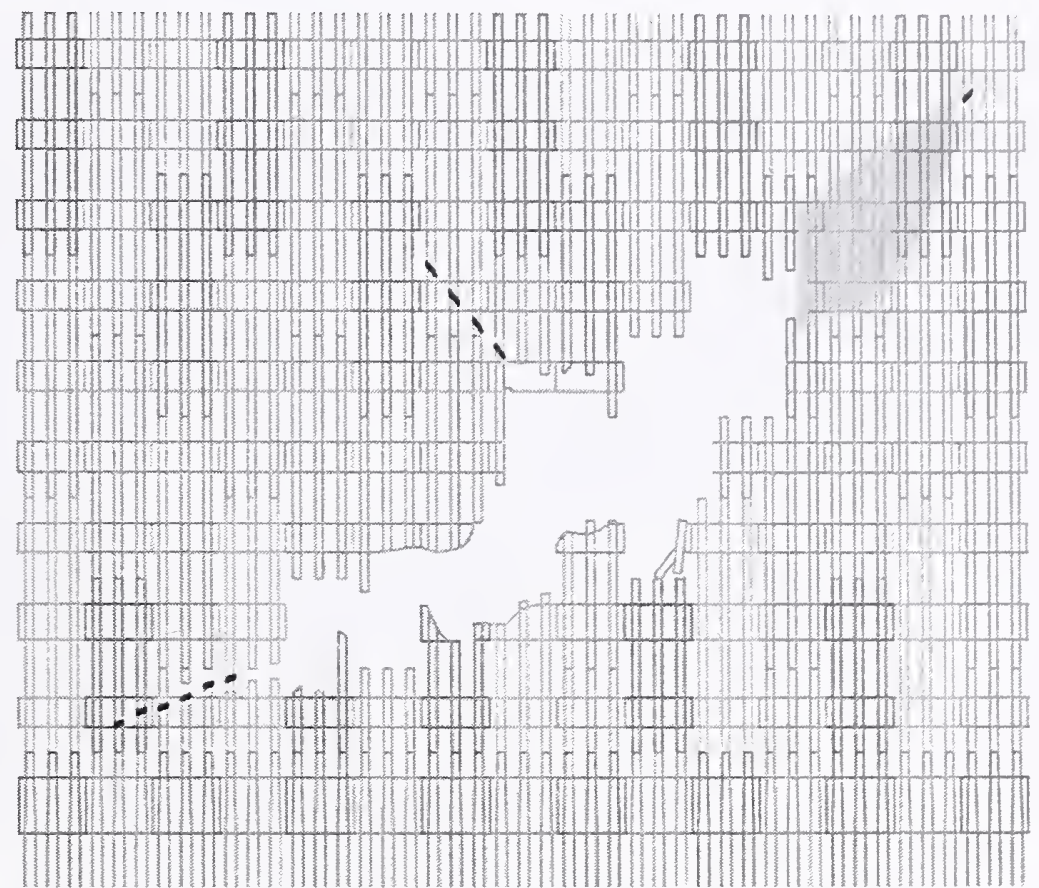

(a) Schematic of observed damage

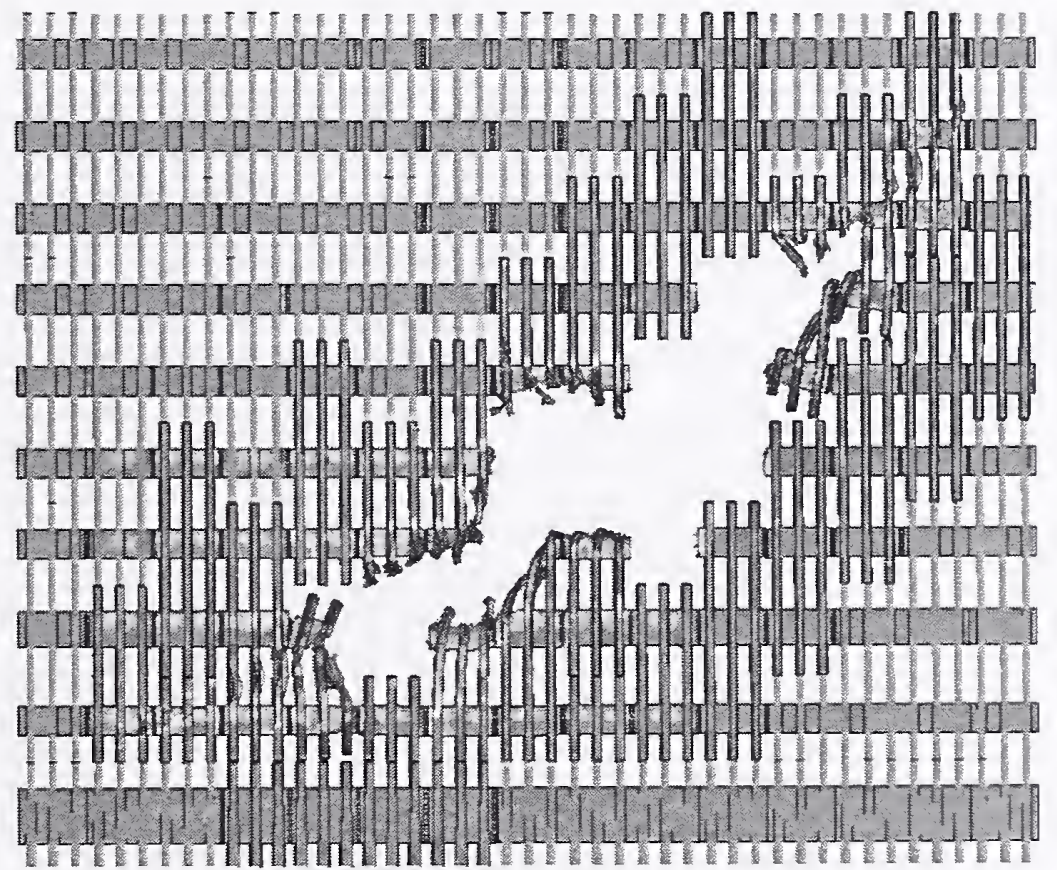

(b) Calculated damage ( $\mathrm{t}=0.66 \mathrm{~s})$

Figure 9-93. Less severe impact damage to the WTC 2 exterior wall. 


\section{Core Structural Damage for the Less Severe WTC 2 Impact}

The overall model of the WTC 2 core structure and calculated response for the less severe global impact analysis is shown in Figure 9-94. The figure shows that the core had significant damage in the region close to the impact point. The columns in line with the aircraft fuselage failed on the impact side, and several of the core beams were also severely damaged or failed in the impact zone. In some cases, failure of the column splices located on floors 77,80 , and 83 contributed significantly to the failure of the core columns.

The calculated damage to the core columns by row is shown in Figure 9-95, and the floor-by-floor damage to the core framing is shown in Figure 9-96. The core structures are shown with color fringes representing plastic strain magnitude, with undamaged sections in blue and strains at or above 5 percent shown in red. A summary of the column damage is provided in Table 9-12 and shown graphically in Figure 9-97, with the qualitative classification of the column damage levels provided previously in Figure 9-12. A total of three columns were severed, and two columns heavily damaged, compared to five severed columns and four heavily damaged columns in the base case WTC 2 impact analysis.

\section{Floor Truss and Slab Damage for the Less Severe WTC 2 Impact}

An overall front view of the floor truss structure in the WTC 2 impact zone, along with the calculated less severe impact damage to the trusses, is shown in Figure 9-98. The truss floor system on floors 79 through 82 had sufficient damage from the impact that portions of the truss floor sections sagged downward as a result of the impact. A plan view of the calculated damage to the trusses on each floor is shown in Figure 9-99. The figure shows that the trusses experienced significant damage in the impact zone, with the heaviest damage on floor 81 . The calculated impact response produced severe damage to the truss structures in the primary path of the fuselage. The truss structures were completely destroyed along the impact path on floor 81 from the exterior wall to the core. 


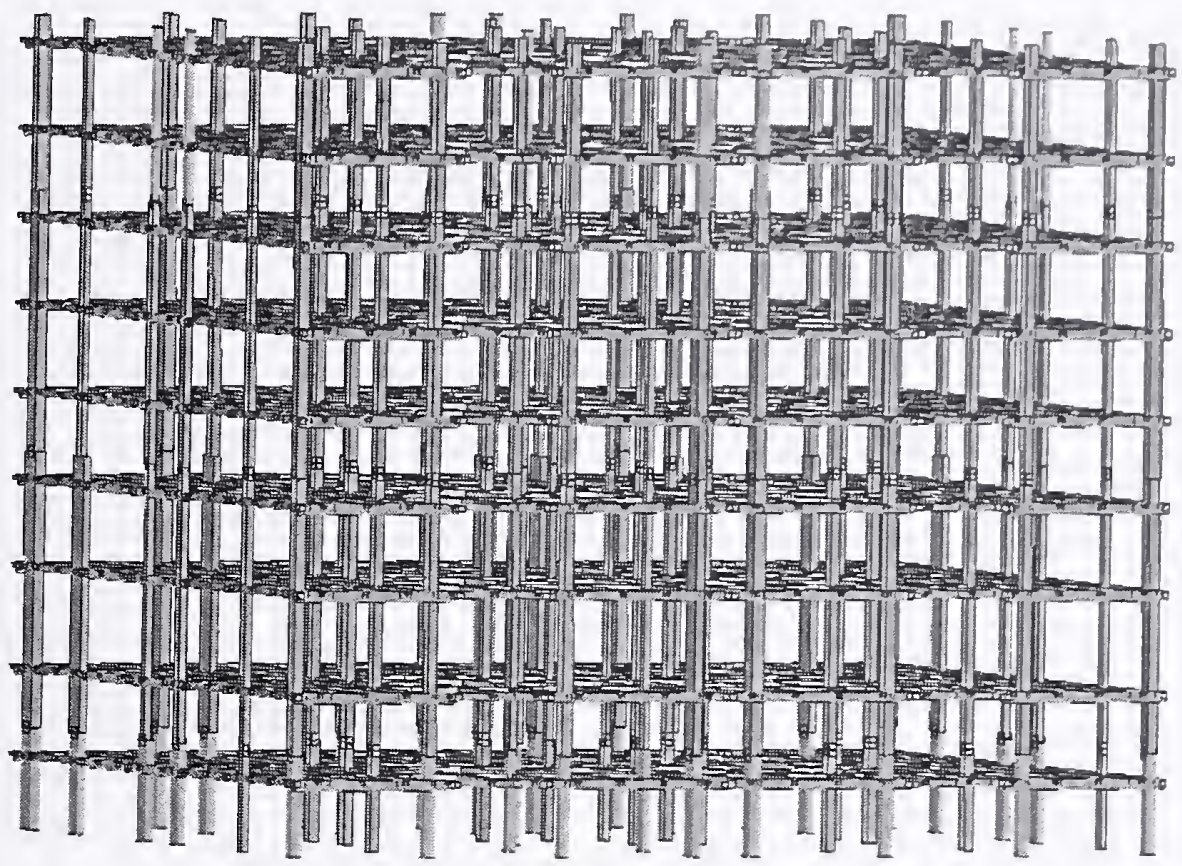

(a) Initial geometry

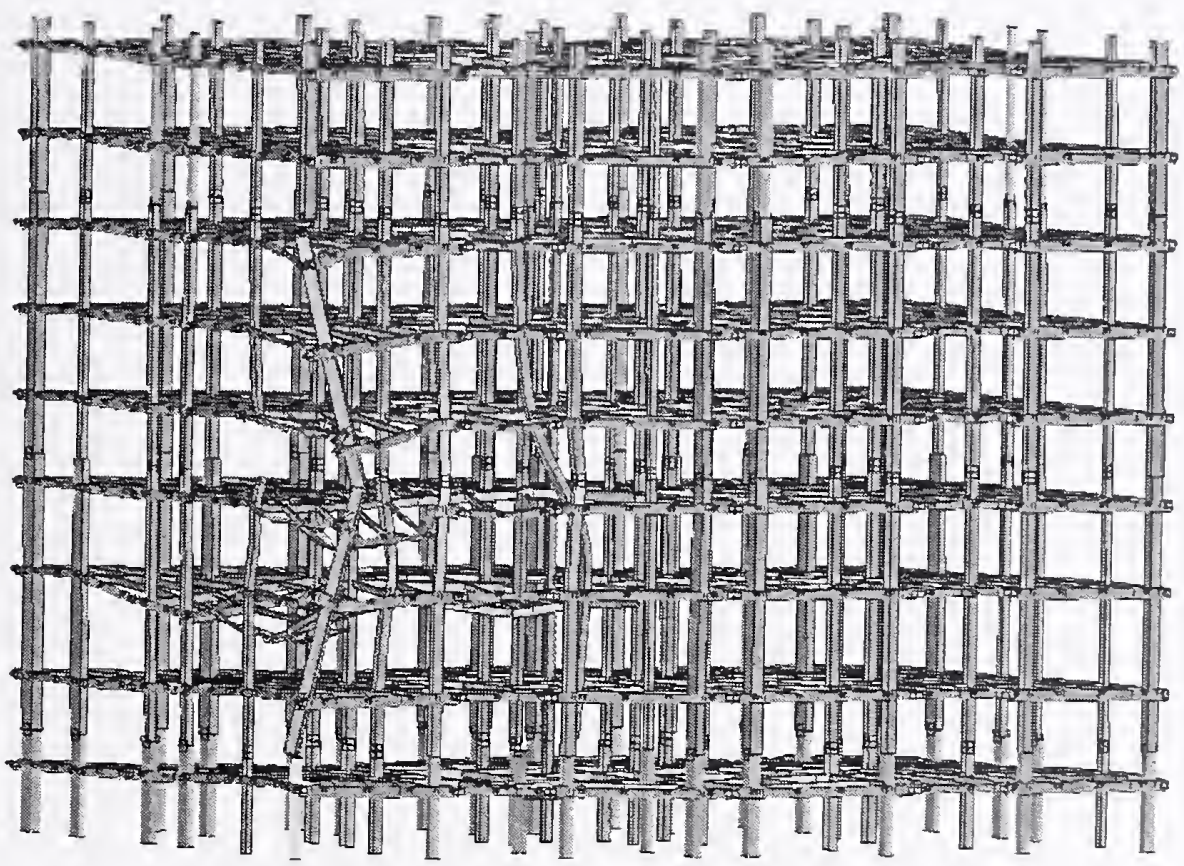

(a) Calculated impact damage

Figure 9-94. Less severe impact response of the WTC 2 core. 


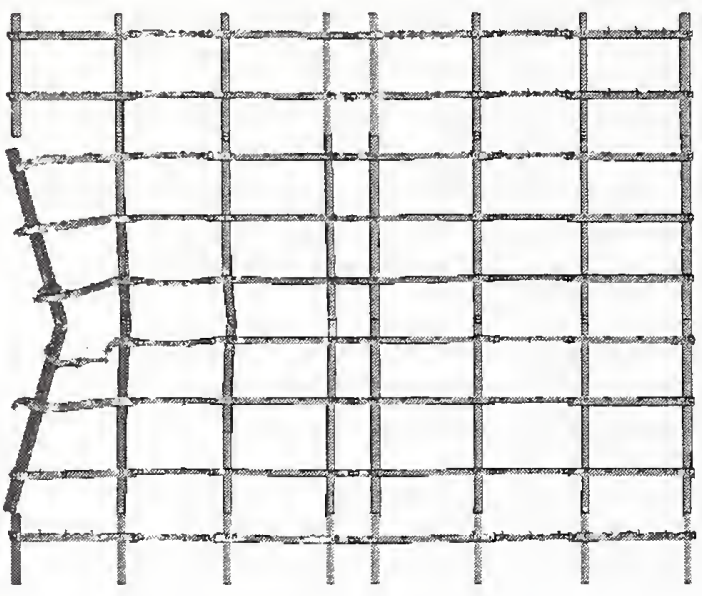

(a) Columns 1001-1008

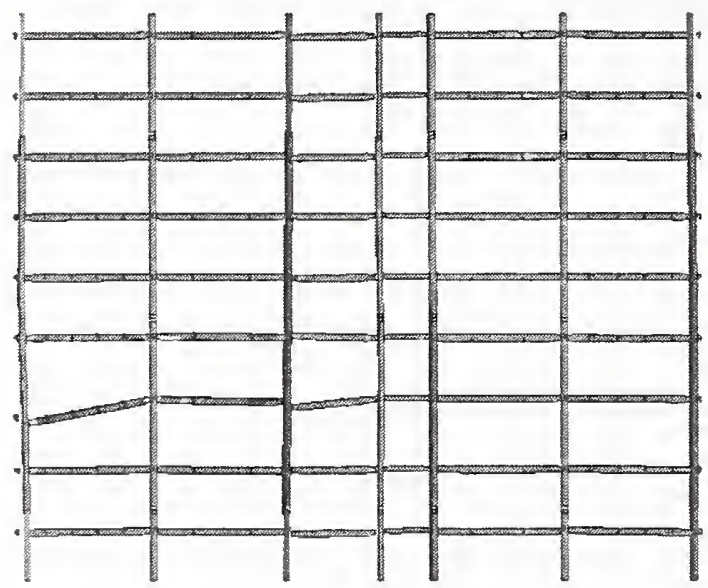

(c) Columns 801-807

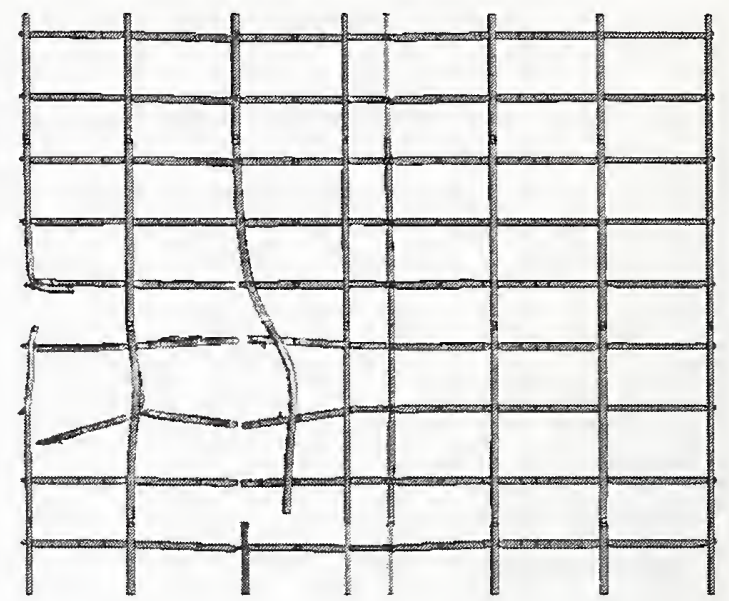

(b) Columns 901-908

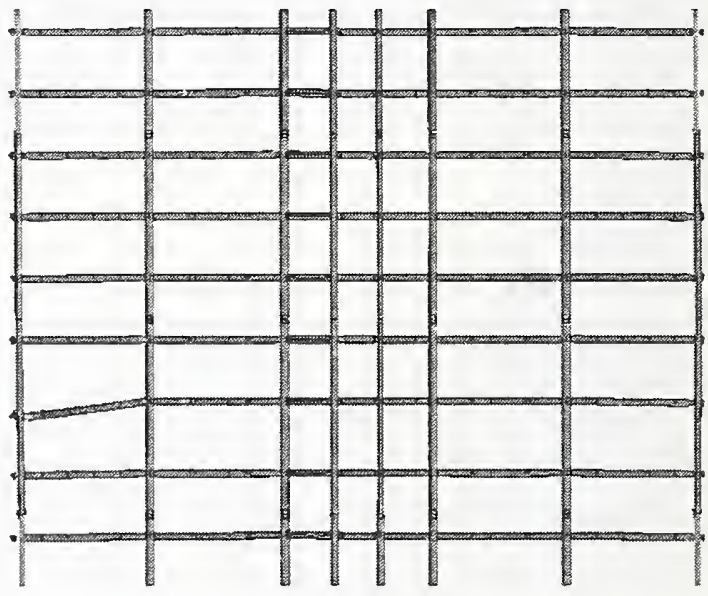

(d) Columns 701-708

Figure 9-95. Less severe impact response of the WTC 2 core columns. 


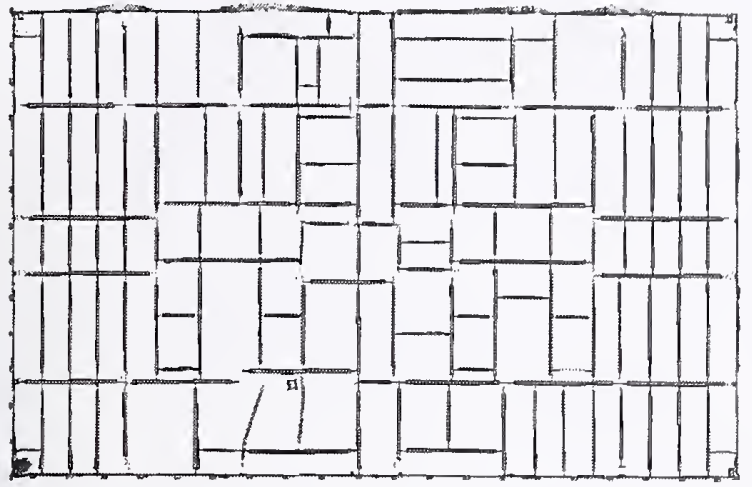

(a) Floor 78 core framing damage

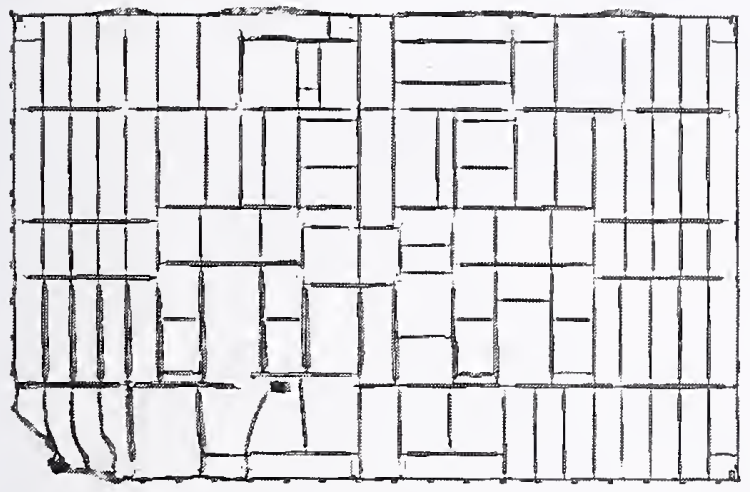

(c) Floor 80 core framing damage

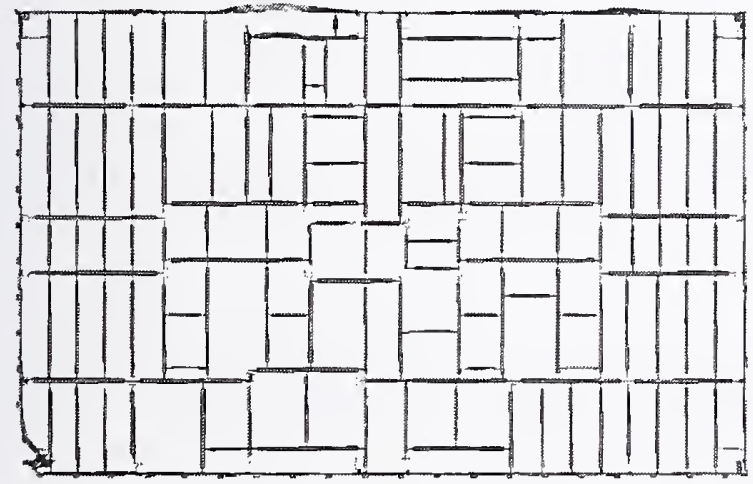

(e) Floor 82 core framing damage

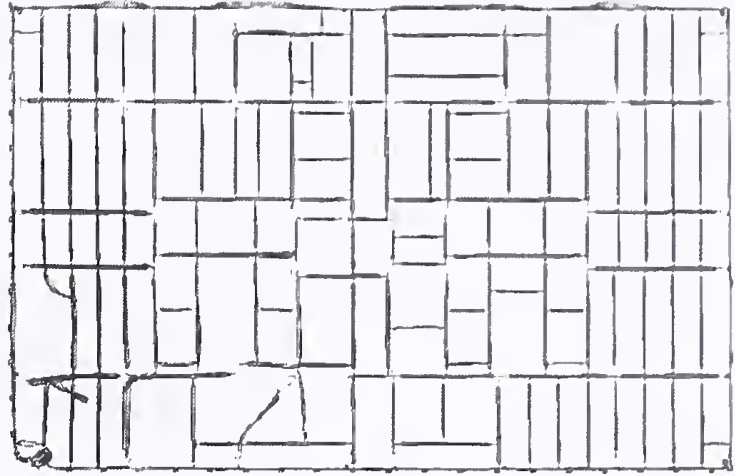

(b) Floor 79 core framing damage

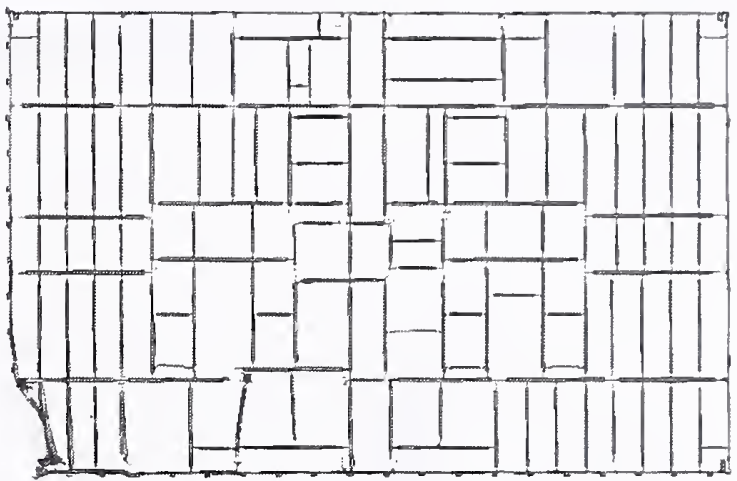

(d) Floor 81 core framing damage

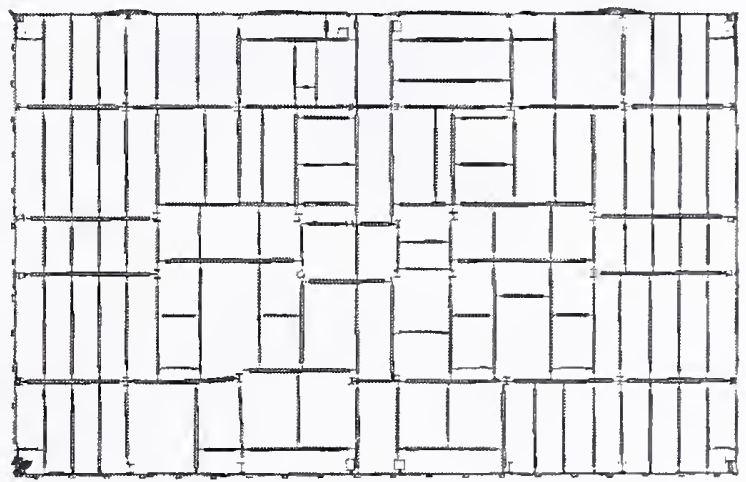

(f) Floor 83 core framing damage

Figure 9-96. Less severe impact damage to the WTC 2 core floor framing (plan view). 
Table 9-12. Core column response for the less severe WTC 2 impact.

\begin{tabular}{|l|c|c|c|}
\hline \multicolumn{1}{|c|}{ Column } & Location & Damage Level & $\begin{array}{c}\text { Lateral Deflection of } \\
\text { Column Centerline (in.) }\end{array}$ \\
\hline Column 801 & Floor 79 & Light & \\
\hline Column 901 & Floors 79-80 & Severed & \\
\hline Column 902 & Floors 78-79 & Heavy & \\
\hline Column 903 & Floors $77-81$ & Severed & \\
\hline Column 1001 & Floors $77-83$ & Severed & \\
\hline Column 1002 & Floors $80-81$ & Moderate & \\
\hline Column 1003 & Floors $79-80$ & Heavy & 16 \\
\hline Column 1004 & Floor 80 & Moderate & \\
\hline
\end{tabular}

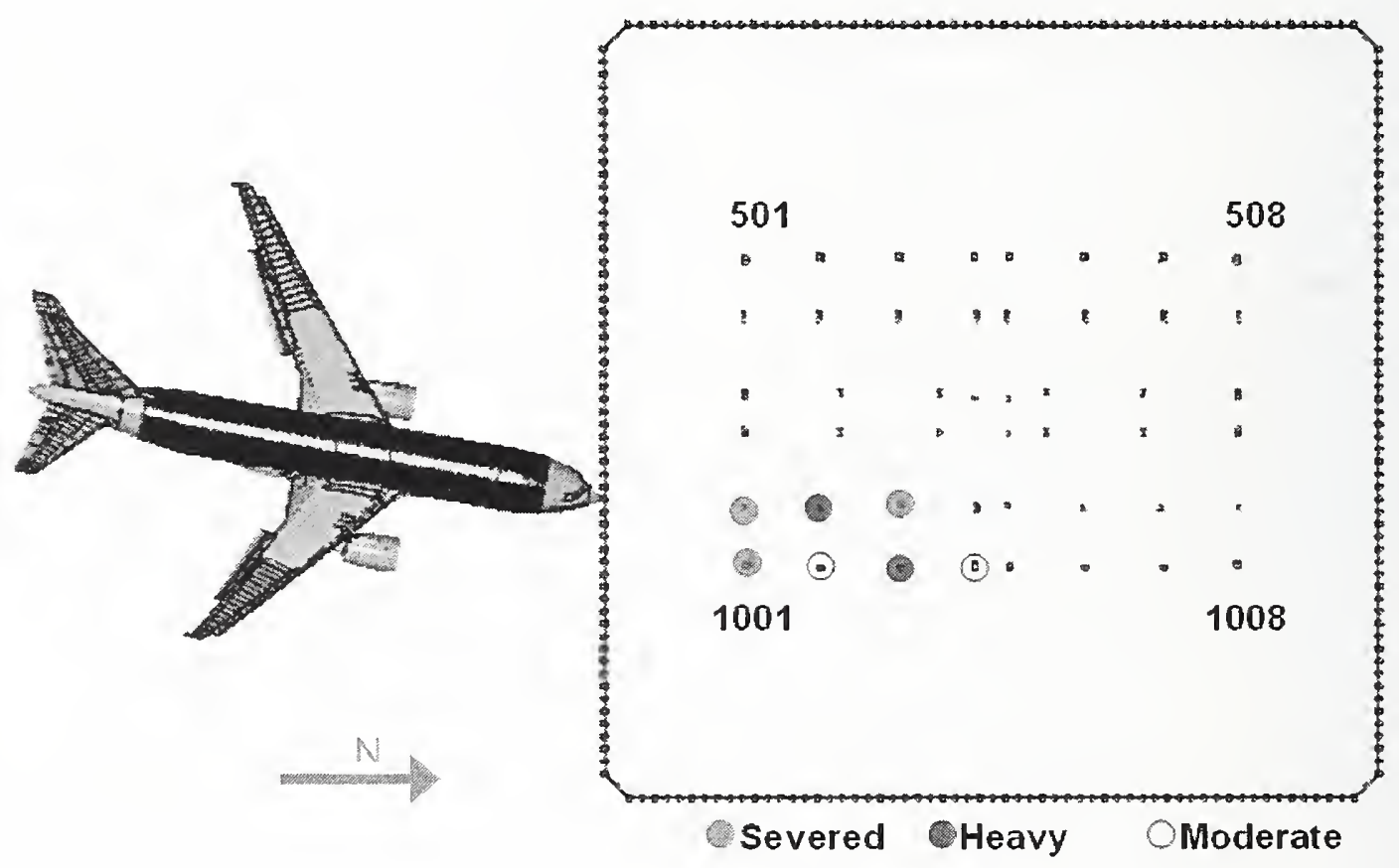

Figure 9-97. Summary of core column damage for the less severe WTC 2 impact. 


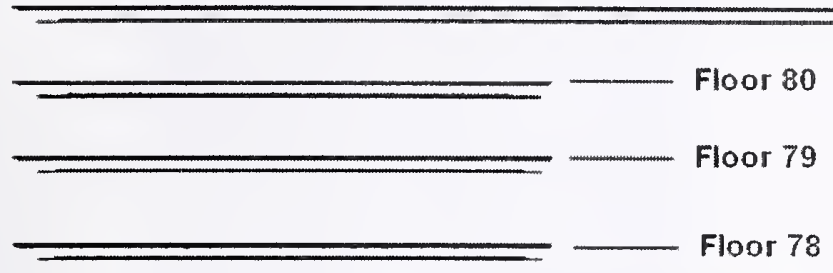

(a) Initial detailed truss structures

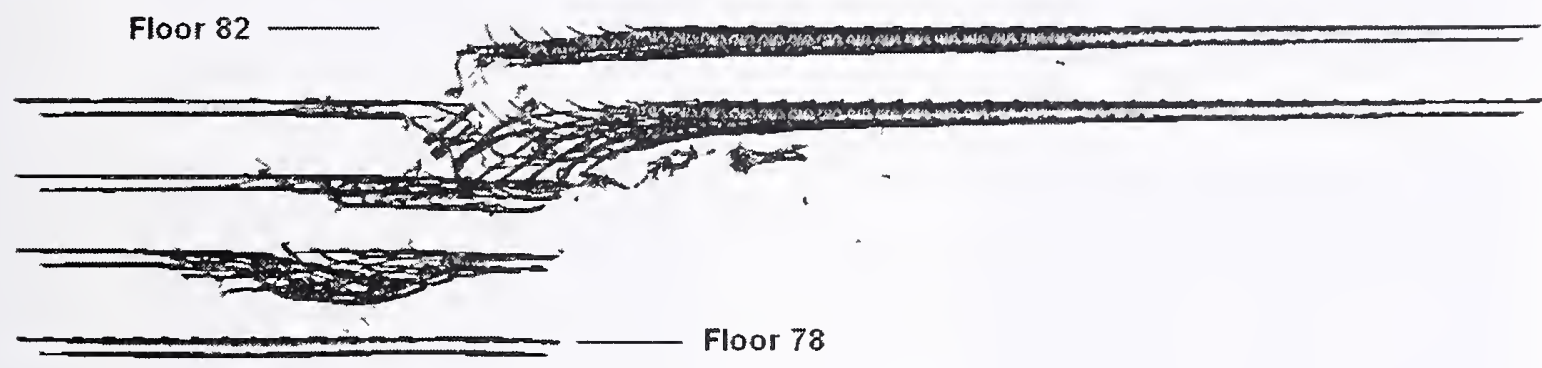

(b) Calculated damage ( $t=0.661 \mathrm{~s})$

Figure 9-98. Less severe impact damage to the WTC 2 floor truss (front view).

The magnitude of truss floor damage was very similar for the base case and less severe global impact analyses. The parameters used in the less severe global impact analysis would primarily contribute to a reduced damage magnitude for the tower structures. However, the downward impact trajectory angle was increased from the 6 degree angle in the base case analysis to an 8 degree angle in the less severe impact analysis. This would have the effect of directing more of the impact energy downward, increasing the normal force on the floor structures in the impact zone. As a result, the combined effects of the analysis parameter variations produced very similar damage to the truss structure.

The calculated damage to the WTC 2 floor slab for floors 78 through 83 for the less severe impact is shown in Figure 9-100. Similar to the damage levels in the floor truss structures, the magnitude of floor slab damage was very similar for the base case and less severe global impact analyses. The increase in the impact trajectory angle from 6 to 8 degrees offset the effects of the other analysis parameters for producing damage to the floor slab. 


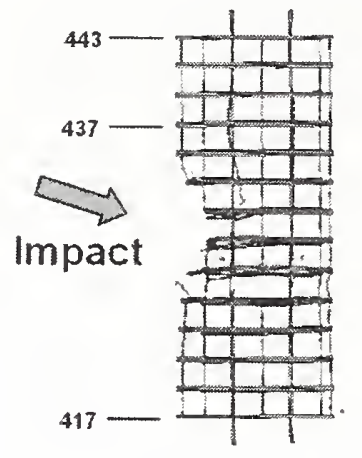

(a) Floor 79 truss damage

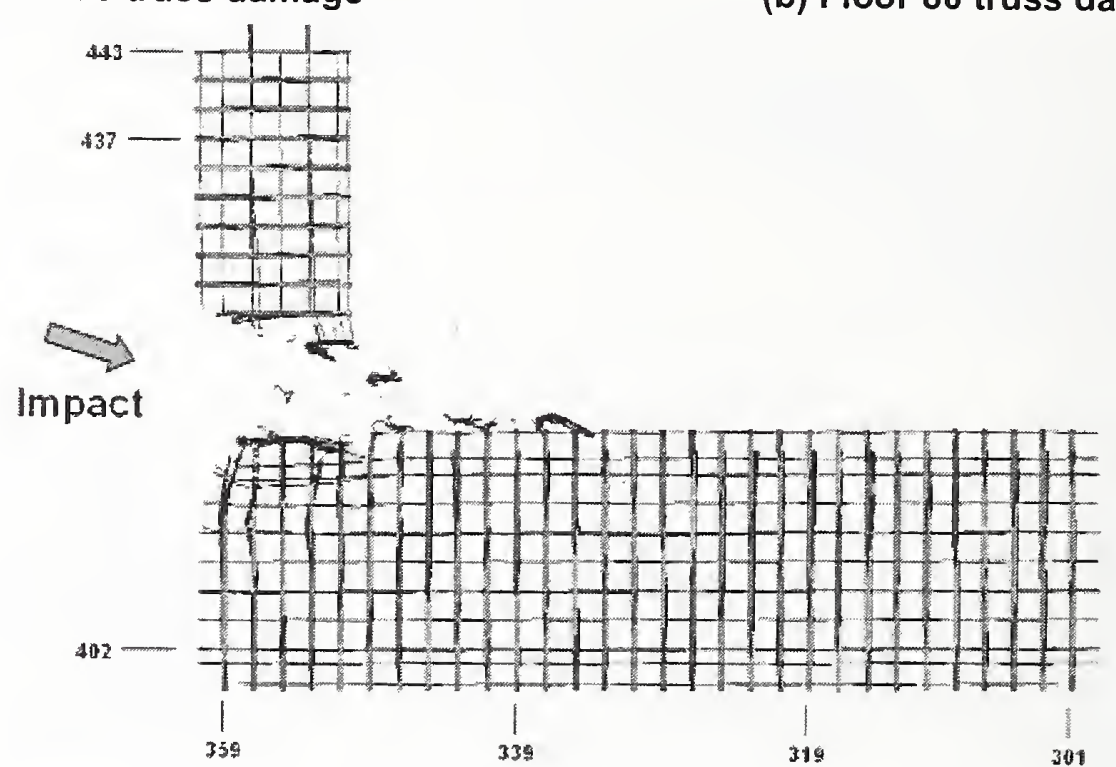

Impact

(c) Floor 81 truss damage

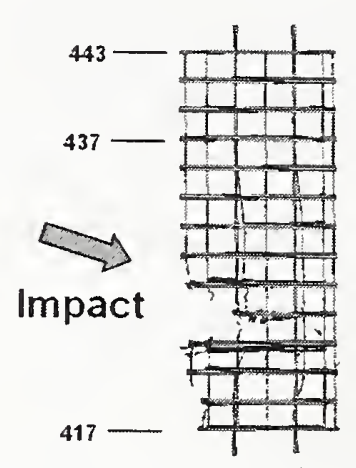

(b) Floor 80 truss damage

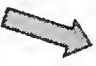

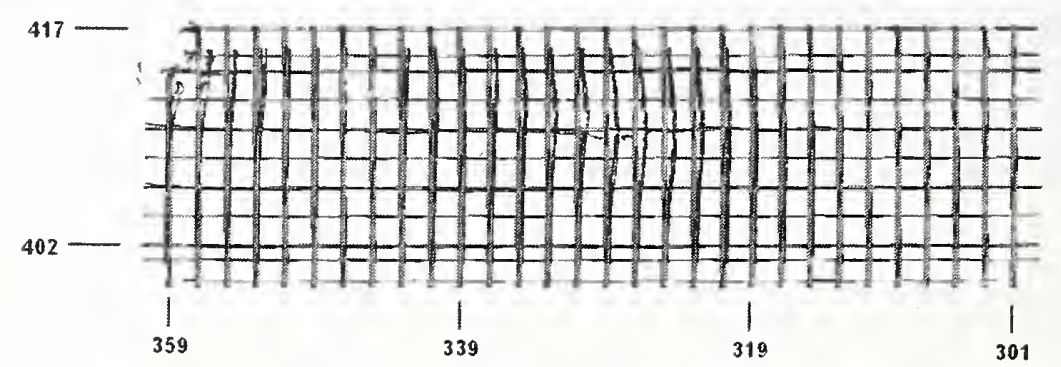

(d) Floor 82 truss damage

Figure 9-99. Less severe impact damage to the WTC 2 floor truss (plan view). 


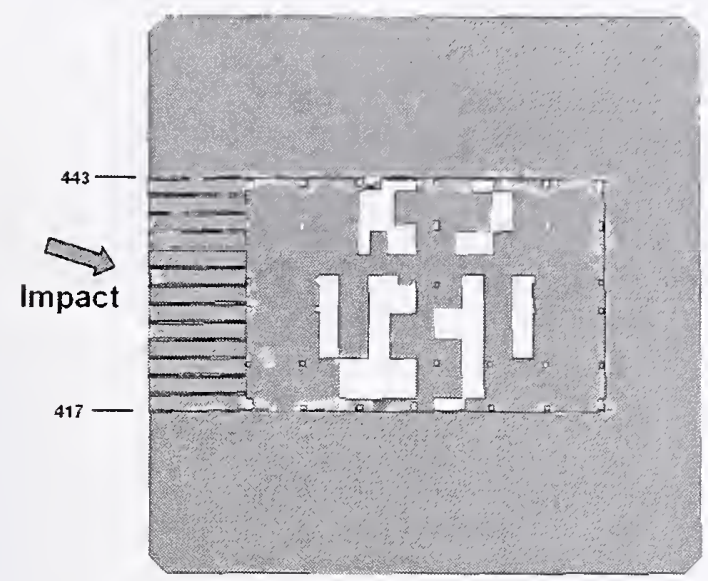

(a) Floor 78 slab damage

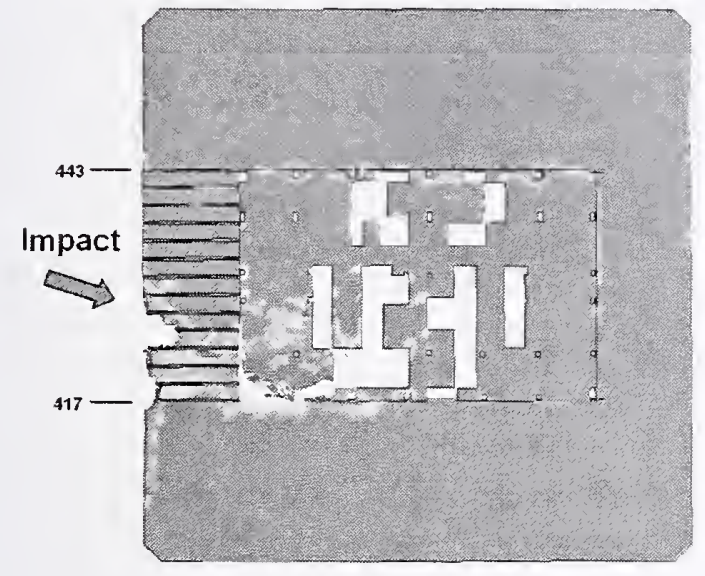

(c) Floor 80 slab damage

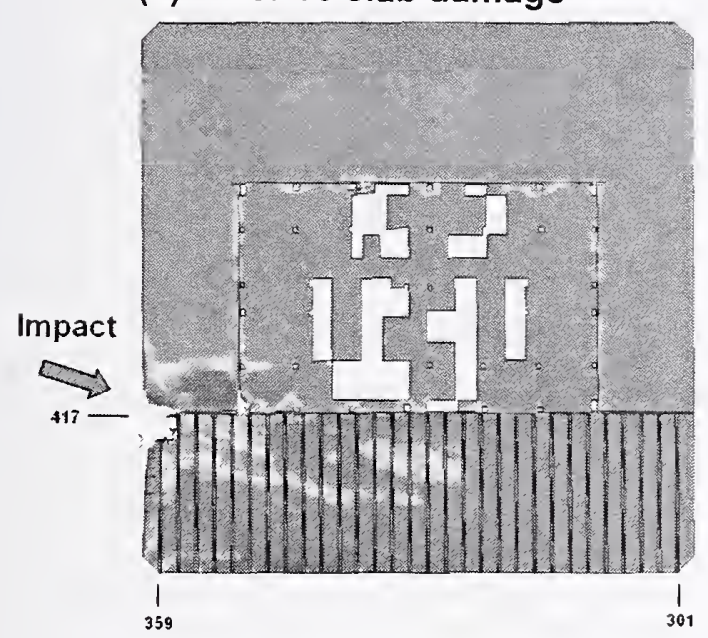

(e) Floor 82 slab damage

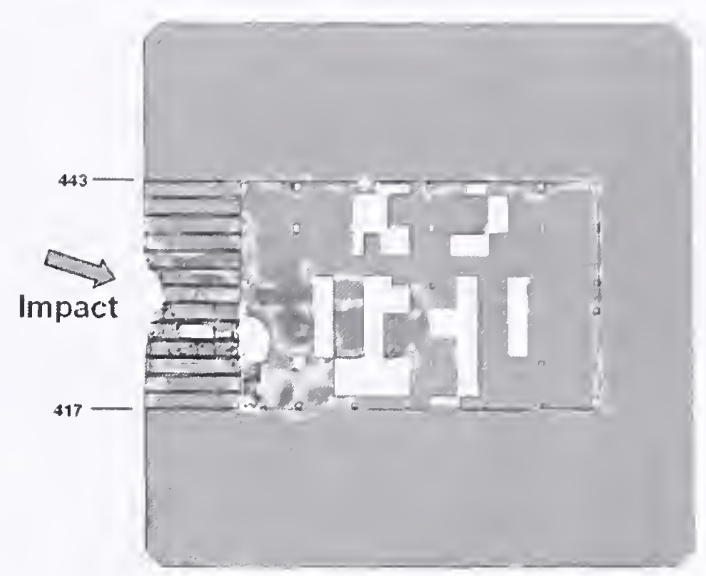

(b) Floor 79 slab damage

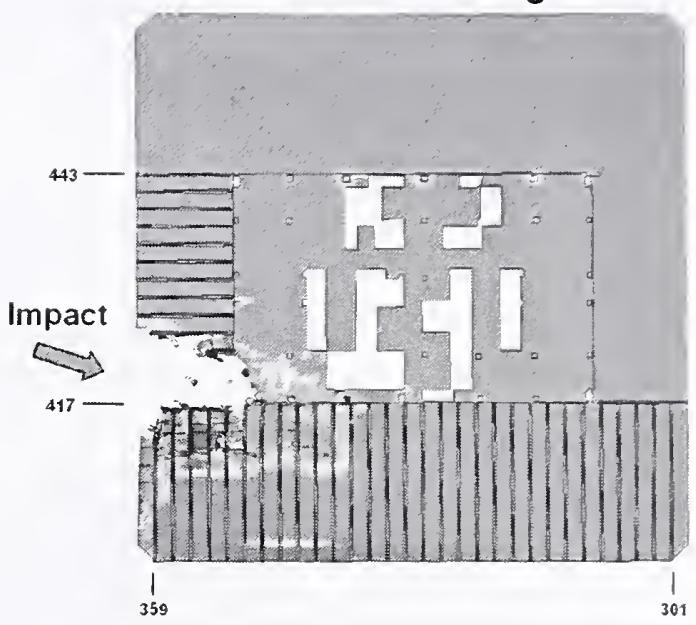

(d) Floor 81 slab damage

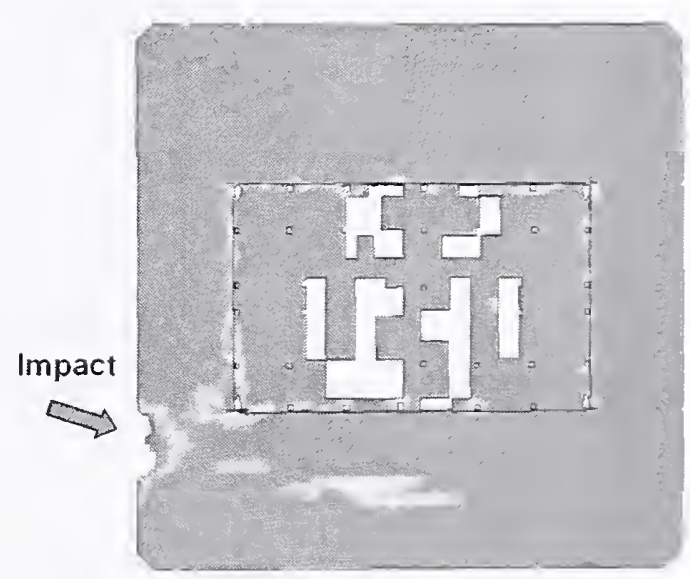

(f) Floor 83 slab damage

Figure 9-100. Less severe impact damage to the WTC 2 floor slab (plan view). 


\section{Damage to WTC 2 Contents for the Less Severe Impact}

The calculated damage to the WTC 2 contents for the less severe impact is shown in plan views in Figure 9-101 through Figure 9-106 for floors 78 through 83, respectively. A comparison to the calculated damage for the base case WTC 2 impact analysis, shown previously in Figure 9-41 through Figure 9-46, indicated that the content damage zone was very similar, with a slight reduction in damage for the less severe impact.

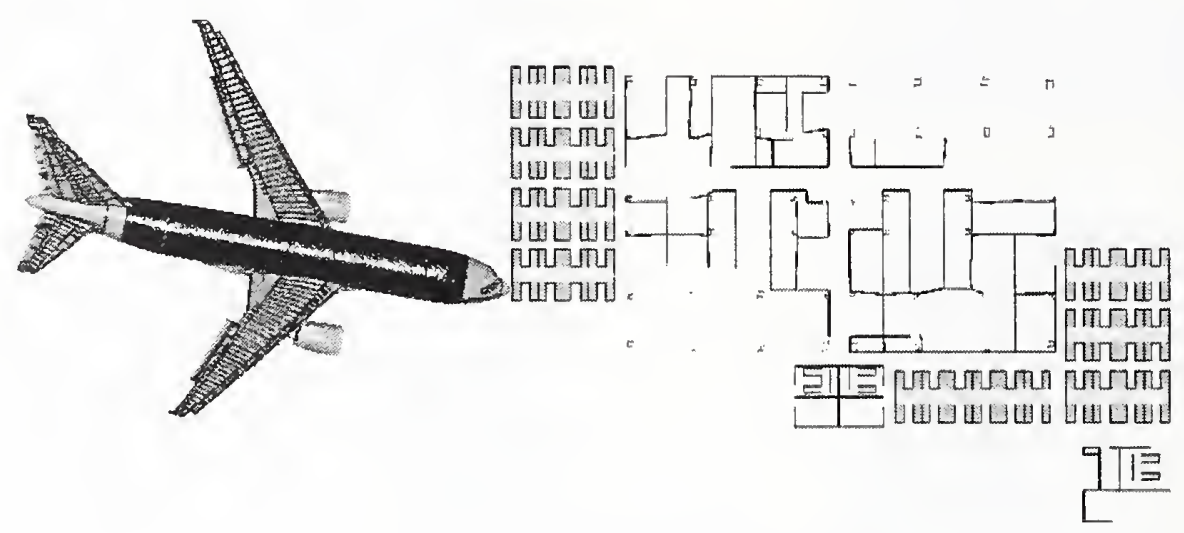

(a) Initial impact configuration

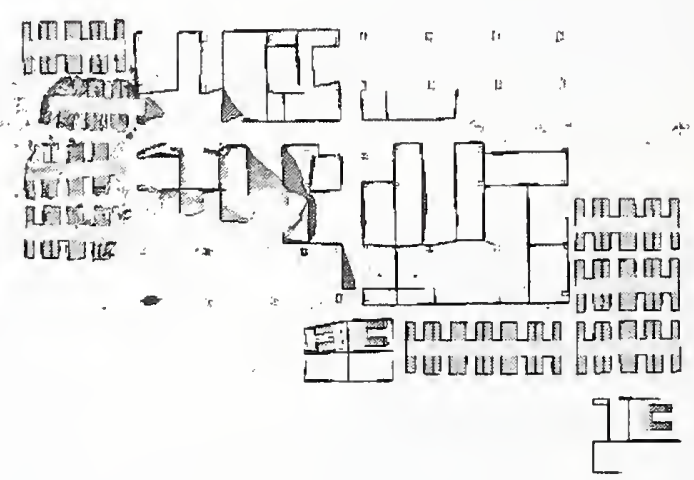

(b) Calculated response of contents

Figure 9-101. Calculated less severe WTC 2 impact response of floor 78 contents. 


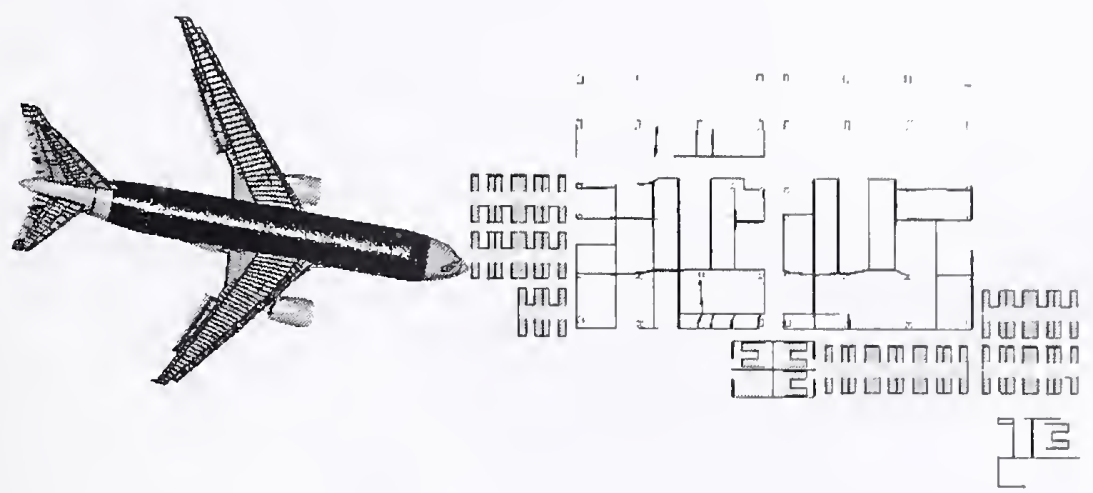

(a) Initial impact configuration

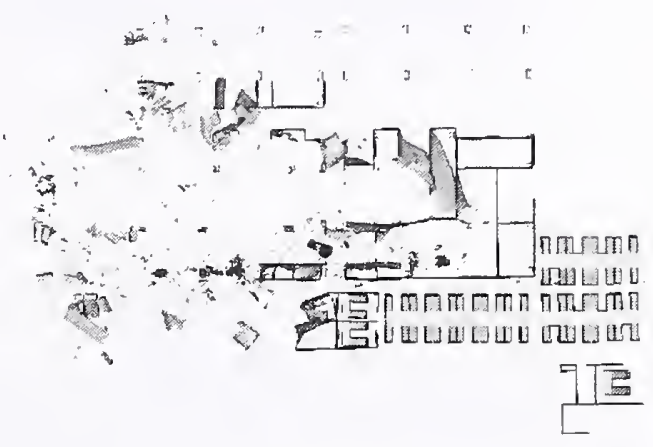

(b) Calculated response of contents

Figure 9-102. Calculated less severe WTC 2 impact response of floor 79 contents. 


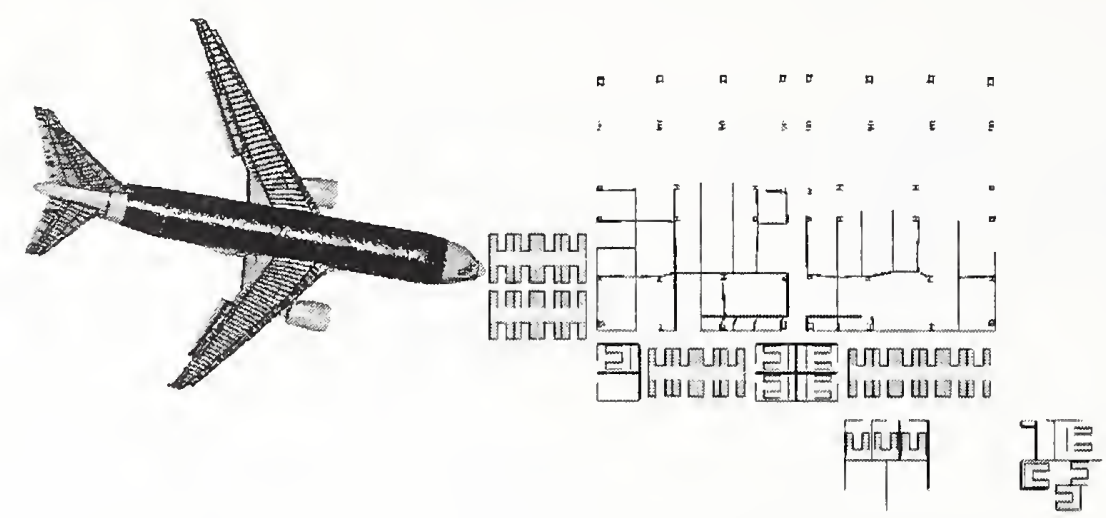

(a) Initial impact configuration

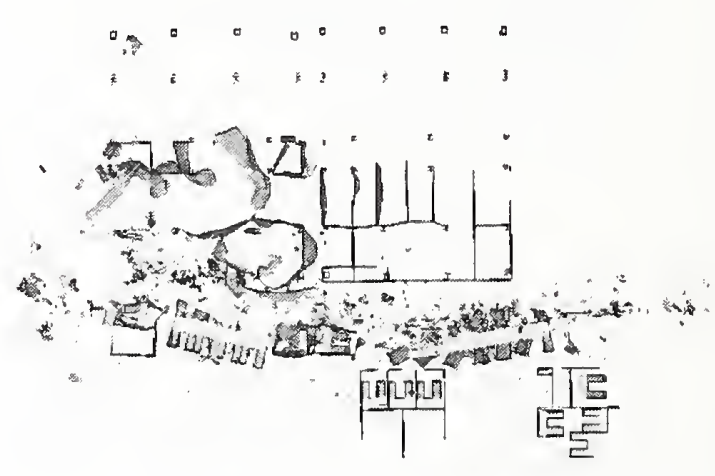

(b) Calculated response of contents

Figure 9-103. Calculated less severe WTC 2 impact response of floor 80 contents. 


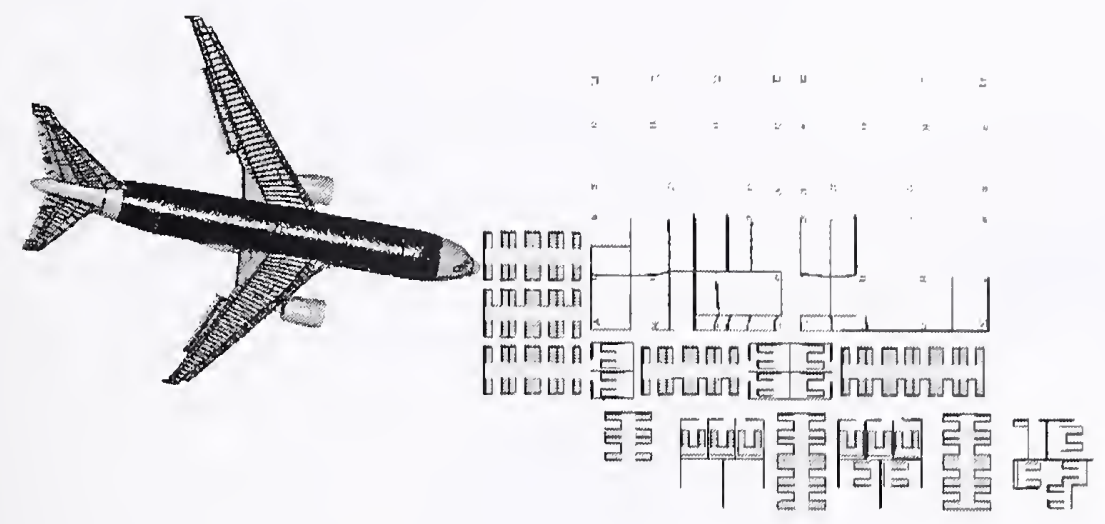

(a) Initial impact configuration

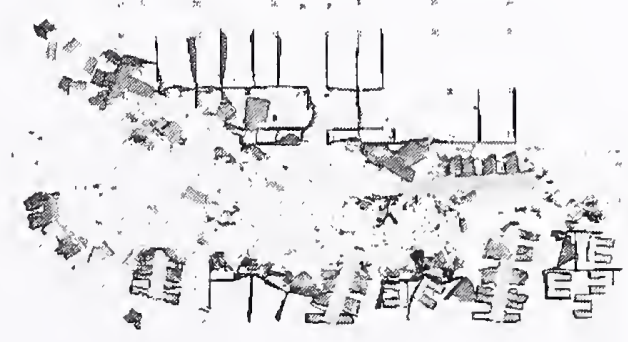

(b) Calculated response of contents

Figure 9-104. Calculated less severe WTC 2 impact response of floor 81 contents. 


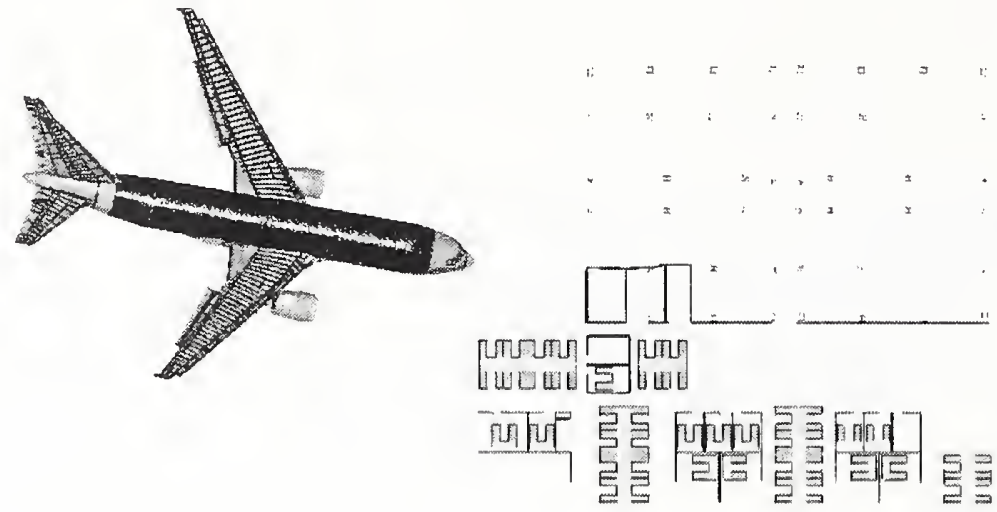

(a) Initial impact configuration

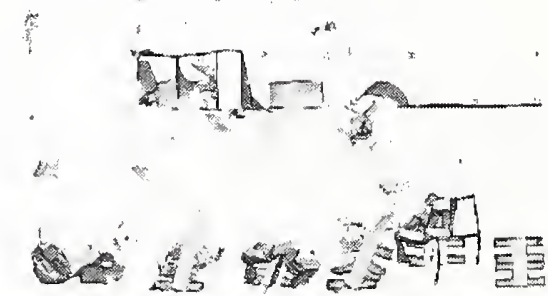

(b) Calculated response of contents

Figure 9-105. Calculated less severe WTC 2 impact response of floor 82 contents. 


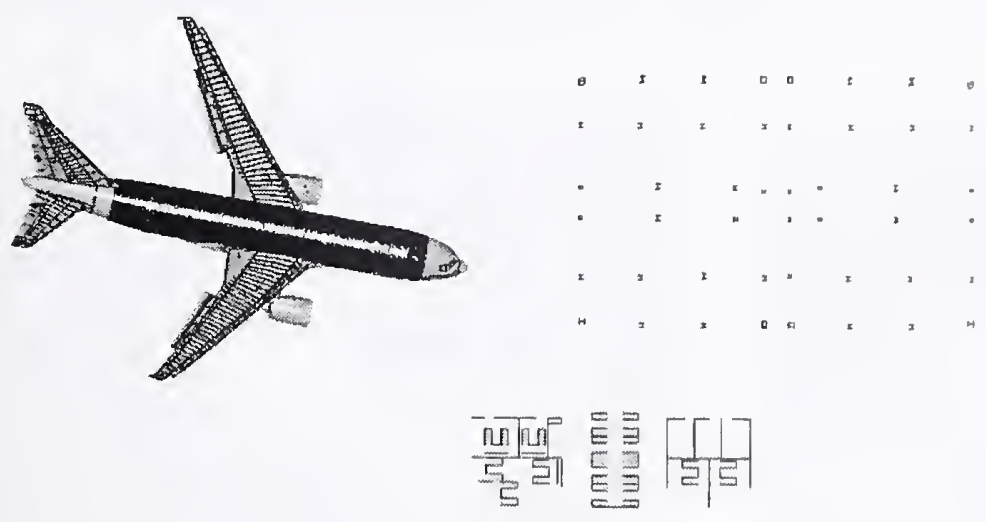

(a) Initial impact configuration

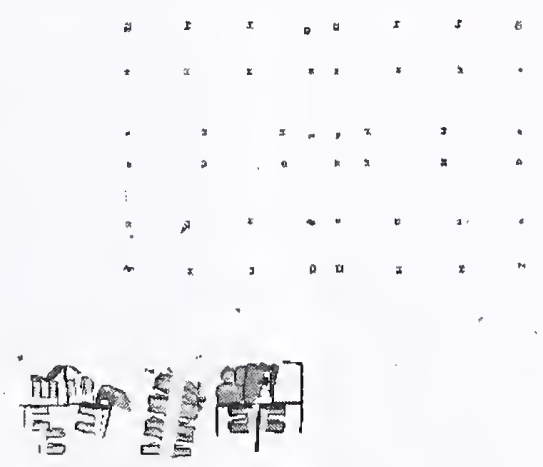

(b) Calculated response of contents

Figure 9-106. Calculated less severe WTC 2 impact response of floor 83 contents.

\section{$9.8 \quad$ COMPARISON OF DIFFERENT SEVERITY WTC 1 IMPACT ANALYSES}

\subsubsection{Exterior Wall Damage for WTC 1}

The calculated damage to the north exterior wall of WTC 1 for the three different severity impacts is shown in Figure 9-107, along with a schematic of the observed damage. The overall agreement with the observed damage was good for all three analyses, with the base case global impact analysis providing the best match to the observed damage. The calculated damage magnitude was similar in each of the global analyses with small differences, as shown in the figure.

The differences in apparent damage were largely due to panels that may have severed columns in one case and were removed at the connections in another. Visually this looks substantial as portions of panels that were damaged but still attached to the wall in the more severe impact, shown in the Figure 9-107(b), were completely removed in the less severe impact, shown in Figure 9-107(c). In general, the trend was for a larger opening produced by the less severe impact and a smaller opening in the more severe impact. The increase in the opening with reduced severity impacts can be explained by the increased tower panel 
material toughness, resulting in a transition from column severing to connection bolt failure and panel removal.

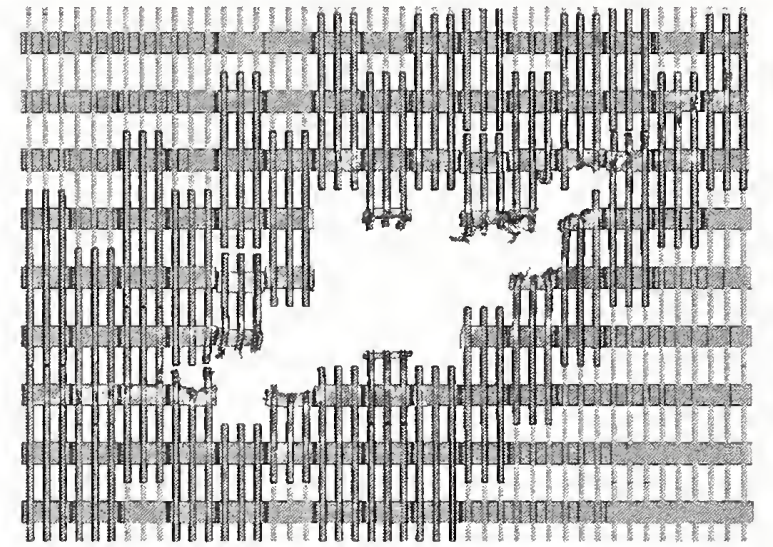

(a) Base case impact damage

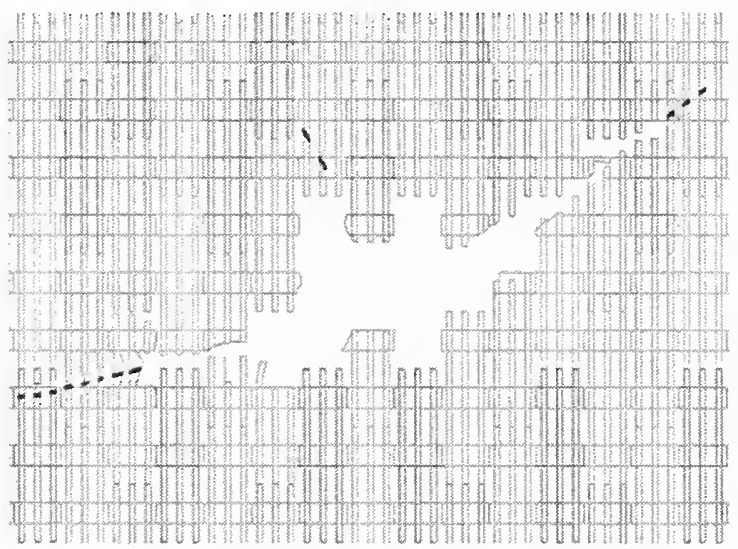

(c) Schematic of observed damage

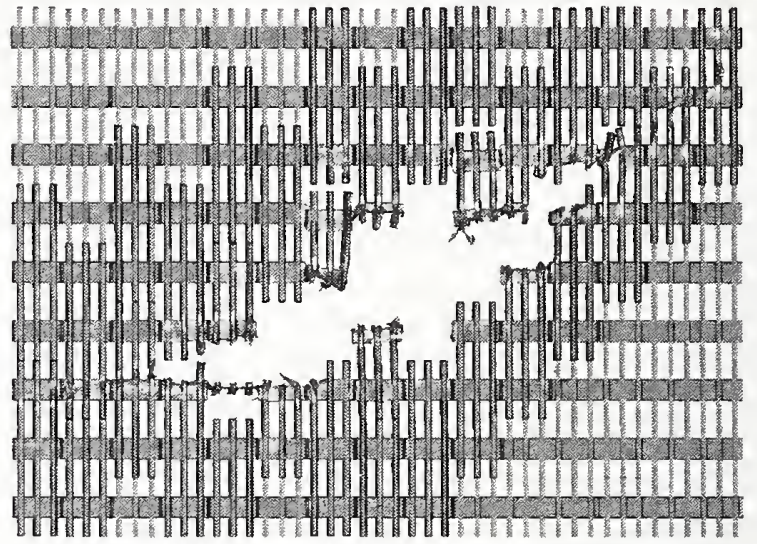

(b) More severe impact damage

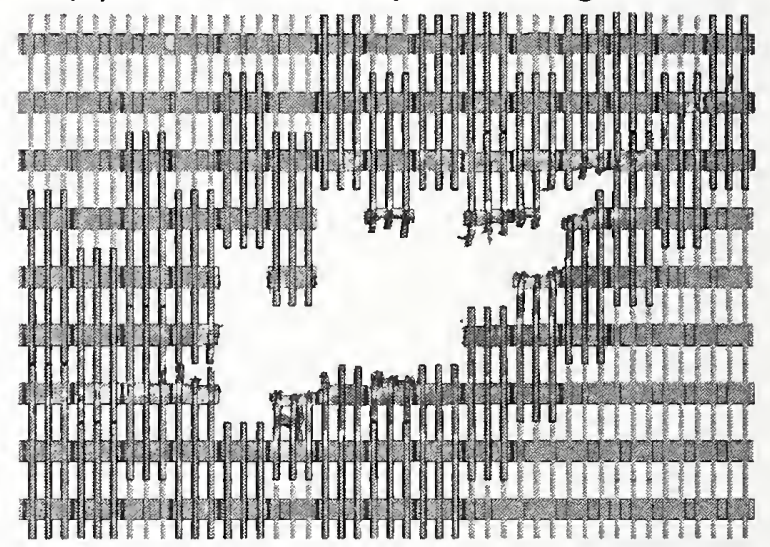

(d) Less severe impact damage

Figure 9-107. Impact damage to the north exterior wall of WTC 1.

Toward the wing tips, where the columns and spandrels were not completely severed, the more severe impact damage analysis calculated higher damage to the exterior wall panels. These columns had the largest amount of material with plastic strains above 5 percent (shown in red in the figure). As would be expected, the less severe impact damage analysis calculated lower damage to the exterior wall, and the base case analysis calculated an intermediate level of damage near the wing tips.

\subsubsection{Core Column Damage for WTC 1}

The calculated damage to the WTC 1 core columns for the three different severity impacts is shown in Figure 9-108. The figure shows that the core damage was concentrated in the region of the core closest to the impact point, and there was a clear correlation in damage magnitude with the impact severity. A total of one column was severed, and two columns were heavily damaged in the less severe impact, compared to three columns severed and four columns heavily damaged in the base case impact analysis and six columns severed and three columns heavily damaged in the more severe WTC 1 impact analysis. 


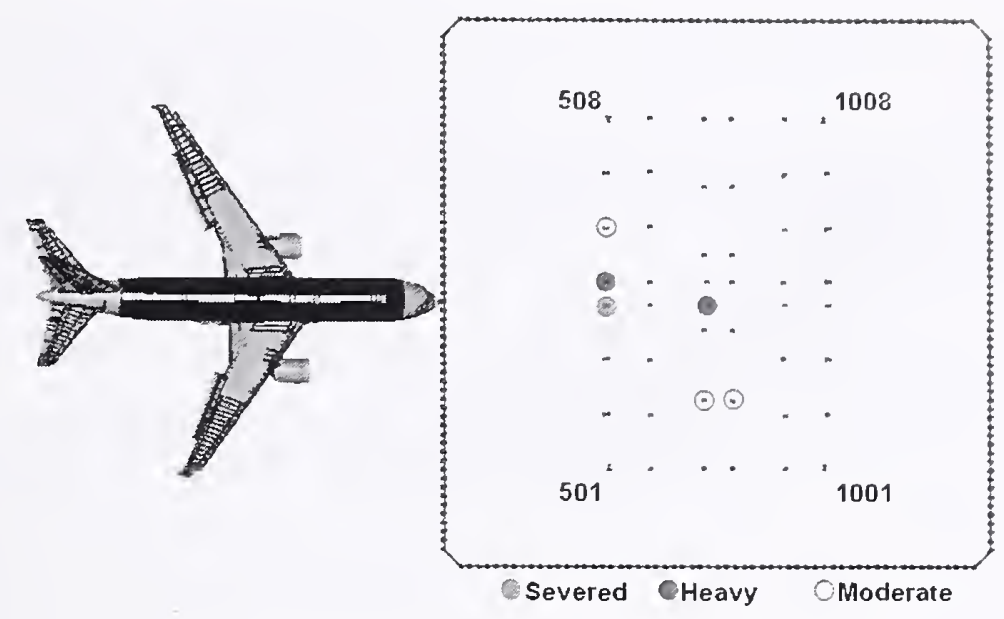

(a) Calculated less severe impact analysis

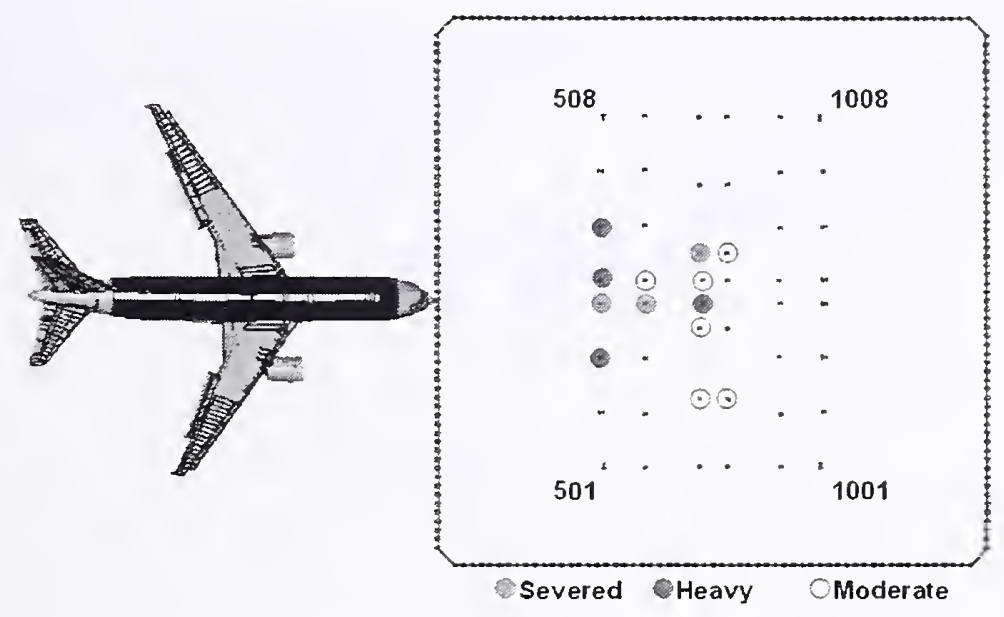

(b) Calculated base case impact damage

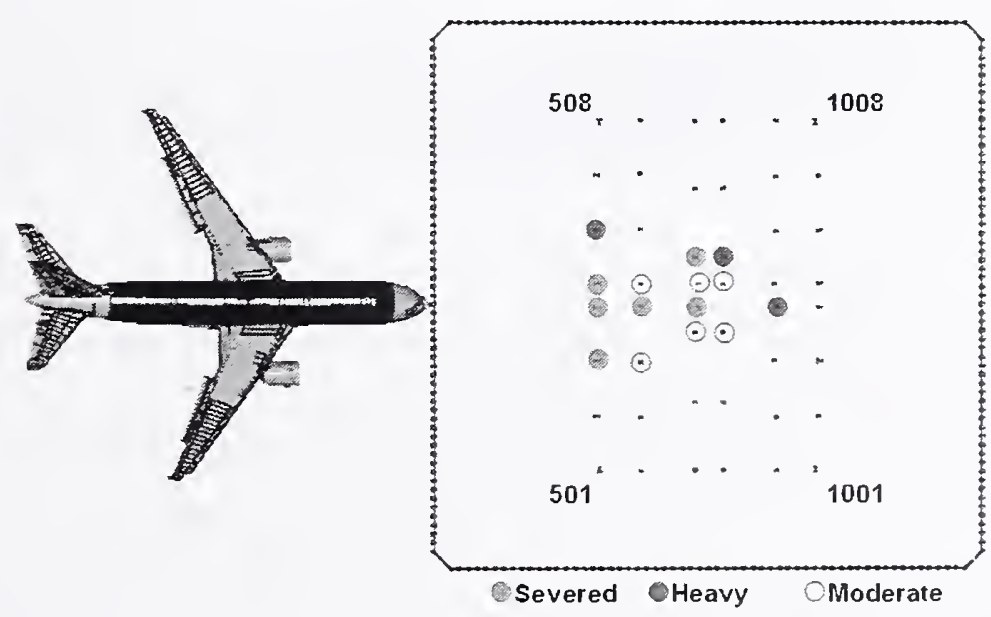

(c) Calculated more severe impact analysis

Figure 9-108. Comparison of core column damage for the WTC 1 impact analyses. 
The strong correlation in the core damage with impact severity was expected. All of the parameter variations in the three increasing severity analyses would be expected to produce an increase in core damage. The flight parameters had an increasing impact speed and a shallower impact angle, directing more energy toward the core. The aircraft had an increasing weight and higher material toughness. The tower had reduced mass in the contents and a reduced material toughness. All of these variations contributed toward the increased core damage with increased impact severity.

\subsubsection{Floor Truss Damage for WTC 1}

The calculated damage to the WTC 1 floor truss structures for the three different severity impacts is shown in Figure 9-109. The magnitude of truss floor damage was very similar for the different severity WTC 1 global impact analyses. The parameters used in the increasing severity global impact analyses would primarily contribute to an increased damage magnitude for the tower structures. However, the downward impact trajectory angle was correspondingly reduced from 13.6 degrees in the less severe impact to 10.6 and 7.6 degrees in the base case and more severe impact scenarios, respectively. This would have the effect of directing less of the impact energy downward, reducing the normal force on the floor structures in the impact zone. As a result, the combined effects of the analysis parameter variations produced very similar damage to the truss structure for the three different severity impact scenarios. 


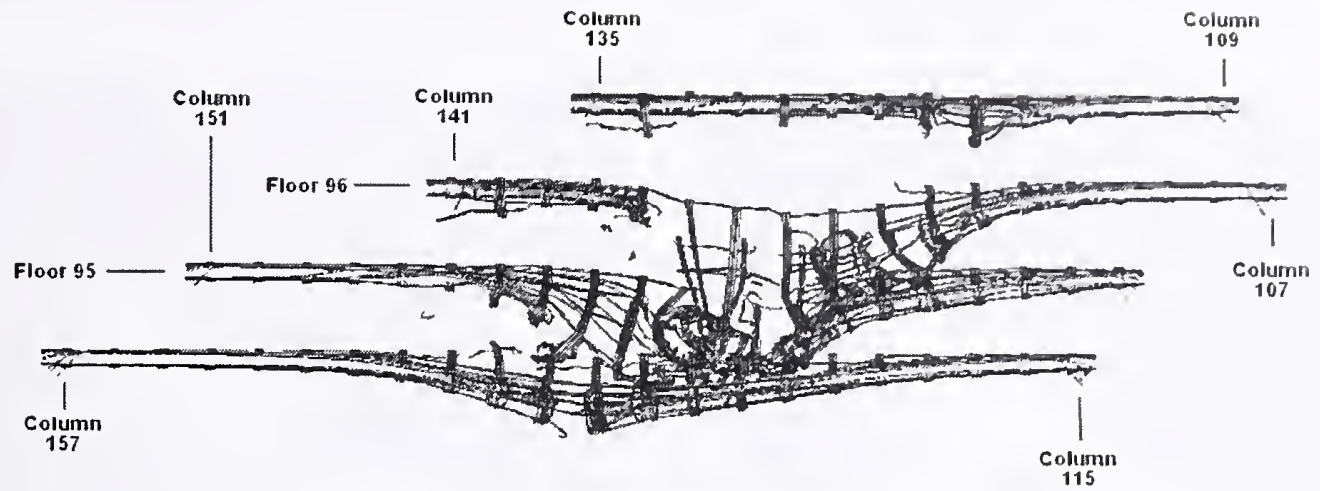

(a) Calculated less severe impact analysis

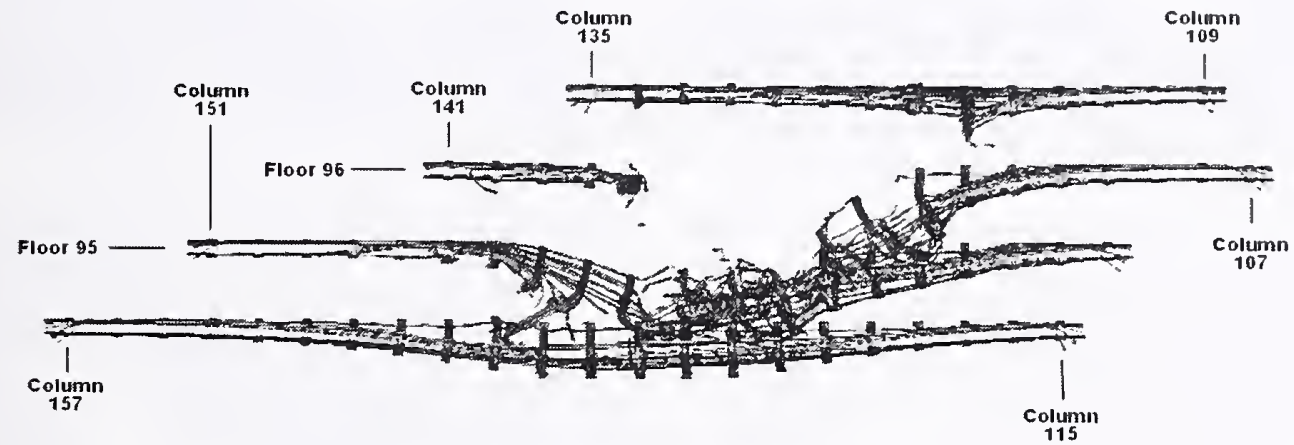

(b) Calculated base case impact damage

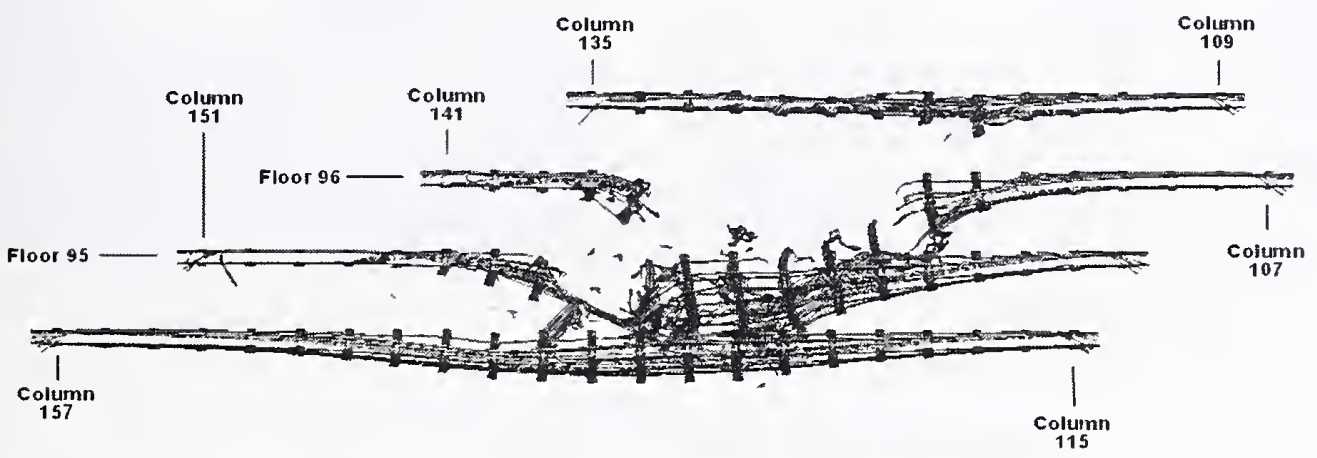

(c) Calculated more severe impact analysis

Figure 9-109. Comparison of floor truss damage for the WTC 1 impact analyses.

\subsubsection{Exterior Wall Damage for WTC 2}

The predicted impact damage to the south exterior wall of WTC 2 for the three different severity impacts is shown in Figure 9-110, with a schematic of the observed damage for comparison. As was the case for WTC 1, there were small differences in the predictions from each of the global analyses shown in the figure. Overall, the agreement with the observed damage from photographs was very good. The most 
obvious differences were largely due to portions of panels that may have severed columns in one case or have been removed at the connections in another.

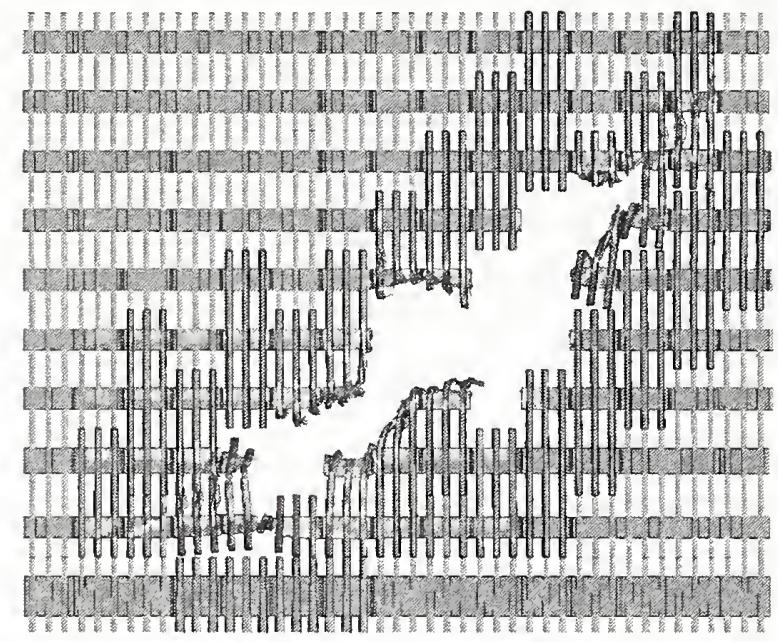

(a) Base case impact damage

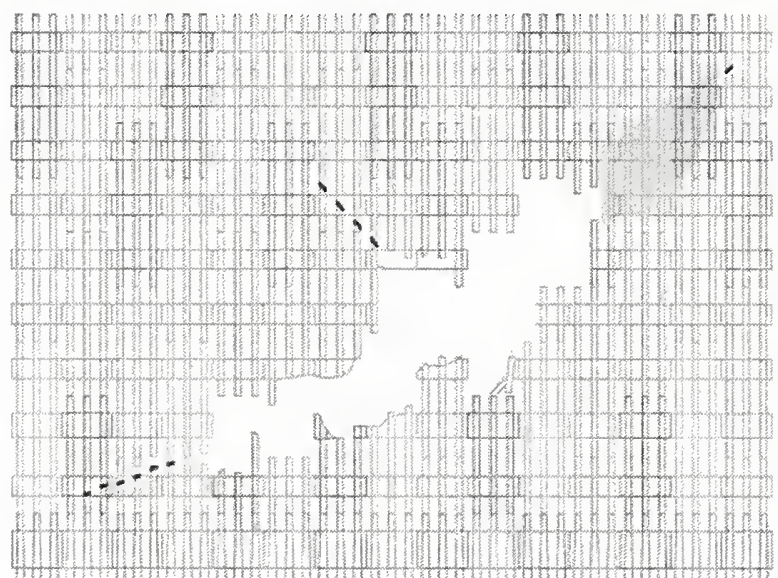

(c) Schematic of observed damage

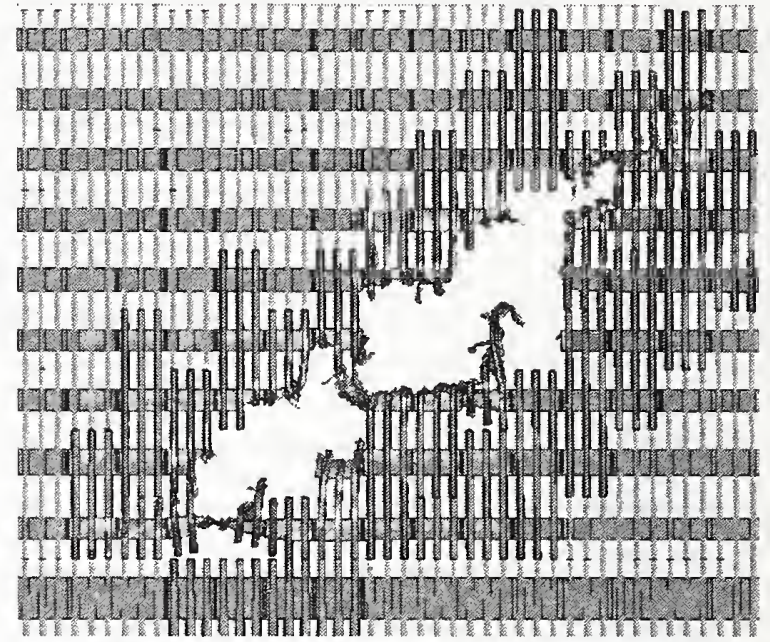

(b) More severe impact damage

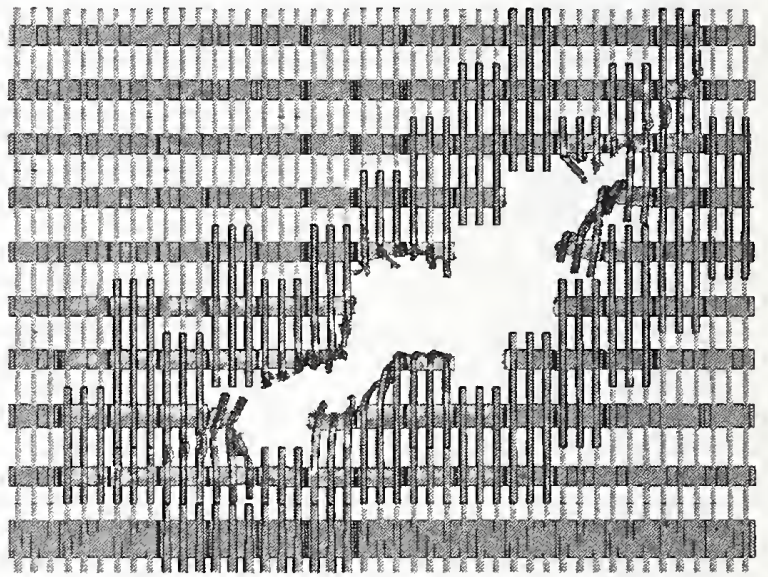

(d) Less severe impact damage

Figure 9-110. Impact damage to the south exterior wall of WTC 2.

\subsubsection{Core Column Damage for WTC 2}

The calculated damage to the WTC 2 core columns for the three different severity impacts is shown in Figure 9-111. The figure shows that the core damage was concentrated in the region of the core closest to the impact point, and there was a clear correlation in damage magnitude with the impact severity. A total of three columns were severed and two columns were heavily damaged in the less severe impact, compared to five columns severed and four columns heavily damaged in the base case analysis and ten columns severed and one column heavily damaged in the more severe WTC 2 impact analysis.

The strong correlation in the core damage with impact severity was expected. All of the parameter variations in the three increasing severity analyses would be expected to produce an increase in core damage. The flight parameters had an increasing impact speed and a shallower impact angle, directing more energy toward the core. The aircraft had an increasing weight and higher material toughness. The 
tower had reduced mass in the contents and a reduced material toughness. Alt of these variations contributed toward the increased core damage with increased impact severity.

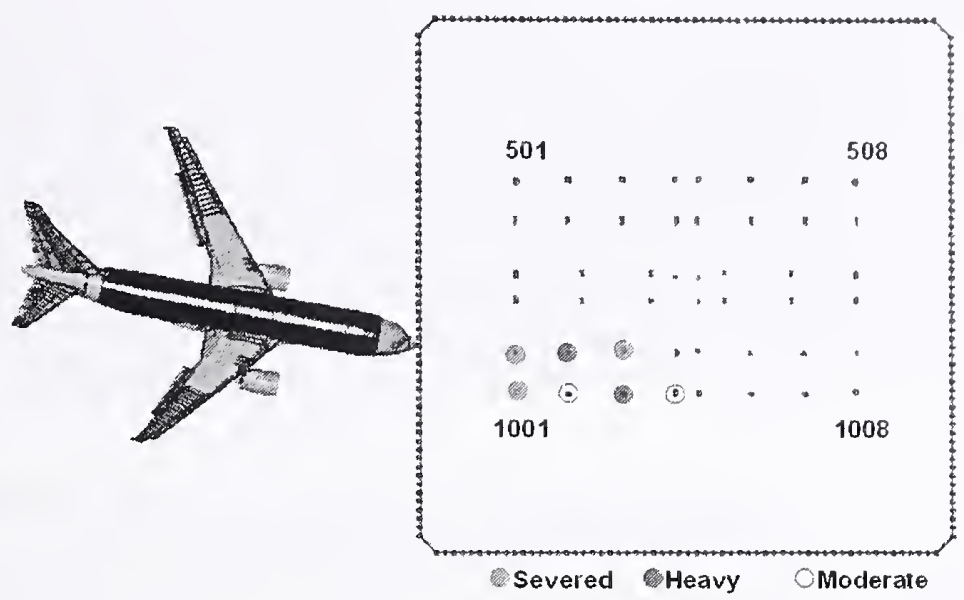

(a) Calculated less severe impact analysis

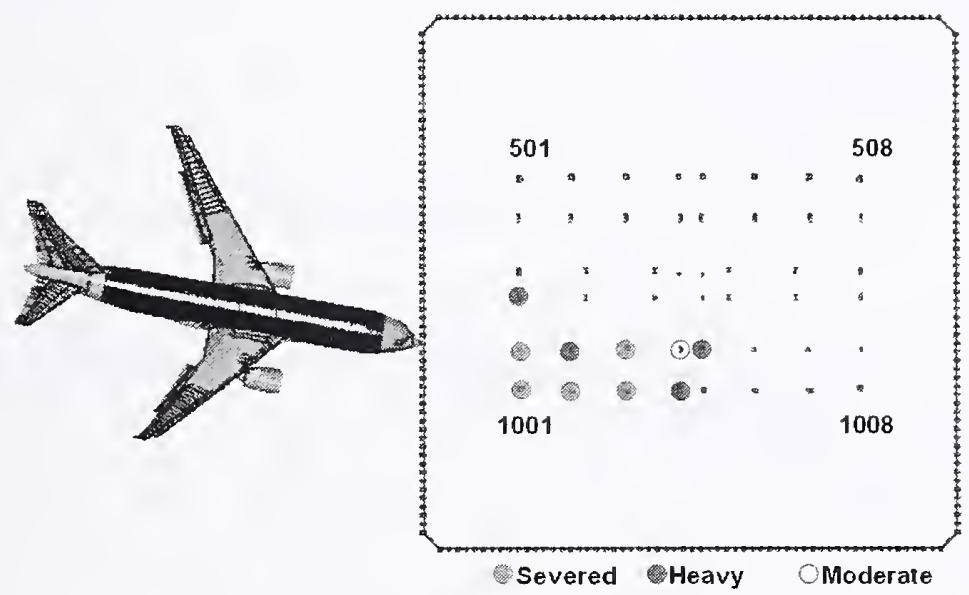

(b) Calculated base case impact damage

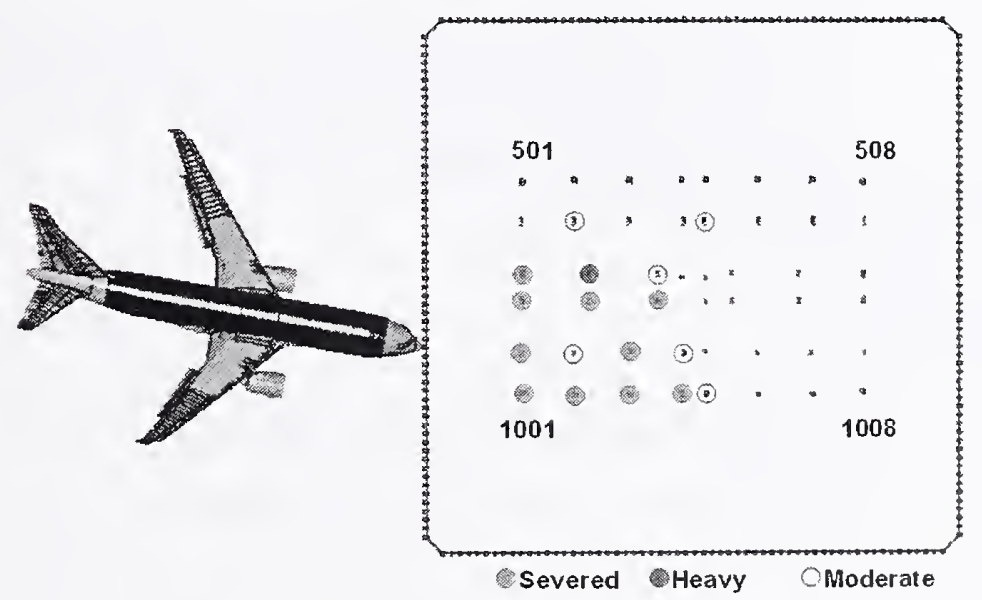

(c) Calculated more severe impact analysis

Figure 9-111. Comparison of core column damage for the WTC 2 impact analyses. 


\subsubsection{Floor Truss Damage for WTC 2}

The calculated damage to the WTC 2 floor truss structures for the three different severity impacts is shown in Figure 9-112. The magnitude of truss floor damage was very similar for the different severity WTC 2 global impact analyses. The parameters used in the increasing severity global impact analyses would primarily contribute to an increased damage magnitude for the tower structures. However, the downward impact trajectory angle was correspondingly reduced from 8 degrees in the less severe impact to 6 and 5 degrees in the base case and more severe impact scenarios, respectively. This would have the effect of directing less of the impact energy downward, reducing the normal force on the floor structures in the impact zone. As a result, the combined effects of the analysis parameter variations produced very similar damage to the truss structure for the three different severity impact scenarios.

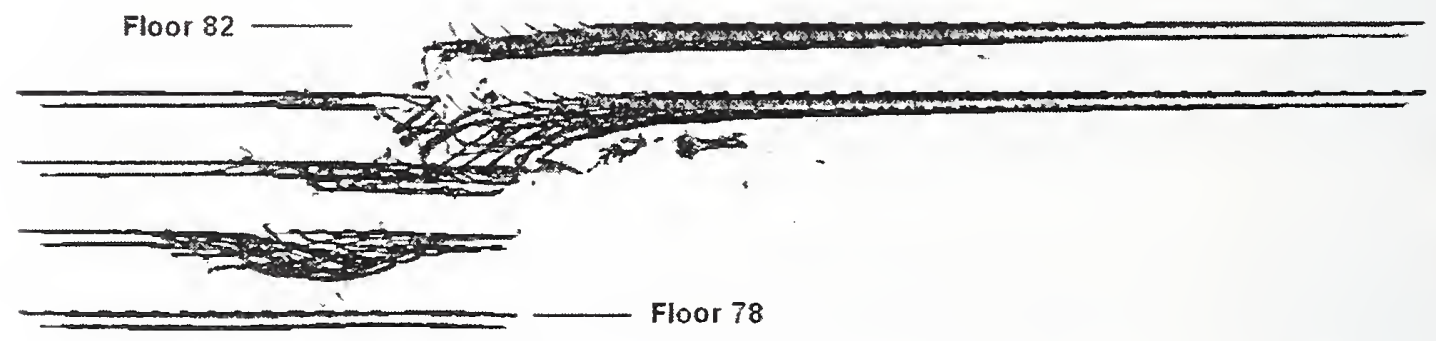

(a) Calculated less severe impact analysis

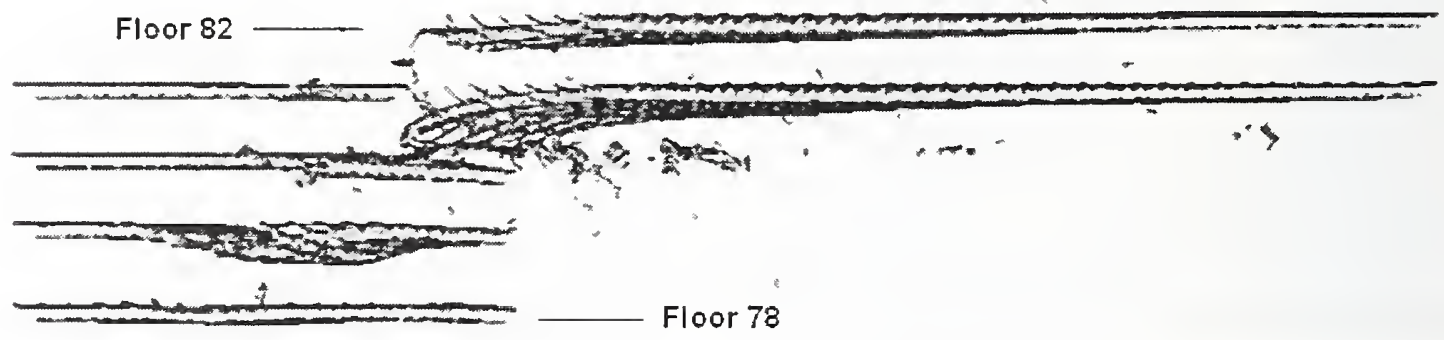

(b) Calculated base case impact damage

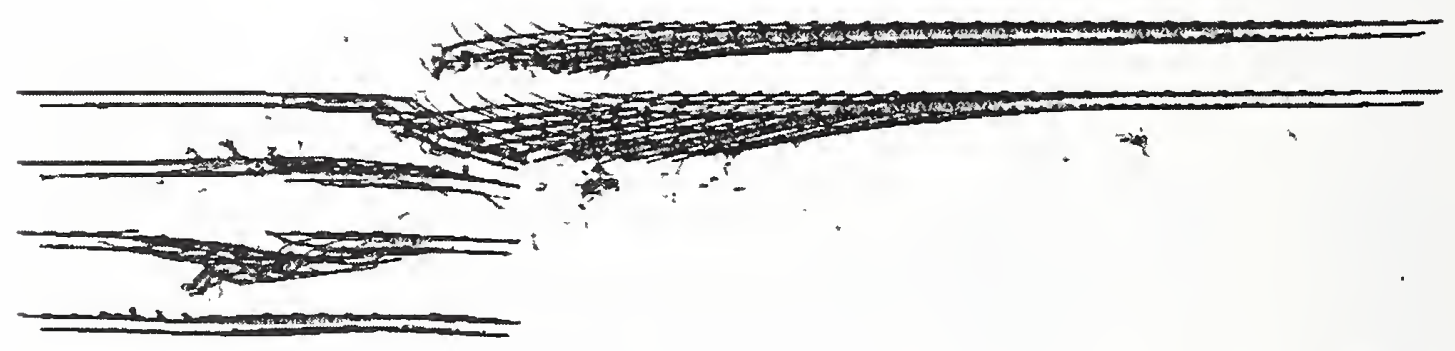

(c) Calculated more severe impact analysis

Figure 9-112. Comparison of floor truss damage for the WTC 2 impact analyses. 


\subsection{COMPARISON BETWEEN WTC 1 AND WTC 2}

The comparison of the aircraft impact response and resulting tower damage for WTC 1 and WTC 2 was complicated by the differences in the two impact scenarios. The basc case WTC 1 impact was closc to centered and perpendicular on the face of the tower, with the long span trusses between the impact point and the core. The base case WTC 1 impact scenario resulted in a debris trajcctory wherc almost all of the aircraft debris passed through the core. The baseline impact conditions for WTC 1 were a $443 \mathrm{mph}$ collision with a downward impact trajectory angle of 10.6 degrces. In contrast, the baseline WTC 2 impact was off center and angled away from the core, resulting in a significant fraction of the aircraft debris cloud outside (east) of the core. The WTC 2 impact had short span trusses between the impact point and the core. Finally, the baseline impact conditions for WTC 2 were a $546 \mathrm{mph}$ collision with a downward impact trajectory angle of 6 degrees.

\section{Exterior Wall Damage}

The calculated exterior wall damage for the base case WTC 1 and WTC 2 impacts are compared in Figure 9-113. Despite the differences in impact conditions, the mode and magnitude of damage to the exterior walls were quite similar in both towers. This was because the impact loads distributed over the majority of the aircraft structures were much larger than the exterior column rupture strength. The details of the failure mode (column deformation and rupture or failure and separation of bolted column end connections) were determined by the proximity of the floor slab and column joints to the impact point. For both impacts, the wing tip structures imparted damage, but did not completely fail the columns.

\section{Core Column Damage}

The calculated core column damage for the base case WTC 1 and WTC 2 impacts are compared in Figure 9-114. In the WTC 1 impact, there were three columns severed and four columns heavily damaged. The calculated region of significant core column damage appears to extend three column rows deep into the core. In contrast, the calculated damage for the WTC 2 impact included five columns severed and four columns heavily damaged, and the region of significant core column damage appears to extend four column rows deep. This increase in core damage was even more significant since the impact zone was 15 floors lower in WTC 2 (and therefore designed to carry more gravity loads), and as a result the core columns were heavier and more resistant to impact damage in the WTC 2 impact zone.

The differences in the core column damage between WTC 1 and WTC 2 can be explained by two primary factors. The first was that the WTC 2 impact speed was 23 percent higher (approximately 50 percent higher impact energy), and the shallower impact angle directed more impact energy inward toward the core. The second factor was that the orientation of the core relative to the impact was different in the two towers, as the core was closer to the impact point in WTC 2. As a result, WTC 2 had reduced energy absorbing capacity due to the shorter floor structures and less building contents between the impact point and the core. 


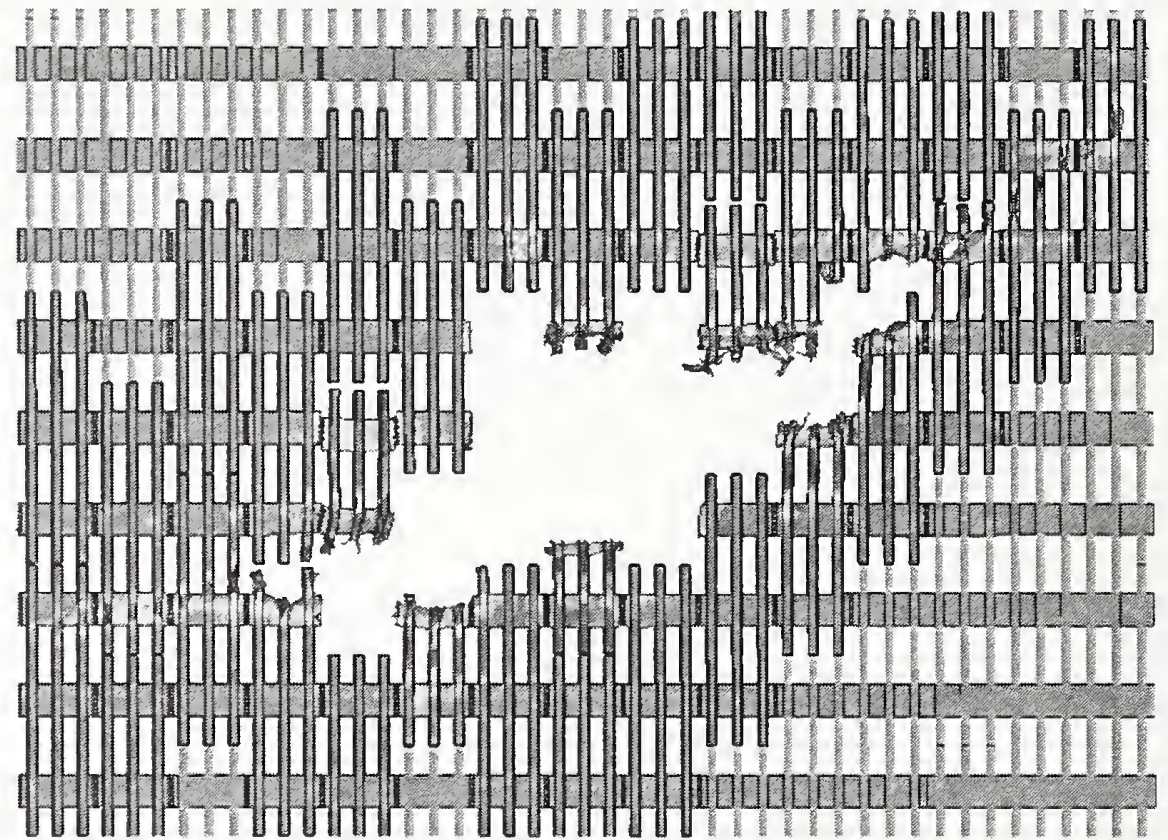

(a) WTC 1 calculated damage $(t=0.715 \mathrm{~s})$

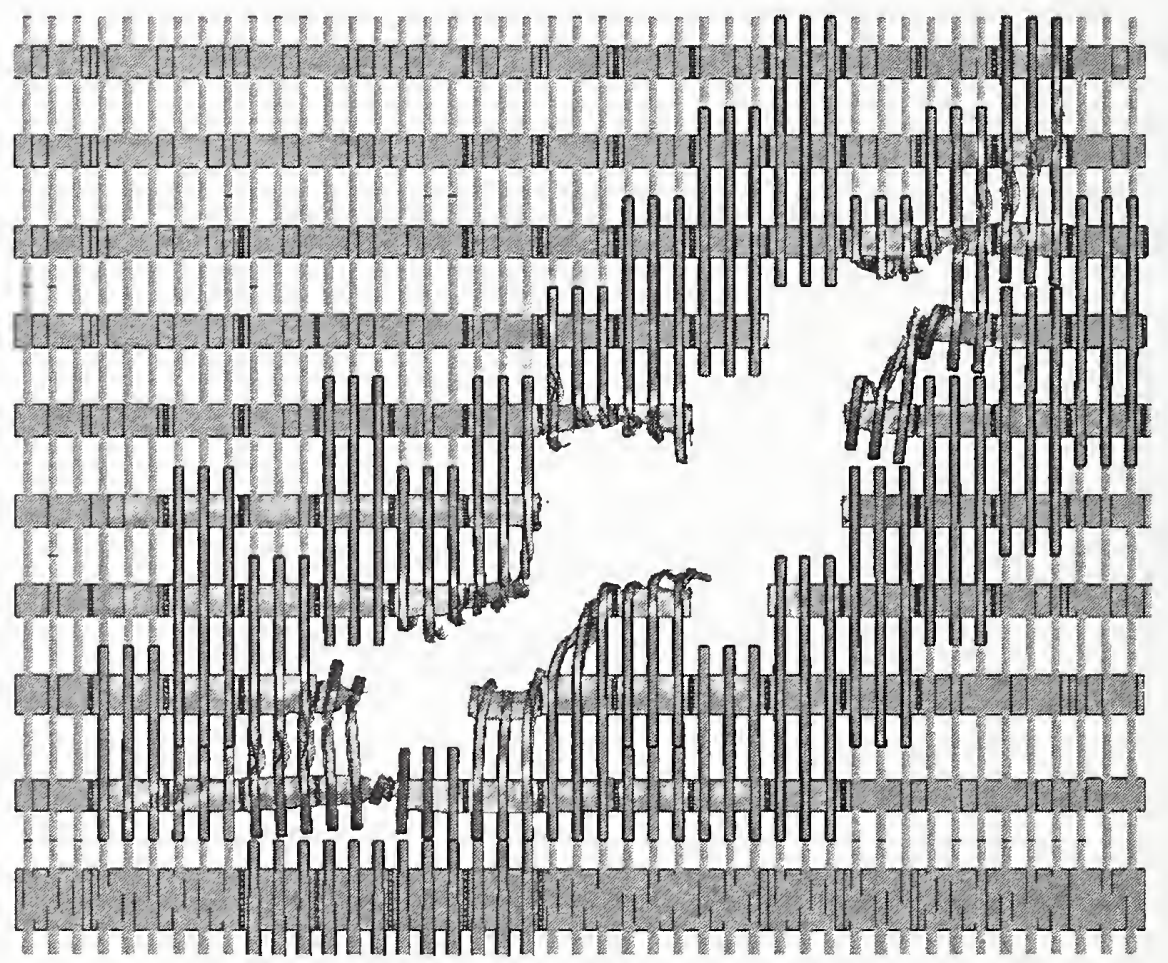

(b) WTC 2 calculated damage ( $t=0.62 \mathrm{~s}$ )

Figure 9-113. Comparison of base case impact damage to the exterior wall. 


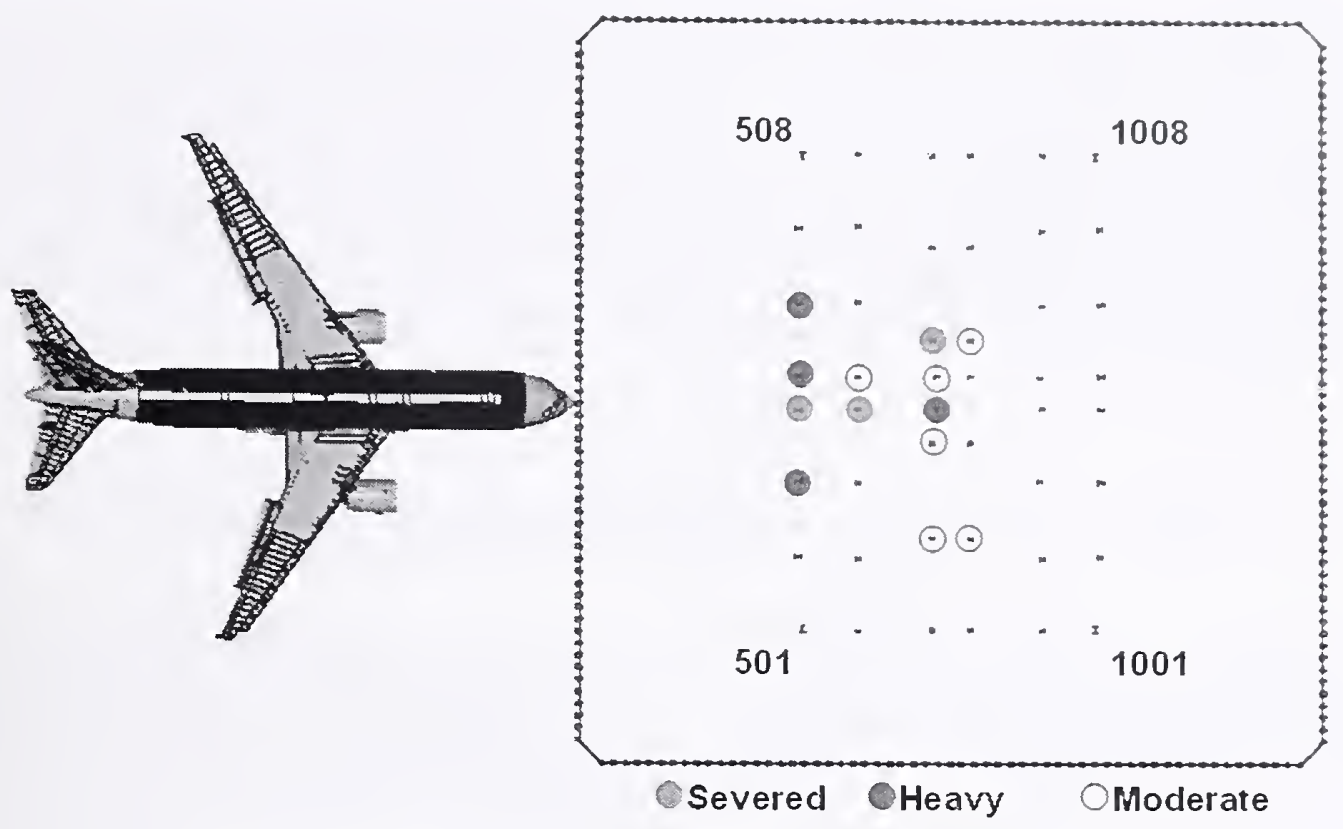

(a) WTC 1 calculated damage ( $t=0.715 \mathrm{~s})$

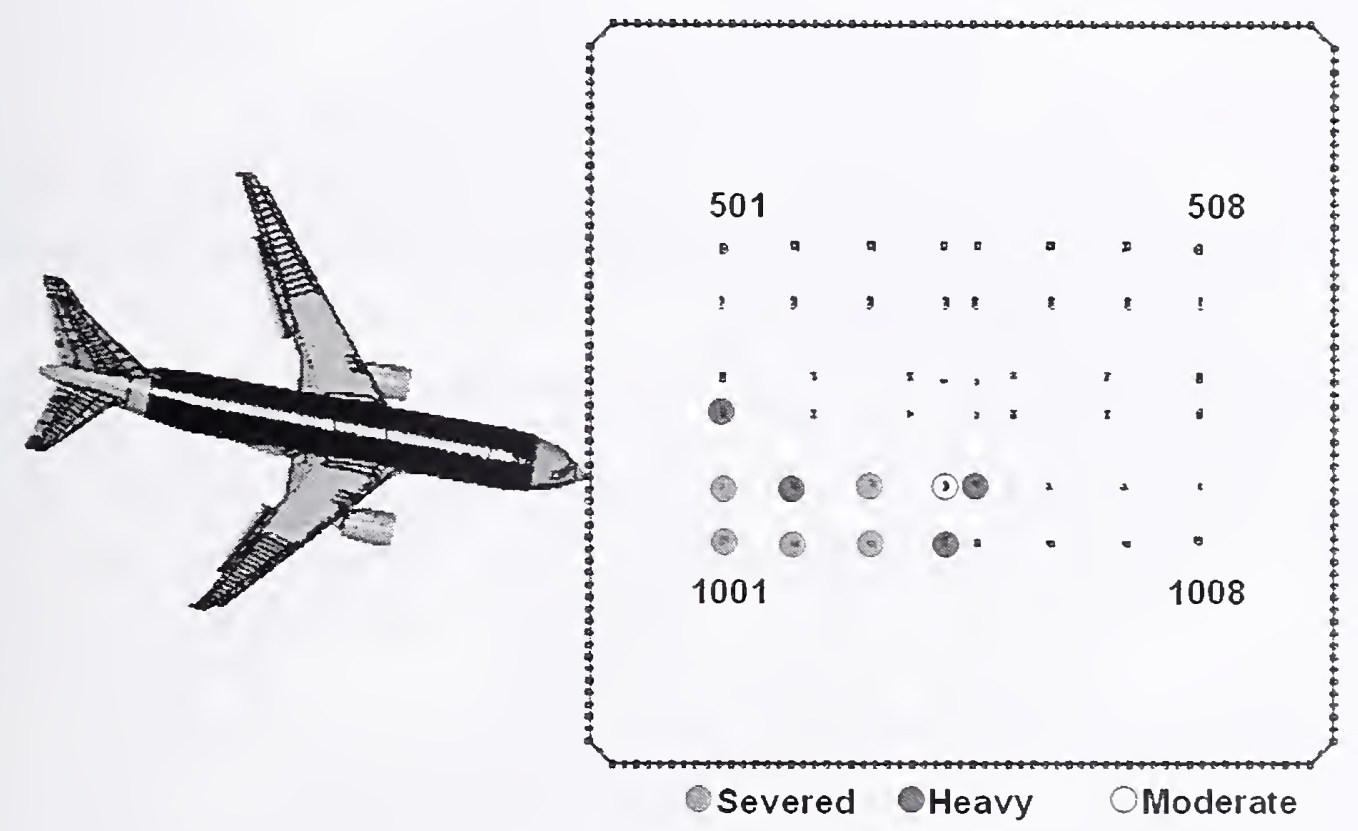

(b) WTC 2 calculated damage ( $t=0.62 \mathrm{~s}$ )

Figure 9-114. Comparison of base case impact damage to the core columns.

\section{Floor Truss Damage}

The calculated floor truss damage for the base case WTC 1 and WTC 2 impacts are compared in Figure 9-115. The comparison shows that the WTC 1 floor truss had greater damage and collapse of the truss floor despite the lower aircraft impact energy. The higher amount of truss floor damage and 
deflection in WTC 1 can be explained by two factors. The primary factor was that the WTC 1 downward impact trajectory was nearly twice as steep as that of the WTC 2 impact. As a result, the steeper impact angle directed more impact energy normal to the floor slab. The vertical component of the impact load in WTC 1 was approximately 40 pcrcent higher than in WTC 2 (the vertical momentum of the aircraft that impacted WTC 1 was about 40 percent higher than that for the aircraft that impacted WTC 2). The secondary factor was that the damage to the long span truss floors in the WTC 1 impact zone produced larger displacements than a corresponding damage level to a short span truss region.

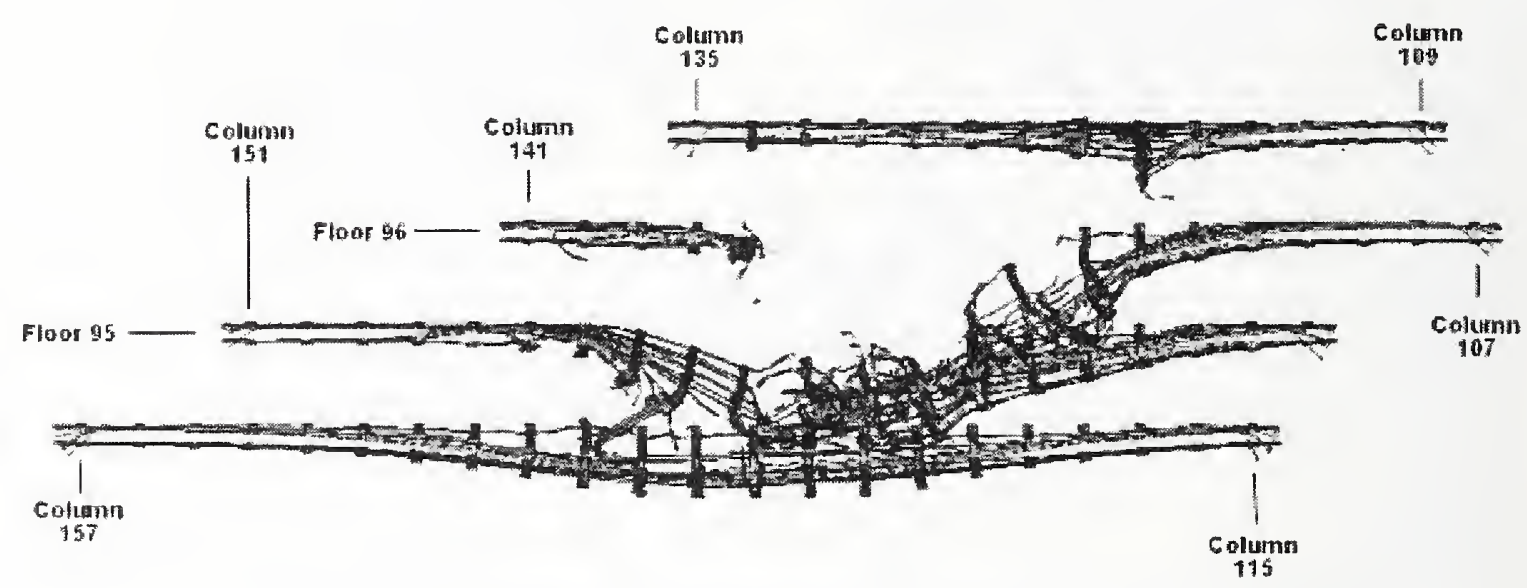

(a) WTC 1 calculated damage $(t=0.715 \mathrm{~s})$

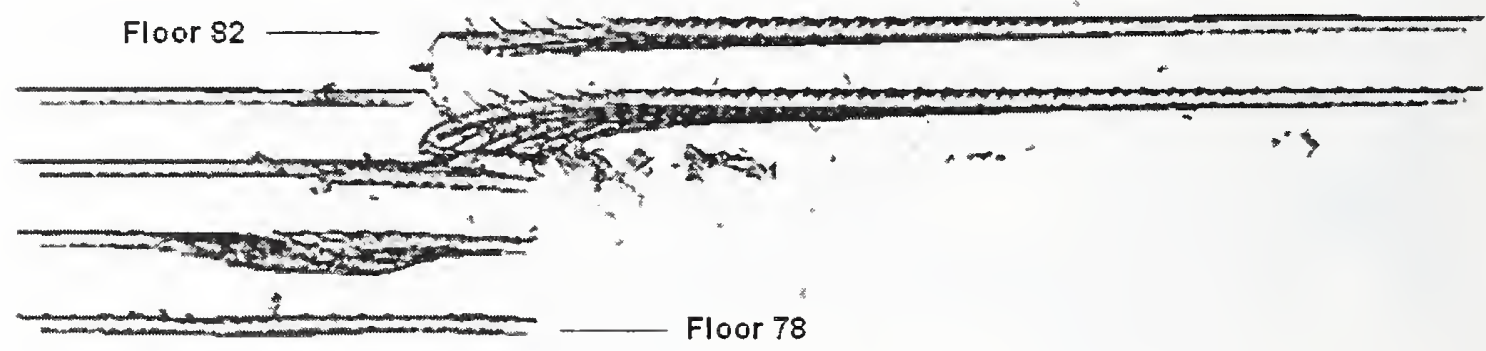

(b) WTC 2 calculated damage ( $t=0.715 \mathrm{~s}$ )

Figure 9-115. Comparison of base case impact damage to floor truss (front view).

\subsection{COMPARISON WITH OBSERVABLES}

The observable evidence available to help validate the global impact analyses included the following:

- Damage to the buildings' exteriors documented by photographic evidence.

- Floor damage visible from the buildings' exteriors documented by photographic evidence.

- Aircraft debris external to the towers as documented by photographic evidence.

- Eyewitness accounts from survivors who were inside portions of the buildings. 
The most valuable observable from a modeling standpoint was the damagc to the impacted cxtcrior wall of each tower. The impact damage to the extcrior tower walls was wcll documented, and the response did not depend much on unknown parametcrs, such as the detailed officc layout on cach floor. Good agreement of the calculated and observed damagc profile indicated that the gcomctric modcling of the aircraft and the initial trajectory and orientation of the aircraft werc accuratc. The agreement of both the mode and magnitude of the structural damage on the impact wall served to partially validatc the constitutive and damage modeling of the aircraft and exterior wall structurcs of the tower. The agrecment in exterior wall damage, based on the modeling methodologics described in this report, contributcd to the confidence that the damage predictions for the interior of the towers were reasonably estimatcd.

The calculated and observed impact damage to the exterior walls were described previously in this chapter and are summarized in Figure 9-116 for the base cases. There were small differences in the damage details, but the overall agreement with the observed damage is very good.

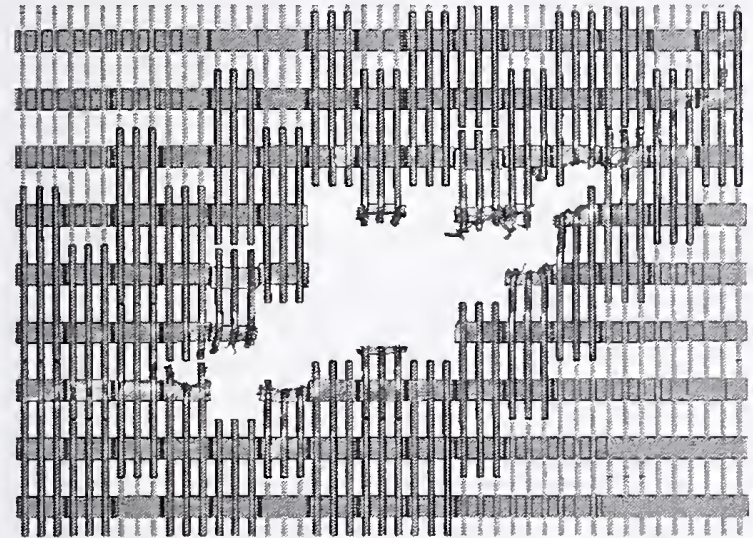

(a) Base case WTC 1 impact analysis

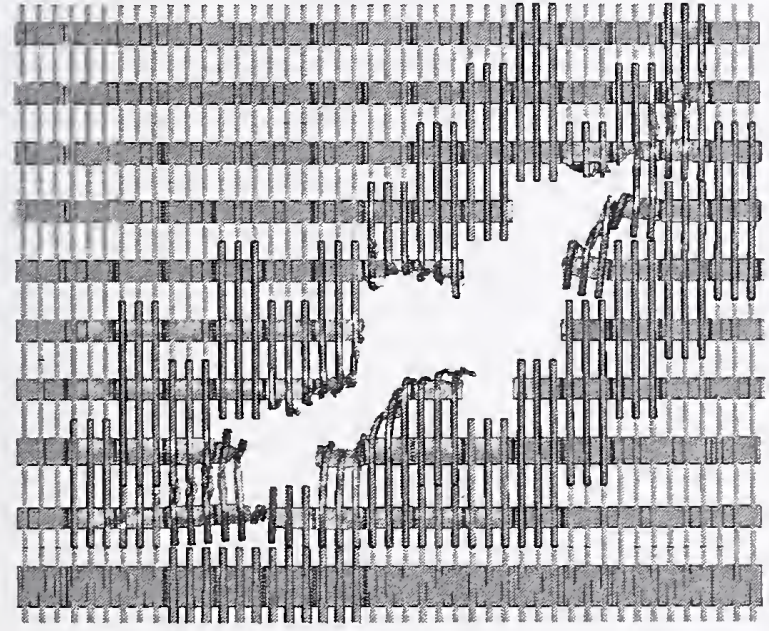

(c) Base case WTC 2 impact analysis

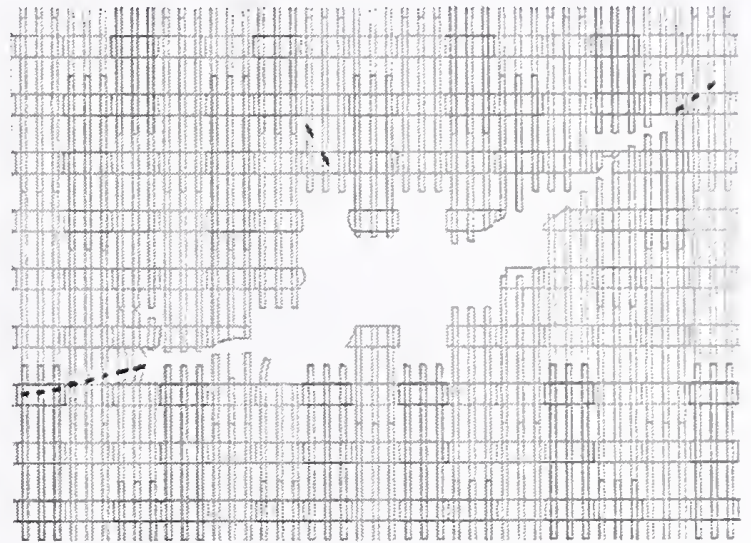

(b) Schematic of observed WTC 1 damage

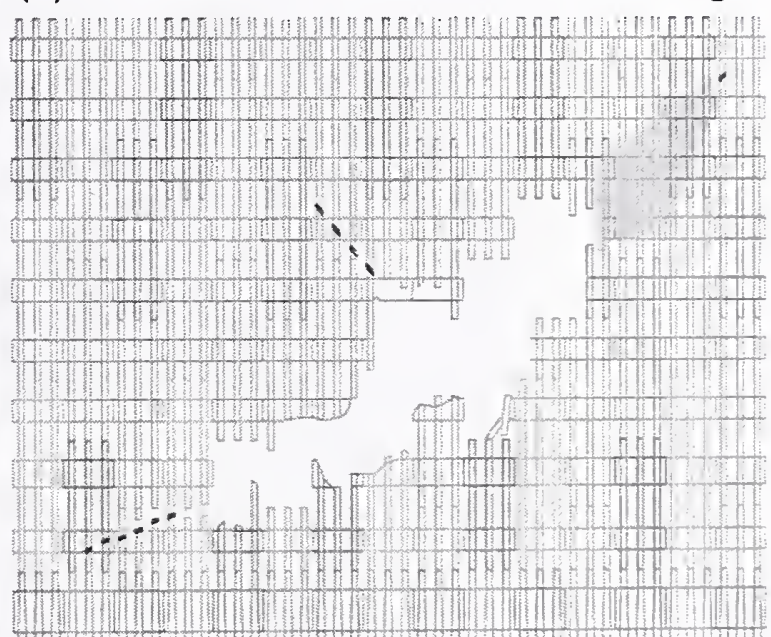

(d) Schematic of observed WTC 2 damage

Figure 9-116. Impact damage to the exterior walls of the WTC towers. 


\subsubsection{Comparison with Observables on WTC 1}

\section{Damage on the South Exterior Wall of WTC 1}

The exterior panel from column 329 to column 331 between floors 94 through 96 on the south face of WTC 1 was knocked free by landing gear and possibly other debris. These columns were located in the center of the south wall of WTC 1, as shown in Figure 9-117. In both the base case and more severe damage global analyses, aircraft debris impacted the south face of the tower, as shown in Figure 9-118 and Figure 9-119, and exited the building. In the less severe damage analysis, as shown in Figure 9-120, none of the aircraft debris that passed through the core was calculated to exit the building. The figures also show the calculated landing gear debris for all simulations. None of the debris impacting the south wall happened to contain landing gear fragments. In the base case analysis, the debris impacted columns 328 to 330 at floor 96 . In the more severe impact analysis, debris impacted columns 328 to 333 on both floors 95 and 96 . In the base case analysis, very little damage was done to the exterior panels on the south wall. However, damage was heavy in the more severe damage analysis, as shown in Figure 9-121.

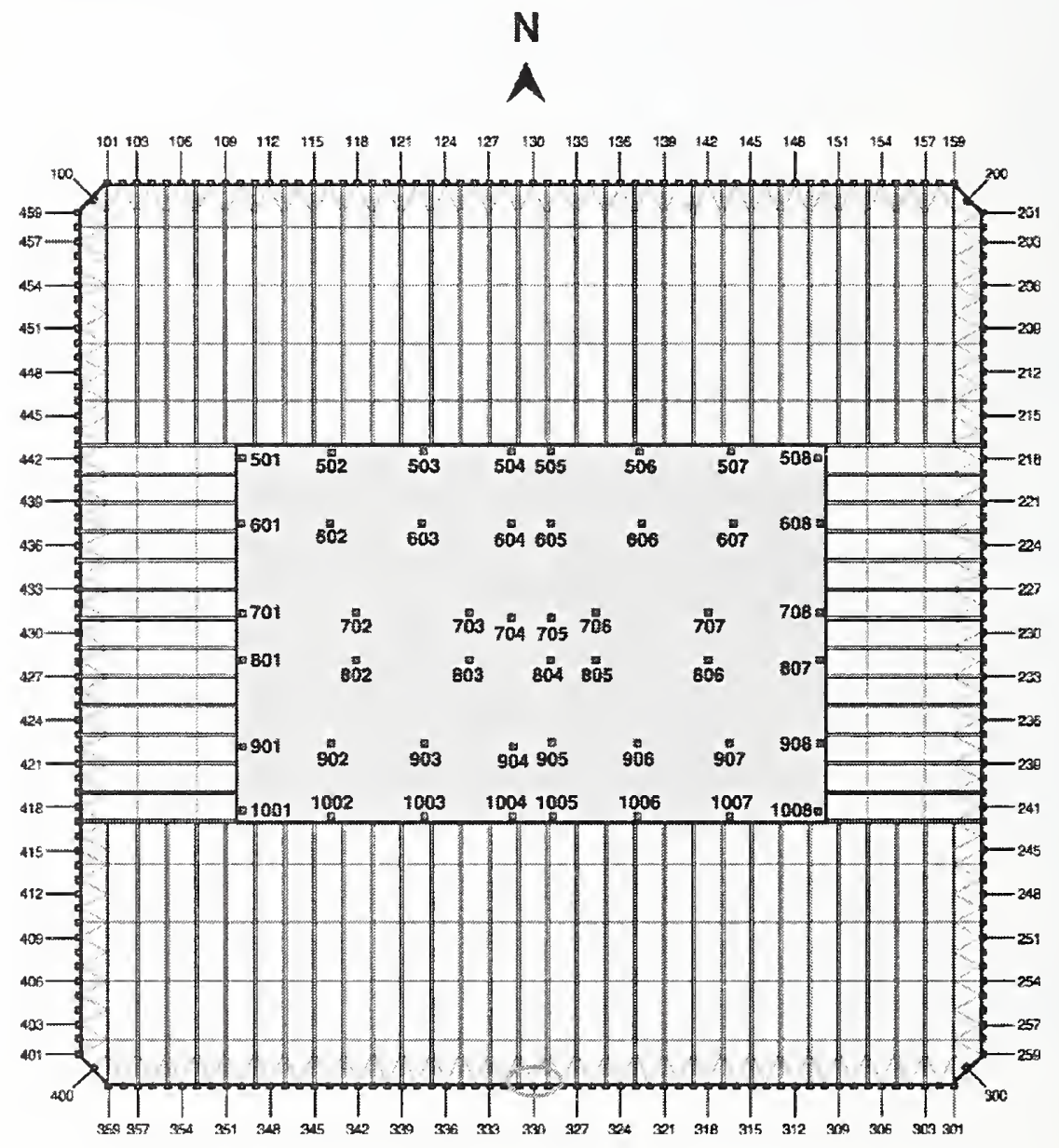

Figure 9-117. Representative floor plan (based on floors 94 to 95 of WTC 1). 


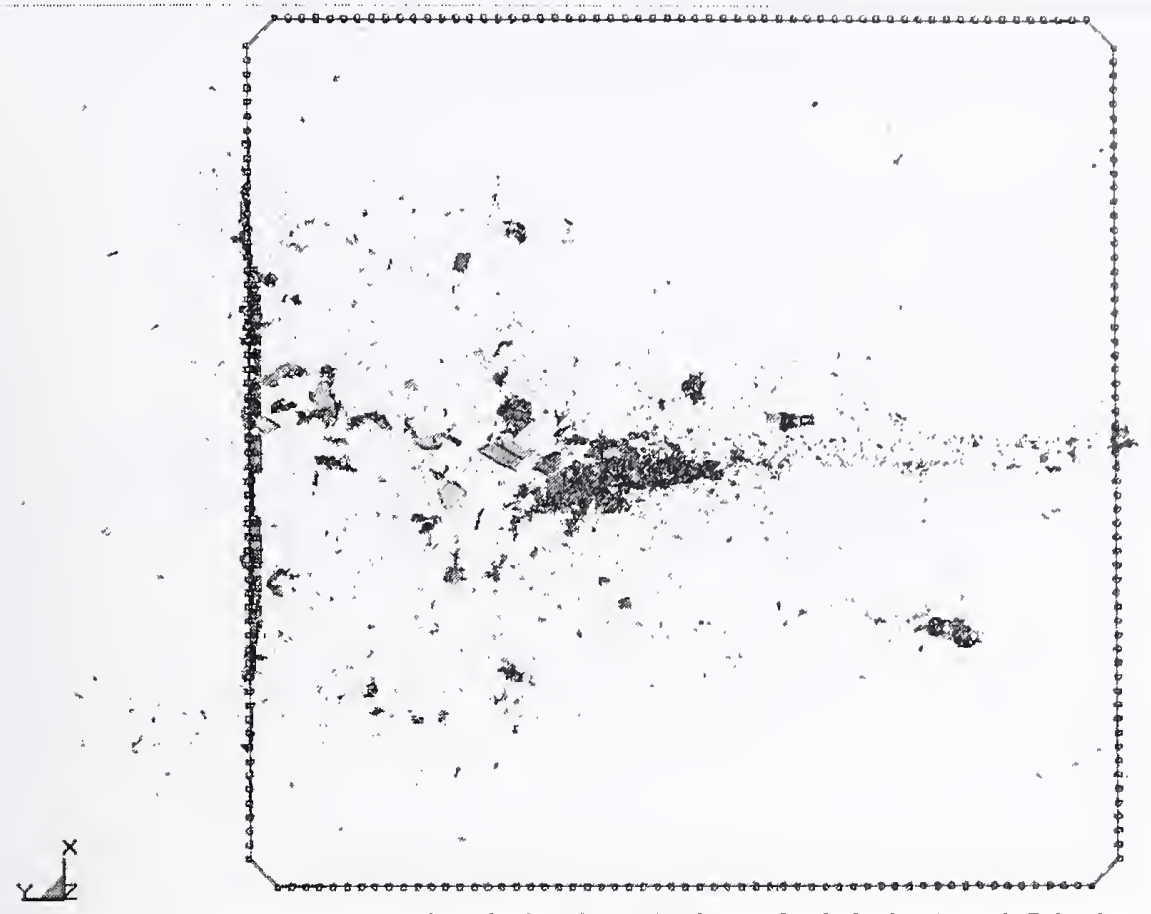

(a) Calculated aircraft debris ( $\mathrm{t}=\mathbf{0 . 7 1} \mathrm{s}$ )

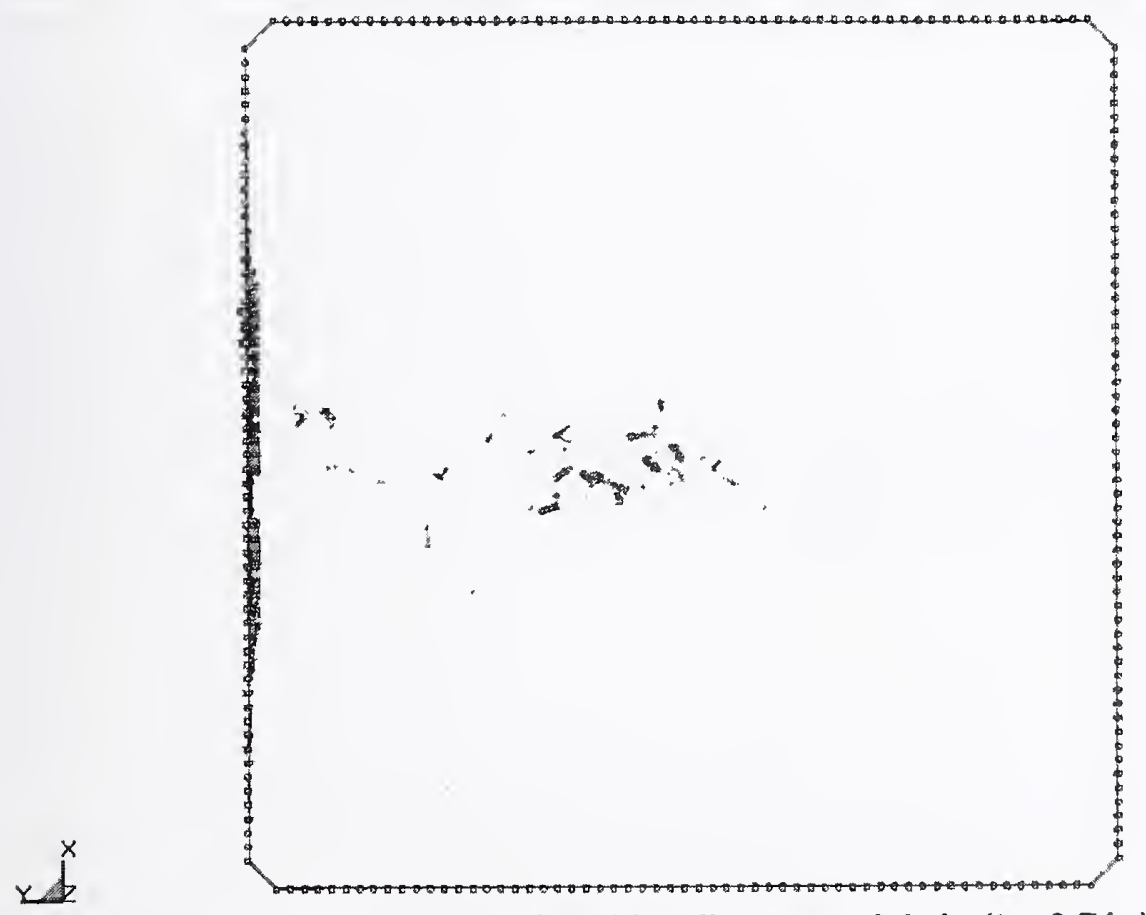

(b) Calculated landing gear debris $(\mathrm{t}=0.71 \mathrm{~s})$

Figure 9-118. Base case aircraft debris distribution in WTC 1. 


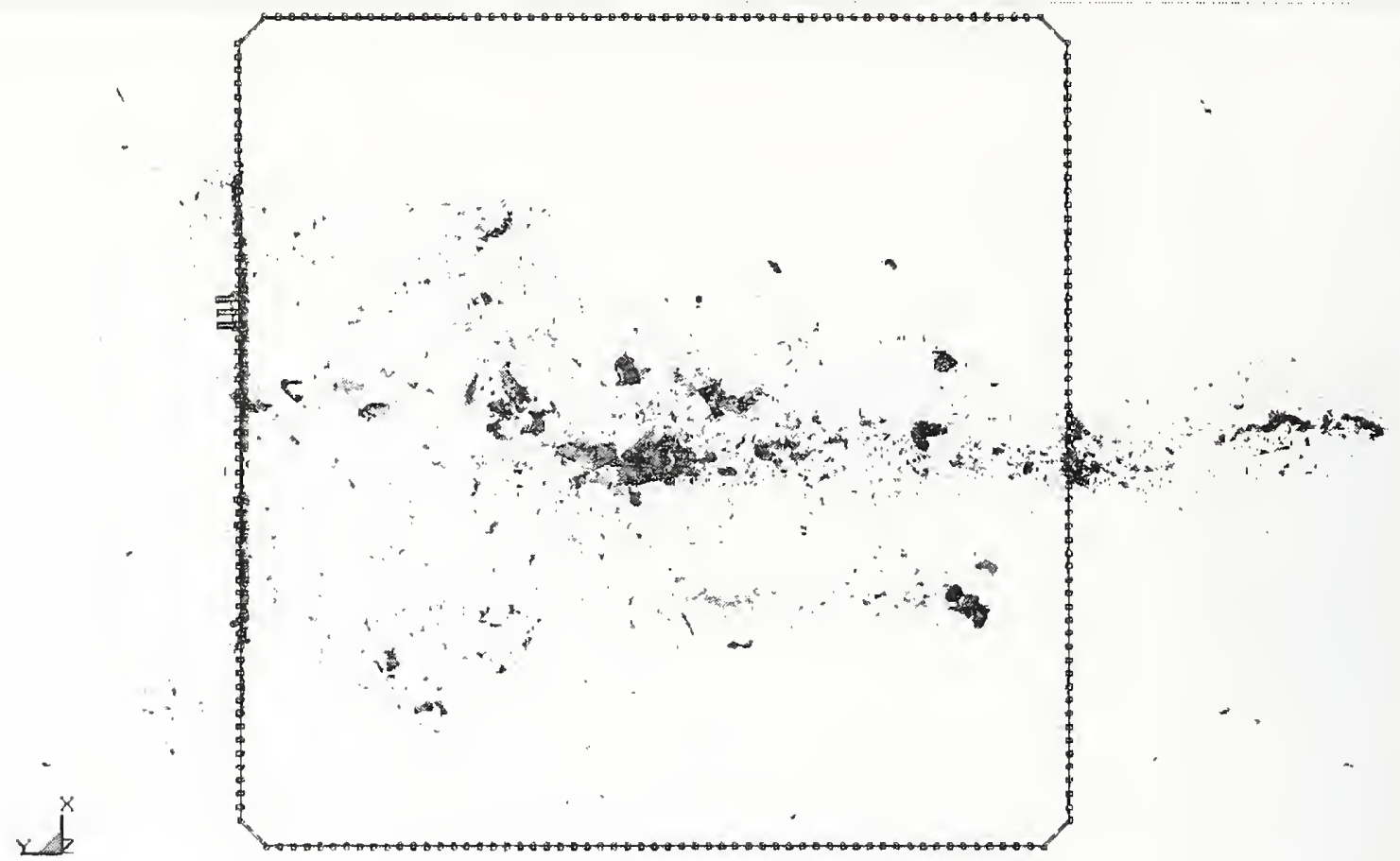

(a) Calculated aircraft debris ( $\mathrm{t}=0.685 \mathrm{~s}$ )

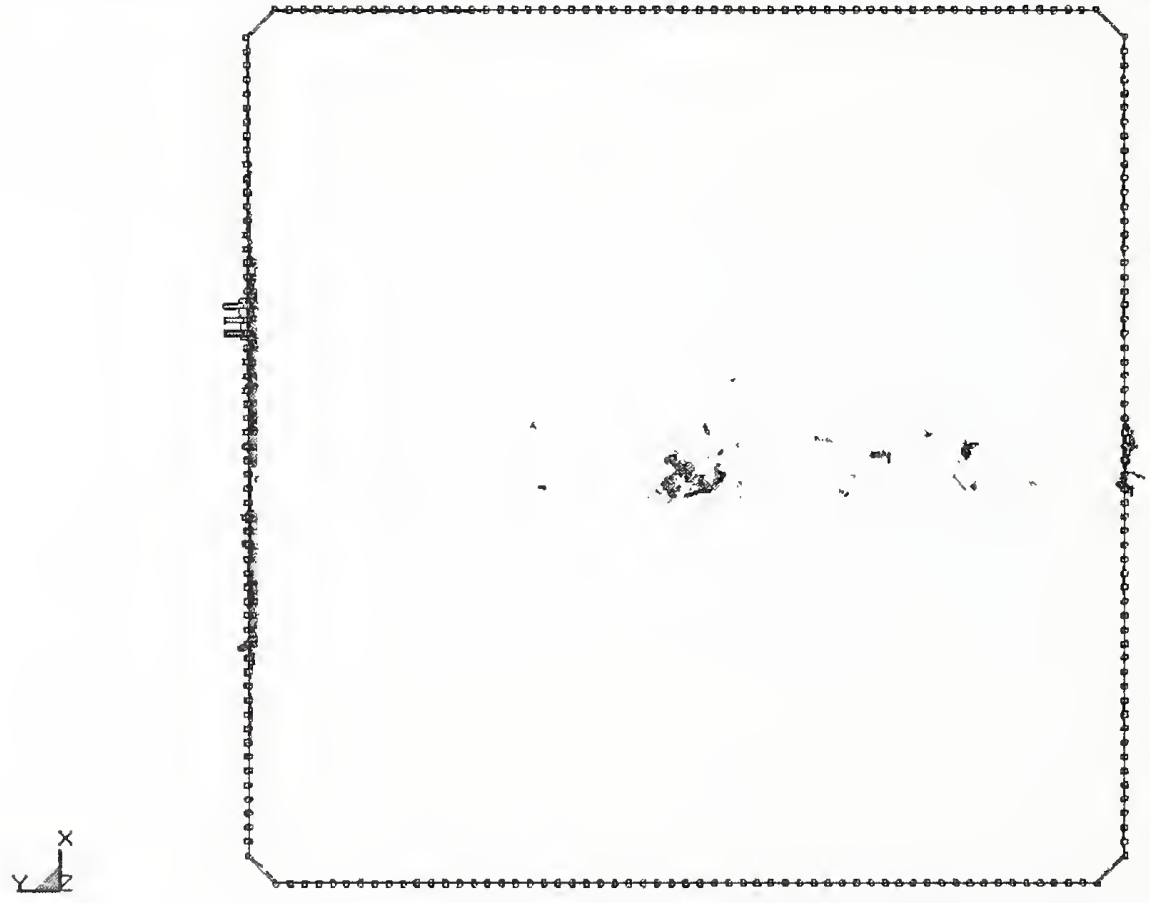

(b) Calculated landing gear debris ( $\mathrm{t}=\mathbf{0 . 6 8 5} \mathrm{s}$ )

Figure 9-119. More severe damage aircraft debris distribution in WTC 1. 


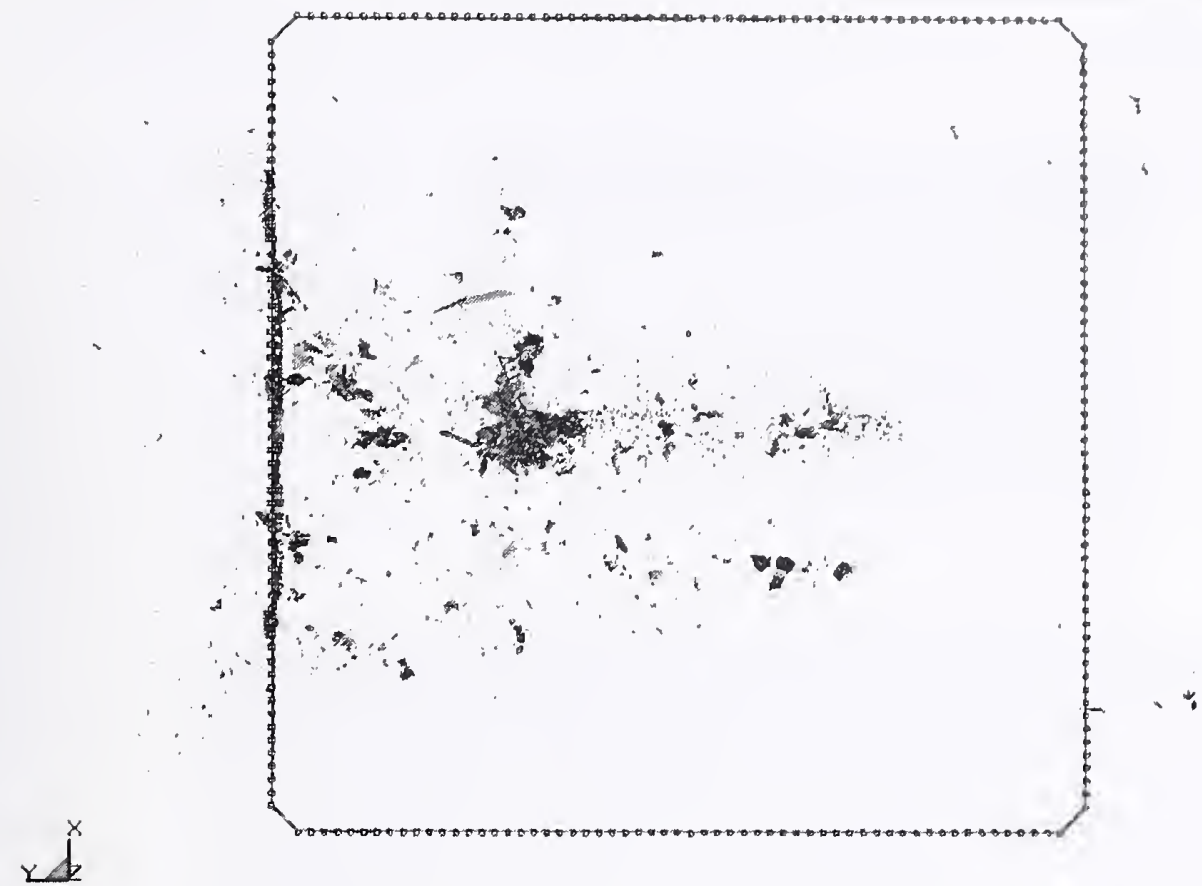

(a) Calculated aircraft debris $(t=0.735 \mathrm{~s})$

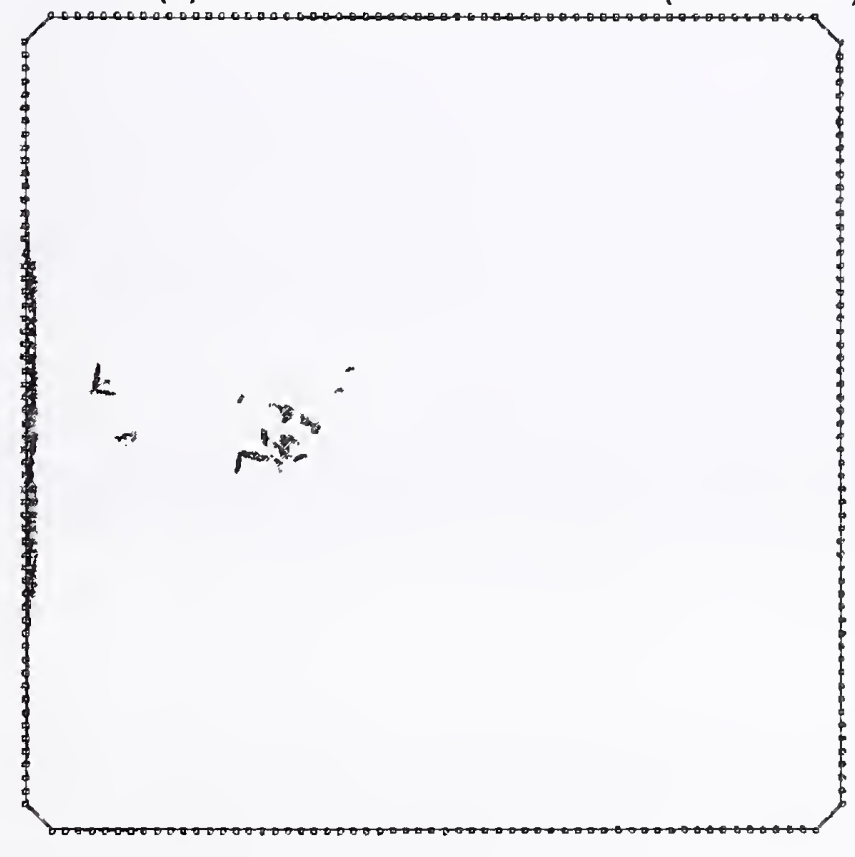

(b) Calculated landing gear debris ( $\mathrm{t}=0.735 \mathrm{~s}$ )

Figure 9-120. Less severe damage aircraft debris distribution in WTC 1. 


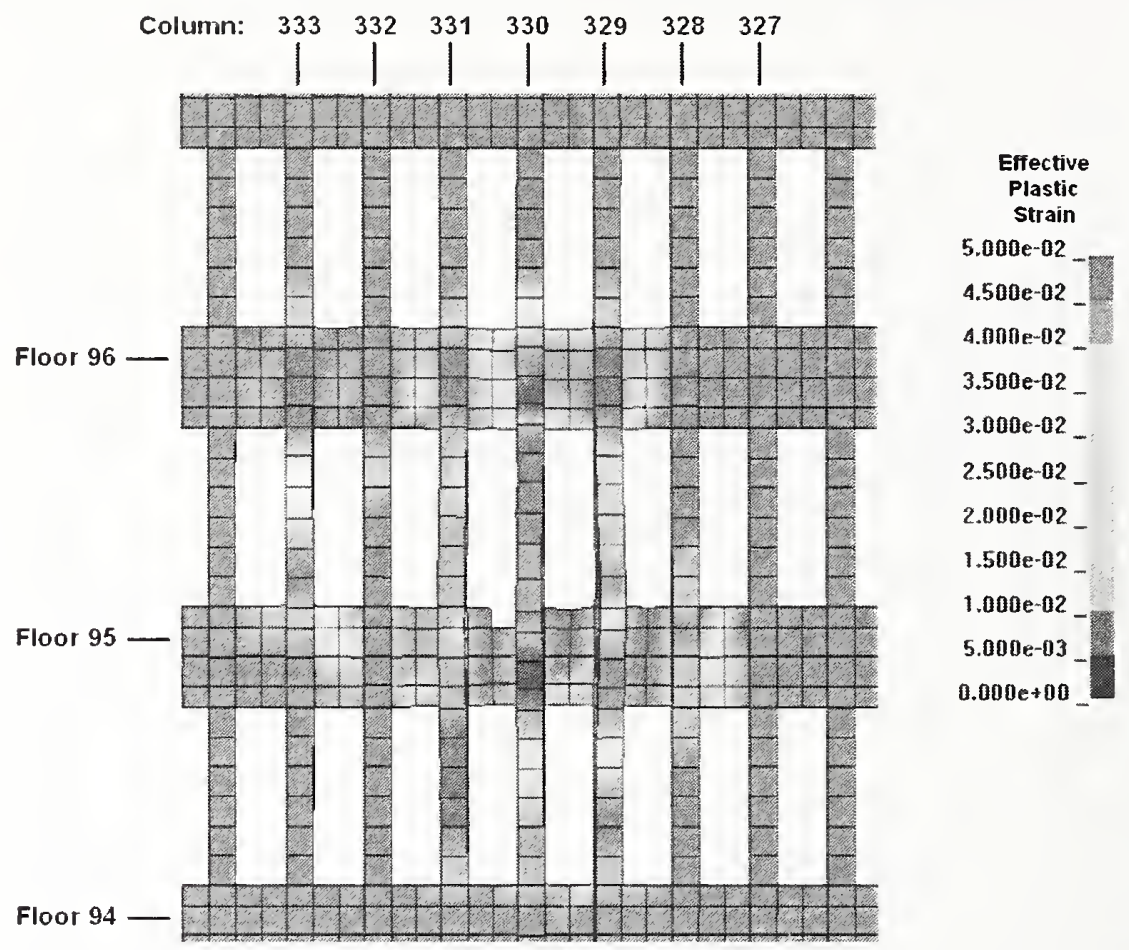

Figure 9-121. Damage to the south face of WTC 1 from the more severe damage global analysis.

Because of model size constraints, the panels on the south face of WTC 1 were modeled with a very coarse resolution. Neither the spandrel splice joints nor exterior column butt joints were modeled. Column ends and spandrel edges were merged together. The model, therefore, underestimates the damage to the tower on this face. The calculated damage produced by the more severe impact is shown in Figure 9-121. Columns 329-331 on floors 94 through 96 had sustained substantial damage. Had a fine mesh been used on these columns, it is likely that they would have failed on floor 95 , and possibly on 94 and 96. Based on the failure modes observed on the north face and on the speed and mass of the debris, the panel would potentially be knocked free by failing at the connections.

\section{Landing Gear Trajectory}

It is believed that a portion of the main landing gear of AA 11 exited WTC 1 at the 94th or 95th floor and landed at the corner of Rector and West Streets. This debris is believed to be a tire, wheel, brake assembly, and hub of a main landing gear, as shown in Figure 9-122. Based on the final position of the landing gear and assuming the landing gear to be a projectile with a horizontal initial velocity, the exit speed of the landing gear from the south wall of WTC 1 can be estimated to be about $105 \mathrm{mph}$. Note that there is a significant uncertainty in this estimate associated with the exit trajectory, aerodynamic effects, landing position rather than final resting position of debris, etc. Another piece of landing gear debris, shown in Figure 9-123, was found embedded in what is postulated to be the panel containing columns $329,330,331$, running from the 93rd to the 96th floors. This panel was dislodged from the building and found at Cedar Street near its intersection with West Street. As little other damage had been 
documented on the south face of WTC 1, it is postulated that the landing gear debris that landed at the corner of Reetor St. and Wcst St. also exited through this panel location.

The amount of aircraft debris found to exit WTC 1 in the global impact analyses varied, as shown in Figure 9-118 to Figure 9-120. However, no portion of the landing gear was obscrved to cxit the tower in the simulations, but rather was stopped inside, or just outside, of the eorc. In order to simulate the trajectory of specific pieces of aircraft debris, a fairly precise knowledgc of the internal configuration of the building would be needed. This is espccially true with eomponents passing through the corc of the building, where some of the most massive building contents and partition walls wcre present. Uncertainties regarding the internal layout of cach floor, such as the location of hallways or walls, can make the difference between debris from a spccifie eomponent passing through or being stopped insidc the structure. Modeling uncertainties may also have eontributed to the inability to predict the trajectory of specific aircraft components.

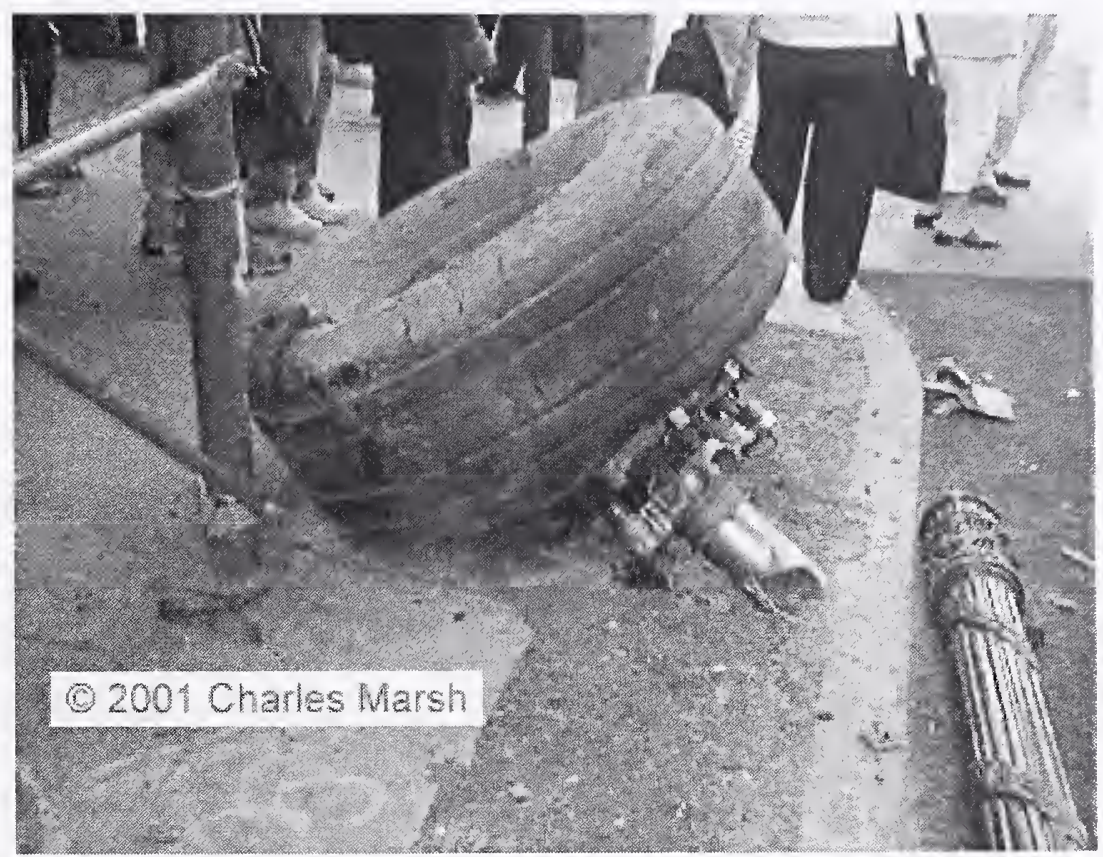

Figure 9-122. Landing gear found at the corner of West and Rector streets. 


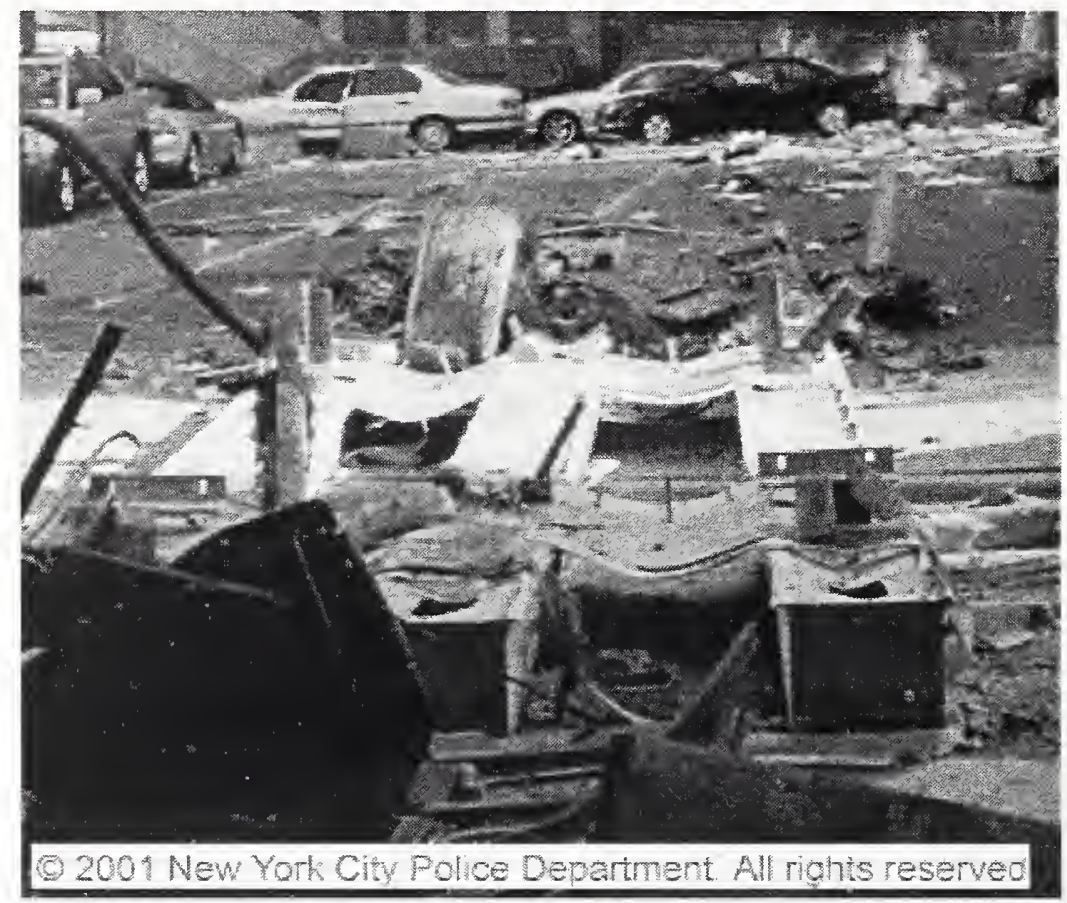

Figure 9-123. Landing gear found embedded in exterior panel knocked free from WTC 1.

\section{Stairwell Disruption}

According to eyewitness interviews, stairwells 1 (referred to also as stairwell A), 2 (stairwell C), and 3 (stairwell B) inside the core were impassable at floor 92 and possibly above after the impact of AA 11 . The calculated base case stairwell disruption is shown in Figure 9-124 for floors 93 through 97. Stairwell positions are outlined with red boxes in the figure. No debris or disruption was observed to the core on floor 92 in the calculation; therefore, it is not shown in the figure. Recall that the global model for WTC 1 only contained partition walls in the core on floors 94 through 97 . Therefore, the ability to ascertain damage and/or debris in the stairwell on floors 92 and 93 was limited. The floor slab was removed from view on floors 94 through 97 so that debris is more visible.

Based on the calculated damage to, or debris in, the stairwells on floors 94 to 96 , all three stairwells appear impassable. Given that falling debris in these areas would cause further subsequent damage to the floors below, as well as block passage on these floors, this result was reasonably consistent with the eyewitness accounts.

\section{Floor Damage Visible on the North Face of WTC 1}

One location where the damage to the WTC 1 truss floors could be observed was through the opening in the tower exterior produced by the aircraft impact. A photograph of the impact damage on the north face of WTC 1 is shown in Figure 9-125(a). The magnitude of damage is difficult to quantify as a result of the strong contrast in lighting between the tower interior and exterior and the smoke inside the building. However, the photograph shows that the truss floor was heavily damaged and/or removed in the primary impact zone. The depth of the floor damage extending into the tower could not be determined. 


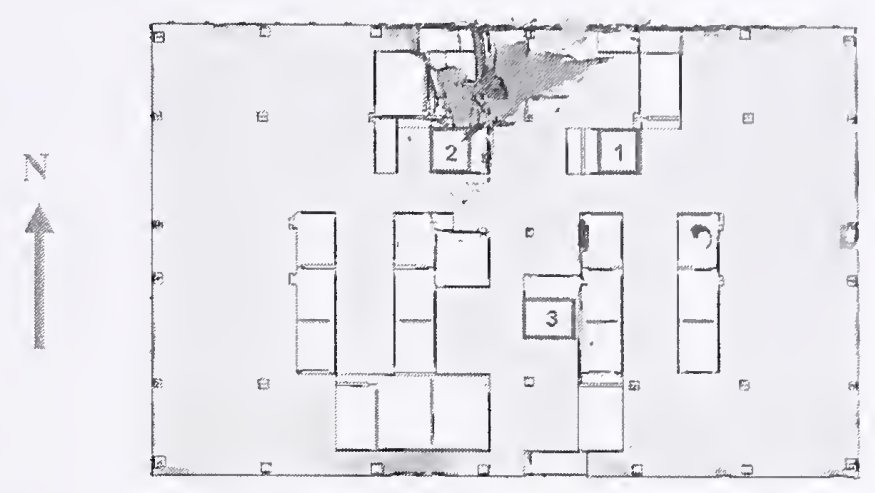

(a) Floor 93

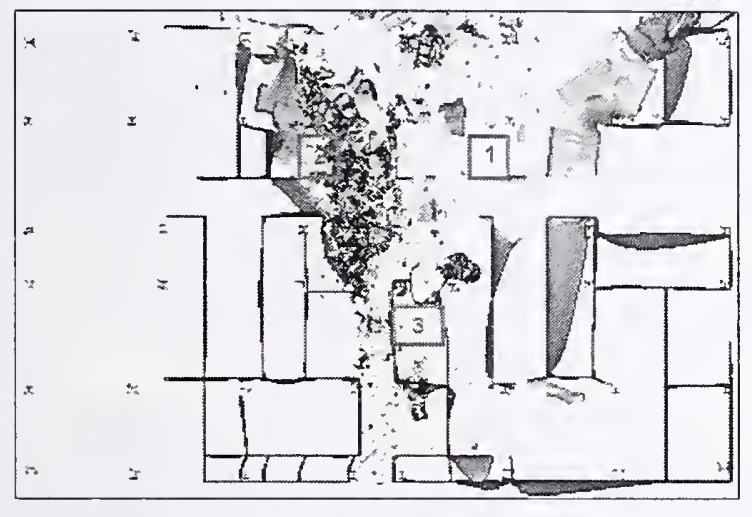

(b) Floor 94

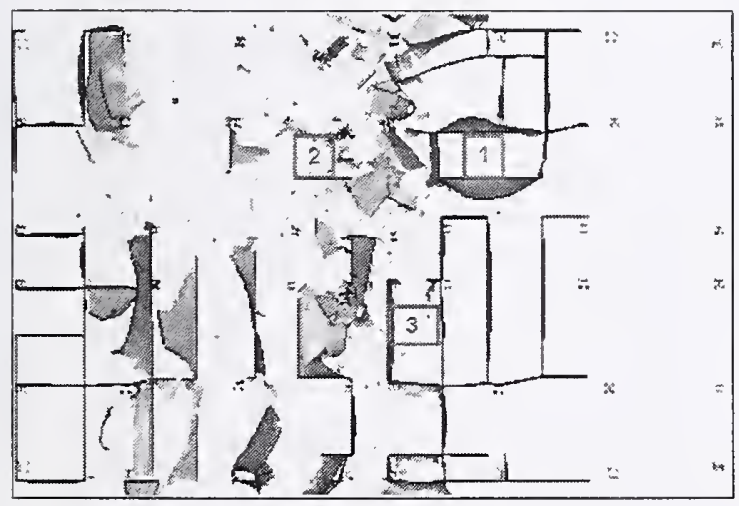

(d) Floor 96

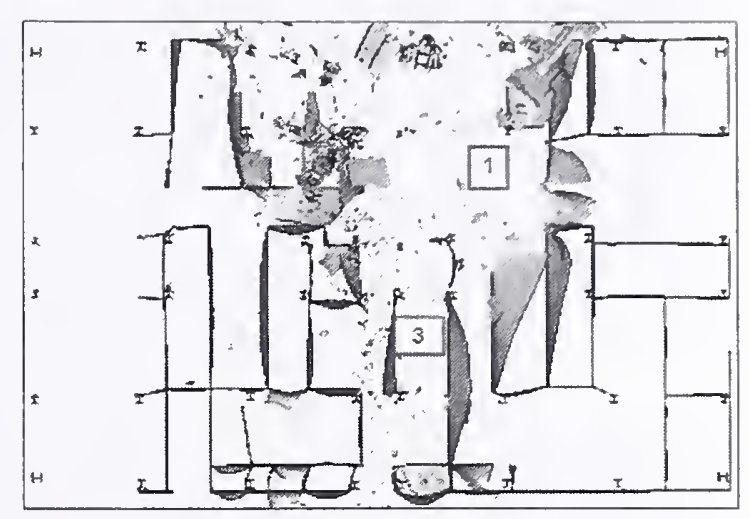

(c) Floor 95

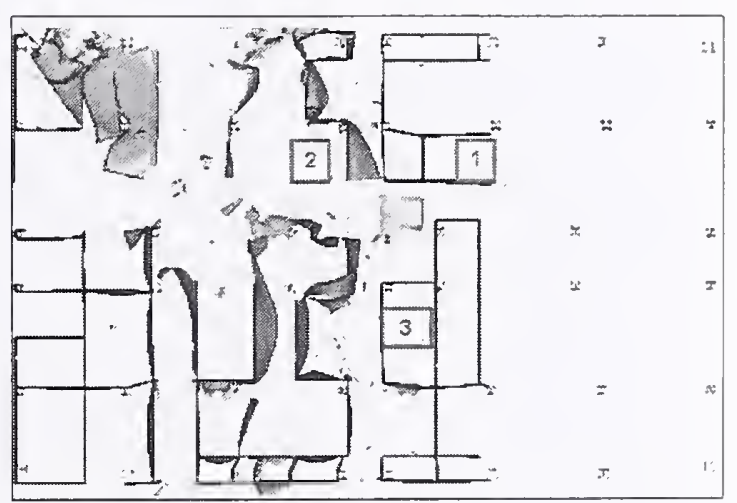

(e) Floor 97

Figure 9-124. Base case stairwell disruption in WTC 1. 


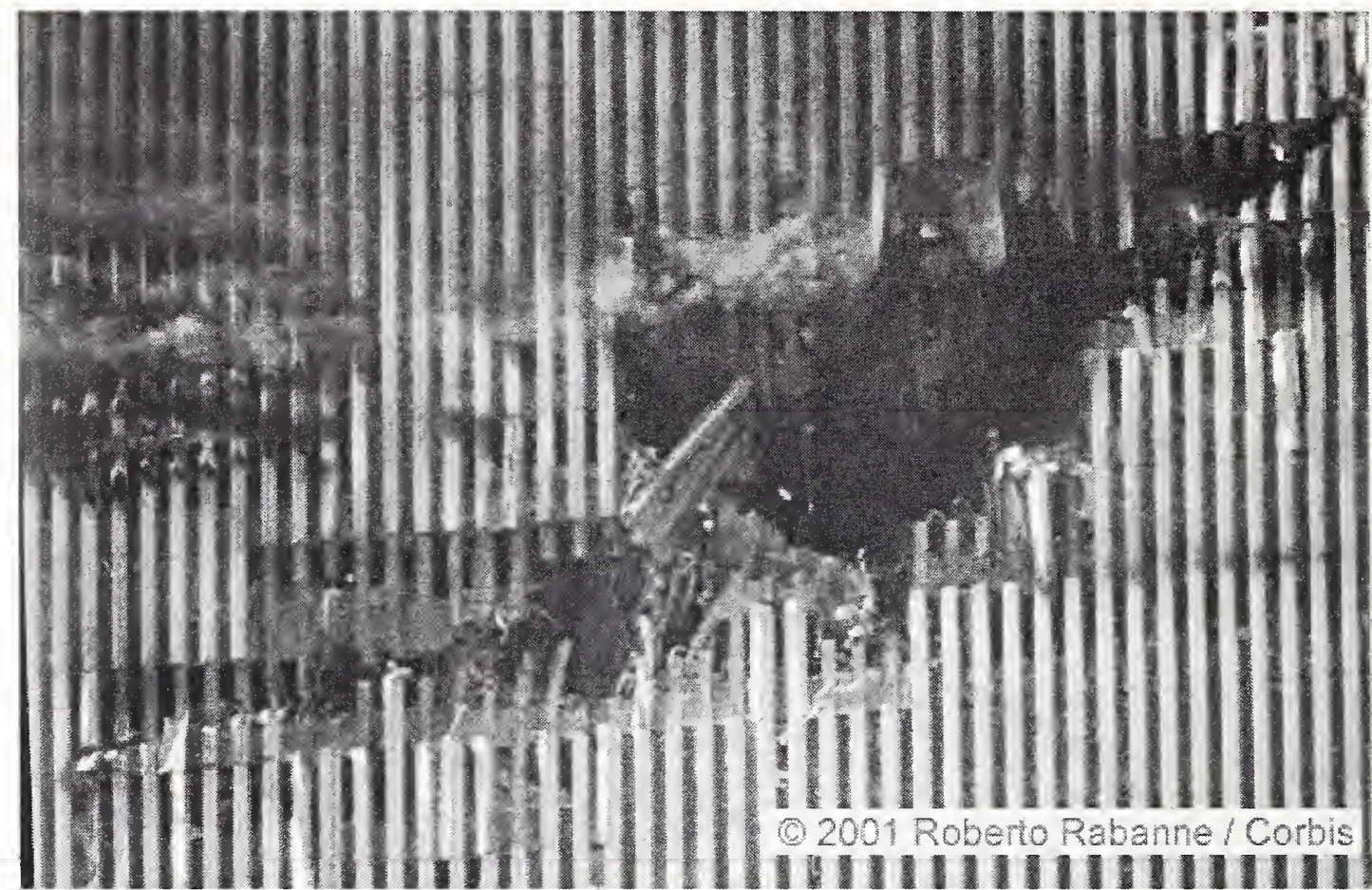

(a) Damage photograph

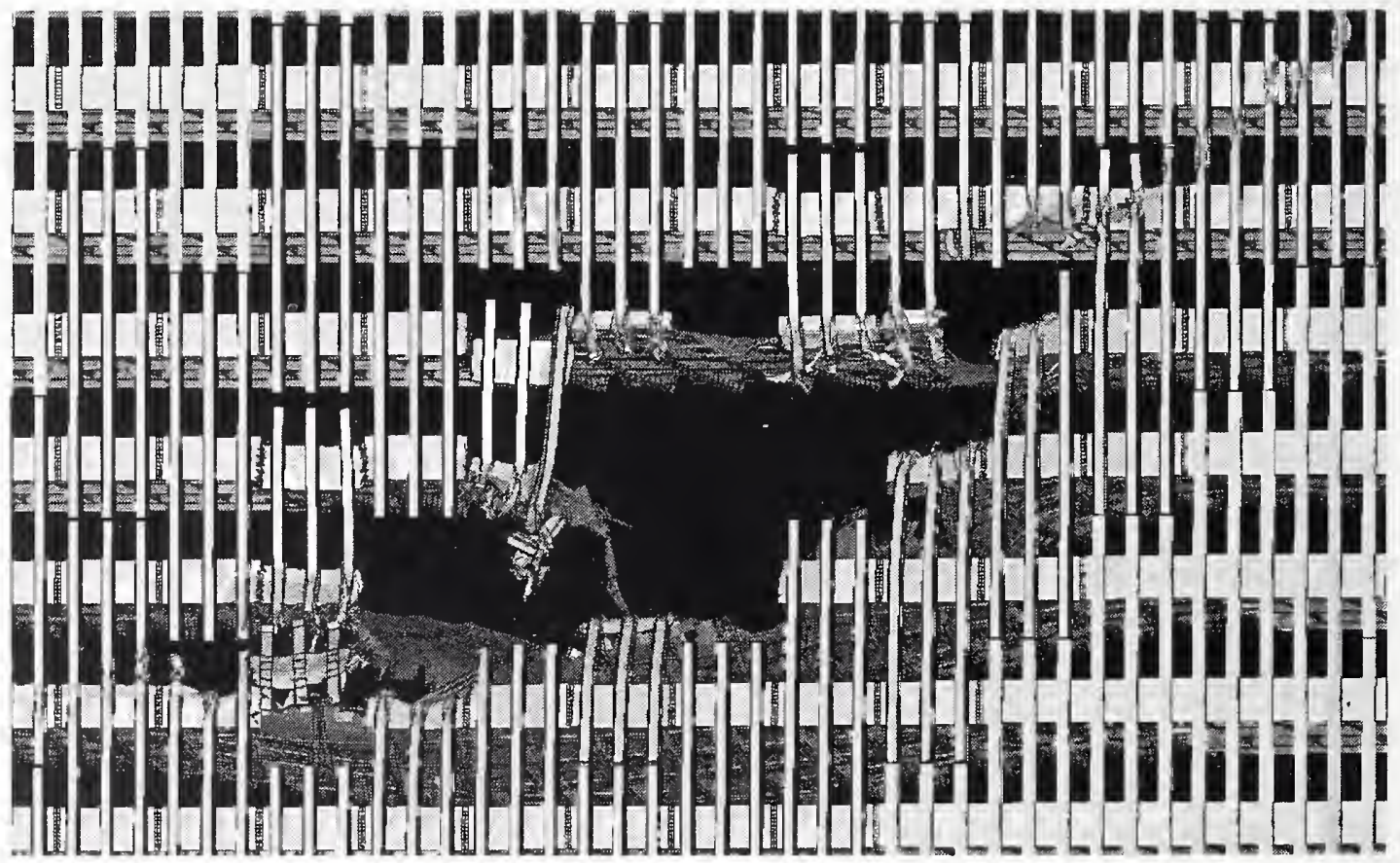

(b) Calculated damage

Figure 9-125. Calculated and observed WTC 1 damage (front view). 
A corresponding image of the calculated damage to the tower structures is shown in Figure9-125(b). The structures beyond the start of the core were removed and replaced with a black background for comparison with the photograph. Although a quantitative comparison of the calculated and observed damage could not be made from the available damage photographs, the truss floor damage appeared to be consistent.

\subsubsection{Comparison with Observables on WTC 2}

\section{Damage on the North Exterior Wall}

From photographic evidence, such as that shown in Figure 9-126, damage on the north wall at the northeast corner of WTC 2 was documented and is shown in Figure 9-127. As mentioned earlier, there was significant uncertainty as to the actual layout of the workstations and other building contents on the impacted floors of the towers. Recall that generic workstation configurations were used to model these building contents, as shown in the northeast corner of WTC 2 in Figure 9-128(a). Uncertainties regarding this layout, such as missing partition walls and workstations. can make the difference between debris from a specific component passing through or being stopped inside the structure. The base case impact response of the northeast corner of WTC 2 on the 81st floor is shown in Figure 9-128(b).

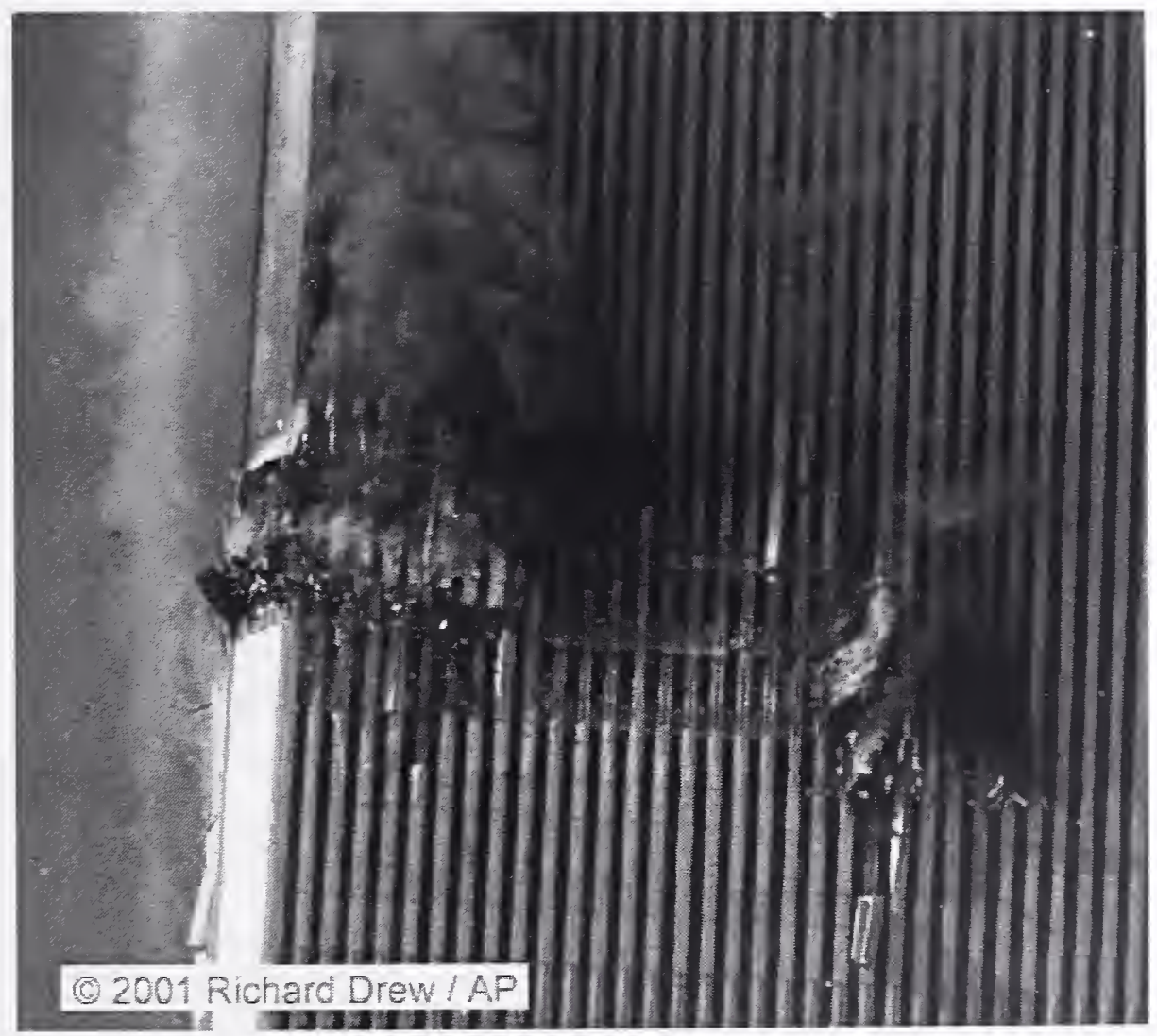

Figure 9-126. Impact Damage to the Northeast Corner of the Exterior Wall of WTC 2. 


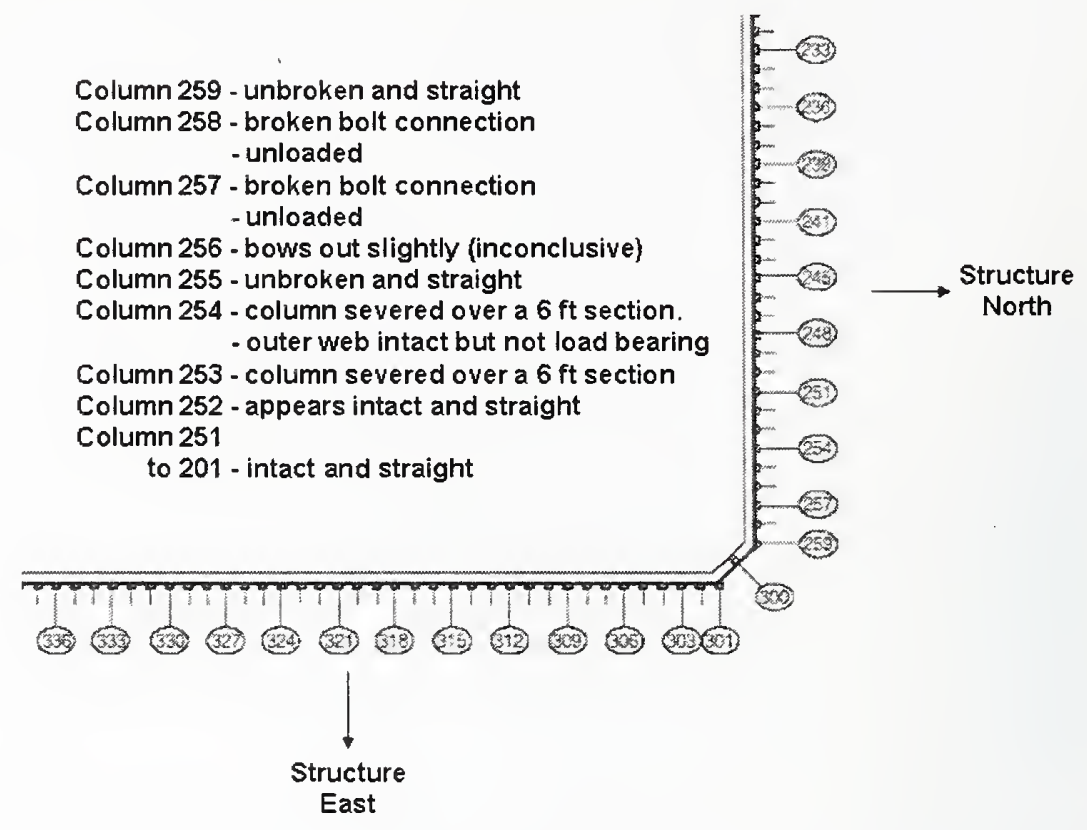

Figure 9-127. Documented damage to the 81st floor of the northeast corner of WTC 2. 

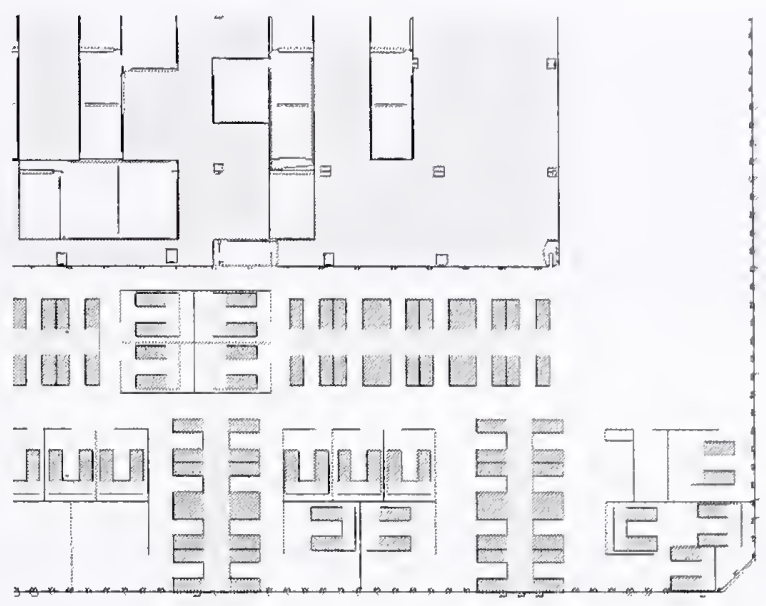

(a) Initial workstation configuration

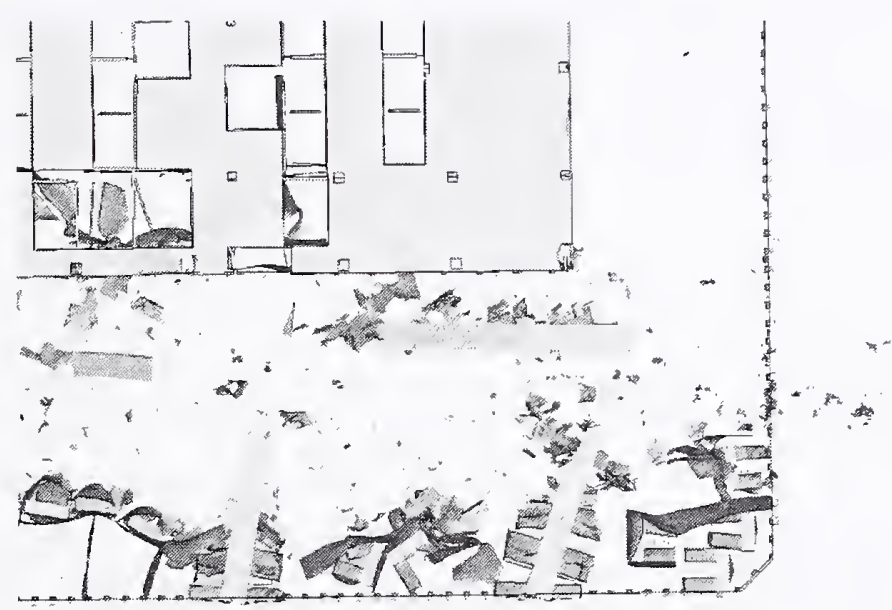

(b) Debris field at $\mathrm{t}=\mathbf{0 . 6 2 \mathrm { s }}$

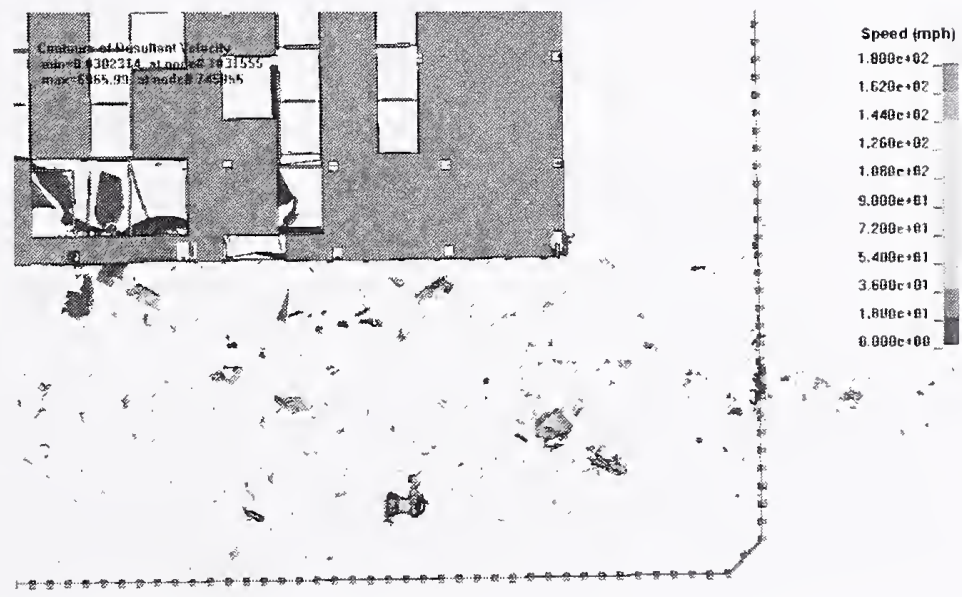

(c) Residual speed of aircraft debris (contours in $\mathrm{mph}$ )

Figure 9-128. Base case analysis on the 81st floor of the northeast corner of WTC 2. 
Aircraft debris on the 81st floor is shown in Figure 9-128(c), with the coloring depicting the residual speed of the debris field. Notice that some of the debris in this figure, weighing approximately $3,800 \mathrm{lb}$, was traveling at $110-150 \mathrm{mph}$ and was projected to impact between columns 252 and 256 . The leading debris was in fact portions of the starboard main landing gear main strut and main landing gear beam. That significant debris was projected to impact in the region of significant damage shows positive agreement with damage evidence available for the north wall of WTC 2.

\section{Stairwell Disruption}

According to eyewitness interviews, stairwells 2 and 3 on floor 78 of WTC 2 were impassable. Stairwell 1 (referred to also as stairwell A), which was located in the northwest comer of the core, was passable. The calculated base case stairwell disruption is shown in Figure 9-129. Stairwells 1 and 2 (stairwell C) on floor 78 of WTC 2 were outside of the core column region. These stairwells were not included in the WTC 2 model. Therefore, a good assessment could not be made for stairwell 2. However, disruption to stairwell 3 (stairwell B) is shown in Figure 9-129. From the damage shown in the figure, the stairwell appears to be impassable. As no damage or debris was seen in the northwest corner of the core, the top right in the figure, stairwell 1 in this area of the core was likely unaffected. Both of these assessments were consistent with the eyewitness accounts.

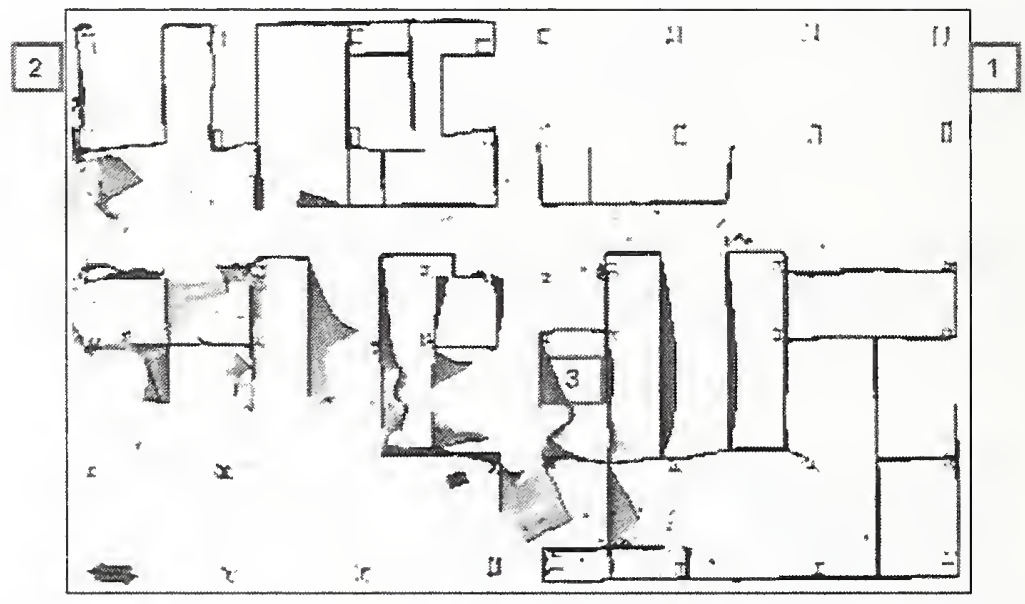

Figure 9-129. Base case stairwell disruption on floor 78 in WTC 2.

\section{Landing Gear Trajectory}

A portion of the landing gear of UAL 175 exited WTC 2 and landed on the roof of 45 Park Place. No photographic evidence was available to document the size of the fragment and whether this was a nose or main landing gear. From the damage to the building, it was believed that the landing gear fragment might have exited somewhere along the north wall between column 251 and the northeast corner on floor 81 . Based on the final position of the landing gear and assuming the landing gear to be a projectile with a horizontal initial velocity, the exit speed of the landing gear from the north wall of WTC 2 can be estimated to be about $102 \mathrm{mph}$. Note that there is a significant uncertainty in this estimate associated with the exit trajectory, aerodynamic effects, landing position rather than final resting position of debris, etc. 
The calculated aircraft debris distribution and landing gear and engine debris distributions for UAL 175 are shown in Figure 9-130 to Figure 9-132 for the three severity scenarios. A portion of the port main landing gear was seen to exit the building at approximately $230 \mathrm{mph}$ in the more scvere impact analysis, as shown in Figure 9-131(b). No landing gear debris exited the building in either the base casc or less severe simulations. At the conclusion of the simulation, the base case analysis had a substantial piece of the starboard main landing gear still at approximately $130 \mathrm{mph}$ that was expected to impact the northeast corner.

\section{Engine Trajectory}

A portion of an engine also exited the tower at the northeast corner of the building and was found at the intersection of Murray and Church Strcets. From the damage to the building, it was believed that the engine exited the building in this corner of WTC 2. Based on this trajectory, it was estimated that the engine exited the building at approximately $120 \mathrm{mph}$. The engine trajectories predicted from the base case global analysis are shown in Figure 9-133, which indicates that the cngine that exited from the northeast corner is likely the starboard engine. The dotted line indicates the extrapolated engine flight path based on the initial trajectory of the starboard cngine. Notice that this trajectory would result in engine fragments exiting at the northeast corner. In the simulations, the engines were projected to stop short of this position, although they followed the extrapolated trajectory reasonably well.

Speed histories for the aft portion of the starboard engine are shown in Figure 9-134. The cngine would typically brcak up into smaller fragments from the forward section of the engine and a larger section from the aft end, as shown in Figure 9-135. In all three simulations, the speed was seen to drop by approximately $200 \mathrm{mph}$ due to impact with the exterior pancl, floor slab, and floor truss. Interaction with these portions of the structure ends by approximately $0.12 \mathrm{~s}$. This initial impact is shown in Figure 9-136. The engine debris then continued through the tenant space of the 81st floor, plowing through the workstations and contents. Whether or not the fragment passes over these contents, or if other debris and fuel remove the contents from the engine's path, affects the deceleration of the fragment. At the end of the simulation, the speed of the aft portion of the engine was below $80 \mathrm{mph}$, and it was more than $60 \mathrm{ft}$ from the northeast corner of the building. For these calculations, it was estimated that the building contents would likely stop the engine fragment prior to impacting the northeast corner of the exterior wall.

None of the three WTC 2 global impact simulations resulted in a large cngine fragment exiting the tower. However, the impact behavior suggests that only minor modifications would be required to achieve this response. For example, if the starboard engine impact location was lowered by 1 to $2 \mathrm{ft}$, which is within the aircraft impact geometry uncertainty range, the engine would likely have a greater residual speed inside the tower (over $100 \mathrm{mph}$ ). In the global analyses performed, the engine impacted the underside of the 82nd floor, as shown in Figure 9-136. This resulted in a large reduction in speed of approximately $200 \mathrm{mph}$. In the component analyses discussed in Chapter 5, the engine speed decreased by roughly $60 \mathrm{mph}$ when impacting an exterior panel alone. This additional speed would likely result in a large engine fragment exiting the northeast corner of the tower. 


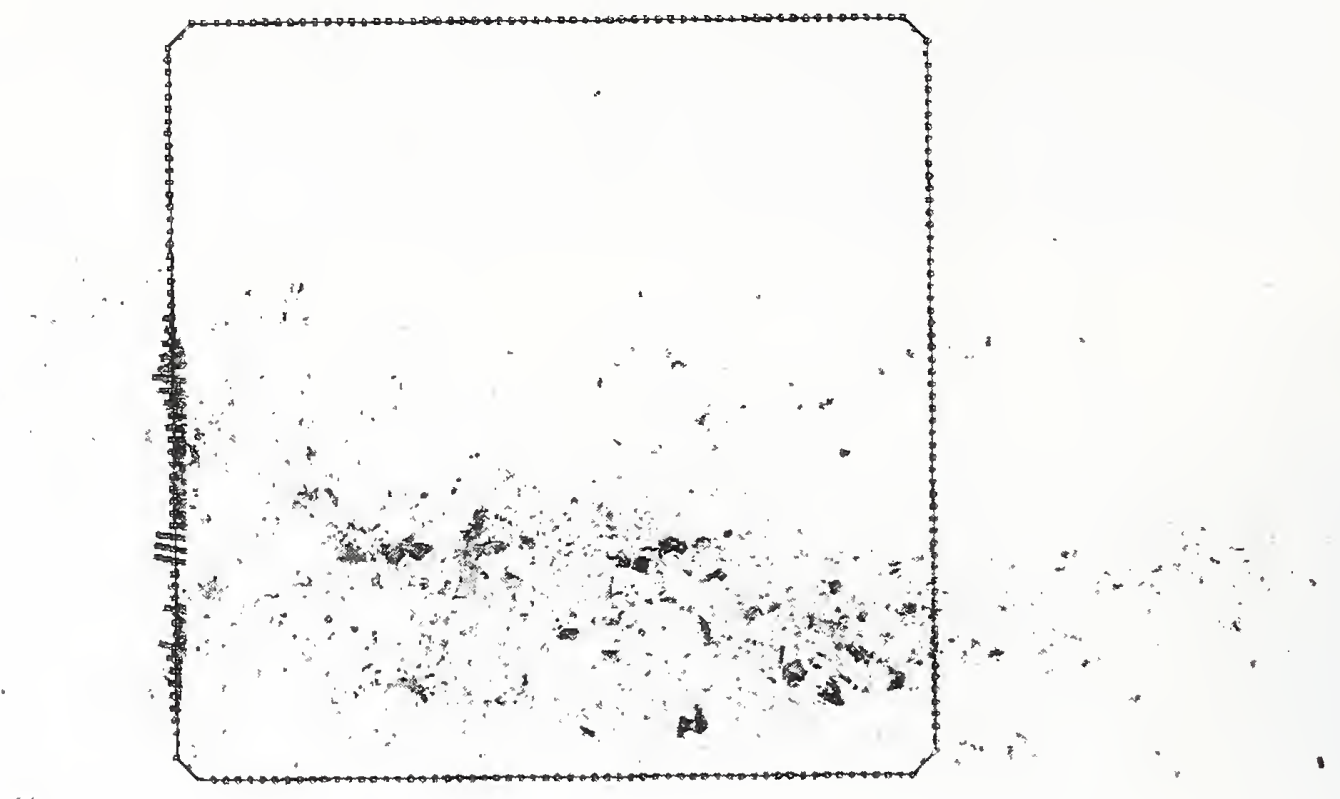

(a) Calculated aircraft debris ( $t=0.62 \mathrm{~s}$ )

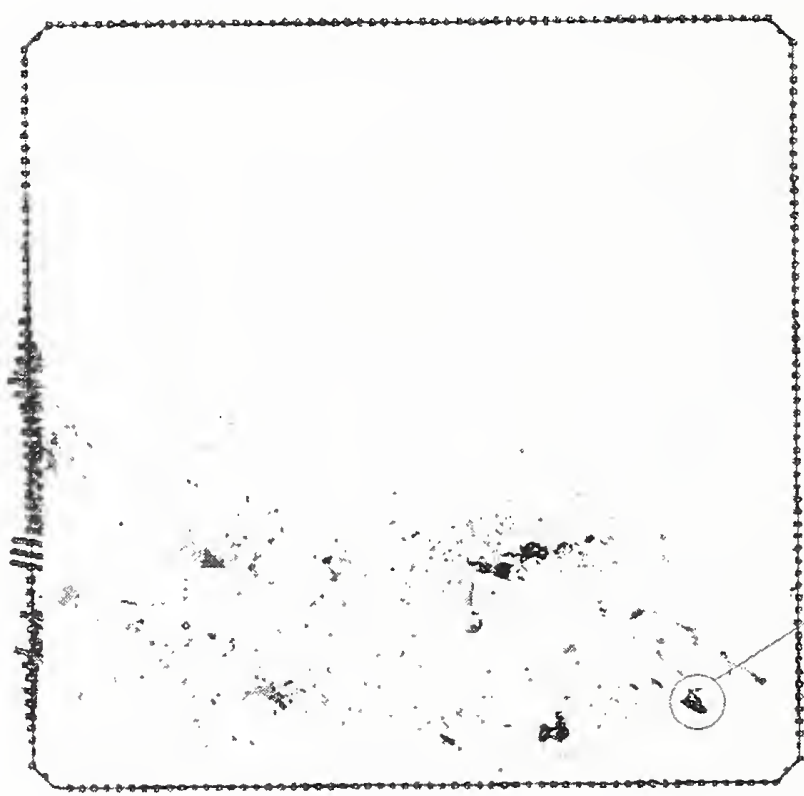

Starboard Main Landing Gear (Main Strut, Main Beam)

(b) Calculated engine and landing gear debris ( $t=0.62 \mathrm{~s}$ )

Figure 9-130. Base case damage aircraft debris distribution in WTC 2. 


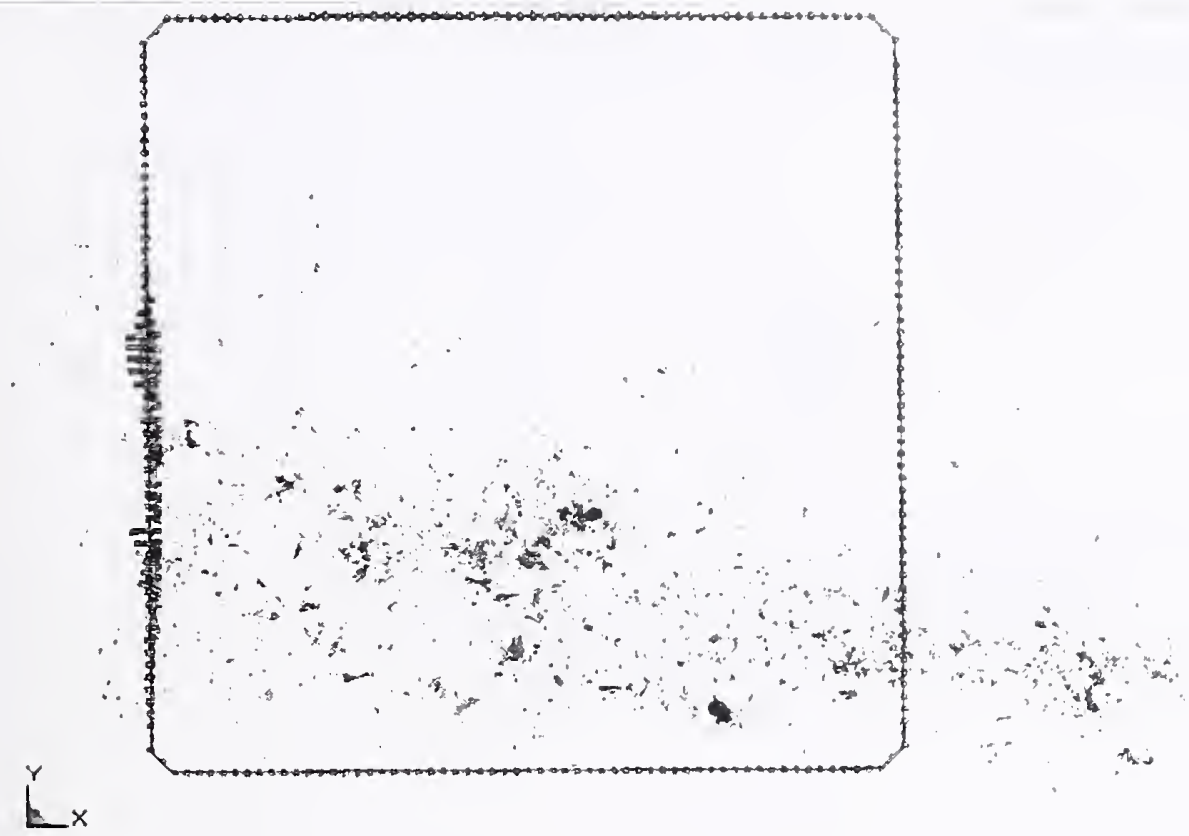

(a) Calculated aircraft debris ( $\mathrm{t}=0.58 \mathrm{~s}$ )

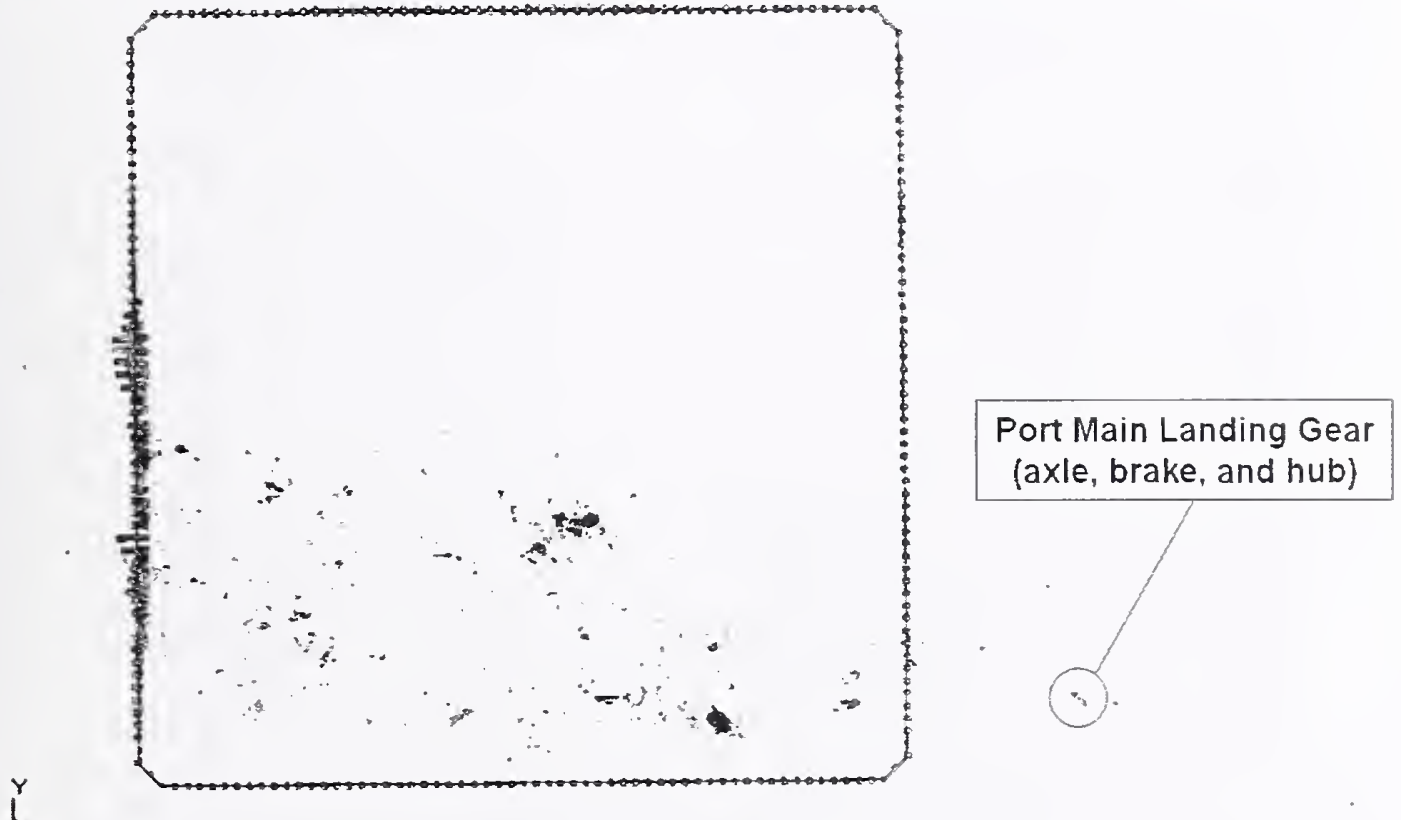

(b) Calculated engine and landing gear debris ( $t=0.58 \mathrm{~s}$ )

Figure 9-131. Aircraft debris distribution in the more severe WTC 2 impact. 


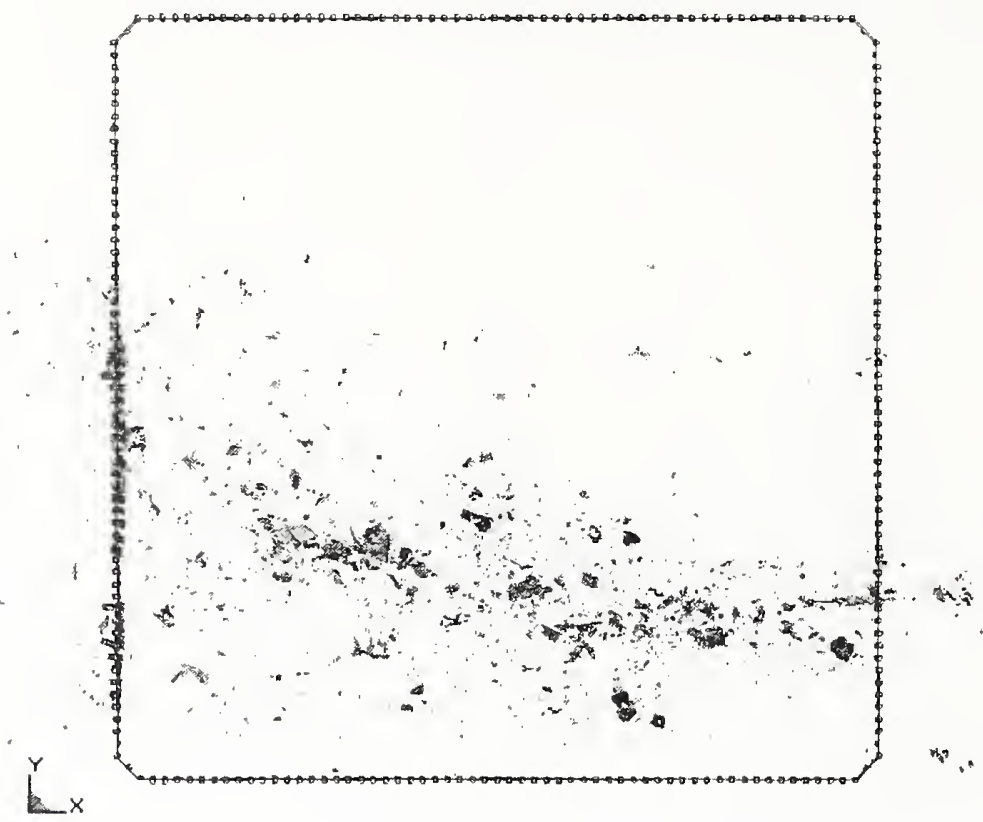

(a) Calculated aircraft debris ( $\mathbf{t}=\mathbf{0 . 6 6} \mathrm{s}$ )

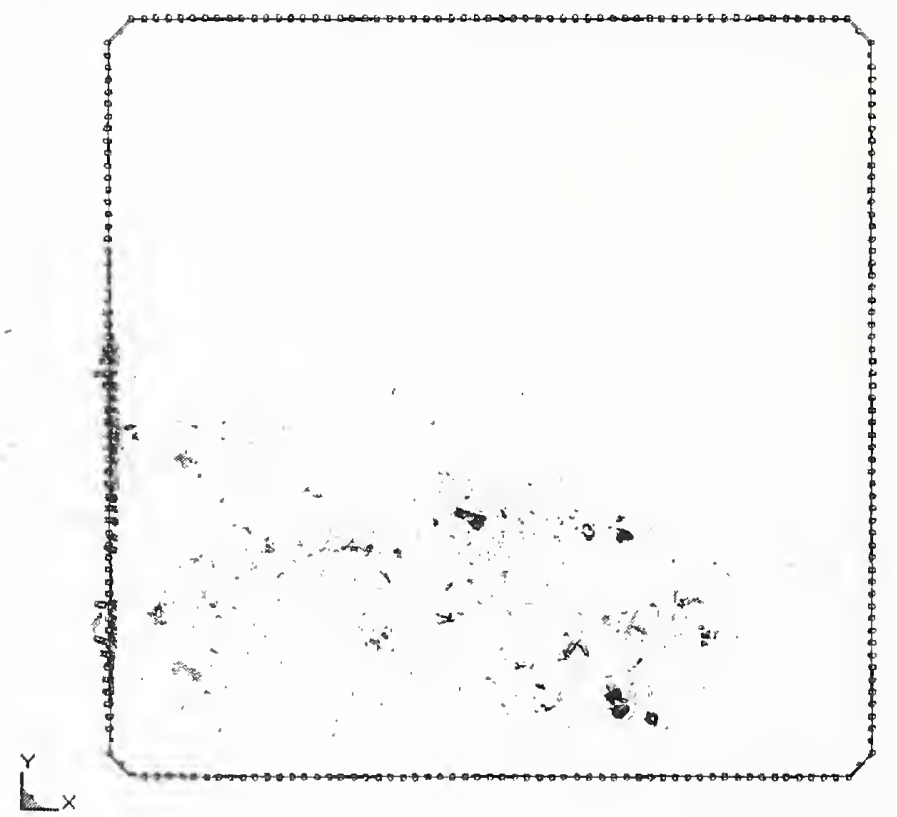

(b) Calculated engine and landing gear debris ( $\mathrm{t}=\mathbf{0 . 6 6} \mathrm{s}$ )

Figure 9-132. Aircraft debris distribution in the less severe WTC 2 impact. 

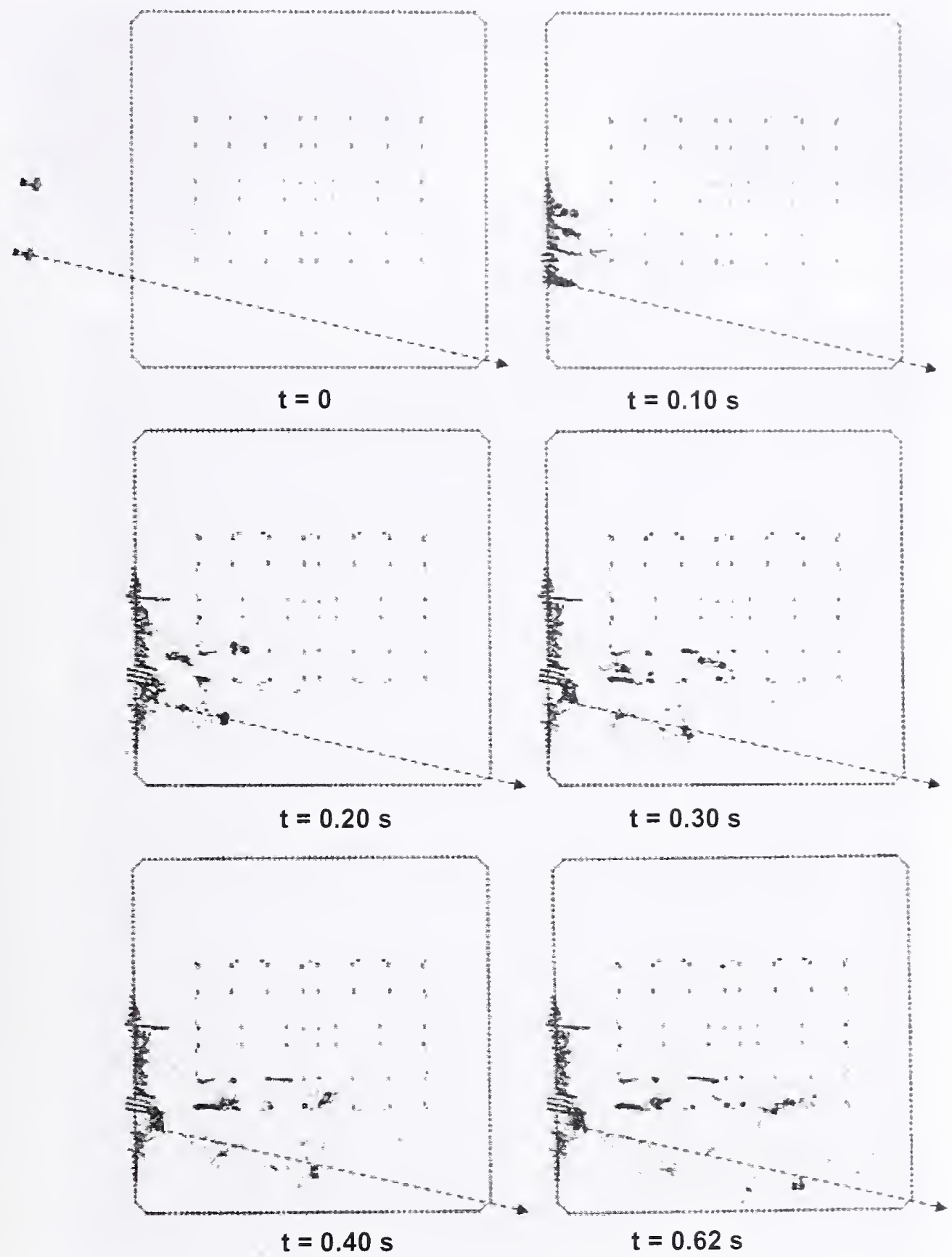

Figure 9-133. Starboard engine fragment trajectory in the base case global analysis of WTC 2. 


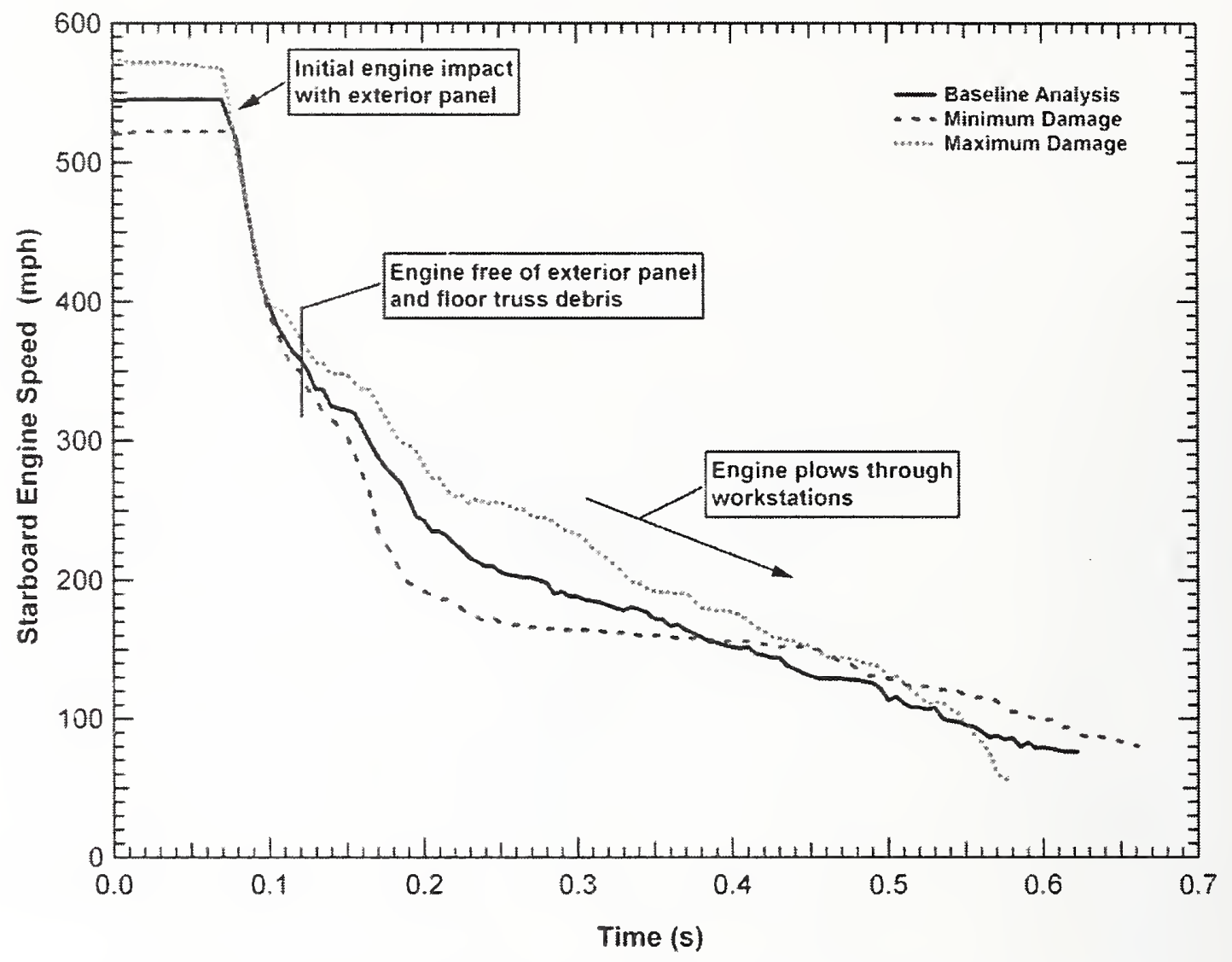

Figure 9-134. Speed of the aft portion of the starboard engine. 


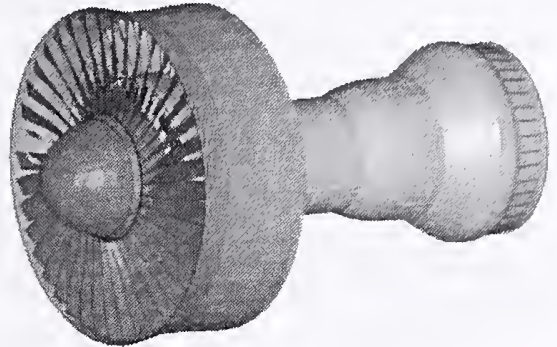

(a) Undamaged engine

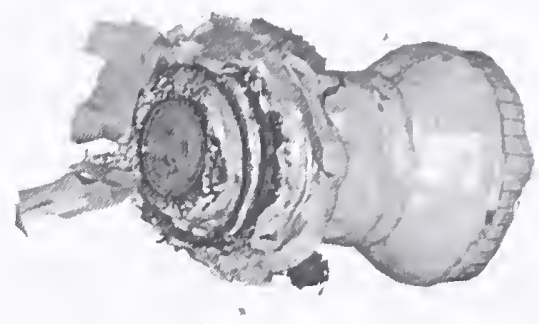

(b) Large engine fragment

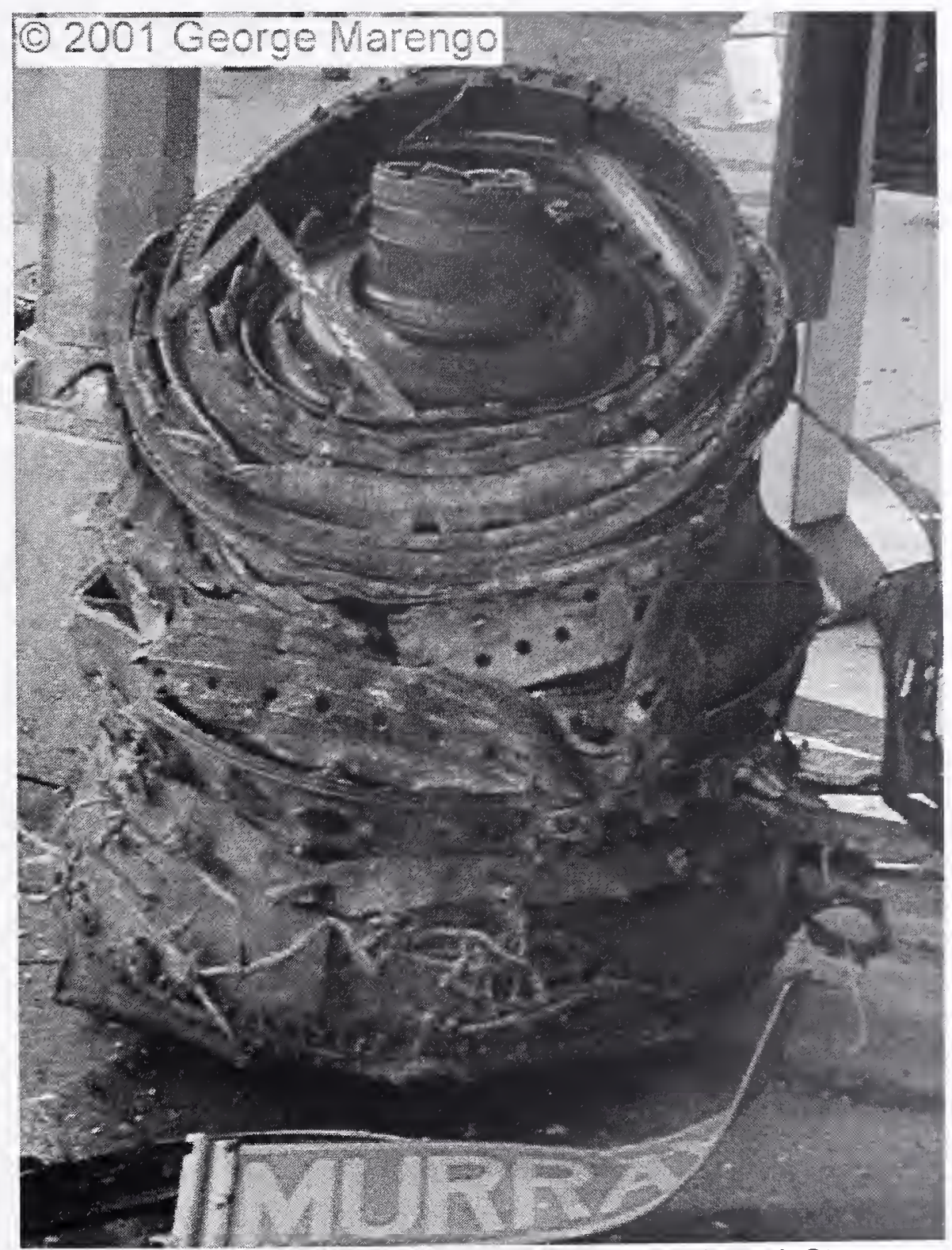

(c) Engine fragment found at Murray and Church St.

Figure 9-135. Calculated and observed engine damage. 

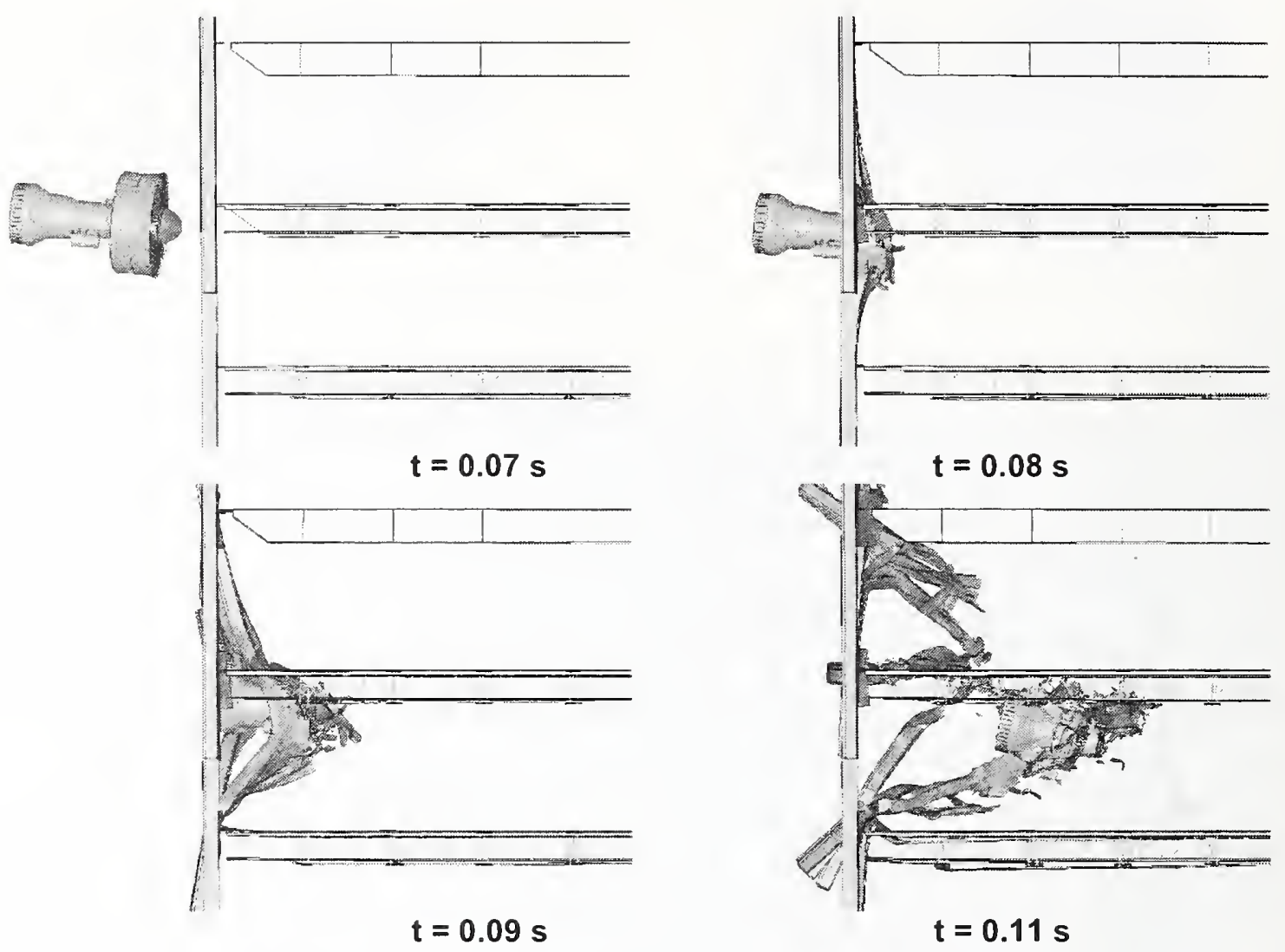

Figure 9-136. Starboard engine impact with the south face of WTC 2 in the base case global analysis.

Other minor modifications to the model could also result in a large engine fragment exiting the building. As mentioned previously, there was significant uncertainty in the distribution of building contents on the floors of the impact area. If any portion of the east side of WTC 2 was relatively free of office materials, the engine fragment would have been free to move relatively unrestricted and would have experienced little loss of speed. After the engine entered the structure, and without office materials, the engine fragment would only slow due to friction with the floor slab and occasional interaction with floor trusses above. After initially entering the building, the engine did not further penetrate the floor slab. Removing much of these building contents from the east side would result in the starboard engine fragment impacting the northeast corner of the tower with sufficient speed to exit the building. Little or no difference in core damage would result, as debris in this area had no chance of impacting the core.

\section{Floor Damage Visible on the South Face of WTC 2}

One location where the damage to the WTC 2 truss floor could be observed was through the opening in the tower exterior produced by the aircraft impact. A similar comparison for the WTC 1 truss floor damage was shown in Figure 9-125. The magnitude of damage was difficult to quantify as a result of the strong contrast in lighting between the tower interior and exterior and the smoke inside the building. This was worse for WTC 2, where the prevailing wind and fire conditions resulted in larger quantities of smoke exiting through the opening on the impact face. The partial photographic evidence did suggest that 
a similar level of truss floor damage in the impact zonc occurred for WTC 2. The severity and the depth of the floor damage extending into the tower could not be detcrmined. Although a quantitative comparison of the calculated and observed damagc could not be madc from the availablc damage photographs, the truss floor damage appears to bc consistent.

\section{The 'Cold Spot' on the North Face of WTC 2}

A 'cold spot' was observed on the north face of the tower between columns 238 and 250 on floors 80,81 , and 82 . The cold spot was a region of the tower where no dcbris could be seen from the exterior of the tower, and no significant fires were observed prior to towcr collapse.

Much of the explanation for the cold spot was obtained from an analysis of the debris trajectory aligned with the cold spot. The debris path, obtained by projecting the width of the cold spot along the initial lateral impact trajectory of the aircraft, is shown in Figure 9-137 (13 degrees relative to the tower face normal). This region was aligned laterally with the left side of the fuselage and the port wing structures. Considering the baseline impact orientation and trajectory, shown in Figure 9-138, it can be seen that much of the wing debris impacted on floors lower than the observed cold spot. Only debris from very close to the fuselage would be expected on floor 80 or above. The debris from the port wing, including the majority of the aircraft fuel in the left side tanks, entered at floors 78 and 79.

The base case WTC 2 global analysis calculated a small amount of aircraft debris passing through the cold zone on floors 80 and 81 . However, the building contents were not completely modeled over the entire path in this section. After clearing the core region, the debris in the calculation had primarily an open path to the cold spot on the North wall of WTC 2. If all of the internal contents had been included, it is likely that all of this debris would have been stopped before reaching the cold spot.

The comparison of the calculated and observed impact response cold spot is inconclusive. Much of the absence of damage and aircraft debris in this region is explained by the impact orientation and trajectory. Much of this rcgion is not directly in the path of significant aircraft fuel and debris. In addition, the debris aligned with the cold spot would be required to pass through a significant portion of the core. A more accurate analysis of the impact mechanics leading to the formation of a cold spot would require a specific survey of the tenant layout, including both contents that acted as a barrier to the debris and walls that provided a barrier to subsequent fire propagation. 


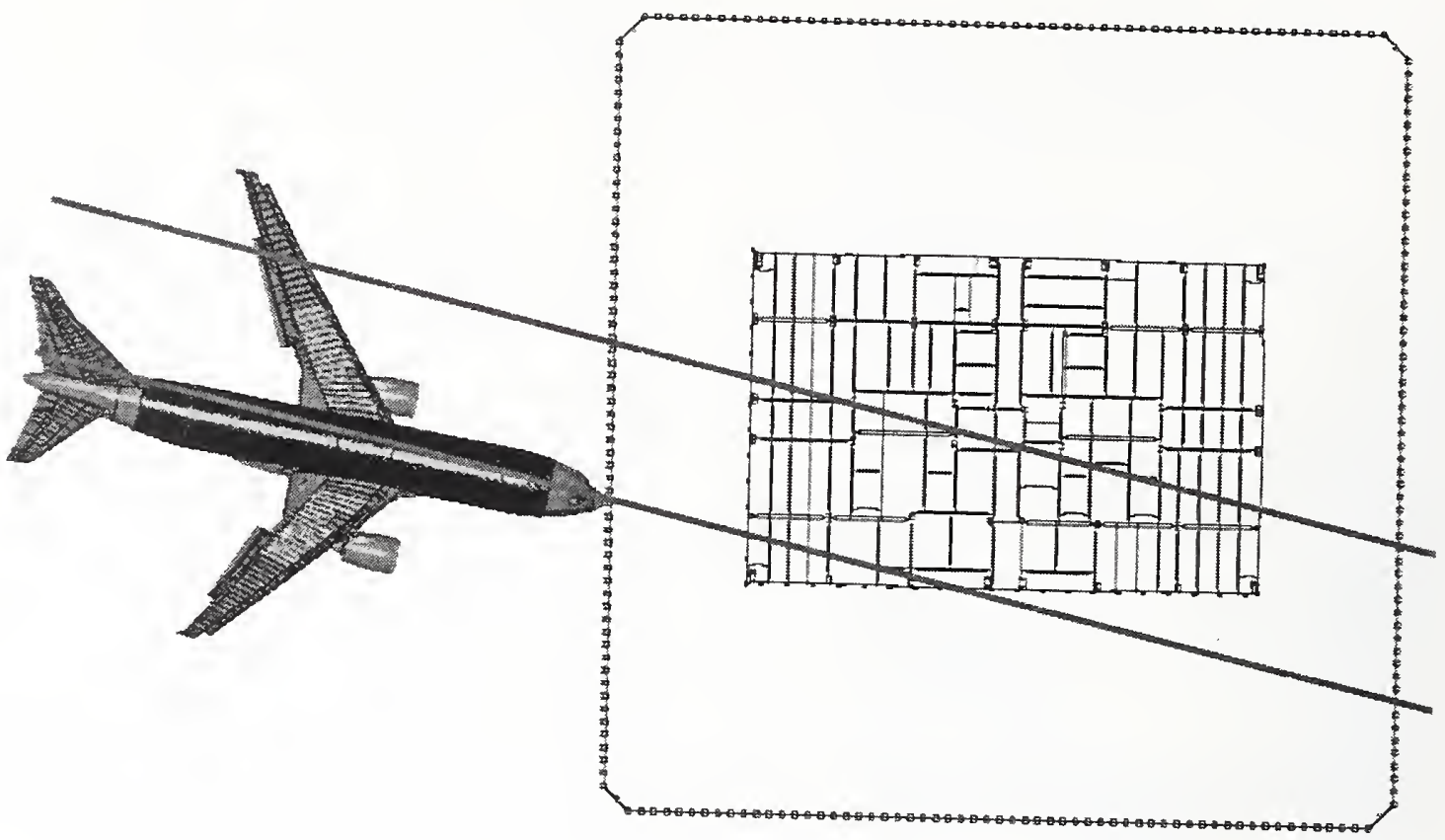

Figure 9-137. Projected debris path for the WTC 2 north face cold spot.

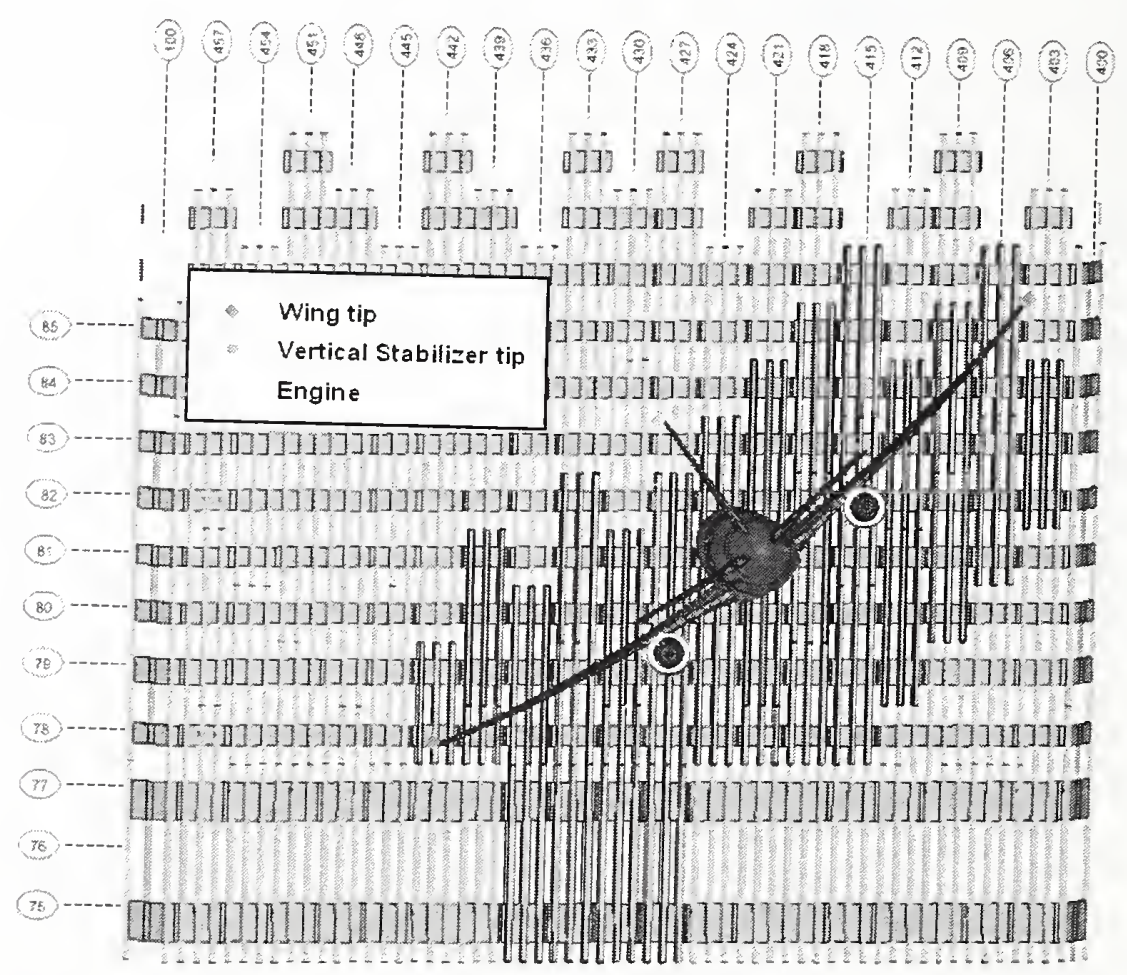

Figure 9-138. Base case WTC 2 impact orientation and trajectory (vertical approach angle $=6^{\circ}$, lateral approach angle $=13^{\circ}$ ). 


\subsubsection{Comparison with Observables - Summary}

A summary of the observables, their relativc significance, and the lcvel of agrecment with these observables seen in the simulations is shown in Table 9-13 and Tablc 9-14 for WTC 1 and WTC 2, respectively. The most valuable observable was the damage to the impactcd cxtcrior wall of cach towcr. The impact damage to the exterior walls was well documented and the response did not depend as much on unknown parameters, such as the detailcd office layout on cach floor. Eyewitncss accounts of damagc to stairwells and visible floor damage were also significant as they wcre the only available data on the damage to the tower interiors. That these observables were in good agrcement adds greater credibility to the predicted damage to the tower interiors.

Observed trajectories of specific aircraft components, such as the landing gear and engines, were considered to be of lower importance in validating the simulated damage to the tower. A fairly precise knowledge of the internal configuration of the building would be necded in order to simulate the trajectory of specific aircraft debris. Damage to the opposite side of each tower from the point of impact was also of lower importance. These parts of the tower were modeled with lower resolution and as a result, the models were not sufficient to capture the detailed damage. The actual damage was also predominantly caused by the landing gear and engine components already discussed. Overall, agreement between the observables and simulations is good.

Table 9-13. Comparison with observables from WTC 1.

\begin{tabular}{|l|c|c|}
\hline \multicolumn{1}{|c|}{ Observable } & Importance & Agreement \\
\hline Damage to the north exterior wall & Very significant & Very good \\
\hline Damage to the south exterior wall & Slightly significant & Fair \\
\hline Landing gear trajectory & Slightly significant & Poor \\
\hline Stairwell disruption & Significant & Good \\
\hline $\begin{array}{l}\text { Floor damage visible on the north } \\
\text { face }\end{array}$ & Significant & Good (unclear) \\
\hline
\end{tabular}

Table 9-14. Comparison with observables from WTC 2.

\begin{tabular}{|l|c|c|}
\hline \multicolumn{1}{|c|}{ Observable } & Importance & Agreement \\
\hline Damage to the south exterior wall & Very significant & Very good \\
\hline Damage to the north exterior wall & Slightly significant & Good \\
\hline Stairwell disruption & Significant & Good \\
\hline Landing gear trajectory & Not significant & Fair \\
\hline Engine trajectory & Slightly significant & Good \\
\hline $\begin{array}{l}\text { Floor damage visible on the south } \\
\text { face }\end{array}$ & Significant & Good (unclear) \\
\hline \begin{tabular}{l} 
The 'cold spot' on the north face \\
\hline
\end{tabular} & Slightly significant & Unclear \\
\hline
\end{tabular}

\section{$9.12 \quad$ COMPARISON WITH PREVIOUS STUDIES}

Two previous studies were conducted to estimate the impact damage to the WTC towers. These studies were performed by staff from Massachusetts Institute of Technology (MIT) (Wierzbicki, Xue, and 
Hendry-Brogan 2002) and Weidlinger Associates, Inc. (WAl) (Levy and Abboud 2002). The MIT study used an energy balance approach to estimate damage to the core columns. Estimates were made for the initial kinetic energy of the impacting aircraft and the internal energy absorbed in fragmentation of the aircraft and damage to the tower exterior columns, floor slab, and core columns. The energy absorbed by the core was used to estimate the number of failed core columns.

The WAI study used the FLEX finite element code to calculate the aircraft impact damage to both towers. The FLEX family of finite element modeling software (Vaughan 1997) was developed and maintained by WAI. FLEX is an explicit, nonlinear, large deformation transient analysis finite element code for the analysis of structures subjected to blast, impact, and shock loadings. The overall code architecture is very similar to that of LS-DYNA, used to calculate the aircraft impact damage in this investigation.

In the WAI calculations, the aircraft and WTC towers models were composed of beam and shell elements. The aircraft model consisted of 27,000 shell elements and 23,000 beam elements. The aircraft fuel was included in the model by increasing the mass of the structures in the wing box. The tower models included the exterior wall on the impact face, the floor structures, and the core frame for floors 91-101 and floors 76 through 86 for WTC 1 and WTC 2, respectively. The tower models had fixed boundary conditions at the top and bottom floors.

\section{Comparison of Exterior Wall Damage}

The calculated base case impact damage to the exterior north wall of WTC 1 from this study is compared to the impact damage calculated by WAl in Figure 9-139. The figure also shows a schematic of the damage observed in photographic evidence. Figure 9-140 shows a similar comparison for the south wall of WTC 2. In both towers, the base case impact damage estimated in this study closely matched the observed damage. The damage profiles in the WAI impact simulations had some noticeable differences. The first is that the damage profile included complete failure of the exterior columns over the entire length of the wings and to the top of the vertical stabilizer. The second difference is that the failure mode of the exterior walls was dominated by local rupture of the columns adjacent to the impact point, with less influence of the bolted connections on panel failure and removal.

The differences in the damage profiles in the two calculations most likely resulted from a variety of differences in the models. One major difference between the two studies was in the fidelity of the aircraft models. The WAI Boeing 767 model was based on their model of a Lockheed C-141 B military transport. In the WAI model, the external geometry of the C-141B was modified to fit the dimensions of the Boeing 767, but the internal components, such as stiffener configuration and material thicknesses and properties, remained the same. The differences in the internal structure and materials could affect the way the aircraft responded to the impact. The aircraft model used in this study also contained an order of magnitude more elements ( 70,000 bricks, 562,000 shells, and $61,000 \mathrm{SPH}$ particles) than the WAI model (27,000 shell elements and 23,000 beam elements). The higher resolution of the NIST model could also account for significant differences in the determination of the impact load distribution and resulting exterior damage. Additionally, the NIST model explicitly modeled the fuel. If the fuel mass in the WAI model was spread out further toward the wing tips as part of the wing structure, it would be expected that the calculated column damage would extend over a wider portion of the wings. 


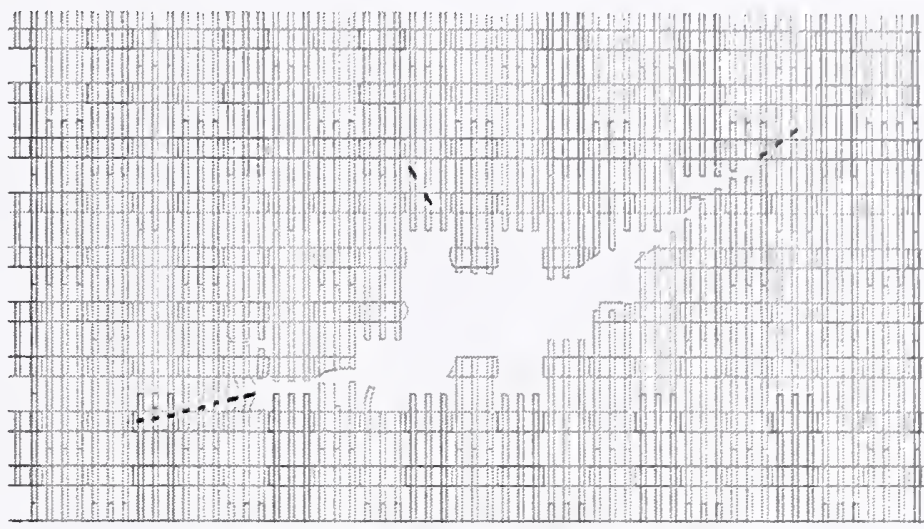

(a) Schematic of observed damage

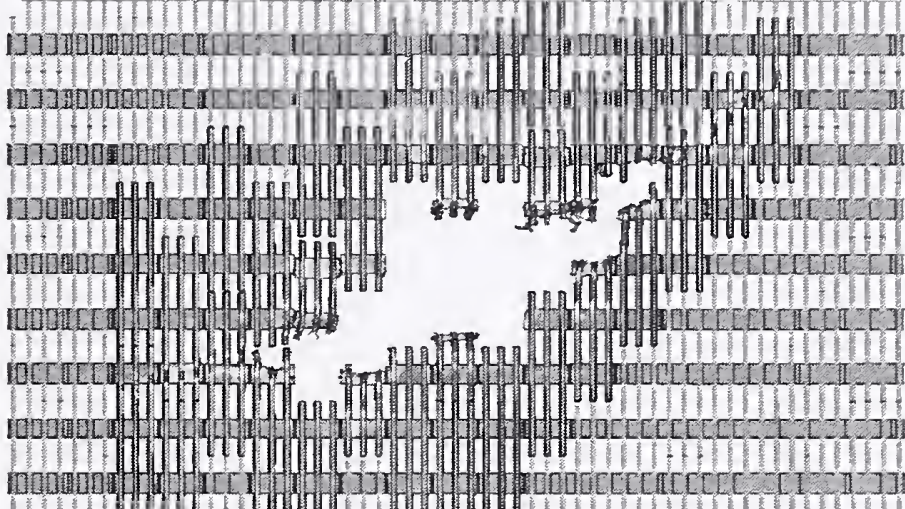

(b) NIST base case impact damage

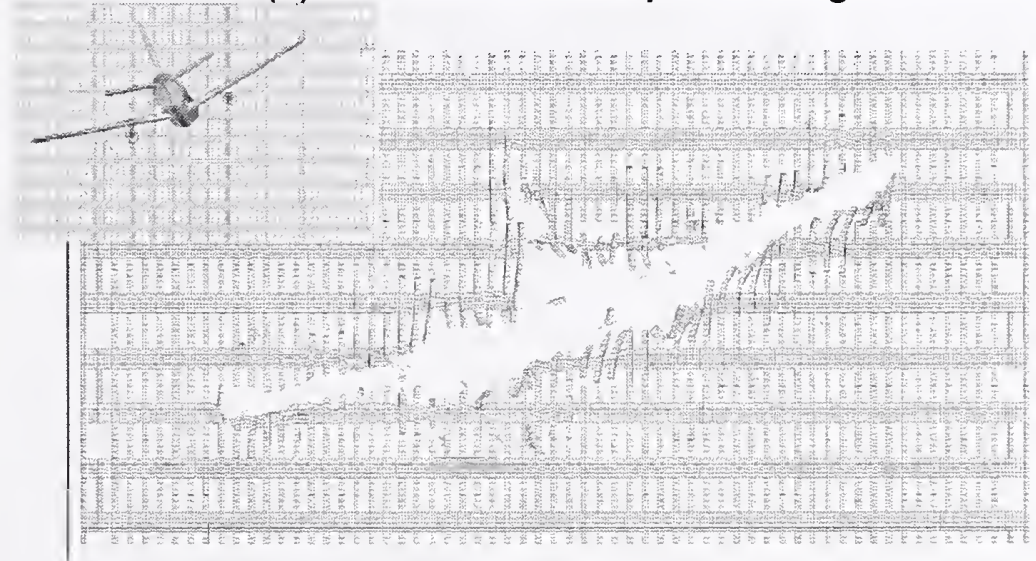

(c) WAl calculated damage (Levy and Abboud, 2002)

Figure 9-139. Comparison of impact damage to the WTC 1 exterior wall. 


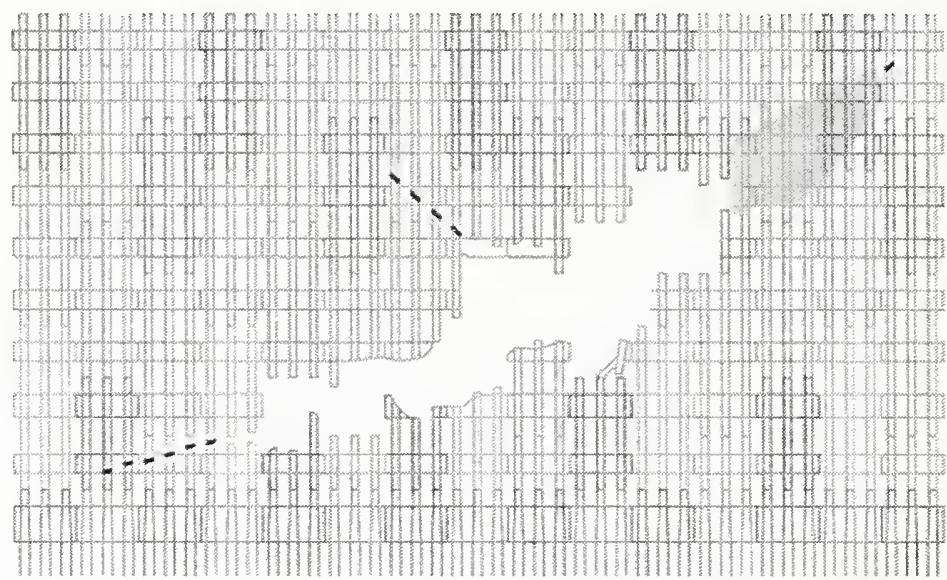

(a) Schematic of observed damage

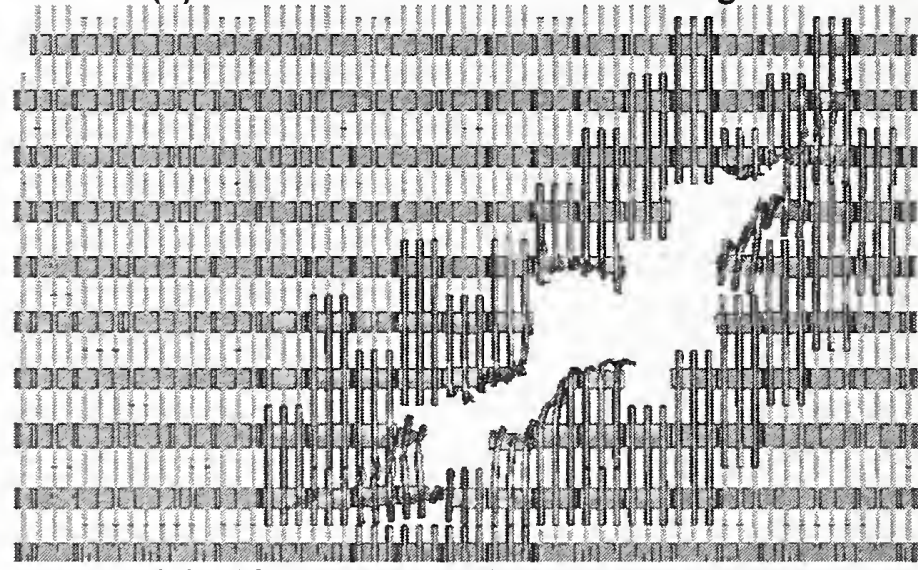

(b) NIST base case impact damage

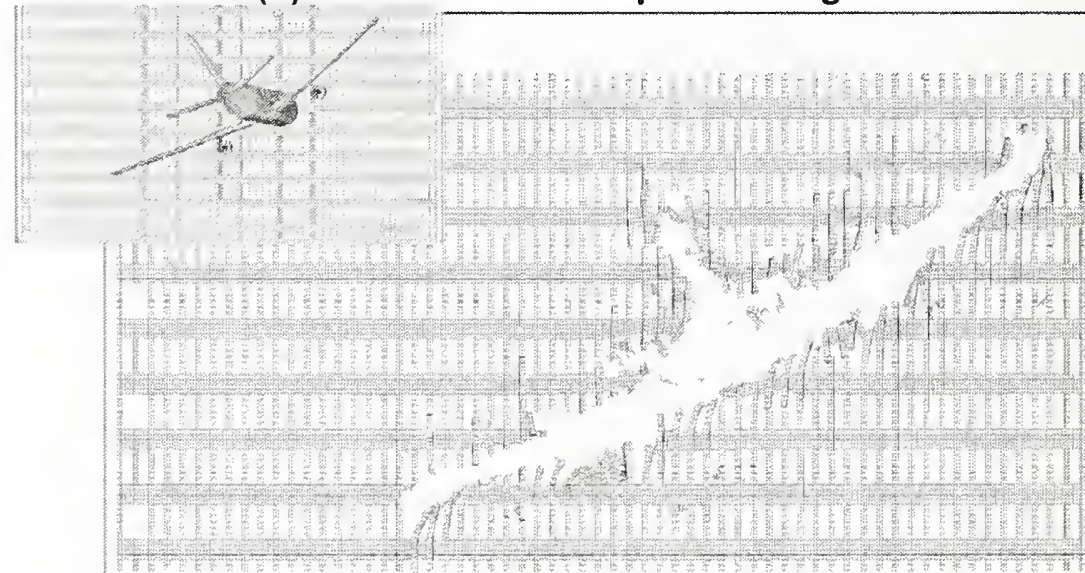

(c) WAl calculated damage (Levy and Abboud, 2002)

Figure 9-140. Comparison of impact damage to the WTC 2 exterior wall.

Secondary differences in the WAI and NIST impact analyses included, but were not limited to, variations in impact conditions (impact velocity, angle, location, etc.), aircraft model differences (airframe geometry, component thicknesses, mass distribution, material properties, etc.) and tower model differences (material properties, geometry, joint modeling, number of elements, etc.). 


\section{Comparison of Core Column Damage}

Table 9-15 compares the estimated core column damage from the various studics. For WTC 1, MIT (Wierzbicki, Xue, and Hendry-Brogan 2002) estimated that four to 12 core columns failcd. This MIT estimate of core columns was based on encrgy balance calculations and corresponded to a damage distribution ranging from four columns failed over a thrce-story length to 12 columns failed over a single floor length. The expected distribution of damage would fall between these bounds, with some columns damaged on a single floor and others with damage distributed on multiple floors. WAI gave two estimates for core column failure. The first estimate of 23 core columns failed and five damaged was obtained from the FLEX impact analysis. The second estimate of 20 failed columns was the number used in their collapse analysis. The NIST base case impact damage of three severed and four heavily damaged and less severe estimate of one scvered and two heavily damaged falls below both the MIT and WAI estimates. The more severe estimate of six severed and three heavily damaged falls in the middle of the MIT range, but still well below the WAI estimates.

Table 9-15. Comparison of damage to core columns from various studies.

\begin{tabular}{|l|c|c|}
\hline \multicolumn{1}{|c|}{$\begin{array}{c}\text { WTC Impact } \\
\text { Investigation }\end{array}$} & WTC 1 Core Column Damage & WTC 2 Core Column Damage \\
\hline $\begin{array}{l}\text { MIT } \\
\text { Impact Analysis }\end{array}$ & $4-12$ Failed & $7-20$ Failed \\
\hline $\begin{array}{l}\text { WAI } \\
\text { Impact Analysis }\end{array}$ & $\begin{array}{c}\text { 23 failed and significantly damaged } \\
\text { Plus 5 damaged }\end{array}$ & $\begin{array}{c}\text { 14 failed and significantly damaged } \\
\text { Plus 10 damaged }\end{array}$ \\
\hline $\begin{array}{l}\text { WAl } \\
\text { Collapse Analysis }\end{array}$ & 20 Failed & 5 Failed \\
\hline $\begin{array}{l}\text { NIST Base Case } \\
\text { Impact Analysis }\end{array}$ & $\begin{array}{c}\text { 3 Severed } \\
\text { Plus 4 Heavily Damaged }\end{array}$ & $\begin{array}{c}5 \text { Severed } \\
\text { Plus 4 Heavily Damaged }\end{array}$ \\
\hline Impact Analysis & $\begin{array}{c}\text { 6 Severed } \\
\text { Plu Severed }\end{array}$ \\
\hline $\begin{array}{l}\text { NIST Less Severe } \\
\text { Impact Analysis }\end{array}$ & $\begin{array}{c}\text { 1 Severed } \\
\text { Plus 1 Heavily Damaged }\end{array}$ \\
\hline
\end{tabular}

A similar trend in the predicted damage to the core columns was found in the WTC 2 analysis. MIT estimated seven to 20 columns failed (from seven columns failed over a three-story length to 20 columns failed over a single floor length). WAl calculated 14 core columns failed and another 10 damaged in their FLEX analysis, but reduced the number of failed columns to five for their collapse analysis. The NIST base case impact damage of five severed and four heavily damaged, as well as the more severe estimate of 10 severed and one heavily damaged fall in the middle of the range predicted by MIT. The less severe impact scenario predicted fewer columns severed and heavily damaged than the MIT and WAI studies.

The MIT prediction for the number of failed core columns agrees remarkably well with the NIST estimates using their simplified analysis. Differences may be a result of the estimates of material properties and structural geometry used (MIT did not have access to the detailed structural drawing of the WTC towers for their study), approximations in the estimates of damage mode and resulting energy absorption, as well as the fact that the MIT study did not include the energy absorbed by internal tower contents. 
The WAI impact analysis predicted much higher core column failure and damage than the NIST estimates. One reason for the higher damage prediction may be attributed to the lack of internal tower contents, such as workstations and other live loads, in the WAI model. This study found that the internal tower material absorbed a significant amount of the impact energy and, therefore, reduced the loads applied to the core columns. Another reason for the higher damage prediction in the WAI study could result from the aircraft model. As noted above, the WAI aircraft impact simulation overpredicted the extent of column damage and failure on the exterior wall. It is possible to assume that the aircraft model would also overpredict the damage to the core columns, especially that this damage configuration resulted in an unstable tower (Levy and Abboud, 2002).

In conducting a collapse analysis, WAI used engineering estimates to reduce the number of failed columns from that predicted by their FLEX model to stabilize the tower immediately after impact. Despite this adjustment, the WAI study still estimates significantly higher damage for WTC 1 than the MIT and NIST studies. For WTC 2, their adjusted estimate falls in line with the MIT and NIST studies.

In general, the MIT and WAI studies appear to over-predict the damage to the core columns compared to the NIST estimates.

\subsection{REFERENCES}

FEMA, 2002, "World Trade Center Building Performance Study: Data Collection, Preliminary Observations and Recommendations," FEMA 403, May.

Kausel, E., 2002, “The Towers Lost and Beyond," Massachusetts Institute of Technology, May, http://web.mit.edu/civenv/wtc/index.html.

Levy, M., and Abboud N., 2002, "World Trade Center - Structural Engineering Investigation," HartWeidlinger Technical Report, Prepared for Wachtel, Lipton, Rosen, and Katz, August 1.

“LS-DYNA Keyword User's Manual,” 2003, Livermore Software Technology Corporation, Version 970, April.

NIST 2003, "May 2003 - Progress Report on the Federal Building and Fire Safety Investigation of the World Trade Center Disaster," NIST Special Publication 1000-3, May.

Vaughan, D. K., FLEX User's Guide, Report UG8298, Weidlinger Associates, Los Altos, CA, May 1983 plus updates through 1997.

Wierzbicki, T., Xue, L., and Hendry-Brogan, M. 2002. "Aircraft impact damage of the World Trade Center towers." Tech. Rep. No. 74, Impact and Crashworthiness Lab, Massachusetts Institute of Technology, Cambridge, MA. 


\section{Chapter 10 \\ SUPPORTING SIMPLIFIED ANALYSES}

\section{$10.1 \quad$ INTRODUCTION}

Approximate, simplified impact analyses were carricd out to provide guidance to the global finitc elcment impact analyses. The primary purpose of these approximate analyses was to support the finite elcment impact analyses and identify aspects of the impact physics that nccded to be included, or could be eliminated from the models. In this chaptcr, a few of the supporting approximatc analyses are presented. The specific analyses described include:

- The analysis of the overall aircraft impact forces and assessment of the relative importance of the airframe strength and weight distribution.

- The evaluation of the potential effects of the energy in the rotating enginc components on the calculated engine impact response.

- The influence of the static preloads in the towers on the calculated impact damage and residual strength predictions.

- The analysis of the load characteristics required to damage core columns compared to the potential loading from impact of aircraft components.

\subsection{SIMPLIFIED ANALYSIS OF AIRCRAFT IMPACT}

A simple analysis of the aircraft impact was performed at the initiation of this study to quantify the relative importance of the airframe structural strength versus the effects of the nonstructural mass and inertial effects on the impact loads and response. The primary objective of this analysis was to develop an improved understanding of the impact physics prior to development of the global impact models.

Most prior aircraft impact analyses were concerned with the collision against nuclear reactor containment structures. Several models have been proposed. and they provide insight into the physics of the aircraft impact problem (e.g., Riera 1980; Gardner 1984; Zimmerman 1981). For example, in one model, the aircraft was viewed as a low-density structure with a crush strength of $\sigma_{c}$ and an average density of $\rho$ (mass per unit axial length) which vary along the axis of the aircraft with axial position $(x)$.

Furthermore, it was assumed that as the aircraft impacted the building, the aircraft crushed from front to back while the building crushed very little. In this way, the force on the building was composed of a contribution from the strength of the aircraft and a contribution from the change in momentum of the material entering the crush zone. With these assumptions, a simple expression for the force exerted on a rigid structure during an impact by the aircraft was

$$
F(t)=\sigma_{c}(x)+\rho(x)\left[\frac{d x}{d t}\right]^{2}
$$


where $x=x(t)$ is the position of the crush zone in the aircraft as a function of time. The first term in Equation (1) is the contribution from the strength of the aircraft, and the second is the contribution from the momentum change of the aircraft and its contents. In the Riera approach, the second term in Equation (1) was multiplied by a constant factor to obtain better correlation with test data. These types of models have often been used to show that the contribution of aircraft strength is on average much smaller than the contribution from momentum change.

Considering the aircraft impact conditions for the WTC towers, the Boeing 767-200ER has a length of approximately $259 \mathrm{ft}$. The empty weight of the Boeing 767 is about $180,000 \mathrm{lb}$, with a weight at impact of approximately $280,000 \mathrm{lb}$. Much of the added weight of $100,000 \mathrm{lb}$ at take-off was fuel (about 60,000 $\mathrm{lb}$ ), with passengers and cargo making up most of the rest. At $500 \mathrm{mph}$, an impact on a rigid structure takes place over a period of about $350 \mathrm{~ms}$ (aircraft length divided by aircraft speed). The global impact analyses described in Chapter 9 show that this is a good approximation to the duration over which the majority of the aircraft momentum was transferred to the towers (although much of the impact and momentum transfer is at depth inside the tower). The average force associated with the impact is the change in momentum divided by the pulse length or:

$$
F=\frac{M^{*} V}{\Delta t}=1.8 \times 10^{7} \mathrm{lbs}
$$

In contrast, an upper bound on the average strength of the aircraft structure can be obtained by estimating the yield strength of the structural mass. The empty fuselage weight was assumed to be $100,000 \mathrm{lb}$, with the remaining $80,000 \mathrm{lb}$ of the empty weight consisting of engines $(18,000 \mathrm{lb})$, wings, and landing gear. In addition, it was assumed that 20 percent or $20,000 \mathrm{lb}$ of the fuselage weight was structural aluminum with non-structural components such as electronics, air conditioning, power units, ductwork, electronic wiring, actuator motors, insulation, hydraulics, galley, and lavatories, etc. It was also assumed that this structural mass was uniformly distributed along the length of the aircraft. The uniform structural weight per unit length was, thus, $77 \mathrm{lb} / \mathrm{ft}$. The aluminum has a density of $175 \mathrm{lb} / \mathrm{ft}^{3}$, resulting in an average crosssectional area of $63 \mathrm{in}^{2}$. Assuming the entire aluminum cross section was at the material yield strength of $50 \mathrm{ksi}$ resulted in an average crush strength of $3.1 \times 10^{6} \mathrm{lb}$, or about 17 percent of the inertial force, from momentum change. Thus, from this simplified analysis, the contribution of the strength and fracture effects should be considerably smaller than inertial effects on the overall impact load.

This simplified analysis confirms the conclusions of previous studies that the momentum transfer is more important than the strength of the impacting aircraft in determining the overall loads on the building. However, the finite element simulations show that the strength and geometry of some components of the aircraft play an important role in the subsequent damage to the building. The engines are an important example, since they are heavy and strong and can penetrate deep into the building. The finite element simulations show that large fragments from heavy structural members such as the wing main spar, wheels, and similar heavy components penetrate the building and change the nature of the damage.

\subsection{ROTATIONAL AND TRANSLATIONAL ENGINE KINETIC ENERGY}

The model of the aircraft engines used in the global finite element impact analyses did not account for the rotational velocity of the spinning components. The additional model complexity required to support the inertial loads for the spinning components (as well as clearances, bearing surfaces, etc.) was not believed 
to be warranted for evaluation of the impaet damage. As a result, the rotational kinetie encrgy of the spinning aireraft engine components was not ineluded in the impaet analyses.

An analysis was performed to quantify the potential effeet of the rotational kinetie energy of the engine turbine and compressor components on the aireraft impaet response. This was investigated using simple encrgy and momentum prineipals. The inertial properties of the engine eomponents were ealeulated from the finite element engine model using LS-DYNA. The inertial properties were automatieally generated for each part (material assignment) by LS-DYNA as part of the model initialization.

The internal engine components for which some portion would be rotating are shown in Figure 10-1. The engine eomponents in the model were separated to estimate the rotating engine mass and obtain an estimated pereentage of the engine that is rotating. The approximation used was that $3,500 \mathrm{lb}$, or 37 pereent of the total engine mass, was rotating.
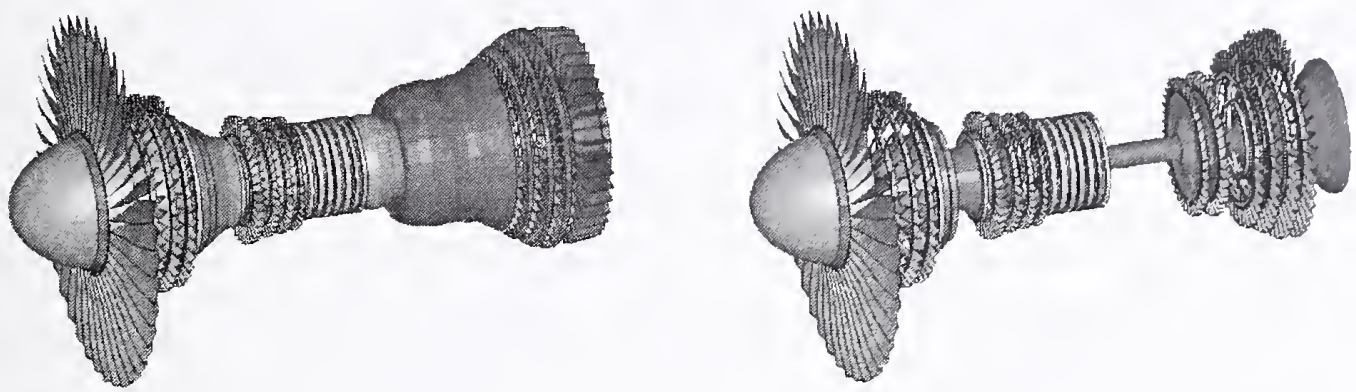

Figure 10-1. Internal components of the aircraft engine model.

Both the kinetie energy from translation and rotation were ealeulated based on an assumed impaet speed of $500 \mathrm{mph}$ and an engine rotational speed of 5,000 RPM. The results are shown in Table 10-1. The initial rotational kinetie energy of the engine eomponents was approximately $2.2 \times 10^{7} \mathrm{lb} \cdot \mathrm{ft}$, which was approximately one-quarter of the translational kinetie energy for the engine or less than one pereent of the initial kinetie energy for the aireraft impact.

Table 10-1. Kinetic energy partitioning in aircraft.

\begin{tabular}{|l|c|c|c|c|}
\hline \multicolumn{1}{|c|}{ Component } & Weight & $\begin{array}{c}\text { Moment of Inertia } \\
\text { about Engine Axis }\end{array}$ & $\begin{array}{c}\text { Translational } \\
\text { Kinetic Energy }\end{array}$ & $\begin{array}{c}\text { Rotational Kinetic } \\
\text { Energy }\end{array}$ \\
\hline Total Engine & $9400 \mathrm{lb}$ & $3.3 \times 104 \mathrm{lb} \cdot \mathrm{ft}^{2}$ & $8.1 \times 107 \mathrm{lb} \cdot \mathrm{ft}$ & $3.5 \times 106 \mathrm{lb} \cdot \mathrm{ft}$ \\
\hline Rotor Components & $3500 \mathrm{lb}$ & $5.2 \times 103 \mathrm{lb} \cdot \mathrm{ft}^{2}$ & $3.0 \times 107 \mathrm{lb} \cdot \mathrm{ft}$ & $2.2 \times 107 \mathrm{lb} \cdot \mathrm{ft}$ \\
\hline Entire Aircraft & $290,000 \mathrm{lb}$ & & $2.4 \times 109 \mathrm{lb} \cdot \mathrm{ft}$ & \\
\hline
\end{tabular}

Sinee the rotational kinetic energy is a nontrivial pereentage of the total engine kinetie energy, additional eonsideration was given to the rotational effeets on the engine impaet response. The eoneern is the eoupling of the rotational energy into the tower and the potential of the rotating engine parts to stabilize the engine trajectory during the impact. However, as the engine impaeted and penetrated the exterior wall of the tower, a signifieant amount of debris from the tower steel, glass, aluminum trim, and eonerete floor slab was forced into the engine. It is expeeted that this would produee signifieant internal damage and loek up the rotating engine components in a relatively short duration. The forces produeed by the internal angular deceleration of the rotating engine eomponents would either be reaeted by the engine support 
structures or cause the entire engine to roll about its major rotational axis. Using conservation of angular momentum for the engine, it was estimated that the rotational energy after the engine locked up was about $3.5 \times 10^{6} \mathrm{lb}-\mathrm{ft}$, or 16 percent of the initial rotational kinetic energy. Therefore, the bulk of the initial engine rotational energy would most likely be dissipated by deformation of the internal engine components rather than damage to the tower. As a result, the potential for the rotational kinetic energy to significantily change the magnitude of the tower impact damage is small.

\subsection{EFFECTS OF STATIC STRUCTURAL PRELOAD}

The global impact analyses required the use of very large and complex tower models of approximately 1.5 million nodes. The global WTC tower impact analysis run times were on the order of two weeks on twelve processors for a 0.65 second impact event. Initialization of a static preload in these tower models was difficult and computationally intensive. As a result, an analysis was performed to determine the importance of the preload effect on the tower impact response and damage. The internal energy associated with the elastic service loads was small compared to the material internal energy capacity that was utilized under impact response and damage. Therefore, the static preload was not expected to have a significant influence on the dynamic impact response and deformation.

A wide flange core column was used for this analysis, with the applied loading and boundary conditions as shown in Figure 10-2. The column dimensions were a 16-in. flange width and 16-in. length between outer flange faces, with a flange thickness of $1.72 \mathrm{in.}$ and a web thickness of $1.07 \mathrm{in}$. These dimensions were typical for the range of wide flange core columns in the impact zones of the WTC towers. A static compressive axial load, $\mathrm{P}_{\text {static, }}$ was applied to the upper end of the column, as shown in Figure 10-2(a). An impulsive load per unit area, $P_{\text {dynamic }}$, was centered between floors at the middle of the column over a distance of $60 \mathrm{in}$. The pressure was applied perpendicular to the flange. The lateral constraints allowed the ends of the horizontal beam sections connected to the column to translate only in the direction of the static load, as shown in Figure 10-2(b).

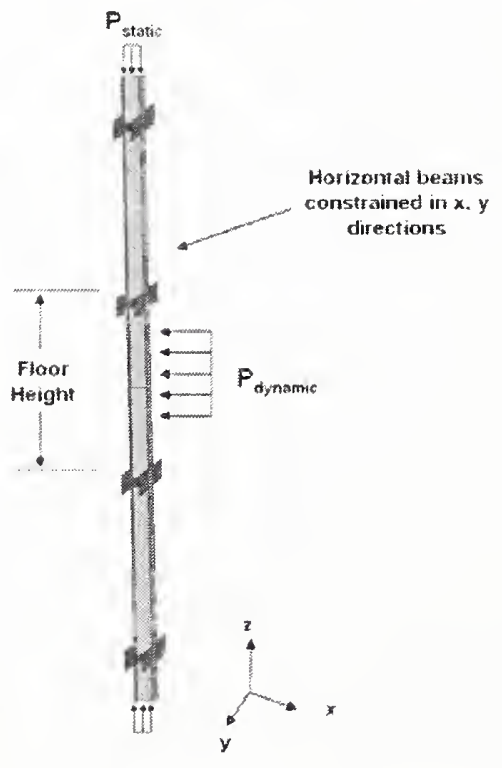

(a) Loading detail

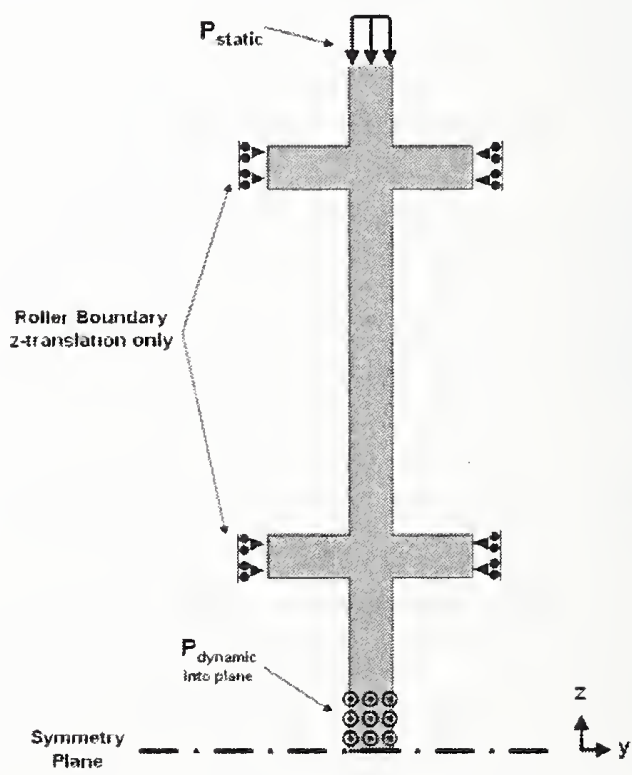

(b) Lateral constraint detail

Figure 10-2. Problem geometry for analysis of axial preload effects. 
Three cases were analyzed to study the effects of the axial prcload:

Case 1: A static axial load was applied with no impulsive pressurc $\left(P_{\text {dynamic }}=0.0\right)$. The column collapsed when the axial force reached 3,360,000 lbf.

Case 2: An impulsive load was applied with $\mathrm{P}_{\mathrm{dynamic}}=2,538 \mathrm{psi}$ and without a static prcload. The pressure pulse had a characteristic time of $4 \mathrm{~ms}$, resulting in a total impulsc of $I=10.2 \mathrm{psi}$-s A static axial load was subsequently applied and increased until collapse. The column collapsed when axial load reached 2,300,000 lbf.

Case 3: An axial preload was applied until stresses in the column equalcd 40 percent of the column's yield strength. Then, the lateral impulsive load uscd in Case 2 was applied. Finally, the axial load was increased until collapse. Collapse occurred when axial load rcachcd 2,240,000 lbf.

Comparing Case 1 with Case 2, it was found that the damage produced by the dynamic load reduccd the amount of axial force the column was able to support by about 32 percent. In Case 3 , with an axial preload, the column required 2.6 percent less axial force for collapse than in Case 2 with no axial preload. This result suggests that the time at which the axial load was applied relative to the application of the dynamic load had little effect on the amount of axial force required to collapse the column. Figure 10-3 shows a comparison of the damage and plastic strains for Case 2 and Casc 3, immediately after the application of the dynamic load. The plastic strains for these two cases were very similar. Therefore, the static preload has little effect on the damage developed by a lateral impulsive load.

These comparisons show that the initialization of a static preload in the columns of the towers would not have a significant effect on the tower impact response, damage, or residual strength.

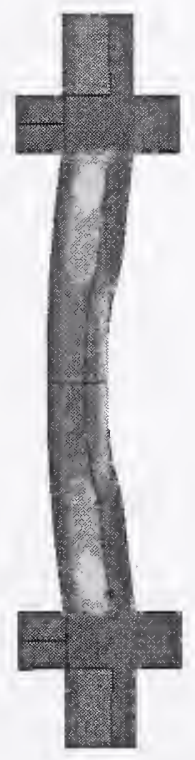

(a) Case 4, no static load

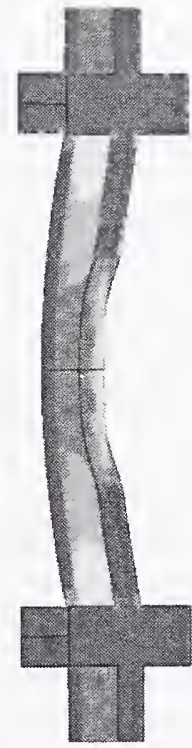

(b) Case 3, static load

\section{Plastic Strain \\ $3.000 \mathrm{c}-001$ \\ 2.700e-001 \\ 2.400e-001 \\ $2.100 \mathrm{e}-001$ \\ $1.800 \mathrm{e}-001$ \\ 1.500e-001 \\ $1.200 \mathrm{e}-001$ \\ 9.000e-002 \\ 6.000e-002 \\ 3.000e-002 \\ $0.000 e+000$}

Figure 10-3. Dynamic column response with and without axial preload. 


\subsection{SIMPLIFIED ANALYSIS OF CORE COLUMN DAMAGE}

In order to better understand the importance of the initial impact and breakup of the aircraft on damage to the WTC tower core structures, a model of resultant impact damage from an aircraft debris cloud on core columns was developed. This model was based on simple momentum and energy conservation concepts, similar to the simplified global analysis discussed in Section 10.2. The fundamental premise of the analysis is that the aircraft debris has negligible strength on impact, and the load on the building columns is due to momentum transfer. As a consequence, the load on the columns is determined by the debris density and impact kinematics. The impact pressure delivered to the column is determined by momentum change. The pulse duration is determined by the debris cloud speed and size. This analysis was used to study the effects of the dispersed fuel cloud on core column response.

The critical loads required to fail a core column were determined based on a combination of the peak impact pressure and impulse intensity. A good description of this characterization of critical loads as Pressure-Impulse or "P-I" damage curves is given by Abrahamson and Lindberg [197.2]. The concept that broad definitions of critical loads can be made based on peak pressure or load and impulse intensity or total impulse is well established. The P-I damage analysis method has been commonly used for evaluation of blast damage to structures and is appropriate for structures where the impacting body has a low strength. This P-I damage curve approach provides a useful way to make a quick evaluation of the damage potential of aircraft debris cloud on core columns.

\subsubsection{Development of P-I Curves}

An example of the process used to develop the P-I curves for a structure is demonstrated in Figure 10-4. A series of simple finite element calculations with various pressure and impulse combinations are performed to bracket the conditions required to initiate damage or failure of the structure. Each calculation is represented by a circle in the figure. The load conditions that resulted in no damage or incipient damage are represented by a solid blue circle. Load combinations resulting in failure of the structure are represented with a solid red circle. Intermediate levels of damage are displayed with open black circles. The results from the simulations are then fit with two P-I curves, one representing the onset of significant damage and the other representing complete failure. The P-I curves have a form that is similar in shape to a hyperbolic curve. The load combinations which fall above and to the right of the red P-I curve in Figure 10-4 produce structural failure. Similarly, load combinations which fall below and to the left of the blue P-I curve in Figure 10-4 produce little or no damage.

Individual P-I curves correspond to a specific magnitude of damage. In this example, separate P-I curves are generated for the onset of damage and for failure. A comparison of the two P-I curves in Figure 10-4 shows that at the limit of a long duration loading, the P-I curves are representing damage and failure are equal for this structure (lower right portion of the P-I curves with a low pressure magnitude and large impulse intensities). This results from unstable behavior of this structure under quasi-static pressure loads. As a result, the quasi-static pressure magnitude that is sufficient to produce yielding will also result in a complete rupture. The knee of the P-I curves in this example corresponds to an effective load duration between one and ten milliseconds, which corresponds to the characteristic response times of the structure (natural frequencies of the important damage modes such as column buckling modes, etc.). 


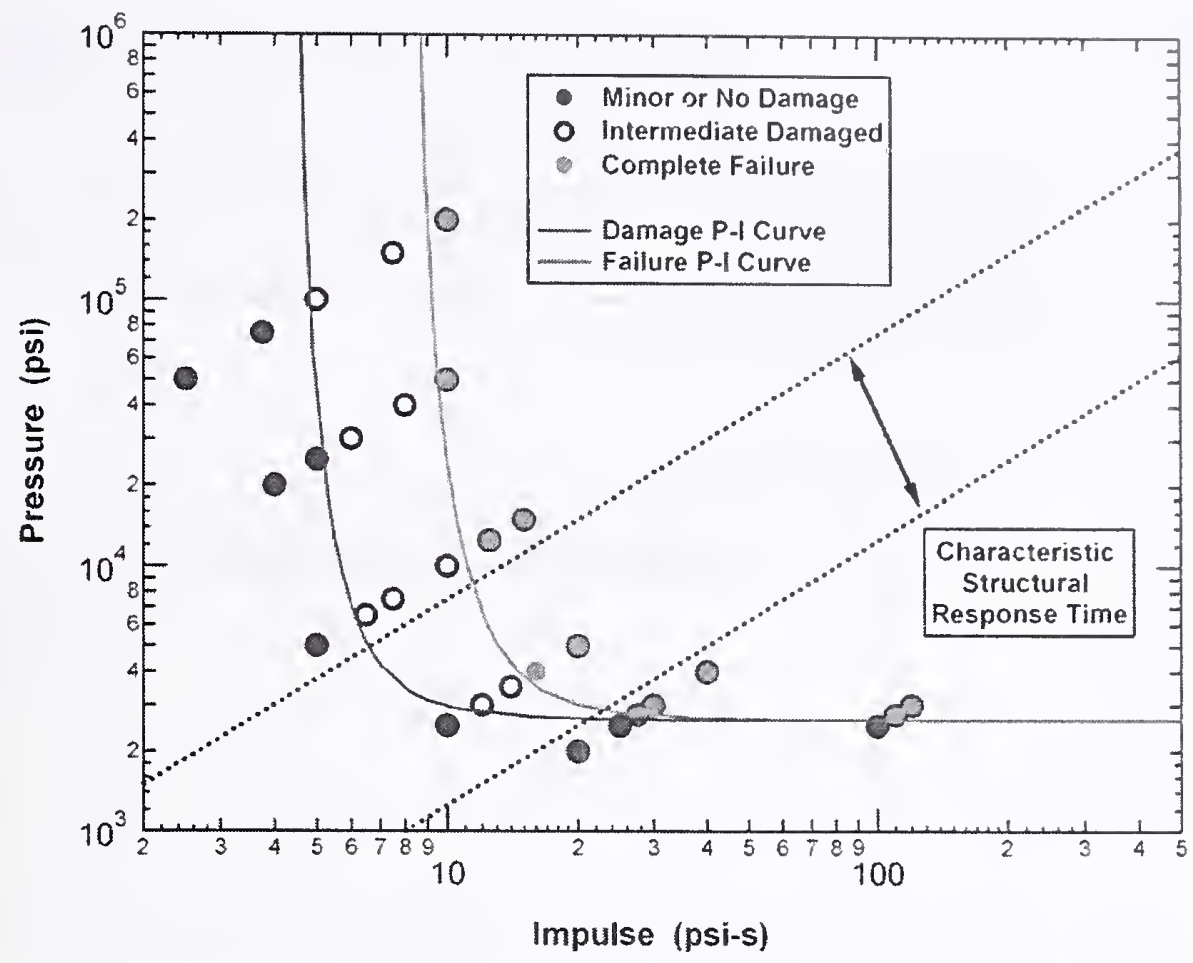

Figure 10-4. Development of damage and failure P-I curves for a structure.

\subsubsection{Core Column Damage Analyses}

Using the procedure outlined in the previous section, P-I curves were developed for core column failure. The column dimensions and boundary conditions were identical to those used in Section 10.4 and shown in Figure 10-2, but without an axial preload. Three different P-I curves were developed for three heights of dynamic pressure loading, as shown in Figure 10-5. Pressure and impulse combinations were applied over $30 \mathrm{in}$., $60 \mathrm{in}$., and $120 \mathrm{in}$. spans on the column. The P-I curves were then used to determine the characteristics of a fuel cloud impact that would be sufficient to fail a core column.

The core column response was analyzed for the aircraft fuel impact loads at four positions along the wing. The impact loading of the fuel was considered separately in this example since it represents a significant fraction of the total mass in the wings. Initially, the effect of a direct impact by a section of the fuel on the core column (no dispersion of the fuel cloud) was considered. To calculate the impact pressure and impulse, the fuel tank dimensions at each location were approximated by a rectangle. Near the root of the wing the approximate tank dimensions were $43 \mathrm{in}$. tall by $161 \mathrm{in}$. across. The position nearest the wing tip had approximate tank dimensions of $14 \mathrm{in}$. tall by $50 \mathrm{in}$. across. The other two positions had relatively uniform spacing and had dimensions of 18 in. tall by 91 in. across and 22 in. tall by 132 in. across, respectively. The peak pressure for the fuel impact was found from the momentum change, which is governed by the fuel density and impact velocity. The duration of the load was calculated using the dimension across the fuel tank divided by the impact velocity. The pressure multiplied by the duration gives the impulse intensity for this impact scenario. 
The impact loads for the four different positions on the fuel tank were calculated for three impact speeds, 537,430 , and $268 \mathrm{mph}$. The corresponding positions of the impact loads in pressure and impulse are shown in Figure 10-5. The comparison of the impact loads to the P-I curve for the $30 \mathrm{in}$. load span (green curve) is most appropriate since the loaded area in this example varies from 43 in. at the wing root to $14 \mathrm{in}$. at the wing tip. These data show that a solid section of fuel directly impacting the core columns at $430 \mathrm{mph}$ or above would cause failure. However, the loads produced by a lower impact speed of $268 \mathrm{mph}$ would not be sufficient to fail this core column.

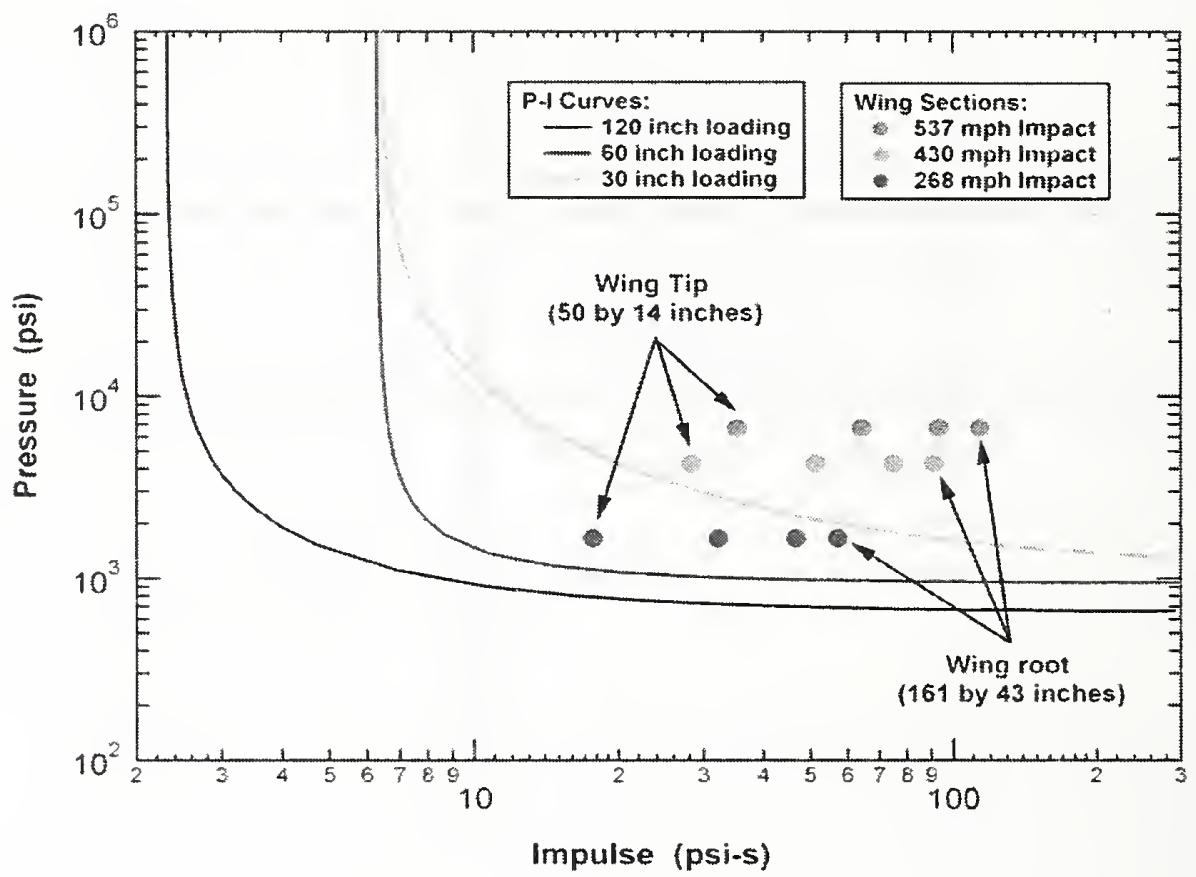

Figure 10-5. Core column P-I failure curves and concentrated fuel impact loading.

The fuel impact loads used in the above example were an upper bound on the damage that could be produced by the fuel at the core since the fuel was still assumed to be in a solid rectangular section at full density. In reality, the impact with the exterior wall broke up the wing structures, and the fuel cloud spreads out to some extent prior to reaching the core columns. The impact with the internal building contents also reduced the severity of the fuel impact at the core.

A first approximation of the effects of the fuel cloud dispersion on the core column loading was performed by assuming that the fuel cloud spread vertically to fill the full floor height prior to reaching the core. A uniform fuel cloud density was used that was scaled by the ratio of the initial fuel section height to the full floor height. No spreading in the longitudinal or lateral direction was assumed. The spreading of the debris cloud, thus, reduced the peak pressure without changing the load duration. These positions of the impact loads in pressure and impulse are shown in Figure 10-6. The comparison of the impact loads to the P-1 curve for the 120 in. load span (black curve) was most appropriate since the loaded area in this example was uniform over the full length of the column. The comparison shows that an expanded fuel cloud did not produce sufficient loading to fail a core column with the exception of points close to the wing root at the highest impact speeds considered. A more realistic fuel cloud dispersion would have included lateral and longitudinal spreading, as well as removal of some fuel from the cloud as 
a result of impact with the outer wall and building contents. Under these conditions, it is expected that the fuel cloud alone would not be sufficient to fail corc columns.

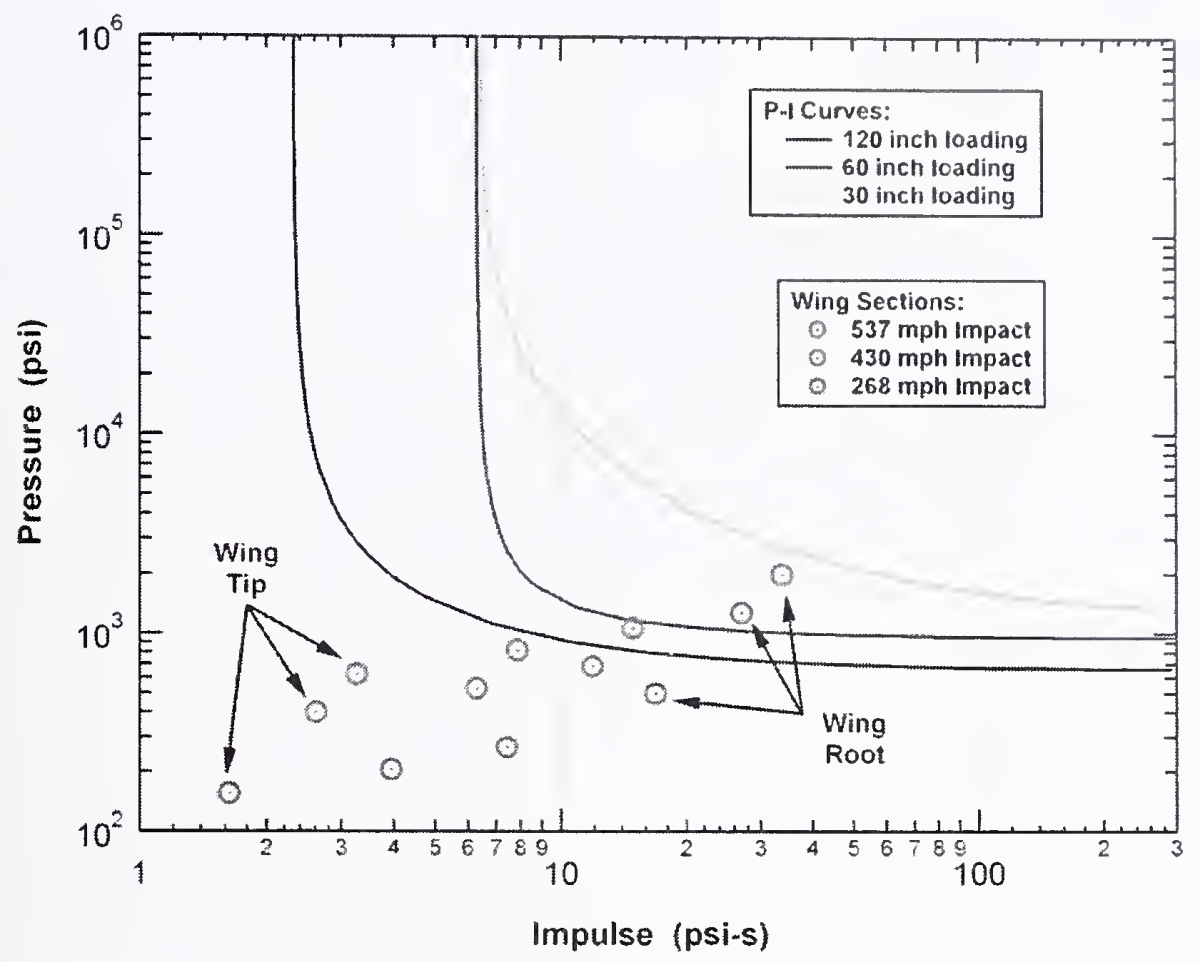

Figure 10-6. P-I curves and expanded fuel cloud impact loading.

\subsection{REFERENCES}

Abrahamson, G.R., and Lindberg, H.E., 1972. "Peak Load-Impulse Characterization of Critical Pulse Loads in Structural Dynamics," in Dynamic Response of Structures, G. Herrmann \& N. Perrone, Eds., Pergamon Press, Inc., New York, pp. 31-52.

Gardner, J.W., 1984. "Calculation of the Forces Acting Upon a Rigid Structure from an Aircraft Impact," Int. J. Impact Engineering, Vol. 2, No. 4, pp. 345-356.

Riera, J.D., 1980. "A Critical Reappraisal of Nuclear Power Plant Safety Against Accidental Aircraft Impact," Nuclear Engineering and Design, Vol. 57.

Zimmerman, Th., Rodriguez, C., and Rebora, B., 1981. "Nonlinear Analysis of a Reactor Building for Aircraft Impact loadings," Trans. $6^{\text {th }}$ International Conference on Structural Mechanics in Reactor Technology, Vol. J, August. 
This page intentionally left blank. 


\section{Chapter 11 \\ SUMMARY}

\section{$11.1 \quad$ INTRODUCTION}

The objective of this project was to analyze the aircraft impacts into the World Trade Center (WTC) towers to provide the following: (1) estimates of probable damage to structural systems, including the exterior walls, floor systems, and interior core columns; (2) estimates of the aircraft fuel dispersal during the impact; and (3) estimates of debris damage to the interior tower contents, including partitions and workstations to be used for estimating damage to fire proofing and to the mechanical and architectural systems inside the towers. This project, thus, established the initial conditions for the fire dynamics modeling in Project 5 and the thermal-structural response and collapse initiation analysis in Project 6 of the National Institute of Standards and Technology (NIST) Investigation.

The WTC aircraft impact analysis is very complex with large scale fracture and fragmentation of both tower and aircraft structures, nonlinear rate-dependent material behaviors, and the fluid-structure interaction of the aircraft fuel. The analyses of the aircraft impacts performed for this investigation are believed to be the highest-fidelity simulations ever performed for this impact behavior using state-of-the art analysis methodologies. Wherever possible, the models were validated against observables or supporting test data developed by the WTC Investigation.

The impact analyses were conducted at various levels of complexity including: (1) the component level, (2) the subassembly level, and (3) the global level to estimate the probable damage to the towers due to aircraft impact. Analysis of uncertainties using the component, subassembly, and global analyses were also conducted to assess the effect of uncertainties associated with various parameters on the damage estimates and to identify the most influential parameters that affect the impact response.

\subsection{MATERIAL CONSTITUTIVE MODELING}

An important requirement for high fidelity simulation of the aircraft impact damage was the development of constitutive models that represented the actual behavior of the WTC towers and aircraft under the dynamic impact conditions. The materials that were considered included: (1) the several grades of steel used in the columns, spandrels, and floor trusses, and beams of the WTC towers, (2) the concrete floor slabs, (3) the various aluminum and titanium alloys used in the aircraft, and (4) the nonstructural contents of the towers. These materials exhibit significant nonlinear, rate-dependent deformation and failure behavior that need to be represented in the constitutive relationship.

The primary constitutive model that was used for the tower steels was the Piecewise Linear Plasticity model in LS-DYNA. This model is sufficient to model the nonlinear rate-dependent deformation and failure of the steel structures. The constitutive model parameters for each grade of steel were based on engineering stress-strain data obtained by Project 3 of the NIST Investigation. Finite element analyses of the test specimens were conducted with a fine and a medium mesh to capture the nonlinear material behavior up to failure. The finite element analysis provided a validation that the constitutive model 
parameters were defined accurately and that the model could reproduce the measured response for the test conditions. Strain-rate effects on the steel yield strength were included in the constitutive model for tower steels with the Cowper and Symonds rate effect model.

The LS-DYNA material Type 16 (pseudo-tensor concrete model) was selected for modeling the concrete floor slabs due to its ability to accurately model the low confinement damage and softening behavior of concrete. The model uses two pressure-dependant yield functions and a damage-dependent function to migrate between curves. This allows for implementation of tensile failure and damage scaling, which are more dominant material behaviors at low confinement. The pseudo-tensor model also accounts for the high strain-rate sensitivity of concrete.

The constitutive and failure properties for the aircraft materials were developed from data available in the open literature. Complete engineering stress-strain curves were obtained for various 2024 and 7075 aluminum alloys that are commonly used in the construction of the Boeing 767 airframe structures. These curves were digitized for the various aluminum alloys. Representative stress-strain curves were then converted into true stress and true strain and used to develop tabular curves for the constitutive models. No rate sensitivity of the aircraft materials was considered.

The primary influence of the nonstructural components on the impact behavior was their inertial contribution. The effects of their strength were small. As a result, relatively simple approximations of their constitutive behavior were used. Typically a bilinear elastic-plastic constitutive model was applied for these materials to allow for efficient modeling of deformation and subsequent erosion from the calculations as their distortions became large.

\subsection{TOWER MODEL DEVELOPMENT}

One of the significant challenges in developing the tower and aircraft models for the global impact analyses was to minimize the model size while keeping sufficient fidelity in the impact zone to capture the deformations and damage distributions. The limitation was that the combined aircraft and tower models should not exceed approximately 2.3 million nodes. These were distributed between the global WTC tower model and the aircraft so that the tower model would be about 1.5 million nodes and the aircraft about 0.8 million nodes. The approach used to meet this objective was to develop models for the various tower components at different levels of refinement. Components in the path of the impact and debris field were meshed with a higher resolution to capture the local impact damage and failure, while components outside the impact zone were meshed more coarsely to primarily capture their structural stiffness and inertial properties.

The towers were modeled primarily with shell elements, with the exception of the exterior wall bolted connections (beam and brick elements) and the floor truss diagonals (beam elements). The WTC 1 model extended between floors 92 and 100, while the WTC 2 model extended between floors 85 and 77. The global impact models of the WTC towers included the following components:

- Core columns and floors: Core columns were modeled using shell elements with two mesh densities, a refined density in the direct impact area and a coarser far field density elsewhere. The spliced column connections were included in the model with proper failure criteria. The floors within the core were modeled using shell elements representing the floor slabs and beams. 
- Exterior walls: The exterior columns and spandrels were modeled using shell clements with two mesh densities, a refined density in the immediate impact zone and a coarscr far field density elsewhere. For the bolted conncetions between cxtcrior panels in the refined mesh areas, brick elements were used to model the butt plates, and beams elements were used for the bolts.

- Truss floor: In the direet impact area, the floor model included shell clements for the combined floor slab and metal decking and for the upper and lower chords of the trusses. Beam elements were used for the truss diagonals. In the far field floor segments, simplified shell element representations were used for the floor slab and trusses. The dampcrs werc not included in the models due to their low mass and strength, particularly in the transverse direction.

- Interior building contents: The interior nonstructural contents of the towers were modeled explicitly. These included the partitions and workstations, which were modeled with shell elements in the path of the aircraft debris. The live load mass was distributed between the partitions and cubicle workstations.

\subsection{AIRCRAFT MODEL DEVELOPMENT}

The finite element model for the Boeing 767-200ER aircraft was constructed through a three-step process: (1) data collection, (2) data interpretation and engineering analysis, and (3) meshing of the structure. The focus of this effort was on gathering sufficient struetural data and including adequate detail in the aireraft model so that the mass and strength distribution of the aireraft and contents were properly captured for implementation in the impact analyses. Structural data were collected for the Boeing 767-200ER aircraft from (1) documentary aircraft structural information and (2) data from measurements on Boeing 767 aircraft.

The airframe model contained most of the significant structural components in the aireraft. The models of the fuselage, empennage, and wing structures were developed completely using shell elements.

Models for the landing gear and engines were primarily developed using shell elements, but contained some brick elements as well. The typical element dimensions were between one and two in. for small components, such as spar or rib flanges, and three to four in. for large parts, such as the wing or fuselage skin.

Special emphasis was placed on modeling the aireraft engines due to their potential to produce significant damage to the tower components. The engine model was developed primarily with shell elements. The objective was to develop a mesh with typical element dimensions between one and two inches. However, smaller element dimensions were required at many locations to capture details of the engine geometry. Brick elements were used for some of the thicker hubs and the roots of the compressor blades.

A detailed analysis was carried out to estimate the fuel distribution in the aireraft wings at the time of impact. 


\section{$11.5 \quad$ COMPONENT LEVEL ANALYSES}

The primary objectives of the component modeling were to (1) develop understanding of the interactivc failure phenomenon of the aircraft and tower components and (2) develop the simulation techniques required for the global analysis of the aircraft impacts into the WTC towers. The approach taken for component modeling was to start with finely meshed, brick and shell element models of key components of the tower and aircraft structures and progress to relatively coarsely meshed beam and shell element representations used in the global models. In addition to determining the optimal element size and type for global modeling, other key technical areas were addressed in the component modeling, including material constitutive modeling, treatment of connections, and modeling of aircraft fuel. Examples of the component impact analyses included:

- Impact of a segment of an aircraft wing with an exterior column.

- Impact of a segment of an aircraft wing with a core column.

- Detailed and simplified modeling of exterior panel bolted connection under impact loading and modeling of the bolted spandrel connection.

- Impact of an aircraft engine with exterior wall panels.

- Impact of a simplified plow type impactor with truss floor assembly.

- Impact of an empty wing segment with exterior wall panels.

- Impact of fuel-filled wing segment with exterior wall panels.

The following results were obtained from the component impact analyses:

- A 500 mph engine impact against an exterior wall panel resulted in a penetration of the exterior wall and failure of impacted exterior columns. If the engine did not impact a floor slab, the majority of the engine core would remain intact through the exterior wall penetration with a reduction in speed between 10 percent and 20 percent. The residual velocity and mass of the engine after penetration of the exterior wall was sufficient to fail a core column in a direct impact condition. Interaction with additional interior building contents prior to impact or a misaligned impact against the core column could change this result.

- A normal impact of the exterior wall by an empty wing segment from approximately midspan of the wing produced significant damage to the exterior columns but not complete failure. Impact of the same wing section, but filled with fuel, resulted in extensive damage to the external panels of the tower, including complete failure of the exterior columns. The resulting debris propagating into the building maintained the majority of its initial momentum prior to impact.

- Three different numerical techniques were investigated for modeling impact effects and dispersion of fuel: (1) standard Lagrangian finite element analysis with erosion, (2) Smoothed Particle Hydrodynamics (SPH) analysis, and (3) Arbitrary-Lagrangian-Eulerian (ALE) 
analysis. Of these approaches, use of the SPH offered the best viable option duc to its computational efficicncy.

\subsection{SUBASSEMBLY IMPACT ANALYSES}

The subassembly analyses werc considered as a transition between the component lcvel analyses and the global impact analyses. With the subasscmbly analyscs, morc complex structural bchavior not capturcd in the component analyses could be investigated with significantly shortcr run times than requircd for the global analyses. The subassembly analyses were primarily used to investigatc differcnt modcling techniques and associated model size, run times, numerical stability, and impact response. The final subassembly model used structural components from the impact zone on the north facc of WTC 1, and included exterior panels, core framing, truss floor structures, and interior contents (workstations). Thc subassembly model was impacted by an aircraft cngine and by a segment of a fuel-filled wing.

The subassembly model was used to investigate the effect of a number of modeling parametcrs on thc response and damage estimates. For the engine impact simulations, these parameters included the strength of the building nonstructural contents and the concrete slab strength. For the wing impact simulations, the effect of the ductility of the exterior column weldment on the impact response was investigated. The results of these parametric studies indicated the following:

- The deceleration profile of the impacting engine indicated that the response of the nonstructural building contents was dominated by the mass of the workstations, rather than by their strength.

- Varying the strength of the floor concrete slab from $4 \mathrm{ksi}$ to $3 \mathrm{ksi}$ did not result in significant change in the impact response. It appears that the mass of the concrete slab had a greater effect on the engine deceleration and damage to the floor than did the concrete strength.

- Varying the ductility of the weld zone in the exterior columns from 8 percent to 1 percent did not result in any noticeable difference in the damage pattern or the energy absorbed by the exterior panels, indicating that the weld ductility had a negligible effect on the impact response.

\subsection{ANALYSIS OF AIRCRAFT IMPACT CONDITIONS}

The initial aircraft impact conditions included aircraft speed, horizontal and vertical angles of incidence, roll angle of each aircraft, and the location of nose impact with each tower. Three different methods were applied to determine the impact conditions for the two aircraft that impacted the towers. The first method used a comparison of videos from different positions to calculate the three-dimensional trajectory of the aircraft. The second method used the relative frame-by-frame motion in a single video scaled to the length of the aircraft in the video to calculate the impact speed. Finally, analysis of the impact damage on the face of each tower was used to refine the relative impact orientation and trajectory. This was done by matching the projected impact points of the wings, fuselage, engines, and vertical stabilizer onto the exterior wall of each tower to the observed damage pattern. 
The analysis indicated that the impact speed on WTC $2(542 \pm 24 \mathrm{mph})$ was about 23 percent larger than the impact speed on WTC $1(443 \pm 30 \mathrm{mph})$. The aircraft that impacted the north tower was steeper than the aircraft that impacted the south tower (vertical approach angle of $10.6^{\circ} \pm 3^{\circ}$ for WTC 1 versus $6^{\circ} \pm 2^{\circ}$ for WTC 2). The roll angle for WTC 1 was $25^{\circ} \pm 2^{\circ}$ while that for WTC 2 was $38^{\circ} \pm 2^{\circ}$.

\subsection{UNCERTAINTY ANALYSES}

The objectives of the uncertainty analyses were to assess the effect of uncertainties associated with the aircraft and WTC towers parameters on the level of damage to the towers after impact and to determine the most influential modeling parameters that affect the damage estimates. Uncertainty arises in these analyses from the following key parameters: (1) aircraft impact parameters (speed, horizontal and vertical angles of incidence, orientation, and location of impact), (2) material properties and failure criteria for the towers and the aircraft, (3) aircraft parameters (mass and stiffness properties, and jet fuel distribution),

(4) tower parameters (structural strength and mass distribution, connections behavior), and

(5) nonstructural building contents that may share in absorbing energy imparted by the aircraft impact.

Another important source of uncertainty is the inaccuracy associated with mathematical or numerical models. These uncertainties, also known as modeling errors, are deterministic in nature, but are often treated as random variables to characterize the effects of the analysis methodologies on the calculated response. All of these variables did not necessarily have a significant effect on the estimated impact damage to the WTC towers.

Because of the complexity of the problem and the limited number of parameters that could be varied in the global analyses, it was necessary to down-select a refined list of uncertainty parameters from all of the possible parameters. Therefore, parameter screening was conducted using design of experiments methodology. Screening was first conducted at component and subassembly levels using orthogonal factorial design techniques in order to identify the most influential parameters and reduce the number of parameters to a more manageable number for the global impact analyses. The sensitivity analyses included engine impacts against core columns, wing section impacts against exterior panels, and engineimpact subassembly analyses.

Based on the three sensitivity analyses, the set of influential modeling parameters was reduced. The following parameters were selected for variation in the global impact analyses:

- Impact speed.

- Vertical approach angle of the aircraft.

- Lateral approach angle of the aircraft.

- Total aircraft weight.

- Aircraft materials failure strain.

- Tower materials failure strain.

- Building contents weight. 
The impact speed and vertical approach angle werc selected as significant parametcrs in the global analyses due to their importance in the component and subassembly impact response. The vertical approach angle played a primary role in the magnitude of the vertical impact loads on the truss floor structures. Lateral approach angle was also selected, as this parameter dictatcd to a largc extent wherc aircraft debris traveled and what part of the core was affected by this debris.

Uncertainties in the strength and ductility (failure strain) of materials had a coupled cffect. An increasc in yield strength or an increase in failure strain resulted in an increase in the cnergy absorbing capacity of the structure. The yield strength of materials was typically known more accurately than the failure strains. This was particularly true within the finite element analyses, where the value of the failure strain needed to be assigned based on the model resolution and failure criteria used. As a result, only the uncertainties in the material failure strain were used as a material uncertainty parameter for both the aircraft and the towers in the subsequent global impact analyses.

The uncertainty in the weights associated with building contents (corresponding to service live loads) was found to be of secondary importance in the engine-subassembly impact analysis. In the global impact analyses, the live load contents were expected to play a more significant role in confining the fuel and debris dispersion. In addition, the partition walls were significant for controlling the subsequent spread of fire through the towers. As a result, the uncertainty in building contents weight was included as an uncertainty parameter in the global analyses.

\subsection{GLOBAL IMPACT ANALYSES}

The primary objective of this project was to determine the condition of the WTC towcrs immediately following the aircraft impacts. This assessment included the estimation of the structural damage that degraded their strength and the condition and position of nonstructural contents such as partitions, workstations, aircraft fuel, and other debris that influenced the behavior of the subsequent fires in the towers. The global impact analyses were the primary method by which the damage to the towers was estimated. The global analyses included, for each tower, a "base case" based on a best estimate of all input parameters. They also provided more and less severe damage estimates based on variations of the most influential parameters. These more and less severe damage scenarios provided a range of damage estimates for the towers due to aircraft impact.

\subsubsection{WTC 1 Base Case Global Impact Analysis}

The base case impact analysis was performed for a $0.715 \mathrm{~s}$ duration following initial impact of the aircraft nose with the north exterior wall. The analysis was performed on a computer cluster using twelve $2.8 \mathrm{GHz}$ Intel Xeon processors, each on a separate node of the cluster. The run time for this analysis was approximately two weeks. The residual kinetic energy of the airframe components at the termination of a global impact simulation was typically less than one percent of the initial kinetic energy at impact.

The aircraft impact response was dominated by the impact, penetration, and fragmentation of the airframe structures. The entire aircraft fully penetrated the tower at approximately $0.25 \mathrm{~s}$. The fuselage structures were severely damaged both from the penetration through the exterior columns and the penetration of the 96th floor slab that sliced the fuselage structures in half. The downward trajectory of the aircraft structures caused the airframe to collapse against the floor, and the subsequent debris motion was 
redirected inward along a more horizontal trajectory parallel to the floor. The downward trajectory of the aircraft structures transferred sufficient vertical load that the truss floor structures on the 95th and 96th floors collapsed in the impact zone.

The wing structures were completely fragmented by the exterior wall. The aircraft fuel cloud began to spread out after impact but remained relatively dense until the leading edge of the fuel reached the tower core. The aircraft fuel and debris cloud eventually penetrated most of the distance through the core before their motion was halted.

\section{Exterior Wall Damage}

The calculated and observed damage in the impact damage zone were in good agreement. The agreement in the position and shape of the impact damage provided partial validation of the modeled geometry of the aircraft, including the aircraft orientation, trajectory, and flight distortions of the wings.

The calculated magnitude and mode of impact damage on the exterior wall also agreed well with the observed damage. The exterior wall completely failed in the regions of the fuselage, engine, and fuelfilled wing section impacts. Damage to the exterior wall was observed out to the wing tips, but the exterior columns were not completely failed in the outer wing and vertical stabilizer impact regions. Failure of the exterior columns occurred both at the bolted connections between column ends and at various locations in the column, depending on the local severity of the impact load and the proximity of the bolted connection to the impact. The agreement of both the mode and magnitude of the impact damage served to partially validate the constitutive and damage modeling of the aircraft and exterior wall of the tower.

\section{Core Damage}

The core had significant damage in the region close to the impact point. The columns in line with the aircraft fuselage failed on the impact side, and several of the core beams were also severely damaged or failed in the impact zone. The calculated damage to the core of WTC 1 consisted of three severed columns and four heavily damaged columns.

\section{Truss Floor Damage}

The trusses experienced significant damage in the impact zone. The calculated impact response produced severe damage to the truss structures in the primary impact path of the fuselage. The truss structures were severely damaged from the exterior wall to the core. The truss floor system on floors 94 through 96 were damaged and sagged downward as a result of the impact loading.

The truss floor and associated slab was heavily damaged or completely destroyed in the impact zone ahead of the fuselage. The zone of heavy damage to the floor slab extended beyond the truss floor and was approximately one-third of the distance through the core on floors 94 through 96. 


\section{Fuel and Debris Distribution}

The bulk of the fuel and aircraft debris was deposited on floors 93 through 97, with the greatest concentration on floor 94 . The calculated debris cloud included $17,400 \mathrm{lb}$ of debris and $6,700 \mathrm{lb}$ of aircraft fuel outside of the towcr at the end of the impact analysis, cither rebounding from the impact facc (north wall) or passing through the tower (south wall). This amount might have becn over-cstimated in the calculation since the exterior walls were not modelcd with windows that would contain the fuel cloud and other small debris inside the towers. In addition, the impact behavior of the aircraft fucl cloud did not include the ability to stick to, or wet, interior components. Rather, the aircraft fucl SPH particles tended to bounce off of internal structures.

\subsubsection{WTC 2 Base Case Global Impact Analysis}

The WTC 2 base case impact analysis was performed for a $0.62 \mathrm{~s}$ duration following initial impact of the aircraft nose with the south exterior wall. Full penetration of the aircraft into the tower was complctcd at $0.2 \mathrm{~s}$ after impact. The aircraft impact response was very similar to that of the WTC 1 impact and was dominated by the penetration and fragmentation of the airframe structures. The fusclage structurcs wcre severely damaged both from the penetration through the extcrior columns and the penetration of the $81 \mathrm{st}$ floor slab that sliced the fuselage structures in half. The downward trajectory of the aircraft structures caused the airframe to collapse against the floor, and the subsequent debris motion was redirected inward along a more horizontal trajectory parallel to the floor. The downward trajectory of the aircraft structures transferred sufficient vertical load that the truss floor structures on the 80th and 81 st floors began to collapse in the impact zone by the end of the simulation.

The aircraft wing structures and fuel tank were fragmented by the impact with the tower exterior. The aircraft fuel cloud started to spread out immediately after impact, but the leading edge of the fuel remained relatively dense until passing approximately one-third of the lateral distance through the tower core (approximately $0.2 \mathrm{~s}$ after impact). At $0.3 \mathrm{~s}$ after impact, the aircraft fuel cloud had penetrated approximately two-thirds the distance through the core and was spreading out. Beyond this time, the subsequent motion of the aircraft fragments and fuel debris cloud was noticeably slowed. The spread of the fuel and debris cloud was more rapid and extensive in the open truss floor regions than through the core as a result of the open volume above the workstations in the truss floor zone.

\section{Exterior Wall Damage}

The exterior wall completely failed in the regions where the fuselage, engine, and fuel-filled wing section impacted the structure. Damage to the exterior wall extended to the wing tips, but the exterior columns were not completely failed in the outer wing and vertical stabilizer impact regions. Failure of the exterior columns occurred both at the bolted connections between column ends and at various locations in the column, depending on the local severity of the impact load and the proximity of the bolted connection to the impact.

The calculated and observed geometry and magnitude of impact damage were in good agreement. That served to partially validate the geometry of the aircraft model, including the aircraft orientation, trajectory, and flight distortions of the wings. Agreement of both the mode and magnitude of the impact damage partially validated the constitutive and damage modeling of the aircraft and exterior wall of the tower. 


\section{Core Damage}

In the base case WTC 2 impact damage analysis, significant damage to the core was calculated in the region close to the impact point (the southeast corner of the core). The columns in line with the aircraft fuselage failed on the impact side of the tower, and several of the core beams were also severely damaged or failed in the impact zone. In some cases, failure of the column splices located on floors 77, 80, and 83 contributed significantly to the failure of the core columns. This was particularly true for the heavy column number 1001 at the southeast corner of the core that failed at three splice locations. A total of five columns were severed and four columns were heavily damaged.

\section{Truss Floor Damage}

The trusses experienced significant damage in the impact zone, with the greatest damage on floor 81 . This severe damage to the floor 81 truss structure and floor slab was in the primary impact path of the fuselage and extended from the exterior wall to the core. The truss floor system on floors 79 and 81 had sufficient damage from the impact that truss floor sections sagged downward as a result of the impact. Trusscs on floor 80 also sustained significant damage as a result of impact.

The calculated truss floor damage to WTC 2 was less than that of WTC 1, despite the higher aircraft impact energy for WTC 2. The larger truss floor damage and deflection in WTC 1 can be explained by two factors. The primary factor was that the WTC 1 downward impact trajectory was nearly twice as stcep as that of the WTC 2 impact. As a result, the steeper impact angle directed more impact energy normal to the floor slab. The secondary factor was that the damage to the long span truss floor in the WTC 1 impact zone produced larger displacements than the corresponding damage level to the short span truss region in WTC 2.

\section{Fuel and Debris Distribution}

The bulk of the fuel and aircraft debris was deposited in floors 78 through 80 , with the largest concentration of aircraft debris on floor 80, and the largest concentration of aircraft fuel on floors 79, 81, and 82 . The calculated debris distribution included $55,800 \mathrm{lb}$ of debris and $10,600 \mathrm{lb}$ of aircraft fuel outside of the tower at the end of the impact analysis, either rebounding from the impact face or passing through the tower. Similar to WTC 1, the calculated debris outside the tower is believed to be larger than is realistic.

\subsubsection{Different Severity Global Impact Analyses}

Additional impact analyses were performed for each tower to provide a range of damage estimates due to the uncertainties in the calculated impact response. Two additional global impact analyses were performed for each tower in order to evaluate the impact response for a more severe and less severe impact scenario. The variations in impact conditions for the different severity global impact analyses were primarily obtained from the uncertainty analyses.

\section{WTC 1 Global Impact Analyses}

The impact speeds were $414 \mathrm{mph}$ and $472 \mathrm{mph}$ in the less severe and more severe impact scenarios, respectively. These were the upper and lower bounds obtained from the analysis of aircraft impact conditions. The vertical trajectory of the aircraft was also varied from 13.6 degrees in the less severe case 
to 7.6 degrees for the more severc impact scenario. The reduced vertical trajectory angle resulted in a greater impact energy directed inward toward the core. The lateral trajectory was not varied since the impact was close to centercd on the tower and normal to the north face of WTC 1. A small variation in the lateral approach angle would have little effect on the cnergy of the aircraft debris cntering the tower and core.

A comparison of the calculated damage to the north exterior wall of WTC 1 from the three different severity impact analyses with the observed damage indicated that the overall agreement with the obscrved damage was good for all three analyses, with the base casc global impact analysis providing the best match to the observed damage. The calculated damage magnitude was similar in cach of the global analyses. The small differences in apparent damage were largely due to panels that may have severed columns in one case and were removed at the connections in another. In general, the trend was for a larger opening produced by the less severe impact and a smaller opcning in the more severe impact. The increase in the opening with reduced severity impact can be cxplained by the increased tower pancl material toughncss in the less severe scenario, resulting in a transition from scvering of columns to the failure of connection bolts and panel removal.

Toward the wing tips, where the columns and spandrels were not completely severed, the more severe impact damage analysis calculated larger damage to the exterior wall panels. These columns had the largest amount of material with plastic strains above 5 percent. As would be expected, the less severe impact damage analysis calculated lower damage to the exterior wall, and the base case analysis calculated an intermediate level of damage near the wing tips.

The core damage was concentrated in the region of the core closest to the fuselage impact point, and there was a clear correlation in damage magnitude with the impact severity. A total of one column was severed, and two columns were heavily damaged in the less severe impact, compared to three columns severed and four columns heavily damaged in the base case impact analysis and six columns severed and three columns heavily damaged in the more severe WTC 1 impact analysis. A strong correlation in core damage with impact severity was expected. All of the parameter variations in the three increasing severity analyses were selected to produce an increase in core damage. A higher impact speed and a shallower impact angle were selected to direct more energy toward the core. The aircraft mass was increased and given a higher material toughness. The mass of the tower contents was reduced, and the tower materials were given a lower toughness. All of these variations contributed toward the increased core damage with impact severity.

All of the WTC 1 global impact analyses resulted in a similar amount of damage to the truss floor and floor slab. Competing parameters canceled their respective effects on the floor damage. Variations in many of the parameters should have caused greater damage to the floor system in the more severe impact analysis. However, the downward impact trajectory angle was also reduced to direct more energy into the core. Therefore, less of the impact energy was oriented into the floor system. The combined effects of varying these parameters led to very similar damage to the floor system in all of the analyses.

\section{WTC 2 Global Impact Analyses}

The impact speeds were $521 \mathrm{mph}$ and $570 \mathrm{mph}$ in the less severe and more severe impact scenarios, respectively. These speeds were the upper and lower bounds obtained from the analysis of aircraft impact 
conditions. The vertical trajectory of the aircraft was also varied from 5 (more severe case) to 8 degrees (less severe case) in order to direct less energy into the core for the less severe case.

Calculated damage to the exterior wall and truss floor of WTC 2 showed similar trends to those seen in the WTC 1 analyses. Only slight changes in damage to these structures were calculated from the different severity impacts. Damage to the exterior was relatively insensitive to the parameter variations. Truss floor damage did not vary significantly due to the competing effect of the parameters varied.

The core damage was concentrated in the core region closest to the impact point. There is also a clear correlation in damage magnitude with the impact severity. A total of three columns were severed, and two columns were heavily damaged in the less severe impact, compared to five columns severed and four columns heavily damaged in the base case analysis and ten columns severed and one columns heavily damaged in the more severe WTC 2 impact analysis.

\subsubsection{Comparison with Observables}

The observables available to help validate the global impact analyses included the following:

- Damage to the building exterior (exterior walls and floors in the immediate vicinity of the impact) documented by photographic evidence.

- Aircraft debris external to the towers (landing gear for WTC 1 and a landing gear and an engine for WTC 2) as documented by photographic evidence.

- Eyewitness accounts from survivors who were inside the towers (blocked or passable stairwells).

Not all of these observables were perfectly matched by the simulations due to the uncertainties in exact impact conditions, the imperfect knowledge of the interior tower contents, the chaotic behavior of the aircraft break up and subsequent debris motion, and the limitations of the models. In general, however, the results of the simulations matched these observables reasonably well.

\subsubsection{Comparison with Previous Studies}

Two studies were previously conducted to estimate the impact damage to the WTC towers. These studies were performed by staff at Massachusetts Institute of Technology (MIT) and Weidlinger Associates, Inc. (WAI). The MIT study used an energy balance approach to estimate damage to the core columns. The WAI study used the FLEX finite element code to calculate the aircraft impact damage to both towers.

In both towers, the impact damage to the exterior wall calculated in this study closely matched the observed damage. The damage profiles in the WAI impact simulations had some noticeable differences. The first was that damage predictions from WAI included complete failure of the exterior columns over the entire length of the wings and top of the vertical stabilizer. The second was that the WAI predictions displayed local rupture of the columns adjacent to the impact point with less influence of the bolted connections on panel failure. Neither is consistent with the observed damage. 
The differences in the damage profiles between the WAI and NIST calculations most likcly resulted from a variety of differences in the aircraft and tower modcls. The WAl aircraft modcl was bascd on their model of a Lockheed C-141B military transport rather than the Boeing 767. The NIST aircraft model also containcd an order of magnitude more elcments and explicit modeling of the fucl. There were also differences in the aircraft impact conditions.

In general, the MIT and WAI studics appeared to predict more damage to the corc columns comparcd to the NIST estimates. For WTC 1, MIT estimated that betwecn four to 12 core columns failcd. WAI gave two estimates for core column failure. The first estimate of 23 core columns failcd and five damagcd was obtained from the FLEX impact analysis. The second estimatc of 20 failed columns was the number used in their collapse analysis. The NIST base case impact damage of three severed and four heavily damaged core columns and less severe estimate of one severed and two heavily damaged core columns fell below both the MIT and WAI estimates. The more severe estimate of six severed and three heavily damaged columns fell in the middle of the MIT range, but still well bclow the WAI estimates.

A similar trend in the predicted damage to the core columns was found in the WTC 2 analysis. MIT estimated between seven to 20 columns failed. WAI calculated 14 core columns failed and another 10 damaged in their FLEX analysis, but reduced the number of failed columns to five for their collapse analysis. The NIST base case impact damage of five severed and four heavily damaged columns, as well as the more severe estimate of 10 severed and one heavily damaged columns fell in the middle of the range predicted by MIT. The less severe impact scenario predicted fewer severed and heavily damaged columns when compared with the MIT and WAI studies.

One reason for the higher damage predictions from WAI may be attributed to the lack of internal tower contents in the WAI model, such as workstations and other building contents. Another reason for the higher damage prediction in the WAI study could result from the aircraft model. In conducting a collapse analysis, WAI used engineering estimates to reduce the number of failed columns from that predicted by their FLEX model to stabilize the tower immediately after impact. Despite this adjustment, the WAI study still estimated significantly higher damage for WTC 1 than the MIT and NIST studies. For WTC 2 their adjusted estimate fell in line with the MIT and NIST studies.

\subsection{SUPPORTING SIMPLIFIED ANALYSES}

Approximate analyses were carried out to provide guidance to the global finite element impact analyses. The specific analyses included:

- The analysis of the overall aircraft impact forces: This analysis indicated that that the momentum transfer was more important than the strength of the impacting aircraft in determining the overall impact loads on the building.

- The effects of the energy in the rotating engine components: This analysis indicated that the potential for the rotational kinetic energy of the engine to significantly change the magnitude of the tower impact damage is small.

- The influence of the static preloads on the calculated impact damage: This analysis showed that the initialization of a static preload in the columns of the towers would not have a significant effect on the tower impact response, damage, or residual strength. 
- The analysis of the load characteristics required to damage core columns: This analysis determined the characteristics of a debris cloud (i.e. density and speed) necessary to fail a core column. Application of this analysis indicated that the dispersed fuel cloud alone would not be sufficient to fail core columns. 


\section{APPENDIX A STILL IMAGES OF THE VIDEO RECORDS USED IN CHAPTER 7}

This appendix provides still images of the video records used to estimate the initial impact conditions of the aircraft that impacted World Trade Center (WTC) 1 and WTC 2 (see Chapter 7). A short description of each of these videos is provided in Table 7-1.

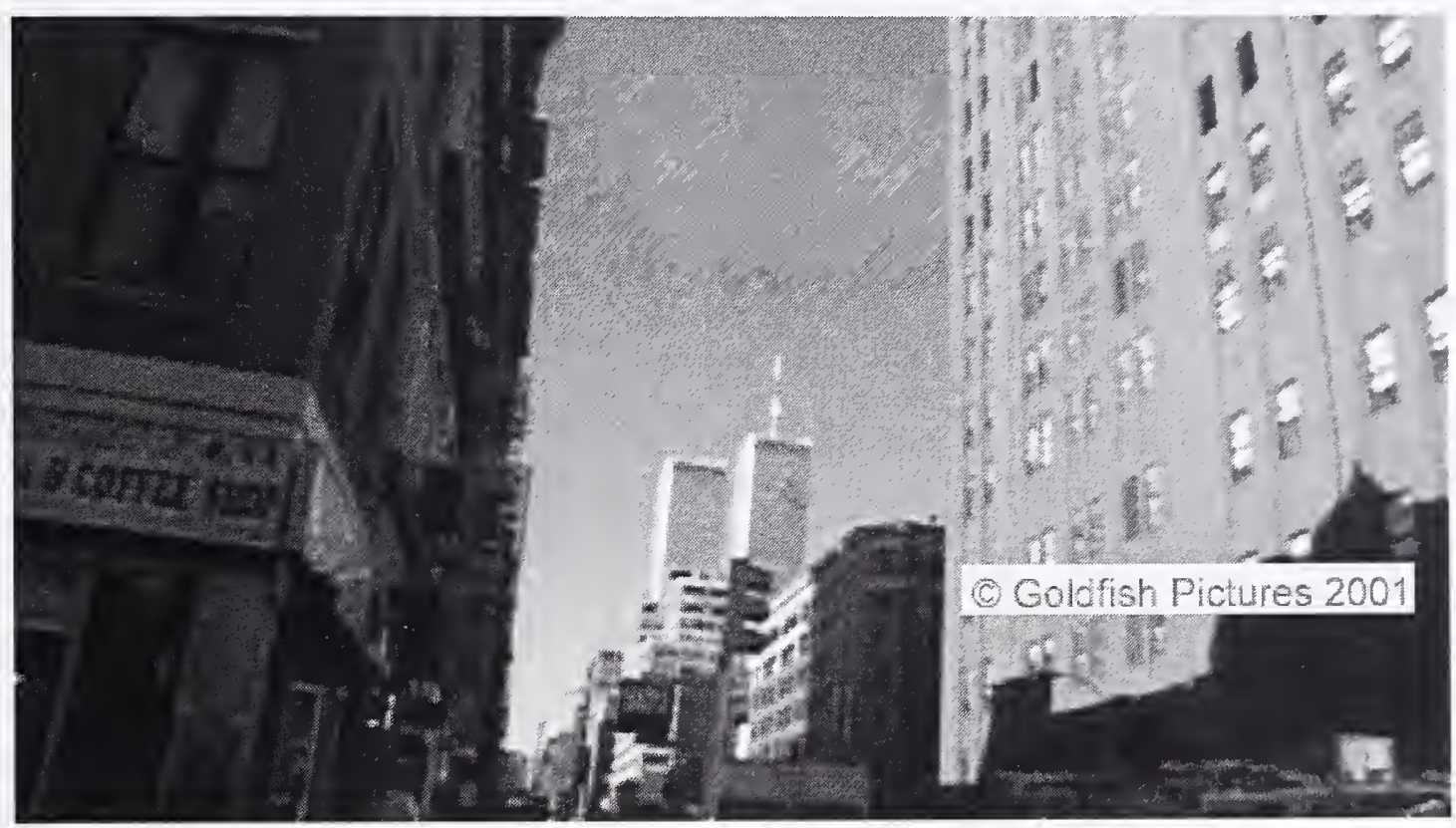

Figure A-1. Still image from Video V1 (WTC 1 impact). 


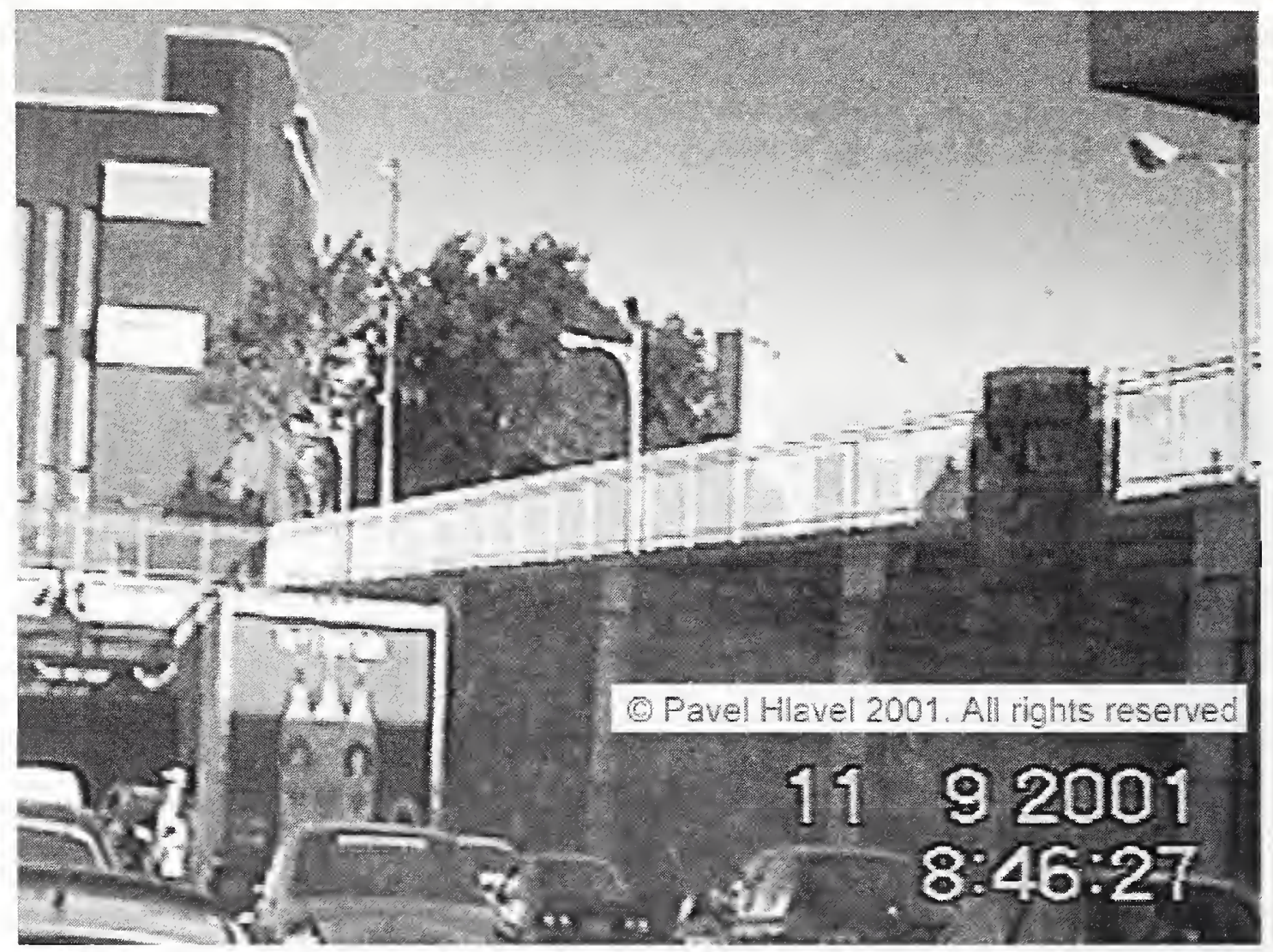

Figure A-2. Still image from Video V2 (WTC 1 impact). 


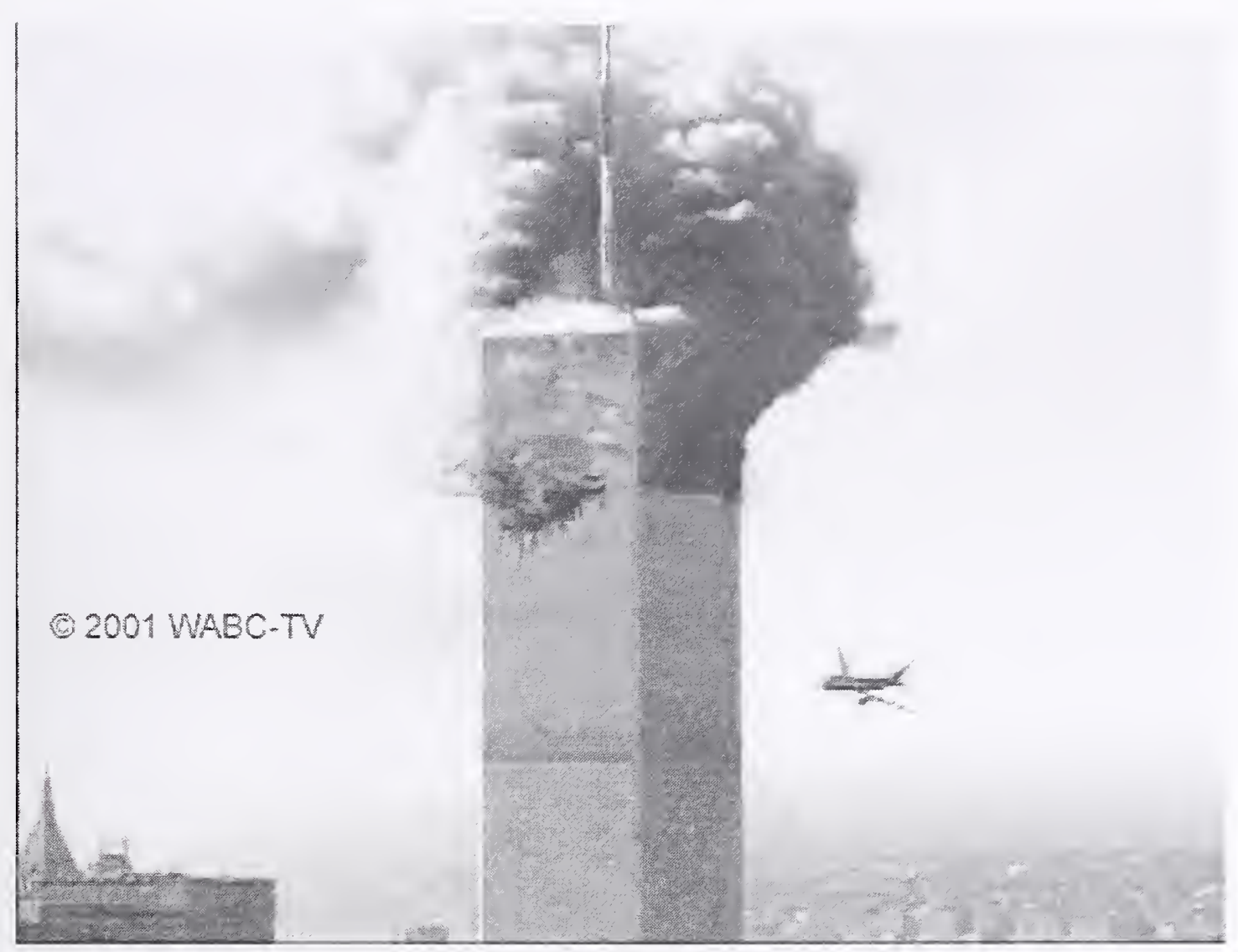

Figure A-3. Still image from Video V3 (WTC 2 impact). 


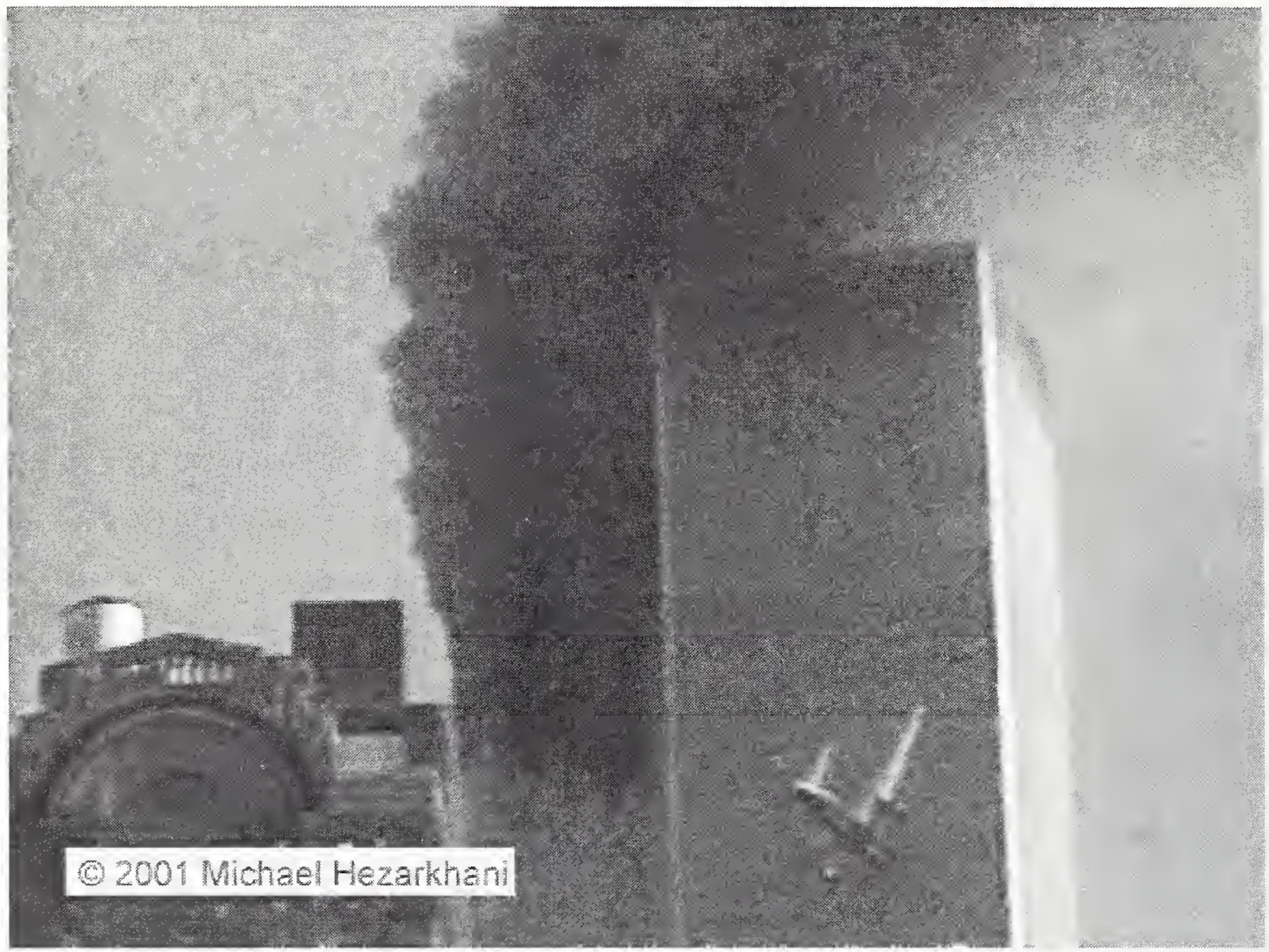

Figure A-4. Still image from Video V4 (WTC 2 impact). 


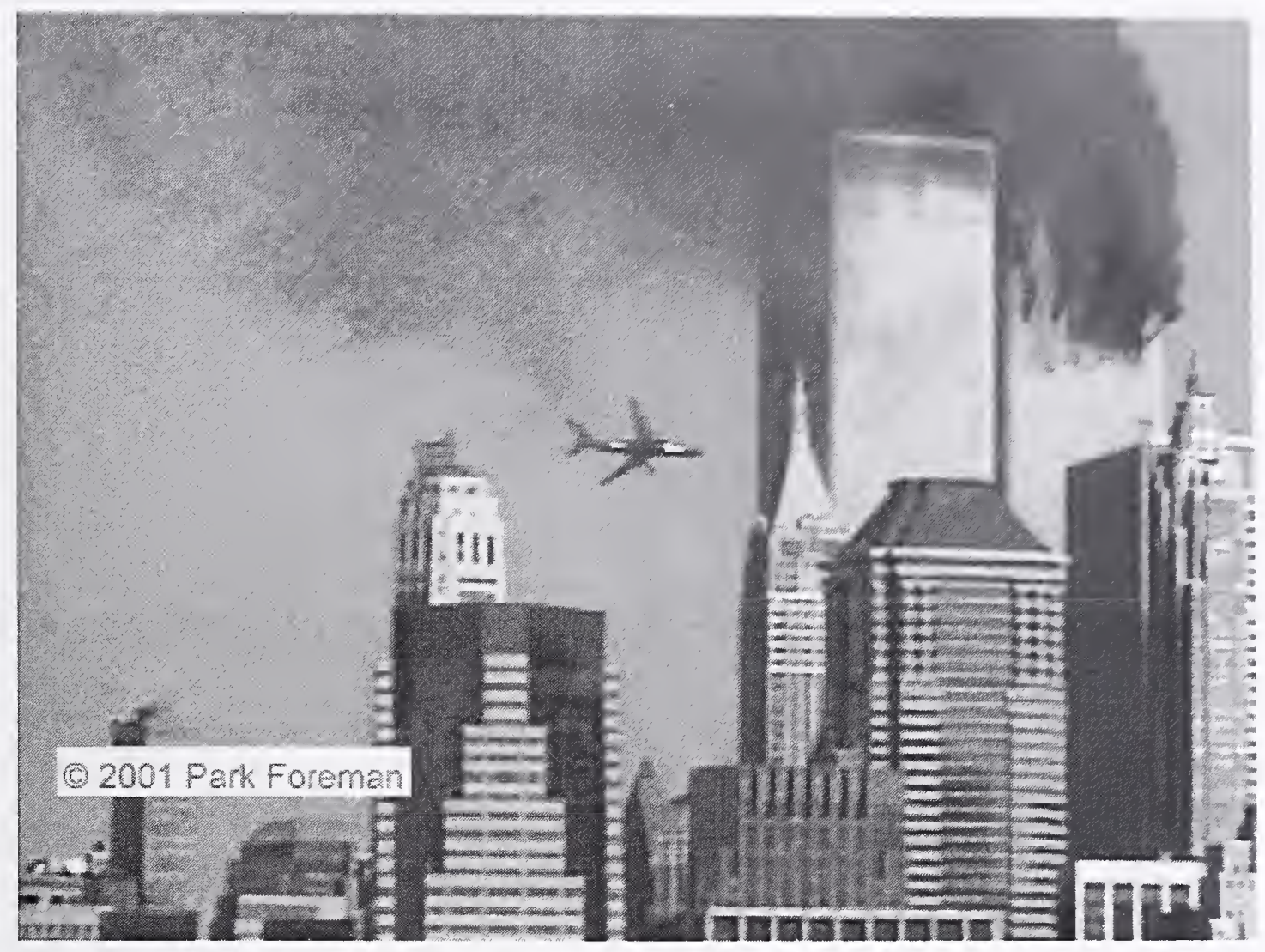

Figure A-5. Still image from Video V5 (WTC 2 impact). 


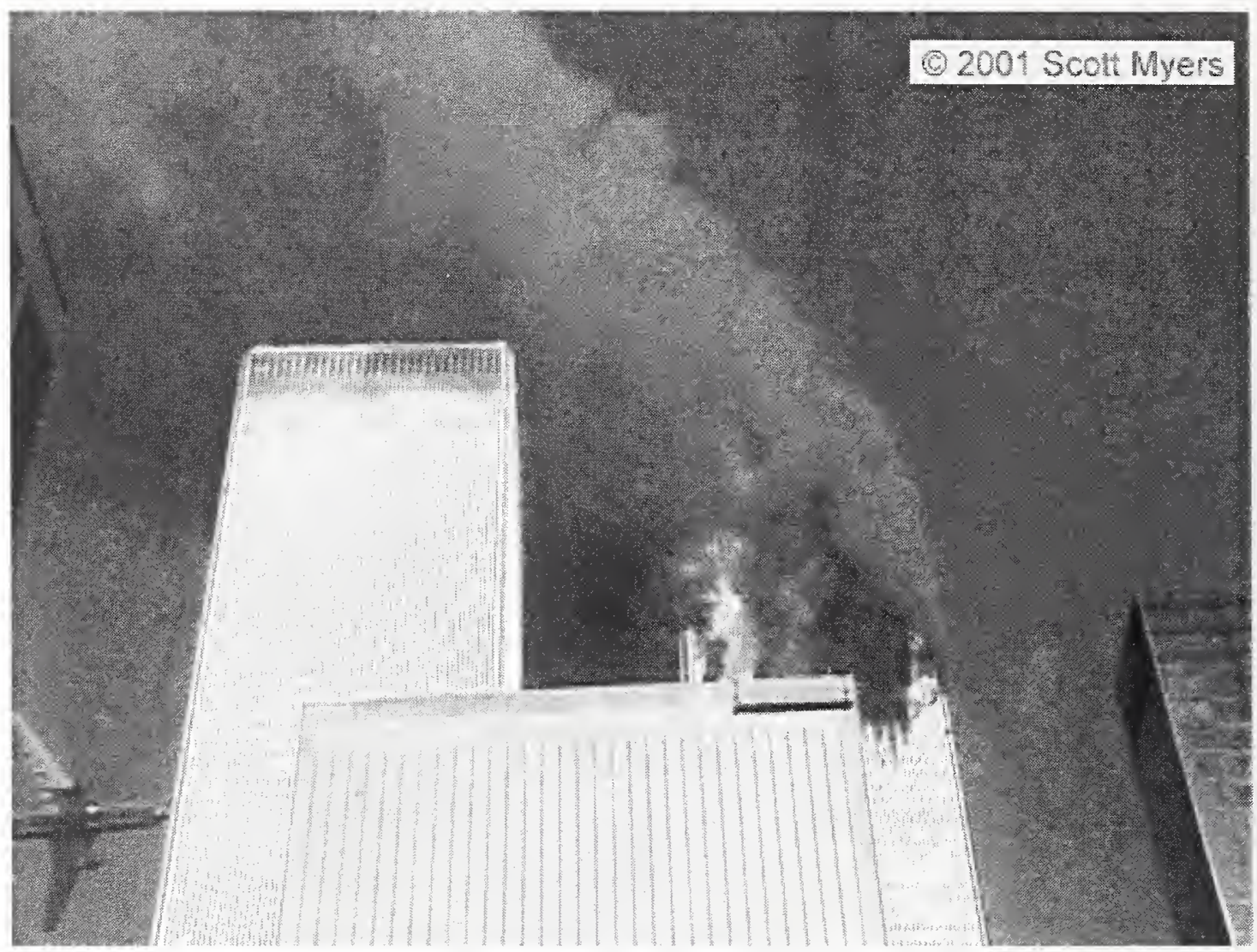

Figure A-6. Still image from Video V6 (WTC 2 impact). 


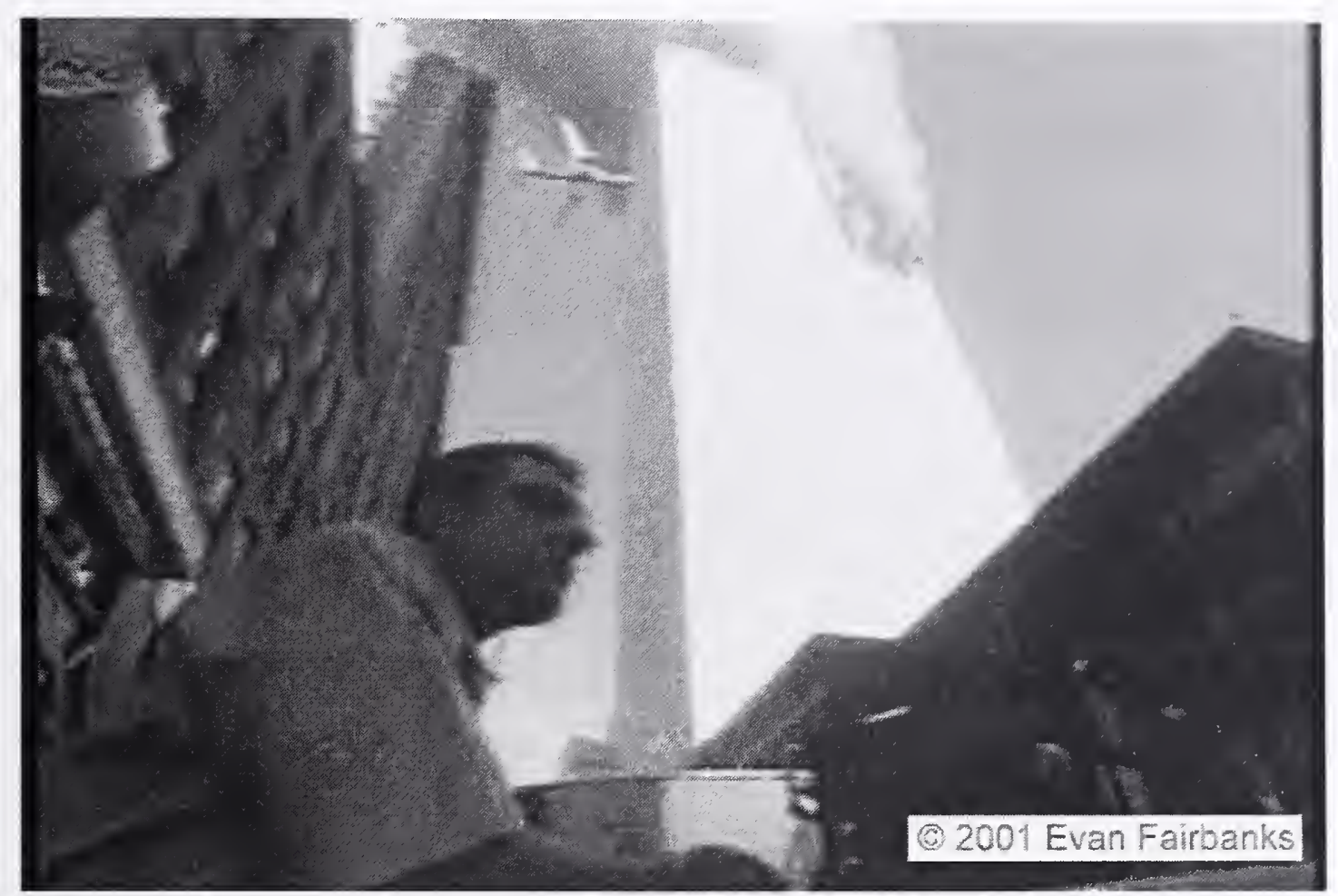

Figure A-7. Still image from Video V7 (WTC 2 impact). 


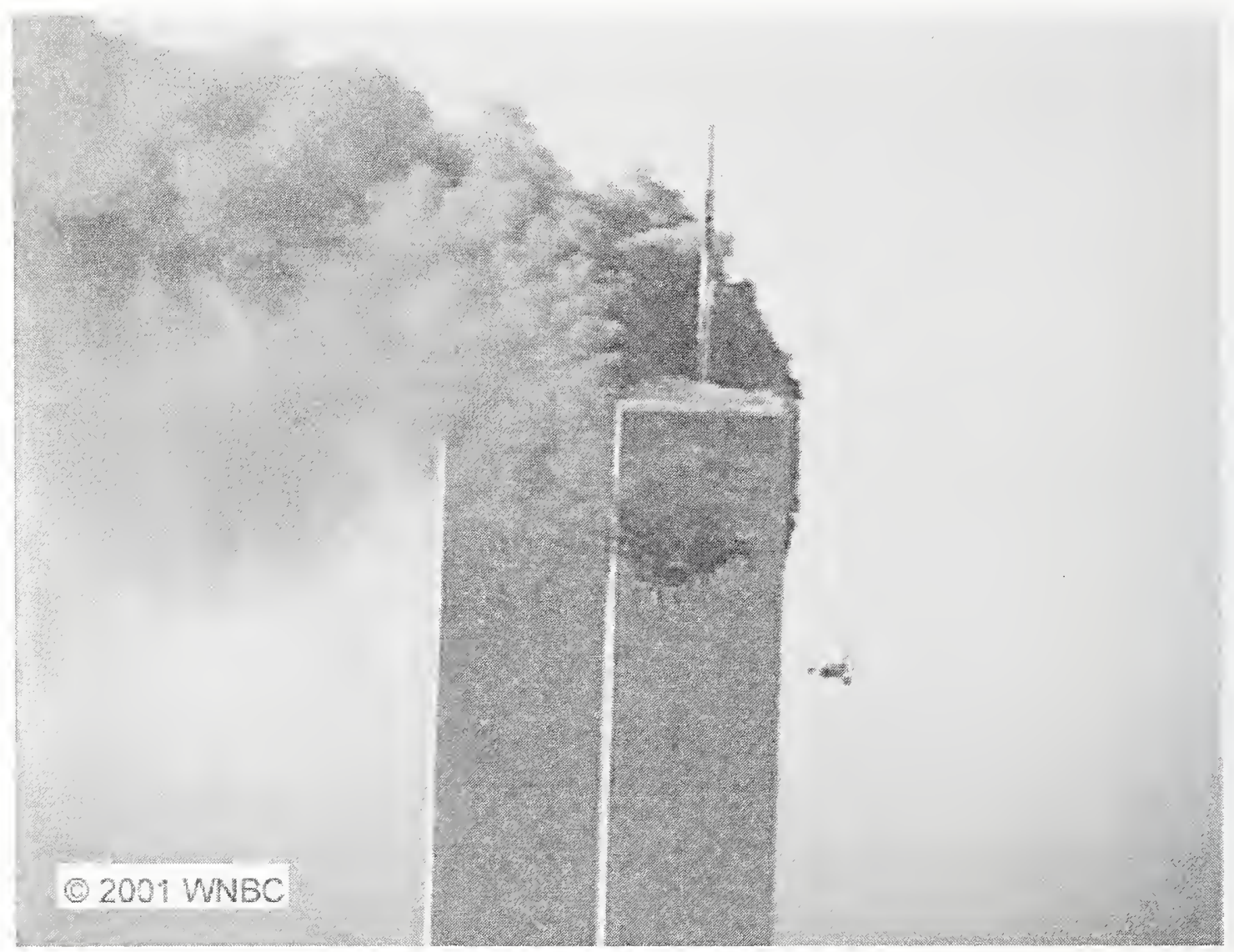

Figure A-8. Still image from Video V8 (WTC 2 impact). 


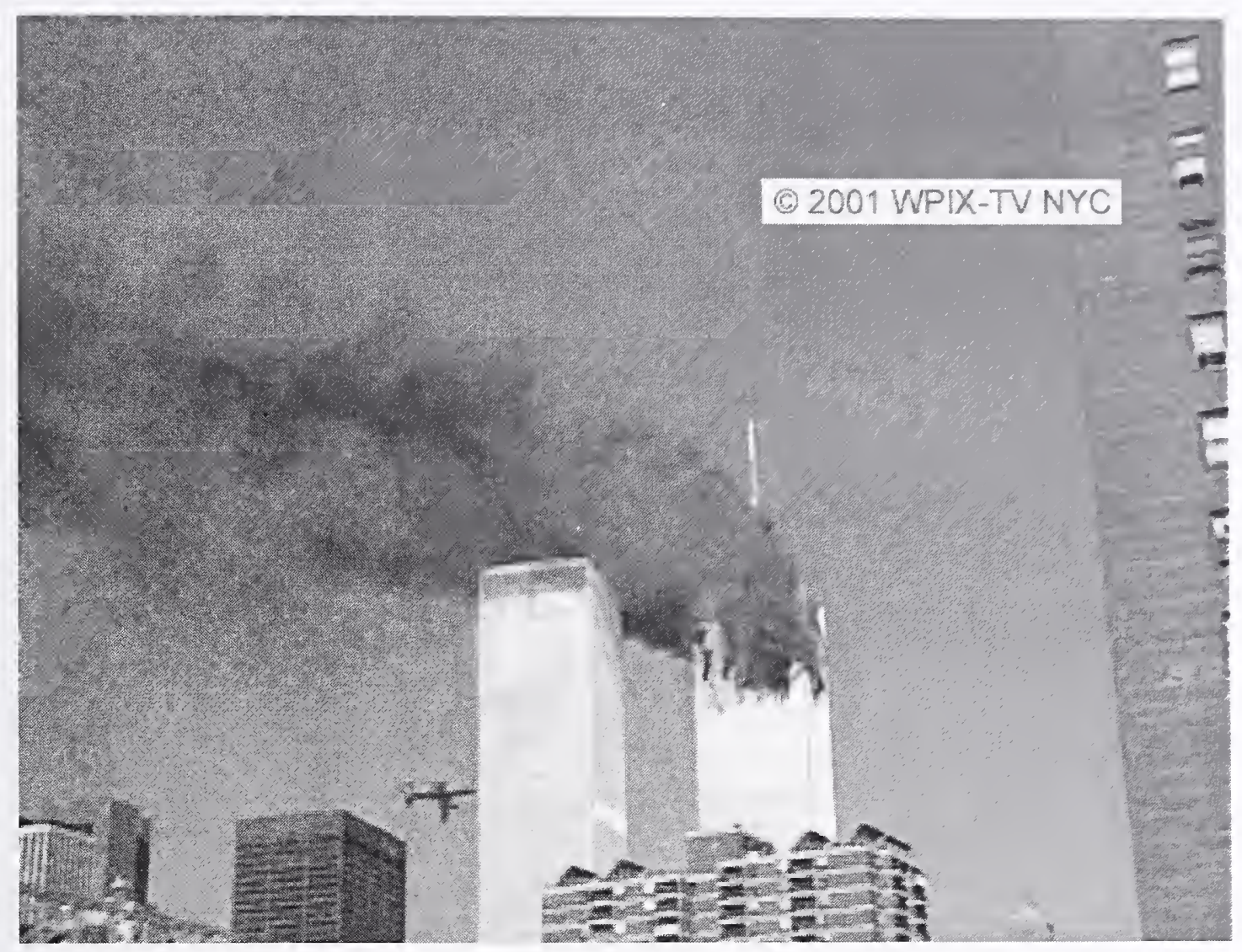

Figure A-9. Still image from Video V9 (WTC 2 impact). 
This page left intentionaily blank 

